
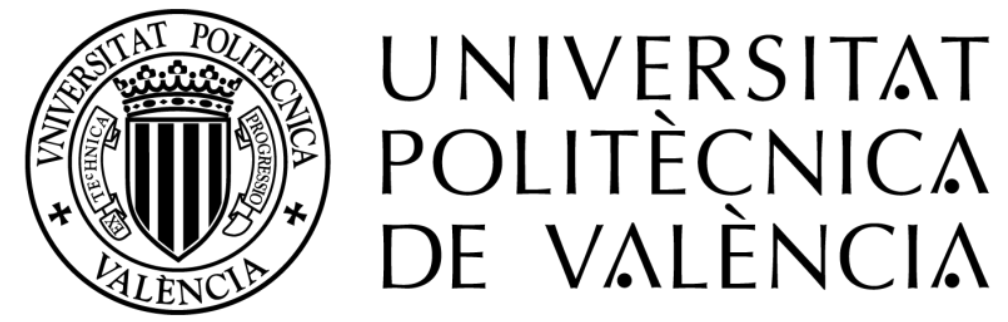

DEPARTAMENTO DE LINGÜÍSTICA APLICADA

\title{
ANÁLISIS DESCRIPTIVO DE LA TRADUCCIÓN DE CULTUREMAS EN EL TEXTO TURÍSTICO
}

\author{
TESIS DOCTORAL \\ DIANA MARÍA GONZÁLEZ PASTOR
}

Director: Miguel Ángel Candel Mora

Valencia, junio de 2012 



\section{INTRODUCCIÓN}

Por medio del lenguaje vivimos y damos vida a una cultura; por medio de la traducción ponemos en comunicación a dos culturas y dos mundos. Por medio de la cultura determinamos lo que es una traducción y lo que no lo es. (Carbonell i Cortés, 1999:48).

El ser humano siempre se ha sentido atraído por el descubrimiento de nuevos paisajes y culturas que han propiciado grandes movimientos migratorios de diversa índole y con diversa finalidad: guerras, hambrunas, comercio, etc. y que han ido modelando la historia de civilizaciones. Las comunidades de la Grecia clásica fueron las primeras que empezaron a realizar importantes desplazamientos por la importancia que atribuían a las actividades de ocio y cultura y que cristalizaron a principios del siglo XIX en una serie de actividades y desplazamientos de placer y carácter lúdico como la base de lo que hoy conocemos como turismo. Este trasiego incesante de personas provoca un cambio en la composición de los pueblos y sus grupos sociales, que han pasado de ser grupos homogéneos a conformarse como grupos heterogéneos y multiculturales.

Con el tiempo, el desplazamiento de personas y mercancías dio lugar a la creación y a la posterior regulación de la actividad turística. En la actualidad, el panorama de la industria turística mundial que contemplamos establece una marcada tendencia hacia los procesos de reajuste y modernización empresarial, provocados por la irrupción de las nuevas tecnologías en la gestión y planificación de los productos turísticos y la crisis económico-financiera. Por otro lado, el cliente o visitante, que está más y mejor informado, está 
desarrollando nuevas pautas de comportamiento en el consumo de productos turísticos, lo que a su vez está imponiendo un abaratamiento de costes de producción y del producto final al cliente y una búsqueda de nuevos nichos de mercado y productos turísticos. Sin embargo, la necesidad de desplazarse y de viajar, de conocer e interactuar con sociedades nuevas y diferentes se nos antoja inmutable debido a la globalización, que hace inevitable el intercambio cultural por muy alejadas que puedan estar las culturas entre sí. Al ser el turismo una de las actividades más generalizadas, los desplazamientos de las personas, por motivos de cualquier índole, se han convertido en un producto global. El intercambio cultural resulta, por tanto, inevitable, al entrar en contacto sociedades cuyas lenguas y culturas pueden hallarse próximas o muy alejadas en lo que a distancia interlingüística e intercultural se refiere.

En esta aldea global en la que vivimos surge con fuerza la figura del mediador intercultural para poder realizar labores y asistir en la transmisión del conocimiento intercultural. Se trata de una figura de gran relevancia, pues sirve como puente para el entendimiento entre culturas y facilita todo tipo de intercambios evitando malentendidos y fallos en la comunicación intercultural.

Hasta hace poco, el papel del traductor se limitaba al de mero técnico lingüístico, que debía traducir un mensaje con la mayor fidelidad posible. En la actualidad, el mediador cultural resulta de vital importancia en el sector turístico y buena prueba de ello es el volumen ingente de traducciones multilingües que se realizan en el mundo de todo tipo de textos turísticos.

La tarea de traducir es mucho más que verter contenidos y elementos lingüísticos de un idioma a otro. Se trata de transmitir saberes únicos y propios de un grupo cultural determinado que a menudo no tienen un equivalente conceptual ni mucho menos lingüístico en la otra cultura. Es por esto que, 
durante el proceso de traducción, el mediador activa una serie de técnicas traductológicas para conseguir transmitir el mayor grado de equivalencia lingüística, contextual, funcional y pragmática.

Este trabajo de investigación tiene una doble vertiente: en primer lugar, el interés por el fenómeno de la interculturalidad y por cómo cada grupo social establece su mapa del mundo y transfiere las realidades culturales; y en segundo lugar, la intención de describir los condicionantes y las variables que operan en la traducción de los textos turísticos, considerados como textos provenientes propios de una cultura. Así, esta tesis doctoral se centra en el análisis de las técnicas de mediación usadas por el mediador para transmitir aquellos elementos culturales o culturemas que no son propios de su cultura.

\subsection{Motivación}

Una de las razones que han motivado la realización de esta investigación fue el desarrollo y la posterior defensa del Trabajo de Investigación presentado bajo el título Traducción y Mediación Intercultural en Turismo: un estudio de los culturemas. Este trabajo ponía fin a los estudios conducentes a la obtención del Diploma de Estudios Avanzados. Los resultados que se obtuvieron de aquella experiencia fueron interesantes y dejaron entrever la magnitud de posibilidades de estudio del texto turístico y la necesidad de ampliar el estudio previo realizado. Otro de los desencadenantes fue mi interés personal por la cultura y por observar cómo los mediadores activan los distintos mecanismos que poseen para poder hacer frente a una de las dificultades y quebraderos de cabeza que constituyen el verdadero reto en mediación: la traducción de la cultura. 
Sin embargo, la principal justificación para la realización de este estudio se basa en que, a pesar de la evidente importancia socio-económica de la actividad turística en España, la reflexión teórica en torno al texto turístico resulta escasa, sobre todo desde un punto de vista académico. La excepción la conforman algunos estudios sobre el texto turístico que se han centrado en el análisis de errores cometidos por los traductores debido a la falta de competencia intercultural del traductor y a las peculiares y complejas características que posee el texto turístico. Durante la fase previa de lectura y estudio de los antecedentes hemos podido constatar que, frente a la bibliografía consolidada que existe sobre otros ámbitos de la traducción (traducción jurídica, traducción científico-técnica, traducción literaria, etc.), en el campo de la traducción turística existe un vacío académico considerable en lo que concierne a la publicación de monografías traductológicas que aborden, de manera específica, la traducción del texto turístico.

Si atendemos a la tipología textual, los textos que han recibido mayor atención por parte de los traductólogos son aquellos textos promocionales y publicitarios en forma de folletos turísticos, por lo que la tipología textual de la literatura de viaje, y, en concreto, las guías turísticas, son un campo inexplorado hasta la fecha y que merecen especial atención por sus peculiaridades discursivotextuales y la gran cantidad de culturemas que presentan.

La mencionada falta de estudios traductológicos previos junto con las características propias del texto turístico, que abarca múltiples tipologías textuales y modalidades discursivas, tienen como consecuencia diferentes encuadres del texto turístico en traductología. Resulta necesario, por tanto, seguir ahondando en el estudio del texto turístico proporcionando nuevos parámetros de análisis que contribuyan a dotarlo de mayor peso académico y 
de un estatus de independencia dentro de los lenguajes de especialidad y de la traductología.

Por otro lado, la traducción de la cultura en general constituye uno de los pilares fundamentales en traductología, y es fuente inagotable de producción científica. Sin embargo, la traducción de la cultura no ha sido estudiada en muchas disciplinas y en ámbitos y temáticas especializadas. En consecuencia, ésta sigue suponiendo un caballo de batalla para los mediadores, que no disponen de recursos teóricos para hacer frente al reto que supone la traducción de las capas de cultura menos visibles. La lengua es la máxima expresión de la cultura, y ambas se nutren en continuo proceso de retroalimentación. A nivel del microtexto, la cultura puede reflejarse en elementos como el léxico realia, entendido éste como aquellas unidades léxicosemánticas arraigadas en una cultura determinada, que no tienen correspondencia en otra cultura. La cultura se muestra también a través de la fraseología y las expresiones idiomáticas. Existen múltiples estudios que ponen el acento en el microtexto. Sin embargo, las implicaciones del uso de los culturemas van más allá e implican un estudio profundo de los mecanismos y los procesos cognitivos que utiliza el traductor para superar el reto de la traducción de la cultura.

Este trabajo se justifica, pues, por la necesidad de presentar una investigación original y novedosa en el contexto académico, si bien, paradójicamente, en el ámbito profesional, la traducción turística es una de las especialidades de traducción más demandadas y menos reconocidas. 


\subsection{Objetivos}

Este estudio aborda de forma combinada dos asuntos, la traducción y la cultura a través del análisis de los elementos lingüístico-culturales o culturemas con el objetivo principal de realizar un análisis pormenorizado de las técnicas de traducción y de la frecuencia de uso de las técnicas empleadas a través del uso de un modelo traductológico ya testado que nos permita establecer cuáles son las técnicas de mediación más usuales en la transferencia de culturemas. A la vista de lo expuesto anteriormente, los objetivos secundarios de esta investigación son los siguientes:

- Describir y analizar las características del texto turístico, así como los condicionantes que operan en la traducción de la cultura presente en este tipo de textos.

- Ahondar en el estudio de la literatura de viajes y, específicamente, en las guías de viajes, tomando para ello como modelo de análisis cinco guías Lonely Planet cuyo destino es alguna ciudad o región española.

- Elaborar una clasificación de los elementos culturales presentes en diferentes campos semánticos que conduzcan a una sistematización de culturemas en el texto turístico junto con sus técnicas de traducción más habituales y sirvan de utilidad y referencia para el mediador turístico.

- Identificar la presencia de focos culturales en los distintos campos semánticos analizados.

- Proponer una catalogación de los culturemas turísticos atendiendo a sus características y su dificultad para la traducción.

- Realizar una aportación al estudio de la traducción del texto turístico, desde un punto de vista traductológico, y contribuir a la consolidación de este ámbito de la traducción como una rama con entidad propia en la 
formación de traductores y en los ámbitos traductológicos de investigación.

\subsection{Hipótesis}

Con los objetivos anteriores en mente, abordamos esta investigación con el siguiente planteamiento de partida:

1. La cultura es dinámica y la percepción de la cultura depende, en última instancia, del sujeto individual, de su conocimiento previo del mundo y de su carácter etnocentrista o receptivo hacia la otredad.

2. Para acortar la distancia intercultural y transmitir la máxima totalidad de la carga semántica, cultural y pragmática de los culturemas (o la máxima posible), los traductores activan un amplio abanico de estrategias o técnicas de traducción, que vienen determinadas, principalmente, por el grado de traducibilidad del culturema en cuestión.

3. El uso mayoritario de determinadas técnicas afectan al método traductor y pueden suponer una estrategia traductora que puede estar preestablecida de antemano. Así, con el uso de técnicas como el préstamo o la adaptación, el mediador sitúa al lector más cerca de la nueva cultura de destino o la propia cultura del turista.

4. En algunos casos se produce la pérdida parcial de la carga cultural del culturema, en la mayoría de casos esto sucede no por falta de conocimientos culturales del mediador, sino por otro tipo de restricciones propias del propio texto turístico.

5. La traducibilidad lingüística y la traducibilidad cultural de los culturemas opera a diferentes niveles. Existen grados de traducibilidad cultural y es 
necesario asumir que no siempre es posible transmitir el cien por cien de la carga cultural.

6. El mediador intenta trasvasar el culturema realizando analogías con elementos culturales propios de su cultura o elementos globalizados con los que puede ofrecer más información y de mayor calado al lector.

7. Por último, debemos señalar el carácter descriptivo de este estudio, que analiza la traducción de los culturemas partiendo de la base fundamental de que las técnicas de traducción no están relacionadas directamente con el propósito fundamental y la funcionalidad del texto meta, si bien algunas de estas sí pueden usarse conscientemente para dar un carácter más o menos centrado en la cultura origen o en la cultura meta.

Cabe señalar que, en nuestra investigación, el enfoque traductológico resulta novedoso, por cuanto el autor del texto en lengua inglesa es el mismo que ha de realizar la mediación de los elementos culturales que no le son propios. Los destinatarios de la mediación son individuos que comparten cultura y lengua con el autor-mediador, por lo que el lector destinatario observa la nueva cultura de llegada a través de los ojos de un individuo con un universo cultural compartido en sus aspectos más generales. La mediación se realiza, pues, no sólo interculturalmente, sino también intraculturalmente.

\subsection{Metodología}

Dado que el carácter de nuestra investigación es eminentemente práctico, la metodología empleada ha sido inductiva y descriptiva. Las etapas que han jalonado la realización de este trabajo de investigación son las que se detallan a continuación: 
1a etapa: Establecimiento del estado de la cuestión y de la evolución del tratamiento de la cultura y los elementos culturales en traductología con las distintas clasificaciones y denominaciones y el marco téorico existente en cuanto a las técnicas de traducción. Asimismo, caracterización del sector turístico en España, así como las características discursivo-textuales y traductológicas y de género de este tipo de lenguaje.

2a etapa: Selección de las guías Lonely Planet que versan sobre ciudades y regiones españolas que constituyesen el objeto de estudio de nuestro trabajo. Hemos seleccionado este tipo de guías tras comprobar la enorme carga cultural presente en este tipo de guías y su contrastado reconocimiento y calidad.

3a etapa: Creación de una ficha de trabajo para la extracción de culturemas. Para la sistematización de la información y la elaboración del corpus, se confeccionó un modelo de datos que permitiera un posterior análisis cuantitativo.

4a etapa: Estudio detallado de todo el material, incluyendo las cinco guías Lonely Planet objeto de la investigación, y alineación de los textos para proceder al vaciado de culturemas. El vaciado de culturemas implica la subsiguiente categorización de los mismos en distintas secciones para poderlos analizar posteriormente.

5a etapa: Asociación de técnica o técnicas de traducción para cada culturema.

6a etapa: Obtención de datos y análisis cuantitativo y cualitativo de las técnicas de traducción en los diferentes campos semánticos. Extracción de datos significativos para nuestra investigación, que fuesen representativos de las dificultades que caracterizan la mediación intercultural en turismo. 
7ạ etapa: Presentación de conclusiones de nuestra investigación, entendida como un todo, y orientada tanto al desarrollo de la didáctica como a la consolidación de la traducción del texto turístico.

\subsection{Estructura de la tesis doctoral}

El presente trabajo está dividido en las siguientes secciones:

La revisión y reflexión teórica sobre la traducción y la cultura se inicia en el capítulo 2, en el que se abordan aspectos como el giro cultural en traducción y el tratamiento que han recibido los culturemas por parte de la traductología. Asimismo, resulta indispensable revisar los estudios previos acerca de las técnicas de traducción, elementos clave de nuestra investigación y que conforman el mecanismo de estudio y análisis de nuestro corpus. Se incluye, además, una breve referencia a la traducción adaptada al ámbito geográfico.

En el capítulo 3, se realiza una descripción teórica general del sector turístico, por un lado, y del texto turístico, por otro. En el primer bloque se presenta el encuadre de la comunicación turística dentro de la industria turística española y en el segundo se exponen las principales características textuales y discursivas del lenguaje del turismo. Del mismo modo, se revisan los estudios previos acerca del género textual de este tipo de lenguaje y se presentan las diversas tipologías textuales existentes. El capítulo 3 también versa sobre la traducción del texto turístico. Así, se pretende revisar qué consideración ha tenido la traducción del texto turístico por parte de los traductólogos y cuáles son los aspectos que se han abordado hasta la fecha, realizando especial hincapié en el tratamiento que ha recibido la traducción de los culturemas en este campo. 
En el capítulo 4 se inicia el análisis del corpus de culturemas turísticos seleccionados. En esta sección diseñamos el corpus y explicamos el modelo de análisis de los culturemas para posteriormente realizar un análisis detallado de los distintos culturemas identificados en los distintos campos semánticos del texto turístico.

En el capítulo 5 se presentarán las conclusiones extraídas tras finalizar nuestra investigación. En este mismo apartado se establecen las posibles vías de estudio que se derivan de esta tesis doctoral.

Para finalizar, en el capítulo 6, presentamos toda la bibliografía citada a lo largo del presente trabajo. El capítulo 7 contiene la documentación anexa, que recoge los culturemas estudiados en prácticos listados que facilitan su consulta. 


\section{ANTECEDENTES. LA TRADUCCIÓN COMO INSTRUMENTO DE MEDIACIÓN INTERCULTURAL}

\subsection{El concepto de cultura: definición y características}

Resulta cuanto menos complicado definir el concepto de cultura, debido a los múltiples significados que se le atribuyen y las distintas perspectivas desde las que se estudia, por lo que ofrecemos, en primer lugar, su acepción básica y, a continuación, las acepciones más relevantes partiendo de la idea moderna de cultura de Tylor para acabar ofreciendo una perspectiva general y antropológica de esta noción en conexión con el lenguaje.

Si atendemos a su etimología, debemos situar la palabra cultura en la voz latina colere, cuyo significado primario es cultivar la tierra, cultivarse y dar culto a Dios. Por extensión, el término sugiere que las personas absorben elementos vitales propios de su ámbito que determinan su comportamiento. No obstante, su significado ha ido variando a lo largo del tiempo en función del ámbito y el contexto en el que se ha utilizado. Si lo consideramos dentro del marco de las Ciencias Sociales puede referirse "a toda la producción material de una sociedad", mientras que en los Estudios Literarios, Culturales o de Traducción "su significado gira en torno a un sistema de significación" (Martínez Sierra, 2004:131, citado por Moreno, 2006:11).

La cultura ha intentado explicarse y abordarse desde diferentes disciplinas (Antropología, Sociología, Estudios Culturales, Psicolingüística, Estudios sobre Traducción) y los autores que la investigan coinciden en que es un término muy 
elástico y generador de polémica. La problemática surge cuando se restringe el término cultura a un ámbito de estudio concreto. Por ejemplo, si definimos cultura como una civilización o sociedad concreta en un período de tiempo específico estamos centrándonos en la historia sin considerar la dimensión total del término.

Los antropólogos norteamericanos Alfred Louis Kroeber y Clyde Kluckhohn llegaron a recoger en 1952 hasta 164 definiciones diferentes del término. A continuación ofrecemos algunas definiciones del término cultura que creemos más representativas:

El antropólogo inglés Tylor (1871) formuló la definición más citada, reproducida y recogida después por importantes lingüistas:

Culture is that complex whole which includes knowledge, belief, art, morals, law, customs and any other capabilities and habits acquired by man as a member of society (Tylor, 1871:1).

La aportación de Tylor resulta muy interesante porque entiende la cultura como un entramado de elementos materiales e intelectuales propios de un grupo social sentando así las bases de la antropología moderna.

Del ámbito de la traducción tomamos la definición de Vermeer, quien incluye las normas de comportamiento y las convenciones de una sociedad, así como los resultados de dichas convenciones y formas de actuar:

Die Menge aller Verhaltensnormen und -konventionen einer Gesellschaft und der Resultate aus den normbedingten und konventionellen Verhaltensweissen (Vermeer 1992:32).

Newmark, por su parte incluye los siguientes elementos como integrantes de una cultura:

Objects, processes, institutions, customs, ideas peculiar to one group of people (Newmark 1998:283). 
A efectos de este trabajo, la cultura no se considera un producto tangible y visible que se pueda aprender, sino que nos hallamos, como apunta Katan (1999), ante una cultura natural, que se adquiere de modo innato dentro de un sistema interno y colectivo. Resulta acertada la definición de David Katan de su obra Translating Cultures, en la que indica que cultura es "what goes without saying" y que se trata de un "normal model of the world" donde no existe sólo una cultura, sino que "each aspect of culture is linked in a system to form a unifying context of culture, which then identifies a person and his or her culture" (Katan, 1999:26).

Este mismo autor retoma la clasificación que elabora Gail Robinson (1988:7-13) desde la antropología social de las distintas definiciones de cultura para establecer dos niveles básicos de cultura, el interno y el externo con sus correspondientes manifestaciones:

\begin{tabular}{|l|l|}
\hline Nivel externo & $\begin{array}{l}\text { comportamientos: lenguaje, gestos, costumbres/hábitos } \\
\text { productos: literatura, folclore, arte, música, artefactos }\end{array}$ \\
\hline Nivel interno & ideas: creencias, valores, instituciones \\
\hline
\end{tabular}

Varios autores han intentado sistematizar la cultura estableciendo modelos para explicar su funcionamiento. En este punto, resulta interesante destacar la teoría de las capas de cebolla de Hofstede (1991) y la teoría del iceberg de Hall (1952). Para Hofstede, en el núcleo de la cultura se encuentran los valores y en las capas más superficiales y visibles, y por ello, más sensible a influencias ajenas (agrupadas bajo el título de prácticas), se encontrarían los elementos externos (rituals, heroes and symbols). La metáfora del iceberg defiende que la parte más importante de la cultura permanece oculta y tan sólo se nos permite ver la punta del iceberg. Hall, en su obra The Hidden Dimension (1982), propone una 
extensión de su teoría del iceberg y afirma que existen tres niveles de cultura, el nivel técnico, el nivel formal y el nivel cultural. Es en este último donde encontramos una forma de cultura que no se puede aprender o enseñar, sino que se adquiere inconscientemente, "out-of-awareness", en palabras del mismo Hall.

Figura 1: Teoría de Hofstede (1991)

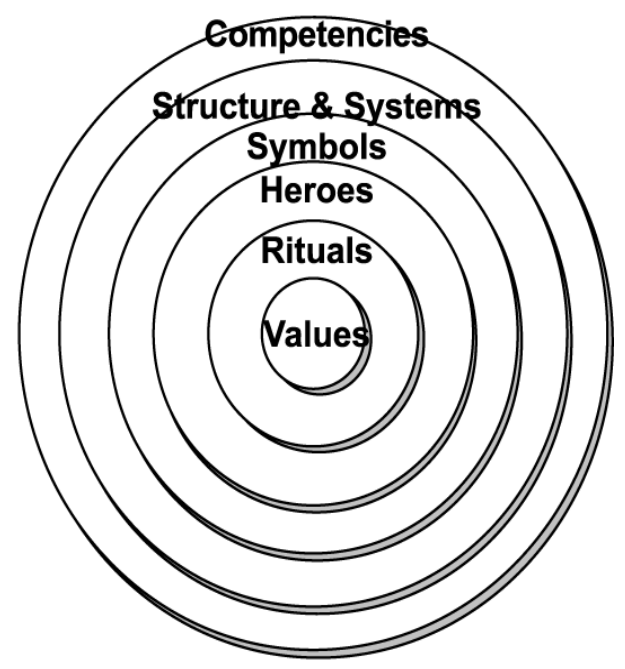

Figura 2: Teoría de Hall (1952)

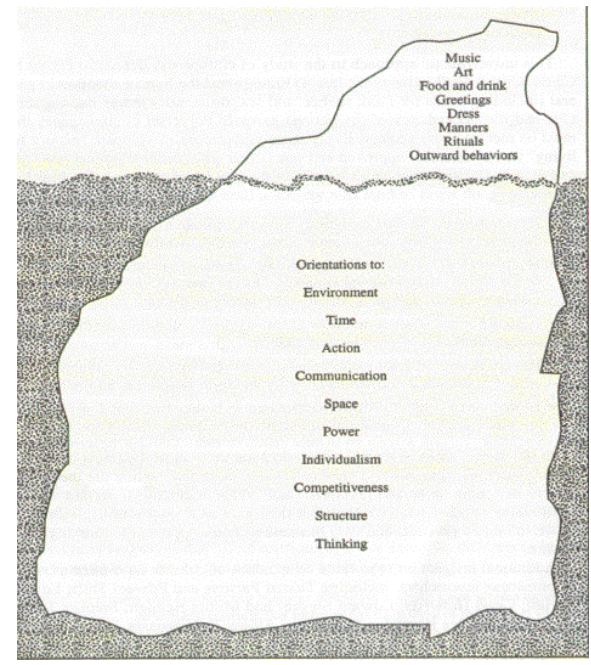

David Katan (1999:52) establece un modelo jerárquico de niveles lógicos que reduce básicamente a dos. Su concepto de cultura, visto desde la corteza hasta el núcleo, constaría de las siguientes capas:

- Entorno: factores externos, ámbito físico y político, el clima, el espacio, las viviendas, y construcciones, la manera de vestir, los olores, la comida y las divisiones y marcos temporales que existen y se experimentan de modo diferente en cada cultura.

- Conducta: reglas y restricciones de comportamiento.

- Capacidades: estrategias y habilidades para comunicarse.

- Valores: conjunto de valores que comparte una sociedad y su jerarquía. 
- Creencias: proporcionan las motivaciones y razones para seguir ciertas reglas de conducta y hacer o no hacer ciertas cosas.

- Identidad: nivel superior de jerarquía.

Existen otros autores que, en lugar de ofrecer una definición o clasificación, prefieren centrarse en las implicaciones y características de la noción de cultura, como es el caso de Samovar y Porter (1997:13), quienes destacan que la cultura "se aprende, es transmisible, dinámica, selectiva, etnocéntrica y sus diferentes facetas están interrelacionadas". De estos seis aspectos, resalta su carácter a un tiempo dinámico y selectivo, es decir, la cultura es porosa y está sometida a diferentes influencias, pero al mismo tiempo, es selectiva y conservadora, receptiva en ocasiones e intransigente en otras. Relacionada con esta peculiaridad, sobresale una segunda característica: la tendencia al etnocentrismo, "que consiste en identificarse con lo conocido y familiar de la cultura propia al tiempo que se subestima lo foráneo" (Moreno, 2006:13).

Carmel Camilleri (1985) ofrece una de las definiciones más completas que se han ofrecido del concepto de cultura, pues resume sus características más importantes:

Cultura es la configuración, más o menos intensamente ligada por la lógica tomada de un modelo, de significaciones persistentes y compartidas, adquiridas por el individuo mediante su filiación a un grupo, que le conducen a interpretar los estímulos del ambiente $y$ a sí mismo según actitudes, representaciones y comportamientos comúnmente valorados; que, además, tienden a proyectarse en las producciones y comportamientos y que, en consecuencia, inducen a asegurar su reproducción a través del tiempo (Camilleri, 1985:25).

A continuación resumimos las peculiaridades de las culturas y su interacción según Moreno (2006:14-16):

- Las culturas (y subculturas) no son equidistantes entre sí y pueden darse relaciones asimétricas de jerarquía y dependencia, de mayor o menor 
prestigio, o de mayor o menor afinidad por motivos históricos o culturales. Lo que constituye para Venuti (1988) el mayor escándalo de la traducción: "assymetries, inequities, relations of domination and dependence exist in every act of translating, of putting the translated in the service of the translated culture" (Venuti, 1988:4). En este sentido, cabe destacar cómo la hegemonía económica y cultural de EEUU y del inglés favorece una mayor familiaridad con su cultura.

- Las culturas son hereditarias y transmisibles. Generación tras generación la cultura se va transmitiendo como herencia social a través de los mecanismos propios del grupo o sociedad en cuestión.

- Las culturas no son homogéneas: dentro de una cultura podríamos distinguir entre una paracultura (las normas y convenciones válidas para toda la sociedad), una diacultura (las normas y convenciones de cada grupo) y una idiocultura (las normas de cada individuo).

- Las culturas no son herméticas, ni en sentido vertical ni horizontal, es decir: entre las diferentes culturas, y entre las diferentes subculturas de una misma cultura, fluyen corrientes con desigual capacidad de penetración e influencia mutua, puesto que el grado de tolerancia y receptividad difiere de una cultura a otra. Las culturas son, por tanto, compartidas en mayor o menor grado.

- Las culturas no son estáticas, la permeabilidad destacada en el punto anterior implica un grado variable de dinamismo y movilidad: un aspecto marginal puede pasar a ser central y un rasgo muy específico de una cultura puede convertirse en un elemento de cultura de masas y a la inversa. Así pues, la cultura responde a la interacción social y se plasma en producciones materiales e intelectuales. 
- Desde finales del siglo pasado hay una serie de factores que vienen propiciando un mayor contacto entre culturas: los avances tecnológicos en telecomunicaciones y transportes, los fenómenos migratorios, el aprendizaje de lenguas extranjeras, etc. Estos hechos contribuyen a la llamada globalización u occidentalización o a la internacionalización desde la cultura anglosajona. En este proceso ocupan un lugar destacado los medios de comunicación y la traducción como elemento de mediación para facilitar el intercambio y la comunicación intercultural.

En esta investigación sobre la traducción de guías turísticas, consideramos la cultura desde su vertiente antropológica, como una manera de vivir y de entender nuestro entorno más próximo. Así pues, la cultura destila una serie de valores, comportamientos sociales, hábitos, creencias, y modos de vida que nos definen como pertenecientes a un grupo. La lengua es la cultura, como vehículo de expresión y parte integrante de ella misma, como explicaremos a continuación.

\subsection{El binomio lengua-cultura}

Como hemos apuntado anteriormente, la lengua es una de las características indisolubles de la cultura, pues es un producto que ella misma genera y que garantiza la evolución y la transmisión de dicha cultura. Podemos situar los primeros estudios sobre la relación entre lengua y cultura en la figura de Guillermo de Humboldt quien, en su obra póstuma Sobre la diversidad de estructura del lenguaje humano y su influjo en la evolución espiritual de la humanidad, definió a principios del s. XIX la lengua como una actividad del ser humano, expresión de su pensamiento (Hurtado, 2001/2008:607). Muchas son 
las corrientes lingüísticas que se han aproximado a explicar las relaciones existentes entre lengua y cultura.

El lingüista norteamericano Sapir, con su obra Language: an introduction to the study of speech de 1921 inicia lo que denominaríamos la corriente antropológica del estructuralismo lingüístico, por el que se considera las lenguas en relación con toda la cultura de las comunidades hablantes (Coseriu, 1981). El mismo Sapir declaraba:

Es indudable la importancia de la lengua como un todo para la definición, expresión y transmisión de la cultura. Es, asimismo, clara la pertinencia de detalles lingüísticos, en el contenido y en la forma a la vez, para la comprensión más profunda de la cultura (Sapir, 1921 citado en Casado 1991:23).

Sin embargo, Sapir matiza indicando que no existe una correspondencia entre la forma de una lengua y la forma de una cultura de sus hablantes y que no existen paralelismos entre los tipos culturales y las estructuras lingüísticas, pues la significación cultural de la forma lingüística "debe buscarse en planos mucho más profundos que del plano manifiesto de las pautas culturales definidas" (Casado, 1991:23).

La Hipótesis de Sapir-Whorf revoluciona el planteamiento de la versión tradicional al supeditar el pensamiento al lenguaje. Plantea que el lenguaje es anterior al pensamiento, lo cual quiere decir que el pensamiento depende del lenguaje o está en función de éste: se plantea así la hipótesis del Determinismo Lingüístico: el lenguaje que habla una persona modula y determina su forma de pensar. Los autores afirman que cuando los niños aprenden su idioma nativo aprenden también una visión concreta del mundo, una determinada forma de entender la realidad.

Los datos que usaron Sapir-Whorf para apoyar dicha hipótesis se basaban en estudios sobre las lenguas indias americanas señalando que, como eran muy 
diferentes a las lenguas europeas, esto era lo que les llevaba a pensar de una manera tan distinta a los indios de los europeos. Whorf consideraba que los hablantes de diferentes lenguas piensan de forma distinta y justificó su teoría basándose, por ejemplo, en los diferentes tipos de nieve que existen según los esquimales: el hecho de que existan palabras diferentes en lengua esquimal, para poder discriminar entre diferentes tipos de nieve, es lo que lleva a los esquimales a pensar en la nieve de diferente forma que los europeos. Una de las críticas a estos trabajos fue su falta de precisión y de consistencia en sus argumentos dando lugar al planteamiento de distintas versiones de esta hipótesis.

La escuela idealista, representada por Karl Vossler (1872-1949), es la corriente lingüística que más énfasis pone en la relación entre lengua y cultura. Vossler retoma al filósofo italiano Croce y a Humboldt para establecer que el lenguaje no es un instrumento automático y de leyes mecánicas, sino una actividad humana, por lo que puede considerarse también una actividad creativa y artística y le otorga un carácter de individualidad en contraposición con las categorías de lingüística externa y lingüística interna saussureanas. Para Casado (1991) la obra de Vossler Cultura y Lengua de Francia (1929) supone la primera obra científica moderna en la que se establece una interacción clara entre lengua y cultura.

En 1964 Dell Hymes edita una obra de ensayos de lingüistas norteamericanos que titula Language in Culture and Society, y en su introducción comenta que si la primera parte de la lingüística del siglo XX ha destacado por una tendencia a preconizar la autonomía del lenguaje como objeto de estudio aislado de su estructura, la segunda parte del s. XX se ha caracterizado "por intentar integrar el lenguaje dentro de su contexto socio-cultural y por un enfoque relativo al análisis de la función" (Hymes, 1964:11). 
Malinowski fue otro estudioso del significado a partir del estudio antropológico. En su obra El problema del significado en las lenguas primitivas (1923), este autor establece las bases de la etnografía del lenguaje y parte de las de la sociolingüística y de la pragmática. El lenguaje es, para Malinowski, un instrumento que sirve para relacionarse en sociedad y que no tiene por qué ser siempre una representación de nuestro pensamiento, sino que sirve a otros fines expresivos y sociales como la cortesía, la expresión del cariño o del odio y no para reflejar nuestras reflexiones intelectuales (Carbonell i Cortés, 1999).

Robins (1971) proporciona un resumen de las conclusiones de Malinowski sobre el significado (Castellà, 1992:79 citado en Carbonell i Cortés, 1999:131) y que le llevan a acuñar el término contexto de situación:

- El lenguaje es una forma de actividad, parecida a otras actividades sociales cooperativas, y no una contraseña del pensamiento.

- Las expresiones no se producen ni se entiende como acontecimientos autónomos, se producen y se entienden en un contexto compartido.

- Las relaciones de significado no se establecen únicamente entre dos elementos, la palabra y su referente, sino en un conjunto multifuncional de relaciones entre lo que se dice y el contexto de aparición.

- Los significados y usos de las formas lingüísticas se adquieren a partir de su aparición en sus contextos respectivos, y así ha de aplicarlos el lingüista.

Por lo tanto, los significados de las palabras y frases no son universales, aunque los de las culturas cercanas sí estén muy relacionados.

Uno de los recientes autores que considera el lenguaje como un fenómeno cultural es Casado Velarde en su obra Lenguaje y cultura. La etnolingüística (1991). Para Casado "el lenguaje, como actividad libre del hombre, y también 
como producto de esa actividad, constituye un fenómeno cultural. Todo acto lingüístico es un acto creador, que se funda en un saber" (Casado, 1991:27). Coseriu (1981) realiza una distinción entre los objetos naturales y los objetos culturales para establecer que la cultura es propia de la parte más libre del hombre y el resultado de las actividades y de su creación, no obedeciendo a ninguna causa o ley formal, por lo que no siguen un patrón único.

La etnolingüística ha planteado tradicionalmente los aspectos culturales del uso de la lengua o el aspecto antropológico de la lengua (Casado, 1991). Se trata hoy de una disciplina científica, que estudia la cultura de una comunidad de hablantes en relación con su lenguaje. Casado se basa en Germán Fernández Guizetti para proporcionar una definición más ajustada de esta disciplina: el objeto de la etnolingüística lo constituyen "las relaciones entre las estructuras idiomáticas y los pueblos que se expresan según sus pautas" y se trata, pues, de una ciencia que estudia "las relaciones entre el idioma y el grupo humano caracterizado por su comunidad cultural" (Fernández Guizetti, 1960:229 en Casado, 1991:40).

El lenguaje se entiende así como saber transmisible fundado previamente sobre una comunidad idiomática (Porzig, 1964:218):

La comunidad idiomática es el primer presupuesto para que sean en general posibles las realizaciones humanas comunes, es decir, la cultura. Por tanto, donde quiera que encontremos obras culturales, hallamos como su condición previa la lengua, es decir, la comunidad de los hablantes.

En A Textbook of Translation, Peter Newmark (1988:94) también define en los mismos términos la noción de cultura:

(...) the way of life and its manifestations that are peculiar to a community that uses a particular language as its means of expression. 
Resulta relevante en este punto señalar que, a la hora de referirse a la etnolingüística, es conveniente indicar cuál es el punto de partida para el estudio: la cultura o el lenguaje, es decir, si estamos ante la interpretación cultural de una lengua o de la expresión idiomática de una cultura. En esta investigación, el objeto de estudio son los hechos lingüísticos del texto turístico en tanto que están determinados por lo que Coseriu denomina los saberes. Así pues, nos hallamos en el ámbito de la lingüística etnográfica o etnolingüística propiamente dicha, que es el estudio de la variedad y variación del lenguaje en relación con la civilización y la cultura. La otra variante de la etnolingüística es la etnografía lingüística, que estudia la interpretación cultural manifestada a través del lenguaje.

Tabla 1: Variantes de la etnolingüística según Casado (1991:41)

\begin{tabular}{|l|l|l|}
\hline \multirow{4}{*}{ Etnolingüística } & $\begin{array}{l}\text { Lingüística etnográfica (o } \\
\text { etnolingüística } \\
\text { propiamente dicha) }\end{array}$ & $\begin{array}{l}\text { Estudia los hechos lingüísticos que } \\
\text { vienen determinados por la } \\
\text { cultura. }\end{array}$ \\
\cline { 2 - 3 } & Etnografía lingüística & $\begin{array}{l}\text { Estudia la cultura según se } \\
\text { determina a través del lenguaje. }\end{array}$ \\
\hline
\end{tabular}

Para Coseriu (1981:17), la relación entre lenguaje y cultura se puede entender en tres sentidos diferentes:

- El lenguaje mismo es una forma primaria y fundamental de la cultura.

- El lenguaje refleja la cultura no lingüística: manifiesta los saberes, las ideas y creencias acerca de lo conocido.

- No se habla sólo con el lenguaje como tal, con la competencia lingüística, sino también con la competencia extralingüística, es decir, los saberes, 
ideas o creencias acerca de las cosas, y estos saberes, ideas y creencias influyen sobre la expresión lingüística y la determinan en alguna medida.

El primer sentido hace referencia a la lingüística en general. Las otras dos acepciones indican que existen elementos culturales paralelos al lenguaje que se relacionan y lo condicionan directamente.

La traducción es el instrumento que media entre culturas para hacer posible el entendimiento entre sociedades. Juega un papel destacado en los procesos de de trasvase cultural (Castillo, 2006) y su último propósito es el de acercar las distintas realidades culturales. Es por eso que los traductores deben aproximarse a los textos siendo conscientes de la importancia del contexto cultural.

En la próxima sección se abordarán los conceptos básicos en traductología y su evolución en las diferentes teorías de la traducción en conexión con la traducción cultural y los culturemas o elementos culturales.

\subsection{El giro cultural en traducción}

Debemos situar la segunda mitad del s. XX como punto de partida del estudio de la relación entre traducción y cultura y, en especial, la década de los 80 , con el Ilamado Cultural Turn, designado así por Bassnett y Lefevere (1990) en su obra Translation, History and Culture ${ }^{1}$. A raíz de la importancia actual de conceptos como historia o tiempo, estos investigadores afirmaron entonces que la unidad operativa para estudiar la traducción pasaba a ser "la cultura que yace

\footnotetext{
${ }^{1}$ Bassnett y Lefevere retomarán la cuestión de la multiculturalidad y la alteridad en traducción en 1998 en Constructing Cultures, Essays on Literary Translation.
} 
tras un texto" (Bassnett y Lefevere, 1990:5-8). Si mediante la traducción podemos entender nuestra propia cultura en relación con otras, no podemos ignorar, pues, el contexto cultural de los textos que se traducen. El siguiente símil que ofrece Susan Bassnett (1988) pone de manifiesto la estrecha relación de necesidad mutua que guardan traducción y cultura:

Language, then, is the heart within the body of culture, and it is the interaction between the two that results in the continuation of life-energy. In the same way that the surgeon, operating on the heart, cannot neglect the body that surrounds it, so the translator treats the text in isolation from the culture at his peril. (Bassnet, 1988:22)

Margot (1979:82) explica la causa principal por la que los traductores no han sido sensibles a la cultura meta:

Lorsqu'on traduit ce message dans une autre langue, il faut tenir compte des différences entre culture source et culture réceptrice. Les traducteurs ont souvent péché à cet égard. L'erreur fondamentale est l'ethnocentrisme.

Así pues, el traductor no traduce palabras aisladas, sino palabras en un contexto sociocultural, comprometiéndose a considerar tanto la cultura de la lengua original como la de la lengua meta.

Es en este período cuando la traducción como actividad de comunicación intercultural cobra fuerza. Varios son los autores que empiezan a proporcionar un enfoque sociocultural y multidisciplinar al estudio del texto y a considerar el contexto cultural como parte de la unidad de traducción. Trivedi (1971) indica que el traductor tiene que enfrentarse a "la estructura cultural y a la estructura lingüística que interactúan" entre ellas (Trivedi, 1971:2). Se trata pues, no únicamente de traducir palabras, sino de transferir palabras dentro de un contexto cultural del que no pueden ser separadas. Por su parte, Snell-Hornby (1999) apunta que la traducción que se realiza no es entre lenguas sino entre culturas, en un proceso en el que es necesario sustituir los términos lengua origen y lengua meta por cultura origen y cultura meta (Vermeer, 1986). La 
prioridad pasa a ser la transferencia del mensaje implícito de la cultura origen. A menudo, eso provoca que el traductor haya de "transferir una cultura entera para traducir un texto único literario" (Seager, 1991:197). La traducción pasa así a definirse como comunicación intercultural (Hurtado, 2001/2008), kultureller Transfer o Transkulturelle Kommunication mit Sprachwechsel (Vermeer, 1986:173). Hewson y Martin (1991) lo denominan ecuación cultural. El traductor, por su parte, recibe la denominación de mediador entre culturas (Hatim y Mason, 1990), mediador cultural (Toury, 1995) y se le atribuye la biculturalidad como competencia (Snell-Hornby, 1999:46).

La traducción (entendida como una actividad de intercambio y mediación cultural) ha tenido siempre una gran trascendencia en los contactos entre los distintos pueblos, "siendo vital y decisiva para la historia política de muchas naciones" (Lozano, 1975:64). Autores como Rodríguez Monroy (1994:307) establecen que la traducción ha sido un "arma de conquistadores", en tiempos pasados y hoy en día lo sigue siendo, ya que el lenguaje y la ideología van unidos de la mano. La tarea del traductor no se trata ya desde una perspectiva puramente descriptiva, sino que se toman en consideración "cuestiones ideológicas y el papel que juegan las instituciones de poder que influyen en la producción de textos traducidos" (Carbonell i Cortés, 1999:31). La sociedad contemporánea está caracterizada por un continuo intercambio cultural, económico y político entre países; la globalización ha hecho posible el acercamiento entre culturas y la traducción su entendimiento. (Castillo, 2006). Sherry Simon (1996:134) afirma que vivimos in translated worlds, por lo que la traducción se ha convertido en una necesidad diaria para poder sobrevivir en el contacto con otras personas. 
Muchos son los autores que han definido la traducción desde la óptica de la cultura. Hurtado (2001/2008:608) entiende la traducción como "una actividad comunicativa que se efectúa entre dos culturas diferentes".

Octavio Paz (1990) y otros reconocidos autores conciben la traducción como medio para lograr entender el mundo en que vivimos. La traducción ya no está considerada un segundo texto derivativo y se ha convertido en un proceso análogo a la actividad creativa. Traducir implica interpretar, crear. En esa faceta interpretativa de la traducción estriba la importancia que ésta adquiere en el mundo moderno como instrumento para la integración de diferentes culturas; Niranjawa (1992:47) afirma que es "the noble task of bridging the gap between peoples, as the quintaessential humanistic enterprise".

Sin embargo, hace relativamente poco, el aspecto de la interculturalidad en la traducción estaba considerado como algo menor y de importancia relativa. Quizás esto se deba a que la traducción no estaba todavía considerada una disciplina independiente, sino que, por su carácter interdisciplinar y por su práctica secundaria, la traducción quedaba relegada a un segundo plano. Lo realmente importante no era el proceso traductológico, sino "el producto final de un proceso mecánico" (Bassnett, 1988:12).

Como indica Castillo (2006), la importancia de la traducción en el mundo actual viene determinada por el hecho de que en la segunda mitad del siglo XX se ha pasado de lo puramente histórico a lo contemporáneo, abandonando los estudios prescriptivos y normativos a favor de los descriptivos. La traducción también ha cambiado con el paso del tiempo y se ha pasado de la palabra como unidad de traducción a la cultura del texto, pasando primero por la oración y más tarde por el texto. En palabras de Dingwaney (1995:3): 
In seeking to transport words (and sentences and texts) from one language to another, the translator cannot merely search for equivalent words in the target language to render the meaning of the source. Rather, the translator must attend to the contexts (a word, a culture) from which these words arise and which they, necessarily, evoke and express. Thus, it seems entirely appropriate that translation theory and practice has, in recent years, turned to both source and target cultures as something to be studied before the translation of a work can proceed.

En muchos casos, el traductor se enfrenta a la mediación entre dos culturas muy lejanas desde el punto de vista lingüístico y cultural. En estos casos, es cuando el traductor se enfrenta a la traducción en su estado más puro, al tener que transmitir saberes que no le son propios ni conocidos en absoluto y que, de algún modo, ha de expresar en la cultura meta. Debido a la complejidad que esto puede conllevar, muchos traductólogos han estudiado y definido un fenómeno complejo y polémico, como es el de la intraducibilidad cultural, que tiene su base en la noción de equivalencia, elemento no menos polémico y ambivalente que el anterior. En el próximo apartado se abordan estos dos conceptos para poder entender hasta qué punto las características culturales del TM condicionan la labor del traductor y las decisiones y técnicas que se emplean en el proceso traductológico.

\subsection{La noción de equivalencia traductora y la intraducibilidad cultural}

Con las teorías modernas de la traducción la noción de equivalencia traductora se ha convertido en uno de los conceptos claves para el análisis de las traducciones superando el hasta hace bien poco omnipresente concepto de fidelidad. Junto con otros conceptos como unidad de traducción, error de traducción, problemas de traducción y calidad de las traducciones, la noción de equivalencia está casi siempre presente actualmente en cualquier trabajo de investigación en traductología. En palabras de Reiss y Vermeer: 
No existe prácticamente ninguna publicación reciente acerca de la teoría y práctica de la traducción en la que no aparezcan los conceptos de equivalencia/equivalente o adecuación/adecuado. $Y$, sin embargo, tampoco existen conceptos traductológicos de uso más arbitrario y definición más imprecisa que estos dos. Creo que hoy en día todo el mundo admite que el concepto de equivalencia, en traductología, se refiere a la relación que existe entre un texto (o elemento textual) de partida y un texto (o elemento textual) final; pero lo que sí plantea dudas es la naturaleza de esa relación, que permanece muy difusa (Reiss y Vermeer, 1996:111).

Snell Hornby (1999:34) apunta que la cuestión de la equivalencia ha sido estudiada desde dos corrientes principales en traductología. La primera, más general, pone el énfasis en los problemas semánticos y de transferencia del contenido semántico desde el TO hasta el TM. En segundo lugar, se ha explorado la equivalencia en los textos literarios por parte de la Escuela Rusa y los Lingüistas de Praga, que ofrecieron una nueva dimensión al problema.

Nord, por su parte, también señala la ambigüedad presente en el mismo concepto de equivalencia:

El concepto de equivalencia es uno de los conceptos más ambiguos en los estudios de traducción, $y$, por consiguiente, se ha interpretado de muchas formas distintas (Nord, 1991:22)

En consecuencia, convendría delimitar siempre el uso traductológico la noción de equivalencia pues, aparte de ser impreciso y estar mal definido, presenta una ilusión de simetría entre lenguas que apenas existe más allá de un nivel de vagas aproximaciones y que "tergiversa el problema básico de la traducción" (SnellHornby, 1999:22) ${ }^{2}$.

Para muchos autores, la equivalencia traductora es tan relevante que definen la misma actividad de traducción en sus términos. Catford define la equivalencia como la cuestión central de la teoría de la traducción: “El problema central de la

\footnotetext{
2 James Holmes (1988) sostiene que el concepto de equivalencia resulta de por sí perverso, debido a la relación de igualdad que se presupone entre lenguas y culturas.
} 
práctica de la traducción es encontrar equivalentes de traducción en la LM" (Catford, 1965/1970:40). Existen varias clasificaciones de la equivalencia traductora dependiendo de los puntos de vista:

- Nivel en el que se sitúa la equivalencia: palabra, frase o texto.

- Tipo de significado reproducido (equivalencia denotativa, connotativa, pragmática, etc.).

- Grado de equivalencia mayor o menor obtenido en el TM (equivalencia aproximada, equivalencia nula, etc.).

Al mismo tiempo, Catford (1965/1970) introduce el concepto de intraducibilidad, que relaciona con la inexistencia en la LM de un sustituto léxico o sintáctico que se corresponda con el de la LO. Catford entiende que el fenómeno de cultural untranslatability se produce "due to the absence in the TL culture of a relevant situational feature for the SL text" (Catford, 1965/1970:157).

En general, la intraducibilidad se puede producir a varios niveles. Sin embargo, no existe la intraducibilidad absoluta y es en este aspecto en el que discrepamos con Catford, pues, como indica Carbonell i Cortés (1999:146), “intraducibilidad implica traducibilidad". Aun asumiendo que existe pérdida de información, a la que Hervey y Higgins (1992) denominan de modo más correcto translation loss, en última instancia lo que se produce es un fenómeno de inadecuación, y del mismo modo que "no puede haber equivalencia absoluta, es difícil también que se dé la intraducibilidad absoluta" (Carbonell i Cortés, 1999:146) ${ }^{3}$.

\footnotetext{
${ }^{3}$ Carbonell (1999) coincide con otros autores en la necesidad de referirnos a la inevitable "pérdida" como inadecuación.
} 
En sus inicios, la noción de equivalencia tenía un carácter restringido al plano lingüístico, sin introducir ningún tipo de consideración contextual, y es la búsqueda de equivalencias entre las lenguas, lo que ha conducido a alegatos en pro de la intraducibilidad (Hurtado, 2001:214-215). Rabadán (1991:80), por su parte, desde una perspectiva global e interdisciplinar del proceso de traducción, sitúa al receptor meta de la traducción como el criterio último de aceptabilidad, pues es uno de los principales que intervienen en la consecución de la equivalencia:

Todo texto meta funciona de forma autónoma dentro del polisistema meta y su fin último es ser leído por una audiencia que pertenece a ese polisistema. Si el TM no responde a las expectativas de esta audiencia la cadena comunicativa se rompe: si no hay aceptabilidad por parte del usuario del polo meta, no hay traducción válida. (Rabadán, 1991:80).

En cualquier caso, el debate de la traducibilidad/intraducibilidad y el concepto de equivalencia no pueden, en ningún caso, centrarse en el estudio de las palabras de los textos de partida y de llegada, pues es el contenido de los mismos, la cultura y el saber en su sentido amplio lo que es el objeto de la traducción.

La intraducibilidad, para algunos autores como Hurtado, es intrínseca al mismo concepto de traducción:

Si la razón de ser de la traducción es la diferencia, lingüística y cultural, no le podemos pedir identidades a la traducción que, por su propia naturaleza, no puede cumplir; esta consideración sitúa la cuestión del literalismo y la intraducibilidad (Hurtado, 2001:29).

Así pues, en este trabajo de investigación sobre la traducción de la cultura, se entiende equivalencia en su sentido más dinámico, lejos de los antiguos cánones de prescripción e igualdad y con un carácter textual, contextual y funcional. Asimismo, se parte de la base de que existe una intraducibilidad cultural intrínseca al acto traductológico mismo, por cuanto existen unos signos 
lingüísticos pertenecientes únicamente al sistema de partida que no pueden ser transferidos en su totalidad con una simple frase explicativa.

\subsection{Las referencias culturales}

Existe una gran diversidad de definiciones para identificar aquellos elementos propios de la realidad cultural. No resulta extraño, por tanto, encontrar múltiples definiciones desde las diferentes teorías de la traducción para dar cuenta de estos fenómenos. También abundan las taxonomías. La variedad terminológica que encontramos refleja la falta de consenso que existe en la comunidad investigadora de traductores para identificar y definir los elementos culturales (Mayoral, 1999/2000), lo cual acaba suponiendo un problema de ambigüedad y de necesidad de explicitación continua de significado.

En este apartado daremos cuenta, por un lado, de las numerosas denominaciones que existen y las clasificaciones existentes que analizaremos para poder utilizarlas como instrumento de análisis en nuestro estudio. Para ello nos basaremos en la revisión que realiza Molina (2001) retomada por Mengshuan Ku (2006), revisada y ampliada.

\subsubsection{Denominaciones}

A continuación rastreamos la evolución de las denominaciones y nos detenemos en mayor medida en las opciones más relevantes.

Los inicios pueden situarse en la escuela soviética o eslava, que tiene como máximo representante a Fiódorov (1953). Esta escuela toma un enfoque comparativista de la traducción y distingue por primera vez entre los signos o referencias lingüísticas y los conceptos o referentes. 
Vlakhov y Florin introducen el término realia en traductología en 1970, definiéndolos como elementos de texto que muestran color social e histórico. Bödeker y Frese (1987) y Koller (1992) retoman más tarde este término pero con una definición más amplia: se refiere a las realidades físicas e ideológicas propias de una cultura concreta:

konkreten Einheiten, die an eine Kultur und/oder an einen geographischen Raum gebunden sind, also: Gegenstände und Konzepte, die mit kulturellem Handlungen zusammengehängen, politische, wirtschaftliche, soziale und kulturelle Institutionen (Bödeker y Freese, 1987:138).

Vinay y Darbelnet (1958) y Vázquez Ayora (1977) representan la corriente teórica comparativista denominada estilística diferencial, por la que se definen los elementos culturales como divergencias metalingüísticas a la hora de traducir y adaptarlos culturalmente.

En Approaches to Translation (1981), Newmark se refiere por primera vez a lo que este autor denomina cultural terms, y los define como sigue:

(...) token-words which first add local color to any description of their countries of origin, and may have to be explained, depending on the readership and the type of text (Newmark, 1981: 82).

La definición nos indica que existen determinados términos con una especificidad intrínseca que están vinculados a un contexto cultural determinado. Asimismo, aborda el problema de la intraducibilidad de los mismos y de la necesidad del conocimiento del mundo del lector y del tipo de texto.

Posteriormente, Newmark, en su obra de 1988 insiste en la diferencia entre lenguaje cultural, lenguaje universal, y lenguaje personal. El lenguaje universal se refiere a morir, vivir, estrella, nadar, etc. Estos conceptos no presentan problemas al estar presentes en todas las culturas. Sin embargo, los lenguajes 
cultural y personal suponen un problema para su traducción. El lenguaje cultural se refiere a palabras como monzón, estepa, dacha, chador, que crean un problema al no existir un referente equivalente en la lengua meta. A este fenómeno Newmark lo denomina palabras culturales extranjeras. El lenguaje personal se entiende como idiolecto, que supone una dificultad evidente por la manera personal que tiene de hablar y explicarse cada persona.

Newmark también acuña el término foco cultural para expresar un fenómeno en el que una comunidad focaliza su atención en un tema particular. Tomemos como ejemplos los términos sobre críquet en inglés, los términos sobre vinos y quesos en francés y en alemán, las salchichas. La distancia cultural y el vacío cultural son los causantes aquí de los problemas de traducción. Sin embargo, Newmark no incluye en sus cultural terms una definición para aquellas palabras que corresponden a una laguna léxica, lo que hoy por hoy entendemos por realia.

Por su parte, los teóricos de la escuela funcionalista han aportado varios términos para definir los elementos culturales. Katharina Reiss (1996) acuña el término determinantes extralingüísticos para referirse a aquellas palabras que determinan la cultura propia o historia específica de una comunidad, es decir, los realia.

El concepto de culturema lo atribuye Nord en 1996 a Oksaar (1988) que lo entendía como "las unidades abstractas de interacción y comportamiento entre los seres humanos" (Nord, 1994:524). En 1997, Nord redefine el término culturema:

Culturema: un fenómeno social de una cultura $A$ que es considerado relevante por los miembros de esa cultura y que, cuando se compara como un fenómeno social correspondiente en la cultura B, se encuentra que es específico de la cultura A. (Nord, 1997:34). 
La autora explica que un fenómeno correspondiente entre las culturas se refiere a una comparación bajo ciertas condiciones definidas, así como de forma diferente pero con función semejante (trenes vs. coches vs. bicicletas) o con la misma función pero con diferente forma (por ejemplo, to have coffee en Inglaterra por la mañana vs. tomar un café en España después de comer vs. Kaffeetrinken en Alemania por la tarde). Nord amplía la definición posteriormente, pues cree que los culturemas pueden ser verbales (palabras $u$ oraciones) o no verbales (expresiones corporales, gestos); paraverbales (sonidos o entonaciones) o una combinación de los tres.

Nord también introduce el concepto punto rico para expresar un fenómeno cultural específico en una determinada cultura. Al afrontar una nueva lengua "algunas cosas resultan chocantes por su dificultad, complejidad e imposibilidad a la hora de ajustarse a los recursos que se utilizan para dar sentido al mundo" (Nord, 1997:25). Define más tarde que los puntos son como la diferencia de comportamiento entre dos culturas, produciendo fricciones y ocasionando la formación de barreras entre sí.

Según Nord (1994:523) los indicadores culturales, tanto implícitos como explícitos, funcionan como término general para los elementos culturales, permitiendo reconocer el escenario cultural de un texto. Nord da varios ejemplos, entre ellos el nombre masculino Bill, como indicador implícito, que es asociado con un chico anglosajón.

Mayoral vuelve sobre este tema en 2001, cuya base se recoge en obras previas de Mayoral (1994). Mayoral explica que en la EUTI de Granada, desde un inicio, se extendió la denominación referencias culturales para hacer alusión a los términos provenientes de una cultura. Si bien se trata de una denominación práctica, esta manera de etiquetar hace referencia tanto a la referencia cultural 
(el signo), como el referente (el concepto). Probablemente sea por este motivo que en 1997, Mayoral y Muñoz establecen la denominación segmentos textuales marcados culturalmente para referirse al signo lingüístico, al que define como "toda porción de un texto aislada del resto para su análisis".

Por su parte, en Culture Bumps: An Empirical Approach to the Translation of Allusions (1997), la finlandesa Ritva Leppihalme utiliza la denominación culture bumps para indicar cualquier "situation where the reader of a target text has a problem understanding a source-cultural allusion". Creemos que los elementos culturales no pueden definirse en función del posible conocimiento o desconocimiento del lector en la cultura meta.

Reproducimos a continuación un cuadro resumen con las denominaciones y sus corrientes traductológicas correspondientes:

Tabla 2: Denominaciones de los culturemas (Moreno, 2006)

\begin{tabular}{|c|c|}
\hline OBJETO & SIGNO \\
\hline - Referencias culturales (Escuela de & - Segmentos marcados \\
Granada) & culturalmente (Mayoral) \\
- Culturemas (Nord) & - Referencias culturales (escuela de \\
- Realias, realias culturales (E. Eslava & Granada) \\
y de Leipzig) & - Palabras realias (escuela Eslava y \\
- Presuposiciones (Nida y Reyburn) & de Leipzig) \\
- Foco cultural (Newmark) & - Nombres de referentes culturales \\
- Referentes culturales específicos & específicos (Cartagena) \\
(Cartagena) & - Indicadores culturales (Nord) \\
- Divergencias metalingüísticas & - Palabras culturales (Newmark) \\
(Vázquez-Ayora, comparativismo) & - Léxico vinculado a una cultura \\
\hline
\end{tabular}




\section{(Katan)}

\subsubsection{Clasificación de las referencias culturales}

Vlakhov y Florin (1970) al mencionar el término realia, lo dividen en cuatro aspectos: geográficos y etnográficos, folclóricos y mitológicos, objetos cotidianos, sociales e históricos. Por su parte, Nida, en su libro Toward a Science of Translating, ya hacía referencia a los problemas que se originan al traducir elementos asociados a un contexto cultural:

Terms associated with social culture pose numerous problems, not only because the basic systems are often so different, but also because the extensions of meaning appropriate to one system rarely work in another. (1964:216-217).

En su artículo Linguistics and the ethnology in translation problems ${ }^{4}$, este autor establece varios ámbitos de diferencias culturales:

- Ecología

- Cultura social

- Cultura religiosa

- Cultura lingüística. En este apartado encontramos diferentes categorías: fonología, morfología, sintaxis y léxico.

Newmark (1988) adapta lo indicado por Nida dividiendo lo que él denomina palabras culturales:

- Ecología: En este apartado se incluye la flora, la fauna la geografía, la topografía, etc.

\footnotetext{
4 Clasificación en Linguistics and Ethnology in translation Problems, publicado en 1945 en Word 1, pp.194-208.
} 
- Cultura material: incluye cuatro subcategorías de (1) comida; (2) ropa; (3) viviendas y poblaciones; (4) transporte.

- Cultura social: incluye trabajo y ocio.

- Organizaciones, costumbres, actividades, procedimientos, conceptos: se dividen en tres subapartados: (1) políticas y administrativas; (2) religiosas; (3) artísticas.

- Gestos y hábitos.

Nord (1994/1997) distingue cuatro funciones textuales de la traducción: referencial, expresiva, apelativa y fática:

- Función referencial: denominada también función denotativa o cognitiva. Hace referencia a objetos o fenómenos del mundo o de un mundo particular. Según la diferencia entre los referentes, puede tener subfunciones como informativa, didáctica, etc. El problema se halla en que cada cultura tiene un modo de referenciar la realidad, con lo que la cultura de origen puede expresarse de distinto modo a la cultura meta.

- Función expresiva: indica Nord que es un término más amplio que el aspecto estético de los textos literales de Reiss. Se refiere a la actitud del emisor hacia los objetos y los fenómenos del mundo. Puede ser, por ejemplo, emotiva (transmisión de sensaciones) o evaluativa (decisión gubernamental). Como cada cultura tiene perspectivas distintas, se producen malentendidos en cuanto a la connotación expresada implícitamente.

- Función apelativa. Nord retoma este término de Jakobson, que la llama conativa. Se refiere a la acción de persuadir para obtener una cierta respuesta. Es una función orientada hacia los receptores, se requiere la 
misma susceptibilidad o experiencia de los receptores de la cultura meta para conseguir la misma función.

- Función fática: se trata de comenzar, mantener o finalizar un contacto. Como la convención cultural difiere según cada comunidad cultural, las maneras de expresarse resultan distintas. Si no se aplica una forma convencional en la cultura de los receptores, la función fática se puede interpretar como otras funciones (referencial, expresiva o apelativa).

Katan explica en Translating cultures (1999), que los aspectos de la cultura no pueden encontrarse en uno o varios niveles aisladamente, sino que funcionan a modo de proceso y operan en todos los niveles. Para Katan, existen seis niveles lógicos de cultura que operan a la vez:

- El entorno. Son los elementos del entorno que influyen en la conducta referente a la cultura. Se incluye el entorno físico, el ideológico, el clima, el espacio, las viviendas y construcciones, la manera de vestir, los olores, la comida, las divisiones y los marcos temporales.

- La conducta. Son las reglas de conducta en diferentes culturas; abarca las acciones y reacciones que se perciben en una cultura cualquiera.

- Las capacidades, estrategias y habilidades para comunicarse. En este nivel importa cómo se transmite y se percibe un mensaje a través de lo que se ha leído, visto o sentido. Katan explica que a partir de ese nivel se llega al marco de referencia cultural; el marco en cuestión es un contexto psicológico interno que hace referencia a un mundo real externo. Este nivel abarca, pues, el modo de transmitir el mensaje (escrito, oral o no verbal), así como los rituales y las estrategias.

- Los valores. Este nivel incluye los valores de una sociedad y su jerarquía. La jerarquía de los valores muestra las prioridades existentes de unos 
valores sobre otros, mientras que el conjunto de valores es el indicativo principal de una sociedad.

- Las creencias. Debido a la diferencia de creencias, la gente de entornos similares en diferentes culturas puede actuar de modo diferente. De las creencias proceden las motivaciones, según Katan, para hacer o no hacer ciertas cosas. Como estas creencias afectan a la lengua y a la conducta, son fuente a menudo de malinterpretaciones y de malentendidos culturales.

- La identidad. Es el nivel más alto de la jerarquía de los niveles lógicos y abarca y domina al resto de niveles anteriormente mencionados.

Molina (2001:91-98) revisa los autores anteriormente citados y propone un concepto amplio para cada categoría. Su propuesta está dividida en cuatro aspectos diferentes:

- Medio natural. Este apartado abarca la ecología de Nida y el ambiente natural de Nord. Además también incluye la cuestión de los topónimos que generan problemas culturales debido al significado dentro del texto. Este apartado también incluye flora, fauna, fenómenos atmosféricos, climas, vientos y paisajes.

- Patrimonio cultural. En este ámbito se ubica una vasta gama de los elementos culturales que abarcan la categoría de la cultura religiosa y la cultura material de Nida, la comunicación referencial y el comportamiento fático de la función referencial de Nord y el ámbito de la cultural material de Newmark y la categoría de realia folclóricos y mitológicos de Vlakhov y Florin. En este apartado se encuentran, pues, elementos culturales como personajes, hechos históricos, conocimientos religiosos, festividades, creencias populares, folclore, obras y movimientos artísticos, obras y movimientos artísticos, cine, música, 
bailes, juegos, monumentos emblemáticos, lugares conocidos, viviendas y objetos, instrumentos musicales, técnicas empleadas en la explotación de la tierra, en la pesca, estrategias militares, medios de transporte, etc.

- Cultura social. Se trata de la cultura social de la clasificación de Nida y de las organizaciones y costumbres de Newmark. Corresponde a las funciones fática, expresiva y apelativa de los comportamientos culturales del modelo de Nord. Se puede dividir en dos aspectos: (1) convenciones y hábitos sociales; y (2) organización social.

- Cultura lingüística. Recoge las subcategorías fonológicas y léxicas de Nida, prescindiendo de las morfológicas y sintácticas, ya que opina que los dos últimos aspectos no pertenecen estrictamente a cuestiones culturales. Este epígrafe incluye los problemas derivados de la transliteración, frases hechas, metáforas generalizadas, asociaciones simbólicas, interjección, blasfemias, insultos, etc.

Además, esta autora señala el fenómeno de la interferencia cultural, que se puede dividir en dos grupos:

- Falsos amigos culturales. Es un fenómeno similar al de los falsos amigos lingüísticos. En vez de una connotación lingüística distinta, los falsos amigos culturales se refieren al mismo concepto, comportamiento o gesto con diferente connotación cultural. Existen, pues, falsos amigos culturales y falsos amigos culturales parciales. Estos últimos se producen cuando la connotación del fenómeno entre dos culturas se corresponde parcialmente. Se da este caso al traducir la asociación de simbología, del comportamiento y los desencuentros culturales entre dos culturas.

- Injerencia cultural. La autora explica que este fenómenos surge cuando aparecen en el texto origen elementos propios de la cultura meta; está 
próximo a la acepción la mirada del otro de Carbonell i Cortés (1997) ${ }^{5}$. Se encuentra con más frecuencia en la traducción de textos de ficción.

Mengshuan Ku (2006) añade a la categorización de Molina lo que esta autora considera otro fenómeno cultural en sí y que resulta fundamental para el análisis de las traducciones del texto turístico, como es el foco cultural, según lo entendemos de Newmark en su aplicación para la traducción (cfr. 2.5.1).

Como hemos podido constatar, existen múltiples denominaciones para designar el elemento lingüístico cultural. No creemos necesario acuñar un nuevo término para definir lo que tantos traductólogos han intentado, con mayor o menor fortuna, designar. La definición con la que más nos identificamos en este trabajo es la de Nord, que acabó de acuñar culturema dándole una denominación un tanto más científica y con cierta especificidad y terminología frente a otras denominaciones como palabras culturales y referencias culturales. Es importante desvincular el término culturema o referencia cultural del problema de traducción, pues los culturemas pueden, siempre, de un modo $\mathrm{u}$ otro, traducirse, $\mathrm{y}$, en muchos casos, existe el equivalente cultural por proximidad de culturas. Las clasificaciones de los culturemas también son variadas $y$, en muchos casos, presentan distintas denominaciones para un mismo tipo de nivel o categoría. La categorización que ofrece Molina y que hemos presentado en última instancia es la que nos resulta más interesante, pues recoge todas las propuestas de los traductólogos anteriores pero sin restricciones y en un sentido amplio.

\footnotetext{
${ }^{5}$ Carbonell i Cortés (1977) reflexiona sobre la actuación de imposición ideológica que puede significar la traducción en el marco de los estudios postcoloniales al convertirse en un medio de dominio cultural y hace un estudio de las traducciones entre el árabe y el español, que se hallan mediatizadas por la visión doméstica que tenemos de Oriente. Para este autor, existe un tercer espacio intermedio (1977:148), desde donde la traducción puede operar para no excluir a las culturas en juego ni homogeneizarlas.
} 
A continuación revisaremos las técnicas de transferencia o traducción cultural, los distintos enfoques que nos ofrecen las distintas escuelas de traducción y su pertinencia de utilización como elemento teórico para el desarrollo del posterior análisis en el capítulo cuarto de esta tesis doctoral.

\subsection{Las técnicas de transferencia cultural}

Una vez considerados los diferentes ámbitos culturales con sus diversas clasificaciones y denominaciones, pasamos a revisar los criterios y las técnicas propuestas para resolver la traducción de las referencias culturales. Sin embargo, como indica Mayoral (1999/2000), para poder llegar a soluciones generalmente aceptables sobre la traducción de las referencias culturales, es necesario alcanzar acuerdos previos sobre a qué corresponden las denominaciones de estrategias de traducción, procedimientos de traducción, técnicas de traducción, recursos o procedimientos expresivos, e incluso otros como enfoques traductológicos. Sin duda, la homogeneidad terminológica no es una de las características de la traductología, por lo que coincidimos con Mayoral en la necesidad constante de explicitar y definir en esta disciplina.

La noción de técnica de traducción resulta a priori una noción confusa en traductología. La primera confusión proviene de la misma denominación por la multiplicidad de denominaciones que acabamos de mencionar y la segunda confusión ha venido dada por el carácter prescriptivo que se le ha querido dar a las técnicas de traducción utilizando distintas clasificaciones que solapan las distintas categorías con variedad de denominaciones.

Autores como Hurtado (2001) plantean la necesidad básica de distinguir entre el método, las técnicas y las estrategias de traducción. Esta necesidad la apuntó ya 
Wilss en 1983, aunque hizo un planteamiento en otros términos, pues este autor entiende por estrategias la perspectiva general, los planteamientos desde los que parte el traductor y por método, los procedimientos utilizados durante el proceso traductor (tanto en la comprensión como en la reexpresión). Nosotros coincidimos con Hurtado (2001:249) en que "el método traductor supone el desarrollo de un proceso traductor determinado regulado por unos principios en función del objetivo del traductor". Se trata, pues de una opción que es global y que afecta a todo el texto.

Tomaremos la definición de técnica de traducción de Hurtado (2001:642), que la define como:

(...) procedimiento visible en el resultado de la traducción, que se utiliza para conseguir la equivalencia traductora a microunidades textuales; las técnicas se catalogan en comparación con el original. La pertinencia del uso de una técnica u otra es siempre funcional, según el tipo textual, la modalidad de traducción, la finalidad de la traducción y el método elegido.

A diferencia del método, que es una opción global, que recorre todo el texto y que tiene efectos en el proceso y el resultado, "la técnica afecta sólo al resultado y a elementos menores del texto". Las estrategias, por su parte, "pueden no ser verbales y afectan a todo el proceso traductor y sirven para dar solución a los problemas encontrados". Las técnicas, sin embargo, "se manifiestan únicamente en la reformulación en una fase final de toma de decisiones" (Hurtado, 2008:257).

Consideramos importante usar las técnicas de traducción como elemento descriptivo de la toma de decisiones que realiza el traductor, puesto que, de este modo, estamos tomando en consideración las unidades menores de texto y el funcionamiento de la equivalencia respecto al TO. A continuación repasamos las propuestas de las técnicas de traducción existentes en traductología con sus 
diversos enfoques y clasificaciones basándonos en la revisión de Molina (2001:99-110).

\subsubsection{La Estilística Comparada de Vinay y Darbelnet (1958)}

Vinay y Darbelnet (1958) son los pioneros en definir los procedimientos técnicos de traducción y proponer una clasificación. Según estos autores, las técnicas de traducción operan en tres niveles: el del léxico, el de la organización (morfología y sintaxis) y el del mensaje. Distinguen siete procedimientos básicos que clasifican en directos o literales y oblicuos, en relación con la traducción directa (literal) y la traducción oblicua. Por traducción literal se entiende una equivalencia exacta en términos estructurales, léxicos e incluso morfológicos. Las categorías de Vinay y Darbelnet son elementos característicos de las Estilísticas Comparadas y tienen un carácter prescriptivo. Según los autores, este tipo de equivalencia es sólo posible en casos en los que las dos lenguas son muy cercanas. Los procedimientos de traducción literal son tres:

- Préstamo, que se utiliza tomando directamente una palabra de la cultura de origen e incorporarla a la lengua de llegada. Los autores ponen como ejemplo la voz inglesa bulldozer.

- Calco. Una palabra extranjera, sintagma nominal o locución es traducida e incorporada a otra lengua (Ej.: fin de semaine a partir de la voz inglesa weekend).

- La traducción literal. Es la traducción palabra-por-palabra (por ejemplo: The ink is on the table y L'encre est sur la table).

La traducción oblicua tiene lugar cuando una traducción literal no es posible. En estos casos encontramos los siguientes procedimientos: 
- Transposición. Esta técnica supone un cambio de categoría gramatical, de sustantivo a verbo, de sustantivo a preposición, como por ejemplo expéditeur y from.

- Modulación. Supone un cambio en el punto de vista, el enfoque o la categoría del pensamiento. Vinay y Darbelnet establecen once categorías de modulación: abstracto por concreto, causa por efecto, método por resultado, una parte por el todo, cambio geográfico, etc. (Ej.: encre de Chine por Indian ink).

- Equivalencia. Da cuenta de la misma situación pero utiliza una redacción completamente diferente. Suele utilizarse a menudo con los refranes o las frases hechas, como por ejemplo Comme un chien dans un jeu de quilles y Like a bull in a China shop.

- Adaptación. Es un cambio en el contexto cultural usando una equivalencia reconocida entre dos situaciones, por ejemplo, cycling para los franceses, cricket para los británicos y baseball para los norteamericanos.

Estos siete procedimientos básicos se complementan con una serie de procedimientos que, a excepción de la compensación e inversión, se enuncian todos ellos como pares opuestos:

- Compensación. Se trata de introducir en otro lugar del TM una parte de información, o un efecto estilístico que no ha podido colocarse en el mismo lugar en el que aparecía en el TO. Ej.: la frase del Libro de la Selva: I was seeking thee, Flathead, donde Kipling utiliza el arcaísmo thee, en lugar de you; al no existir en francés un uso arcaico en las formas del pronombre equivalente ( $t u, t e, t o i)$, se traslada el matiz mediante el 
empleo del vocativo $O$ y se coloca en otro lugar de la frase: En vérité, c'est bien toi que je cherche, O Tête-Plate.

- Disolución vs. concentración. Ej.: archery es una disolución de la voz francesa tir à l'arc.

- Amplificación vs. condensación. Estos procedimientos son parecidos a los de disolución y concentración. La amplificación se da cuando en la LM se usa un mayor número de significantes para cubrir los posibles vacíos léxicos o sintácticos. El procedimiento contrario es el de economía, por ejemplo: Nous ne pourrons plus vendre si nous sommes trop exigeants por We'll price ourselves out of the market.

- Explicitación vs. implicitación. La explicitación consiste en la introducción de información implícita del contexto o situación del TO, por ejemplo: hacer explícito el sexo del paciente al traducir his patient al francés. Por el contrario, la implicitación supone dejar que el contexto o la situación precisen información explícita en el texto original, por ejemplo, el significado de sortez como go out o come out.

- Generalización vs particularización. La generalización consiste en traducir un término por otro más general y la particularización es el caso contrario. Ej.: la distinción que existe en francés entre guichet, fenêtre y devanture, cuando en inglés sólo existe window.

- Articulación vs. yuxtaposición. Son procedimientos opuestos que dan cuenta del uso o la ausencia de marcas lingüísticas de articulación a la hora de enunciar un razonamiento. Ej.: In all this immense variety of conditions, the objective must be... y Et cependant, malgré la diversité des conditions.

- Gramaticalización vs. lexicalización. La primera consiste en reemplazar signos léxicos por gramaticales. Ej.: la preposición léxica inglesa in en 
muchas ocasiones se gramaticaliza en francés: $A$ man in a blue suit y Un homme vêtu de bleu.

- Inversión. Se trata de trasladar una palabra o sintagma a otro lugar de la oración o del párrafo para conseguir la estructura normal de la frase en la otra lengua. Ej.: Pack separately (...) for convenient inspection y Pour faciliter la visite de la douane mettre à part (...)

Tabla 3: Procedimientos de traducción de Vinay y Darbelnet (1958:55)

\begin{tabular}{|c|c|}
\hline Borrowing & Bulldozer $(E)=>$ Bulldozer $(F)$ \\
\hline Calque & Fin de semaine $(F)=>$ Week-end $(E)$ \\
\hline Literal translation & L'encre est sur la table $(F)=>$ The ink is on the table \\
\hline Transposition & Défense de fumer $(F)=>$ No smoking $(E)$ \\
\hline $\begin{array}{l}\text { Crossed } \\
\text { transposition }\end{array}$ & $\begin{array}{l}\text { He limped across the street }(E)=>\| \text { a traversé la rue en } \\
\text { boitant }(F)\end{array}$ \\
\hline Modulation & Encre de Chine $(F)=>$ Indian ink $(E)$ \\
\hline Equivalence & $\begin{array}{l}\text { Comme un chien dans un jeu de quilles }(F)=>\text { Like a bull } \\
\text { in a China shop }(E)\end{array}$ \\
\hline Adaptation & Cyclisme (F) => Cricket (E) => Baseball (U.S.) \\
\hline Compensation & $\begin{array}{l}\text { I was seeking thee, Flathead }(E)=>\text { En vérité,, c'est bien } \\
\text { toi que je cherche, } \underline{\text { O Tête-Plate }(F)}\end{array}$ \\
\hline Amplification & $\begin{array}{l}\text { He talked himself out of a job }(E)=>\| \text { a perdu sa chance } \\
\text { pour avoir trop parlé }(F)\end{array}$ \\
\hline Economy & Nous ne pourrons plus vendre si nous sommes trop \\
\hline
\end{tabular}




\begin{tabular}{|c|c|}
\hline & $\begin{array}{l}\text { exigeants }(F)=>\text { We'll price ourselves out of the market } \\
\text { (E) }\end{array}$ \\
\hline Reinforcement & $\begin{array}{l}\text { Shall I phone for a cab? (E) => Voulez-vous que je } \\
\text { téléphone pour faire venir une voiture? (F) }\end{array}$ \\
\hline Condensation & Entrée de la garde $(F)=>$ To the station $(E)$ \\
\hline Explicitation & His patient $(E)=>$ Son patient/Son patiente $(F)$ \\
\hline Implicitation & Go out/come out $(E)=>$ Sortez $(F)$ \\
\hline Generalization & Guichet, fenêtre, devanture $(F)=>$ Window $(E)$ \\
\hline Particularization & Window $(E)=>$ Guichet, fenêtre, devanture $(F)$ \\
\hline Articularization & $\begin{array}{l}\text { In all this immense variety of conditions... }(E)=>\text { Et } \\
\text { cependant, malgré la diversité des conditions,... (F) }\end{array}$ \\
\hline Juxtaposition & $\begin{array}{l}\text { Et cependant, malgré la diversité des conditions,... (F) => } \\
\text { In all this immense variety of conditions... (E) }\end{array}$ \\
\hline Grammaticalization & A man in a blue suit $(E)=>$ Un home vêtu de bleu $(F)$ \\
\hline Lexicalization & Un home vêtu de bleu $(F)=>A$ man in a blue suit $(E)$ \\
\hline Inversion & $\begin{array}{l}\text { Pack separately }(. . .) \text { for convenient inspection }(E)=> \\
\text { Pour faciliter la visite de la douane mettre à part (...) (F) }\end{array}$ \\
\hline
\end{tabular}

\subsubsection{Los traductores bíblicos}

Los traductores bíblicos más representativos y que se han centrado en el estudio de la transferencia cultural son Nida, Taber y Margot. Su propuesta es muy interesante, pues aunque no ofrecen una taxonomía de técnicas de 
traducción al uso, sí ofrecen varias categorías para los casos en los que no existe un equivalente cultural en la LM. Estas categorías las denominó Nida genéricamente técnicas de ajuste.

Nida (1964) propone tres tipos: adición, sustracción, alteración y notas a pie de página. Se usan, principalmente, 1) para ajustar la forma del mensaje a las características de la estructura de la LM; 2) para producir estructuras semánticamente equivalentes; 3) para generar equivalencias estilísticamente equivalentes; 4) para producir un efecto comunicativo equivalente.

- Adiciones. Varios de los procedimientos de Vinay y Darbelnet de la Estilística comparada del inglés y del francés (ECIF) están recogidos en esta categoría. Nida elabora una lista de las circunstancias que pueden obligar al traductor a realizar una adición: clarificar una expresión elíptica, evitar la ambigüedad en la LM, realizar un cambio de categoría gramatical (esta técnica se corresponde con la trasposición de ECIF), amplificar elementos implícitos (se corresponde con la explicitación de ECIF), y añadir conectores (se corresponde con la articulación de ECIF según las necesidades de la LM, etc.).

- Sustracciones. Nida lista cuatro situaciones en las que el traductor debería usarlas, además de cuando es necesario por las características propias del LM: repetición innecesaria, referencias específicas, conjunciones y adverbios.

- Alteraciones. Estos cambios se deben realizar debido a las incompatibilidades que existen entre las dos lenguas en cuestión. Nida las divide en:

- Cambios debido a problemas causados por la transliteración o cuando se introduce una nueva palabra del TO. 
- Cambios debido a diferencias estructurales entre las dos lenguas, por ejemplo, cambios en el orden de los elementos en la oración, categorías gramaticales, etc. (similar a la trasposición de ECIF).

- Cambios debido a errores en adaptaciones semánticas, especialmente en las expresiones idiomáticas. Una de las sugerencias para solucionar este tipo de problema es el uso de un equivalente descriptivo, es decir, un equivalente satisfactorio para objetos, eventos, o atributos que tienen un término estándar equivalente en la LM. Se usa para objetos que son desconocidos en la $\mathrm{CM}$ y para acciones que no tienen un equivalente léxico.

Nida incluye las notas a pie de página como otro procedimiento de técnica de ajuste y señala que tienen dos funciones principales: 1) corregir las diferencias culturales y lingüísticas, por ejemplo, explicar costumbres contradictorias en dos culturas, identificar elementos geográficos o físicos desconocidos, proporcionar equivalentes para pesos y medidas, explicar los juegos de palabras, añadir información sobre los nombres propios, etc.; 2) añadir información sobre el contexto cultural e histórico del texto en cuestión.

Jean-Claude Margot (1979) establece tres criterios básicos de adaptación cultural y se refiere a ellos como diferencias esenciales.

- Elementos desconocidos por la CM. Sugiere añadir un elemento clasificador junto a la palabra (tal como hace Nida), ej.: the city of Jerusalem, o utilizar un equivalente cultural (procedimiento similar a la adaptación de ECIF). Sin embargo, este autor advierte al lector de que este procedimiento no siempre es posible. Taber y Nida (1974) realizan una lista de cinco factores que deben tenerse en cuenta a la hora de usar esta técnica: a) la importancia simbólica y teológica del ítem en cuestión; b) su relación semántica con otras 
palabras; c) las similitudes de funcionamiento y forma entre los dos ítems y d) la respuesta emocional del lector.

- El marco histórico. Aquí Margot propone una traducción lingüística y no cultural, arguyendo que los hechos históricos no se pueden cambiar.

- Adaptación a la situación específica de la audiencia del TM. Margot mantiene que la tarea del traductor es la de traducir y que corresponde a los sacerdotes, religiosos y estudiosos de la Biblia adaptar el texto bíblico a la situación específica de la audiencia meta. Considera que las notas a pie de página son una ayuda para la adaptación cultural.

Nida, Taber y Margot coinciden en distinguir entre paráfrasis legítima e ilegítima. La paráfrasis legítima es una herramienta muy útil que consiste en utilizar un giro idiomático distinto en la LM dentro de las distintas posibilidades que las lenguas tienen para expresar el mismo concepto. En palabras de Margot (1979:128-129):

(...) Ce genre de paraphrase repose sur le principe que chaque langue a diverses manières de dire la même chose, auquel s'ajoute le fait que, du point de vue de la traduction, les langues ont des façons diverses et originales d'exprimer la même chose.

(...) Dans le domain de la traduction, on y recourt constamment pour résoudre les problems posés par les différences de structures des langues. Chaque fois qu'on rend une tournure idiomatique de la langue source par une tournure idiomatique equivalente de la langue réceptrice, on procède à une paraphrase légitime.

La paráfrasis legítima supone, pues, un cambio léxico y, en algunos casos, gramatical, que puede dar lugar a que el TM sea más largo que el TO, pero sin embargo, el significado primario del TO nunca se ve alterado (técnica similar a la amplificación/disolución de ECIF). Por el contrario, la paráfrasis ilegítima suponer explicitar elementos del TO en el TM. Nida, Taber y Margot alertan de los peligros que puede suponer introducir elementos subjetivos y no lo consideran tarea del traductor. Tal como apunta Margot (1979:130): 
Le traducteur doit rendre le texte fidèlement, c'est-à-dire, le traduire de telle façon qu'il ne soit en principe ni plus difficile, ni plus facile à comprendre dans la langue réceptrice que dans la langue source. II n'a pas à le completer par des explications ou des opinions subjectives (...)

Según Margot (1979) la redundancia intenta conseguir la simetría entre los lectores del TO y los del TM. Esto se consigue bien añadiendo información (elementos gramaticales, sintácticos, estilísticos,...) cuando las diferencias entre las dos lenguas y las dos culturas hacen que sea imposible una recepción similar de los lectores del TM, bien suprimiendo información cuando los elementos del TO son redundantes para los lectores del TM. Este procedimiento es muy similar al de implicitación/explicitación de ECIF.

El concepto de naturalización lo introdujo Nida (1964) después de utilizar el término natural para definir la equivalencia dinámica ("the closest natural equivalent to the source language message"). Se trata de un concepto próximo a la adaptación de ECIF. Nida establece que la naturalización puede realizarse teniendo en cuenta los siguientes parámetros: la LO y la cultura de origen (CO) entendidas como un todo, el contexto cultural del mensaje y el lector al que va destinado la traducción.

Tabla 4: Propuestas de Nida y los Traductores Bíblicos (Molina y Hurtado, 2002)

\begin{tabular}{|l|l|}
\hline Elemento clasificador & The city of Jerusalem \\
\hline Alteración & Messiah (E) => Mezaya (Loma) \\
\hline Equivalente cultural & $\begin{array}{l}\text { Grapes/thorn bushes and figs => otras plantas que } \\
\text { sean más comunes en la CM. }\end{array}$ \\
\hline Descripción equivalente & $\begin{array}{l}\text { Synagogue => The house were the law was read } \\
\text { (Maya) }\end{array}$ \\
\hline
\end{tabular}


Notas al pie de página

\subsubsection{Los procedimientos técnicos de Vázquez Ayora}

Vázquez Ayora (1977) utiliza la expresión procedimientos técnicos operativos, si bien en algunos casos opta por referirse a estos como método traductor. Se trata de una combinación de la visión prescriptiva de la ECIF y de la visión descriptivista de los traductores bíblicos. Su contribución más relevante son las siguientes técnicas:

- Omisión. Se usa para evitar la repetición y redundancia típica del TO, por ejemplo, traducimos The committee has failed to act por La comisión no actuó, omitiendo el verbo to fail y evitando la sobretraducción que supondría La comisión dejó de actuar.

- Desplazamiento e inversión. El desplazamiento corresponde a la inversión de ECIF, en el que dos elementos cambian de posición (ej.: The phone rang y Sonó el teléfono).

Tabla 5: La contribución de Vázquez Ayora (Molina y Hurtado, 2002)

\begin{tabular}{|l|l|}
\hline Omisión & $\begin{array}{l}\text { The committee has failed to act }(E)=>\text { La commision no } \\
\text { actuó }(\mathrm{Sp})\end{array}$ \\
\hline Inversión & The phone rang $(\mathrm{E})=>$ Sonó el teléfono $(\mathrm{Sp})$. \\
\hline
\end{tabular}

\subsubsection{Delisle}

Delisle (1993) introduce algunas variaciones a la ECIF y mantiene el término procedimiento según lo consideran Vinay y Darbelnet. No obstante, para otro tipo de categorías nuevas que ofrecen como propias, Delisle utiliza terminología distinta como estrategias de traducción, errores de traducción, operaciones en 
el proceso cognitivo de traducción, etc. Delisle realiza una lista con categorías que clasifica como pares opuestos.

Al revisar las categorías de Vinay y Darbelnet, propone simplificar las dicotomías de refuerzo/compensación y de amplificación/economía y reducirlas a un solo par, refuerzo/economía. El refuerzo consiste en utilizar más palabras en el TM que en el TO para expresar la misma idea. Distingue tres tipos de refuerzo: 1) disolución; 2) explicitación y 3) perífrasis (corresponde de a la amplificación de ECIF). Economía se refiere al uso de menos palabras en el TM que en el TO para expresar la misma idea. Delisle distingue entre tres tipos de economía: 1) concentración; 2) implicitación (estos dos últimos se corresponden con sus homónimos de ECIF y son opuestos a la disolución y la explicitación); y 3) concisión (se corresponde stricto sensu con la economía de ECIF y se establece por oposición a la perífrasis).

Las otras categorías que Delisle introduce son:

- Adición vs omisión. Los define como perífrasis no justificadas y concisión y los considera errores de traducción. Delisle establece un cierto carácter prescriptivo en esta categorización. La adición consiste en introducir elementos estilísticos injustificados e información que no está en el TO, y la omisión es la supresión injustificada de elementos en el TM.

- Paráfrasis. Delisle la define como el uso excesivo de paráfrasis que hace que el TM resulte complicado y sin que exista una justificación estilística o propósito retórico. También lo clasifica como error. La paráfrasis y la adición de Delisle coinciden con la paráfrasis ilegítima de Margot.

- Creación discursiva. Se trata de una operación en el proceso cognitivo de traducir por el cual se establece una equivalencia no léxica que sólo funciona en un contexto determinado, por ejemplo, si In the world of 
literature, ideas become cross-fertilized, the experience of others can be usefully employed to mutual benefit se traduce en francés como Dans le domain des lettres, le choc des idées se révèle fécond; il devient posible de profiter de l'éxperience d'autrui. Este concepto es similar al de alteración de Nida, cuando se produce por incompatibilidades semánticas y transliteración.

Tabla 6: La contribución de Delisle (Molina y Hurtado, 2002)

\begin{tabular}{|c|c|c|c|}
\hline \multirow{3}{*}{ Refuerzo } & \multicolumn{3}{|l|}{ Disolución } \\
\hline & \multicolumn{3}{|l|}{ Explicitación } \\
\hline & Perífrasis (+) & Adición (-) & Paráfrasis (-) \\
\hline
\end{tabular}

\begin{tabular}{|c|c|c|}
\hline \multirow{3}{*}{ Economía } & \multicolumn{2}{|l|}{ Concentración } \\
\hline & \multicolumn{2}{|l|}{ Implicitación } \\
\hline & Concesión (+) & Omisión (-) \\
\hline
\end{tabular}

\subsubsection{Los procedimientos de Newmark}

Newmark indica que, para transferir los elementos culturales, es necesario tener en cuenta una serie de factores contextuales como son: 1) la finalidad del texto; 2) la motivación y el nivel cultural, técnico y lingüístico de los lectores; 3 ) la importancia del culturema en el TO; 4) el marco; 5) la novedad del 
término/referente; 6) el futuro del referente. Este autor indica doce procedimientos o técnicas de traducción que pueden utilizarse para trasponer esos elementos (1988:145):

- Préstamo

- Equivalente cultural

- Neutralización (explicación del referente)

- Traducción literal

- Naturalización

- Análisis componencial o explicitación

- Supresión

- Doblete (combinación de dos técnicas)

- Traducción estándar aceptada

- Paráfrasis

- Glosas y notas

- Otras

Los culturemas, además de pertenecer a categorías diferentes, presentan problemas distintos al traductor. Hurtado (2001) analiza los distintos criterios que pueden usarse para la traducción de culturemas retomando a Margot (1979), quien plantea que hay que tener en cuenta tres cuestiones: 1) cuándo las culturas recurren a medios diferentes para alcanzar objetivos similares; 2) cuándo los mismos objetos o acontecimientos pueden tener sentidos diferentes (los falsos amigos culturales); 3) cuándo algunos objetos o acontecimientos no existen en otras culturas (la inequivalencia).

Por otro lado, Hewson y Martin (1991), desde un enfoque variacional, señalan una serie de opciones que se le abren al operador cultural según la relación existente entre las dos culturas: 1 ) la reducción, cuando el sistema cultural del 
partida domina al de llegada; 2) la marginalización, el caso contrario; 3) la inserción, cuando pueden integrarse algunos valores culturales; 4) la conversión, cuando se utilizan valores similares.

Otros autores se interesan más por las técnicas que conviene adoptar. Así, Vlakhov y Florin (1970) proponen seis maneras de traducir los realia: transcripción, calco, formación de una palabra nueva, asimilación cultural, traducción aproximada (trasladar el significado general de la palabra) y traducción descriptiva. Según estos autores, el traductor debe dar a la traducción un color local sin producir por ello un exceso de extrañeza. Florin (1993) recoge un inventario de técnicas de traducción para resolver los realia donde se recoge la propuesta de 1970 introduciendo algunos matices y proponiendo una serie de condicionantes que intervienen en la elección de una técnica u otra, como son:

- El carácter del texto y su tipología textual

- La importancia del elemento cultural en el contexto del conjunto del texto

- La naturaleza del elemento cultural

- El par de lenguas en cuestión

- Las características del lector

Hervey y Higgins (1992), por su parte, utilizan la noción de filtro cultural. Se trata de un concepto que manejan en didáctica de la traducción dentro de la categoría de filtros textuales. Éstos pueden ser de diversa índole: filtro cultural, formal, semántico, de variación lingüística, y de género. El filtro cultural se enmarca dentro de lo que los autores denominan trasposición cultural, que incluye todas aquellas soluciones que no comporten una traducción literal. Así, en la transposición, el traductor dispone de una serie de alternativas que 
pueden estar más alejadas o cercadas a la cultura del texto origen o del texto meta, según considere conveniente el traductor. Las reproducimos en la siguiente figura:

Figura 3: Grados de transposición cultural (Hervey y Higgins, 1992:28)

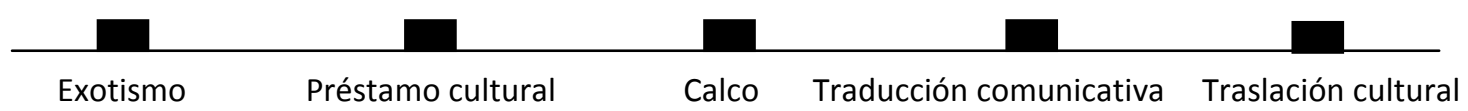

Las opciones más extremas son el exotismo y la traslación cultural. Traducir de modo exotizante significa trasvasar de una cultura realizando adaptaciones mínimas y usando constantemente rasgos lingüísticos y culturales de la lengua de partida. La traslación cultural, en el otro extremo, significa una adaptación total a la cultura de llegada. El traductor puede usar también préstamos culturales cuando no es posible encontrar en la lengua de llegada expresiones o conceptos de la lengua de partida o acudir a traducciones comunicativas cuando es posible usar equivalentes comunicativos que se identifican claramente en la lengua de partida (para fórmulas codificadas, proverbios, clichés, etc.). El calco se emplea respetando el léxico y la sintaxis de la lengua meta, pero no son idiomáticos porque están formados según la lengua de partida.

\subsubsection{Katan y los marcos conceptuales}

Katan (1999) introduce el concepto marco como una herramienta importante en lingüística. Los marcos tienen un carácter cognitivo y son representaciones mentales de situaciones que sirven para caracterizar la experiencia de un individuo y el modo en que estos perciben, interpretan y se comunican. Para Katan existen tres procesos básicos que configuran el mapa del mundo y la representación semántica: son los procesos de generalización, supresión y distorsión. 
The world
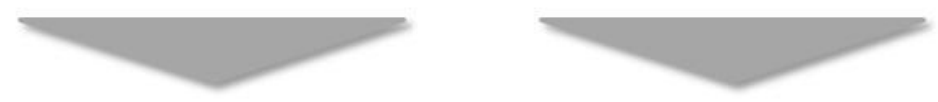

\section{Deletion Distortion Generalisation}

FILTER 1

physiological

\section{Deletion Distortion Generalisation}

FILTER 2

Social engineering

culture-bound beliefs and values

\section{Deletion Distortion Generalisation}

FILTER 3

\section{Map of the world}
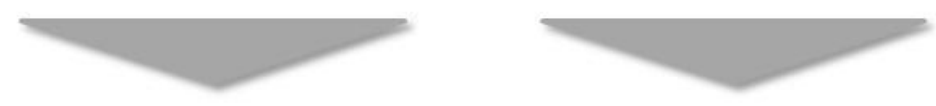

The semantically complete linguistic representation

En la figura anterior, observamos el proceso inconsciente que, según Katan, los humanos hacemos para dotar de significado al mundo que nos rodea y que conforma el map of the world. Existen una serie de filtros mentales (fisiológicos, socio-culturales y de concepción y valores individuales) que se aplican al mismo tiempo que los procesos de generalización, supresión y distorsión para que lo que Katan denomina model of reality. Katan añade también un cuarto filtro, el lenguaje, que también generaliza, suprime y distorsiona. El mismo Katan indica que estos tres modelos "are instruments that can aid in making speaker or 
writer assumptions more explicit in translation studies and practice- and in all aspects of cross-cultural mediation" (Katan, 1999:128).

La generalización es el primero de los grandes mecanismos de Katan para trasvasar el contenido cultural. Consiste en sustituir un elemento específico de la lengua de partida por otro más general en la lengua de llegada. En la supresión, Katan incluye la explicitación, o adición de información y la implicitación u omisión de información que pudiera estar presente el texto original. La distorsión se centra en las varias técnicas que distorsionan o, de algún modo, transforman el sentido del culturema del texto original.

\subsubsection{La concepción dinámica de Hurtado}

Hurtado (2001) aborda la traducción de los culturemas desde una perspectiva que esta autora denomina como funcional y dinámica y establece que no existen "soluciones unívocas ni técnicas características para la traducción de los culturemas, sino una multiplicidad de soluciones y de técnicas". Para Hurtado, sin embargo, resulta absolutamente conveniente considerar los distintos factores que se deben considerar antes de enfrentarse a una tarea de traducción cultural (Hurtado 2001/2008:614-615):

- La relación entre las dos culturas (si la traducción se efectúa de una cultura minoritaria a una dominante, o al revés, si existe paridad o similitudes entre las dos culturas, cercanía o lejanía cultural), que determina el grado de acercamiento o visión que una cultura tiene de la otra, así como el trasvase de los elementos culturales. Hay que considerar que, en algunos casos, pueden existir focos o puntos ricos de cultura para los que no existan equivalencias en la lengua de llegada, falsos amigos culturales (gestos, conceptos o comportamientos iguales 
pero con connotaciones diferentes según la cultura), injerencias culturales (cuando en una cultura se utilizan elementos de otra cultura, a veces distorsionados), etc.

- El género textual en el que se inserta. Las características del TO condicionan la función del culturema en el texto. El culturema puede aparecer en cualquier ámbito (literario, técnico, publicitario, etc.) y en cualquier género textual, produciendo en cada caso problemas de traducción diferentes.

- La función del culturema en el texto original, es decir, su relevancia o no relevancia, en relación con el conjunto del texto.

- La naturaleza del culturema: el registro a que pertenece, su grado de novedad, de universalidad, etc.

- Las características del destinatario: su motivación, nivel cultural, etc.

- La finalidad de la traducción, que, al determinar la elección del método traductor (traducción interpretativa-comunicativa, adaptación, etc.) llevará al traductor a optar por una solución traductora u otra y a utilizar diferentes técnicas.

De acuerdo con estas premisas, Molina y Hurtado (2002) realizan una propuesta de clasificación con la que analizan la traducción de los elementos culturales de la obra 100 años de soledad, de Gabriel García Márquez y que se muestran en la tabla 7. 
Tabla 7: Propuesta de Molina y Hurtado de Técnicas de Traducción (2002:128)

\begin{tabular}{|l|l|}
\hline Adaptación & Generalización vs particularización \\
\hline Ampliación lingüística vs compresióntica & Modulación \\
\hline Amplificación vs elisión & Préstamo \\
\hline Calco & Sustitución \\
\hline Compensación & Traducción literal \\
\hline Descripción & Transposición \\
\hline Creación discursiva & Variación \\
\hline Equivalente acuñado & \\
\hline
\end{tabular}

A continuación se detallan las técnicas de traducción y se ofrecen algunos ejemplos:

- Adaptación. Un elemento cultural de una lengua es reemplazado por otro propio de la cultura meta. Ej.: cambiar baseball por fútbol en una traducción al español. Se corresponde con la adaptación de Vinay y Darbelnet, la sustitución cultural de Taber y Nida y el equivalente cultural de Margot.

- Ampliación lingüística. Se usan más palabras o recursos lingüísticos. Ej.: traducir la expresión inglesa No way por la expresión en español De ningún modo o De ninguna de las maneras, en vez de utilizar una expresión con el mismo número de palabras, como podría ser En absoluto o Para nada. 
- Amplificación. Se introducen precisiones no formuladas en el texto original: informaciones, paráfrasis explicativas, notas del traductor, etc. Incluye la explicitación de Vinay y Darbelnet, la adición de Delisle, la paráfrasis legítima e ilegítima de Margot, la paráfrasis explicativa de Newmark y las perífrasis y paráfrasis de Delisle. Las notas a pie de página son un tipo de amplificación. Se opone a la elisión.

- Calco. Es la traducción literal de una palabra o sintagma extranjero, ya sea de tipo léxico o estructural.

- Compensación. Se trata de introducir en otro lugar del texto traducido un elemento de información o efecto estilístico que no se pudo reflejar en el mismo punto en el que aparece en el TO.

- Compresión lingüística. Se resumen los elementos lingüísticos. Se usa abundantemente en interpretación simultánea y subtitulación. Ej.: traducir al castellano la frase interrogativa inglesa Yes, so what? por ¿Y? en vez de optar por una expresión con el mismo número de palabras. Se opone a la ampliación lingüística.

- Creación discursiva. Se establece una equivalencia efímera, totalmente imprevisible fuera de contexto. Como ejemplo podemos poner las traducciones libres de los títulos de algunas películas.

- Descripción. Es usar una expresión que define la forma o función del término o significante del TO. Ej.: traducir panetone por el bizcocho tradicional que se toma en Nochevieja en Italia.

- Elisión. Se omiten elementos informativos que sí están presentes en el TO. Aúna la implicitación de Vinay y Darbelnet y Delisle y la concisión de este último y la omisión de Vazquez Ayora. Su opuesto es la amplificación. 
- Equivalente acuñado. Se usa un término o expresión reconocido como equivalente en la LM (ya sea reconocido en el diccionario, o por el uso lingüístico). Ej.: traducir la expresión inglesa They are as two peas y Se parecen como dos gotas de agua. Se corresponde con la equivalencia y la traducción literal de Vinay y Darbelnet.

- Generalización. Se utiliza un término más general o neutro. Ej.: traducir los vocablos franceses guichet, fenêtre o devanture por window. Coincide con la acepción de Vinay y Darbelnet y se opone a la particularización.

- Modulación. Se trata de realizar un cambio en el punto de vista, enfoque o categoría de pensamiento respecto al TO. Puede ser léxica o estructural. Coincide con la acepción de Vinay y Darbelnet.

- Particularización. Es la utilización de un término más preciso o concreto que en el TO. Ej.: traducir el término inglés window por guichet. Coincide con Vinay y Darbelnet y se opone a la generalización.

- Préstamo. Se integra una palabra o expresión de otra lengua sin realizar ningún cambio en dicha palabra del TO (préstamo puro), o se integra dicha palabra naturalizándola en la LM. Como ejemplo de préstamo puro podemos ofrecer la palabra lobby y de préstamo naturalizado palabras como fútbol, líder, y gol.

- Sustitución (lingüística, paralingüística). Se cambian elementos lingüísticos por paralingüísticos (entonación, gestos), o viceversa. Ej.: traducir el gesto árabe de llevarse la mano al corazón por gracias.

- Traducción literal. Es la traducción palabra por palabra de un sintagma o expresión. Ej.: traducir They are as two peas por Se parecen como dos guisantes. Se corresponde con el equivalente formal de Nida y con la traducción literal de Vinay y Darbelnet. 
- Transposición. Se modifica la categoría gramatical. Ej.: traducir al castellano He will soon be back por No tardará en venir cambiando el adverbio soon por el verbo tardar.

- Variación. Se cambian elementos lingüísticos o paralingüísticos (entonación, gestos) que afectan a aspectos de la variación lingüística: cambio de tono textual, estilo dialecto social, dialecto geográfico, etc. Ej.: introducción o cambios de marcas dialectales para la caracterización de personajes en la traducción teatral, cambios de tono en adaptaciones de novelas para niños, etc.

\subsection{La traducción adaptada al ámbito geográfico: la localización}

\subsubsection{Justificación y antecedentes}

La traducción entre culturas ha existido desde siempre y ha hecho posible el intercambio lingüístico. Los traductores de todos los tiempos han desarrollado su labor con los medios existentes, escribiendo con distintos materiales que han ido cambiando y modernizándose. Las herramientas auxiliares del traductor históricamente han sido escasas. Sin embargo, la revolución tecnológica ha traído consigo una revolución también en el quehacer diario de los traductores. Para estos ahora "el ordenador es el elemento esencial e imprescindible en la tarea traductora" (de la Cruz Cabanillas y Valero Garcés, 2001:11 y 12). La world wide web ha ido ganando en importancia en el número de usuarios y las empresas han apostado decididamente por una presencia y gestión y ventas de sus productos para a un público internacional en la red. Este es el caso del sector turístico que, paralelamente, también ha experimentado cambios 
radicales $^{6}$ en el modo y, especialmente, el canal de promoción y venta de sus productos: Internet es hoy por hoy el canal por excelencia en el sector turístico.

La preponderancia que está adquiriendo la localización como salida profesional actual para los traductores y el interés académico por parte de la traductología hacia la localización son innegables. Estas consideraciones, unidas a la importancia de Internet en la comunicación turística y a la presencia generalizada de textos turísticos en la red, nos llevan a ofrecer una pequeña pincelada sobre localización en nuestra investigación a nivel teórico.

Debemos situar el nacimiento de la localización como actividad traductológica en los años 80 con la adquisición masiva de ordenadores personales en EEUU y concretamente con la necesidad de la empresa Microsoft de adaptar sus productos de software a los distintos mercados mundiales de modo que pudieran ser introducidos en las lenguas maternas de los usuarios de estos nuevos mercados. Ya en el año 1998, más del $60 \%$ de los beneficios de Microsoft provenían de mercados diferentes al de EEUU. Es por ello que la estrategia de Microsoft ha sido la de "liderar la industria de la localización de productos, en especial de software" (Brooks, 2000:43). Más tarde, la localización se ampliaría también al hardware.

A principios de los 90 "eran los traductores freelance los que copaban este tipo de trabajo en EEUU" (Brooks, 2000:5). Estos eran contratados por proyecto y su nivel de conocimientos técnicos y de software era muy limitado. Es así cuando empieza a gestarse esta nueva modalidad de traducción con la necesidad de traducir de la lingua franca al resto de lenguas del mundo.

\footnotetext{
${ }^{6}$ Según Álvarez (1998) dos hechos permiten pensar en una estrecha relación entre la industria turística y la informática. Por un lado el hecho de que el turismo, al ser la primera industrial mundial, se convierte potencialmente en el principal cliente de la industria informática y, por otro lado, el hecho de que la información está en los mismos cimientos de la industria turística.
} 
En la década de los ochenta empiezan a operar una serie de empresas informáticas en Irlanda impulsadas por la política gubernamental que ofrecía "negocios llave en mano" (Esselink, 2000a: 7) con importantes subvenciones y beneficios fiscales a cambio de establecer allí sus empresas.

Más tarde, en los 90, con la aparición de la world wide web y el desarrollo de Internet, el acceso a la información se democratiza y el inglés pasa a convertirse en la lengua de referencia del canal. Este hecho genera una necesidad por parte de los usuarios de entender las páginas web que están consultando y demandar sitios web en su lengua materna. Según Corte (2002), "aunque el inglés se acepte como lingua franca, es natural que a un usuario le resulte más atractivo y fácil utilizar un sitio web en su lengua materna" (Corte, 2002:1). En este punto comienza la expansión de la localización hacia otro nuevo campo, el de los sitios web (Pérez Fernández, 2010).

El boom ocasionado por Internet y las distintas aplicaciones y productos informáticos en el sector conformaron desde 1990 una nueva industria cuyos beneficios $y$ volumen de productos localizados ha ido creciendo vertiginosamente desde entonces. A principios del s. XXI se crearon grandes compañías conocidas como multi-language vendors (Esselink, 2000b), que ofrecían una variada gama de servicios además de la localización, como podían ser sistemas de reconocimiento de voz, de servicios lingüísticos y de testeo en Internet $y$ de aprendizaje de idiomas ${ }^{7}$. Los beneficios que obtuvieron estas empresas ascendieron a 70 millones de dólares. Otro tipo de empresas conocidas como single-language vendors conforman el grupo de empresas de

\footnotetext{
${ }^{7}$ Esselink (2000b) cita, entre otras empresas, a ALPNET, Lionbridge, Berlitz GlobalNET, Bowne Global Solutions y Lernout \& Hauspie.
} 
localización más numeroso. Son las que se centran el una sola LM y en las que trabajan también la mayoría de localizadores freelance.

La importancia de la localización quedó reflejada en la constitución de distintas organizaciones para apoyar y promover esta actividad. La primera en crearse fue la Asociación de Estándares de la Industria de la Localización (LISA) ${ }^{8}$. Este organismo se fundó en Suiza en 1990 con el objetivo principal de servir de mecanismo para el intercambio de información de aquellos procesos, herramientas, tecnologías y modelos de negocios en relación con la localización:

LISA defines its mission as promoting the localization and internationalization industry and providing a mechanism and services to enable companies to exchange and share information on the development of processes, tools, technologies and business models connected with localization, internationalization and related topics (Lommel, 2007:53).

Este organismo organiza foros y conferencias regularmente en las que sus miembros pueden intercambiar información y recibir formación. Estos foros generalmente tratan los aspectos empresariales de la localización y la globalización. Sin embargo, se presta poca atención a las actividades o problemas de los traductores (Esselink, 2000b).

En Irlanda, foco europeo de empresas dedicado a la localización, se fundaron dos organizaciones para establecer contactos entre los editores de software, proveedores de servicios de localización y las universidades de Dublín y su periferia. Por un lado, el Localisation Research Centre (LRC) ${ }^{9}$ fue creado en 1995 en la Universidad de Dublín y fue posteriormente absorbido por la Universidad de Limerick en 1998. Este centro es actualmente uno de los centros de referencia mundial en el sector de la localización. Por otro lado, se creó el

\footnotetext{
${ }^{8}$ www.lisa.org

${ }^{9}$ www.localisation.ie
} 
Software Localisation Interest Group $(\mathrm{SLIG})^{10}$, que es un grupo especial que estudia todos los integrantes del proceso localizador. Este grupo lo fundó el mismo Localization Research Centre en febrero de 1994.

\subsubsection{Globalización, internacionalización, localización y traducción (GILT)}

En el punto anterior hemos considerado los antecedentes del fenómeno de la localización y su impacto económico. En esta sección nos proponemos situar la localización y definir la noción de localización. Con este objetivo, nos valemos del acrónimo GILT ampliamente utilizado en traductología y localización que hace referencia a los distintos procesos que intervienen en la localización de un producto: Globalización, Internacionalización, Localización y Traducción.

Estos cuatro procesos son interdependientes. Pym (2004:30) entiende como proceso general la globalización, del que dependen el resto de subprocesos:

We might say that there is one wide process called "globalization", of which "internationalization" and "localization" are parts. In order to globalize, you first make your product general in some way ("internationalization"), then you adapt ("localize") to specific target markets ("locales") (Pym, 2004:30).

La localización tiene como parte fundamental la traducción y constituye el foco central del proceso (Pérez Fernández, 2010:58) ${ }^{11}$. A continuación reproducimos el gráfico que muestra la interdependencia de los cuatro procesos en juego y la importancia de la traducción como el núcleo central del proceso localizador:

Figura 5: Interdependencia de procesos GILT (Pérez Fernández, 2010)

\footnotetext{
${ }^{10}$ www.slig.ie

11 Algunos autores como Dunne (2006:4), citado por Pérez Fernández (2010:57), consideran que el acrónimo GILT debe invertirse para explicar todos los procesos traductológicos de acuerdo con el orden en el que se ha producido su evolución desde el punto de vista de la traducción.
} 


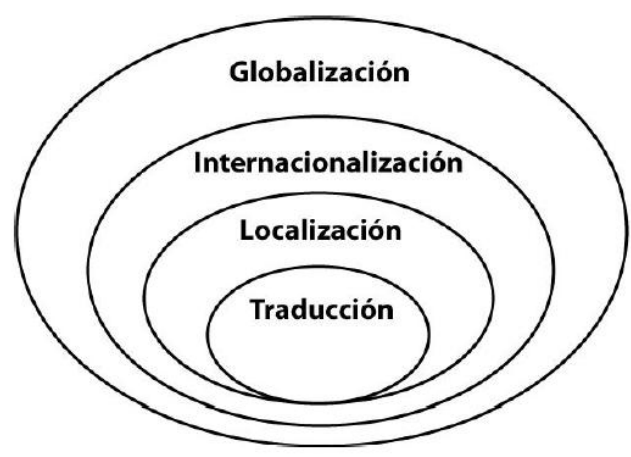

A continuación daremos cuenta de los procesos menos traductológicos y más técnicos, como son la globalización, la internacionalización y la traducción.

La globalización ${ }^{12}$ es el proceso más amplio y se tiene su epicentro en la empresa misma que es la que pone en marcha el proceso para conseguir que sus productos se puedan transformar para ser usados por cualquier usuario del mundo ${ }^{13}$ :

Globalization (...) refers to all of the business decisions and activities required to make an organization truly international in scope and outlook. Globalization is the transformation of business and processes to support customers around the world, in whatever language, country, or culture they require (LISA, 2007:1).

Corte (2002) incluye dentro de la globalización los procesos de internacionalización y localización y pone un ejemplo práctico de aplicación de este proceso: el diseño de sitios web que puedan ser utilizados en diferentes países con un mínimo de modificaciones.

La globalización como proceso se produce antes y después de la localización. La distribución de productos y la asistencia multilingüe al cliente son ejemplos de

\footnotetext{
${ }^{12}$ En el sector se abrevia este proceso con la forma gn11. La " $\mathrm{g}$ " y la " $\mathrm{n}$ " se obtienen de la primera y la última letra de la palabra en sí y 11 es el número de letras entre ambas.

${ }^{13}$ Según Jiménez Crespo (2008:35), en la localización de los sitios web el término globalización se usa para identificar la aspiración de muchos sitios web de llegar al mayor número posible de usuarios, por lo que en algunos casos la "localización web" es considerada "globalización web".
} 
tareas que corresponden al proceso de globalización y que se producen a posteriori (Lommel, 2007).

El proceso de internacionalización tiene en cuenta aspectos técnicos y procedimentales. La definición más aceptada la ofrece la organización LISA, que define internacionalización como "the process of enabling a product at a technical level for localization". (Lommel, 2007:17). The Localization Institute ${ }^{14}$, por su parte, describe el proceso de internacionalización como "una forma de diseñar y producir productos que se pueden adaptar fácilmente a diferentes regiones. Esto implica extraer todos los elementos que dependen del idioma o de la cultura".

Podemos establecer que, en general, el conjunto de procedimientos de la internacionalización ${ }^{15}$ están destinados a "garantizar que el documento o aplicación no esté limitado culturalmente, que sea independiente de la lengua de desarrollo y que sea fácil de localizar sin que se requieran grandes modificaciones técnicas" (Jiménez Crespo, 2008:35). Así pues, la internacionalización implica el diseño de un producto neutro, tanto cultural como técnicamente para que pueda ser fácilmente localizado. Este es el fin que se persigue en última instancia en este proceso. Siguiendo estas premisas, Pérez Fernández (2010:65) nos ofrece una definición de internacionalización desde la perspectiva traductológica: “(...) proceso de diseño de un producto para que pueda ser posteriormente adaptado lingüística y culturalmente a otro mercado meta más fácilmente y sin necesidad de efectuar cambios de ingeniería".

\footnotetext{
14 http://www.localizationinstitute.com/. Instituto fundado en 1996 dedicado principalmente a la formación de localizadores. Ofrece seminarios y conferencias, así como servicio de consultoría y asesoría a empresas.

${ }^{15}$ La forma I14n se ha cuñado para denominar a la internacionalización. Entre la "i" y la " $\mathrm{n}$ " se cuentan 14 letras.
} 
A continuación reproducimos el esquema del ciclo por el que pasa el producto localizado. La fase de internacionalización resulta necesaria para facilitar el siguiente proceso de la localización a través de la internacionalización primero del diseño y después del desarrollo del producto:

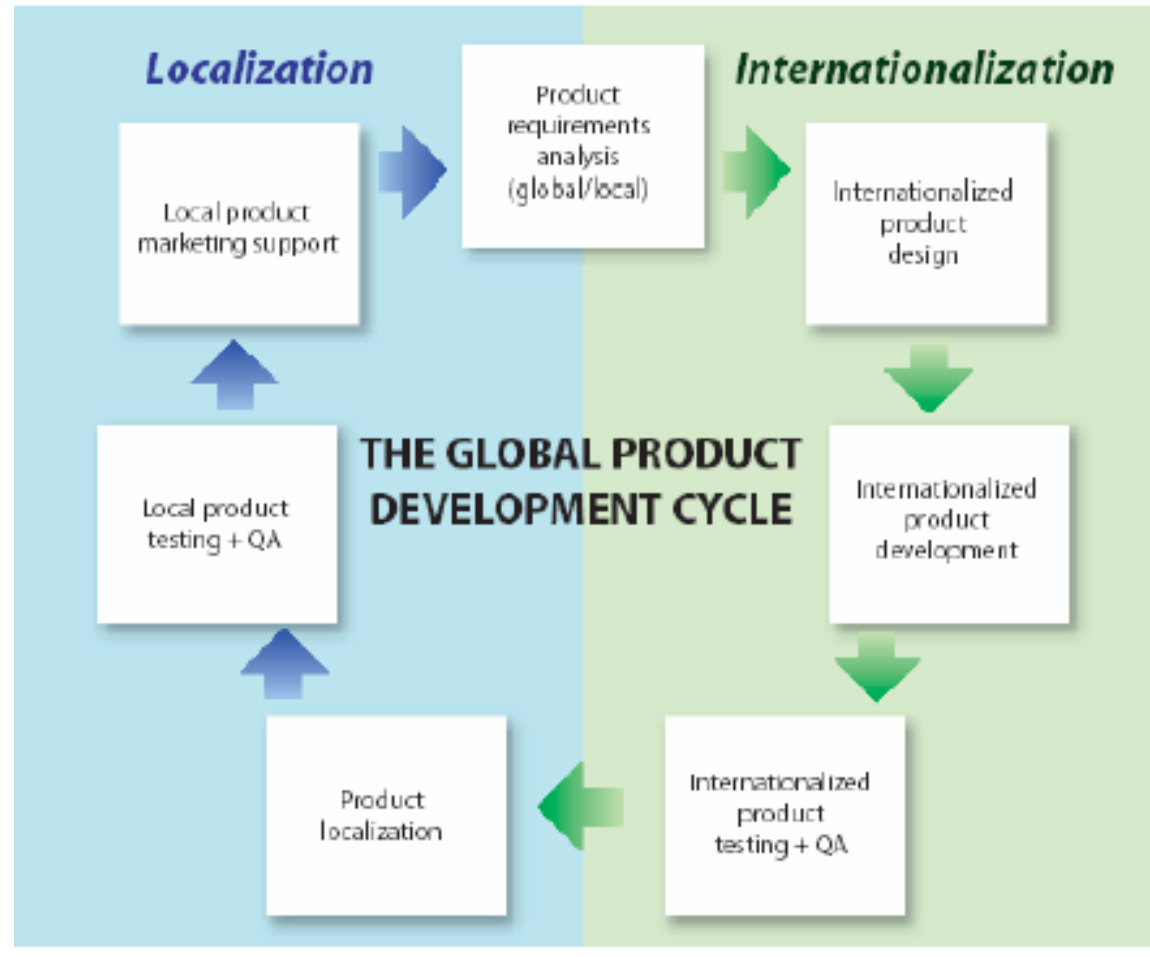

Figura 6: Ciclo de desarrollo de un producto global según LISA (2007:19)

La inclusión del proceso de internacionalización como uno de los procesos clave dentro de la actividad localizadora tiene su raíz en el coste económico. El hecho de generar un producto genérico conlleva que los elementos que necesitan de traducción o adaptación quedan separados del producto mismo. Como bien afirma Pym (2004:31) $)^{16}$ :

${ }^{16}$ Pym (2004) advierte del problema terminológico que existe con internationalization, pues no refleja
los subprocesos que de este se derivan e ideológicamente también puede considerarse que un texto 
The main reason for internationalization is that high costs and numerous cultural problems result from just taking a home product (usually software produced for the US market) and directly translating its natural language strings into another language (...). Overall expenses are lower if the home product is first prepared for all or some of its later localizations (Pym, 2004:31).

Corte (2002) detalla aquellos elementos que son susceptibles de internacionalización en un sitio web y pone como ejemplos fechas, números, moneda, e información de contacto. El trabajo de internacionalizar supone aislarlos y guardarlos de forma independiente para luego poder ser localizados (Corte, 2002).

Una vez hemos establecido las características principales de la globalización y la internacionalización, retomamos en este punto las referencias teóricas del proceso de localización ${ }^{17}$, que es, a nuestro modo de ver, el proceso en el que interviene de modo más directo el traductor. Dunne (2006:1) explica que existe una falta de consenso respecto a lo que constituye la localización, "due in large part to the ways in which it is perceived". En general, encontramos definiciones del sector informático y del sector de la traducción y el ámbito académico. En algunos casos, la definición de localización se realiza particularizando en el producto localizado en cuestión. A continuación reproducimos las definiciones provenientes del mundo de la informática:

The processes by which digital content and product developed in one locale (defined in terms of geographical area, language and culture) are adapted for sale and use in another locale (Dunne, 2006:18).

Localization is the process of changing the documentation of a product, a product itself or the delivery of services so that they are appropriate and acceptable to the target society and culture (Quah, 2006:19).

\footnotetext{
"internacional" es un texto válido para todos los locales. No obstante, este término tiene un amplio consenso en el sector.

${ }^{17}$ Frecuentemente encontramos referencia a este fenómeno como L10N.
} 
La localización es el proceso de adaptar un sitio web a un idioma y una cultura diferente (Corte, 2002:1).

Del sector de la industria de la localización destacan, de las muchas definiciones existentes, la de Esselink (2000a y 2000b), autor pionero en la investigación en localización y la del Localization Institute (2009), instituto estadounidense de profesionales de la localización:

Generally speaking, localization is the translation and adaptation of a software or web product, which includes the software application itself and all related product documentation (Esselink, 2000a:1).

Localization is the process of creating or adapting a product to a specific locale, i.e., to the language, cultural context, conventions and market requirements of a specific target market. With a properly localized product a user can interact with this product using her/his own language and cultural conventions. It also means that all user-visible text strings and all user documentation (printed and electronic) use the language and cultural conventions of the user. Finally, the properly localized product meets all regulatory and other requirements of the user's country/region (The Localization Institute, 1999:48).

LISA (2003) ofrece la definición que en la práctica ha recibido más consenso (Pym, 2004:29):

Localization involves taking a product and making it linguistically and culturally appropriate to the target locale (country/región and language) where it will be used and sold.

Del ámbito traductológico, debemos destacar la aportación de Pérez Fernández:

(...) el proceso de adaptar, tanto lingüística como culturalmente, cualquier producto informático, página web o producto multimedia, así como toda la documentación que lo acompaña, a la cultura meta en la que va a ser comercializado, con el fin de que el usuario meta perciba el producto como si se tratase de un producto creado originalmente en su idioma y su contexto cultural y geográfico (Pérez Fernández, 2010: 63).

Jiménez Crespo sitúa la localización como una modalidad de traducción y tiene en cuenta aspectos tan relevantes para el proceso traductor como el lector destinatario y el iniciador de la traducción: 
La localización constituye una modalidad de traducción que comprende un complejo proceso textual, comunicativo, cognitivo y tecnológico, por el que un texto en formato digital y en un entorno interactivo se modifica para su uso en una lengua y contexto sociocultural de recepción distintos a los originales, siempre según las expectativas de la audiencia a la que se dirija y las especificaciones o grado de localización que encargue el iniciador (Jiménez Crespo, 2008: 45).

Observamos que el denominador común en todas estas definiciones es la adaptación del producto a una cultura o locale ${ }^{18}$ final. Sin embargo, dependiendo del sector desde donde se formula la noción de localización poca o ninguna relevancia se le otorga al proceso traductor y a la tarea del traductor ${ }^{19}$. Echamos de menos en la mayoría de definiciones la inserción de la localización como subproceso en conexión con los procesos anteriormente descritos y a efectos de nuestro trabajo, debemos señalar la distinción que se realiza entre lengua y cultura como elementos y realidades separadas y elementos de localización distintos, cuando sabemos que lengua y cultura son dos caras de una misma moneda que no pueden separarse, puesto que la cultura condiciona la lengua en la cual se halla inmersa (Malinowski, 1923). Sin embargo, creemos que la mayor dificultad de la localización reside precisamente en el trasvase y la adaptación de los culturemas o la información cultural la LO. Quizás sea este el motivo por el lengua y cultura se presentan como elementos independientes en muchas de las definiciones aportadas.

En su definición Pérez Fernández (2010) coincide con la idea de Fry (2003) al hacer referencia a la necesidad de que el producto localizado sea considerado por el usuario como si fuera un producto diseñado originalmente en su LO, " $a$

\footnotetext{
${ }^{18}$ Conjunto de información asociado a un lugar determinado o una cultura (Esselink: 2000).

19 Jiménez Crespo (2008) destaca que en sólo tres definiciones que parten del sector se encuentra una mención expresa a la traducción. Estas corresponden a Esselink (2001:2), Microsoft (Dr. International 2003) y Chandler (2005).
} 
product that looks like it has been developed in country" (Fry, 2003:11) y que a su vez dispone de "the look and feel of locally made products" (Fry, 2003:5).

Los estudios y la investigación académica en localización han llevado a los autores a reflexionar sobre cuál es la relación entre la localización y la traducción tradicional. El componente técnico durante el proceso localizador es el elemento determinante que diferencia la localización de la traducción convencional $^{20}$. Si bien algunos autores clasifican la localización como una traducción especializada, la postura que va cobrando mayor adhesión es la que otorga a la localización la categoría de modalidad o variedad de traducción (Hurtado, 2001:86-87), y en la que esta autora engloba diferentes tipos de traducción como son los programas informáticos y la traducción de productos informáticos multimedia.

A grandes rasgos, podemos distinguir tres tipos de productos generales que son susceptibles de localización: los programas informáticos, las páginas web y los productos multimedia. Se entiende por programa informático "cualquier producto en soporte informático" (Pérez Fernández, 2010:67). Esta autora distingue tres subtipos en función de su uso: profesional, académico o educativo y de entretenimiento. En segundo lugar destaca la localización de las páginas web. Por último, destaca la categoría de productos multimedia ${ }^{21}$.

\footnotetext{
20 Según Quirion (2003), para esta nueva modalidad de traducción es necesario que el traductor actualice sus competencias técnicas.

${ }^{21}$ Fernández Pérez (2010) divide los productos multimedia en cuatro tipos: comunicativos, herramientas de navegación, productos didácticos e informativos y aquellos destinados al entretenimiento como los videojuegos.
} 


\section{TURISMO Y TEXTO TURÍSTICO}

\subsection{La actividad turística}

Puesto que el ámbito de nuestra investigación es el texto turístico ${ }^{22}$, resulta necesario considerar el marco general en el que se generan los elementos objeto de nuestro estudio. Es por ello que a continuación exponemos las principales claves del sector turístico, su enclave en España, y las estrategias de promoción turística en particular, generadoras de gran parte de textos y materiales turísticos y, en consecuencia, demandantes de un gran volumen de traducciones.

El estudio de la actividad turística se ha llevado a cabo desde múltiples puntos de vista: en clave económica, por ejemplo, se han enfocado los aspectos relacionados con la gestión y comercialización de los productos turísticos; en clave geográfica, antropológica y sociológica se han desarrollado reflexiones sobre la experiencia turística, tanto desde el punto de vista del turista como de la comunidad de acogida (Calvi y Mapelli, 2010). Sin embargo, a pesar de la importancia y el peso de la actividad turística a nivel mundial, son escasos los estudios y reflexiones lingüísticas del texto turístico. En palabras de Dann (1996:2):

And, amazingly, no one has comprehensively analyzed this (tourism) language as a phenomenon in its own right. Certainly, there have been some studies which have alluded to the linguistic features of tourist promotion, but none has so far brought them together and systematically examined tourism as a language per se.

\footnotetext{
22 Utilizamos en esta investigación la denominación "texto turístico" para referirnos a aquellos materiales susceptibles de traducción o traducidos en distintos formatos y canales. Se trata de una denominación genérica que engloba el lenguaje especializado del turismo con sus peculiares características y sus condicionantes traductológicos.
} 
Y en palabras de Calvi (2010:10):

(...) los estudios de corte lingüístico sobre el lenguaje del turismo han tenido menos impacto y repercusión en la comunidad científica que, por un lado, las investigaciones dedicadas a otros lenguajes de especialidad (jurídico, académico...) y, por otro, los enfoques del fenómeno turístico elaborados en ámbitos disciplinares tales como la geografía, la antropología, la sociología, la psicología social y los estudios culturales ${ }^{23}$.

Los estudios de cierto peso sobre la actividad turística surgen a mitad de los años noventa ${ }^{24}$ con la aparición de teorías sociológicas que intentan sistematizar y teorizar acerca del turismo. Nigro (2006:24 y siguientes) sitúa los inicios del estudio sociológico del turismo en 1961 con la publicación por parte de Boorstin del libro The Image: a Guide to Pseudo-Events in America, en el que se analiza la realidad norteamericana y se concluye que los norteamericanos no realizan turismo a través del consumo de experiencias turísticas sino que se nutren de pseudo-eventos y disfrutan de atracciones que no son auténticas sino que trascienden el mundo real creando las fantasy-cities ${ }^{25}$. Posteriormente, Cohen (1972) publica un artículo en el que pone en valor "the appreciation of the strangeness and novelty" (Cohen, 1972:165), y sostiene que el descubrimiento de una novedad y de la diferencia respecto a lo que nos es familiar es un elemento fundamental en la experiencia turística.

De especial relevancia resulta el trabajo de Turner y Ash (1975), The Golden Hordes, según el cual el turista se halla en el centro de un mundo circunscrito y controlado por agentes de viajes, por lo que el turista pasa sus vacaciones en

\footnotetext{
${ }^{23}$ Según Calvi (2010), estos estudios dotan de peso teórico al texto turístico pero dejan en la sombra otros aspectos de la comunicación entre especialistas.

${ }^{24}$ Los años 90 son conocidos también como los años dorados del turismo.

${ }^{25}$ Deborah Parsons (2000) explica la diferencia entre los turistas europeos y los norteamericanos. Los primeros consideran la ciudad como centro de atracción turística y cultural, mientras que los segundos necesitan crear los fantasy-lands, en las que todo parece construido expresamente para el turista. Parsons retoma el concepto de ciudad-fantasía del estudio de John Harrigan, Fantasy City: Pleasure and Proficit in the Postmodern Metropolis (London, 1998).
} 
una especie de burbuja en la que ve solamente aquello que la industria turística le permite ver.

El téorico del turismo McCannell (1976) aborda un punto fundamental de la teoría del viaje. Según este autor, los turistas quieren vivir experiencias auténticas y están en constante búsqueda de aquello que es real y auténtico en una versión post-moderna de la búsqueda de lo sagrado. En palabras de Dann (1996:7):

While concurring with Boorstin that much of present day life was inauthentic (...), MacCannell disagreed that tourists were emblematic of such authenticity. Rather, he believed that tourists sought out authentic experiences in other times and places, and that this search for meaning was a contemporary version of the pre-modern quest for the sacred. Thus the tourist of today was to be understood as a pilgrim of the secular world paying homage to many and varied attractions which were symbolic of modernity and represented the differentiations of society.

La percepción del turista ha sido estudiada por John Urry en su famosa obra The Tourist Gaze (1990) que principalmente analiza el modo en que la percepción del turista ha cambiado y se ha desarrollado en diferentes sociedades, diferentes grupos sociales en periodos de tiempo diferentes. Urry desarrolla su estudio en diferentes niveles: histórico, económico y cultural y presta especial atención a los cambios experimentados por la sociedad postmoderna. Esta última se caracteriza por pasar del antiguo turismo de masas, cuyas características principales eran la confección y la estandardización, al nuevo turismo, segmentado, flexible y reflexivo. Así, a partir de los años 80, la actividad turística se sectorializa y nacen los "mil tipos de turismo" (Bernardi y Filippi, 2002, citados por Nigro, 2006: 26).

Dann (1996) realiza un análisis sociolingüístico en el que destaca la preponderancia del lenguaje en la configuración del destino turístico y describe 
el texto turístico como un mecanismo de control social analizando el uso de keywords en diferentes medios de comunicación.

El turismo, por definición ${ }^{26}$, implica un viaje realizado entre un origen y un destino. El turismo internacional implica viajar entre diversos países que a menudo presentan grandes divergencias culturales. Así, los viajes nos permiten descubrir y compartir, como indica Nigro (2006:13):

Attraverso il viaggio l'uomo ha potuto scoprire nuove culture, principi e valori. Esso è lo stimolo naturale alla ricerca del nuevo, l'istintiva attrazione/repulsione per ciò che è estreaneo, la sfida al confronto, l'abilità di relazionarsi con il diverso da noi, la capacità di adattamento a situazioni imprevedibili.

Dado el carácter global del turismo, es necesario tenerlo en cuenta desde un punto de vista universal. En consecuencia y a los efectos de nuestro estudio, consideramos el texto turístico desde un punto de vista holístico, al tener en cuenta factores fundamentales que le caracterizan y que condicionan la comunicación turística.

Uno de estos factores es el desarrollo experimentado por esta actividad desde sus inicios hasta la actualidad. Es por ello que a continuación se ofrece una visión general de la evolución del turismo.

Desde sus orígenes, el hombre se ha visto impulsado a trasladarse de un lugar a otro con distintos fines: la caza, el comercio, las guerras o el ocio. En la Antigua Grecia, sus habitantes fueron los primeros en dedicar tiempo al ocio, para el descanso y el deporte. Los romanos, por su parte, pasaban sus vacaciones en sus villas alejados de las grandes urbes para descansar y visitar templos y termas y disfrutaban de espectáculos en teatros y anfiteatros. De la Edad Media

\footnotetext{
${ }^{26}$ Según la OMT "el turismo comprende las actividades que realizan las personas durante sus viajes y estancias en lugares distintos a su entorno habitual, por un período de tiempo consecutivo inferior a un año, con fines de ocio, por negociación y otros" (OMT, 1998: 9).
} 
debemos destacar las peregrinaciones de grandes multitudes desde Europa a Tierra Santa, desarrollándose la industria de hospedaje y de rutas. Durante la época de la llustración, las clases adineradas realizaban los famosos Grand Tours $^{27}$, viajes de turismo cultural. Fue también durante los siglos XVII y XVIII cuando se pusieron de moda los baños de mar como tratamiento terapéutico.

Sin embargo, la eclosión del turismo no se produjo hasta el siglo XIX y su popularización no tuvo lugar hasta la segunda mitad del siglo XX. La invención de la máquina de vapor y la aparición del tren, unidos al advenimiento de una clase media generada por la revolución industrial dieron paso a lo que conocemos hoy por industria turística ${ }^{28}$.

En los años 50 el viaje internacional se fue haciendo cada vez más accesible para la población debido a la aparición de los aviones de pasaje a reacción, la mayor renta disponible para las familias y el aumento del tiempo libre en los países industrializados. El desarrollo de las comunicaciones y de los medios de transporte posibilitó llegar a nuevas y más lejanas regiones o destinos turísticos. Pero, sin duda, el factor que contribuyó a lanzar el turismo internacional fue el "crecimiento progresivo de las relaciones comerciales y entre distintos países, con la consiguiente necesidad de desplazamientos por motivos profesionales" (OMT, 1998:10).

Los años 80 destacan en el panorama turístico como una etapa de consolidación mundial de la industria turística, al integrarse como actividad dentro de las economías nacionales y generando empleo y buscando nuevas oportunidades

\footnotetext{
${ }^{27}$ Richard Lessels acuñó el término en su obra Italian Voyage en 1970 y lo definió como "uno de los fenómenos más interesantes de la cultura europea moderna en el que se mezclan lo efímero y lo duradero, el desconocimiento y el gusto por la observación, la curiosidad y el espíritu de aventura".

${ }^{28}$ Destaca la aportación de Thomas Cook como pionero en la comercialización de productos turísticos a través de las agencias de viajes, Henry Wells y William F. Fargo que crearon American Express o César Ritz, que está considerado el padre de la hotelería moderna.
} 
de negocio que derivan en nuevas variantes turísticas y de ocio (Chamizo, 2003). Más tarde, en la década de los 90 se observa un marcado interés de la población por disfrutar de tiempo para el descanso y el ocio de modo fragmentado durante todo el año, interés que se mantiene en la actualidad.

Según la OMT, para el año 2020 los turistas habrán conquistado cualquier parte del mundo. El estudio Turismo, Panorama 2020 prevé que el número de llegadas de turistas internacionales en todo el mundo aumentará hasta casi 1.600 millones en 2020 (véase figura 7). Esto representa 2,5 veces el volumen registrado a finales de los años 90.

Figura 7: Previsión de llegadas e ingresos por turismo a nivel internacional (OMT)

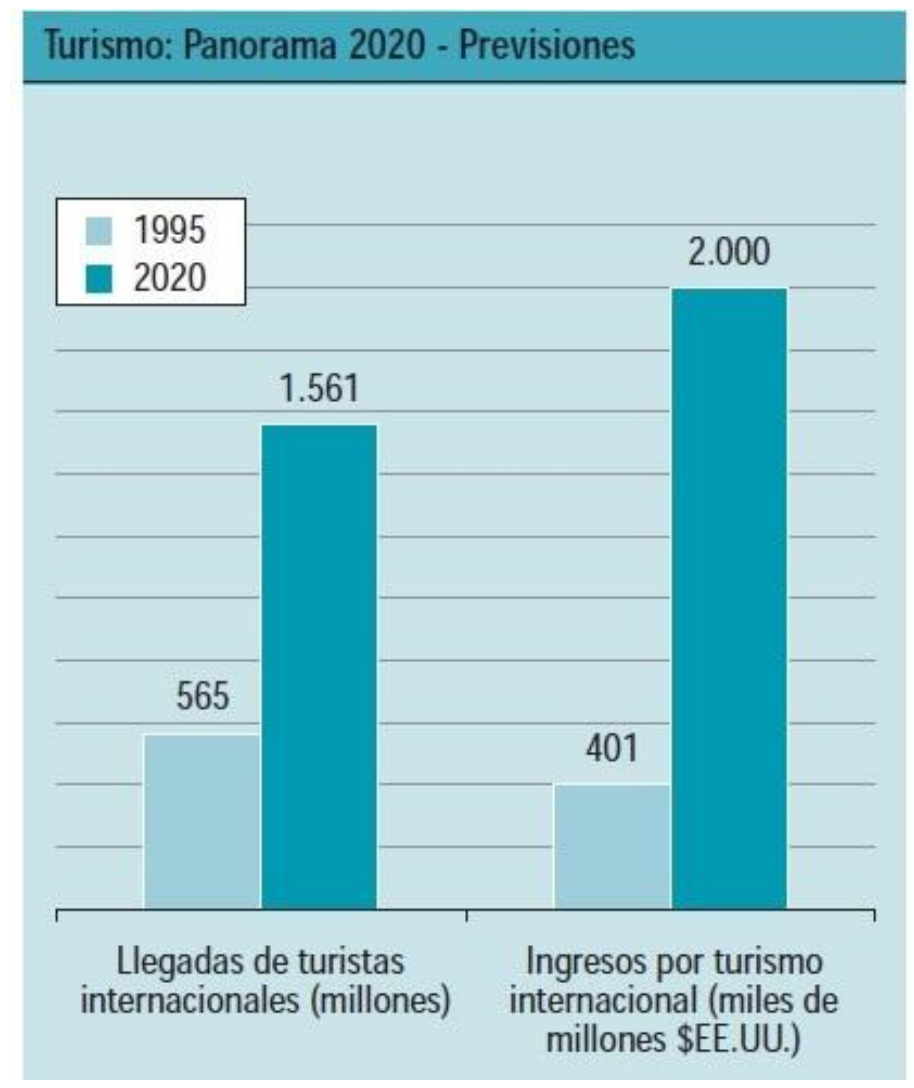

El estudio concluye que en los próximos años los mercados intensificarán sus actividades promocionales y aumentarán el gasto promocional sobre todo en el exterior con campañas de márketing más agresivas. En los destinos turísticos 
desarrollados, como es el caso de España, se prevé que las oficinas de turismo diversifiquen sus productos turísticos para fomentar la creación de nuevos mercados ampliando la demanda más allá de las zonas tradicionales. Así mismo, los sitios web experimentarán un mayor desarrollo y se convertirán en el elemento clave para la promoción e información turística y en el canal de referencia en el futuro.

En todas estas acciones de promoción turísticas son las distintas organizaciones turísticas las que adquieren una relevancia fundamental para la consecución de los objetivos propuestos. En el siguiente apartado realizamos, pues, una radiografía de estas instituciones y ponemos en valor su actividad de difusión de información y de desarrollo de las políticas turísticas.

\subsubsection{Las organizaciones turísticas: la comunicación y el márketing turístico}

El turismo, como hemos señalado en el apartado anterior, se desarrolla en un entorno global que a menudo sufre cambios y turbulencias ${ }^{29}$. El turismo es una actividad efímera y dinámica que necesita de unas condiciones estables para su práctica y futuro desarrollo. Es por ello que las diversas organizaciones turísticas juegan un papel fundamental en el desarrollo del turismo y sobre todo, en el control de su comercialización y comunicación.

A nivel internacional debemos destacar la Organización Mundial del Turismo $(\mathrm{OMT})^{30}$. Se trata de la principal organización internacional en el campo del turismo, que depende de las Naciones Unidas y que constituye un foro mundial para debatir cuestiones de política turística y una fuente útil de conocimientos

\footnotetext{
${ }^{29}$ Fenómenos meteorológicos adversos, guerras, migraciones, etc. condicionan la actividad turística.

30 La OMT nació en 1929 con el nombre Unión Internacional de Organismos Oficiales de Promoción Turística como un organismo técnico. Hoy es una organización supranacional que representa a los gobiernos locales, el sector privado, asociaciones de turismo e instituciones docentes.
} 
especializados en este campo. La OMT desempeña un papel central y decisivo en la promoción del desarrollo de un turismo responsable, sostenible y accesible para todos, prestando especial atención a los intereses de los países en desarrollo.

Entre sus miembros figuran 154 países, siete territorios ${ }^{31}$ y más de 400 Miembros Afiliados ${ }^{32}$ que representan al sector privado, a instituciones de enseñanza, a asociaciones de turismo y a autoridades turísticas locales. Los Representantes Regionales (de África, las Américas, Asia Oriental y el Pacífico, Europa, Oriente Medio y Asia Meridional), desde la sede en Madrid, emprenden actuaciones directas que refuerzan y complementan los esfuerzos de las administraciones nacionales de turismo ${ }^{33}$.

En su papel promocionador del turismo, la OMT desarrolla diferentes campañas promocionales $^{34}$ del turismo, cuyo ámbito geográfico de la campaña pueden ser todos los destinos, empresas turísticas y medios de comunicación, de modo que todos ellos pueden tomar parte en la campaña, independientemente de su relación de afiliación con la Organización.

Debemos destacar el papel de TOURCOM, institución de la OMT que se ocupa de la comunicación de la OMT y que sirve de punto de encuentro para compartir las novedades en comunicación y campañas promocionales y a través

\footnotetext{
${ }^{31}$ Los territorios son miembros asociados que no son responsables de la dirección de sus relaciones exteriores.

32 Los miembros efectivos son los estados soberanos, los miembros afiliados son entidades internacionales, intergubernamentales y no gubernamentales que tienen actividades directamente relacionadas con los viajes, el turismo o los sectores afines.

${ }^{33}$ Datos extraídos de www.unwto.org.

34 Destaca la campaña "EL TURISMO ES RIQUEZA", campaña mundial de sensibilización con la que la Organización Mundial del Turismo (OMT) quiere crear una conciencia de los beneficios que el turismo puede generar para la vida, la cultura y la economía o, dicho brevemente, para la sociedad en todos sus planos. A solicitud de los miembros de la Organización Mundial del Turismo, se preparó una campaña mundial para promover los efectos positivos del turismo, como parte de la I Conferencia Mundial sobre las Comunicaciones en el Turismo (TOURCOM) celebrada los días 29 y 30 de enero de 2004 en Madrid.
} 
del cual se vela por la cobertura que hacen los medios de comunicación en los diferentes sucesos que tienen un fuerte impacto en el desarrollo de los destinos turísticos y su población local. Las conferencias de TOURCOM en comunicación estratégica en turismo están enfocadas a la mejora de las relaciones entre los stakeholders públicos y privados dentro del sector turístico y los medios de comunicación, y apuestan por la creación de una comunicación profesional en el sector turístico. A su vez TOURCOM recoge las buenas prácticas en el diseño e implementación de la comunicación turística aplicada a los destinos y sus proveedores, tanto privados como públicos y los medios con los que los medios de comunicación contribuyen al desarrollo del turismo internacional.

Otras organizaciones turísticas destacadas a nivel internacional son el Consejo Mundial de los Viajes y el Turismo (World Travel and Tourism Council, WTTC) ${ }^{35}$, que es una organización global que representa al sector empresarial en turismo y la Unión Mundial para la Naturaleza (International Union for Conservation of Nature, IUCN) ${ }^{36}$, organismo que agrupa a estados soberanos, entidades gubernamentales y otros organismos no gubernamentales con el objetivo de ayudar a las sociedades del mundo a conservar la naturaleza y asegurar el buen uso de los recursos naturales. Estas dos organizaciones desarrollan también campañas de comunicación y de promoción globales que tienen un impacto local en diferentes sectores y ámbitos ${ }^{37}$.

\footnotetext{
${ }^{35}$ www.wttc.org

36 http://www.iucn.org/

37 Existen otros organismos que se ocupan también del turismo como actividad económica, como son la Organización para la Cooperación y el Desarrollo (OCDE), el Fondo Monetario Internacional (FMI), el Banco Internacional de Reconstrucción y Desarrollo (BIRD), la Organización Internacional del Trabajo (OIT), la Asociación del viajes del Pacífico y Asia (PATA), la Confederación de Organizaciones Turísticas de la América Latina (COTAL) y la Organización Turística del Caribe (CTO), entre otras.
} 
El sector público no sólo desarrolla sus políticas turísticas a nivel internacional, sino que existen otros tres niveles básicos de organización como son el nacional, el regional y el local.

A nivel nacional, el turismo representa una responsabilidad del gobierno, que debe formular una Política Turística general especificando el peso que se le va a dar al sector en la economía nacional. Las competencias y ámbito de actuación varían enormemente de un país a otro dependiendo del grado de delegación por parte del gobierno y de la delegación de estos organismos en estas organizaciones. En España, el Gobierno central y el Ministerio de Industria, Energía y Turismo $^{38}$ se ocupan de la promoción exterior a través de un organismo autónomo, Turespaña ${ }^{39}$, y gestionan otras entidades públicas a la vez como los Paradores de Turismo. La Sociedad Estatal para la Gestión de la Innovación y las Tecnologías Turísticas, S.A. (SEGITTUR), dependiente del Ministerio de Economía y Hacienda, y adscrita a la Secretaría General de Turismo y Comercio Interior, es otra de las sociedades públicas que nace con el propósito de convertirse en un nexo de unión entre las nuevas tecnologías y el sector turístico. En este sentido, tiene como objetivos apoyar la promoción turística y la comercialización de los productos y servicios mediante el uso de las nuevas tecnologías, haciendo especial hincapié en Internet. Asimismo, pretende contribuir, mediante la investigación, el desarrollo y la innovación, a mejorar los niveles de profesionalidad del sector proporcionando para ello instrumentos que faciliten el acceso a las nuevas tecnologías. Otra de sus facetas es la preparación, el tratamiento y la difusión de información con

\footnotetext{
${ }^{38}$ Ministerio de Industria, Energía y Turismo, http://www.minetur.gob.es/es-ES/Paginas/index.aspx

${ }^{39}$ www.tourspain.es
} 
relevancia no sólo para la promoción, sino también para impulsar la innovación en el sector, en todos sus ámbitos.

Las Comunidades Autónomas disfrutan de plenas competencias para la gestión, planificación y promoción del sector turístico ${ }^{40}$. La creciente complejidad del fenómeno turístico aconseja la descentralización en la toma de decisiones que afectan al sector y por ende, a la promoción y la comunicación. La Región, en muchas ocasiones, es considerada un destino turístico en sí misma, y es responsable de su propia promoción institucional, del mismo modo en que los son las administraciones locales o las Diputaciones, que poseen competencias en su ámbito territorial.

En todos estos organismos se desarrollan campañas comunicacionales y de promoción turística que deben ser traducidas a distintas culturas. Las organizaciones supranacionales como la OMT disponen de sus propios traductores que realizan las labores de trasvase intercultural. A nivel nacional y regional, sin embargo, las tareas de mediación de los distintos proyectos y campañas de promoción suelen licitarse a empresas de traducción, que son las encargadas de la realización del proyecto.

\subsubsection{Las marcas turísticas y la promoción de destinos turísticos}

A menudo no se explican bien ciertos comportamientos de los consumidores de turismo, es decir, por qué turistas provenientes de entornos sociodemográficos

\footnotetext{
${ }^{40}$ Uno de los mecanismos de que disponen las distintas comunidades autónomas por los que establecen sus líneas de actuación en materia de turismo son los libros blancos del turismo. En el caso de la Comunidad Valenciana el Libro Blanco del Turismo de la Comunidad Valenciana lo editó el Instituto Turístico Valenciano, ITVA, organismo adscrito a la Conselleria de Industria, Comercio y Turismo en 1990 (Solà y Bernad, -). El Libro Blanco del Turismo en España fue publicado por la Secretaría General de Turismo en 1990.
} 
idénticos eligen destinos distintos, por qué algunos turistas viajan con unas compañías y no con otras, etc.

La realidad es que existen múltiples factores que conforman la toma de decisiones, y que son de tipo motivacional, económico, sociológico, psicológico, etc. Así la toma de decisiones del turista es un proceso complejo en el que intervienen varios elementos y el turista toma una decisión sobre algo que se caracteriza por (Crampon y Rothfield, 1976):

- Una inversión que no le va a reportar nada tangible.

- La experiencia turística representa un gasto considerable en relación con el esfuerzo empleado para ganar el dinero.

- Implica la necesidad de planificar y ahorrar antes de la decisión final.

- El gasto turístico casi nunca se realiza de forma espontánea o caprichosa.

Otra de las características del producto turístico y que afecta a la toma de decisiones es la simultaneidad existente entre el acto de producción y el acto de consumo, es decir, es imposible separar el producto turístico de su consumo, con lo que la calidad y su evaluación sólo pueden realizarse a posteriori. Por regla general la decisión de realizar turismo suele ser una decisión meditada. Normalmente nos solemos guiar por una mayor cautela a la hora de adquirir productos turísticos que cuando adquirimos otros productos.

Es por estos motivos que la imagen que exista en la mente del consumidor sobre un destino o servicio será decisiva a la hora de la toma de decisiones, aunque esa imagen no se corresponda con la realidad. 
En este sentido, la OMT define la imagen ${ }^{41}$ de un destino turístico como las ideas o conceptos que se tienen del mismo a nivel individual o colectivo.

Según Cooper et al. (1993) existen dos tipos de imágenes: la imagen orgánica, que es la que se forma a partir de información externa, que no proviene de la publicidad directa (libros, periódicos, etc.) y la imagen inducida, que es la que proviene directamente de la promoción que de un país hacen sus órganos o entes turísticos.

Desde el amplio marco del turismo, observamos cada vez más la proliferación de marcas cada vez más enlazadas con los estilos de vida de los consumidores y con las crecientes tendencias de los destinos turísticos. Según Solà y Climent (2007:151 y siguientes) muchas de las actividades promocionales que se realizan en los destinos turísticos van dirigidos al establecimiento y creación de marcas turísticas ${ }^{42}$. A través de los años, han ido apareciendo las marcas de los diferentes territorios dentro de un mismo país. Así, por ejemplo, la megamarca turística España ${ }^{43}$ ampara la mayoría de submarcas que se gestionan principalmente desde sus gobiernos autonómicos. Así, por ejemplo, las marcas reconocidas por la Conselleria de Turismo de la Comunitat Valenciana son Benidorm, València Terra i Mar, Costa Blanca y Costa Azahar y utilizan la marca

\footnotetext{
${ }^{41}$ Para definir el concepto de imagen turística ofrecemos la definición extendida de la OMT: "conjunto de representaciones efectivas y racionales que resultan de la confrontación de elementos generatrices manifestaciones del país en todos los planos (promociones, actualidad): experiencia propia y rumores con motivaciones preexistentes que se asocian espontáneamente al país desde la evocación de aquel. La imagen puede reducirse al límite, a un simple símbolo o a un logotipo: la hoja del arce para Canadá, el trébol para Irlanda, etc." Fuente: OMT, Estudio sobre la formación de la imagen turística y nacional, Madrid, 1980.

${ }^{42}$ Valls, J.F. (1992:16) apunta que "el concepto de marca es muy amplio y pueden observarse matices muy particulares según sea la perspectiva desde la que se analiza: económica, legal, publicitaria, etc."

${ }^{43}$ En España rige actualmente la actual Ley de Marcas del 7 de diciembre de 2001.
} 
paraguas Comunitat Valenciana ${ }^{44}$. A continuación mostramos algunas de las marcas en vigor con sus logos y eslóganes, así como el logo de la marca país España:

Figura 8: Ejemplos de promoción turística local

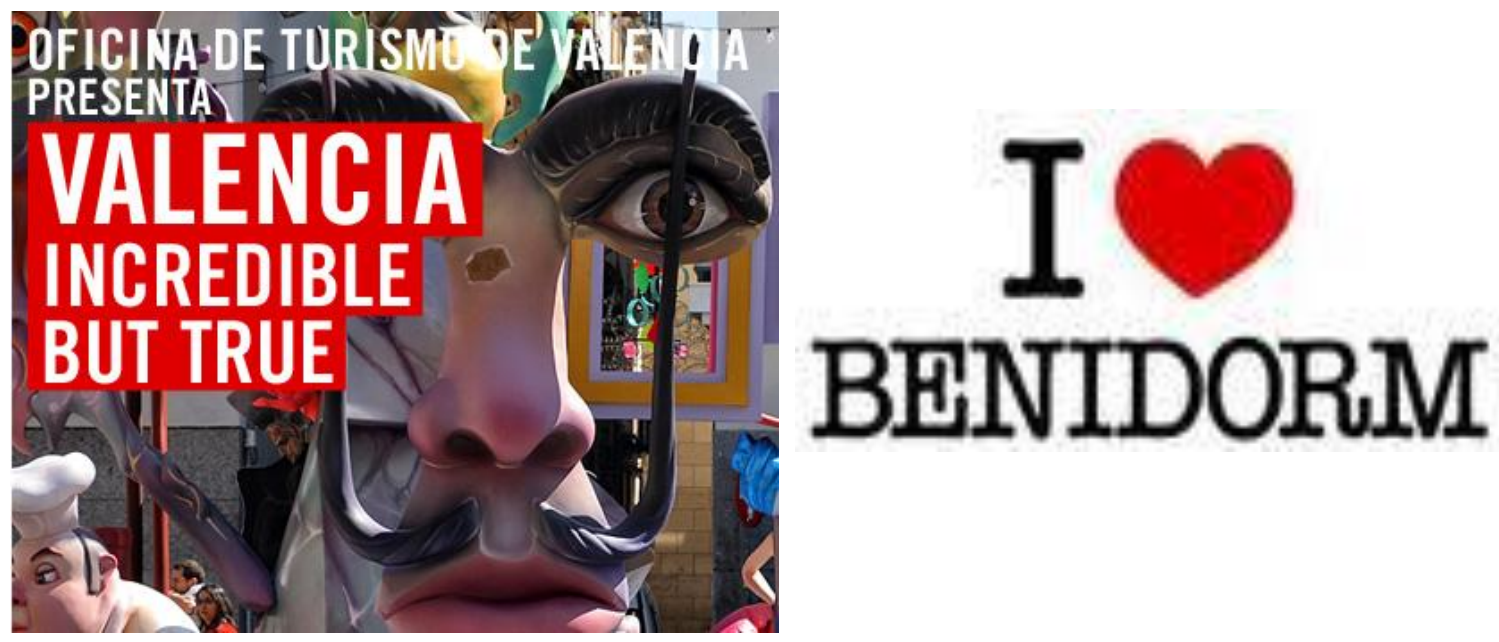

Figura 9: Ejemplos de marcas turísticas

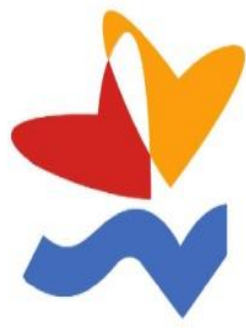

\section{València Terra i Mar}

Diputació de València

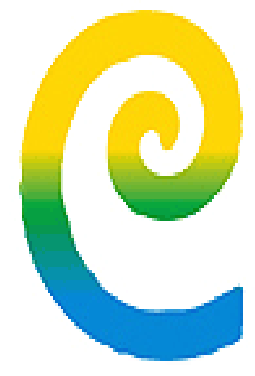

Costa Azahar

Interior

44 En el caso de la Comunidad Valenciana, el planteamiento de elaboración y control de una marca turística propia "Comunitat Valenciana" aparece en 1987 con la creación del Instituto Turístico Valenciano (ITVA). 

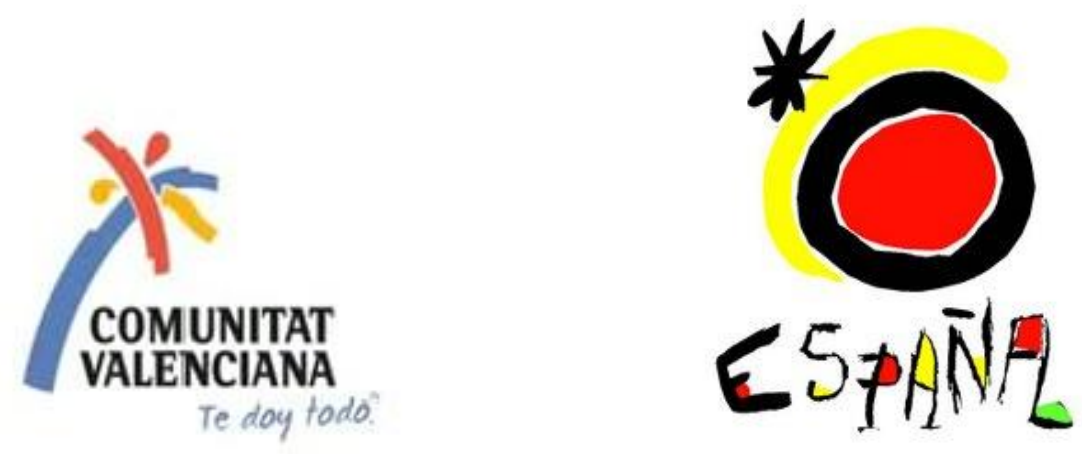

Hoy ya son muchos los países, regiones e incluso ciudades que están intentando construir marcas turísticas fuertes y están consiguiendo tangibilizar su imagen a través de ellas. ${ }^{45}$ La marca es asimismo, un modo de crear una identidad clara y diferenciada de los competidores turísticos y está llamada a ser la base de la supervivencia en el mundo global y competitivo, en donde el poder de una imagen de marca asentada y potente unido a una correcta promoción turística es sinónimo de éxito. ${ }^{46}$

Según Solá Climent (2007:134) se considera la marca como "uno de los ingredientes intangibles más poderosos y valorados en las empresas y la creación de la marca como experiencia es la nueva concepción de marca que se ha establecido en el campo del turismo". Se trata de crear marcas turísticas en las que la formación de la experiencia es el punto clave de la misma. En general las marcas turísticas poseen unas características especiales que las definen, ya que son marcas que apoyan el producto turístico entendido como sensaciones

\footnotetext{
${ }^{45}$ Solá Climent (2007) pone como ejemplo el caso de Nueva Zelanda que lleva desde 2003 rediseñando su imagen alrededor de una estrategia global de marca.

${ }^{46}$ Tómense como ejemplos marcas de fuerte posicionamiento como I love New York, París como ciudad del amor (Ville de l'Amour) y Roma como Ciudad Eterna (Città Eterna).
} 
producidas por la imagen mental que evoca el destino que las conforma (Solá Climent, 2007:149).

El traductor de textos turísticos debe conocer cuáles son las marcas turísticas pertenecientes a la cultura de origen y a la cultura de destino. Sin embargo, no sólo debe ser capaz de identificar las marcas turísticas, sino también debe ser consciente de qué características quiere transmitir dicha imagen en un determinado texto. Si bien la imagen de la marca es un elemento subjetivo que sugiere diferentes realidades dependiendo de cada turista, el traductor debe ser capaz de realizar su mediación trasvasando los elementos que van asociados a dicha marca y siendo fiel a su espíritu que la imagen de la marca desea mostrar.

La comunicación turística es una de las variables de marketing mix bajo la cual se integran una serie de elementos como la publicidad, la promoción de ventas, las relaciones públicas, las ferias y la venta personal. Aunque pueden ejecutarse aisladamente, todos estos elementos contribuyen en la construcción de una identidad propia en la organización para proyectar una imagen adecuada del producto o destino turístico ${ }^{47}$ (Bigné, Font y Andreu, 2000:54).

Figura 10: Interrelación de las variables del marketing mix y la comunicación (Bigné, Font y Andreu, 2000)

\footnotetext{
${ }^{47}$ Las otras tres variables del mix turístico son el producto, el precio y la distribución.
} 


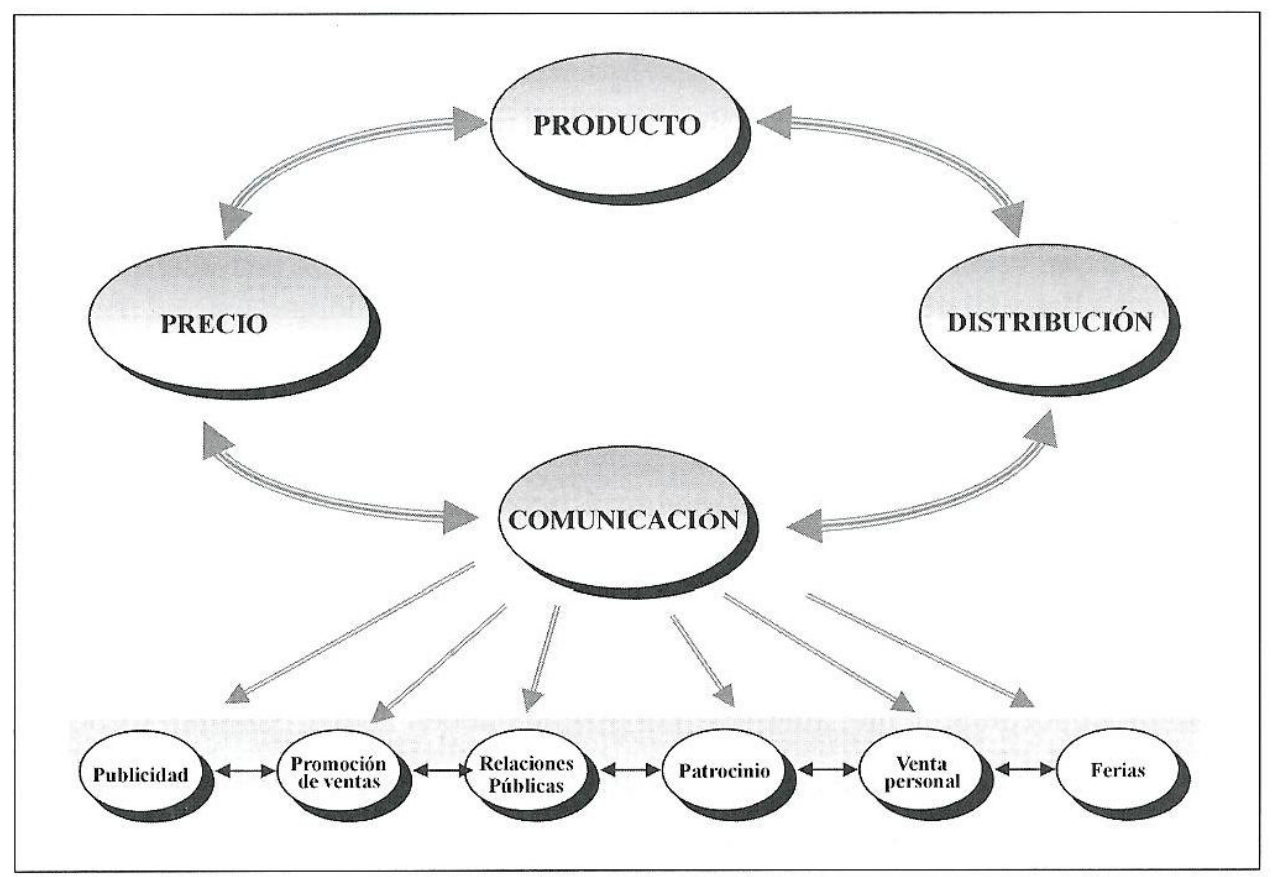

Los cientos de miles de folletos, guías, pósters y otros tipos de materiales turísticos que se editan en todo el mundo son, en muchos casos, el fruto de una estrategia de comunicación para la tangibilización de la marca de un destino turístico. Sin embargo, suelen estar enmarcados en actividades o campañas promocionales con diversos fines y de diverso carácter. Entendemos, pues, la promoción turística en el sentido en el que la consideran Morgan et al. (2004: $59)^{48}$ y que definen como:

Uso consciente de marketing y publicidad para comunicar imágenes selectivas de zonas específicamente situadas, localidades o áreas a un público definido.

Los objetivos de la promoción turística son básicamente los siguientes:

- Informar: el turista es un tipo de consumidor que consume grandes cantidades de información antes y durante el consumo del producto

\footnotetext{
${ }^{48}$ Traducción propia
} 
turístico. La información contribuye a reducir el riesgo percibido durante la toma de decisiones.

- Persuadir: sin duda la mayoría de textos turísticos orientados al lector destinatario (en nuestro caso, el turista) van destinados a convencerle de las bondades de un determinado producto turístico, ya sea un vuelo en un avión, una estancia en un hotel o una cena en un restaurante.

- Recordar: la promoción es una actividad clave para la fidelización del cliente y para la creación y el mantenimiento de la imagen de marca.

- Posicionar: no sólo se trata de persuadir y recordar, sino de diferenciarse del resto de competidores turísticos.

La promoción turística de las empresas del sector turístico representa uno de los ejes principales para no sólo dar a conocer el producto, sino para posibilitar que el producto se mantenga en el mercado. A nivel institucional, la promoción alcanza una relevancia excepcional, pues son los propios entes públicos los que, a modo de empresa privada, desarrollan sus campañas promocionales, como es el caso de España. En el próximo apartado damos cuenta de su coyuntura turística y su estrategia de promoción turística.

\subsubsection{El sector turístico en España}

España dispone de unas características excepcionales para la práctica del ocio y de las estancias vacacionales: su climatología, su patrimonio natural y paisajístico, etc. Sin embargo, uno de los elementos que más atrae a los turistas de España es su cultura: su gastronomía, su patrimonio artístico-cultural y sus tradiciones y fiestas.

La cultura española constituye una de las grandes culturas del mundo. España se sitúa en el mundo como uno de los países con un mayor volumen de calidad y 
diversidad de productos culturales: desde nuestro patrimonio monumental y museístico hasta la oferta singular en artes escénicas y la incorporación de nuestra gastronomía de vanguardia.

La influencia de la cultura española tiene hoy en día una importante proyección en el exterior gracias al peso y a la relevancia del español como una de las grandes lenguas de comunicación internacional (Quilis, 2002), proyección que se consolida debido al creciente interés que adquiere día a día el aprendizaje del español en el mundo, con una repercusión en la oferta de empresas dedicadas al turismo y a la difusión lingüística y cultural, y por extensión, en la traducción.

En paralelo, España es líder mundial en turismo vacacional ${ }^{49}$, pero a pesar de tener una oferta cultural de primera magnitud, prima la imagen de un destino de sol y playa ${ }^{50}$. España es uno de los destinos preferidos por los miles de turistas de todo el mundo que nos visitan para pasar sus vacaciones. Actualmente, es el tercer destino vacacional por detrás de los Estados Unidos y Francia. Sin embargo, el aumento de la competitividad que vive el sector turístico hace que la fidelidad, la calidad y la satisfacción sean un objetivo permanente para poder mantener la posición de liderazgo mundial.

El clima es uno de los motivos esenciales que animan a los turistas a viajar a España. Muchos de los turistas que nos visitaron en 2010 quedaron fidelizados y desearían volver. Los turistas más fieles son los británicos ${ }^{51}$, pues alrededor de un 70\% están dispuestos a repetir y volver a España. El concepto de satisfacción

\footnotetext{
${ }^{49}$ La actividad turística en España supone casi el 11\% del PIB, lo que la convierte en la primera industria nacional.

${ }^{50} \mathrm{http}: / /$ www.mityc.es/-es/gabineteprensa/notasprensa/documents/planpromocionturismointern.pdf

${ }^{51}$ Encuesta Habitur 2010. www.iet.tourspain.es
} 
resulta de vital importancia, pues del grado de satisfacción ${ }^{52}$ percibida depende una posible repetición y lealtad de las visitas. Además, la percepción de un alto grado de satisfacción es un factor clave que favorece la mejor promoción, que es la difusión gratuita y recomendación de la marca España entre amigos, familiares y desconocidos. Según la encuesta Habitur, en 2010, el grado de satisfacción general respecto a los diferentes recursos turísticos percibido por los turistas no residentes en su estancia en España alcanzó una nota media de 8,5 en una escala del 1 al 10. En la tabla 8 observamos la valoración que los turistas internacionales hicieron por productos en su visita a España:

Tabla 8: Valoración de la satisfacción de los turistas internacionales por producto, año 2010 (IET, Habitur)

\begin{tabular}{lr}
\hline Productos & $\begin{array}{r}\text { Valoración } \\
\text { sobre }\end{array}$ \\
\hline Alojamiento & $\mathbf{7 , 8}$ \\
Gastronomía & $\mathbf{8 , 0}$ \\
Ocio (oferta cultural, deportiva, nocturna) & $\mathbf{7 , 6}$ \\
Entorno turístico (belleza, tranquilidad, seguridad, limpieza, etc.) & $\mathbf{7 , 9}$ \\
Uso de transportes en destino (tren, bus, taxi, etc.) & $\mathbf{8 , 0}$ \\
Infraestructuras (carreteras, telecomunicaciones, aeropuertos, etc.) & $\mathbf{8 , 0}$ \\
\hline Grado de Satisfacción General & $\mathbf{8 , 5}$ \\
\hline
\end{tabular}

\footnotetext{
${ }^{52}$ Philip Kotler (2000), el padre del márketing moderno, define satisfacción como "el nivel del estado de ánimo de una persona que resulta de comparar el rendimiento percibido de un producto o servicio con sus expectativas".
} 
Asimismo, en la tabla 9 observamos algunos de los indicadores turísticos básicos del mercado español y su evolución desde el año 2005 hasta el año $2009^{53}$. Podemos observar los efectos de la crisis económica mundial que se traducen en una bajada en la llegada de visitantes desde el año 2007 hasta el año 2009, lo que provoca que España reciba en 2009 el mismo número de visitantes que en el año 2005. Por lo que respecta a la tipología de turista, el turista europeo es el que visita mayoritariamente nuestro país (en su mayoría son alemanes, británicos y franceses) y el turista que mayor decrecimiento experimenta. La gran mayoría de turistas que visita nuestro país lo hace para pasar sus vacaciones y disfrutar de su ocio, lo hace por avión y utiliza vías alternativas a los paquetes turísticos.

Tabla 9: Indicadores turísticos básicos del mercado español (Evolución 2005-2009), OMT.

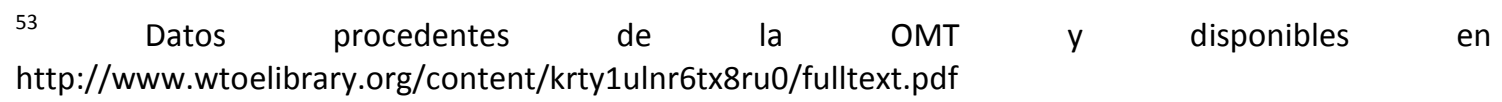




\section{SPAIN}

\begin{tabular}{|c|c|c|c|c|c|c|c|c|}
\hline \multicolumn{2}{|c|}{ Basic data and indicators } & \multirow[t]{3}{*}{ Notes } & \multirow[t]{3}{*}{ Units } & \multirow[t]{3}{*}{2005} & \multirow[t]{3}{*}{2006} & \multirow[t]{3}{*}{2007} & \multirow[t]{3}{*}{2008} & \multirow[t]{2}{*}{2009} \\
\hline \multirow{2}{*}{\multicolumn{3}{|c|}{$\begin{array}{l}\text { 1. INBOUND TOURISM } \\
\text { Data }\end{array}$}} & & & & & & \\
\hline & & & & & & & & \\
\hline \multicolumn{2}{|c|}{ Arrivals } & \multirow[t]{5}{*}{ (1) } & & & & & & \\
\hline 1.1 & Total & & ('000) & 92.563 & 96.152 & 98.907 & 97.670 & 92.054 \\
\hline 1.2 & \multirow{3}{*}{$\begin{array}{l}\text { Overnight usitors (tourists) } \\
\text { * of which, cruise passengers }\end{array}$} & & ('000) & 55.914 & 58.004 & 58.666 & 57.192 & 52.231 \\
\hline 1.3 & & & ('000) & 36.649 & 38.148 & 40.241 & 40.478 & 39.823 \\
\hline 1.4 & & & $(' 000)$ & .. & .. & .. & .. & .. \\
\hline \multicolumn{2}{|r|}{ Arrivals by region } & \multirow[t]{4}{*}{ (1) } & & & & & & \\
\hline 1.5 & \multirow{3}{*}{$\begin{array}{l}\text { Total } \\
\text { • Africa } \\
\text { - Americas }\end{array}$} & & $(' 000)$ & 55.914 & 58.004 & 58.666 & 57.192 & 52.231 \\
\hline 1.6 & & & ('000) & .. & .. & .. & .. & \\
\hline 1.7 & & & ('000) & 2.233 & 2.378 & 2.313 & 2.398 & 2.679 \\
\hline 1.8 & - East Asia and the Pacific & \multirow[t]{6}{*}{$(2)$} & ('000) & 181 & 255 & 346 & 237 & 229 \\
\hline 1.9 & - Europe & & ('000) & 52.190 & 54.313 & 54.927 & 53.512 & 47.871 \\
\hline 1.10 & - Middle East & & ('000) & .. & .. & .. & .. & .. \\
\hline 1.11 & South Asia & & ('000) & .. & .. & .. & .. & \\
\hline 1.12 & - Other not classified & & ('000) & 1.310 & 1.058 & 1.080 & 1.045 & 1.452 \\
\hline 1.13 & ${ }^{*}$ of which, nationals residing abroad & & ('000) & .. & & & 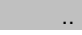 & \\
\hline \multicolumn{2}{|c|}{ Arrivals by main purpose } & \multirow[t]{6}{*}{$(1)$} & & & & & & \\
\hline 1.14 & Total & & ('000) & 55.913 & 58.005 & 58.666 & 57.192 & 52.231 \\
\hline 1.15 & - Personal & & ('000) & 49.973 & 53.090 & 53.391 & 51.921 & 47.896 \\
\hline 1.16 & * holidays, leisure and recreation & & ('000) & 43.898 & 46.990 & 47.752 & 46.733 & 42.592 \\
\hline 1.17 & * other personal purposes & & ('000) & 6.075 & 6.100 & 5.639 & 5.188 & 5.304 \\
\hline 1.18 & - Business and professional & & ('000) & 5.940 & 4.915 & 5.275 & 5.271 & 4.335 \\
\hline \multicolumn{2}{|c|}{ Arrivals by mode of transport } & \multirow[t]{8}{*}{ (1) } & & & & & & \\
\hline 1.19 & Total & & $(' 000)$ & 55.913 & 58.005 & 58.665 & 57.192 & 52.231 \\
\hline 1.20 & - Air & & ('000) & 40.730 & 42.445 & 44.324 & 44.397 & 40.278 \\
\hline 1.21 & - Water & & ('000) & 1.772 & 1.460 & 1.456 & 1.452 & 1.397 \\
\hline 1.22 & - Land & & ('000) & 13.411 & 14.100 & 12.885 & 11.343 & 10.556 \\
\hline 1.23 & * railway & & ('000) & 290 & 281 & 146 & 143 & 142 \\
\hline 1.24 & * road & & ('000) & 13.121 & 13.819 & 12.739 & 11.200 & 10.414 \\
\hline 1.25 & ${ }^{*}$ others & & $(' 000)$ & & & & & \\
\hline \multicolumn{2}{|c|}{ Arrivals by form of organization of the trip } & & & & & & & \\
\hline 1.26 & Total & & ('000) & 55.913 & 58.005 & 58.666 & 57.192 & 52.228 \\
\hline 1.27 & - Package tour & & ('000) & 20.391 & 19.651 & 17.871 & 17.071 & 15.524 \\
\hline 1.28 & Other forms & & ('000) & 35.522 & 38.354 & 40.795 & 40.121 & 36.704 \\
\hline
\end{tabular}

Como acabamos de observar, la recesión económica mundial ha influido directamente en el panorama turístico internacional. Durante el año 2009, el flujo turístico internacional descendió un 4,3\% a nivel mundial, el mayor en catorce años.

Por lo que respecta a 2010, 52,7 millones de turistas visitaron España y gastaron más de 48.000 millones de euros. En total, España recibió 6 millones de viajeros menos desde el año $2007^{54}$. Sin embargo, el turismo en España cerró el año

54 Datos extraídos de la Conferencia titulada "Estrategias y programa de la administración turística española" impartida el 26/11/2010 por Joan Carles Cambrils, Jefe de la Unidad de Apoyo de Turespaña en la Escuela Politécnica Superior de Gandia en el marco de las Primeras Jornadas sobre Universidad, Empresa y Administración Turística desarrolladas en la Universidad Politécnica de Valencia. 
2011 con un incremento del 7,6 por ciento en el número de turistas internacionales que han visitado nuestro país respecto al año precedente ${ }^{55}$. Los últimos datos auguran aún mejores perspectivas para el año 2012.

Esta caída considerable de la actividad turística en España experimentada en el año 2010 se produce en paralelo a la aparición de cambios reseñables en el comportamiento del viajero que visita nuestro país: se trata de un viajero con múltiples motivaciones a la hora de hacer turismo, que busca productos despaquetizados en diversos canales de compra, comparando precios y reservando sus viajes en el último minuto. Así mismo, el nuevo viajero prefiere disfrutar de estancias más cortas en destinos más cercanos a su lugar de residencia y comparte experiencias y consulta en Internet antes de elegir y programar su viaje ${ }^{56}$. Estos comportamientos nuevos de los visitantes tienen su causa, entre otros, en la revolución tecnológica que ha supuesto el acceso rápido a la información y a los productos turísticos a través de Internet.

Goytia (1997) ya avanzó los cambios que está experimentando el nuevo visitante y que a continuación resumimos. Los nuevos hábitos vacacionales son los siguientes:

- Reducción de la duración de las vacaciones principales.

- Incremento de los viajes cortos.

- Incremento de los viajes de largo recorrido.

- Reducción de nivel de fidelidad a un destino.

\footnotetext{
${ }^{55}$ Según los datos del informe Frontur, del Instituto de Estudios Turísticos, en 2011 visitaron España 56,7 millones de turistas internacionales.

${ }^{56}$ En 2010 el 44\% de los turistas recibidos en España consultó Internet a la hora de planificar su viaje, un $22 \%$ habló con amigos o algún familiar y un $21 \%$ recurrió a agencias de viajes. Los turistas británicos y nórdicos recopilaron Internet en el $63 \%$ de los casos. Datos procedentes de Habitur 2010, en www.iet.tourspain.es.
} 
Cambio en los hábitos de compra:

- Incremento de la preferencia por los viajes organizados individualmente.

- Búsqueda de canales de compra alternativos.

- Cambios en los hábitos de consumo.

- Alojamiento y comida no es suficiente.

- Mayor nivel de actividad (de "pasar" a "vivir" las vacaciones).

- Preferencia por establecimientos con mayor nivel de equipamiento.

- Preocupación por el entorno medioambiental.

- Combinación de sol y playa con actividades lúdico-culturales.

- Deseo de un servicio personalizado y flexible.

- Deseo de garantía de servicio y servicios de atención y quejas.

El Instituto de Turismo de España (Turespaña) tiene encomendada la misión de promocionar el turismo español en el exterior, lo que implica formular y ejecutar los planes de actividades de promoción turística y los planes de apoyo a la comercialización de los productos turísticos españoles que se realicen en los mercados exteriores.

Bajo tal misión, TURESPAÑA ha decidido apostar firmemente por mejorar la eficacia de su actuación diseñando un Plan de Objetivos para la Promoción Exterior del Turismo ${ }^{57}$ que tiene como fin consolidar y mejorar la posición alcanzada por los productos y destinos turísticos españoles, promoviendo el consumo de productos turísticos de mayor rentabilidad potencial para el sector turístico español en su conjunto.

\footnotetext{
57 Disponible en http://www.tourspain.es/NR/rdonlyres/13F1FB80-5E18-4AD1-9DB564D86F58EA5E/19896/PLANESTRATEGICAPORMERCADO20194.pdf
} 
El modelo turístico actual se encuentra en fase de transformación por lo que es necesario dar un impulso conjunto para consolidar España como líder mundial en turismo. Lo que en definitiva se persigue es un reposicionamiento de la imagen de marca española, demasiado identificada con el turismo de sol y playa. Para lograr que el sistema turístico español sea el más competitivo y sostenible, el anterior Ministerio de Industria, Turismo y Comercio promovió el desarrollo del Plan Turismo 2020 58 Este Plan se aprobó en Consejo de Ministros de 8 de noviembre de 2007, fruto del consenso entre el sector público y privado.

El Plan Turismo 2020 responde a los retos que tiene planteado el Turismo a presente y futuro a través de:

- un nuevo modelo para los destinos turísticos maduros, mejorando nuestro posicionamiento en los mercados,

- promoviendo y desarrollando productos innovadores, impulsando una cultura del detalle y atención al cliente,

- avanzando en la asunción de fuertes compromisos de sostenibilidad, revalorizando recursos que fomenten un equilibrio socio-territorial del turismo,

- profundizando en el terreno del conocimiento, promoviendo la innovación, y atrayendo y mejorando el talento.

Para conseguir los objetivos del Plan Turismo 2020, se prevé un aumento del $67 \%$ en promoción turística y materiales promocionales disponibles en las oficinas de Turespaña.

${ }^{58}$ http://www.turismo2020.es 
Según se desprende del Plan Operativo Turespaña $2008^{59}$, existe un tipo de consumidor que está demandando un turismo experiencial e individualizado, en el que entran en juego valores emocionales y de personalización para el turista. La diversidad de España posibilita crecer estratégicamente en este segmento y definir nuevos productos como Privilege Spain ${ }^{60}$, que se ha lanzado ya en distintos mercados. Se trata de itinerarios experienciales en el que se promociona un destino personalizándolo, como el de Valencia, cuyo slogan es Días que nunca acaban y va dirigido a un público joven y urbano.

La promoción de estos productos se realiza por Internet. En general, la promoción que antaño se realizaba con folletos turísticos tiende a desaparecer pues observamos que cada vez más la información para la promoción turística se crea digitalizada y se vende en diferentes mercados a través de Internet como único canal dando lugar a los folletos electrónicos. Así, por ejemplo, el producto Privilege Spain Valencia está localizado a la cultura italiana (su slogan en italiano reza Giorni che non finiscono mai) y a la cultura alemana (Nie endende Tage) y es accesible a través de la página web creada expresamente para esta marca.

La campaña I need $\operatorname{Spain}^{61}$ (que sustituye a la anterior Smile! You are in Spain), que se mantuvo desde 2005 hasta 2009, (véase figuras 11 y 12) lanzada a principios del año 2010 propone una nueva línea de promoción internacional con la que se pretende llegar a todas las regiones del mundo incidiendo en aquellas donde la imagen de España es más débil como China, India, Oriente Próximo o EEUU. Así, por primera vez se incluyen anuncios destinados al mercado asiático o al norteamericano. Para ello la campaña cuenta con

\footnotetext{
${ }^{59} \mathrm{http}: / /$ www.ashotur.org/wp-content/uploads/plan-operativo-turespana-2020.pdf

${ }^{60}$ http://www.privilegespain.es/

${ }^{61}$ Véase el portal turístico oficial español en http://www.spain.info/
} 
soportes específicos adaptados a las particularidades de cada mercado emisor, destacando spots promocionales destinados al mercado asiático, novedad en la promoción turística de España.

Figura 11: Campaña de promoción internacional de España (2005-2009).

Fuente: www.spain.info
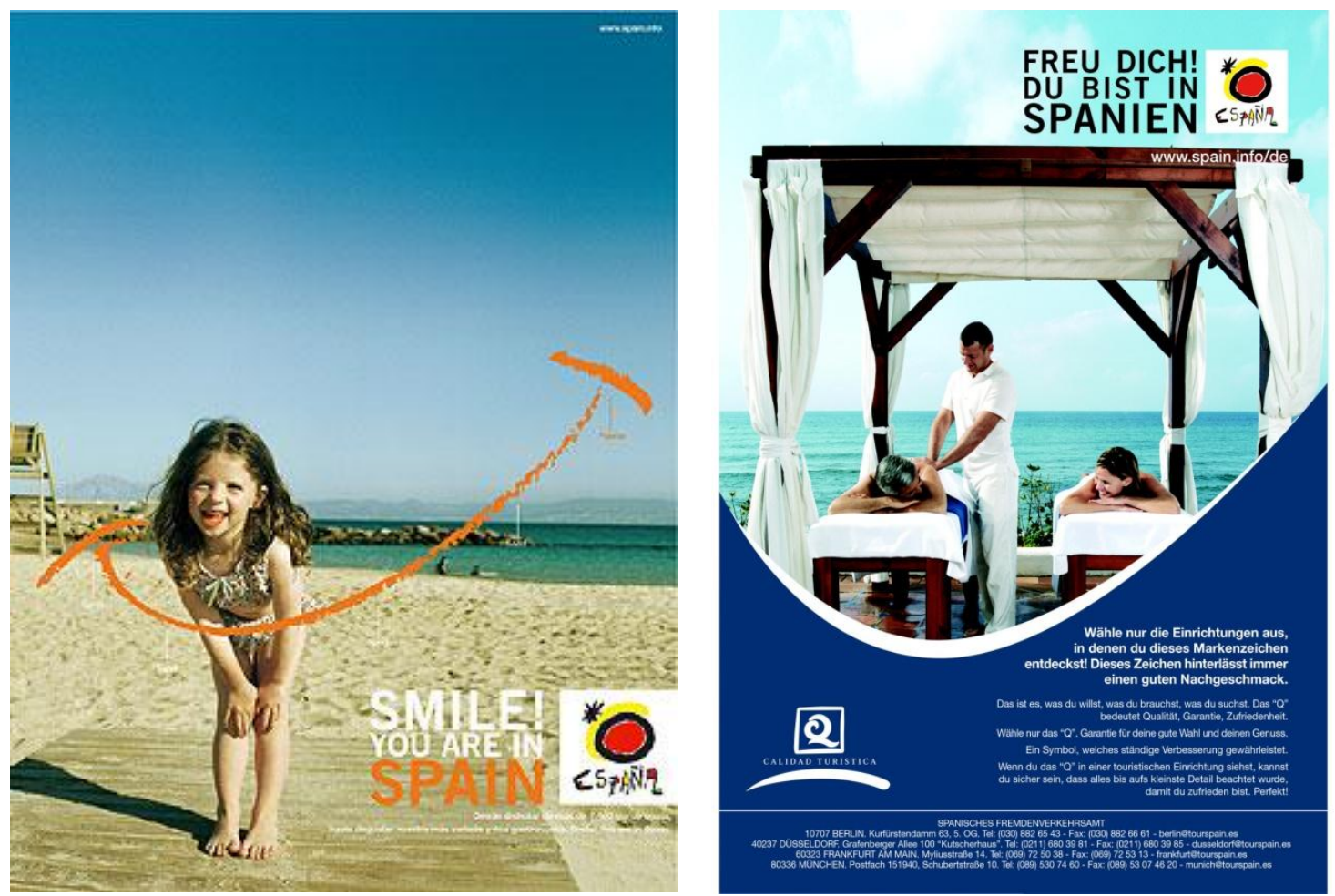

Figura 12: Campaña de promoción internacional de España en 2010 

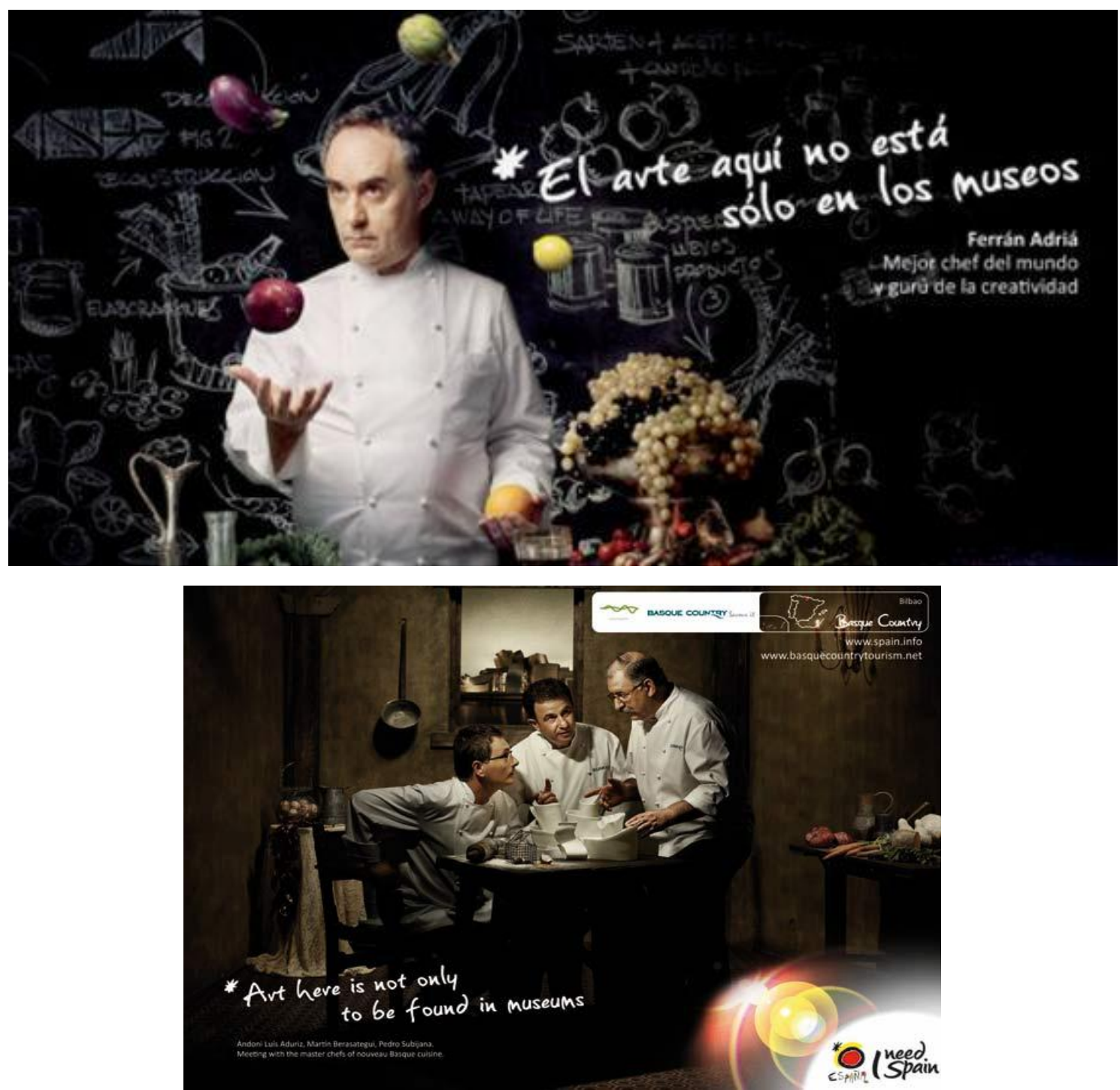

La promoción de España como destino turístico en el extranjero ha visto aumentar su presupuesto más del $20 \%$ en dos años ${ }^{62}$. Ello ha permitido, que sólo en 2009, se hayan alcanzado 259 acuerdos con las Comunidades Autónomas, entes públicos y privados, touroperadores, aerolíneas, etc. que han permitido sumar más de 25 millones de euros en promoción a la aportación de Turespaña, que ha superado los 42 millones.

${ }^{62}$ http://www.mityc.es/gabineteprensa/notasprensa/2010/Paginas/npcampanaineedspain040310.aspx 
En 2009 las Oficinas de Turismo en el Exterior (OET) ejecutaron 3.173 actividades de comunicación, marketing, promoción y apoyo a la comercialización, un 3\% más que en 2008. Desde la Secretaría de Estado de Turismo se ha organizado el viaje de más de 2.200 periodistas que han publicado 3.500 artículos y reportajes sobre nuestro país, con un valor publicitario de 126,5 millones de euros. Cerca de 3.580 operadores y agentes de viajes visitaron España, invitados también por Turespaña, en viajes de familiarización ${ }^{63}$.

Según las previsiones de la OMT, España seguirá siendo uno de los destinos turísticos de referencia, si bien perderá posiciones por la entrada de nuevos competidores que experimentarán un fenomenal ascenso en la llegada de visitantes. Los diez países más visitados verán un cambio con la entrada de China y de Hong Kong como principales destinos. La Federación Rusa también entrará en el top ten de destinos turísticos a nivel mundial ${ }^{64}$, como se observa en la tabla 10:

Tabla 10: Principales destinos del mundo en 2020 (OMT, 2000)

\footnotetext{
63 Según Martí Marco (2007:115) se invierten más de 40 millones de euros anuales en publicidad turística, para campañas publicitarias y ferias internacionales.

${ }^{64}$ Tailandia, Singapur y Sudáfrica se perfilan como nuevas potencias turísticas aunque no figuren entre las diez principales.
} 


\begin{tabular}{|c|c|c|c|c|c|}
\hline \multirow[t]{2}{*}{ Pals } & \multirow{2}{*}{$\begin{array}{c}\text { Ano base } \\
\text { (millones) } \\
1995\end{array}$} & \multirow{2}{*}{$\begin{array}{c}\text { Proyecciones } \\
\text { (millones) } \\
2020\end{array}$} & \multirow{2}{*}{$\begin{array}{c}\text { Iasa de crecimiento } \\
\text { medio anual (\%) } \\
1995-2020\end{array}$} & \multicolumn{2}{|c|}{$\begin{array}{c}\text { cuota de } \\
\text { mercado }(\%)\end{array}$} \\
\hline & & & & 1995 & 2020 \\
\hline 1. China & 20,0 & 130,0 & 7,8 & 3,5 & 8,3 \\
\hline 2. Francia & 60,0 & 106,1 & 2,3 & 10,6 & 6,8 \\
\hline 3. [stados Unidos & 43,3 & 102,4 & 3,5 & 7,7 & 6,6 \\
\hline 4. España & 38,8 & 73,9 & 2,6 & 6,9 & 4,7 \\
\hline 5. Hong Kong (China) & 10,2 & 56,6 & 7,1 & 1,8 & 3,6 \\
\hline 6. Italia & 31,1 & 52,5 & 2,1 & 5,5 & 3,1 \\
\hline 7. Reino Unido & 23,5 & 53,8 & 3,4 & 4,2 & 3,4 \\
\hline 8. México & 20,2 & 48,9 & 3,6 & 3,6 & 3,1 \\
\hline 9. Fed de Rusia & 9,3 & 48,0 & 6,8 & 1,6 & 3.1 \\
\hline 10. República Checa & 16,5 & 44,0 & 4,0 & 2,9 & 2,0 \\
\hline Total $(1-10)$ & 273,0 & 716,2 & 3,9 & 48,3 & 45,9 \\
\hline
\end{tabular}

A la luz de estos datos podemos afirmar que el turismo es y seguirá siendo una actividad de nuestra economía de gran magnitud en la que se realizan costosas inversiones en promoción y edición de materiales y textos, y que, por extensión, la traducción turística tiene un papel predominante en el sector al tener que ser trasladadas a la cultura meta las publicaciones del sector turístico cuyo destino final es el visitante extranjero.

Estamos asistiendo en los últimos años a la irrupción de las nuevas tecnologías y aplicaciones multimedia en todos los ámbitos económicos y sociales. El modo de promocionar el turismo por parte de los agentes implicados en el sector ha experimentado, en consecuencia, un cambio radical. Como bien indica Fuentes y Le Poder (2005:64) "la mayoría de las oficinas de turismo nacionales y regionales cuentan hoy día con sitios web bien estructurados y completos, dedicados a destinos turísticos concretos". Se trata de anuncios dinámicos y experienciales que intentan captar visitantes a través de Internet, el canal de 
referencia actualmente en el sector turístico. Es por estos motivos que cada vez más los traductores desarrollan su labor localizando textos, para lo cual necesitan hacer uso de tecnología aplicada a la localización.

Ante este panorama de necesidad de traducción de materiales y textos turísticos, el traductor turístico adquiere una preponderancia como traductor especializado y su labor como mediador entre culturas resulta fundamental para contribuir a que el sector turístico en España alcance las mayores cotas de reconocimiento y calidad.

\subsection{El texto turístico: género y discurso}

\subsubsection{Los géneros del texto turístico}

El desarrollo de la actividad turística es un fenómeno que surge a raíz de las profundas transformaciones políticas, sociales y económicas de la primera mitad del siglo XIX. Se producen nuevas necesidades de viaje que traen consigo nuevas empresas de organización de viajes y desplazamientos y la especialización dentro del ámbito del turismo. El primer tipo de texto del ámbito del turismo en surgir es la guía turística, que daría paso, con el tiempo, a los folletos turísticos y a otro tipo de materiales como las revistas especializadas y los catálogos (Calvi, 2006).

Para poder dar cuenta de las características del texto turístico, debemos, en primer lugar, hacer referencia al concepto de tipología textual o género. El concepto de género se ha convertido en uno de los ejes centrales en la investigación en traductología. Este concepto ha sido estudiado ampliamente 
por parte de la teoría lingüística y la literatura (Halliday y Hassan, 1985; Swales, 1990; Bhatia, 1993) o la sociología (Bakhtin, 1978).

Según García Izquierdo (2005), en todas estas teorías se entiende el género como representación de productos semióticos (textos), por lo que la conexión con la traducción es clara, ya que la traducción se considera como una operación intertextual e intercultural. Esta autora entiende el género en traducción como el recipiente en el que convergen todas las nociones fundamentales para el traductor. Así, el género es un constructo semiótico que puede facilitar la comprensión de los actos comunicativos y muestran cómo las diferentes culturas construyen los textos dependiendo de distintos parámetros preestablecidos, atendiendo a cuestiones como el registro, la ideología, etc., en definitiva, cuestiones culturales. Siguen la misma línea Gamero Pérez (2000) y Borja (2000), quienes defienden la importancia de este concepto en traductología como herramienta con fines didácticos ${ }^{65}$.

En el caso del lenguaje del turismo, el primer parámetro para la identificación del tipo textual texto turístico nos la ofrece Delisle y la escuela canadiense: el texto turístico sería un texto pragmático por oposición al texto artístico, puesto que comparte en cierta medida con aquel cinco de los siete rasgos que enumera Delisle:

[le texte pragmatique] est plus dénotatif que connotatif; il renvoie à une réalité plus ou moins objectivée; il a pour but principal de communiquer une information; il donne lieu généralement à une seule interprétation; il a une utilité immédiate et souvent éphémère. (1993:31 y ss.)

\footnotetext{
${ }^{65}$ Autores pertenecientes al grupo de investigación GENTT, de la Universitat Jaume I, que ha venido desarrollando su investigación precisamente en el ámbito de las aplicaciones del concepto de género en el campo de la traducción.
} 
No obstante, si bien es cierto que la tipología delisliana marca, en principio, algunos de los límites que definen nuestro tema, también es verdad que en su afán de abarcar textos muy variados, la clasificación resulta imprecisa e insatisfactoria, al igual que lo son los cuatro primeros rasgos enumerados por el escritor canadiense. En efecto, en los textos turísticos, encontramos denotación y connotación, la realidad es rara vez objetiva, dado que este tipo de texto comunica una información selectiva y ligada a las emociones; en cambio, coincide claramente con el punto quinto: la inmediatez de su utilidad y su carácter efímero.

Nosotros entendemos el género según la definición de Alcaraz Varó (2000:133), por el cual género es el conjunto de textos, escritos u orales, del mundo profesional o académico, que se ajustan a una serie de convenciones formales y estilísticas.

Para Hatim y Mason (1990) los textos no se pueden clasificar de una forma rígida. Tampoco el tipo de texto determina obligatoriamente el método de traducción que se tenga que utilizar, sino que se tienen en cuenta otros factores y conceptos como el de multifuncionalidad y foco contextual dominante:

It is sometimes claimed that texts are too fuzzy to yield distinct typologies, and that more than one purpose is always being attended to in a given context. However, although we recognise multifunctionality as an important property of texts, we submit that only one predominant rhetorical purpose can be served at one time in a given text. This is the text's dominant contextual focus. Other purposes may be as well present, but they are in fact subsidiary to the overall function of the text (Hatim y Mason, 1990:146).

Hatim y Mason explican que los textos son unidades variables en su naturaleza y los propósitos del texto deben considerarse teniendo en cuenta dicha multifuncionalidad y el propósito retórico dominante, aunque pueden existir otros de mayor o menor relevancia dentro del mismo texto e ir alternándose. En ocasiones aparecen textos híbridos que son los que para Hatim y Mason 
"resultan más problemáticos cuando un texto cambio de un tipo a otro y, en consecuencia, pasa al servicio de otro propósito". A este fenómeno Hatim y Mason lo llama intertextualidad.

Existen multitud de tipologías textuales y clasificaciones de tipos de textos. Reproduciremos a continuación la propuesta de Hatim y Mason (1995), muy sencilla, que distingue entre:

- Tipo textual argumentativo

- Tipo textual expositivo

- Tipo textual exhortativo o de instrucción

El texto argumentativo tiene como foco textual la valoración de las relaciones entre diversos conceptos, es decir, los que se utilizan para establecer algún tipo de valoración de las ideas que se expresan. Son textos en los que abundan las estrategias de énfasis e insistencia, la paráfrasis y otros recursos retóricolingüísticos. Por su parte, en el texto expositivo se descompone una serie de información y conceptos y puede dividirse en texto expositivo-descriptivo o texto expositivo-narrativo. En la primera variante se produce la descripción de objetos o situaciones, mientras que en la variante narrativa, el texto expositivo refiere acciones o acontecimientos. Hatim y Mason indican que la diferencia entre estos dos tipos de textos es de gran importancia para los traductores, es decir, es sumamente importante distinguir un texto argumentativo de la simple exposición de conceptos y no siempre es fácil, pues la diferencia entre estos dos tipos de textos puede ser a veces muy sutil.

El texto exhortativo o de instrucción es aquel en el que el foco textual al que aludían Hatim y Mason está en mover a la modificación o formación de acción o conducta de las personas. Estos autores distinguen dos subtipos: la exhortación 
con alternativa (como en la publicidad o los anuncios publicitarios) y la exhortación sin alternativa (como en los contratos).

La exhortación con alternativa propia de la publicidad ofrece paralelismos con las estructuras usadas para dar instrucciones. Así, los esloganes de campañas turísticas que suele ser frecuentes suele combinar varios imperativos (por ejemplo el de la campaña Ven y verás). Es por este motivo que otros autores como Reiss tratan estas dos tipologías textuales como una única, denominada el texto operativo. Más tarde, Reiss y Vermeer (1996) introducen el término de función para clasificar los textos, pues entienden que no es posible realizar clasificaciones temáticas de los textos y establecen así una tipología textual basada en las tres funciones del lenguaje de Bühler (1934) con tres tipos de texto fundamentales: informativos, expresivos y operativos. Por lo que se refiere al texto turístico, éste viene implícitamente incluido en la tercera categoría, la categoría textual operativa y, aunque Reiss no mencione el tipo texto turístico, lo incluye bajo el nombre genérico de Propagandatexte.

Autores como Elena García (1990) no están de acuerdo con esta clasificación rígida que hace Reiss del texto operativo al otorgarle al texto una sola función, por lo que matiza la propuesta de Reiss:

Sin embargo, su tipología tampoco es totalmente satisfactoria; estudios prácticos realizados demuestran que un texto pocas veces es unifuncional, más bien suele participar de dos o más funciones a la vez y aún en el caso de la presencia de una única función del texto, esta clasificación tampoco contendría todos los pormenores de los restantes niveles textuales (Elena García, 1990:42).

Calvi (2006) explica que el texto turístico puede enmarcarse dentro de los lenguajes para fines específicos dentro de su interpretación más flexible, que incluye la comunicación entre expertos y usuarios, no sólo entre especialistas y define las características de este tipo de texto desde un marco alejado del análisis del léxico para abarcar aspectos comunicativos y pragmáticos que 
atienden en mayor medida a las propiedades discursivas. En su artículo Los géneros discursivos en la lengua del turismo: una propuesta de clasificación $(2010)^{66}$, Calvi establece que el lenguaje del turismo puede ser considerado como una lengua de especialidad en razón de la existencia de géneros propios funcionales para los objetivos comunicativos, pero también desde el punto de vista de la creación del léxico especializado (Calvi, 2010:20) y realiza un estudio sistemático de los géneros utilizados en el sector turístico y los clasifica de modo flexible y abierto para dar cabida a toda su heterogeneidad ${ }^{67}$. Establece una taxonomía con un nivel superior, en la que sitúa a las familias de géneros, definidas por la comunidad profesional de origen y sus objetivos. Así, dentro de esta familia, encontramos los géneros editoriales, institucionales, comerciales, organizativos, legales, científicos y académicos e informales. La segunda gran categoría la denomina macrogéneros ${ }^{68}$, y en ella incorpora los productos tangibles, identificables por el emisor y canal utilizado y en los que existe un propósito dominante, pero afectados por la hibridez. Algunos ejemplos son la guía de turismo, el folleto, la revista de viajes, el catálogo de viajes, las páginas web, etc. Seguidamente, nos encontramos con el nivel de los géneros propiamente dichos, en el que ya se disciernen géneros autónomos y con rasgos lingüísticos propios. En este apartado se ofrecen ejemplos como las guías descriptivas, el itinerario, la guía práctica, el programa de viaje, el reportaje, el anuncio, entre otros. Finalmente, la categoría subgéneros da cuenta de los

\footnotetext{
${ }^{66}$ En este artículo Calvi ofrece una clasificación textual del texto turístico en el marco del proyecto de investigación Linguaturismo, que tiene por objetivo la creación de corpus textuales paralelos y comparables en español e italiano. Véase http://www.linguaturismo.it/

67 De este modo, explica Calvi (2010), es posible que tengan cabida las posibles ramificaciones, intersecciones y modalidades combinatorias que están presentes en los distintos subgéneros del texto turístico.

${ }^{68}$ Los macrogéneros son combinaciones de géneros que dan como resultado un valor autónomo.
} 
textos pertenecientes a apartados temáticos recurrentes en turismo, como el paisaje, el arte, la gastronomía, la historia, etc.

A nuestro modo de ver, se trata de una clasificación relevante para el estudio del texto turístico, no sólo por ser la primera aproximación a la sistematización textual turística, sino porque da una visión de la ingente multitextualidad presente en el texto turístico; sin embargo, en muchas de las categorías que Calvi propone, surge la duda de dónde situar cada género debido a su heterogeneidad.

En nuestra opinión, el texto turístico está enmarcado dentro de los lenguajes de especialidad, entendidos estos como lenguajes para fines específicos, pues disponen de unos elementos terminológicos, discursivos, pragmáticos y macro textuales comunes que los caracterizan como lenguaje propio.

Si atendemos a la clasificación de géneros del texto turístico respecto de su función debemos mencionar a Kelly (1997), quien expone que existen- desde una perspectiva comunicativa- dos tipos generales de funciones del texto turístico: informativa o persuasiva o vocativa en diferentes grados según los diferentes textos. Esta situación es válida tanto para el TO como el TM. La diferencia estriba en el lector, su experiencia y su conocimiento del mundo.

Martínez Motos (2005) en su análisis de las convenciones textuales de textos turísticos retoma este mismo concepto ampliado por Nobs (1996). Esta autora (1996) indica que los textos turísticos tienen una doble función, informativa y apelativa, en lo que considera una doble estrategia apelativa y los considera desde el punto de vista funcionalista, como textos operativos, puesto que en la realización de la función apelativa, ningún texto operativo puede prescindir ni de la utilización de elementos informativos ni de elementos expresivos específicos. Sin embargo, no se ha considerado que en estos textos también se 
da la función informativa. Nobs (1996:243) explica cómo se manifiesta esta doble estrategia apelativa:

- la estrategia argumentativa, que se sirve de argumentos para dirigirse al intelecto.

- la estrategia emocional, que pretende despertar emociones mediante la evocación de actitudes esperadas y escalas de valores deseadas. Especialmente la estrategia emocional se sirve con frecuencia de medios expresivos y estilísticos que caracterizan los textos operativos en general.

A continuación procedemos a definir el texto turístico. Gross (1998:3) señala que el texto turístico incluye una amplia gama de textos como pueden ser folletos, guías turísticas, guías de monumentos, menús, programas de conferencias, artículos publicitarios sobre un destino de vacaciones,...) en el que existe un denominador común que es el turista como destinatario del texto:

El término texto turístico es un hiperónimo que abarca varias subclases de texto como guías turísticas, catálogos de los grandes operadores, artículos sobre destinos vacacionales en los suplementos de los diarios, folletos de las oficinas de información de turismo, etc. Su denominador común es el destinatario, o sea, el turista, o viajero al que se ofrece información sobre un determinado lugar, sus monumentos, su historia, sus tradiciones, itinerarios para visitarlo, alojamiento... con la intención latente o manifiesta de invitarle a visitarlo.

Kelly (1997:35) coincide con Gross al señalar la gran diversidad textual que existe dentro de esta tipología:

For our purposes the tourist text is any text published by a public or private organisation of any kind intended a) to give information to any kind of visitor or b) to advertise a destination (city, hotel, restaurant, etc.) and encourage visitors to go there. This clearly covers a very wide range of text types, from brochures sent abroad to promote a particular destination through brochures available at the destination itself, tourist guides available in the tourist's home country, to menus, information brochures published by authorities responsible for monuments and other places of interest as written guides to them, conference programmes and other conference material, or police warnings regarding dos and don'ts for visitors. 
Según Kelly, por texto turístico entendemos todo aquello que una organización pública o privada publique y cuya finalidad sea ofrecer información a los potenciales visitantes o para anunciar o promocionar un destino y fomentar los viajes a ese destino. En este último punto coincide con Fischer ${ }^{69}$, quien de modo más sucinto, define texto turístico como "todo escrito dirigido al público general, y al no autóctono en especial, que informa sobre las cualidades de un lugar y sugiere su visita".

En esta investigación, nos proponemos realizar una aproximación a la definición de texto turístico que englobe, todas las características más importantes que lo condicionan e introducir el término producto turístico que abarca mucho más que el consabido destino turístico. Asimismo, resulta relevante destacar su pertenencia ámbitos especializados y profesionales y a otros géneros textuales nuevos surgidos por el avance de las nuevas tecnologías:

El texto turístico es un texto multifuncional, multidiscursivo y multidisciplinario, cuyo denominador común es informar, promocionar o convencer al destinatario de un determinado producto turístico. Sin embargo, en el texto turístico también tienen cabida textos especializados y profesionales cuyos destinatarios son los mismos profesionales del sector, así como nuevas modalidades textuales surgidas del uso géneros discursivos novedosos, como son los blogs, los foros, los libros de visita o las páginas web privadas e institucionales de promoción de hoteles, vinculados todos ellos a Internet.

Desde nuestra óptica, no es posible clasificar todos los textos turísticos como un subgénero de los textos publicitarios, pues de ese modo no estamos considerando aquellos textos que pertenecen a los ámbitos profesionales y que

\footnotetext{
${ }^{69}$ Publicación electrónica en la revista ELE Espéculo. Se desconoce el año de publicación.
} 
no van únicamente destinados a la promoción turística y cuyos destinatarios no son los turistas. Ahora bien, la mayoría de textos promocionales que van dirigidos al turista sí contienen el elemento persuasivo, de ahí que muchos autores los consideren publicitarios.

\subsubsection{Clasificación de la tipología textual turística}

Según la propuesta de Kelly (1997), los distintos tipos de textos turísticos que podemos encontrar son los siguientes:

- Material promocional del sector privado (hoteles, bares, restaurantes, espectáculos, instalaciones de ocio, instalaciones deportivas, etc.):

- Folletos

- Pósteres

- Anuncios publicitarios

- Material promocional del sector público (Patronatos de Turismo municipales y provinciales, empresas públicas, etc.):

- Folletos

- Pósteres

- Anuncios publicitarios

- Guías de organismos públicos (también promocionales)

- Guías de editoriales comerciales (no promocionales)

- Textos informativos para el turista:

- De las empresas hoteleras (servicios disponibles)

- De las empresas de restauración (cartas)

- De las empresas de organización de congresos (servicios disponibles, programas de congresos, información práctica). 
- De las empresas de transporte (ferrocarril, avión, carretera, etc.), (rutas, servicios de urgencia, información práctica)

- Textos operativos para el turista:

- De las autoridades (aduana, policía) (legislación sobre importación/exportación, advertencias sobre la seguridad ciudadana, etc.)

- De las diferentes empresas del sector (instrucciones, recomendaciones, etc.)

Esta taxonomía da cuenta de la gran variedad de textos que comprenden el texto turístico, desde trípticos para promocionar un destino, pasando por guías turísticas disponibles en el país de origen, folletos informativos publicados por instituciones responsables de monumentos u otros lugares de interés, etc. Las áreas temáticas presentes en estos textos incluyen "disciplinas tan diferentes entre ellas como son la arquitectura, historia del arte, historia, geografía, meteorología, gastronomía, economía, deportes, costumbres, música y danza, entre otras" (Kelly, 1997:35).

Calvi (2006:32) admite la multitemática y la gran cantidad de textos existentes en el ámbito del turismo y apunta que los textos puramente turísticos son aquellos que van dirigidos al público, frecuentemente el turista y que es en estos donde se podemos detectar los rasgos más distintivos del texto turístico:

Los géneros discursivos propios del turismo se han desarrollado más bien en la comunicación dirigida al público, tanto en las interacciones orales (por ejemplo, entre el guía y los turistas) como en las modalidades escritas.

A continuación veremos algunas de las clases textuales más comunes según Calvi (2006) y que representan al texto turístico por antonomasia: 


\subsubsection{Guías turísticas}

Antes de la aparición de las guías turísticas, existían ya manuales y cuadernos especializados con glosarios en varias lenguas, pero es a partir del s. XIX cuando empieza a divulgarse este tipo de género con entidad propia. Hoy en día las guías turísticas están experimentando una revolución, que creemos que se produce por la gran diversificación de la oferta temática y las nuevas tendencias y características del turista o viajero.

Los padres del nuevo fenómeno de la literatura de viajes que surgió en el s. XIX fueron Murray y Baedecker. Al nuevo material, que Murray denominó handbook, le asignó las tareas de guiar al turista por la cultura, las tradiciones y el folclore de los lugares visitados de un modo práctico, accesible y exhaustivo (Buzard, 1993). La consecución del nuevo género la llevaron a cabo los dos autores mencionados mezclando diversos géneros textuales ya existentes (Nigro, 2006:34) $)^{70}$. Podemos considerar, pues, a estos dos autores como los precursores de la literatura de viajes y las guías turísticas tal como las conocemos hoy.

Las guías turísticas suelen tener un formato de libro y coinciden en ofrecer los siguientes elementos básicos:

- descripción, más o menos detallada, de uno o más lugares geográficos.

- documentación práctica sobre cómo realizar la visita e informaciones diversas (hoteles, restauración,...).

- materiales complementarios (mapas, fotos, croquis,...).

\footnotetext{
${ }^{70}$ La primera guía Murray se publicó en 1836 y se tituló Handbook for Travellers on the Continent, y fue seguida por otra guía de Baedecker en 1839.
} 
Si bien hemos comentado que el formato que toman las guías turísticas es el de libro, se observan guías turísticas muy variadas y de diferente extensión. También el contenido es muy variado: existen guías temáticas (de lugares comunes), de una región, de un país o de ciudades o zonas concretas. El material se organiza teniendo en cuenta diferentes criterios, como puede ser el orden alfabético y las zonas geográficas. En la mayoría de guías existe un apartado de información práctica que es una especie de cajón de sastre donde se da cuenta de los medios de transporte, alojamiento, restauración, horarios de espectáculos y visitas, compras, y otros consejos útiles para planificación y el desarrollo del viaje. Debemos destacar el auge que han tenido las Ilamadas guías visuales, en las que aparecen dibujos y croquis tridimensionales que ayudan al visitante a desentrañar los aspectos arquitectónicos más relevantes de un monumento y su interior.

Desde el punto de vista de su función, las guías tienen una función básicamente informativa y de transferencia de la información y el conocimiento, pues son las primeras fuentes de información de los viajeros, pero al mismo tiempo, son elementos con una misión directiva o instructiva, pues el turista los utiliza para elegir una ruta o planificar su viaje atendiendo a los consejos y recomendaciones que en ella lee.

Respecto a su tipología discursiva, las guías optan por un estilo impersonal y objetivo, principalmente en su función descriptiva. Algunos autores, sin embargo, han señalado la falsa objetividad de las guías turísticas al ser éstas capaces de anular la capacidad de observación del turista (Barthes, 1957), pues tratan al turista como un niño al que llevan de la mano. En general, lo que predomina es la modalidad descriptivo-prescriptiva. 
Giovanna Nigro, en su obra II Linguaggio specialistico del Turismo (2006) realiza un recorrido por los aspectos históricos, teóricos y traductológicos de la literatura de viajes con especial atención a las guías turísticas y destaca aquellas que entiende se han convertido en las guías de referencia en el presente:

Dalle guide italiane Touring Club, De Agostani, Mondadori, alle francesi Michelin, Les Guides du Routard, Les Guides Bleus, o ancora le inglesi Lonely Planet, Time Out, Rough Guide, Insight Compact Guide, per indicarne solo alcune, accompagnano $i$ turisti per I'intero viaggio. (Nigro, 2006:37) ${ }^{71}$.

Las guías turísticas, a pesar de su importancia y el uso generalizado que de ellas hacen los turistas, no han recibido tanta atención por parte de la traductología como los folletos turísticos, de los que damos cuenta a continuación.

\subsubsection{Folletos turísticos}

EI DRAE define folleto como "obra impresa, no periódica, de reducido número de hojas". Si añadimos el adjetivo turístico, tenemos como resultado un nuevo género o clase de texto en este ámbito. Se trata también de un subtipo muy heterogéneo y variado: encontramos folletos que pueden ser meros trípticos hasta pequeños cuadernillos, aunque en ningún caso suelen tener la extensión de una guía.

Del mismo modo que las guías, el foco textual dominante es expositivo, y su funcionalidad fundamentalmente informativa. Existe, no obstante, otra función promocional que le confiere el carácter propagandístico y gratuito que se le presupone a cualquier tipo de texto de esta naturaleza. Es, por tanto, también

\footnotetext{
${ }^{71}$ Dentro del panorama español, debemos citar las guías del País Aguilar, las guías Viva de Anaya, o las guías Azules del Trotamundos de Gaesa.
} 
persuasivo y combina elementos del lenguaje publicitario con otros recursos puramente descriptivos.

Debido a las limitaciones que los folletos ofrecen en cuanto a su extensión, es habitual encontrar folletos monotemáticos de varios atractivos turísticos que, unidos, formarían la información que podríamos encontrar en una guía la turística. En muchos casos, las fotografías son las que toman protagonismo, mientras que en otros, pueden aparecen datos secundarios como informaciones prácticas y de utilidad.

A diferencia de las guías, los folletos turísticos utilizan recursos que poco o nada tienen que ver con la imparcialidad, sino que son frecuentes elementos de elogio y énfasis que le confieren al texto un carácter hiperbólico. Resulta de gran dificultad la sistematización de los diferentes tipos de folletos que podemos encontrar hoy en día en el mercado turístico, pues existe una gran diversidad temática, diferencias de formato, de organización de contenidos, etc. Sin embargo, destacamos el trabajo realizado por Febas Borra (1978) que sistematizó 250 folletos turísticos del antiguo Ministerio de Información y Turismo agrupándolos por series temáticas. En sus conclusiones, este autor destaca que "el lenguaje turístico es una modalidad del lenguaje extremo. Recurre a un universo semántico polarizado en torno a lo fuerte y lo suave, lo endógeno y lo exógeno, lo científico y lo popular, lo antiguo y lo moderno...." (Febas Borra, 1978:39). En resumen, el folleto tiene las propiedades de un anuncio publicitario para ser consumido por un público del sector turístico y aportar una serie de informaciones básicas. A diferencia de las guías, los folletos no suelen sobrevivir al viaje, sino que son un producto de promocional de rápido consumo. 


\subsubsection{Anuncios publicitarios}

Los anuncios publicitarios son, junto con los folletos y carteles, uno de los principales medios para la promoción turística. Comparten la función persuasiva de los folletos, pero se diferencian de ellos por la escasez de elementos persuasivos. Son materiales que motivan o anticipan la visita a un lugar determinado, por lo que son eminentemente persuasivos y generan gran expectativa. Los anuncios se dividen en dos categorías principales:

- Anuncios emitidos por entidades públicas. En principio estos anuncios no están destinados a la venta directa de un producto, sino a la promoción de un lugar turístico, pero a menudo se produce la cooperación entre las entidades públicas y los turoperadores. El tema puede ser variado, desde un festival de música o una exposición de arte hasta una feria culinaria, una ciudad, un país, etc.

- Publicidad comercial. Se trata de anuncios que sí conducen a la venta de un producto turístico, difundidos por agencias, turoperadores, hoteles y otras empresas turísticas. Muchos de ellos llevan indicaciones precisas sobre los precios y los servicios ofrecidos y breves fragmentos de texto descriptivo de los hoteles y otros servicios. En general, los anuncios turísticos están relacionados con la experiencia del viaje y la proyección mental en el turista y suelen aparecer en prensa, y en otros medios, como las vallas e Internet.

\subsubsection{Catálogos y programas de viajes}

De nuevo tomamos la definición del DRAE para definir este subtipo textual. Un catálogo es "una relación ordenada en la que se incluyen o describen de forma individual libros, documentos, personas, objetos, etc. que están relacionados entre si". Aplicado al campo del turismo, el término define "una publicación que 
lista una serie de programas o propuestas de itinerarios de vacaciones ofrecidos por agencias o turoperadores, en los que se ofrece una breve descripción del alojamiento o alojamientos ofertados". Son publicaciones comerciales. En general, estas obras incluyen los siguientes elementos:

- Consejos prácticos de viaje e informaciones esenciales sobre los destinos propuestos (arte, paisaje, clima, moneda, documentación, compras, gastronomía, etc.).

- Descripción del programa del viaje o las instalaciones turísticas. En estas frases predominan las frases nominales y la terminología típica de la organización turística (HA: sólo alojamiento, MP: media pensión, SP: según programa....).

- Precios, descuentos y modalidades de reserva.

- Condiciones del contrato y normativa: la consabida letra pequeña para salir al paso de las posibles reclamaciones en un espacio ínfimo a pie de página y con un lenguaje técnico-jurídico.

En comparación con otras categorías de las clases textuales comerciales, en el turismo este género presenta unas características propias relacionadas con las propiedades del producto. Se produce una descripción técnica breve y escueta del programa y se interpela al receptor con las formas apelativas típicas del lenguaje publicitario. Por último, encontramos secuencias de tipo instructivo y, a diferencia del resto de subtipos analizados hasta ahora, textos jurídiconormativos.

\subsubsection{Artículos y reportajes en revistas especializadas}

En los últimos años se ha multiplicado en España (y, en general, en Europa) la oferta de revistas especializadas en viajes y turismo, que se dirigen, en general, 
al público que gusta de viajar, a excepción de algunas publicaciones para expertos. Dentro del periodismo, se trata de un sector que podríamos calificar de emergente, lejos de otros tipos de periodismo tradicionales, como el económico o político.

El modelo de mayor prestigio está representado por revistas como el National Geographic, en el que se mezclan el relato de viaje con el texto divulgativo científico multidisciplinar (geografía, historia, arte, antropología). No obstante, además del género del reportaje se han desarrollado otro tipo de textos del periodismo turístico, como es la literatura de viajes. En general, todos estos textos tienen un planteamiento práctico y combinan descripción con prescripción, subjetividad y objetividad e implicación del lector.

A diferencia de otras clases textuales, los artículos y reportajes no son de tipo promocional, sino informativo. A diferencia de las guías, que organizan la información de manera sistemática, las revistas de viajes ofrecen una selección heterogénea de contenidos, que van desde el reportaje en sí hasta consejos prácticos para viajar. El propósito final del texto es la de potenciar la afición por los viajes y despertar la curiosidad.

\subsubsection{Otros géneros profesionales}

Existen otras clases de textos que no son puramente de descripción y de promoción del producto turístico, que son los que hemos visto hasta ahora. Debemos mencionar la existencia de géneros profesionales surgidos de la misma práctica y actividad turística:

- Documentos de viaje: incluyen billetes, bonos, reservas, etc. Estamos ante una comunicación prefijada con fórmulas y esquemas llenos de 
terminología técnica de las empresas y la organización turística y algunos textos de tipo jurídico.

- Exposiciones orales de los guías turísticos: son muy similares a las guías en papel, pero añaden elementos de apelación e interlocución con el receptor, que le da un carácter más dinámico.

- Interacciones entre los operadores turísticos y el público: el trato directo con el cliente por parte de los actores u operadores, como puede ser un recepcionista, un guía o un camarero, genera un tipo de discurso que gira alrededor de la cortesía.

- Otros textos que el viajero encuentra a lo largo de su viaje y que le proporciona ciertas informaciones o instrucciones, como puede ser la tarjeta con el número de habitación o un cartel con las instrucciones en caso de incendio o información sobre los servicios del hotel. En este grupo podemos situar también los cuestionarios de evaluación que se ponen a disposición del viajero en los hoteles para conocer su opinión. Se trata de diferentes géneros que tienen en común su vinculación con la fase activa del viaje del turista durante su desplazamiento.

\subsubsection{Páginas web}

Es importante señalar la importancia que tiene la difusión del texto turístico y la traducción del texto turístico en su versión electrónica. Internet se ha convertido en una agencia más de viajes, desde donde podemos contratar un vuelo low cost hasta confeccionarnos un viaje a la medida (vuelo + hotel + excursiones), construirnos una guía personal reuniendo información de distintas páginas, consultar páginas especializadas en hoteles que incluyen la opinión de los usuarios, etc. 
En este contexto ya han surgido y se están consolidando cada vez más las páginas web que permiten contratar los viajes programados por el propio turista, que quiere disfrutar de la experiencia de diseñar y personalizar su viaje de un modo único, al tiempo que ve reducido el importe total de la factura al eliminar la intermediación y el servicio que una agencia tradicional supone.

Así, por tanto, y, como es lógico, las empresas del sector no se han quedado a la zaga en lo que a presencia electrónica respecta: prácticamente todos los actores que hemos considerado anteriormente en nuestro trabajo disponen hoy en día de una página web donde, en mayor o menor medida, ofrecen sus servicios como intermediarios: touroperadores, hoteles, restaurantes, centros de ocio, etc. Es más, algunos de ellos se han especializado en la venta online de sus productos (como es el caso de las agencias de viaje), al ver reducidos su ingresos en su forma tradicional de operar.

En muchos casos, como pueden ser, por ejemplo, las agencias de viajes, la información que encontramos en Internet es la misma información disponible en papel que se pone a disposición en la red. En otros casos, encontramos información especialmente diseñada y concebida para la web a modo de hipertexto.

Quisiéramos poder establecer a continuación una clasificación de los tipos de páginas web turísticas que existen, pero desgraciadamente, esto resulta imposible por la cantidad de páginas existentes y su heterogeneidad. A este respecto, Calvi (2006) ofrece una clasificación somera y tentativa de los géneros turísticos que podemos encontrar en Internet:

- Páginas relacionadas con la organización turística, destinadas a la reserva y compra de billetes, servicios, etc.: contienen descripciones de los servicios ofrecidos, precios, normativa, instrucciones, formularios, etc. 
- Páginas de publicidad directa: anuncios, catálogos, ofertas, etc.

- Páginas de carácter promocional, emitidas por diferentes instituciones, que presentan características parecidas a los folletos.

- Páginas con información de interés turístico: descripciones de lugares e infraestructuras, planos y mapas, foros de discusión, blogs de viajeros, etc.

Debemos señalar que, aunque pudiera parecerlo, los textos turísticos electrónicos no son un género en sí. Internet es la gran caja donde están todos los subgéneros que combinan con libertad las propiedades de los macrogéneros (guías de viaje, folletos, anuncio, catálogo, reportaje, etc.).

Tampoco debemos desdeñar aquí el papel que juega el canal. El hecho de que el texto sea electrónico le confiere una serie de propiedades determinadas por el medio. Estamos hablando de la organización del hipertexto, las preferencias de lectura, las búsquedas personalizadas, etc.

Para recapitular, diremos que el texto turístico está formado por una gran variedad de modalidades comunicativas y que reúne distintos géneros y subgéneros, que en algunos casos, poco o nada tienen que ver entre sí, pero que respetan una serie de principios básicos. Resulta poco operativo intentar establecer una clasificación exhaustiva de todos los tipos de texto existentes dentro del sector turístico, puesto que nos hallamos ante un sector heterogéneo en sus actividades, perfiles profesionales, empresas y organizaciones. Más sentido tiene aproximarse a la industria turística desde los distintos actores o sectores que la componen (agencias de viajes, hostelería, restauración). Sin embargo, cada uno de estos sectores tiene una gama muy variada de estrategias o recursos comunicativos para dirigirse a sus receptores 
internos o externos y con distintos objetivos y funcionalidad y se producen, por tanto una variedad de textos muy heterogénea y multifuncional.

A continuación reproducimos un cuadro de Calvi (2006) que resume los géneros que hemos mencionado anteriormente:

Tabla 11: Géneros textuales turísticos según Calvi (2006:54-55)

\begin{tabular}{|c|c|c|c|c|}
\hline Género & $\begin{array}{l}\text { Formato o } \\
\text { medio de } \\
\text { difusión }\end{array}$ & Función & Tipología textual & $\begin{array}{l}\text { Etapa de la } \\
\text { experiencia } \\
\text { turística }\end{array}$ \\
\hline Guías turísticas & Libro & $\begin{array}{l}\text { Informar, } \\
\text { aconsejar, } \\
\text { dirigir }\end{array}$ & $\begin{array}{l}\text { Descriptiva, } \\
\text { expositiva, } \\
\text { instructiva }\end{array}$ & $\begin{array}{l}\text { Antes, durante, } \\
\text { y después del } \\
\text { viaje }\end{array}$ \\
\hline Folletos & $\begin{array}{l}\text { Desplegable o } \\
\text { cuadernillo }\end{array}$ & $\begin{array}{l}\text { Informar, } \\
\text { promover una } \\
\text { imagen, } \\
\text { seducir }\end{array}$ & $\begin{array}{l}\text { Descriptiva, } \\
\text { expositiva, } \\
\text { argumentativa }\end{array}$ & $\begin{array}{l}\text { Antes y durante } \\
\text { el viaje }\end{array}$ \\
\hline $\begin{array}{l}\text { Anuncios } \\
\text { publicitarios }\end{array}$ & $\begin{array}{l}\text { Prensa, medios } \\
\text { de difusión }\end{array}$ & $\begin{array}{l}\text { Persuadir, } \\
\text { promover una } \\
\text { imagen, } \\
\text { vender un } \\
\text { producto }\end{array}$ & $\begin{array}{l}\text { Argumentativa, } \\
\text { exhortativa, } \\
\text { Conversacional }\end{array}$ & Antes del viaje \\
\hline Catálogos & $\begin{array}{l}\text { Fascículo, } \\
\text { cuaderno }\end{array}$ & $\begin{array}{l}\text { Persuadir, } \\
\text { vender un } \\
\text { producto, } \\
\text { informar }\end{array}$ & $\begin{array}{l}\text { Descriptiva, } \\
\text { instructiva, } \\
\text { argumentativa }\end{array}$ & Antes del viaje \\
\hline $\begin{array}{l}\text { Artículos y } \\
\text { reportajes }\end{array}$ & $\begin{array}{l}\text { Revistas, } \\
\text { periódicos }\end{array}$ & $\begin{array}{l}\text { Informar, } \\
\text { aconsejar, } \\
\text { dirigir, }\end{array}$ & $\begin{array}{l}\text { Descriptiva, } \\
\text { expositiva, } \\
\text { narrativa, }\end{array}$ & $\begin{array}{l}\text { Antes y después } \\
\text { del viaje }\end{array}$ \\
\hline
\end{tabular}




\begin{tabular}{|l|l|l|l|l|}
\hline Género & $\begin{array}{l}\text { Formato o } \\
\text { medio de } \\
\text { difusión }\end{array}$ & Función & Tipología textual & $\begin{array}{l}\text { Etapa de la } \\
\text { experiencia } \\
\text { turística }\end{array}$ \\
\hline $\begin{array}{l}\text { Documentos de } \\
\text { viaje }\end{array}$ & $\begin{array}{l}\text { Tarjetas, hojas } \\
\text { sueltas }\end{array}$ & $\begin{array}{l}\text { Dirigir, } \\
\text { prescribir }\end{array}$ & $\begin{array}{l}\text { Textualidad } \\
\text { reducida a } \\
\text { formularios }\end{array}$ & Durante el viaje \\
\hline Páginas web & Internet & $\begin{array}{l}\text { Informar, } \\
\text { aconsejar, } \\
\text { persuadir, } \\
\text { promover una } \\
\text { imagen, } \\
\text { vender un } \\
\text { producto }\end{array}$ & $\begin{array}{l}\text { Descriptiva, } \\
\text { expositiva, } \\
\text { narrativa, } \\
\text { instructiva, } \\
\text { argumentativa, } \\
\text { conversacional }\end{array}$ & Antes y después \\
del viaje
\end{tabular}

\subsubsection{Las características del texto turístico}

Algunos autores han estudiado el lenguaje del turismo desde el ámbito comunicativo-funcional $^{72}$ y han establecido sus características teniendo en cuenta, por un lado, los participantes en el modelo, y, por otro, el propio fenómeno turístico. La actividad turística se entiende así como una actividad compleja en la que intervienen multitud de elementos heterogéneos y sobre la cual influyen factores diversos: económicos, sociales, medio-ambientales, factores socio-profesionales, factores asociados al individuo y por último, factores políticos. (Borrueco, 2006).

\footnotetext{
${ }^{72}$ Borrueco (2006:34) explica que esta corriente o perspectiva comunicativa se intensificó en los años 80 y después le han seguido muchos estudios centrados en la descripción lingüística focalizados en la situación de la comunicación. Así, en los lenguajes de especialidad, se relegan a un segundo plano los estudios terminológicos y se impulsan los estudios del ámbito comunicativo especializado.
} 
En paralelo a la evolución del sector turístico y conformación como fenómeno híbrido y complejo, han surgido nuevas disciplinas que lo estudian desde diversas perspectivas diferentes de las anteriores. Algunos modelos recogen esta complejidad y distinguen tanto el ámbito comunicativo de los expertos como el de los turistas. Las relaciones comunicativas derivadas son, por tanto, simétricas, si se desarrollan entre profesionales o gestores del producto turístico; o asimétricas, en el caso de darse entre los gestores de producto y el turista o consumidor. En consecuencia, los textos turísticos que se producen a raíz de estas dos actividades comunicativas proceden de las siguientes situaciones comunicativas:

- información acerca del producto (localización de destinos, servicios incluidos, precios, etc).

- reserva y venta de servicios (alojamiento, transporte, etc.).

- anulación y modificación de servicios (alojamiento, transporte, etc.).

- consumo de servicios (intermediación, alojamiento, transporte, actividades complementarias, etc.).

- reclamaciones en relación con el servicio obtenido.

La comunicación simétrica, por su parte, se genera entre expertos y presenta un elevado grado de especialidad. Los productores y los destinatarios de dichos textos orales o escritos se identifican como elementos que constituyen el colectivo especializado en la gestión turística y organizan su discurso en función de los elementos temáticos concretos (reserva, anulación, destino, etc.) (Borrueco, 2006:36).

Según Gotti (2006:21), en el ámbito del turismo se producen tanto comunicación interna como comunicación externa, entendiendo la primera 
como la comunicación que se produce entre especialistas de la misma profesión y externa como la comunicación entre especialistas y legos:

El lenguaje turístico tiene diferentes niveles de expresión: por un lado, este lenguaje representa una instancia de un discurso altamente especializado utilizado por los expertos del campo turístico para comunicarse; por otro lado, cuando se adopta a interacciones entre especialistas y legos, tiene a asimilarse más a discursos generales. (Gotti, 2006:21).

En el caso del lenguaje turístico especializado, el conocimiento compartido y los procedimientos estandarizados quedan patentes en expresiones propias y en los géneros textuales establecidos y adoptados en el ámbito profesional. En el segundo caso, se suelen encontrar características propias del lenguaje cotidiano.

El Libro Blanco para el título de Grado en Turismo de la Agencia Nacional de la Evaluación de la Calidad y Acreditación establece algunos de los ámbitos de actuación en los que se lleva a cabo la comunicación turística interna:

- Alojamiento

- Restauración

- Intermediación

- Comunicación e información

- Empresas de transporte

- Logística

- Ocio, recreación y cultura (actividades complementarias)

- Convenciones/reuniones

- Instituciones públicas (planificación, gestión pública, promoción...)

- Consultoras

- Agencias de publicidad

- Productos y actividades turísticas 
- Formación, investigación y consultoría

- Planificación y gestión pública de destinos

\subsubsection{El léxico del texto turístico}

Anteriormente hemos señalado que la actividad turística se enmarca dentro de una gran variedad de sectores empresariales y que engloba componentes temáticos muy variados y heterogéneos. Las áreas léxicas y los niveles de especialidad que existen son, por tanto, múltiples y de distinta naturaleza.

Alcaraz Varó et al. (2006) en su Diccionario de términos de turismo y ocio (DTTO), establece una clasificación con cuatro grandes áreas temáticas dentro de la industria turística según su finalidad:

- el viaje y los seguros, que incluyen el vocabulario de las agencias de viajes, los aeropuertos, las estaciones de transporte, etc.

- el alojamiento, que comprende hoteles y campings.

- la gastronomía.

- el recreo y las industrias del ocio, entre las que destacan las visitas al patrimonio cultural o ecológico, la asistencia a espectáculos y la práctica de deporte.

Estos sectores están ubicados en organizaciones empresariales, cuya función se divide en dos principales apartados:

- gestión, a nivel macroeconómico, como en la organización microeconómica (agencias de viajes, hoteles,...).

- márketing, que incluye la promoción y venta de producto turísticos.

De estas dos clasificaciones deriva la lista de epígrafes que definen los principales campos semánticos de los textos turísticos (Calvi, 2000:57): 


\begin{tabular}{|ll}
\hline- Alojamiento & - Gestión \\
- Arte & - Juego \\
- Arte/cultura & - Márketing \\
- Clima & - Paisaje \\
- Deportes & - Restauración \\
- Derecho & - Espectáculos \\
- Seguros & - Viaje \\
\hline
\end{tabular}

Dentro de todo el caudal léxico del turismo es posible aislar un núcleo terminológico que es altamente especializado y otra área periférica que constituye un uso especial de palabras corrientes. El bloque terminológico incluye términos pertenecientes al turismo y a otros campos distintos. Así pues, desde el punto de vista de su especialización, el léxico del turismo comprende los siguientes bloques (Calvi, 2000: 57-59):

- Palabras que designan las estructuras y la organización turística: se trata del léxico más propio del turismo y que se usa para la comunicación entre los profesionales de los distintos sectores. Así, por ejemplo, las agencias de viajes y los transportes se caracterizan por el uso masivo de anglicismos (charter, check-in, code share, IT or inclusive tour, overbooking, slot, stand-by, void, etc.).

- Palabras que pertenecen a sectores y disciplinas relacionadas con el turismo (economía, historia del arte, gastronomía, etc.). Se trata de 
palabras muy usadas en los textos turísticos que mantienen su significado terminológico ${ }^{73}$ original en su disciplina original. En este caso podemos mencionar términos arquitectónicos como artesonado, bóveda, capitel, fachada, etc. También encontramos terminología dentro de las denominaciones deportivas, sobre todo las que se desarrollan al aire libre, que dan lugar a términos turísticos como deportes de aventura, trekking, descenso de barrancos, cañoning, rafting, parapente, etc.

- Palabras que se sitúan en el área periférica del léxico del turismo, y que se utilizan en su función valorativa cuando la comunicación va dirigida al público. Pueden ser palabras del lenguaje general, como adjetivos calificativos que nos hablan de la belleza de un lugar turístico (espléndido, bellísimo, extraordinario, magnífico, elegante, lujoso) y que dan lugar a combinaciones con nombres de lugares comunes del turismo (aguas cristalinas, selvas inexploradas, espléndidas vistas, etc.). En otros casos son los verbos los que tienen una función simbólica en los anuncios publicitarios (ir, venir, llegar, escapar, etc.) o que toman un significado distinto al de su palabra en el lenguaje general, como ocurre con la palabra escapada. Se trata de un uso peculiar de esta palabra, que viene a expresar un viaje breve, de fin de semana o puente para dejar por unos días la rutina diaria. Esta escapada se combina con los elementos puramente turísticos para dar lugar a escapadas gastronómicas o escapadas culturales.

\footnotetext{
73 En http://www.unwto.org/trad/index_s.php, la Organización Mundial del Turismo dispone de TourisTerm, una base de datos terminológica de los traductores de la Organización Mundial del Turismo (OMT). Además de los equivalentes en los cinco idiomas de la Organización (árabe, español, francés, inglés y ruso), algunas fichas contienen definiciones, enlaces a referencias en línea y otros datos de interés. Por otra parte, gracias a un acuerdo con el Foro Internacional de Abogados Especializados en el Derecho de los Viajes y el Turismo (IFTTA), se ha agregado el glosario en inglés de dicha organización.
} 
En el año 2001, la OMT publicó el Tesauro de Turismo y Ocio multilingüe ${ }^{74}$ en el que estableció 20 campos semánticos ${ }^{75}$ para representar las actividades del sector turístico:

Tabla 13: Campos semánticos de la actividad turística (OMT, 2001)

\begin{tabular}{|l|l|}
\hline Actividades deportivas & Ocio \\
\hline Legislación turística & Acontecimientos turísticos \\
\hline Alojamiento & Patrimonio turístico \\
\hline Ecología del turismo & Política turística \\
\hline Economía del turismo & Servicios turísticos \\
\hline Instalaciones turísticas & Profesionales del turismo \\
\hline Movimientos turísticos & Promoción turística \\
\hline Formación y empleo & Ciencia e información \\
\hline Sociología del ocio & Turismo sectorial \\
\hline Transportes & Países y agrupaciones de países \\
\hline
\end{tabular}

Alcaraz Varó et al. (2006) concluyen que el turismo es un ámbito generador de palabras nuevas que se forman por el recurso de la composición y por la estrategia de conceder nuevas acepciones a palabras conocidas y que presentan cierta analogía. Existe un equilibrio entre las palabras de origen latino y las de origen anglosajón. Entre las primeras destacan aquellas de origen francés sobre todo dentro del campo de la restauración.

\footnotetext{
${ }^{74}$ La OMT publicó en primer lugar un tesauro monolingüe en francés en 1991. En 2001 se incorporaron el inglés y el español. En su prólogo se argumenta la dificultad del trabajo por la multiplicidad de actividades imbricadas en el sector turístico y se considera el turismo como un eje semántico que agrupa diversos campos semánticos. Véase http://pub.worldtourism.org:81/WebRoot/Store/Shops/Infoshop/Products/1218/1218-1.pdf

75 El campo semántico representa el conjunto de descriptores pertenecientes a una misma familia conceptual.
} 
Mira Rueda (2008) retoma a Saorín Iborra (2003), quien establece que la mayoría de vocablos en el campo turístico pueden considerarse vocabulario semitécnico. Son palabras "con una frecuencia mayor en un determinado campo de conocimiento o que poseen un significado más especializado en una disciplina concreta" (Mira Rueda, 2008:29). Podemos tomar como ejemplo los verbos accept, advise, confirm, o expresiones como "make a booking o launch a campaign" (Dudley-Evans y St. John (1998:83), que encuentran en español una correspondencia terminológica a través de la equivalencia formal.

En cuanto al léxico marcado culturalmente, observamos que los elementos culturales que no tienen referente en la cultura meta, tienen mayor presencia en algunas disciplinas más que en otras. Este es el caso de la gastronomía, pues los platos típicos de una región forman parte de sus costumbres más arraigadas y se transmiten de generación en generación. Calvi (2000) indica que en estos casos se suele optar por el préstamo para traducir el elemento cultural, para conseguir una mayor implicación del lector o interlocutor en la cultura local. Otro sector con gran abundancia de elementos culturales con equivalencia cero en la LM es el de la arquitectura de los edificios y empresas turísticas cuando se trata de construcciones históricas. Para denominar a estos establecimientos se toman palabras que designan ciertas viviendas tradicionales o regionales. El ejemplo más famoso nos lo ofrece Calvi (2000:69) con el término parador, usado para referirnos a la cadena de hoteles españoles fundada en 1928; o la palabra mesón; estos vocablos se combinan con otros propios del turismo rural como hospedería, hostería, parada, posada, ...

Coincidimos con Calvi (2000:70) en que muchas de estas palabras no son auténticos realia, "puesto que tienen una palabra homóloga o forma equivalente en otras lenguas que responde a un referente en otra cultura". Sin 
embargo, la carga y sobre todo, las connotaciones culturales relacionadas con la historia y la arquitectura tradicional hispánica son evidentes.

Por lo que respecta a la formación de palabras, Calvi (2000:60 y siguientes) entiende, como nosotros, que el lenguaje del turismo es innovador y está lleno de neologismos:

Aunque no está caracterizado por una alta densidad terminológica, el lenguaje del turismo también hace recurso a la formación de términos aptos para expresar los conceptos que maneja y para describir sus propias actividades. (Calvi, 2000:60).

La derivación es un proceso usado escasamente, los sufijos más destacados son -al (vacacional), -dad (estacionalidad), -ción (fidelización), -ero (mochilero), ismo (termalismo). Los prefijos que tienen mayor presencia son multi(multiaventura), y varios caso de formas parasintéticas, sobre todo en el ámbito de la economía (desestacionalización) o del transporte aéreo (reencaminamiento) $^{76}$.

La composición es un procedimiento muy productivo en este ámbito lingüístico. Se usa para definir las estructuras organizativas y las manifestaciones que lo caracterizan y, aunque se encuentran varias unidades simples, es más frecuente encontrar unidades complejas, por su mayor flexibilidad, aunque no siempre es fácil atribuir la condición de compuesto a las numerosas formaciones sintagmáticas presentes en el lenguaje turístico (Calvi, 2000:61).

A continuación reproducimos las formas características de composición en el texto turístico ofrecidas por Calvi (2000):

- Sustantivo + sustantivo $=$ sustantivo. En ocasiones los ítems del compuesto aparecen unidos (aerotaxi, agroturismo, aparthotel y sus

\footnotetext{
${ }^{76}$ Todos los ejemplos ha sido tomados de Calvi (2000), Lengua y Comunicación en el español del turismo.
} 
variantes apartotel, bonoavión, bonocoche, bonohotel, cicloturismo, ecoturismo, trenhotel); en otros casos, están separados por un guión (aparto-hotel, barco-restaurante, boutique-hotel, desayuno-buffet, hotelapartamento, hotel-residencia, restaurante-mirador) o completamente separados (ala delta, clase turista, desayuno buffet, terraza mirador, turismo aventura).

- Sustantivo + de + sustantivo = sustantivo. En este apartado encontramos compuestos que designan la organización turística y sus aspectos (acompañante de grupo, albergue de carretera, bono de hotel, cheque de viajero, ciudad de vacaciones, guía de turismo, localizador de reserva, régimen de alojamiento, talonario de viajes, tarjeta de embarque,...) y distintos deportes (bicicleta de montaña, descenso de barrancos, esquí de travesía, ...). Son frecuentes los compuestos con la palabra turismo, que dan nombre a los distintos tipos de modalidades turísticas: turismo de salud y belleza, turismo de sol y playa, turismo de aventura, etc. El término ruta es muy productivo y se observa en distintos aspectos temáticos, tanto históricos como para la promoción turística (La Ruta del Románico, La Ruta del Vino).

- Sustantivo + adjetivo = sustantivo. Se usa fundamentalmente para definir la nomenclatura de los diferentes tipos de turismo (Turismo interior, Turismo exterior, turismo cultural, turismo gastronómico, turismo idiomático, turismo sostenible, turismo rural). Es conveniente señalar que existen multitud de formas que son recurrentes, como los adjetivos turístico y vacacional flujo turístico, destino turístico, complejo vacacional, paquete vacacional), y otros tipos de combinaciones que se han acuñado con el tiempo (pensión completa, puente aéreo, clase preferente, parque temático, billete electrónico). Todas estas formas son 
más o menos estables y perduran en el tiempo dependiendo de si tienen asociada normativa reguladora que los reconoce y utiliza de un modo u otro.

El texto turístico, entendido como lenguaje de especialidad, está formado por un caudal léxico que incluye terminología propia muy variada. Además existen una serie de rasgos a nivel morfosintáctico y del discurso que le confieren un carácter independiente. (Mira Rueda, 2008:51) establece algunas de las características propias de los textos turísticos en español:

- Las comparaciones: se trata de establecer analogías entre la cultura de origen y la cultura meta, de modo que el visitante se acerque con más confianza a la nueva realidad.

- La significación histórica: el texto turístico enmarca la información dentro de un contexto histórico y artístico-monumental.

- El anclaje visual: son los símbolos e imágenes que se asocian a un país, región o ciudad.

- Las manifestaciones y acontecimientos culturales, deportivos o políticos: en este caso, se usan para promover el destino turístico.

- El elogio: son juicios de valor favorables para resaltar los aspectos turístico-culturales.

- El valor de la evocación: el uso de los sentidos y las percepciones sensoriales, los olores y los sabores para transportar al visitante a la nueva cultura. 


\subsubsection{Características discursivas}

Una vez hemos identificado las características del léxico turístico de la mano de Calvi (2006), nos adentramos en caracterizar el texto turístico desde el punto de vista discursivo y de los mecanismos lingüísticos que lo conforman.

Calvi (2006:71-88), señala como elementos esenciales los siguientes:

- El uso de los pronombres personales y la implicación del interlocutor. Según Calvi, el emisor en la comunicación turística puede ser, según los casos, una agencia de viajes, un profesional del turismo, un periodista o alguna institución promotora (Calvi, 2006:77), de ahí que casi siempre podemos identificar al emisor, si bien es posible encontrar fórmulas despersonalizadas del discurso en catálogos y programas de viaje. Respecto al destinatario y su implicación, esta puede variar dependiendo del subgénero: si se trata de una guía turística, la implicación del emisor en el texto suele ser mínima $y$, al contrario ocurre en materiales destinados a la promoción turística. En muchos casos, la inclusión del receptor en el texto se realiza indirectamente a través de elementos metafóricos. La guía turística es un ejemplo de despersonalización del discurso (Calvi, 2006:76), pues estos géneros describen lugares e itinerarios en tercera persona con el objetivo de conseguir mayor objetividad. Sin embargo, en las partes en las que proporcionan consejos prácticos, las guías abandonan el estilo impersonal. Suele ocurrir también que el interlocutor queda incluido en el texto de modo neutro, con el uso de sustantivos como viajero, visitante, entre otros, precedido del artículo definido. Esto permite indirectamente también incluir al interlocutor que se identifica así como destinatario y se imagina en el destino turístico propuesto. 
- El uso del espacio y el tiempo.

- Las formas deícticas juegan un papel fundamental en el texto turístico. Puesto que los materiales turísticos recrean escenarios donde sitúan al interlocutor es frecuente encontrar locativos (aqui), y un amplio abanico de preposiciones, adverbios y otras expresiones locativas.

- Asimismo, el uso del tiempo en la experiencia turística cobra relevancia. A menudo se interpela al turista sobre si conoce o ha estado ya en algún lugar determinado. Por otro lado, en los programas de los touroperadores, los viajes organizados establecen claramente las etapas y horarios rígidos que deben seguir los viajeros. En cuanto a los tiempo verbales, predomina el presente de indicativo, al ser habituales las descripciones. En muchos casos se trata de un presente atemporal. Los tiempos del pasado se observan en textos turísticos que combinan el texto, el relato o la narración histórica. Y finalmente, destacamos el uso del futuro, que refuerza la credibilidad del viaje por su valor predictivo, además del uso en los fragmentos dedicados a la normativa o cláusulas contractuales. Sin embargo, por su carácter vocativo, el texto turístico usa abundantemente el imperativo.

\subsubsection{El destinatario del texto turístico}

El destinatario del texto turístico es, en primer lugar, y como ocurre inevitablemente en toda relación comercial, el cliente-emisor. El texto de origen debe corresponder a los objetivos marcados en el encargo del documento primario y a las expectativas de aquél. Del mismo modo, el cliente del encargo de traducción es el primer destinatario del texto meta. Pero no cabe duda de que, para conseguir la finalidad acordada, la elaboración del texto y su 
traducción giran alrededor del perfil del receptor y sus necesidades tal como lo pone de relieve Hurtado (2001:29):

La finalidad comunicativa de la traducción, nacida de la necesidad de la comunicación para subsanar la barrera de la diferencia lingüistica y cultural, es crucial en traducción. El otro aspecto clave es el destinatario de la traducción; sus necesidades, lo que sabe y lo que no sabe respecto al medio circundante del texto original y la finalidad con la que se enfrenta al texto son elementos que rigen la traducción y también la reflexión en torno a ella.

El receptor de los textos originales en castellano es o suele ser originario del país emisor o es hispanohablante. No tan evidente se revela el hecho de que el emisor decida publicar el TO y el TM (o los distintos TM) simultáneamente: el resultado de este tipo de encargo queda visible ya en la concepción del texto de origen: cuando es así, se interpela directamente al visitante extranjero (the tourist) o se incluye información innecesaria para el visitante nacional como un breve análisis de las instituciones nacionales. En estos casos, los distintos perfiles de los destinatarios se incluyen en un TO que luego habrá de ser trasvasado a un idioma cuyo perfil de destinatario no será coincidente.

Para Bugnot (2005) es evidente que siempre resulta algo azaroso intentar definir el perfil del receptor medio al que apunta el texto turístico. Más categórica se muestra aún Rabadán (1991:74) al respecto cuando afirma que "es imposible caracterizar a los receptores potenciales meta, en base a un parámetro único". Si tomamos como primer parámetro la condición de nohispanohablante, el receptor del texto turístico meta es, además y obviamente, aquella persona que llega a España con suficiente curiosidad para conseguir (en el hotel, en la Oficina de Información) la guía o el folleto que necesita para enriquecer sus vacaciones, lo que, de hecho, excluye a: 
- Los visitantes que, en su primera estancia, poseen información previa sobre el destino turístico, pues han comprado una guía en su país de origen.

- Los visitantes habituales que no necesitan esta referencia, porque ya les es familiar.

- Los que no están interesados en dicha información, perfil que corresponde principalmente a los adeptos de lo que se ha dado en llamar turismo de sol y playa.

Bugnot (2005) comprueba que el texto turístico no se elabora en función del género del receptor, aunque la distribución por sexos muestre que los hombres aventajan a las mujeres. Si bien no se tiene en cuenta el género del visitante, Bugnot destaca que sí se encuentran en los textos más recientes indicios semánticos que revelan una cierta consideración hacia el receptor femenino. Se debe el hecho de que, en el tradicionalmente masculino mundo de los negocios, las denominaciones con morfemas de género se vean cuidadosamente reemplazadas por términos neutros, la voz pasiva o nominalizaciones abstractas, de modo y manera que existe una tendencia generalizada a excluir del léxico toda connotación discriminatoria en cuanto a sexo. Tampoco inciden en el planteamiento previo del texto turístico la edad del receptor potencial del texto-meta, mayoritariamente por encima de los treinta, ni su perfil socioeconómico (elemento igualmente importante), que podría determinar una adaptación temática y lingüística del texto a un perfil más especializado.

El receptor de una guía de viajes, comprada en el país de origen o en el lugar de destino, es, en todo caso una persona que desea ver más allá de lo meramente aparente. Esta distinción implícita entre viajero (culto y ávido de penetrar en un mundo extraño) y turista (gregario, etnocentrista, indiferente a la cultura local) es inherente a todo texto turístico y se desarrolla en el siguiente apartado. 


\subsubsection{Turista, visitante, viajero: denominación del destinatario}

Las guías y los folletos apuntan hoy en día al viajero, no al turista de sol y playa, que se adueña del espacio con una visión etnocentrista. El turista, como denominación genérica, es una no-entidad (Bugnot, 2005), es un número revestido de los símbolos propios de su condición pasajera: es el estereotipo vestido con un pantalón corto, unas playeras, y una cámara fotográfica, tal como lo hemos considerado en España por el tipo de turismo de masas que ha predominado en nuestro país desde hace décadas y que le confieren al término una connotación peyorativa.

La palabra turista rara vez aparece en las guías. Es más, en la clasificación de los viajes, la clase turista es la clase barata como también lo es el menú turístico. Según Bugnot (2005) el sustantivo turista ha llegado a ser término tabú en el texto turístico y, aún hoy día, en los medios de comunicación españoles, se prefiere a este término la sinécdoque el turismo perteneciente a la terminología socioeconómica. En el lenguaje turístico actual, si bien ocasionalmente aparece la sinécdoque el turismo, se prefiere a la voz turista el término neutro visitante.

La OMT (1998) nos proporcionar una definición precisa de visitante: "toda persona que se desplaza a un lugar distinto al de su entorno habitual, por una duración inferior a doce meses y cuya finalidad principal del viaje no es la de ejercer una actividad que se remunere en el lugar visitado". En general, en la comunicación turística dirigida al público se prefiere el vocablo visitante porque tiene connotaciones positivas y estratégicas que en realidad ocultan la transacción comercial que realizan todos los turistas al hospedarse en un hotel o realizar una visita guiada a un monumento. 
La palabra viajero tiene un significado muy general de persona que viaja, pero también se le atribuye una carga valorativa que se refiere a la decisión autónoma y de control del turista sobre su propio viaje y experiencia turística.

En su novela El cielo Protector, Paul Bowles (1949:13) ofrece una definición original de turista. Se trata de una definición por exclusión:

La diferencia entre un turista y un viajero es que, mientras el primero piensa en regresar desde el mismo momento de su llegada, el viajero puede no regresar nunca.

Esta definición, lejos de ser acertada, nos acerca a la idea de que el viaje representa una aventura en la que el turista está abierto a nuevas realidades y experiencias.

La OMT (1995) ofrece, por su parte, una definición de dos conceptos, el de viajero y el de visitante, y los distingue entre sí. El viajero es "cualquier persona que viaje entre dos o más países o entre dos o más localidades de su país de su residencia habitual" y se entiende por visitante "todos los tipos de viajeros relacionados con el turismo".

Como se desprende de la definición de la OMT, todos los viajeros relacionados con el turismo se denominan visitantes, de ahí que el término visitante sea el concepto básico de uso para el conjunto del sistema turístico. ${ }^{77}$

Al margen de que se le denomine turista, viajero o visitante, la creación textual meta siempre va dirigida, en definitiva, al receptor de un polisistema complejo, con lo que coincidimos con Elena (1994:16) cuando apunta que, aparte de amplios conocimientos del sistema lingüístico de llegada, tan importantes o más

\footnotetext{
77 Según la OMT (1998), a efectos de estadísticas y clasificaciones en turismo, los visitantes se pueden clasificar en visitantes internacionales o visitantes internos. Tanto los visitantes internacionales como los visitantes internos se subdividen a su vez en turistas (aquellos que pernoctan) o visitantes del día (excursionistas).
} 
serán para el traductor los conocimientos que posea sobre las circunstancias culturales, históricas, sociológicas de los receptores a los que va dirigida la traducción.

Resulta por ello interesante en este punto, destacar las características del visitante y consumidor actual de productos turísticos. Chamizo (2003:32-35) establece las siguientes facetas del consumidor de productos turísticos, de las que reproducimos las más relevantes a continuación:

- Multiconsumidor: en general, el visitante no realiza un único tipo de actividad al combinar turismo cultural con turismo rural, de nieve, etc.

- Busca la satisfacción plena: el visitante desea vivir intensamente la experiencia turística y hacer de ella algo único e inolvidable.

- Exigente y activo: en la búsqueda de información y consumo y cada vez más controla la planificación de su viaje desde el inicio para adaptarlo a sus gustos y necesidades gracias a las nuevas tecnologías.

En general, la experiencia turística supone para cualquier visitante un modo de realización personal y de desarrollo de su personalidad (Chamizo, 2003:32). Los visitantes disponen de un nivel cultural mayor y su participación en la elección del producto hace que exija cada vez más mayor calidad y especialización en los productos turísticos. 


\subsection{La traducción del texto turístico}

En el ámbito de la traducción profesional es bien sabido que la primera tarea del traductor es la de reconocer el texto que le ha sido encomendado. Partiendo de su presentación formal, de las distintas modalidades discursivas que lo componen, de los elementos verbales y no-verbales, del canal empleado, pueden derivarse una serie de parámetros que permitirán al traductor ejercer sus competencias.

Autores como Fuentes y Le Poder (2005) han centrado parte de su estudio del texto turístico en el texto turístico publicitario. Para estos autores, las dos funciones principales de un texto turístico publicitario son informar y persuadir. Debido al proceso de diversificación que ha sufrido el sector turístico en los últimos años, han surgido una serie de publicaciones turísticas distintas, cada una con una especificidad, formato, presentación, y tipología de lector.

Las últimas tendencias en traductología sitúan al texto turístico muy cerca del texto publicitario (Cómitre Narváez, 2004:120) y como hemos citado anteriormente, Nobs (2006:63) establece la operatividad del texto turístico ligándola a la del texto publicitario para causar un efecto en el lector. Nosotros, sin embargo, creemos que el texto turístico es un lenguaje con fines específicos por su propia naturaleza, pues puede comportarse como un subsistema de la lengua que se puede utilizar en ámbito tanto profesional como técnico o científico, con finalidad descriptiva o comunicativa. Entendemos, además, como Calvi (2000) que combina las dos tipologías textuales, expositiva y exhortativa, y que resulta imposible establecer categorías cerradas puesto que en cada caso concreto deberemos tener en cuenta el género particular al que nos refiramos. Así, por ejemplo, un anuncio o folleto turístico son necesariamente más 
persuasivos y más cercanos por tanto al lenguaje publicitario, que un artículo en una revista o una guía tradicional.

La lengua inglesa juega un papel fundamental como lingua franca en los textos turísticos. En los textos turísticos españoles es frecuente encontrar anglicismos (Lorenzo, 1996:250) que ya forman parte de nuestro lenguaje cotidiano como overbooking, catering o ferry u otros calcos derivados del inglés como aire acondicionado, turoperador. La lengua inglesa ha ido imponiéndose paulatinamente como idioma global, de modo que resulta un vínculo de unión y comunicación en cualquier parte del mundo entre gentes de cualquier cultura, religión o clase social. A ello han contribuido también las nuevas tecnologías e Internet, que han acabado optando por el inglés como su lengua vehicular. El hecho de que el inglés se haya ido imponiendo como idioma global hace que los nuevos giros, palabras y términos que se van acuñando en el sector turístico sean en lengua inglesa y que idiomas como el español adopten la denominación inglesa. La preponderancia de la lengua inglesa también repercute indirectamente en la traducción de los textos turísticos, que pasa a tener un valor secundario.

En el sector turístico no se tardó mucho tiempo en comprobar que resultaba infinitamente más complejo describir algo sencillo en sesenta idiomas que en uno solo que todo el mundo comprendiera (Olivares y Urquía, 2006). Y también fue el inglés la lengua que se impuso y en todas y cada una de las áreas del negocio turístico. Como indican Olivares y Urquía (2006:150):

(...) En la parcela de la macrogestión irrumpieron vocablos de la jerga económica (...) perfectamente aplicables al turismo: takeovers (absorciones), sustainable (sostenible), development (desarrollo),... Y lo mismo sucedió en el área de la microgestión, donde la terminología general y de comprensión universal escogida fue también la inglesa: desde el cash (...) hasta términos tan usuales como staff, check-in, o check-out. 
La industria del ocio es la que refleja más claramente el uso de anglicismos con palabras como surf, skate-board, o adaptaciones como puenting. También se han creado parcelas muy especializadas con términos muy concretos aplicables al viaje (travel), el alojamiento (accommodation), el ocio (leisure) y la restauración (catering). Una parcela interesante e interesante en el sector turístico es la gastronomía. A diferencia del resto, existe una proporción bastante equilibrada entre las palabras de origen anglosajón y las palabras de raíz latina (Olivares y Urquía, 2006:151). Existen, pues, una serie de palabras que han entrado a formar parte de la cultura de viajes y que en su mayoría, son de origen francés. Podemos poner como ejemplos chef, hors-d'oeuvres, etc. Estos vocablos se alteran con vocablos de otros lugares como pizza, Frankfurt, chop-suey, paella, sangría, strudel, sushi, cous-cous, etc. Son palabras que definen platos universales en sus respectivos idiomas vernáculos y que forman parte de un diccionario universal del viajero.

Así pues, la traducción del texto turístico se presenta como un texto multilingüe y multicultural, en el que el traductor debe saber cuáles de esos vocablos son ya universales y serán reconocidos por el lector o turista como provenientes de una determinada cultura y además, debe conocer su significado e implicaciones culturales.

El sector turístico ha sido uno de los pilares fundamentales sobre los que se ha desarrollado la economía española tradicionalmente, y, a pesar de la actual situación de revolución del sector por la bajada generalizada de precios para los paquetes turísticos y el desembarco de la filosofía de los viajes low-cost, la gestión turística tradicional todavía juega un papel muy destacado como agente económico internacional (cfr.3.1). Es por eso, que, al ser un gran generador de empleo, podríamos pensar que la traducción en el sector turístico se ha convertido en una de los ámbitos de especialidad de la traducción como ocurre 
con otras especialidades como la traducción literaria o jurídica. Sin embargo, esto no es así. Como bien indican Fuentes y Le Poder (2005:35) "existen muchas personas que entienden que la traducción poco o nada tiene que ver con el turismo". Curiosamente, muchas veces son las mismas instituciones oficiales las que estructuran las campañas de promoción turística sin tener en cuenta si los productos o servicios turísticos que se ofrecen disponen de una calidad en su traducción que haga de ellos un objeto de mediación lingüístico-cultural, no únicamente como simple trasvase lingüístico.

El problema básico se encuentra en la insuficiente profesionalización del sector: las personas que traducen no suelen ser traductores profesionales, sino personas con escaso conocimiento de la cultura y de la lengua meta.

La mayoría de los estudios existentes sobre traducción turística se fundamentan en esta problemática de la calidad de las traducciones. Newmark (1991) y Duff (1981) coinciden en señalar que la calidad de las traducciones del sector turístico es peor debido a que muchos textos están traducidos a una de las muchas lenguas extranjeras del traductor. Duff (1981: 125-6) atribuye esto a la situación del mercado, a pesar de que es "una situación indeseable aunque inevitable". Es decir, el traductor se utiliza para traducir no a su lengua materna, sino que se aprovecha su conocimiento de otras lenguas extranjeras para conseguir traducciones a múltiples idiomas como traductor-productor multilingual.

Kelly aborda los retos que surgen para el traductor al enfrentarse a la traducción de un texto turístico, en particular la transferencia de las expectativas del lector provenientes de las convenciones textuales derivadas del contenido y el estilo propios del texto en cada cultura. En su artículo The translation of texts of the tourist sector: textual conventions, cultural distance and other constraints 
(1997) Kelly ahonda en esta problemática y denuncia que la baja calidad de la traducción turística se debe a la falta de profesionalización de este tipo de traducciones y se pregunta si debería considerar la inclusión de asignaturas específicas en los Estudios de Traducción sobre traducción turística.

Creemos que esto se produce porque al ser el texto turístico un texto heterogéneo y que combina abundante lenguaje general con terminología básica propia, el lector no necesita unos conocimientos específicos ni técnicos para entenderlo, de ahí que a menudo se crea que estamos ante un tipo de texto rígido y prototípico, sencillo y fácil de traducir, cuando en realidad los textos turísticos son multidisciplinares y en la mayoría de ocasiones incorporan elementos culturales específicos tan distantes en la cultura meta, que nos llegan a plantear la intraducibilidad de la cultura. Coincidimos también con Kelly en que lo que subyace es un menosprecio y un bajo reconocimiento a la actividad traductora y aunque, no podemos generalizar, a menudo esta actitud "contributes greatly to many people's hilarity" (Beeby 1996:6-8, citado en Kelly (1997:34).

Para Fuentes y Le Poder el texto turístico combina distintos ingredientes de diferentes disciplinas y distintos códigos, por lo que la traducción adquiere una dificultad especial y requiere, por lo tanto, especial atención:

En su versión original, un texto turístico es el resultado de un complejo proceso que conlleva una gran dosis de marketing, cultura (en el sentido más amplio del término), y el uso de diferentes sistemas lingüísticos y semióticos, todo en forma muy concentrada. Se podría pensar que la versión traducida debería seguir, al menos, en principio, las mismas convenciones. Sin embargo, no siempre es así y a menudo ven la luz traducciones poco acertadas que comprometen seriamente el objetivo del producto final (Fuentes y Le Poder, 2005:63).

Como vemos, la tan llevada y traída mala calidad de las traducciones de los textos turísticos se debe a múltiples factores. Es necesario realizar una 
consideración seria de la traducción de los textos turísticos para poderles otorgar una independencia textual propia de modo que se evite que las traducciones turísticas sean siempre citadas en los manuales de la teoría de la traducción "como ejemplos de traducción defectuosa, realizada por traductores cuya lengua meta no es la materna y que, además, carecen de formación en traducción inversa" (De la Cruz Trainor, 2003:3).

Anteriormente hemos descrito el texto turístico como un texto híbrido (multitextual) y multifuncional. Sin embargo, debemos prestar atención a otra característica esencial del texto turístico, como es la combinación de distintos códigos semióticos. Fuentes y Le Poder (2005) se refieren a la multitud de elementos que conforman la tipología textual turística como una "eficaz combinación de elementos gráficos, icónicos y textuales. Los contenidos, la distribución, el diseño y la edición de dichos diferentes sistemas semióticos son de una importancia clave a la hora de provocar un efecto positivo en el lector y lograr los objetivos informativo y persuasivo deseados" (2005:63). El traductor, como mediador intercultural debe transmitir la intencionalidad que todos estos elementos persiguen.

Estos autores también apuntan que las traducciones en el sector turístico siguen un criterio de direccionalidad. Este criterio implica que las traducciones que se realizan toman como base un único texto de partida que se transfiere hacia una o varias lenguas extranjeras mediante traducción inversa. Creemos que esto se produce por criterios básicamente económicos y pensamos que muy, probablemente, en muchos casos, es el inglés el TO debido a su carácter de lingua franca.

María M. de la Cruz Trainor (2004) en su artículo Traducción al inglés de términos culturales en textos turísticos menciona que es urgente que exista una 
teoría válida, que sirva para la realización de traducciones inversas en el ámbito turístico, de manera que la gran demanda de traducciones quede satisfecha en un campo que califica como inexplorado.

La realidad demuestra que no abundan los estudios traductológicos del texto turístico. De nuestro estudio, hemos podido localizar algunos estudios basados en la comparación de textos turísticos procedentes de dos culturas distintas enfocados en algunos casos hacia la didáctica de la traducción (Perton, 2010; Ponce, 2008; Martínez Motos, 2005; Kelly, 1997 y 2000; Gross 1998; Nobs 1996). Sin embargo, los estudios exhaustivos en determinadas parejas de lenguas son escasos. Debemos destacar en este punto la investigación de María M. de la Cruz Trainor (2003) que realiza una radiografía de las técnicas de traducción más utilizadas en conexión con los errores más frecuentes en la traducción de este tipo de textos. ${ }^{78}$

Respecto a los estudios de traducción turística en géneros especializados hemos podido localizar en nuestra investigación algunos artículos aislados en los que se realiza un análisis traductológico de las estrategias de traducción en general y de los elementos culturales en particular en las guías turísticas (Payo Peña, $2002^{79}$; Pérez Vicente, $2008^{80}$ ). En otros casos, se trata de estudios aislados que van aportando nuevas visiones y aproximaciones hacia la teorización del texto

\footnotetext{
78 De la Cruz Trainor realiza una clasificación de todo el material promocional recopilado para la promoción de un destino turístico. Se trata, pues, de un estudio más exhaustivo al combinar el análisis de diferentes géneros turísticos.

${ }^{79}$ Payo Peña (2002) aborda la traducción de referencias culturales desde la óptica del perfil del lector tipo al que va destinado el texto turístico. Payo realiza una serie de encuestas sobre los referentes culturales y concluye que existen tres tipologías de lector en cuanto a conocimientos sobre otras culturas y que dependiendo del lector prototipo, el traductor debe activar unas estrategias u otras.

80 Pérez Vicente (2008) realiza un estudio comparativo español-italiano y analiza la transferencia cultural de los campos semánticos siguientes: flora y fauna, festividades y folclore, gastronomía y arquitectura y ciudades. Esta autora concluye que existe una alto grado de transmisibilidad de los culturemas españoles a la cultura italiana, aunque el uso de las técnicas varía dependiendo del campo semántico concreto.
} 
turístico, desde distintos puntos de vista (la competencia traductora, la cultura o culturas en juego o el lector destinatario) y que resultan de especial interés para nuestro estudio.

Un ejemplo de la investigación existente del texto turístico es el proyecto TURICOR impulsado por Departamento de Traducción e Interpretación de la Universidad de Málaga. Se trata de un proyecto interuniversitario ${ }^{81}$ cuyo objetivo es seleccionar y compilar textos turísticos para analizar sus características para posteriormente generar textos turísticos multilingües (inglés, francés, italiano, alemán).

Si bien la traducción vive actualmente un auge en cuanto a investigación se refiere, hasta ahora la reflexión sobre cuestiones traductológicas no ha representado un pilar fundamental en torno a la traducción. Quizás esto pueda deberse a que los estudios de traducción son muy jóvenes en España. La aprobación de la Licenciatura (actualmente Grado) en 1991 en cuatro años "supuso el comienzo generalizado de un proceso de implantación de estudios por todo el territorio español" (Pegenaute, 2004:606) y las diferentes universidades que los imparten han ido perfeccionando sus planes de estudios para hacerlos más competitivos y fieles a la demanda real de profesionales que existe hoy en el mercado de la traducción. Como indica Postigo (2007:320):

(...) The discipline of Translation Studies has made great progress and is achieving high standards in Spain due to the great effort of universitites, its popularity among students and the promising opportunities it offers in the work market.

Actualmente casi todos los planes de estudios de las Universidades de Traducción españolas incluyen alguna asignatura de traducción de textos turísticos, debido a las múltiples dificultades que estos presentan, el gran

\footnotetext{
${ }^{81}$ Universidad de Málaga, Universidad de Alcalá de Henares y Universidad Pablo de Olavide.
} 
volumen de demanda de traducciones existente y a la conciencia general que existe de la necesidad de mejorar la calidad de estas traducciones en el mercado. En algunos planes de estudios, como la Universidad Pompeu Fabra (UPF) los textos turísticos se traducen bajo la asignatura genérica de Traducción Inversa, junto con otros textos que presentan los mismos problemas de transferencia cultural como textos de cocina, textos publicitarios y los llamados de información turístico-cultural. La Universidad de Alicante ofrece una asignatura completa denominada Traducción de textos turísticos y de las industrias del ocio, al igual que la Universidad de las Palmas (ULPGC), a la que denominan Traducción turístico-comercial. La Universidad de Granada ofrece una asignatura optativa de Traducción de textos divulgativos que incluye la traducción de folletos turísticos. Como observamos, en mayor o menor medida, o de un modo u otro, los planes de estudios de las Universidades españolas incluyen el texto turístico como género específico de traducción.

Del mismo modo, y, al preparar los estudios de Traducción e Interpretación a los futuros mediadores y comunicadores interculturales, las universidades se han apresurado a incluir entre sus asignatura obligatorias aquellas que aportan fundamentos culturales y temáticos para la traducción. A nuestro modo de ver, la principal dificultad y caballo de batalla de los traductores, una vez hemos pormenorizado en el texto turístico, es el componente intercultural de los textos. Un traductor no puede solo ser competente trasvasando de un idioma a otro y de una cultura a otra de modo bienintencionado, sino que es necesaria una conciencia y una competencia interculturales globales. En palabras de Fuentes y Le Poder (2005:87):

Muchos autores han hablado sobre la importancia de la competencia intercultural del traductor. Para que puedan llevar a cabo su papel de un modo eficaz, no basta con ser consciente de las diferencias culturales, sino también de cómo se ven las culturas origen y término. Un conocimiento sólido de las percepciones mutuas y los estereotipos de 
ambas culturas le permitirá al traductor utilizarlos en formas diferentes para lograr un texto término eficaz y funcional.

Becher (2002) indica que cualquier estudio del lenguaje propio de un sector, en nuestro caso el turístico, tiene que incluir en el análisis no sólo los "meros" términos en cuestión, sino también los parámetros que inducen a lo específico cultural de la comunicación entre hablantes de comunidades de lenguas distintas.

Para Ortega Arjonilla (1996), el traductor siempre tiene ante sí una tarea ardua, por lo que, como si fuera un malabarista, debe ir haciendo equilibrios en las decisiones traductológicas que adopta para poder transmitir la carga cultural de los textos.

Para nosotros, el traductor de textos turísticos necesariamente debe ser bicultural (Hatim y Mason, 1990, Reiss/Vermeer, 1996) y constituir la figura clave en el proceso de mediación y trasvase de información desde la cultura de origen hasta la cultura meta.

Proporcionamos, a continuación, la definición de mediador cultural de Taft (1981:53), en la que queda patente la característica de biculturalidad del mediador:

A cultural mediator is a person who facilitates communication, understanding, and action between persons or groups who differ with respect to language and culture. The role of the mediator is performed by interpreting the expressions, intentions, and expectations of each cultural group to the other, that is, by establishing and balancing the communication between them. In order to serve a as link in this sense, the mediator must be able to participate to some extent in both cultures. Thus, a mediator must be to a certain extent bicultural.

Taft (1981:73) enumera y detalla además las competencias que todo traductor debe poseer en ambas culturas para realizar la mediación con éxito: 
- Conocimiento sobre la sociedad: historia, folclore, tradiciones, costumbres, valores, prohibiciones, entorno natural y su importancia, pueblos vecinos, personalidades importantes en el grupo social, etc.

- Destrezas comunicativas: escritas, orales y no verbales.

- Destrezas tecnológicas: aquellas requeridas por el estatus del mediador: alfabetización tecnológica.

- Destrezas sociales: conocimiento de las reglas que gobiernan las relaciones sociales en una sociedad y la competencia emocional (por ejemplo: un nivel adecuado de autocontrol).

El ejercicio de mediar entre culturas exige, pues, al traductor un evidente bilingüismo y una clara biculturalidad (Snell-Hornby, 1999:46), y en cualquier caso, "el desarrollo de un alto nivel de sensibilidad intercultural" (Katan, 1999:18). Para Hatim y Mason (1990:223-224) no todos los traductores son mediadores e indican que existen dos maneras de actuar a la hora de traducir por las que el traductor sí ejerce de mediador. En primer lugar, es necesario tener una visión bicultural, de modo que el traductor se sitúa en territorio neutral para poder solucionar la disparidad entre signo y significado entre culturas. Por otro lado, el traductor debe actuar como lector crítico, puesto que es un lector privilegiado del TO. En sus manos está la oportunidad de leer el texto atentamente antes de proceder a la traducción y por tanto, se halla en una posición de poder ayudar al lector meta.

En muchos casos, el traductor se enfrenta a la mediación entre dos culturas muy lejanas desde el punto de vista lingüístico y cultural. En estos casos, es cuando el traductor se enfrenta a la traducción en su estado más puro, al tener que transmitir saberes que no le son propios ni conocidos en absoluto y que, de algún modo, ha de expresar en la cultura meta. 
Sin embargo, como indica Katan (1999:7), es cada vez más fácil traducir términos conceptuales culturales, puesto que se están llevando a cabo esfuerzos internacionales encaminados hacia la armonización de legislaciones y códigos de prácticas que superen fronteras. También se ha mejorado muchísimo en la creación y desarrollo de glosarios on-line. Por otro lado, mucho de lo que se produce nace ya globalizado, de modo que existe siempre una traducción previa, algo que antes era prácticamente impensable.

Ortega Arjonilla (2002:186) plantea que no necesariamente existe siempre un sustrato cultural implícito o explícito; en algunos casos, el traductor no realiza la mediación cultural, pues los textos a traducir "no reflejan una relación estrecha entre cultura y sociedad". Coincidiendo con Katan (1999), Ortega Arjonilla indica que, a menudo, el traductor se enfrenta a textos con sustrato cultural transnacional o textos en los que los elementos lengua y cultura conforman una sola unidad.

Sin embargo, no todos los traductores, en el caso de la lengua extranjera, se hallan inmersos en el mismo contexto lingüístico y cultural del hablante, lo que genera inseguridad respecto al éxito en la transmisión del mensaje durante la toma de decisiones que conlleva el proceso de traducción. En el caso de la traducción turística, queda patente que los traductores en general, no son biculturales, pues ni siquiera, en muchas ocasiones, son traductores profesionales, como indica Alesón Carbonell (2001):

This lack of consciousness of having good professionals doing quality work is due maybe to the fact that most of the Tourism professionals know foreign languages and think that for a good translation it is not necessary to pay a profesional translator (Alesón Carbonell, 2001:108).

Cabe señalar que el traductor de textos turísticos, además de ser bicultural, debe tener amplios conocimientos del mundo que le rodea. Con esto queremos 
decir que, al ser el turismo una disciplina que contiene múltiples temáticas y se alimenta de diferentes disciplinas (arte, historia, entre otras), es absolutamente necesario que el traductor sea especialista en la traducción de los elementos discursivos, léxicos y macrotextuales característicos del texto turístico, pero además debe tener una cultura general elevada que le permita poder afrontar un texto multitemático de turismo o un texto unitemático especializado de turismo, según sea necesario. Esta es a la postre la dificultad mayor y el reto que el texto turístico plantea a los traductores turísticos: la elevada exigencia de conocimientos previos del mundo (ya no solo de las dos culturas que se estén traduciendo). Así pues, las técnicas de traducción que deberá desplegar el traductor en el proceso traductológico del texto turístico deberán ser, a buen seguro, variadas y dependerán de i) la distancia intercultural existente entre la $\mathrm{CO}$ y la $\mathrm{CM}$ ii) el subtipo de texto turístico que estemos traduciendo (folleto, guía, documentación de tipo legal,...) iii) la modalidad de traducción (escrita, oral, para una página web, ..) y iv) la finalidad de la traducción y las características del destinatario.

La realidad del ejercicio profesional de la traducción nos muestra que, en muchas ocasiones, el traductor está a merced de la oferta y la demanda y que a menudo debe aceptar encargos que le suponen un verdadero reto, pues no dispone de las herramientas terminológicas y de información adecuadas, ni de la formación especializada adecuada en una determinada disciplina. Para Candel Mora (2010:1377) los traductores deben "optar por especializarse en unos campos específicos suficientes para compensar cualquier carencia de conocimientos sobre las áreas especializadas". 82

\footnotetext{
${ }^{82}$ Se hace necesaria así la consulta exhaustiva de material existente para familiarizarse con la temática y la expresión habitual de los diferentes tipos de textos, o mediante la consulta a especialistas.
} 
Finalmente, quisiéramos recalcar que el proceso de traducción del texto turístico es un acto comunicativo no exento de dificultades, pues combina problemas de la traducción general y la traducción especializada como son: la traducción de nuevos conceptos, de la imagen cultural, de los juegos de palabras, de fraseología, e incluso de la traducción del nombre propio y que requiere la especialización del traductor y la concienciación de las instituciones públicas o empresas privadas o iniciadores de la traducción para elaborar traducciones turísticas de calidad.

Sin duda, la traducción del texto turístico supone una actividad de especialización y "un campo en el que existen enormes posibilidades de trabajo" (Cerdá Redondo, 2001:181), en especial dentro de la industria turística con presencia en Internet.

Debido a esta presencia abrumadora de textos turísticos y traducciones en Internet (algunas con mejor o peor fortuna), consideramos imprescindible abordar de un modo más extenso la traducción de textos turísticos en Internet.

\subsubsection{La localización de productos turísticos}

A continuación explicaremos cuáles son las características principales de las páginas web turísticas y daremos cuenta de la localización del componente cultural y del texto turístico.

\subsubsection{Las páginas web turísticas}

En la década de los 90 confluyeron una serie de fuerzas que impulsaron la industria turística; entre ellos podemos citar la aparición de nuevos operadores turísticos mucho más especializados, nuevos métodos de gestión aplicados a la 
industria turística, una revolución tecnológica que posibilita nuevas formas de comercializar productos turísticos y, por último, un nuevo turista.

Dicho turista busca experiencias de viaje y en consecuencia necesita disponer de información. Se trata de una persona más conocedora, exigente, más culta y preocupada por los impactos sociales, medioambientales y económicos. El turista tradicional ha dejado de ser un turista pasivo para convertirse en un sujeto dinámico y participativo (Majó y Galí, 2000).

De todos es bien sabido que una de las ventajas que nos ofrece Internet es el ingente volumen información que pone a nuestra disposición. Por otro lado, si por algo se caracteriza la industria turística es por su carácter intensivo en información. Ya en 1998 Álvarez observaba la presencia del turismo en Internet a partir de tres bloques:

1. Las páginas web de las compañías de transporte y de los sistemas de distribución global ${ }^{83}$.

2. Los entornos impulsados por las organizaciones turísticas públicas o de representación sectorial.

3. Nuevos espacios con propuestas de información, comunicación y márketing turístico.

A estos elementos hoy se añaden las novedosas y múltiples posibilidades que nos ofrece el desarrollo de Internet como son las listas de distribución, los productos multimedia ${ }^{84}$, las redes sociales, los blogs, entre otros. ${ }^{85}$

\footnotetext{
${ }^{83}$ La industria turística se convirtió en uno de los primeros sectores en informatizarse aplicar en los años 60 el comercio electrónico de forma computerizada. De este modo nacieron los sistemas de reserva (CRS) y los sistemas de reservas globales (GDS).

${ }^{84}$ Ofrecen videos, fotos y podcasts que brindan una experiencia integral al usuario, que requiere de más información a la hora de adquirir un producto o servicio online.
} 
Por otra parte, Internet ofrece la posibilidad de la inmediatez en la venta y la adquisición. Sheldon (1997) hace referencia al hecho de que el producto turístico es perecedero y a la ventaja que Internet supone para su comercialización:

The internet and the World Wide Web are other sources of electronic travel information which are now widely used. Almost all products in the tourism industry (accommodation, attractions and transportation) are perishable in the sense that if they are not sold they are lost. By using high speed data communication networks, firms could sell their products before they are no longer possible to be sold (Sheldon, 1997 citado por Cerdá Redondo, 2001:173).

Así pues, Internet representa un medio lleno de oportunidades para todos los participantes en la actividad turística.

Si se atiende a la promoción turística, la importancia de la world wide web está fuera de toda duda. No sólo representa un medio con una cantidad enorme de usuarios y potenciales clientes, sino que además permite interactuar con ellos. Como medio de promoción, la Web presenta ventajas que no se habían conocido antes para cualquier otro medio de comunicación ${ }^{86}$.

Debemos destacar el concepto de portal turístico, una herramienta diseñada para la promoción turística integral que se está generalizando en el sector y que asiste al turista desde que comienza a planear su viaje hasta que vuelve casa. Estos portales se caracterizan por su inteligencia y dinamismo, pues son capaces de personalizar la información adaptándose a las características culturales e idiomáticas del turista y de interactuar con él. Resulta, pues, fundamental que la

\footnotetext{
${ }^{85}$ Debemos destacar las comunidades de viajes, donde millones de turistas comparten sus experiencias viajeras con blogs, fotos o videos (véase www.tripadvisor.com). También las agencias de viajes están creando sus propios grupos en redes sociales como Facebook (véase www.facebook.com), pues la inteligencia colectiva y la difusión de los productos turísticos a través de las redes sociales están cobrando mucha importancia. Este fenómeno ha sido denominado "'Travel 2.0"

${ }^{86}$ Nos referimos aquí a medios de comunicación convencionales como pueden ser la radio, la prensa o la televisión.
} 
información que aparezca en este tipo de páginas sea "efficient, accurate, and fast" (Cerdá Redondo, 2001:73) para que el turista pueda tener una idea clara del producto en el que está interesado.

Uno de los rasgos diferenciales de los portales turísticos son los contenidos multimedia que ofrecen, con los que a través de vídeos y fotografías acercan el destino al turista con sus rutas virtuales. Cabe señalar el uso de mapas y funcionalidades de servicios (buscadores, newsletter, info práctica para antes del viaje, etc.) además del uso masivo de fotografías, que relegan el texto a un segundo plano. Observamos, sin embargo, un uso reiterado de la marca turística junto a sus esloganes y/o palabras clave. Así, las imágenes, junto con la marca y las palabras clave constituyen el elemento central textual en la promoción de destinos turísticos y conforman la imagen que se desea proyectar en el turista

Sin embargo, una de los principales inconvenientes de las páginas webs turísticas en general es la falta de oferta de sus contenidos en otras lenguas distintas al inglés, como denuncia Cerdá:

More than ever the traveler has access to addresses on-line that exhibit remote places, present or past, from any place around the planet or fictional places from out of space to travel via the internet. The possibilities seem infinite though the majority of these websites are in English (Cerdá Redondo, 2001:176).

A continuación examinamos las bases teóricas de la localización del componente cultural y su conexión con el texto turístico.

\subsubsection{La localización del componente cultural}

El uso general que se realiza de textos controlados (Dollerup, 2004), es decir, textos sencillos de leer y de traducir, con una terminología compatible y una sintaxis relativamente sencilla juegan a favor de una adaptación del componente cultural. Estos textos se generan de modo controlado en origen y 
se combinan con otros textos con el objetivo de localizarlos. Esselink (2000a:28) indica las características culturales que han de omitirse en la fase de internacionalización:

Do not use culturally-specific text or jargon, e.g. humor, political references, slang, references to TV shows, national monuments (...) Avoid references to seasons, time zones, weather, or holidays, such as Christmas tres or Halloween pumpkins.

El modelo del proceso de localización que siguen los textos internacionalizados según Dollerup (1999) es el siguiente:

Figura 13: Modelo de proceso de localización de textos internacionalizados (Dollerup, 1999:5)

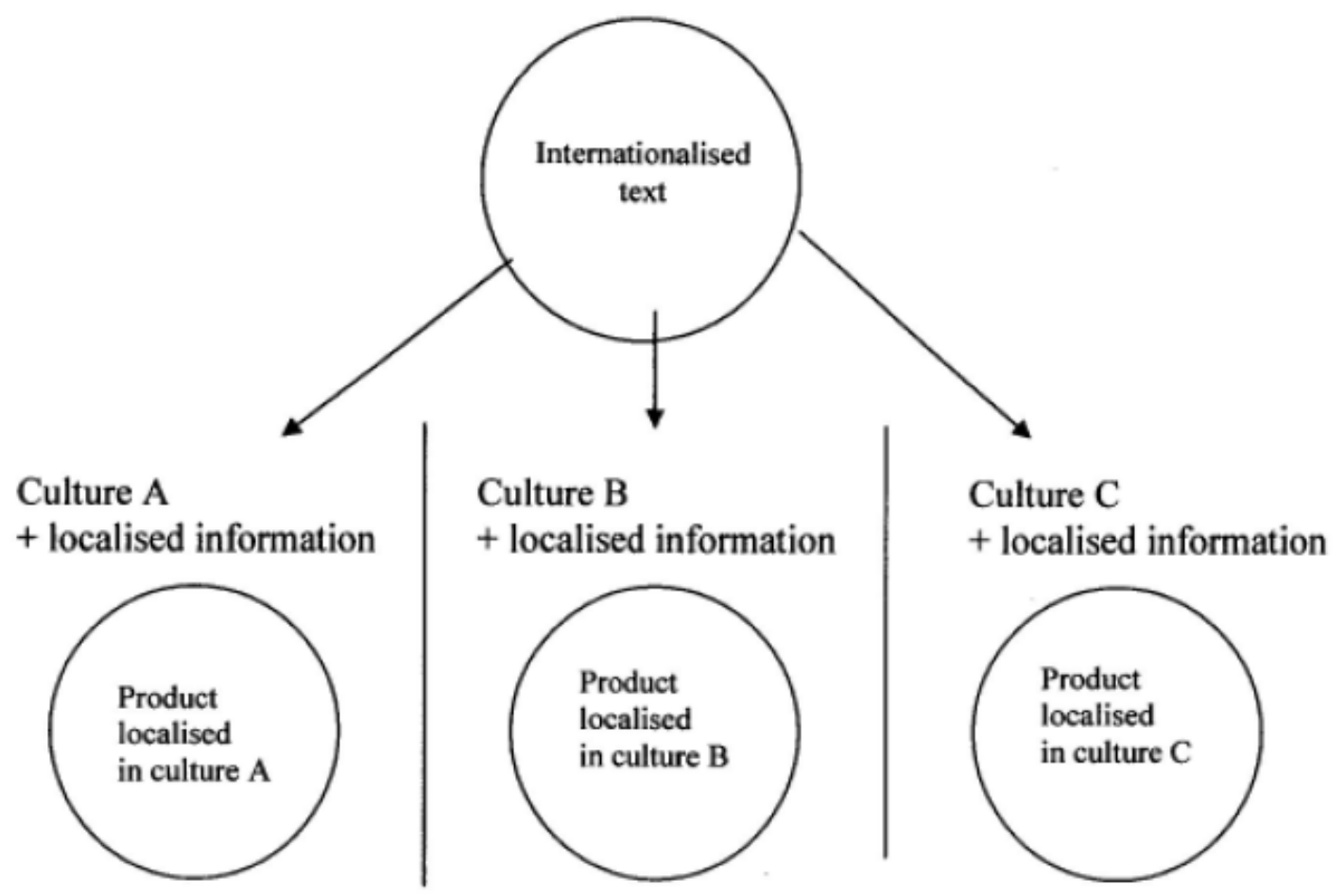

Se puede observar que el concepto mismo de localización choca frontalmente con la traducción de textos culturales. Los textos creados para localización son textos convencionales en sí mismos, pero desprovistos del sustrato cultural que 
se elimina por parte de los autores, redactores técnicos o personal técnico de apoyo.

La adaptación del componente cultural dentro del proceso de localización resulta fundamental. Para ello, se ha intentado desarrollar productos que fueran lo más neutros posibles en cuanto a carga cultural (Cronin, 2003:18).

Para dar cuenta de los elementos que forman parte de la adaptación hacemos referencia, en primer lugar, a la aportación pragmático-cognitiva de Tercedor $(2005: 153)^{87}$, quien indica que existen cinco ítems principales, a saber, los iconos, los aspectos lingüístico-textuales (como la intertextualidad, el registro o el macrotexto), los aspectos gráficos, los aspectos técnicos y los aspectos cognitivos, que incluyen la navegación, las metáforas, los modelos mentales y la interacción.

Destaca, además, la contribución de los investigadores Singh y Pereira (2005), que realizaron un estudio de las adaptaciones culturales en sitios web desde la perspectiva de la disciplina de márketing. La cultura está formada por elementos como la percepción, el simbolismo, el comportamiento, que tienen su reflejo en valores compartidos y patrones de pensamiento estructurados ${ }^{88}$ (Jiménez, 2008). Los autores en su estudio establecen un marco de elementos culturales identificando valores culturales y analizando su adaptación en la localización web. Como resultado, Singh y Pereira (2005) establecen que existen ciertos elementos en los sitios web que son variables cuantificables que permiten comparar culturas diferentes.

\footnotetext{
${ }^{87}$ Citado por Jiménez (2008:51).

${ }^{88}$ Véanse a este respecto las cinco dimensiones de Hofstede en http://www.geert-hofstede.com/: individualismo vs. colectivismo, distancia al poder, tolerancia a la incertidumbre, masculinidad vs feminidad y contexto cultural alto o bajo.
} 
La adaptación cultural no siempre es completa, es decir, dependiendo del encargo de la traducción o de las órdenes del iniciador ${ }^{89}$ y de su dimensión económica y la importancia del mercado o locale en cuestión nos encontramos con distintos grados de localización de los productos, y, por tanto, de su componente cultural.

Respecto a los modelos de grados de localización web existentes tomamos el de Singh y Pereira (2005:10-15) que se basan en la importancia de la cultura meta en la localización (Jiménez, 2008: 56):

- Sitios web únicos: suelen ser páginas web de empresas globales. En ellos la web es similar para todas las locales, en una sola lengua y sin traducción, por ejemplo www.tyco.com.

- Sitios web semilocalizados: en ellos se ofrece información de contacto de la filial local, pero no contenido específico para distintos países (www.gap.com).

- Sitios web localizados: existen ciertas páginas web localizadas que son específicas para cada locale, pero no se adapta la estructura profunda de las páginas.

- Sitios web localizados extensivamente: la localización es global y el contenido está adaptado totalmente al mercado de destino, como www.amazon.com.

- Sitios web culturalmente adaptados: en estos se reproduce totalmente la cultura de destino. Existen tres niveles de adaptaciones culturales: la percepción, el simbolismo y el comportamiento. Un ejemplo es www.ikea.com.

\footnotetext{
${ }^{89}$ Terminología de Nord (1999)
} 


\subsubsection{La localización del texto turístico}

El turismo es un sector en el que la necesidad de intercambio de información es un hecho incontestable ${ }^{90}$. Esta conexión de la industria turística con los sistemas de información (Majó y Galí, 2000) queda patente en el intercambio de información que se produce entre todos los agentes involucrados en el turismo. Puesto que los servicios que el sector turístico ofrece son bienes intangibles es necesario que el visitante disponga de una información actualizada y completa de aquel producto que desea o acaba de adquirir. Por su parte, "Ias grandes mayoristas y consorcios de proveedores de productos y servicios turísticos proveen de información en tiempo real a cientos de compañías aéreas y decenas de miles de hoteles" (Álvarez, 1998:136).

Álvarez (1998) establece una clasificación de la presencia del turismo en Internet atendiendo a las clasificaciones temáticas que ofrecen los grandes servidores de acceso a la red. Según esta autora, se puede observar la presencia del turismo en Internet a partir de tres bloques:

- Las compañías de transporte y de los sistemas de distribución global.

- Las organizaciones turísticas públicas o de representación sectorial.

- Nuevas propuestas de información, comunicación y marketing turístico, incluyendo las divisiones especializadas de las consultoras de negocio y las aportaciones individuales que facilita la propia web, como las listas de distribución de news especializados.

\footnotetext{
${ }^{90}$ Véase Sheldon (1997). Su modelo de flujos de información ilustra la amplitud y la variedad de fuentes y formas de información que se produce en la industria turística.
} 
Si nos centramos en el texto turístico, Internet ofrece al sector turístico la posibilidad de ofrecer su información turística y de promoción de modo ágil y con posibilidad de modificación y actualización en todo momento. Según Majó y Galí (2000), actualmente la principal herramienta que se usa, y por tanto, el texto y subgénero turístico que tiene mayor presencia y relieve en Internet es el folleto electrónico (Majó y Galí, 2000:23):

Actualmente la principal herramienta que se usa son los folletos que comportan un elevado coste de impresión, la dificultad de modificación/actualización y la dificultad, a menudo, de su distribución.

Otra de las ventajas que tienen los folletos electrónicos frente a los tradicionales es que, gracias al canal y al propio proceso de localización, no nos hace falta determinar tan claramente cuál será el mercado objetivo, pues potencialmente nos encontramos delante de un mercado global.

Debemos destacar en este punto la ausencia de bibliografía en el entorno académico por lo que respecta a la localización de textos web. De nuestra búsqueda de documentación y bibliografía sobre localización turística hemos podido localizar escasa literatura que se ocupe de la localización del texto turístico. Todavía menor es la existencia de investigación sobre localización de la cultura en el texto turístico.

Resulta de gran interés para nuestra investigación un artículo que trata sobre la localización del género estrella en turismo, el folleto turístico. En este artículo Localisation and Tourist Brochures, su autora Tine Kristensen (2002) realiza un estudio de la localización de folletos turísticos pertenecientes a una campaña de promoción turística institucional en Dinamarca. El objetivo de la campaña era el de generar una nueva imagen del país para hacerlo más atractivo a los turistas de diversos países europeos por lo que se editaron folletos en inglés, finlandés, francés, alemán y español. 
De la investigación traductológica Kristensen deduce que algunos elementos en el folleto español son traducción desde el inglés. La autora pone el ejemplo de la traducción de campos de maíz (maize fields), mientras que el texto inglés indica corn fields. Maize $e^{91}$ es un tipo de cultivo impropio de Dinamarca, mientras que los cereales como el trigo y la cebada sí lo son.

Asimismo, la autora constata la apreciación de Esselink (2000a:45) por la que en la práctica de la localización se suelen agrupar las lenguas en grupos separados. Según Kristensen las diferencias entre los dos grupos de lenguas que esta autora observó venía determinada "in terms of markets and translation procedures" (Kristensen, 2002:195). De este modo, los textos localizados de un mismo grupo mostraban características comunes.

Lo que para Kristensen resultó más revelador fue el hecho de que en la fase de internacionalización de los textos, aquella en la se desnuda al texto eliminando la información y valores culturales, el texto que se generó fue un texto en lengua inglesa que posteriormente se localizó también y se redirigió hacia el mercado británico. El texto inglés, pues, funcionó en este caso como texto internacionalizado. Dollerup (2004:10) indica a este respecto que "es necesario revisar los actuales conceptos en traductología" ${ }^{\prime \prime 2}$, y acuña el término de vanishing original, para referirse a este nuevo fenómeno en traducción por el cual la traducción cada vez está más cerca a la producción del TO.

El proceso de internacionalización de textos turísticos, según Kristensen, en realidad, elimina las características culturales conformando un nuevo texto

\footnotetext{
${ }^{91}$ El Oxford Dictionary online define maize como a Central American Plant which yields large grains (corn or sweetcorn) set in rows on a cob.

92 Conceptos tradicionales de texto de partida y texto de llegada como dos elementos separados y dentro del mismo proceso traductor
} 
impersonal y global. Sin embargo, la cultura que acaba subyaciendo en los textos una vez internacionalizados es la cultura y la visión occidentales:

In localisation, culture is normally used as an umbrella term for elements and features that a translator masters and is fully cognizant of. This attitude implies that culture can be introduced or removed at will from a text. This concept of culture also implies that culture-free texts can be produced eliminating all deviations from a global standard. But this attitude disregards the fact that most so-called "internationalized texts" typically subjected to localization are written in accordance with Western standards (...). In other words, these de-nationalised texts continue to conform to Western cultures and relate to Western technological products. (Kristensen, 2002:199-200).

Kristensen establece también una clara diferenciación entre los textos impersonales (manuales e instrucciones) y los textos culturales (entre ellos, el texto turístico). Estos últimos "requieren un cuidado especial en el proceso de localización debido a la complejidad misma derivada del concepto de cultura $^{\prime \prime 93}$ (Kristensen, 2002:204) y se pregunta si es posible internacionalizar y eliminar el sustrato cultural de estos textos tan enraizados en sus culturas. Concluye indicando que la localización es un proceso complejo en el que el localizador debe tener una competencia cultural importante de la cultura de destino y que es difícil internacionalizar y estandarizar un texto culturalmente. También establece que en el proceso de localización el texto cultural está expensas del localizador, puesto que la localización es un proceso arbitrario y en muchos casos depende del conocimiento y la visión cultural del localizador.

Cerdá Redondo (2001) en su artículo Tourism Industry and Translating Technology analiza los problemas que presentan las páginas web traducidas automáticamente destacando que en muchos casos el TM es absurdo o ambiguo. Esta autora establece que la causa principal de este fenómeno tan

\footnotetext{
${ }^{93}$ Traducción propia
} 
habitual es la rapidez con la que se demandan las traducciones turísticas en la red:

Because of this urge to advertise the tourism product as fast as possible before it perishes, many of these companies are probably more interested in solving the problem of the difference in language than in providing a correct translation. These errors may difficult the effective transmission of information and the prospect customer could be lost (Cerdá Redondo, 2001:178).

A modo de recapitulación, en esta sección dedicada a la traducción del texto turístico hemos podido observar que la traducción de este tipo de textos requiere de un mediador especialista y profesional en la materia, que necesariamente ha de ser bicultural y que, además, debe ser capaz de localizar y enfrentarse a los requisitos añadidos que comporta la traducción de este tipo de textos en Internet. Por otro lado, existe un creciente interés investigador en el texto turístico, pero no abundan los estudios exhaustivos y aquellos existentes se centran en la paupérrima calidad que presentan. 


\section{ANÁLISIS DE LOS CULTUREMAS EN EL TEXTO TURÍSTICO}

\subsection{Metodología}

En el primer capítulo de esta investigación hemos revisado los elementos principales que condicionan la cultura y su íntima vinculación con la lengua y los hemos contextualizado en el texto turístico, un género que no facilita el estudio traductológico debido a su variedad y multitematicidad. Asimismo, hemos encuadrado la categoría textual denominada texto turístico como tipología textual independiente.

Por otro lado, hemos observado cómo los estudios de traducción han ido abandonando la teoría lingüística de la traducción como punto de partida para tomar en consideración la cultura como elemento último en la tarea traductora y considerar la traducción como un acto de comunicación intercultural complejo y fruto de ello, han ido surgiendo distintas categorizaciones de las denominaciones de los elementos culturales y de las estrategias de traducción existentes disponibles. Finalmente, y dada la importancia del turismo en España, pues esta industria constituye, desde el punto de vista profesional, "un área tan importante como las áreas clásicas de traducción, por ejemplo, la traducción de textos jurídicos, socioeconómicos y técnicos" (De la Cruz Trainor, 2003:10), hemos proporcionado las principales claves del sector turístico en España ligando esta actividad a la traducción de la promoción turística.

Al final de nuestro recorrido del primer capítulo confluyen cultura, lengua, turismo y mediación. Es en este punto en el que nos disponemos a abordar un análisis cuya metodología describimos en detalle a continuación. 
Partimos de la base de que consideramos que existe un culturema en español que posee un contenido cultural determinado y que ha de ser transferido al turista anglófono o lector en inglés. Nos alejamos así del vetusto concepto de equivalencia por el que la traducción se lleva a cabo únicamente a través de la comparación entre palabras de dos textos. Como indica Moya (2007:125), "en un TT siempre habrá múltiples interferencias del sistema terminal, prueba del algodón de que el traductor a la hora de configurar una traducción no se sirve exclusivamente del TO como modelo".

Tras la confección de nuestra selección de culturemas se analizarán los procedimientos del trasvase de la cultura y se identificarán aquellos mecanismos utiliza el mediador cultural para la transferencia de la información. La mediación que se lleva a cabo en estas guías se produce conectando el mediador y el lector, de modo que ambos comparten cultura pero la cultura de destino (en este caso, la española) es para ambos el elemento foráneo, lo que nos permite, desde nuestra visión cultural española, describir y analizar en los aspectos más relevantes que influyen en la mediación intra e intercultural. La investigación traductológica se enmarca, pues, dentro de la categoría que Jakobson (1959) denomina interlingual, o traducción propiamente dicha. ${ }^{94}$

Así pues, nuestro análisis se inicia tomando como base los postulados de Holmes, quien defiende en 1972 que, como disciplina empírica, la traducción debe superar dos fases: la primera consiste en describir los fenómenos del traducir y de las traducciones, que comprende en este punto la doble vertiente que supone la traducción como proceso y como producto (Bell, 1991); y la segunda, que consiste en establecer principios y generalidades que puedan

\footnotetext{
94 Jakobson (1959) considera que existen, además de la traducción interlingual, la traducción intralingual, que concibe como proceso de reescritura, y la traducción intersemiótica, que consiste en la interpretación de signos verbales a través de un sistema de signos no verbal.
} 
explicar estos fenómenos al tiempo que predecirlos. Holmes distingue así dos áreas principales dentro de la traducción, un área que denomina pura, y otra aplicada. En el área pura encontramos una subdivisión que incluye la descripción de las traducciones desde tres puntos de vista diferentes: el análisis de la traducción como producto, el análisis de la función de la traducción y, por último el análisis del proceso traductor. Esta división queda reflejada en el siguiente cuadro.

Figura 14: Clasificación de la traductología según Holmes, 1972/1988

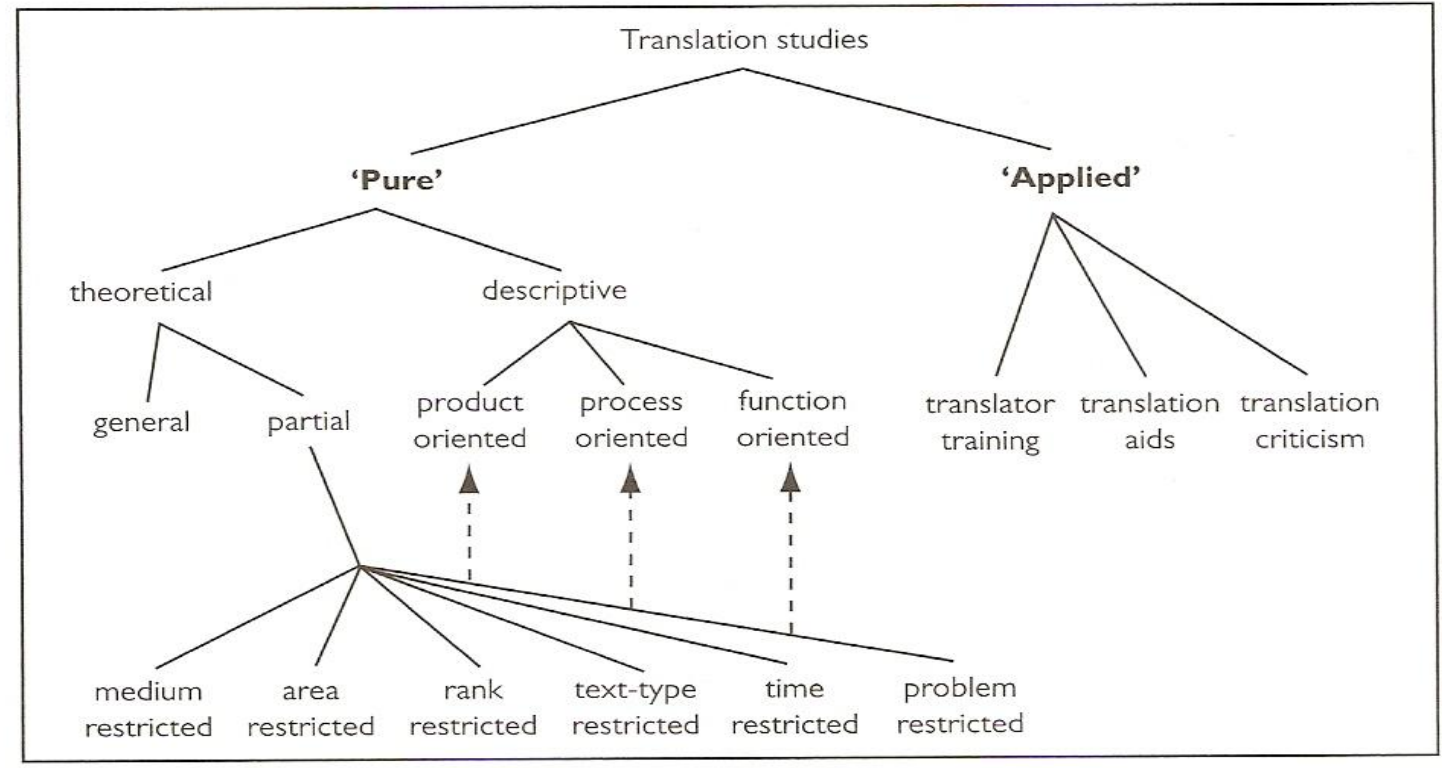

Nuestro trabajo se centra, pues, según los postulados de Holmes (1972/1988), en la parte más pura del estudio de la traducción y en la descripción enfocada al proceso, a aquello que ocurre en la caja negra del traductor, quien se aproxima a un tipo textual determinado, en nuestro caso, el texto turístico.

En las siguientes secciones se da cuenta de la metodología empleada y del modelo de análisis, incluyendo el proceso de selección de los elementos de análisis para la creación del corpus textual y su posterior estudio traductológico. 


\subsubsection{Diseño del corpus y modelo de análisis}

Nuestra investigación se fundamenta en el análisis de las técnicas de traducción de los culturemas propios de distintas regiones de la cultura española extraídos de una selección de culturemas procedentes de las guías Lonely Planet en lengua inglesa. Para nuestro análisis tomaremos como referencia el listado de técnicas de traducción de Molina y Hurtado (2002) (cfr. 2.6.7). Esta taxonomía servirá de base para nuestro análisis de las técnicas de traducción de los culturemas seleccionados y nos permitirán identificar, denominar y clasificar las técnicas elegidas por el traductor para las unidades turísticas microtextuales. Como indica Hurtado (2001:257):

Las técnicas sirven como instrumentos de análisis para la descripción y comparación de traducciones (...) y permiten identificar, clasificar y denominar las equivalencias elegidas por el traductor para microunidades textuales, así como obtener datos sobre la opción metodológica utilizada.

Debemos insistir en este punto en el carácter absolutamente descriptivo que tiene esta clasificación y su valoración en el contexto propio en el que aparece cada uno de los culturemas para poder ser analizados junto con la técnica empleada en una situación concreta de mediación.

A nuestro juicio, la clasificación de Molina y Hurtado es completa, sencilla, y

clara frente al resto de clasificaciones existentes, llenas de salvedades y confusiones entre técnica y denominación de la técnica. Elegimos también esta clasificación porque las denominaciones que utilizan estas autoras son muy definitorias del mecanismo procesual de la técnica en cuestión.

La hoja de ruta del análisis incluye los pasos que a continuación se describen.

Paso 1. Creación de una ficha de trabajo para la extracción de los culturemas. Para la sistematización de la información y la elaboración del corpus, se confeccionó una ficha de datos que contiene las siguientes secciones: 
- Código de guía. A cada guía (destino turístico) se le asigna un código de modo que pueda utilizarse para el posterior análisis de datos y facilitar su tratamiento. Así pues, las codificaciones que se emplean en esta investigación para hacer referencia a las distintas guías son las siguientes:

Tabla 14: Codificación de las guías Lonely Planet

\begin{tabular}{|l|l|}
\hline Título de la guía & Código \\
\hline Lonely Planet Valencia & LPVLC \\
\hline Lonely Planet Andalucía & LPA \\
\hline Lonely Planet Barcelona & LPBCN \\
\hline Lonely Planet Madrid & LPM \\
\hline Lonely Planet Mallorca & LPMLL \\
\hline
\end{tabular}

- Descripción de guía. Indica el nombre de la guía turística de donde se ha extraído el culturema y que queda asociado al código de guía al que corresponde.

- Elemento de análisis. Es el campo en el que se introducen los culturemas identificados y que conforman el corpus de la investigación.

- Tipología. Refleja el tipo de elemento que se ha extraído. Puede tratarse de un culturema, una marca turística o una palabra globalizada.

- Campo semántico. Otro campo de especial significación es el de campo semántico. Con este campo pretendemos acotar a qué ámbito cultural o subespecialidad dentro del turismo pertenece el culturema identificado, pues el texto turístico presenta temáticas muy variadas y diferentes entre sí. En este se establece la temática en la que se agrupa el culturema con otros culturemas relacionados. Para nuestra investigación se ha tomado como base la taxonomía de campos semánticos de Alcaraz Varó en su 
Diccionario de Términos de Turismo y Ocio (2006) y se ha adaptado teniendo en cuenta la finalidad de esta investigación.

La clasificación derivada que proponemos teniendo en cuenta los objetivos de nuestra investigación es la siguiente:

- alojamiento

- arquitectura

- artesanía

- escultura

- fiestas y espectáculos

- gastronomía y restauración

- historia

- música

- paisaje y geografía

- pintura

- viaje

Nuestra taxonomía no incluye, a diferencia de la de Alcaraz Varó, las categorías de arte ni arte/cultura. Puesto que esta investigación tiene por objetivo el estudio de la cultura, se ha considerado necesario establecer una subdivisión independiente para crear varias categorías relacionadas con la cultura, como son: arquitectura, escultura, música, pintura y que adquieren así mayor preponderancia al ser tratadas como campos semánticos y posibilitan su estudio de modo individual. Se ha añadido también la categoría de historia por el elevado número de referentes culturales de contenido histórico que aparecen en las guías y que hacen necesario la creación de un campo semántico propio. Asimismo, la categoría que Alcaraz Varó denomina espectáculos pasa a ser en nuestro 
trabajo fiestas y espectáculos y recoge todas aquellas manifestaciones artísticas y culturales, además de eventos relacionados, que se producen en torno a una cultura.

El campo semántico restauración pasa a denominarse gastronomía y restauración, pues entendemos que, en el contexto de esta investigación, el vocablo gastronomía refleja una conexión directa con la cultura y las prácticas culinarias y platos típicos de una sociedad determinada. Del mismo modo, el descriptor paisaje y geografía sustituye a paisaje en nuestro trabajo, pues con esta doble referencia hacemos referencia directa no sólo aquellos elementos típicos que conforman nuestro panorama, sino también aquellos elementos geográficos y situacionales típicos de las ciudades españolas.

Por último, debemos señalar que hemos omitido las categorías clima, deportes, derecho, gestión, juego, marketing, y seguros, pues responden a terminología propia del lenguaje turístico pero no resultan relevantes para la conformación de nuestro corpus de culturemas en guías turísticas, por el escaso número de culturemas que presentan. Son, no obstante, categorías semánticas óptimas para el estudio terminológico del texto turístico, por la abundancia de términos propios que presentan.

- Contexto. La categoría contexto incluye el fragmento textual en el que está inserido el culturema. Se trata de la manifestación lingüística de la que se parte para realizar el posterior análisis a nivel microtextual.

- Técnica de Traducción 1, 2 y 3. En estas secciones se sistematizan las técnicas de traducción que el mediador ha realizado para la transmisión del contenido cultural del culturema de modo individual, es decir, las 
ocurrencias de cada una de las técnicas de traducción de modo aislado, sin tener en cuenta su combinación con otras técnicas.

- Técnica de traducción: refleja la combinación de técnicas usadas para la transferencia del culturema, ya sea en doblete o triplete.

A continuación reproducimos la ficha de trabajo utilizada para la conformación del corpus:

Tabla 15: Ficha de trabajo

\begin{tabular}{|c|c|c|c|c|c|c|c|c|c|c|}
\hline $\begin{array}{l}\text { Código } \\
\text { Guía }\end{array}$ & Guía & Provincia & \begin{tabular}{|c|} 
Elemento \\
análisis
\end{tabular} & Tipología & $\begin{array}{c}\text { Campo } \\
\text { semántico }\end{array}$ & Contexto & Técnica 1 & Técnica 2 & Técnica 3 & $\begin{array}{c}\text { Técnica } \\
\text { combinada }\end{array}$ \\
\hline & & & & & & & & & & \\
\hline
\end{tabular}

Paso 2. Vaciado de culturemas en contexto, categorización y clasificación por campos semánticos. El segundo paso tras el vaciado de culturemas es la categorización de los mismos. Las categorías existentes son culturema, marca turística y palabra globalizada.

De la lectura previa al análisis se ha podido apreciar que muchas unidades léxicas que a priori no parecen culturemas, sí contienen en mayor o menor medida algún tipo de sustrato cultural. En algunos casos, la carga cultural es parcial, como por ejemplo en el culturema museo taurino. Un museo es una realidad que no es propia de ninguna cultura en concreto, sino que es una realidad global; sin embargo, un museo taurino es una realidad perteneciente cultural española. En otros casos, la carga cultural es completa, como en corrida de toros. Es por este motivo que hemos decidido considerar también los elementos culturales con carga cultural parcial. En otros casos, los culturemas objeto de análisis resultan ser nombres propios (antropónimos, topónimos, nombres de accidentes geográficos, etc.) que están enraizados en la cultura a la que representan, pero que en ocasiones, son conocidos universalmente y 
poseen una clara equivalencia en la cultura de llegada (como por ejemplo Cristóbal Colón). Los elementos realia con información cultural genuinamente española son los elementos que resultan de mayor interés para nuestro estudio pues, al ser propios de una cultura ajena a la del mediador, requieren un conocimiento cultural por parte del mismo para poderlos transmitir.

El concepto de culturema se ha desarrollado a lo largo del capítulo 2 de esta investigación, y hemos hecho referencia al concepto de marca turística (cfr. 3.1.2), con el objetivo de estudiar el uso de las técnicas de traducción existentes para esta tipología de elementos léxicos del texto turístico. La tercera categoría textual que hemos introducido la hemos denominado palabra globalizada y surge de la observación de un reducido grupo de préstamos léxicos que registran una alta frecuencia de aparición y repetición en las distintas guías turísticas y que son los culturemas por excelencia de la cultura española, pues son los iconos indispensables que identifican a España fuera de sus fronteras.

\section{Paso 3. Asociación de técnica o técnicas de traducción para cada culturema.}

Tras la identificación del culturema, su categorización y clasificación en el campo semántico pertinente, se procede a establecer la técnica o técnicas de traducción que intervienen en el proceso de transferencia cultural de cada uno de los elementos culturales. El modelo de Molina y Hurtado (2002) de técnicas de traducción (cfr. 2.6.7) se ha tomado como base para la confección de la lista de técnicas de traducción y el uso de la terminología de los procedimientos traslatorios. Esta tercera fase ha resultado ser la más ardua por la dificultad que entraña el establecimiento de la técnica de traducción para cada culturema. En algunos casos, como por ejemplo la técnica de la amplificación lingüística, la amplificación sirve no sólo para describir un elemento cultural que es desconocido, sino también como recurso discursivo propio del texto descriptivo- 
narrativo típico de las guías turísticas. Como indica Hurtado (2001:267), en estos casos "Ias técnicas pueden funcionar como técnicas y estrategias".

A continuación se reproduce, a modo de ejemplo, la ficha de trabajo del culturema trencadís, una vez completadas todas las fases de sistematización de la información del culturema y las técnicas de traducción utilizadas.

Tabla 16: Ejemplo de ficha de trabajo (culturema trencadís)

\begin{tabular}{|c|c|c|c|c|c|c|c|c|c|c|}
\hline $\begin{array}{l}\text { Código } \\
\text { Guía }\end{array}$ & Guía & Provincia & $\begin{array}{c}\text { Elemento } \\
\text { análisis }\end{array}$ & Tipología & $\begin{array}{c}\text { Campo } \\
\text { semántico }\end{array}$ & Contexto & Técnica 1 & Técnica 2 & Técnica 3 & $\begin{array}{c}\text { Técnica } \\
\text { combinada }\end{array}$ \\
\hline LPVLC & $\begin{array}{l}\text { Lonely Planet } \\
\text { Valencia }\end{array}$ & Valencia & trencadís & culturema & arquitectura & $\begin{array}{l}\text { Beyond it, the Palau de les Arts Reina } \\
\text { Sofia, the most imposing structure, its } \\
\text { shell shimmering with bright, white } \\
\text { trencadis (slivers-of-broke-tile-mosaic) } \\
\text { resembles a supine armadillo. }\end{array}$ & amplificación & préstamo & & $\begin{array}{l}\text { amplificación+ } \\
\text { préstamo }\end{array}$ \\
\hline
\end{tabular}

Paso 4. Obtención de datos y análisis de las técnicas de traducción. La última fase del análisis comprende la obtención de datos y el posterior análisis traductológico de las técnicas de traducción. Este análisis incluye en primer lugar, un estudio cuantitativo de la frecuencia de uso de las técnicas de traducción; seguidamente, se realiza un análisis de las técnicas utilizadas en cada uno de los campos semánticos seleccionados y se ofrecen los resultados acerca del modo en el que se transmite el contenido cultural.

\subsubsection{Descripción del Corpus: Las guías Lonely Planet}

Podemos situar los inicios de la empresa Lonely Planet a principios de la década de 1970 , en la que se respiraba una atmósfera de libertad que hizo que algunos valientes y aventurados pioneros emprendieran el camino. Durante un año, Maureen y Tony Wheeler atravesaron Asia acabando su periplo en Australia y lo hicieron sin un céntimo en el bolsillo. Los innumerables consejos que la gente les pidió se convirtieron a su regreso en la guía Across Asia on the Cheap 
(Atravesar Asia con poco dinero) ${ }^{95}$. Los 1.500 ejemplares editados artesanalmente resultaron todo un éxito y les motivó para partir de nuevo en expedición y publicar South-East Asia on a Shoestring (El sudeste asiático para presupuestos reducidos) $)^{96}$. Se vendieron 800.000 ejemplares de esta guía, bautizada como la biblia amarilla por sus admiradores. Éste fue el comienzo de la colección, que en la actualidad abarca el mundo entero. Lonely Planet se ha convertido en la mayor editorial independiente de viajes, una empresa internacional con delegaciones en Australia, Estados Unidos y Reino Unido. Las guías Lonely Planet se traducen actualmente a 11 idiomas.

Cuando compramos una guía lo hacemos entendiendo que estamos pagando por información de primera mano con un alto valor añadido, que es el de la experiencia del autor. El horario de un autobús se puede encontrar en Internet. Sin embargo, no ocurre así con muchas de las experiencias sensoriales asociadas intrínsecamente a los viajes. Las guías Lonely Planet están consideradas las más prestigiosas y destacadas del mercado precisamente por este motivo, porque acercan al viajero aspectos experienciales por parte de autores que no comparten la cultura ni las costumbres de las sociedades de destino. El hecho de que exista una publicación Lonely Planet de un destino turístico concreto eleva exponencialmente las posibilidades de que la ciudad, región o país en cuestión sea elegido como destino turístico. En enero de 2011 se anunció que la ciudad de Granada tendrá una guía Lonely Planet, con lo que se convertirá en la cuarta ciudad española, tras Madrid, Barcelona y Valencia, en contar con una publicación en exclusiva de esta colección de guías de viajes del mundo.

\footnotetext{
${ }^{95}$ Traducción propia.

${ }^{96}$ Traducción propia.
} 
Las Lonely Planet son las guías de viaje más reconocidas en todo el mundo también por su trayectoria y su clara posición dominante en el mercado. En 2010 se publicó la guía número 100 millones y su catálogo internacional abarca más de 500 títulos publicados en siete idiomas, entre ellos el castellano. Se trata de guías destinadas al viajero independiente, famosas en todo el mundo por su fiabilidad, meticulosidad y rigurosa información, sus mapas, fotografías y sus referencias históricas y culturales. Además, las guías se actualizan periódicamente, en su mayor parte cada dos años.

Los autores de Lonely Planet son entusiastas y experimentados viajeros independientes al acecho de informaciones interesantes y útiles así como de detalles curiosos sobre los destinos que cubren. Tienen como principal objetivo que los viajeros puedan realizar sus propios descubrimientos. Sus métodos de investigación no se basan en extraer información por teléfono o vía Internet, y se precian de ser completamente independientes en sus valoraciones. Viven temporal o permanentemente en el país y visitan personalmente miles de hoteles, restaurantes, cafés, bares, galerías, palacios, museos y se enorgullecen de conocer y transmitir fielmente cada detalle.

Desde hace diez años GeoPlaneta (que pertenece a la editorial Planeta) traduce y adapta para el mercado español y latinoamericano las guías de viaje Lonely Planet $^{97}$, organizadas en las colecciones siguientes:

- Guías de país

- Guías de ciudad

- Guías de región

\footnotetext{
${ }^{97}$ Planeta es el distribuidor de las guías Lonely Planet en inglés e italiano para todo el territorio de habla hispana.
} 
- Para mochileros

- De cerca

- Lo mejor de

- Itinerarios

- Guías de conversación.

En los diez años de Lonely Planet en España, GeoPlaneta ha publicado guías de casi 150 destinos, ha diversificado y modificado las colecciones adaptándolas a las peticiones de los viajeros y ha desarrollado una web que cuenta con una extensa y activa comunidad de visitantes.

En la actualidad Lonely Planet afronta el reto de adaptarse para sobrevivir a la era digital. Ya en 2007 Lonely Planet empezó a vender las guías desde su página web a precios módicos. Así, el viajero escoge capítulos individuales de sus guías de viajes, los descarga en formato pdf y puede colocarlos en el orden deseado. De este modo, el lector puede confeccionar una guía personalizada, hecha a medida de sus intereses y preferencias. Un ejemplo es la edición digital de guía de Estados Unidos que incluye 16 capítulos correspondientes a las grandes áreas del país, además de una introducción histórica general y un directorio ${ }^{98}$. Asimismo, se comercializan otros títulos impresos o digitalizados relacionados con la temática escogida. Este sistema ofrece la compra de capítulos individuales de cerca de 100 guías de viajes de países y áreas de todo el mundo: África, Canadá, el Caribe, América Central, México, América del Sur, el Pacífico Sur y Nueva Zelanda y los Estados Unidos de América.

\footnotetext{
98 El precio de cada capítulo varía según el número de páginas (Nueva Inglaterra, 78 páginas 3,75€,
} Tejas, 50 páginas 2,50€, Hawai, 26 páginas $1,25 €)$. 
En 2008 Lonely Planet firmó un acuerdo con Nokia Maps para integrar vender sus guías como complemento a los datos y mapas de los sistemas de posicionamiento global. En 2010 Lonely Planet lanzó sus guías Discover (Lo mejor de en su versión en castellano) para el iPad. Actualmente estas guías están disponibles en iBookstore y permiten tomar notas interactivas, consultar mapas con señalizaciones, buscar contenidos en Wikipedia o Google y contienen más de 3.000 hipervínculos. Inspiradas en la serie Discover (Lo mejor de) de guías en color, la versión en formato de libro electrónico permite a los viajeros a descubrir los lugares de visita obligada y los puntos de interés turístico.

Las nuevas guías electrónicas de Lonely Planet son una herramienta interactiva donde se señalan los lugares que un viajero no debe perderse, permiten tomar notas durante el viaje, utilizar Google o Wikipedia para obtener más información, enviar emails o compartir sugerencias con los amigos y enlazar con hipervínculos para llegar directamente a la web de un hotel, restaurante o atracción turística. Además, las guías electrónicas Discover permiten a los usuarios de iPad acceder a las recomendaciones y experiencias de Lonely Planet a través de imágenes tomadas por fotógrafos de prestigio. Los itinerarios a medida por región, temática o duración del viaje ayudan a sacar el máximo partido al tiempo, mientras que los expertos locales ayudan a descubrir los secretos de cada destino. Estas sugerencias viajeras, experiencias y recomendaciones están dirigidas a todos los presupuestos, desde los más económicos hasta los viajes de lujo. Las guías incluyen más de 3.000 hipervínculos, mapas detallados con señalización de puntos de interés, imágenes de los lugares más emblemáticos, posibilidad de marcar páginas y 
tomar notas sobre los viajes y un motor de búsqueda para encontrar de manera exacta el contenido que se desea ${ }^{99}$.

En esta investigación del texto turístico, el foco se sitúa en la transferencia cultural presente en las guías de viajes, que, como también hemos abordado en el capítulo tercero, cuentan con unas propiedades discursivas y convenciones macrotextuales definidas en gran medida. Existen diversos tipos de guías ${ }^{100}$, si bien a diferencia de otros géneros turísticos, estas no presentan la misma variedad ni versatilidad.

El corpus ha sido creado partiendo de una serie de guías publicadas por Lonely Planet, que presentan las características descritas anteriormente. La elección de esta guía se debe al reconocido prestigio mundial que posee dicha publicación y al hecho de que sus mediadores son reconocidos internacionalmente como expertos en la cultura sobre la cual realizan la mediación. El corpus es, pues, homogéneo, si bien al frente a cada publicación están uno o varios mediadores diferentes. En el capítulo tercero hemos podido comprobar que España cuenta con una gran variedad de destinos turísticos y que atrae a una gran variedad de turistas. Es por este motivo que se han elegido para nuestro análisis las guías correspondientes a aquellos destinos en España que cuentan con mayor número de visitantes y que resultan más atractivos para el turista extranjero. Así, se han tomado como fuente para la configuración de nuestro corpus las siguientes guías Lonely Planet:

\footnotetext{
99 El lanzamiento incluye los cinco títulos europeos más populares: Gran Bretaña, Italia, España, Francia e Irlanda, a un precio de 15,99 €.

${ }^{100}$ Existen diversos tipos de guías turísticas que pueden centrarse en diversos aspectos del viaje, desde el viaje de aventura al viaje de relajación o estar dirigidas a viajeros con presupuestos más altos o más bajos. Otras se centran en intereses particulares y preocupaciones de ciertos grupos sociales. Del mismo modo, existen guías visuales que contienen gran cantidad de imágenes del destino y otras más enfocadas en las informaciones prácticas del viaje o las guías básicas de conversación.
} 
- Lonely Planet Andalucía 2007 (5a edición)

- Lonely Planet Barcelona 2008 (6a edición)

- Lonely Planet Madrid 2008 (5a edición)

- Lonely Planet Mallorca 2008 (1a edición)

- Lonely Planet Valencia Encounter 2010 (1a edición)

Resulta especialmente interesante la inclusión de las guías de Mallorca y Valencia, pues son guías, que a diferencia de los otros destinos, se editan por primera vez, por lo que no han superado las correcciones y revisiones de las primeras ediciones que ven la luz.

A continuación reproducimos los datos bibliográficos básicos de cada una de las guías y ofrecemos una captura de pantalla de las portadas:

Figura 15: Portadas de las Guías Lonely Planet

Título: Lonely Planet Andalucía

Editor: Lonely Planet, 2007

Edición 5, ilustrada

ISBN: 1740599733

№ páginas: 472

Autores: John Noble, Susan Forsyth,

Vesna Maric

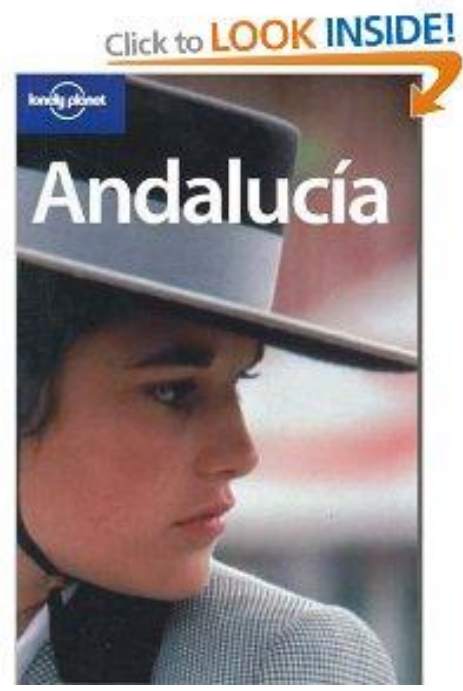


Título: Lonely Planet Barcelona Editor: Lonely Planet, 2008

Edición 6, ilustrada

ISBN: 1741048966

№ páginas: 308

Autor: Damien Simonis

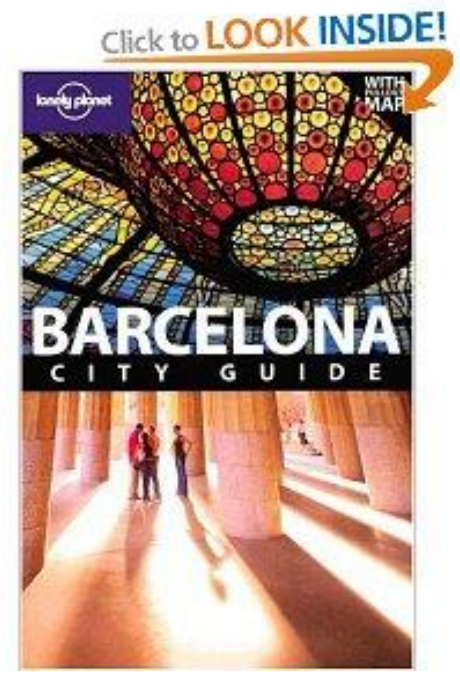

Título: Lonely Planet Madrid

Editor: Lonely Planet, 2008

Edición 5, ilustrada

ISBN: 9781741048957

№ páginas: 292

Autor: Anthony Ham

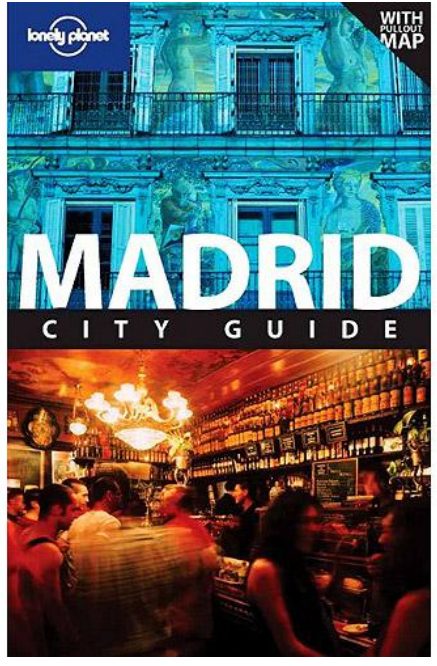

Título: Lonely Planet Mallorca

Editor: Lonely Planet, 2008

Edición 1, ilustrada

ISBN: 9781741790900

№ páginas: 244

Autor: Damien Simonis, Sarah

Andrews

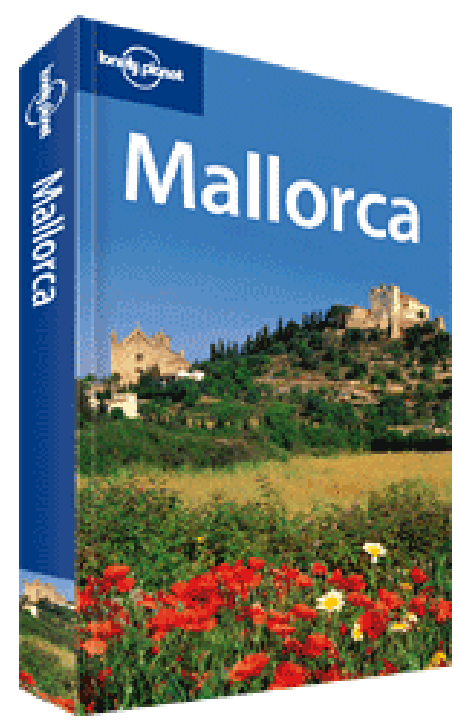


Título: Lonely Planet Valencia

Editor: Lonely Planet, 2010

Edición 1, ilustrada

ISBN: 9781741048131

№ páginas: 160

Autor: Miles Roddis

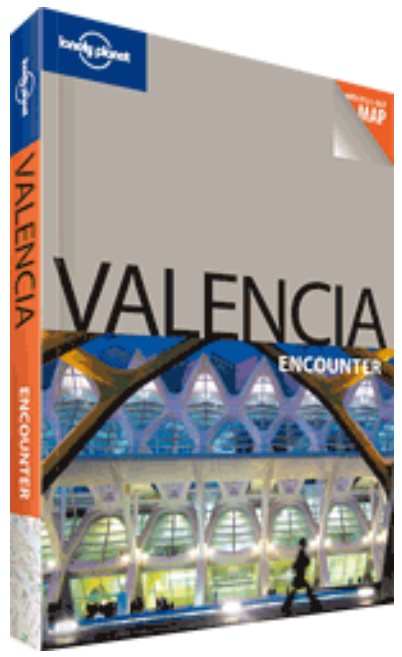

En cuanto a la estructura de las guías, todas ellas siguen un patrón de estructura similar. En primer lugar se ofrece la sección Getting Started, que correspondería a la información práctica destinada para el consumo antes de la experiencia turística. En este apartado destacan las secciones When to go, Costs and Money, Travel and Literature e Internet Resources para que el futuro turista pueda planificar mejor su viaje. En esta sección se ofrece también un resumen de atracciones y/o itinerarios y de Fast facts, así como las reseñas y el biodata de los autores.

A continuación se realiza una breve introducción del destino turístico, que en algunas guías (LPBCN) se acompaña de fotografías. Seguidamente se ofrece la sección Highlights, que normalmente se resumen en un cuadro esquemático. A continuación suele aparecer un mapa del destino turístico, en el caso de tratarse de una provincia, se ofrece tanto el mapa político de la provincia en cuestión además de un callejero de la capital de provincia. Suele ser frecuente también la inclusión de pequeños mapas relativos a zonas o barrios de las ciudades (LPBCN, LPA, LPVLC). 
Las diferentes secciones de las guías Lonely Planet no siempre siguen el mismo orden en todas las guías analizadas, pero sí se hallan presentes bajo los mismos epígrafes. En general encontramos las siguientes secciones:

- History: la información histórica suele indicar el origen de la ciudad o de la región en cuestión y los principales pueblos que lo han habitado a lo largo de la historia.

- Orientation: este apartado sirve para situar al lector y ofrecerle los puntos geográficos clave del destino turístico, que servirán como lugares de referencia y de orientación en sus visitas turísticas.

- Sights/Highlights: el grueso de la información turística dedicada al turismo monumental suele localizarse en esta sección. Algunas guías contienen apartados específicos dedicados a artes en concreto (Por ejemplo, LPBCN dedica una sección completa a Architecture).

- Information: en esta sección se incluye información práctica sobre librerías, emergencias, servicios médicos, oficinas de correos, etc.

- Sleeping: incluye la sección The author's choice, en la que se resaltan las bondades de un establecimiento hotelero por encima del resto según la opinión del mediador.

- Eating: Algunas guías tienen secciones propias como ocurre en la LPA bajo el epígrafe Food and drink .

- Entertainment: este apartado da cuenta de todos las actividades lúdicas y culturales, festivales y eventos que ofrece el destino turístico y, en algunos casos, incluye también el apartado drinking\&nightlife.

- Shopping: el mediador ofrece una selección de tiendas y establecimientos típicos de la zona donde el turista puede proveerse de artesanía y souvenirs, prestando especial atención a los mercadillos. 
- Drinking \& Nightlife: este apartado ofrece información sobre los bares y clubes más importantes de las ciudades y recomendaciones sobre la etiqueta y el tipo de público que suele frecuentarlos.

- Sports and Activities: los mediadores de las guías Lonely Planet no se olvidan de los lectores más intrépidos y suelen incluir información sobre actividades deportivas y al aire libre que permitan al mismo tiempo, descubrir el nuevo destino turístico.

- Excursions: esta sección ofrece información de las empresas que ofrecen tours y excursiones.

- Getting there \& away y Getting around: indica al lector cuál es el modo más cómodo de moverse desde, hasta y en la ciudad de destino y da pistas y recomendaciones útiles para el viajero.

- Guías de conversación: se trata de un pequeño anexo que suele acompañar a todas las guías, sea cual sea su tamaño. En la Guía Lonely Planet Spain (2009) este apartado se titula Language e incluye contenidos muy diversos: desde una guía de pronunciación española hasta un apartado de frases clave para viajar con niños.

- Glossary: colección de palabras de uso frecuente y de tipo práctico para el turista, así como algunos términos especializados del lenguaje turístico y otros culturemas desconocidos para el lector.

\subsection{Identificación y análisis de las técnicas de traducción de los culturemas}

A continuación procedemos a realizar un análisis exhaustivo de las técnicas de traducción que se han utilizado en el trasvase de los culturemas considerando otras variables que intervienen en el contexto traductor de estos elementos, 
como es el ámbito cultural en el que se inscriben. En primer lugar, se ofrece un análisis de la frecuencia de uso de las técnicas de traducción y a continuación el análisis de los elementos culturales en los distintos ámbitos temáticos establecidos.

\subsubsection{Frecuencia de uso de las técnicas de traducción}

Con el objetivo de conocer cuáles son las técnicas más usadas en la mediación cultural en turismo resulta de gran utilidad realizar un estudio cuantitativo de la frecuencia de uso de las técnicas de traducción. De este modo, podemos determinar qué técnicas son las preferidas por los mediadores para poder posteriormente aislarlas y analizarlas desde un punto de vista cualitativo.

En esta investigación se han identificado en total 713 culturemas pertenecientes a los diversos campos semánticos. A continuación mostramos el número total de técnicas de traducción que se han registrado en el análisis para la transmisión de la información cultural de todos culturemas identificados, bien utilizadas como única técnica o bien en combinación con otras.

Figura 16: Frecuencia de uso de técnicas de traducción (totales)

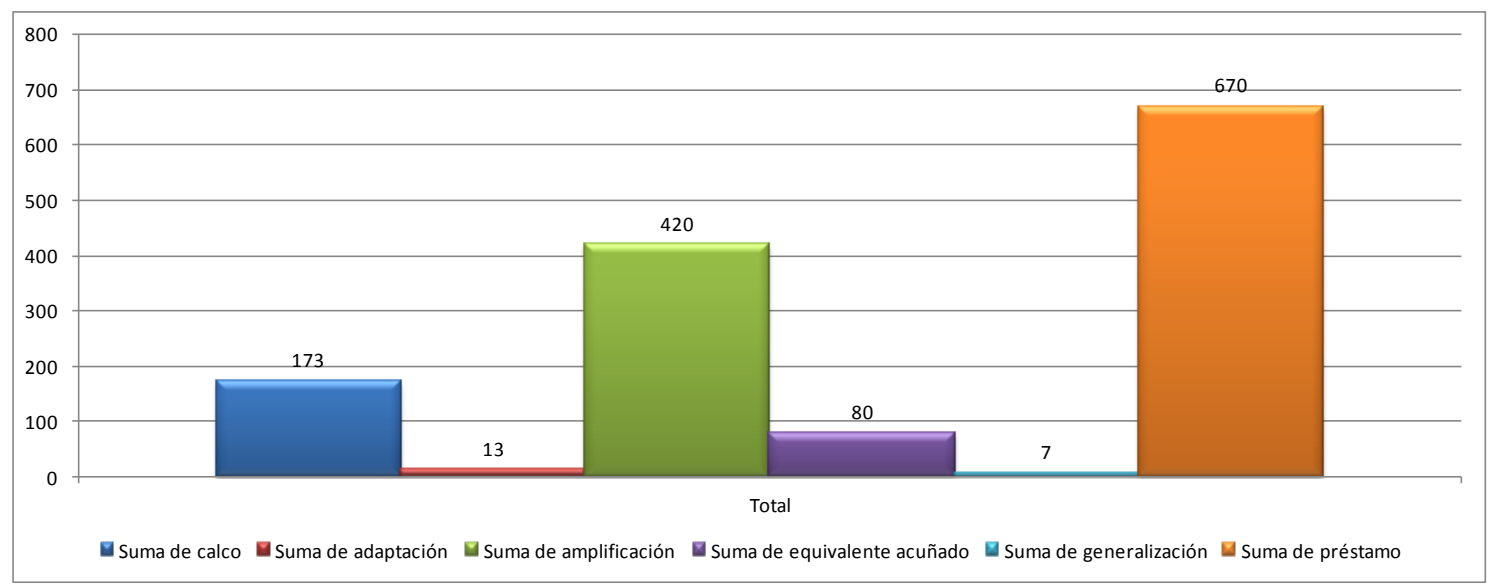


Del análisis traductológico se ha constatado el uso de las técnicas siguientes: el préstamo, el calco, la adaptación, la amplificación, el equivalente acuñado y la generalización. En la tabla se observa que el préstamo es la técnica más utilizada. De un total de 1.363 técnicas registradas (incluyendo el uso de técnicas tanto simples como usadas en combinación de dobletes o tripletes), en 670 casos, se ha aplicado la técnica del préstamo. En segundo lugar se halla la amplificación, con 420 ocurrencias, seguido del calco (173 ocurrencias) y el equivalente acuñado (80). Por último, señalamos la aparición casi anecdótica de técnicas como la adaptación (13 ocurrencias) y generalización (7 ocurrencias). Estos datos revelan a priori un marcado interés de los mediadores carácter por mantener el color local a través del uso del culturema de la cultura de origen en el TM.

A continuación mostramos la frecuencia de uso de las técnicas de traducción simples, es decir, todas las ocurrencias de técnicas de traducción que aparecen como una única elección de traducción para la transmisión del contenido cultural, sin aparecer combinadas con otras técnicas de traducción.

Figura 17: Frecuencia de uso de técnicas de traducción (simples)

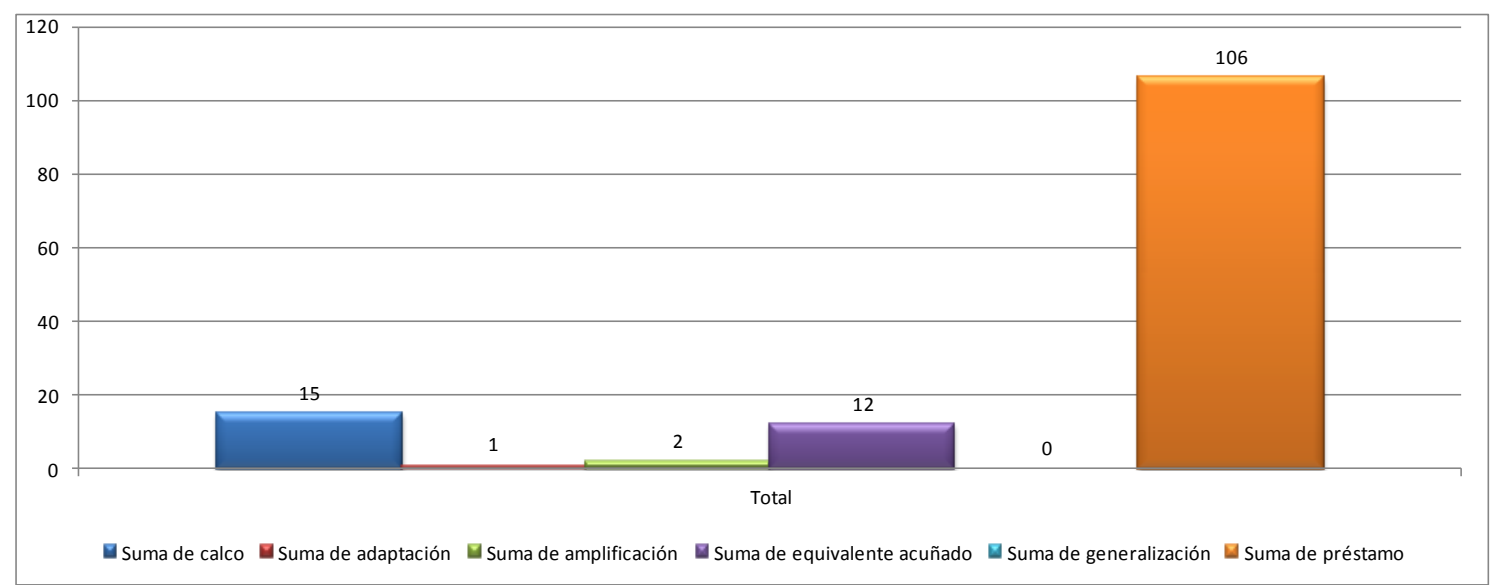


En los casos en los que el mediador ha optado por trasvasar el contenido cultural a través de una única técnica de traducción, el préstamo ha sido también la técnica más utilizada (cfr. figura 17). De un total de 136 técnicas usadas de modo simple, el préstamo ha sido con diferencia el más utilizado, mientras que el uso de otras técnicas queda relegado a un segundo plano.

A la luz de estos datos, la amplificación es una técnica que, como hemos podido observar en la gráfica anterior, se utiliza de forma continuada, pero no en ocurrencia única, es decir, suele aparecer en combinación con otras técnicas en doblete o triplete.

Por lo que respecta a las técnicas de traducción compuestas, se observa de nuevo (cfr. figura 18) que el préstamo es la técnica más utilizada en asociación con otras técnicas. Le sigue la amplificación, el calco, y el equivalente acuñado, por este orden.

Figura 18: Frecuencia de uso de técnicas de traducción compuestas

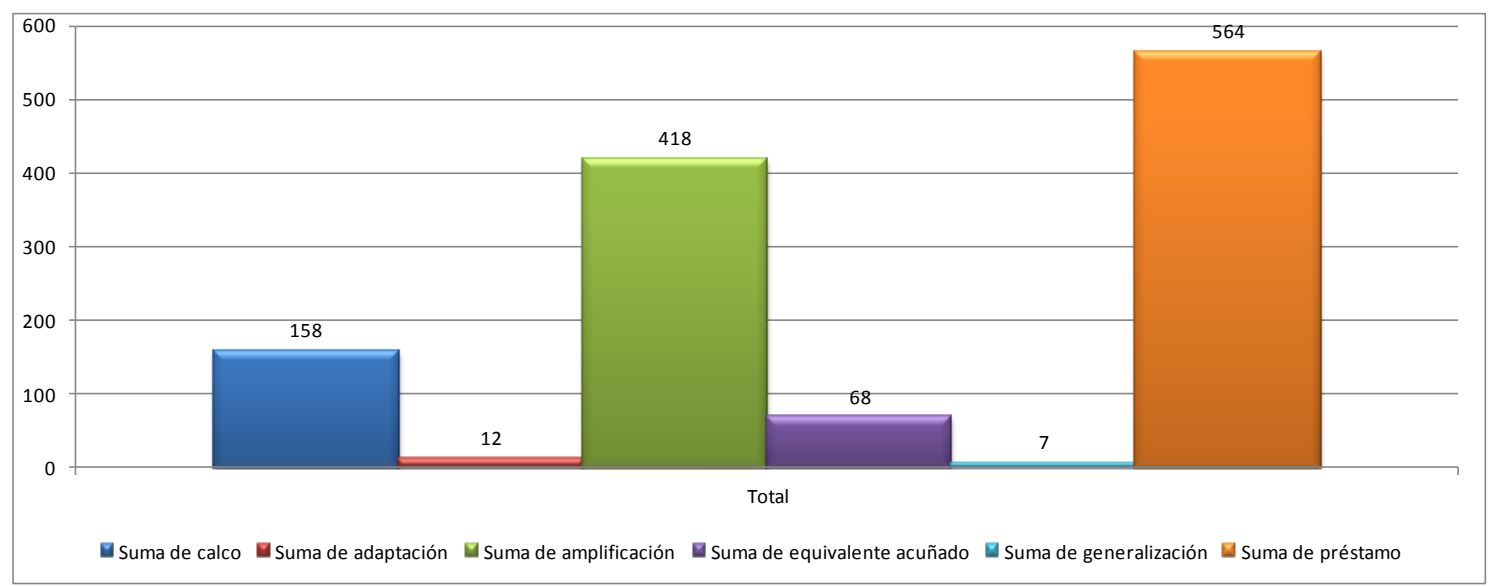


En total se han registrado 1.227 técnicas utilizadas en combinación con otras. Esta cantidad dista mucho de las 136 técnicas registradas como técnicas de traducción simples, por lo que podemos afirmar que, en general, se prefiere el uso de una técnica combinada antes que el uso de una única técnica para la traducción de los culturemas.

Si atendemos a los datos en porcentajes (cfr. figura 18), los diagramas de sectores muestran que en el caso de un uso combinado de distintas técnicas de traducción, en aproximadamente el 50\% de los casos el préstamo es una de las técnicas utilizadas, seguido de la amplificación, el calco y el equivalente acuñado.

Cuando el mediador opta por el uso de una única técnica de traducción el préstamo es la única opción en casi el $78 \%$ de los casos. El uso de la amplificación queda relegado a su utilización en técnicas combinadas. Destaca el uso del calco (11\%) como única opción para la traducción de un culturema por delante de la técnica del equivalente acuñado.

Figura 19: Comparativa de técnica de traducción simple/compuesta

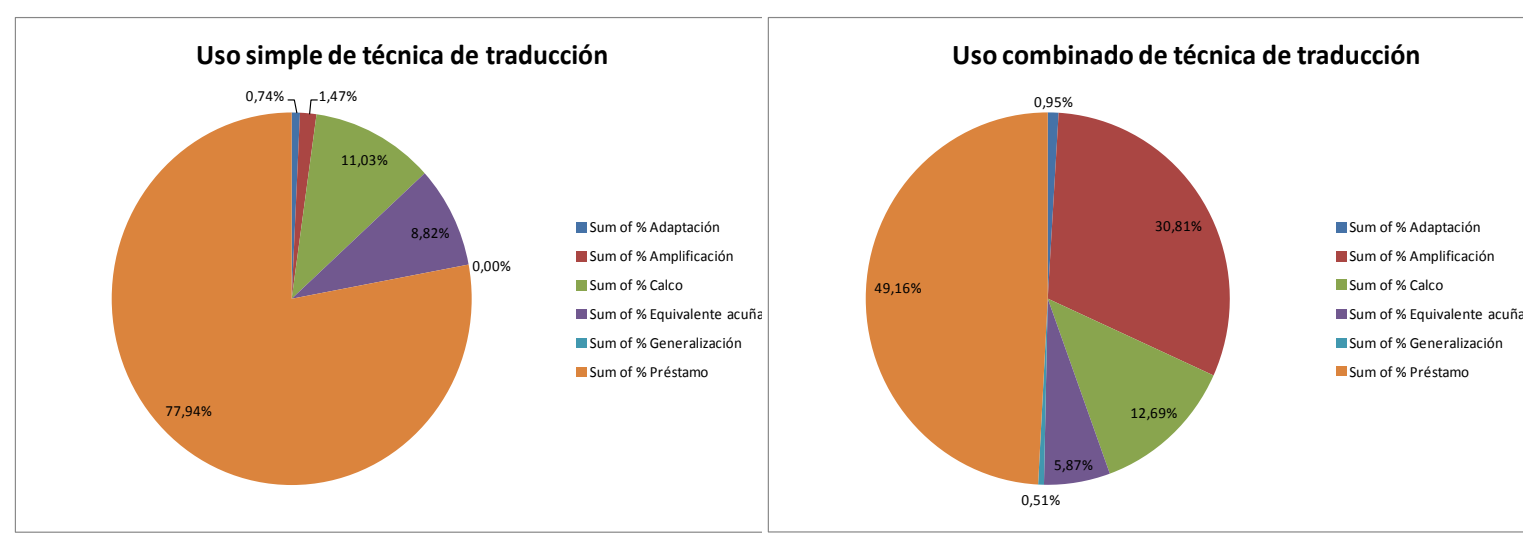

Los datos correspondientes a la frecuencia de uso que se han expuesto muestran claramente la preponderancia del uso del préstamo por delante del 
resto de técnicas, ya sea en su uso simple o en técnica combinada. La amplificación resulta ser una técnica muy productiva en este tipo de textos, y es la segunda más utilizada, si bien su uso queda restringido a la combinación con otras técnicas. El calco y el equivalente acuñado son otras técnicas que tienen un uso reseñable, mientras que la presencia de técnicas como la adaptación y la generalización es casi anecdótica.

El uso del préstamo por parte del mediador para la traducción de la información cultural refleja, pues, una intención clara de mantener el color local y de hacer partícipe con el culturema en LO de la nueva realidad al lector destinatario de la guía turística. El mediador presupone, en estos casos, un conocimiento cultural previo por parte del lector, quien, dependiendo de su nivel de conocimientos de la cultura foránea se verá obligado a realizar un esfuerzo adicional para desentrañar el significado del mismo.

A continuación se presentan los resultados del análisis de datos relativos al uso de las técnicas de traducción en los distintos campos semánticos analizados en esta investigación: alojamiento, arquitectura, artesanía, escultura, fiestas y espectáculos, gastronomía y restauración, historia, música, paisaje y geografía, pintura y viaje.

\subsubsection{Técnicas de traducción vs ámbito cultural}

El estudio de las técnicas de traducción por ámbitos culturales permite establecer cuáles son las técnicas utilizadas para cada uno de estos ámbitos. En las siguientes secciones ofrecemos un análisis de las técnicas de traducción de los culturemas enmarcados dentro de su propio campo semántico. 


\subsubsection{Alojamiento}

La traducción de los elementos culturales propios del ámbito cultural alojamiento se realiza a través de técnicas en doblete y técnicas simples. En primer lugar, destacamos el uso del doblete formado por amplificación y préstamo, como técnica fundamental para la traducción de estos elementos, mientras que la técnica simple del préstamo y la combinación de equivalente acuñado y préstamo son técnicas que se utilizan con una frecuencia menor, como se observa en la siguiente figura.

Figura 20: Técnicas de traducción del campo semántico alojamiento

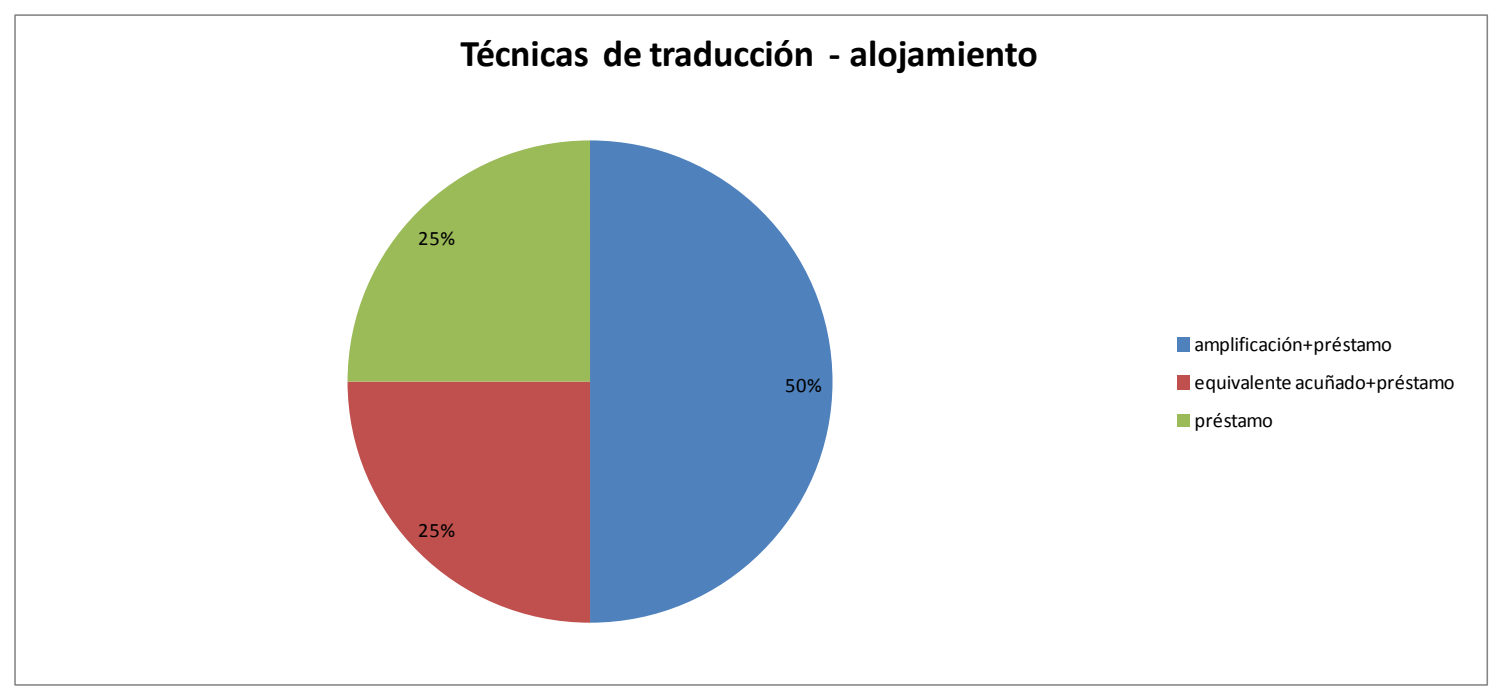

El campo semántico alojamiento alude a los lugares en los el turista puede alojarse, que pueden ir desde un clásico hotel hasta un camping. Este campo semántico proporciona al lenguaje una gran cantidad de términos propios del lenguaje turístico, pero también pueden observarse culturemas propios de la cultura como es el caso de posada. El Diccionario de la Real Academia Española define posada como "lugar donde por precio se hospedan o albergan personas, en especial arrieros, viajantes, campesinos, etc.", así como "casa de huéspedes" 
o "lugar donde acampa la tropa". Se hace, pues, referencia, al carácter histórico que poseen este tipo de instalaciones, que conservan, en muchos casos, la decoración y la estructura pertenecientes a una época determinada.

A continuación mostramos la ficha de análisis del culturema posada, extraído de nuestro corpus de culturemas:

Tabla 17: ficha de análisis del culturema posada

$\begin{array}{ll}\text { ID } & 153 \\ \text { CODIGO GUÍA } & \text { LPA } \\ \text { GUÍA } & \text { Lonely Planet Andalucía } \\ \text { PROVINCIA } & \text { Córdoba } \\ \text { ELEMENTO DE ANÁLISIS } & \text { posada } \\ \text { TIPOLOGÍA } & \text { culturema } \\ \text { CAMPO SEMÁNTICO } & \text { alojamiento } \\ \text { CONTEXTO } & \text { Posada del Potro (\%957 48 50 18; Plaza del Potro 10; admission } \\ & \text { free; h10am-2pm \& 5-8pm Mon-Fri Aug-May), described in Don } \\ & \text { Quijote as a 'denof thieves'. Cervantes once lived here for a short } \\ & \text { period, and was no doubt robbedand cheated several times by } \\ & \text { the rough lot hanging out on the square. The picturesque posada } \\ \text { (inn), charmingly arranged around a small animal yard, regularly } & \text { hosts interesting temporary exhibits of art, artefacts and } \\ \text { photography } & \text { equivalente acuñado } \\ \text { préstamo }\end{array}$

Las técnicas utilizadas son el equivalente acuñado y el préstamo. El mediador ha optado en este caso por dejar constancia del culturema en LO y realizar una explicitación del significado a través del uso de un equivalente cultural en la LM como el vocablo inn. El Oxford English Dictionary Online define inn como "a pub, typically one in the country, in some cases providing accommodation", y también "a house providing accommodation, food, and drink, especially for travelers", en referencia a una acepción histórica. En el caso que nos ocupa, 
queda claro el sentido histórico que el mediador quiere reflejar, pues incluye informaciones acerca de la época de la que data la posada al introducir un referente literario universal de la literatura española como El Quijote y su autor Miguel de Cervantes.

Si existe un elemento cultural por excelencia dentro del ámbito cultural alojamiento, ese es parador. Se trata de un realia por lo que la dificultad en la transmisión del contenido cultural presenta todo un reto para el traductor. $\mathrm{A}$ continuación mostramos la ficha de análisis del culturema parador.

Tabla 18: ficha de análisis del culturema parador

ID
CODIGO GUÍA
GUíA
PROVINCIA
ELEMENTO DE ANÁLISIS
TIPOLOGÍA
CAMPO SEMÁNTICO
CONTEXTO
TÉCNICA TRADUCCIÓN 1
TÉCNICA TRADUCCIÓN 2

\begin{tabular}{l}
162 \\
LPA \\
\hline Lonely Planet Andalucía \\
\hline Córdoba \\
\hline parador \\
\hline culturema \\
alojamiento \\
Something of a hike if you're not driving, this parador (state- \\
owned luxury hotel) is $3 \mathrm{~km}$ north of the city centre. \\
amplificación \\
préstamo
\end{tabular}

En este caso, de nuevo el mediador ha optado por mantener la denominación en LO a través del uso del préstamo, pero, al no disponer de un equivalente funcional o cultural en la LM, se ve obligado a indicar las características de este tipo de alojamiento realizando una amplificación en la que se explicitan lo que el mediador considera fundamental sobre este tipo de alojamientos. El mediador realiza una amplificación a través de una premodificación adjetival indicando que son hoteles de propiedad estatal y de lujo, si bien no incluye una de sus características más relevantes, como el hecho de que sean en su gran 
mayoría palacios, conventos, castillos, y edificios singulares en los que se degustan los platos típicos de las distintas regiones en las que se ubican.

De nuestro análisis del campo semántico alojamiento debemos destacar también una realidad cultural típica de amplias zonas de España como el culturema cortijo. El Diccionario de la Real Academia Española (en adelante, DRAE) lo define como "finca rústica con vivienda y dependencias adecuadas, típica de amplias zonas de la España meridional". De nuevo, se trata de un realia de difícil traducción. La transmisión de la cultura en este caso se ha realizado a través del uso en técnica simple del préstamo:

Tabla 19: ficha de análisis del culturema cortijo

CODIGO GUÍAS
GUÍA
PROVINCIA
ELEMENTO DE ANÁLISIS
TIPOLOGÍA
CAMPO SEMÁNTICO
CONTEXTO

TÉCNICA TRADUCCIÓN 1

\begin{tabular}{l} 
LPA \\
Lonely Planet Andalucía \\
\hline Málaga \\
\hline cortijo \\
\hline culturema \\
alojamiento \\
La Posada del Torcal (\%952 $03 \quad 11 \quad 77$; www.la \\
posadadeltorcal.com; Villanueva de la Concepción; $r € 180 ;$ pasw) \\
Outside Antequera, close to El Torcal, this fantastic hilltop \\
cortijo is surrounded by wonderful panoramic views. It offers \\
luxurious rooms and facilities including tennis courts, riding \\
treks and a pool with a view.
\end{tabular}
préstamo

El lector destinatario puede entender perfectamente por el contexto que se trata de un lugar donde alojarse alejado de un núcleo urbano, aislado y en lo alto de una montaña. Sin embargo, el uso único del préstamo presupone el conocimiento cultural por parte del lector de este tipo de construcciones propias de la mitad sur de España, dedicadas en su mayoría a la explotación agrícola y ganadera y con unas características arquitectónicas e históricas 
propias. En este caso, el travase cultural total no se produce, pues no se detallan las peculiaridades arquitectónicas ni decorativas típicas de este tipo de construcciones.

Cabe señalar el uso que se realiza de ciertos vocablos que no son culturemas, pero que sí reciben un tratamiento como tales por parte del mediador. Ese es el caso del término hostal. El mediador decide incluir el uso de este término del lenguaje turístico en LO en lo que creemos que es un ejercicio pedagógico de palabras clave en español por parte del mediador. A continuación mostramos la ficha de análisis de este término.

Tabla 20: ficha de análisis del culturema hostal

ID
CODIGO GUÍA
GUíA
PROVINCIA
ELEMENTO DE ANÁLISIS
TIPOLOGÍA
CAMPO SEMÁNTICO
CONTEXTO

TÉCNICA TRADUCCIÓN 1 TÉCNICA TRADUCCIÓN 2
159

LPA

Lonely Planet Andalucía

Córdoba

hostal

culturema

alojamiento

This is budget traveller's heaven. There are more hostales (budget hotels) and pensiones (guesthouses) around the Mezquita area than you can shake a pillow at, and those mentioned here are just a selection amplificación préstamo

EI DRAE define hostal como "casa donde se da comida y alojamiento mediante pago". El mediador, por su parte, introduce una precisión con la característica de establecimiento económico (budget hotels) cuando podría haber usado un equivalente acuñado en la cultura meta como guesthouse para referirse a este 
tipo de hoteles. Lo cierto es que el término hostal puede variar mucho entre los distintos países, y en España existen hostales de distinta categoría y precio ${ }^{101}$.

El caso de pensión es similar al de hostal. De nuevo el mediador utiliza el término turístico en LO y, en este caso, sí explicita su significado con una amplificación que incluye el uso de un equivalente acuñado en la LM guesthouse. Este último término se define en el Oxford Dictionary Online como "a private house offering accommodation to paying guests". Más explícito resulta el Merriam Webster Dictionary Online al indicar que es "a building used for guests especially a house run as a boardinghouse or bed-and-breakfast". Sin embargo, el DRAE no precisa el término pensión en español y alude a un establecimiento o "casa donde se reciben huéspedes". Sin embargo, las pensiones en España suelen ser establecimientos de menor rango que los hostales.

En el caso de hostal y pensión, el mediador era consciente de que ambos establecimientos tienen el denominador común de pertenecer a una categoría de establecimientos más económicos que los hoteles. Sin embargo, a través de la mediación realizada no consideramos que el lector destinatario pueda hacerse una idea de las diferencias existentes entre ambos establecimientos e incluso pudiera llegar a considerar que hostal es un establecimiento de categoría inferior a pensión y no a la inversa.

A través del análisis de este campo semántico hemos podido constatar, por un lado, que es un campo semántico donde encontramos elementos culturales que presentan un gran reto para el traductor, que suele optar generalmente por

\footnotetext{
${ }^{101}$ En España cada Comunidad Autónoma es la encargada de definir y regular estos establecimientos. En el caso de la Comunidad Valenciana, por ejemplo, los hostales se clasifican en el grupo segundo y se distinguen dos tipos: hostales de dos y una estrella y hostales-residencia de dos y una estrella. Las pensiones se contemplan en el grupo tercero.
} 
la técnica del préstamo y amplificación. Del mismo modo, conviene señalar que es un campo en el que es fundamental que el mediador entienda y tenga un profundo conocimiento de las regulaciones de los establecimientos hoteleros tanto en la cultura de origen como en la cultura de destino, pues los distintos alojamientos hoteleros tienen distinta clasificación y diferente correspondencia conceptual en la cultura de origen y la cultura de destino.

\subsubsection{Arquitectura}

La arquitectura es un campo semántico imbricado en la cultura de un pueblo o una sociedad, así como en la historia, que se refleja en las distintas corrientes arquitectónicas que le son propias. Si atendemos a la frecuencia de uso de las técnicas de traducción, podemos observar que en las guías Lonely Planet el uso de técnicas compuestas es muy superior al uso de una única técnica para la traducción de los culturemas. En los diagramas de sectores siguientes (cfr. figuras 21 y 22) se recogen todos los datos relativos a la frecuencia de uso de las técnicas en el campo semántico arquitectura.

Figura 21: Técnicas de traducción simples del campo semántico arquitectura 


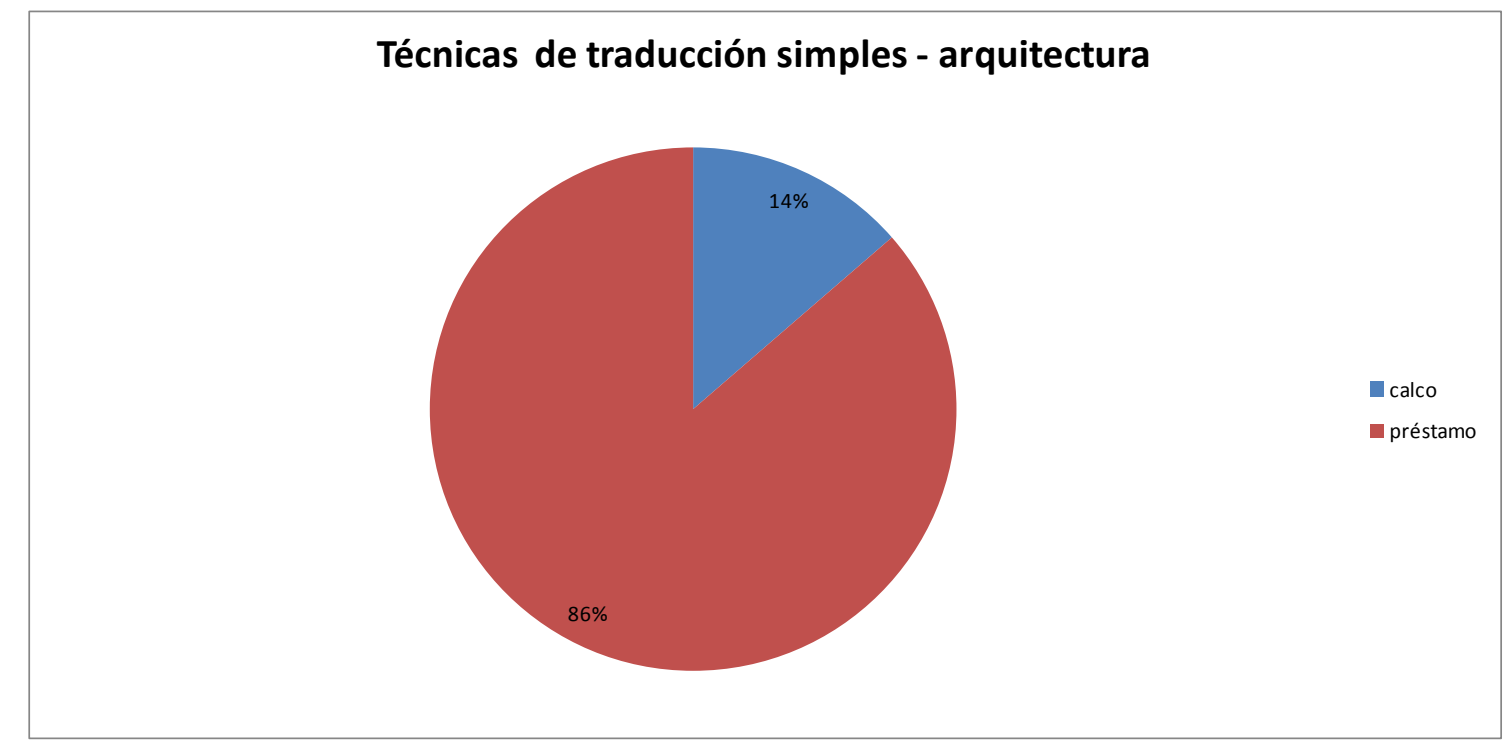

Figura 22: Técnicas de traducción compuestas del campo semántico arquitectura

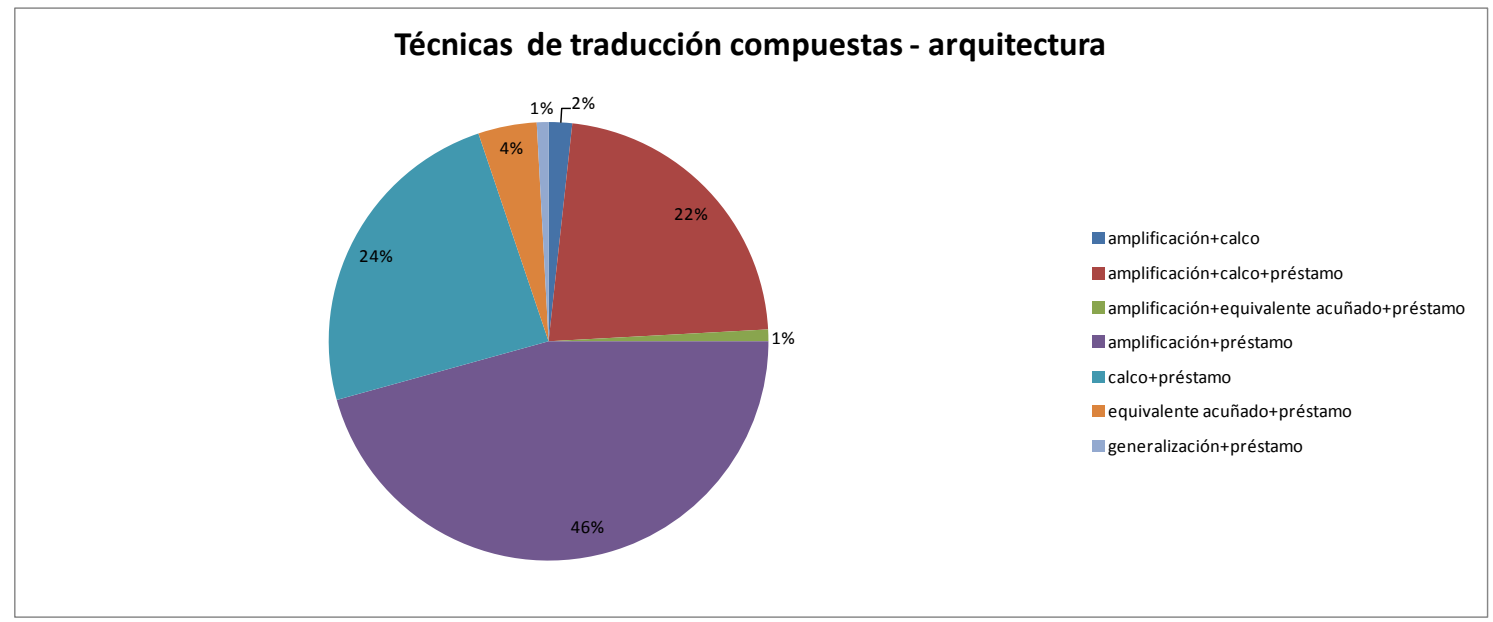

En las figuras anteriores se observa el uso casi generalizado del préstamo cuando la técnica de traducción utilizada es individual, y el uso de la técnica del calco utilizada de modo simple en un porcentaje menor. Cuando el mediador ha optado por una técnica combinada, en un $46 \%$ de los casos la técnica escogida 
ha sido el préstamo junto con la amplificación. En segundo lugar, la técnica compuesta más utilizada ha sido el préstamo y el calco (24\%), y en tercer lugar el triplete préstamo - amplificación - calco (22\%). Otras elecciones muy poco frecuentes incluyen la combinación de equivalente acuñado y préstamo.

A continuación presentamos el análisis cualitativo pormenorizado de una serie de culturemas representativos del uso de estas técnicas de traducción pertenecientes al campo semántico arquitectura.

En primer lugar, analizamos el culturema alcazaba, que en las guías Lonely Planet se caracteriza por su alta frecuencia de aparición. En todos los casos en los que se ha utilizado este culturema, la técnica utilizada ha sido el préstamo combinado con la amplificación. La amplificación realizada es en cada caso bien diferente, como observamos en las distintas fichas de análisis de este culturema.

En la guía Lonely Planet de Almería, se realiza una explicitación de información general de la Alcazaba almeriense ${ }^{102}$, indicando que se trata del "only remaining Islamic monument in town". Dentro de la amplificación se ofrece como sinónimo de alcazaba el elemento watchtower, que no es sino una parte de la fortaleza o la torre vigía de que disponen algunos castillos o fortalezas. Así pues, la amplificación incluye una particularización del elemento cultural:

\footnotetext{
102 La Alcazaba de Almería se divisa desde cualquier punto de la ciudad y es la mayor de las ciudadelas construidas por los árabes en España. Su construcción fue iniciada en el año 955 por Abderramán III y terminada por Hayrán, rey taifa de Almería, en el siglo XI. Tras la conquista cristiana es reformada por los Reyes Católicos y Carlos I. Posee 3 recintos amurallados, uno de los cuales fue construido por los Reyes Católicos. Fue residencia real y hoy permanece en pie el palacio de Al-Mutasin con todas sus estancias, su mezquita, convertida en iglesia desde finales del siglo XV, y sus baños. Tiene una sola puerta de acceso, casi invisible por las enormes murallas, y amplias estancias de techos abovedados y puertas góticas. Desde lo alto de las murallas de la Alcazaba se pueden observar unas maravillosas vistas de la ciudad y del puerto.
} 
Tabla 21: ficha de análisis del culturema alcazaba

ID

CODIGO GUÍA

35

GUÍA

PROVINCIA

ELEMENTO DE ANÁLISIS

TIPOLOGÍA

CAMPO SEMÁNTICO

CONTEXTO

TÉCNICA TRADUCCIÓN 1

TÉCNICA TRADUCCIÓN 2

LPA

Lonely Planet Andalucía

Almería

alcazaba

culturema

arquitectura

Almería's watchtower, the grand Alcazaba,is the only remaining

Islamic monument in town and a reminder of the city's former

historical importance

amplificación

préstamo

La amplificación en otras ocasiones, se realiza con el uso de un elemento en la LM que hace la función equivalente, como es el siguiente caso, que se produce en la misma guía y en el que se explicita el significado de la palabra alcazaba asociándolo al vocablo citadel:

Tabla 22: ficha de análisis del culturema alcazaba

ID

CODIGO GUÍA

34

GUíA

PROVINCIA

ELEMENTO DE ANÁLISIS

TIPOLOGÍA

CAMPO SEMÁNTICO

CONTEXTO

TÉCNICA TRADUCCIÓN 1

TÉCNICA TRADUCCIÓN 2

LPA

Lonely Planet Andalucía

Almería

alcazaba

culturema

arquitectura

There's already plenty in Almería for a couple of days' stay: the enormous Alcazaba (citadel) is a major historical site;

amplificación

préstamo 
Se trata de una opción más que acertada, teniendo en cuenta que alcazaba es un culturema difícil de transmitir, pues pertenece a un período histórico que ambas culturas no comparten. EI DRAE define alcazaba como "recinto fortificado, dentro de una población murada, para refugio de la guarnición", por lo que el uso de citadel, ofrece de modo sintético la información principal e informa de la la función para la que servía este edificio.

La misma guía Lonely Planet Andalucía, en su sección provincial Almería, menciona una y otra vez este culturema, y para ello va utilizando distintas versiones de amplificación. En la siguiente ficha de análisis podemos observar de nuevo la técnica del préstamo combinado con la amplificación a modo de definición-descripción, que trata de sintetizar el principal contenido informativo pero no incluye el contenido cultural fundamental de la alcazaba, su origen y carácter musulmán:

Tabla 23: ficha de análisis del culturema alcazaba

ID

CODIGO GUÍA

GuÍA

PROVINCIA

ELEMENTO DE ANÁLISIS

TIPOLOGÍA

CAMPO SEMÁNTICO

CONTEXTO

TÉCNICA TRADUCCIÓN 1

TÉCNICA TRADUCCIÓN 2

36

$$
\text { LPA }
$$

Lonely Planet Andalucía

Almería

alcazaba

culturema

arquitectura

The Alcazaba is Almería's premier attraction: a monstrous fortress that rises austerely from impregnable cliffs to dominate the city.

amplificación

préstamo

Podemos observar que esta vez, el mediador define alcazaba como premier attraction, aportando información de carácter turístico general y la define como 
fortress, haciendo uso con el adjetivo monstrous de la exageración tan propia del lenguaje turístico para, a continuación, describir su situación geográfica.

A lo largo del estudio y análisis de las guías Lonely Planet hemos podido observar que, como ocurre con alcazaba, los mediadores se refieren en varias ocasiones al mismo culturema. En cada ocasión ofrecen una información adicional a la anterior o una perspectiva nueva, y se sirven de la amplificación para ir conformando, a través de las distintas ocurrencias de un mismo culturema una representación del objeto cultural en la mente del turista.

Las páginas de la guía Lonely Planet Andalucía que están dedicadas a la provincia de Málaga también recogen el culturema alcazaba. El portal turístico de esta ciudad ${ }^{103}$ presenta este monumento como un "palacio fortaleza de los gobernantes musulmanes de la ciudad. Fue construido en su mayor parte en el siglo XI y es uno de los monumentos emblemáticos de la capital malagueña".

La técnica de traducción combina el uso del préstamo y la amplificación. El mediador casualmente utiliza la terminología oficial del portal turístico municipal para definir esta construcción (palace-fortress) y la sitúa cronológicamente en el período musulmán:

Tabla 24: ficha de análisis del culturema alcazaba

${ }^{103}$ www.malagaturismo.com 
ID

CODIGO GUÍA

GUíA

PROVINCIA

ELEMENTO DE ANÁLISIS

TIPOLOGÍA

CAMPO SEMÁNTICO

CONTEXTO

TÉCNICA TRADUCCIÓN 1

TÉCNICA TRADUCCIÓN 2
224

LPA

Lonely Planet Andalucía

Granada

torre de la vela

culturema

arquitectura

What remains of the Alcazaba is chiefly its ramparts and several towers, the most important and tallest being the Torre de la Vela (Watch Tower), with a narrow staircase leading to the top terrace, which has splendid views. The cross and banners of the Reconquista were raised here in January 1492

calco

préstamo

La amplificación de la alcazaba malagueña incluye una descripción detallada de algunos elementos arquitectónicos que, desde el punto de vista del mediador, son dignos de ver. Finalmente, la amplificación recoge información de carácter práctico y subjetivo, al recomendar el verano como período óptimo para la visita, en una clara alusión a las buenas condiciones climatológicas del sur de España.

Las técnicas de traducción amplificación y préstamo se combinan de nuevo para la transmisión del contenido cultural del culturema alhambra. En el caso de alhambra, la amplificación recoge otro tipo de información que refiere la etimología de la palabra misma:

Tabla 25: ficha de análisis del culturema alhambra 
ID

CODIGO GUíA

GUíA

PROVINCIA

ELEMENTO DE ANÁLISIS

TIPOLOGÍA

CAMPO SEMÁNTICO

CONTEXTO

TÉCNICA TRADUCCIÓN 1

TÉCNICA TRADUCCIÓN 2
215

LPA

Lonely Planet Andalucía

Granada

alhambra

culturema

arquitectura

The Alhambra takes its name from the Arabic al-qala'at al-hamra (red castle). The first palace on the site was built by Samuel HaNagid, the Jewish grand vizier of one of Granada's 11th-century

Zirid sultans (whose own fortress was in the Albayzín).

amplificación

préstamo

El mediador explica al turista de dónde proviene la palabra Alhambra en lo que creemos que es una marcada intención de acercar al viajero a la cultura musulmana. La inclusión de la denominación en árabe de esta palabra no aporta información turística de relevancia para el lector, pero lo introduce en el mundo árabe reforzando el color local con el uso de palabras como vizier y sultan propias del contexto histórico. El contenido principal del culturema queda expresado a través de las explicitaciones castle y palace, que dan la idea de conjunto fortificado.

En el campo arquitectónico hemos constatado una gran variedad de culturemas referidos a edificaciones defensivas, entre los cuales debemos destacar el culturema alcázar. La técnica empleada en este caso es el triplete préstamoamplificación-calco:

Tabla 26: ficha de análisis del culturema alcázar 
ID

CODIGO GUÍA
GUÍA
PROVINCIA
ELEMENTO DE ANÁLISIS
TIPOLOGÍA
CAMPO SEMÁNTICO
CONTEXTO

TÉCNICA TRADUCCIÓN 1

TÉCNICA TRADUCCIÓN 2 TÉCNICA TRADUCCIÓN 3
149

LPA

Lonely Planet Andalucía

Córdoba

alcázar de los reyes cristianos

culturema

arquitectura

Continuing southwest from the Mezquita, down Calle Amador de los Ríos, will bring you to the massive fortified Alcázar de los Reyes Cristianos (Castle of the Christian Kings; \%957 4201 51; Campo Santo de los Mártires $\mathrm{s} / \mathrm{n}$; adult/child €4/2, Fri free; h10am-2pm \& 4.30-6.30pm Tue-Satmid-Oct-Apr, 10am-2pm \& 5.30-7.30pm Tue-Sat May,Jun \& Sep-mid-Oct, 8.30am-2.30pm TueSat Jul \& Aug,9.30am-2.30pm Sun \& public holidays year-round). Built by Alfonso $X$ in the 13th century on the remains of Roman and Arab predecessors, the castle began life as a palace, hosting both Fernando and Isabel. From 1490 to1821 it became a home for the Inquisition,later being converted into a prison that only closed in 1951. Its large terraced gardens, full of fish ponds, fountains, orange trees, amplificación calco préstamo

El Alcázar de los Reyes Cristianos es una fortificación militar declarado Bien de Interés Cultural. EI DRAE define alcázar en primer lugar como "fortaleza o recinto fortificado" y en segundo lugar como "casa real o habitación del príncipe, esté o no fortificada". El mediador en este caso deja claro la doble dualidad de esta construcción al proveer al lector de una breve explicación histórica de las funciones de este edificio. Pensamos que el uso del calco resulta muy conveniente para transferir la información lingüística de una parte del culturema: Reyes Cristianos.

La técnica combinada del calco y el préstamo es la segunda técnica con más frecuencia de uso en el campo semántico arquitectura. Se ha podido constatar que el uso de esta técnica se emplea muy frecuentemente en el caso de tener que realizar la mediación sobre culturemas con contenido cultural parcial, como 
es el caso de teatro romano. En este caso, el elemento principal es una realidad común a cualquier cultura, pero lo que genera la dificultad en la traducción es elemento secundario, que es el que aporta la carga cultural. Si observamos las fichas de análisis, observamos que la dificultad en este caso queda salvada haciendo uso del calco léxico:

Tabla 27: ficha de análisis del culturema teatro romano

ID
CODIGO GUÍA
GUÍA
PROVINCIA
ELEMENTO DE ANÁLISIS
TIPOLOGÍA
CAMPO SEMÁNTICO
CONTEXTO

TÉCNICA TRADUCCIÓN 1 TÉCNICA TRADUCCIÓN 2
59

LPA

Lonely Planet Andalucía

Cádiz

teatro romano

culturema

arquitectura

On the seaward edge of the Barrio del Pópulo, drop into the excavated Teatro Romano (Roman Theatre; \%956 2122 81; Campo del Sur s/n; admission free; h10am-2pm), where you can walk along the gallery beneath the tiers of seating. The remains of the ancient stage are still buried beneath the adjacent buildings.

calco

préstamo

En el caso de teatro romano, el préstamo está acompañado por un calco léxico. Con esta pequeña operación y la información adicional arquitectónica que proporciona el contexto, el mediador considera que queda suficientemente claro el significado y la connotación cultural de este tipo de construcción. Este culturema es propio de la cultura española, pero también es compartido con otras culturas de otros países europeos, por lo que el mediador también aprovecha el carácter transcultural de este culturema y el conocimiento previo 
del lector, por lo que no necesita realizar una amplificación mayor para explicar el significado del culturema.

En otros casos, la dificultad es mayor cuando del elemento secundario del culturema no se infiere claramente una función, una característica o un detalle que pueda explicarse con facilidad al visitante. En muchos casos, tampoco llega a transferirse la carga cultural o histórica que subyace detrás de un elemento cultural determinado. Este es el caso de Torre de la Vela ${ }^{104}$, que constituía la torre de defensa más grande del conjunto militar de la Alhambra, y que por su altura domina toda la vega granadina. Su nombre procede de la campana que los cristianos colocaron en la torre tras la conquista de la ciudad. Cuando los cristianos tomaron Granada, trajeron una campana cuyo nombre era La Vela, o La centinela, utilizándola para sonar las campanadas de la victoria desde el punto más alto de la Alcazaba mora. En la lucha entre las religiones, la campana se había convertido en el símbolo del cristianismo, de la misma forma que la lámpara era el símbolo del Islam. El mediador, en este caso, ha optado por transferir la finalidad fundamental del objeto descrito que estaba destinado a la defensa y a la vigilancia (Watch tower):

Tabla 28: ficha de análisis del culturema torre de la vela 
ID

CODIGO GUÍA

GUíA

PROVINCIA

ELEMENTO DE ANÁLISIS

TIPOLOGÍA

CAMPO SEMÁNTICO

CONTEXTO

TÉCNICA TRADUCCIÓN 1

TÉCNICA TRADUCCIÓN 2
224

LPA

Lonely Planet Andalucía

Granada

torre de la vela

culturema

arquitectura

What remains of the Alcazaba is chiefly its ramparts and several towers, the most important and tallest being the Torre de la Vela (Watch Tower), with a narrow staircase leading to the top terrace, which has splendid views. The cross and banners of the Reconquista were raised here in January 1492

calco

préstamo

El uso del triplete amplificación-calco-préstamo ha quedado registrado para una serie de elementos culturales que necesitan de una mayor explicitación por su gran contenido en información cultural. Este es el caso de la Sala de la Barca, una de las estancias de La Alhambra, en la que el medidador opta, después de mencionar el culturema en LO, por calcar en la lengua meta la estructura del culturema en la LO, y amplificar el calco lingüístico con una explicitación informativa acerca de la etimología del culturema, como observamos en la siguiente ficha de análisis:

Tabla 29: ficha de análisis del culturema sala de la barca 
ID

CODIGO GUÍA

GUíA

PROVINCIA

ELEMENTO DE ANÁLISIS

TIPOLOGÍA

CAMPO SEMÁNTICO

CONTEXTO

TÉCNICA TRADUCCIÓN 1

TÉCNICA TRADUCCIÓN 2

TÉCNICA TRADUCCIÓN 3
229

LPA

Lonely Planet Andalucía

Granada

sala de la barca

culturema

arquitectura

Through the northern portico, inside the Torre de Comares

(Comares Tower), is the Sala de la Barca (Hall of the Blessing) from the Arabic al-baraka for blessing, a word endlessly carved on the walls. This room leads into the square Salón de Comares

(Comares Hall), also called the Salón de los Embajadores (Hall of the Ambassadors), where the emirs would have conducted their negotiations with Christian emissaries

amplificación

calco

préstamo

A través de esta técnica de traducción el mediador consigue transmitir casi la totalidad de la información más relevante de esta sala. Sin embargo, en otros casos no se reproduce este tipo de estrategia para la transmisión de la información cultural. En el caso del culturema Torre de Comares, el mediador transmite el culturema con el calco léxico (Comares Tower) sin ningún tipo de amplificación adicional. En este caso, pues, no se realiza la mediación sobre el contenido cultural del culturema, pues el mediador omite que su nombre se debe a las vidrieras de colores de los balcones que iluminan la gran sala que ocupa el interior de la torre, denominadas Comarías. En este caso, el lector recibe una información muy reducida de esta torre, quizás porque en su interior se encuentra la Sala de Comares, que sí merece una atención especial por parte del mediador que, a través la amplificación da cuenta de la función de dicha sala dentro del conjunto arquitectónico.

La cultura popular también es un elemento importante y difícil de transmitir. Muchas denominaciones de culturemas, algunas de ellas del campo semántico 
de la arquitectura tienen su origen en el saber popular como es el caso de La Manquita:

Tabla 30: ficha de análisis del culturema la manquita

ID

417

CODIGO GUÍA

LPA

GUÍA

PROVINCIA

Lonely Planet Andalucía

ELEMENTO DE ANÁLISIS

Málaga

TIPOLOGÍA

la manquita

culturema

CAMPO SEMÁNTICO

arquitectura

CONTEXTO

Such was the project's cost that by 1782 it was decided that work would stop. One of the two bell towers was left incomplete, hence the cathedral's well-worn nickname, La Manquita (the onearmed lady). The cathedral entrance is on Calle Císter

TÉCNICA TRADUCCIÓN 1

amplificación

TÉCNICA TRADUCCIÓN 2

calco

TÉCNICA TRADUCCIÓN 3

préstamo

El mediador realiza con éxito la mediación de este culturema valiéndose de la productiva asociación de las tres técnicas. La denominación en LO se mantiene y se calca la estructura en la LM para dar una primera traducción del elemento. La amplificación es, en este caso, la técnica en la que se transmite el detalle de que la denominación proviene de la sabiduría popular, pues con esta se indica que es un "well-worn nickname".

Cabe destacar la elección realizada por el mediador para acercar al visitante o turista no sólo la información turística y cultural del destino turístico, sino también la lengua propia de la cultura sobre la cual se realiza la mediación. En el campo semántico arquitectura el lector se encuentra con palabras propias de la 
lengua árabe que ayudan a contextualizar el lugar descrito, como es el caso de los baños árabes:

Tabla 31: ficha de análisis del culturema baños árabes

ID

121

CODIGO GUÍA

LPA

GUÍA

Lonely Planet Andalucía

PROVINCIA

Cádiz

ELEMENTO DE ANÁLISIS

baños árabes

TIPOLOGÍA

culturema

CAMPO SEMÁNTICO

arquitectura

CONTEXTO

Live like a sultan or Muslim princess and pamper yourself at Jerez's new hammam (Arabic baths; \%956 3490 66;

www.hammamandalusi.com; Calle Salvador 6; baths $€ 15$, plus 15 min massage $€ 25$, plus full-body massage $€ 40$ ) or baños Árabes.

TÉCNICA TRADUCCIÓN 1

amplificación

TÉCNICA TRADUCCIÓN 2

préstamo

La técnica empleada para la mediación incluye el uso del préstamo puro hammam tomado de la lengua árabe, junto con la amplificación, que se compone de una traducción literal y la expresión en lengua española. Este uso de la lengua árabe es completamente intencionado por parte del mediador, en un intento de situar el objeto de mediación en conexión con su cultura de pertenencia.

En este campo semántico hemos podido constatar la dificultad que entraña la traducción de los distintos edificios destinados a usos religiosos: iglesias, catedrales, basílicas, ermitas, capillas, colegiatas, conventos, monasterios... La dificultad reside en la multiplicidad de culturemas arquitectónicos de signo religioso con unas peculiaridades muy específicas que algunos de estos edificios 
comparten entre sí, y otros no. A continuación analizamos algunos de los casos más representativos: capilla, ermita y colegiata.

El DRAE, en sus dos acepciones más importantes, define capilla como "edificio contiguo a una iglesia o parte integrante de ella, con altar y advocación particular y como oratorio privado". La mediación que se realiza de este culturema sobre la Capilla de San Antonio, nos muestra el uso del préstamo y la amplificación para explicitar la segunda parte del culturema, que es la que presenta dificultad en su traducción. La primera parte del culturema queda resuelto con un equivalente acuñado:

Tabla 32: ficha de análisis del culturema capilla

ID
CODIGO GUÍA
GUíA
PROVINCIA
ELEMENTO DE ANÁLISIS
TIPOLOGÍA
CAMPO SEMÁNTICO
CONTEXTO

TÉCNICA TRADUCCIÓN 1 TÉCNICA TRADUCCIÓN 2

295
LPA
Lonely Planet Andalucía
Sevilla
capilla de san antonio
culturema
arquitectura
SOUTHERN \& NORTHERN CHAPELS The chapels along the southern
and northern sides of the cathedral hold riches of sculpture and
painting. Near the western end of the northern side is the Capilla
de San Antonio, housing Murillo's large 1666 canvas depicting
the vision of St Anthony of Padua; thieves cut out the kneeling
saint in 1874 but he was later found in New York and put back.

amplificación

préstamo

Así pues, el culturema capilla no entraña una gran dificultad, pues se dispone del equivalente en la cultura meta. El Oxford English Dictionary recoge tres acepciones principales de chapel: "a small building or room used for Christian 
worship in a school, prison, hospital, or large private house"; "a part of a large church or cathedral with its own altar and dedication"; y "a small building or room used for funeral services".

En muchos casos la equivalencia puede hacerse extensiva para la traducción de algunos culturemas que tienen una gran similitud, pero para las que no existe un equivalente acuñado. Es el caso de ermita:

Tabla 33: ficha de análisis del culturema ermita

ID
CODIGO GUÍA
GUíA
PROVINCIA
ELEMENTO DE ANÁLISIS
TIPOLOGÍA
CAMPO SEMÁNTICO
CONTEXTO

TÉCNICA TRADUCCIÓN 1 TÉCNICA TRADUCCIÓN 2

\begin{tabular}{l}
185 \\
LPA \\
\hline Lonely Planet Andalucía \\
Córdoba \\
\hline ermita \\
culturema \\
arquitectura \\
The tourist office (\%957 1582 29;Plaza Mayor 1; h9am-2.30pm \\
Mon-Fri) in the ayuntamiento (town hall) also has a leaflet (in \\
Spanish) detailing two walks, one up to the castle and the other \\
to the nearby ermita (chapel). \\
equivalente acuñado \\
préstamo
\end{tabular}

En la ficha de análisis observamos que ermita se asocia a chapel. En este caso, con esta la elección el mediador da la idea de que se trata de un edificio religioso destinado al culto. Sin embargo, una ermita no sólo se caracteriza por ser generalmente pequeña, sino por estar "situada por lo común en despoblado y que no suele tener culto permanente" (DRAE). Esta última salvedad no queda reflejada a través del equivalente chapel, con lo que no se transmite la totalidad de la información perteneciente al culturema en la cultura meta. 
La dificultad es aún mayor cuando el mediador no dispone de equivalentes en la lengua y la cultura meta ni de elementos análogos que puedan facilitar la transferencia. Observemos el caso de colegiata:

Tabla 34: ficha de análisis del culturema colegiata

ID
CODIGO GUÍA
GUÍA
PROVINCIA
ELEMENTO DE ANÁLISIS
TIPOLOGÍA
CAMPO SEMÁNTICO
CONTEXTO

TÉCNICA TRADUCCIÓN 1 TÉCNICA TRADUCCIÓN 2

\begin{tabular}{l}
258 \\
LPA \\
Lonely Planet Andalucía \\
Granada \\
\hline colegiata del salvador \\
culturema \\
arquitectura \\
Continue $200 m$ (initially uphill) to Plaza del Salvador, dominated \\
by the Colegiata del Salvador (5; \%958 278644 ; admission $€ 0.80 ;$ \\
h10am-1pm \& 4-7.30pm Mon-Sat Apr-Oct, 10.30am- 12.30pm \& \\
$4.30-6.30 p m$ Mon-Sat Nov-Mar), a 16thcentury church on the site \\
of the Albayzín's main mosque \\
amplificación \\
préstamo
\end{tabular}

El mediador en este caso utiliza el préstamo y la amplificación pero pasa de puntillas sobre la información del culturema, indicando que colegiata ${ }^{105}$ es una "16th century church". En este caso, la mediación supone la obligación por parte del mediador de investigar y documentarse acerca de los tipos de edificios religiosos y los usos para los que están concebidos. En este caso, pues, observamos una pérdida de información cultural que no ha sido compensada, como suele ser habitual, a través de la técnica de la amplificación.

\footnotetext{
${ }^{105}$ EI DRAE define colegiata como iglesia colegial e indica que es aquella que, no siendo sede propia del arzobispo u obispo, se compone de abad y canónigos seculares, y en ella se celebran los oficios divinos como en las catedrales.
} 
A modo de resumen, podemos decir que la técnica de préstamo y amplificación es la técnica más utilizada en el ámbito arquitectónico. El uso de la denominación en la LO se respeta y se utiliza la amplificación para ofrecer la información específica y más relevante del culturema (su función, su etimología,...) u otro tipo de información práctica y de interés turístico. La dificultad de los culturemas de este campo semántico se halla en la inclusión de una cultura dentro de otra cultura. En LPA, por ejemplo, el lector debe tener un mínimo conocimiento de la cultura y la historia musulmana para entender las manifestaciones artísticas presentes actualmente en la cultura española. Los diversos monumentos arquitectónicos no son en sí una dificultad para el traductor, pues se dispone de elementos del lenguaje general en la LM con una funcionalidad equivalente o parcialmente equivalente que no incluyen el elemento cultural, pero de los que el traductor se vale para la transmisión del significado primario. La cultura popular también se halla presente en este campo semántico, a través de culturemas que refieren a los nombres que los oriundos de un lugar utilizan para referirse a los distintos edificios y monumentos arquitectónicos. Sí existen ciertos culturemas relacionados entre sí (como los diferentes edificios religiosos) que necesitan de una gran explicitación por parte del mediador y un gran trabajo previo de estudio e investigación por la especificidad y las peculiaridades que presentan.

\subsubsection{Artesanía}

Dentro de la categoría o campo semántico artesanía hemos registrado los elementos culturales que se refieren tanto al trabajo, a las técnicas, como a los objetos y productos que se elaboran de modo artesanal de acuerdo con la tradición. Sin duda, existe un nexo cultural entre los pueblos y regiones que los producen y la historia de los mismos. En España existe artesanía variada y cada 
Comunidad Autónoma dispone de productos identificativos. Entre los más populares destacan la cerámica, el vidrio, el cuero, y la cestería o el esparto.

Para transmitir la carga cultural de estos elementos en las guías Lonely Planet la técnica predominante es la amplificación en combinación con el préstamo como se observa en la siguiente figura:

Figura 23: Técnicas de traducción compuestas del campo semántico artesanía

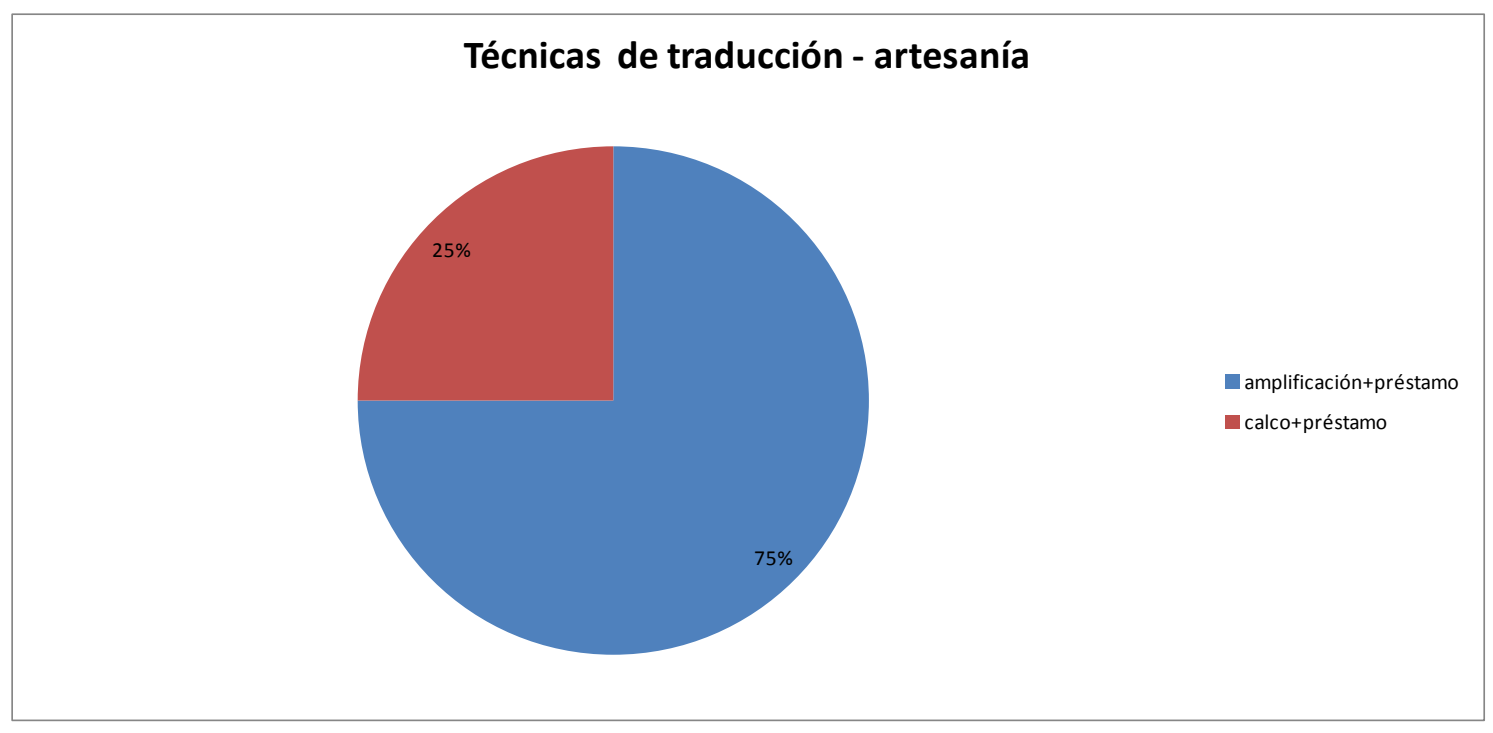

Cabe señalar que hemos identificado en esta investigación pocos elementos culturales de este campo semántico, a diferencia de otros campos semánticos en los que existe una abundante presencia de culturemas. En artesanía, en general, estos elementos suelen ser objetos o técnicas que no suelen ser muy conocidos en la cultura meta, pues, retomando de nuevo la teoría de las capas de Hofstede (cfr. 2.1), estas manifestaciones artísticas suelen encontrarse en las capas más profundas de una cultura. Quizás por este motivo no observamos el 
uso del préstamo como técnica individual y el mayor porcentaje de técnicas son las que combinan el préstamo con la amplificación.

Si atendemos a la traducción de elementos en contexto, observamos la dificultad que entraña la expresión de la cultura presente en los elementos artesanales, como ocurre en el caso del culturema alpargatas ${ }^{106}$. El mediador recomienda una tienda típica de Valencia por su artesanía en cestería poniendo en contexto al lector a través de los elementos madera y paja, para poner como ejemplo uno de los productos artesanales más típicos de la Comunidad Valenciana, como observamos en la siguiente ficha de análisis:

Tabla 35: ficha de análisis del culturema alpargatas

ID
CODIGO GUÍA
GUÍA
PROVINCIA
ELEMENTO DE ANÁLISIS
TIPOLOGÍA
CAMPO SEMÁNTICO
CONTEXTO

TÉCNICA TRADUCCIÓN 1 TÉCNICA TRADUCCIÓN 2
24

LPVLC

Lonely Planet Valencia

Valencia

alpargatas

culturema

artesanía

This wonderful clutteres shop sells everything fashioned from whippy wood and straw: baskets, boxes, trunks, screens, and more. Its alpargatas (lightweight esparto grass slippers; $7 €$ ) make original presents and will be easily tucked into your luggage.

amplificación

préstamo

\footnotetext{
${ }^{106}$ Se cree que la alpargata tuvo su origen en la sandalia egipcia, en la que luego se inspiraron los romanos para elaborar una pantufla cubierta y proteger el pie del sol y el calor. Introducida posteriormente a Europa, el registro más antiguo en América de una alpargata forma parte de una colección de artículos de la región del Chaco (Argentina). Otros argumentan que puede ser de origen pirenaico, y está documentado desde al menos 1322, año en que un documento redactado en catalán describe las espardenyes o alpargatas.
} 
En este caso, el mediador ofrece el préstamo puro y utiliza una amplificación que incluye información muy variada; la información de la función principal del culturema queda reflejada con slippers, a través del uso de una palabra que proporciona una equivalencia funcional parcial; la principal característica de este producto, el material, se expresa a través del uso de un elemento generalizador y la introducción de otro préstamo puro, esparto. Se trata de un barbarismo cuya acepción recoge el Oxford English Dictionary Online y define como "a coarse grass with tough narrow leaves, native to Spain and North Africa. It is used to make ropes, wickerwork, and good-quality paper". Por último, la transmisión de la información se completa con el uso del adjetivo lightweight y la información práctica que se apostilla a la lingüística sobre el coste del producto.

Si bien la amplificación realizada para alpargatas resulta en una gran cantidad de información relativa al culturema y que puede ser de interés para el turista, cabe señalar que con la elección de la inclusión de un segundo préstamo no creemos que se haya llegado a transmitir las características propias del material fundamental de este producto, y que sólo el lector que posea un amplísimo conocimiento previo podrá hacerse una composición de lugar de lo que son unas alpargatas.

En otras ocasiones, la técnica amplificación no da como resultado una diversidad de informaciones y de explicitación, sino una única información que sirve para transmitir la característica fundamental del culturema. Es el caso del culturema cuero repujado ${ }^{107}$. El mediador se sirve del adjetivo embossed (el Oxford English Dictionary define emboss como "carve or mould a design on a

\footnotetext{
107 El repujado es una técnica de artesanía que consiste en trabajar planchas de metal, cuero u otros materiales de similares características para obtener un dibujo ornamental en relieve.
} 
surface so that it stands out in relief" con gran acierto. A continuación ofrecemos el culturema en contexto:

Tabla 36: ficha de análisis del culturema cuero repujado

ID

CODIGO GUÍA

GUÍA

PROVINCIA

ELEMENTO DE ANÁLISIS

TIPOLOGÍA

CAMPO SEMÁNTICO

CONTEXTO

TÉCNICA TRADUCCIÓN 1

TÉCNICA TRADUCCIÓN 2
180

LPA

Lonely Planet Andalucía

Córdoba

cuero repujado

culturema

artesanía

Córdoba is known for its cuero repujado (embossed leather) products and silver jewellery (particularly filigree). Shops selling these crafts concentrate around the Mezquita and go for the tourist with meanprices, so shop around for the best deal. amplificación préstamo

La técnica usada para el culturema cuero repujado es de nuevo una combinación de préstamo y amplificación, pero a diferencia del culturema alpargatas, el lector destinatario sí puede formarse una idea clara de este culturema. Asimismo, observamos que el contexto proporciona información que circunscribe el culturema en el área temática de la artesanía (elementos léxicos como crafts, shops,...). Así pues, observamos que el uso de la técnica de amplificación que incluya una serie larga y variada de elementos informativos no es siempre sinónimo de información cultural pertinente para el lector.

A continuación damos cuenta del análisis de un elemento cultural que, junto con ensaimada, es uno de los iconos de la isla de Mallorca, y por ende, de las 
Islas Baleares: el siurell. El siurell es una figura de arcilla, símbolo de la isla de Mallorca. Se distinguen por ser figuras de arcilla blanca muy esquemáticas, con pinceladas al azar de color verde y rojo principalmente. Su nombre proviene del característico silbato que suelen tener acoplados en la parte trasera. Los antiguos ganaderos y pastores los usaban para controlar a su ganado y algunos incluso sabían componer canciones para danzas folklóricas mallorquinas.

Su origen se remonta a épocas ancestrales. Hay quien piensa que proceden de un antiguo juguete árabe. En la isla de Mallorca, de donde es propio el siurell, la opinión popular apunta a que los fenicios lo importaron, aunque el origen puede ser griego, sardo, chipriota o cretense. Muchos investigadores intentan descubrir el verdadero origen del siurell pero sólo son hipótesis sin conclusiones definitivas.

El mediador recoge este culturema en la LPMLL a través de una amplificación y el uso del préstamo puro. El mediador pone el acento en el origen desconocido de este elemento cultural y lo transmite indicando que es "a funny white, green and red clay figurine-whistle". En esta explicitación se hace referencia, del mismo modo que ocurría con alpargatas, al material (clay), y a los colores. La información relativa al silbato se transmite mediante una composición de nombres que dan la idea de la forma del objeto. Resulta interesante la inclusión del adjetivo funny en primera posición de la estructura de premodificación, en la que el mediador transmite una opinión subjetiva del objetivo y que contrasta con la amplificación que presume tener un carácter absolutamente descriptivo y objetivo, como se observa en la ficha de análisis del culturema:

Tabla 37: ficha de análisis del culturema siurell 
ID

CODIGO GUÍA
GUÍA
PROVINCIA
ELEMENTO DE ANÁLISIS
TIPOLOGÍA
CAMPO SEMÁNTICO
CONTEXTO

TÉCNICA TRADUCCIÓN 1 TÉCNICA TRADUCCIÓN 2
692

LPMLL

Lonely Planet Mallorca

Mallorca

siurells

culturema

artesanía

DON'T GRUMBLE, GIVE A WHISTLE Some historians claim the funny white, green and red clay figurine-whistles known as siurells were introduced to Mallorca by the Phoenicians and may have represented ancient deities. Classic figures include bulls, horseriders and dog-headed men. You'll occasionally see them in museums but they are mostly found nowadays in shops as massproduced souvenirs

amplificación

préstamo

Por último, presentamos el análisis de un objeto de artesanía español por excelencia, el traje de flamenca. Si bien este culturema también podría pertenecer al campo semántico fiestas y espectáculos, ha quedado registrado en el ámbito temático artesanía por el contexto en el que aparece.

Las técnicas de traducción empleadas del préstamo y el calco son una combinación minoritaria en relación con el uso casi generalizado del préstamo más amplificación que hemos constatado en este campo semántico. Sin embargo, si observamos el contexto de la ficha de análisis en el que aparece el culturema traje de flamenca $^{108}$, podemos observar que la amplificación de la información sí está presente mediante la adición de la información sobre el estampado de los trajes de flamenca:

\footnotetext{
108 El origen del atuendo se remonta a finales del siglo XIX y principios del siglo XX, cuando las vendedoras acudían a la feria con los tratantes de ganado vestidas con modestas batas de percal adornadas con volantes. Enseguida, las clases pudientes copiaron el vestido de las trabajadoras del campo. A partir de la Feria de Abril celebrada en el año de 1929, el traje se consagró como la vestimenta oficial para acudir al evento, tradición que se ha mantenido hasta la actualidad. El traje, inicialmente utilizado por las mujeres de etnia gitana, se ha popularizado como traje típico andaluz.
} 
Tabla 38: ficha de análisis del culturema traje de flamenca

ID

CODIGO GUÍA

GUÍA

PROVINCIA

ELEMENTO DE ANÁLISIS

TIPOLOGÍA

CAMPO SEMÁNTICO

CONTEXTO

TÉCNICA TRADUCCIÓN 1

TÉCNICA TRADUCCIÓN 2
406

LPA

Lonely Planet Andalucía

Sevilla

traje de flamenca

culturema

artesanía

The lovely cluster of pedestrianised shopping streets is among the prettiest in Europe.Calles Sierpes, Velázquez/Tetuán and de la Cuna (all on Map pp102-3) have retained their charm with a host of smallshops selling everything from polka-dot trajes de flamenca (flamenco dresses) and trendy Camper shoes to diamond rings and antique fans

calco

préstamo

El mediador cuenta en este caso con la ventaja de que el elemento cultural que a priori podría presentar mayor dificultad, flamenco, es un culturema globalizado, pues es un icono internacional de la cultura española. La segunda parte del culturema, traje, es un vocablo perteneciente al lenguaje general, con lo cual la mediación en este caso no supone un problema para el traductor. Sin embargo, el mediador añade la expresión polka-dot para señalar el estampado de lunares prototípico de estos trajes e introduciendo de este modo un detalle más que ayude al lector a formarse una representación mental del atuendo.

Creemos, sin embargo, que es necesaria una desambiguación del significado, pues en contexto, a un lector sin conocimientos de español posiblemente no llegue a saber si el traje de flamenca es un traje para el hombre o para la mujer y cuáles son las connotaciones culturales fundamentales que estos poseen. Cabe señalar, por otro lado, las múltiples variedades de diseños que existen 
actualmente y las distintas denominaciones, que pueden resultar confusas para el turista y que el mediador no menciona, como traje de faralaes, traje de gitana y traje de sevillana.

En conclusión, el campo semántico de la artesanía es un área donde se da una frecuencia baja de elementos culturales. No obstante, dichos elementos resultan complicados de traducir para un traductor que no haya estado inmerso completamente en la cultura y subculturas de origen, pues están enraizadas en la historia y la tradición de dichos pueblos. Las técnicas de traducción predominantes son, por un lado, el préstamo, con el que se respeta la denominación propia se mantiene el color local y se familiariza al turista con la nueva realidad lingüística; y por otro, la amplificación, que puede informar acerca de diferentes características y servir a distintas funciones dentro del texto.

\subsubsection{Escultura}

La escultura es una de las Bellas Artes que refleja las manifestaciones artísticas de un pueblo. La cultura, la religión, el momento histórico y otros parámetros quedan reflejados a través de este tipo de obras.

A continuación ofrecemos el análisis de la frecuencia de técnicas de traducción empleadas en la mediación de estos culturemas del campo semántico escultura, tanto combinadas como individuales.

Figura 24: Técnicas de traducción compuestas del campo semántico escultura 


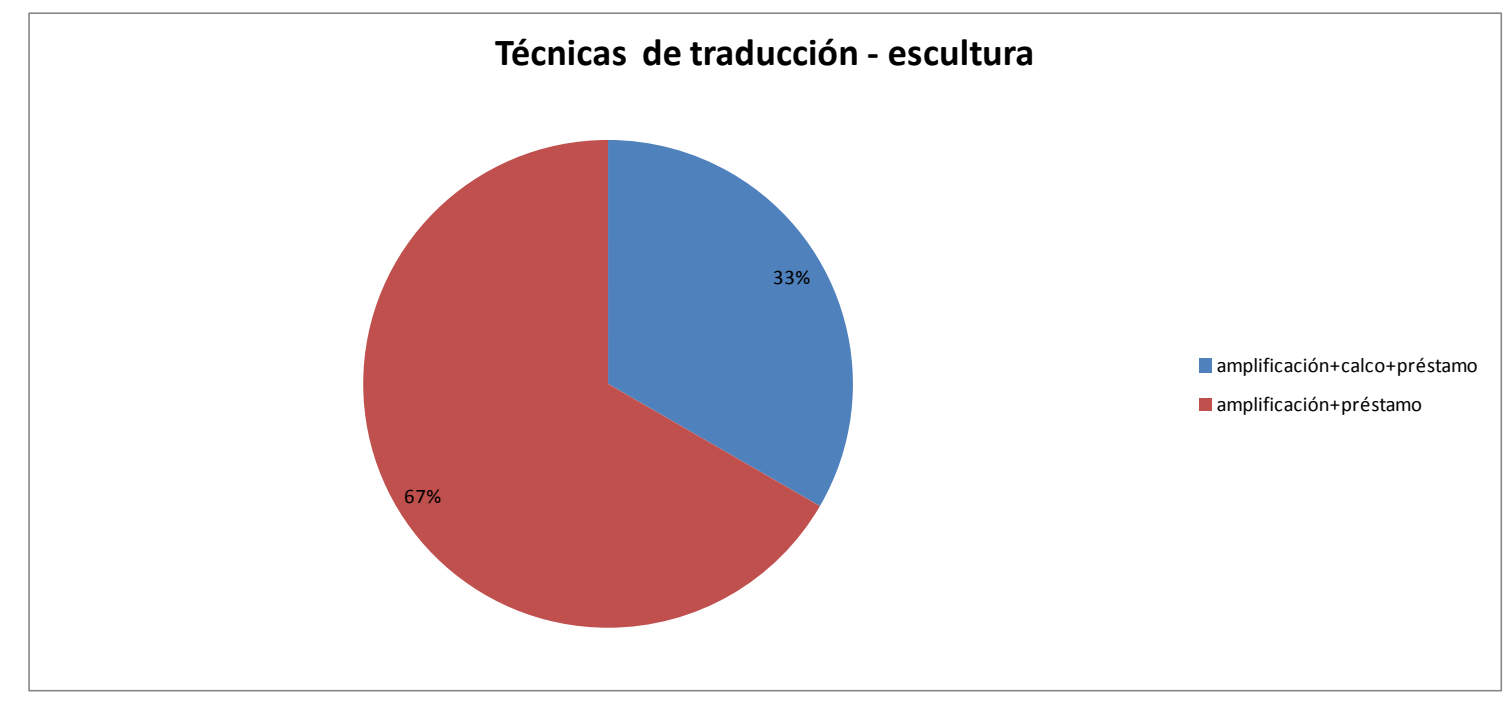

El gráfico nos indica que, para este campo semántico, los mediadores eligen mayoritariamente el uso de un doblete que combina préstamo y amplificación. El calco se une a la amplificación y el préstamo también,pero en un número menor de casos (33\%). Observamos que, al igual que ocurre con el campo semántico artesanía, no se produce el uso individual del préstamo.

En el caso de las guías Lonely Planet los culturemas relativos a la escultura muestran, en muchos casos, la religión como parte de la cultura española. Es el caso del culturema Descendimiento. En este caso, el mediador utiliza las técnicas de préstamo más amplificación para la traducción, como se observa en la ficha de análisis:

Tabla 39: ficha de análisis del culturema descendimiento 
ID

\section{CODIGO GUÍA}

GUÍA

PROVINCIA

ELEMENTO DE ANÁLISIS

TIPOLOGÍA

CAMPO SEMÁNTICO

CONTEXTO
TÉCNICA TRADUCCIÓN 1

TÉCNICA TRADUCCIÓN 2
342

LPA

Lonely Planet Andalucía

Sevilla

descendimiento

culturema

escultura

IGLESIA DE LA MAGDALENA One of Seville's outstanding baroque churches, the Iglesia de la Magdalena (Map pp102-3 ;Calle San Pablo 12; hMass times, usually 8-11.30am \& 6.30-9pm) was built between 1691 and 1709.Two paintings by Zurbarán hang in the Capilla Sacramental (the first chapel on the right from the entrance), and a fine 1612 Crucifixion sculpture, El Cristo del Calvario (The Christ of Calvary) by Francisco de Ocampo, is in the chapel to the right of the main altar.The church is the home of the Quinta Angustia brotherhood, whose 17th-century Descendimiento tableau, showing Jesus being taken down from the cross, is carried through Seville's streets during Semana Santa

amplificación

préstamo

La amplificación en este caso es una descripción del tipo de obra escultórica de que se trata, así como otros elementos informativos sobre la antigüedad del conjunto escultórico y la descripción del motivo que representa.

La misma técnica de traducción se emplea para la traducción de otro culturema similar, La Virgen de las Huertas. En este caso, el mediador opta por una amplificación en la que no realiza la mediación sobre la información de la denominación del culturema, sino que describe qué tipo de escultura es (woodcarving) y la época de la que data. En este caso, el mediador hace uso de la similitud existente entre las palabras virgen y virgin y no considera relevante el apelativo de las Huertas, que alude a una advocación concreta.

Tabla 40: ficha de análisis del culturema virgen de las huertas 
ID

CODIGO GUÍA

GUÍA

PROVINCIA

ELEMENTO DE ANÁLISIS

TIPOLOGÍA

CAMPO SEMÁNTICO

CONTEXTO

TÉCNICA TRADUCCIÓN 1

TÉCNICA TRADUCCIÓN 2
148

LPA

Lonely Planet Andalucía

Córdoba

virgen de las huertas

culturema

escultura

The palace also houses the MuseoDiocesano (Diocesan Museum; \%957 4960 85; Calle de Torrijos; admission €1.20; h9.30am$3 \mathrm{pm})$, which has a collection of religious art. The best of this art is some outstanding medieval woodcarving, including the 13thcentury Virgen de las Huertas

amplificación

préstamo

El culturema Virgen de la Sede es de la misma naturaleza que el que acabamos de analizar. Sin embargo, en este caso las técnicas empleadas son el préstamo, la amplificación y el calco en triplete, como se observa en la ficha de análisis:

Tabla 41: ficha de análisis del culturema virgen de la sede

ID

CODIGO GUÍA

GUíA

PROVINCIA

ELEMENTO DE ANÁLISIS

TIPOLOGÍA

CAMPO SEMÁNTICO

CONTEXTO

TÉCNICA TRADUCCIÓN 1 TÉCNICA TRADUCCIÓN 2
297

LPA

Lonely Planet Andalucía

Sevilla

virgen de la sede

culturema

escultura

CAPILLA MAYOR East of the choir is the Capilla Mayor (Main chapel). Its Gothic retable is the jewel of the cathedral and reckoned to be the biggest altarpiece in the world. Begun by Flemish sculptor Pieter Dancart in 1482 and finished by others in 1564 , this sea of gilded and polychromed wood holds over 1000 carved biblical figures. At the centre of the lowest level is the tiny 13th-century silver-plated cedar image of the Virgen de la Sede (Virgin of the See), patron of the cathedral.

amplificación

calco 
La amplificación consiste en la inclusión de información variada, como la antigüedad, el tipo de escultura, el material usado para la ornamentación. Acompañando al préstamo encontramos un calco que incluye un equivalente acuñado (See). Se puede observar la técnica de la amplificación resulta de una gran productividad en algunos casos, pues con ella es posible dar cuenta de las características más relevantes del culturema.

De nuevo el triplete préstamo+amplificación+calco vuelve a utilizarse en culturemas que presentan mayor dificultad. Es en estos casos en los que la amplificación cobra aún mayor preponderancia, mientras que la técnica del calco se limita únicamente a transferir el contenido formal del nombre propio. Observemos a continuación la ficha de análisis del Cristo del Cachorro:

Tabla 42: ficha de análisis del culturema cristo del cachorro 
ID

\section{CODIGO GUÍA}

GUíA

PROVINCIA

ELEMENTO DE ANÁLISIS

TIPOLOGÍA

CAMPO SEMÁNTICO

CONTEXTO

TÉCNICA TRADUCCIÓN 1

TÉCNICA TRADUCCIÓN 2

TÉCNICA TRADUCCIÓN 3
356

LPA

Lonely Planet Andalucía

Sevilla

cristo del cachorro

culturema

escultura

Triana has several diverse and important churches and chapels. Among the most important are the Iglesia del Cristo de la Expiración (Map pp94-5;\%954 3333 41; Calle Castilla 182; h10.30am-1.30pm \& 6-9.30pm Tue-Sat, 10.30am-1.30pm Sun) houses a much-loved figure of the dead Christ, dating from 1682, that takes an honoured place in Seville's Semana Santa processions. The image is known as El Cachorro (The Puppy): sculptor Antonio Ruiz Gijón was reputedly inspired by the agonised body of a Gitano singer of that name who had died in a fight in this street. In the southern part of Triana,the Capilla del Rocío (Map pp94-5 ; Calle Evangelista 23) is home to the Hermandad del Rocío deTriana amplificación calco préstamo

A modo de resumen, podemos afirmar que el campo semántico escultura presenta un uso mayoritario de la técnica del préstamo más la amplificación y un uso poco frecuente del triplete formado por el préstamo, la amplificación y el calco y que este tipo de culturemas son realia, por lo que la presencia de técnicas como el préstamo puro y el equivalente funcional es casi anecdótica.

\subsubsection{Fiestas y espectáculos}

El campo semántico fiestas y espectáculos destaca especialmente en esta investigación por el elevado número de manifestaciones culturales y del folclore que posee España a lo largo y ancho de su geografía. Existen fiestas patronales, regionales, nacionales, fiestas populares y un sinfín de actos programados, espectáculos, eventos y festivales dedicados a la gastronomía y las artes 
escénicas. Todas estas expresiones artísticas quedan reflejadas en el lenguaje y dan lugar a multitud de elementos culturales propios de la cultura española y de sus diferentes regiones y pueblos.

La mayoría de estas manifestaciones culturales poseen la categoría de Fiesta de Interés Turístico Nacional en España, una denominación honorífica otorgada a festejos o acontecimientos que se celebran en España y que ofrecen interés real desde el punto de vista turístico. La declaración de Fiesta de Interés Turístico Internacional también es una distinción de carácter honorífico que se concede en España ${ }^{109}$ a las fiestas o acontecimientos que supongan manifestaciones de valores culturales y de tradición popular, con especial consideración a sus características etnológicas y que tengan una especial importancia como atractivo turístico. Sin duda, son este tipo de manifestaciones artísticas y culturales, junto con la gastronomía, las que más llaman la atención de los turistas extranjeros que deciden visitar España.

En cuanto a las técnicas de traducción más frecuentes utilizadas en este campo semántico, observamos que, a efectos del número total de técnicas utilizadas, el préstamo, ya sea usado como técnica individual o en combinación con otras técnicas, es de nuevo la técnica más usada. A continuación la amplificación es la técnica más empleada, seguida del calco y el equivalente acuñado. La adaptación y la generalización son técnicas con un uso muy limitado, como se observa en la siguiente tabla:

Figura 25: Técnicas de traducción del campo semántico fiestas y espectáculos

\footnotetext{
109 La Secretaría General de Turismo del Ministerio de Industria, Turismo y Comercio del Gobierno de España concede estos títulos, que están regulados por la Orden ITC/1763/2006. Las Comunidades Autónomas que cuentan con más fiestas turísticas de interés internacional son Andalucía y la Comunidad Valenciana.
} 


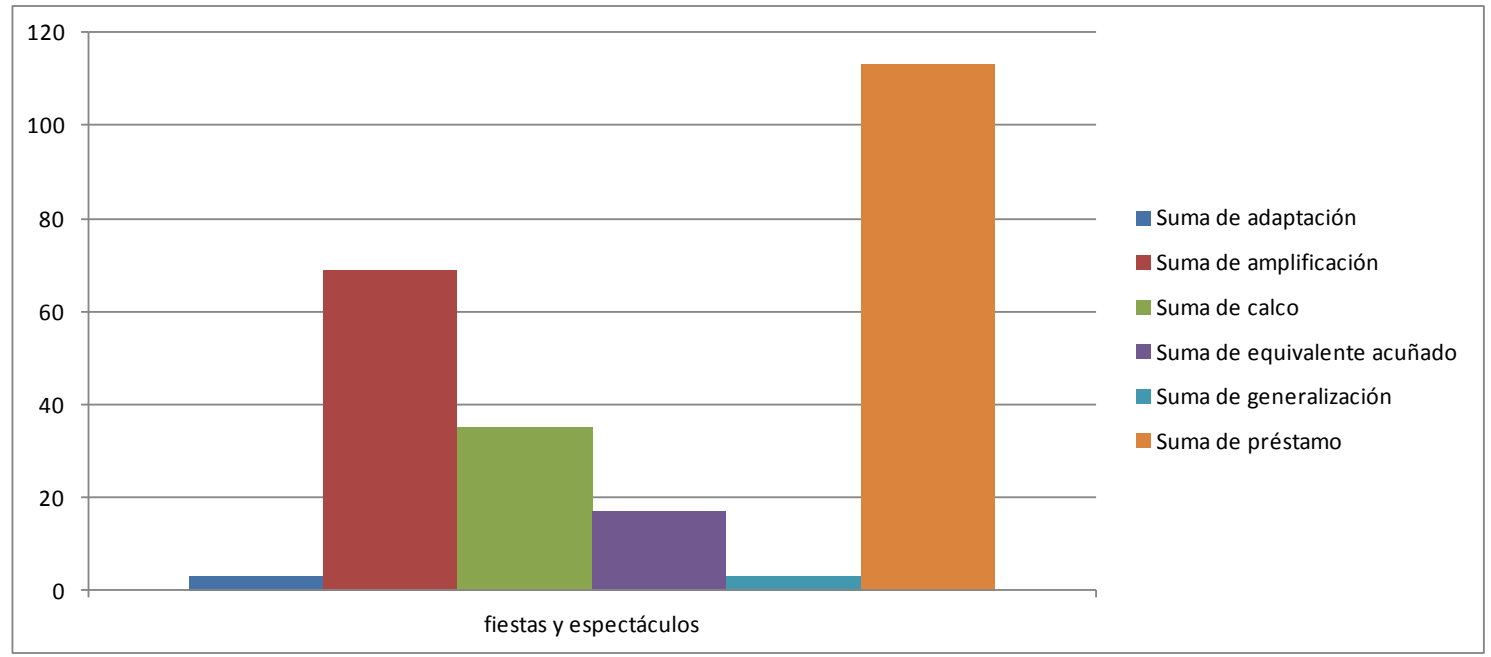

De nuevo, pues, se observa el uso mayoritario del préstamo como técnica más utilizada para la expresión de culturemas relativos a las fiestas y tradiciones de la cultura española. Sin embargo, si atendemos al uso de las técnicas de traducción, tanto simple como combinado, se puede constatar la asociación del préstamo y la amplificación como combinación de técnicas más usadas para este tipo de culturemas (40\%), calco y el préstamo como técnicas combinadas (15\%) y del préstamo usado como técnica simple (12\%) y del equivalente acuñado en combinación con el préstamo (9\%).

Figura 26: Técnicas de traducción (compuestas y simples) del campo semántico fiestas y espectáculos 


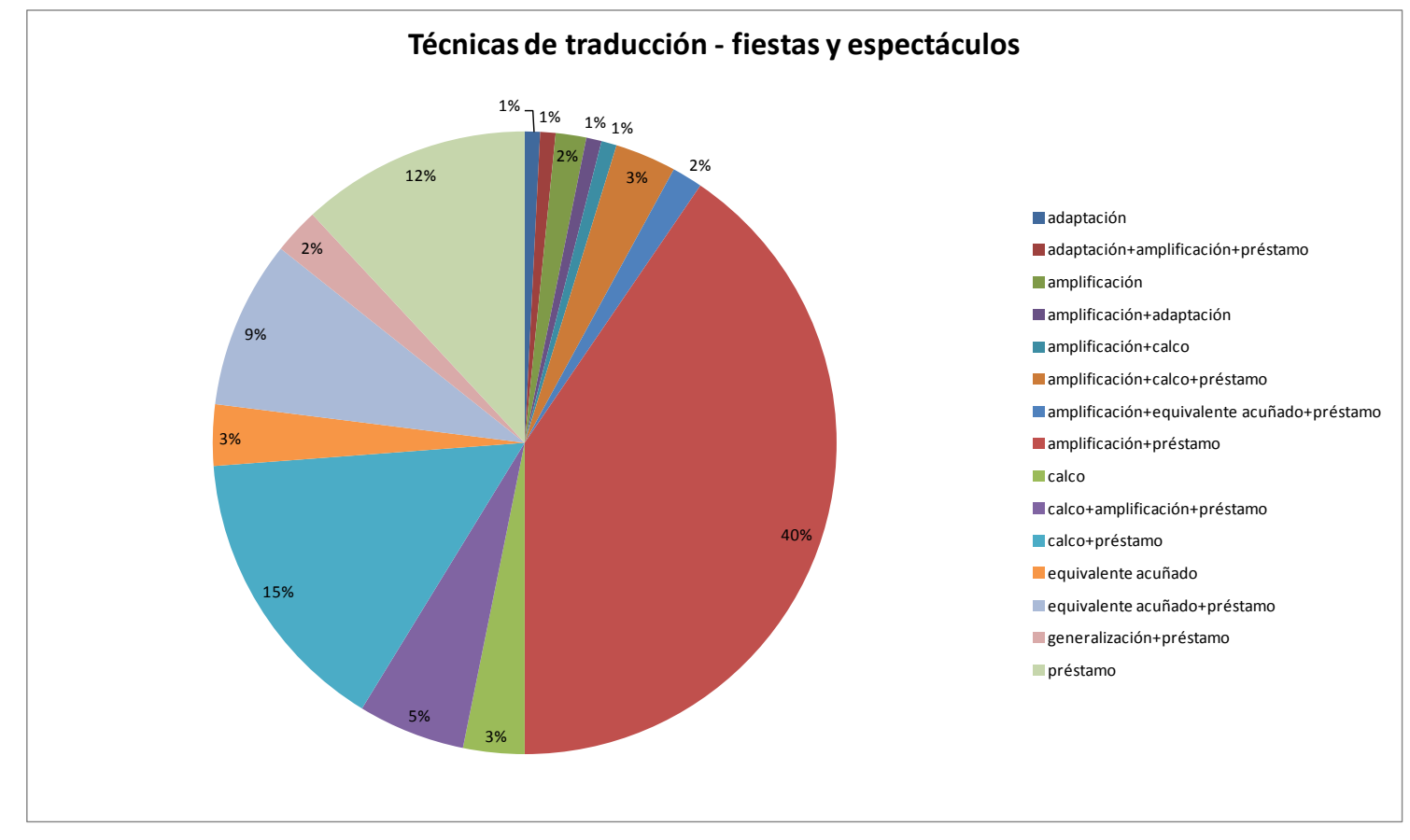

De esta distribución de porcentajes resulta llamativo el uso en un $12 \%$ de casos del préstamo utilizado como técnica simple, cuando en otros campos semánticos este porcentaje suele ser mucho menor.

La causa de la alta frecuencia de uso del culturema flamenco, que aparece en numerosas ocasiones en diversas guías (LPBCN, LPA,...), es el hecho de que flamenco se ha convertido en una palabra globalizada, es decir, que el mediador la utiliza entendiendo que el lector conoce ya dicho culturema, por lo que no es necesario realizar una descripción ni explicitación adicional, ni buscar un equivalente funcional de esta manifestación cultural:

Tabla 43: ficha de análisis del culturema flamenco 
ID

CODIGO GUíA

GUÍA

PROVINCIA

ELEMENTO DE ANÁLISIS

TIPOLOGÍA

CAMPO SEMÁNTICO

CONTEXTO

TÉCNICA TRADUCCIÓN 1
103

LPA

Lonely Planet Andalucía

Cádiz

flamenco

palabra globalizada

fiestas y es pectáculos

Music Festivals Summer revs up in July and August with jazz, flamenco and classical music festivals, and one-off concerts by top Spanish bands

préstamo

El flamenco se sitúa en este caso a la altura del jazz, un estilo musical con raíces culturales en los Estados Unidos y como elemento representativo de dicho país. El culturema jazz se usa en este contexto como icono global, de lo que se deduce, pues, que el mediador supone que el lector no sólo es conocedor de los elementos culturales representativos de la cultura española, sino también de otros elementos universales, como el fado, que el mediador también utiliza como culturema, realizando así una mediación transcultural:

Tabla 44: ficha de análisis del culturema fado 
ID

CODIGO GUÍA

GUÍA

PROVINCIA

ELEMENTO DE ANÁLISIS

TIPOLOGÍA

CAMPO SEMÁNTICO

CONTEXTO

TÉCNICA TRADUCCIÓN 1
576

LPBCN

Lonely Planet Barcelona

Barcelona

fado

culturema

fiestas y espectáculos

The two historic music houses are the Gran Teatre del Liceuand the Palau de la Música Catalana. The former is the city's opera house and the latterputs on an infinitely more eclectic programme,from choral to Portuguese fado. Both have been given a 21st-century remake,the Liceu because it was burned to the ground and the Palau because it so badly needed it! The modern Auditori is home to the city's orchestra préstamo

A menudo observamos el uso de colocaciones del culturema flamenco con otros elementos que sí aportan al lector una información adicional, pero que en ningún caso proveen de información acerca de las connotaciones culturales del culturema:

Tabla 45: ficha de análisis del culturema flamenco 
ID

CODIGO GUÍA

GUÍA

PROVINCIA

ELEMENTO DE ANÁLISIS

TIPOLOGÍA

CAMPO SEMÁNTICO

CONTEXTO

TÉCNICA TRADUCCIÓN 1
95

LPA

Lonely Planet Andalucía

Cádiz

flamenco

palabra globalizada

fiestas y espectáculos

Flamenco happens (at least) every Friday at $9.30 \mathrm{pm}$ at Peña Flamenca El Nitri (\%956 5432 37; Calle Diego Niño 1) and Peña Flamenca El Chumi (\%956 5400 03; Calle Luja 15). Bodega Obregón (Calle Zarza 51), the oldest bar in town, has flamenco on Sunday from $12.30 \mathrm{pm}$ to $3.30 \mathrm{pm}$. There are more flamenco performances in July and August.

préstamo

En el caso anterior, observamos la colocación de flamenco performances. Más habitual, sin embargo, es la colocación de flamenco show, de la que ofrecemos un ejemplo en contexto a continuación:

Tabla 46: ficha de análisis del culturema flamenco

ID

CODIGO GUíA

GUíA

PROVINCIA

ELEMENTO DE ANÁLISIS

TIPOLOGÍA

CAMPO SEMÁNTICO

CONTEXTO

TÉCNICA TRADUCCIÓN 1
277

LPA

Lonely Planet Andalucía

Granada

flamenco

palabra globalizada

fiestas y es pectáculos

El Upsetter (Map p366 ; \%958 2272 96; Carrera del Darro 7; admission for flamenco show €10; h11pm-late)For a decent Saturday-night flamenco show head to El Upsetter, which doubles as a dreadlock-swinging reggae bar for the rest of the week 
De este estudio hemos podido constatar que el culturema flamenco se ha internacionalizado de tal modo que representa a la cultura española fuera de España. Las diversas campañas turísticas de promoción en España han puesto el acento en este tipo de manifestación artística para atraer a los turistas con gran éxito, convirtiéndose el flamenco en un icono de la cultura española y un reclamo turístico. Los esfuerzos por consolidar el flamenco como una atracción turística se vieron culminados en 2010 con la consecución de la mención de Patrimonio Mundial Inmaterial ${ }^{110}$, hecho que le confiere una mayor difusión y protección a esta manifestación artístico-cultural.

En este estudio, flamenco es el culturema que aparece utilizado en mayor número de ocasiones en las guías Lonely Planet analizadas, como se observa a continuación, seguido de alcazaba, tapas, jamón, montadito y bocadillo. Otros culturemas recurrentes son Costa del Sol y procesión, entre otros, como se observa a continuación:

Tabla 47: culturemas de alta frecuencia

\begin{tabular}{|l|c|}
\hline Rótulos de fila & Count of Frecuencia \\
\hline Flamenco & 10 \\
\hline Alcazaba & 8 \\
\hline Tapas & 7 \\
\hline Jamón & 6 \\
\hline Montadito & 6 \\
\hline Bocadillo & 5 \\
\hline costa del sol & 5 \\
\hline
\end{tabular}

${ }^{110}$ Declarado por la UNESCO en 2010 


\begin{tabular}{|l|c|}
\hline Rótulos de fila & Count of Frecuencia \\
\hline Procesión & 5 \\
\hline Salmorejo & 5 \\
\hline Giralda & 5 \\
\hline Manzanilla & 5 \\
\hline Ración & 4 \\
\hline reyes católicos & 4 \\
\hline Reconquista & 4 \\
\hline feria de abril & 4 \\
\hline semana santa & 4 \\
\hline
\end{tabular}

Destacamos de este cuadro de frecuencias el hecho de que los elementos culturales que más se repiten pertenecen al campo semántico de las fiestas y espectáculos y a la gastronomía.

Además del préstamo, otra de las técnicas que merece especial atención en este campo semántico es el uso del calco. En ocasiones, se observa su uso como técnica simple ( $\sin$ el préstamo puro) en casos en que el culturema es transparente y resulta fácil de traducir, debido a la morfología misma del culturema, que está formado por dos elementos fácilmente reproducibles en la LM, como ocurre en el caso del culturema siguiente: 
ID

\section{CODIGO GUÍA}

GUÍA

PROVINCIA

ELEMENTO DE ANÁLISIS

TIPOLOGÍA

CAMPO SEMÁNTICO

CONTEXTO

TÉCNICA TRADUCCIÓN 1
677

LPA

Lonely Planet Andalucía

Córdoba

sombrero cordobés

culturema

fiestas y espectáculos

The tradicional flamenco costume- shawl, fan, and long frilly bata de cola dress, and for men, flat Cordoban hats and tight black trousers-dates from Andalucian fashions of 19th century. calco

En el caso de sombrero cordobés, no nos encontramos ante un elemento opaco completamente, pues uno de los elementos que lo conforman pertenece al lenguaje general. El contenido cultural, y, en este caso, el rasgo distintivo lo aporta el adjetivo cordobés, Cordoban, por lo que, analizando la mediación desde el punto de vista del proceso, se traduce transmitiendo la denominación del culturema. La posibilidad de calcar la estructura de la LO es frecuente en algunos culturemas formados por un nombre combinado con un gentilicio o ciudad. En el mismo contexto se observa otro culturema que el mediador resuelve con una descripción sin utilizar el préstamo puro. Es el caso de calzona ${ }^{111}$, el pantalón flamenco, que el mediador define como "tight black trousers". Así pues, el mediador ha decidido en este caso concreto transmitir cómo es la vestimenta flamenca del hombre sin utilizar ningún préstamo y ayudándose únicamente del calco estructural del culturema y de la descripción.

Sin embargo, como estamos constatando a lo largo de este análisis, el calco suele ir acompañado del préstamo y en muchos casos, de la amplificación, ya que debido a la complejidad de algunos culturemas, el calco no es suficiente

\footnotetext{
${ }^{111}$ EI DRAE no recoge el término calzona, aunque sí el término calzón, pero no con esta acepción.
} 
para transmitir la totalidad o la información más relevante que contiene el culturema. Este es el caso del culturema besapiés ${ }^{112}$ :

Tabla 49: ficha de análisis del culturema besapiés

\begin{tabular}{ll}
$\begin{array}{l}\text { ID } \\
\text { CODIGO GUÍA } \\
\text { GUÍA } \\
\text { PROVINCIA } \\
\text { ELEMENTO DE ANÁLISIS } \\
\text { TIPOLOGÍA }\end{array}$ & $\begin{array}{l}614 \\
\text { LPM }\end{array}$ \\
$\begin{array}{l}\text { CAMPO SEMÁNTICO } \\
\text { CONTEXTO }\end{array}$ & $\begin{array}{l}\text { Madrid Planet Madrid } \\
\text { besapié }\end{array}$ \\
\hline $\begin{array}{l}\text { culturema } \\
\text { fiestas y espectáculos }\end{array}$ \\
$\begin{array}{l}\text { Jesús de Medinaceli Up to 100,000 people crowd the Iglesia de } \\
\text { Jesús de Medinaceli (Map pp84-5 ) on the first Friday of Lent to } \\
\text { kiss the right foot of a wooden sculpture of Christ (besapié, } \\
\text { kissing of the foot). Pilgrims make three wishes to Jesus, of which } \\
\text { he is said to grant one. } \\
\text { TÉCNICA TRADUCCIÓN 1 } \\
\text { TÉCNICA TRADUCCIÓN 2 } \\
\text { TÉCNICA TRADUCCIÓN 3 }\end{array}$ \\
$\begin{array}{l}\text { amplificación } \\
\text { préstamo }\end{array}$
\end{tabular}

Este término alude al acto de rendir culto a una imagen religiosa por parte de los fieles a través del beso. En la tradición religiosa en España, son frecuentes tanto en Semana Santa, como en Navidad los besamanos y los besapiés. El mediador transmite la denominación del culturema, en este caso, a través del préstamo y el calco el culturema y se vale de la descripción para ofrecer los detalles de la talla y de la tradición que rodea esta tradición religiosa. Cabe señalar en este punto la dificultad normativa

${ }^{112}$ EI DRAE no recoge el culturema besapiés, aunque sí el de besamanos. 
que presenta el culturema para el mediador, que lo reproduce como besapié mientras que su forma correcta es besapiés. Este tipo de irregularidades de una lengua son muy difíciles de detectar para un mediador que no tenga un conocimiento muy profundo de la lengua desde la cual está realizando la mediación.

La mediación en algunos casos se realiza sobre culturemas que son parte fundamental de la cultura de todos los individuos de dicha sociedad. Esta situación es poco frecuente, pues la cultura, tal como está conformada, acaba siendo individual y diferente según el mapa del mundo de cada persona.

Este es el caso de las 12 campanadas. Esta tradición de dar la bienvenida al nuevo año con las Campanadas de la Puerta del Sol al tiempo que se comen las 12 uvas de la suerte es compartida por todos los españoles. La mediación que se ha realizado en este caso recoge varios elementos culturales relacionados (Nochevieja, Año Nuevo), y se circunscribe únicamente a los ciudadanos de Madrid. La mediación que realiza el traductor en este caso es acertada, pero la tradición de las 12 campanadas y las 12 uvas es extensible al resto de regiones en España, información que no queda reflejada en el TM:

Tabla 50: ficha de análisis del culturema las doce campanadas 


\begin{tabular}{|c|c|}
\hline ID & 604 \\
\hline CODIGO GUÍA & LPM \\
\hline GUÍA & Lonely Planet Madrid \\
\hline PROVINCIA & Madrid \\
\hline ELEMENTO DE ANÁLISIS & las 12 campanadas \\
\hline TIPOLOGÍA & culturema \\
\hline CAMPO SEMÁNTICO & fiestas y espectáculos \\
\hline CONTEXTO & $\begin{array}{l}\text { Noche Vieja (New Year's Eve) is often celebrated at home with } \\
\text { family, before people head out after midnight to paint the town } \\
\text { red and all other sorts of colours. Many madrileños gather in } \\
\text { Plaza de la Puerta del Sol to wait for the } 12 \text { campanadas (bell } \\
\text { chimes) that signal Año Nuevo (New Year's Day), whereupon they } \\
\text { try to stuff } 12 \text { grapes }\end{array}$ \\
\hline TÉCNICA TRADUCCIÓN 1 & calco \\
\hline TÉCNICA TRADUCCIÓN 2 & préstamo \\
\hline
\end{tabular}

Observamos, por tanto, que en algunos casos, el mediador debe tener la capacidad de reconocer la pertenencia de una manifestación cultural no sólo a un determinado grupo.

De nuestra revisión teórica y descripción de texto turístico en el capítulo 1 de esta investigación se desprende el uso de marcas turísticas, un tipo de elementos lingüísticos reconocidos como imagen para la promoción de un destino o evento turístico determinado (cfr. 3.1.2). En nuestro análisis se han identificado varias marcas turísticas, la mayoría presentes en el campo semántico paisaje y geografía (cfr. 4.2.2.9). Sin embargo, las marcas turísticas se encuentran presentes asimismo en el campo semántico de fiestas $y$ espectáculos. La Tomatina, que empezó siendo una fiesta local y popular, se ha convertido en una fiesta internacional de gran renombre. Dicha popularidad llevó al Ayuntamiento de Buñol, ciudad donde se celebra, a registrar la marca Tomatina y utilizarla institucionalmente para promocionar la ciudad. El culturema, identificado en LPVLC, se transmite a través del uso del préstamo y la amplificación, si bien la amplificación queda restringida a explicitar el tipo de manifestación artística con el uso del vocablo festival: 
Tabla 51: ficha de análisis del culturema tomatina

ID

CODIGO GUÍA

GUÍA

PROVINCIA

ELEMENTO DE ANÁLISIS

TIPOLOGÍA

CAMPO SEMÁNTICO

CONTEXTO

TÉCNICA TRADUCCIÓN 1

TÉCNICA TRADUCCIÓN 2
15

LPVLC

Lonely Planet Valencia

Valencia

tomatina

marca turística

fiestas y espectáculos

Men with fresh ammunition at La Tomatina Festival

amplificación

préstamo

El Diccionario Oxford English Online define festival como "an organized series of concerts, plays, or films, typically one held annually in the same place". Atendiendo a esta definición, festival no refiere ningún tipo de información del culturema ni de su carga cultural, simplemente ofrece la idea de un evento programado periódicamente, especialmente eventos dedicados a las artes escénicas. La Tomatina, sin embargo, posee una carga cultural importante y una tradición antigua que se ha mantenido a través de los años y que se ha convertido hoy en día en una de las batallas festivas más famosas en el mundo. La explicitación, pues, quedaría en este caso abierta a la completa interpretación del turista, de no ser porque la fotografía actúa en este caso como elemento de apoyo al culturema. Una de las características de las guías Lonely Planet generales es el predominio del texto sobre los elementos visuales, que quedan relegados a un segundo plano. No ocurre así en la guía Lonely Planet Valencia Encounter, diseñada como una guía de bolsillo para disfrutar de la ciudad de Valencia y sus alrededores y que incluye una gran cantidad de fotografías representativas de los lugares y atracciones más relevantes. 
A efectos de este estudio se considera Tomatina como marca turística. No obstante, se trata asimismo de un culturema que representa una manifestación cultural y festiva que está sufriendo un proceso de internacionalización muy rápido. Esto puede deberse a que muchas culturas están adoptando esta fiesta ${ }^{113}$, por lo que su estudio en los próximos años resulta de gran interés por las posibilidades que presenta de convertirse en una palabra globalizada, tal como ocurre con flamenco.

Del análisis del campo semántico fiestas y espectáculos hemos identificado una serie de culturemas que se relacionan entre sí en torno a una única temática o cultural. A continuación los mostramos agrupados en los diferentes focos culturales.

\begin{tabular}{|l|l|}
\hline \multicolumn{2}{|l|}{ FOCO CULTURAL: LAS FALLAS } \\
\hline Fallas & Fallero \\
\hline Mascletá & Castillo \\
\hline
\end{tabular}

\begin{tabular}{|l|l|}
\hline \multicolumn{2}{|l|}{ FOCO CULTURAL: TAUROMAQUIA } \\
\hline Museo taurino & Torero \\
\hline Plaza de toros & Novillada \\
\hline Banderillero & Picador \\
\hline Muleta & Corrida goyesca \\
\hline Corrida de toros & Cuadrilla \\
\hline
\end{tabular}

${ }^{113}$ En la última década, la Tomatina ha inspirado distintas celebraciones en países con culturas tan diversas como Chile, Costa Rica, China y Estados Unidos, y algunas de ellas han tomado incluso el culturema Tomatina como referencia para denominarla. 


\begin{tabular}{|l|l|}
\hline \multicolumn{2}{|l|}{ FOCO CULTURAL: SEMANA SANTA } \\
\hline Madrugá & Paso \\
\hline Semana Santa & Procesión \\
\hline Hermandad & Via crucis \\
\hline Saeta & Cofradía \\
\hline Costalero & Capataz \\
\hline Nazareno & \\
\hline
\end{tabular}

\begin{tabular}{|l|l|}
\hline \multicolumn{2}{|l|}{ FOCO CULTURAL: FIESTAS DE S. JORDI } \\
\hline Castell & Anxaneta \\
\hline Folre & Sant Jordi \\
\hline Correfoc & Sardana \\
\hline
\end{tabular}

\begin{tabular}{|l|l|}
\hline FOCO CULTURAL: FLAMENCO & Sevillanas \\
\hline Peña flamenca & Tablao \\
\hline Flamenco & Tocaor \\
\hline Bailaora & Cantaor \\
\hline Cante jondo & Taconeo \\
\hline Castañuelas & Soleás \\
\hline Coplas & Bata de cola \\
\hline Seguiriyas & \\
\hline Sombrero cordobés & \\
\hline
\end{tabular}

FOCO CULTURAL: FIESTAS DE S. ISIDRO

Castizo

Besapié 


\begin{tabular}{|l|l|}
\hline Manola & Chulapo \\
\hline Mantón de manila & Chotis \\
\hline
\end{tabular}

De nuestro análisis de los culturemas del campo semántico fiestas y espectáculos hemos podido establecer una serie de focos culturales que merecen una atención detallada en lo que a la traducción de sus culturemas se refiere.

En este sentido, se constata el hecho de que el foco cultural tauromaquia presenta una frecuencia elevada del uso de la técnica equivalente cultural, en algún caso combinada con la técnica del préstamo. Observamos a continuación la mediación realizada para los culturemas corrida de toros y plaza de toros en su contexto:

Tabla 52: ficha de análisis del culturema plaza de toros

\begin{tabular}{|c|c|}
\hline ID & 83 \\
\hline CODIGO GUÍA & LPA \\
\hline GUÍA & Lonely Planet Andalucía \\
\hline PROVINCIA & Cádiz \\
\hline ELEMENTO DE ANÁLISIS & plaza de toros \\
\hline TIPOLOGÍA & culturema \\
\hline CAMPO SEMÁNTICO & fiestas y espectáculos \\
\hline CONTEXTO & $\begin{array}{l}\text { Four blocks southwest from Plaza de España is El Puerto's grand } \\
\text { 19th-century Plaza de Toros (Plaza Elías Ahuja; admission free; } \\
\text { h11am-1.30pm \& 6-7.30pm Tue-Sun May-Sep, 11am-1.30pm } \\
\& 5.30-7 p m \text { Tue-Sun Oct-Apr), one of Andalucía's most beautiful } \\
\text { and important bullrings, with room for 15,000 spectators. It's } \\
\text { closed on days before and after bullfights }\end{array}$ \\
\hline TÉCNICA TRADUCCIÓN 1 & equivalente acuñado \\
\hline TÉCNICA TRADUCCIÓN 2 & préstamo \\
\hline
\end{tabular}


El culturema plaza de toros se transmite a través del uso del préstamo y un equivalente acuñado (bullring) integrado en una descripción discursiva. Por su parte, corrida de toros destaca en este caso por el uso que presenta a través de un equivalente acuñado sin la presencia recurrente del préstamo que se ha venido observando a lo largo del análisis junto con la amplificación del significado. El mismo tratamiento recibe el culturema torero, que no aparece en español, como supondríamos, sino que el mediador recurre al equivalente establecido en la lengua meta y se refiere a este como matador.

Sin duda, esto se produce por la globalización que ha sufrido este tipo de expresión artístico-cultural ${ }^{114}$ practicada desde muy antiguo por distintas culturas, que se ha erigido en icono de la cultura española y latinoamericana ${ }^{115}$. La actividad más conocida de la tauromaquia es la corrida de toros y su actor principal también despierta gran interés, motivos por los cuales existen equivalentes establecidos en algunas culturas meta. Sin embargo, el número de culturemas que forman parte de este foco cultural es amplísimo, si bien el mediador reproduce en las guías Lonely Planet aquellos más relevantes.

\subsubsection{Gastronomía y restauración}

Sin duda, uno de los atractivos de España como destino turístico es su variada y rica gastronomía, lo que ha llevado en los últimos años a un aumento exponencial de visitantes extranjeros de turismo gastronómico en nuestro país. Hoy España ocupa la vanguardia gastronómica universal y dispone de la mejor materia prima, sobre todo, en la relación calidad-precio. Seis de los 52 millones

\footnotetext{
${ }^{114}$ El Diccionario de la Real Academia Español le otorga en su definición la categoría de arte.

115 La tauromaquia se practica en varios países latinoamericanos y se considera parte integral de la cultura nacional. Países europeos como Francia y Portugal también la practican en áreas geográficas muy localizadas.
} 
de turistas que llegaron a España en 2009 se han sentido atraídos no sólo por el sol y playa, sino también por la gastronomía y los vinos. Así mismo, manifestaron que la comida resultó lo más satisfactorio del viaje ${ }^{116}$.

Como hemos descrito en el capítulo 3 (cfr.3.2.1), el texto turístico es un texto multifuncional que combina distintas disciplinas y modalidades discursivas. La abundante presencia de elementos culturales en este tipo de textos le otorga unas características óptimas para el estudio traductológico de estos elementos. La gastronomía es un ámbito especialmente enraizado en la cultura de un pueblo y que ofrece multitud de elementos que revelan la tradición y las costumbres de un grupo social.

Estas marcas culturales tan sumamente complicadas de transmitir se reflejan claramente en uno de los ámbitos más recurrentes de los textos turísticos: la temática gastronómica, sobre la cual coincidimos con Newmark cuando afirma que "Food is for many the most sensitive and importante expression of national culture" (Newmark, 1991:137).

En nuestro análisis de los culturemas del texto turístico y sus técnicas de traducción se ha podido constatar que la gastronomía y la restauración conforman el campo semántico en el que existe un mayor número de culturemas, como se refleja en la siguiente tabla:

Figura 27: Número de culturemas por campo semántico

\footnotetext{
${ }^{116}$ Datos extraídos del I Congreso Europeo de Gastronomía y Turismo celebrado en Madrid el 24 y 25 de mayo de 2010.
} 


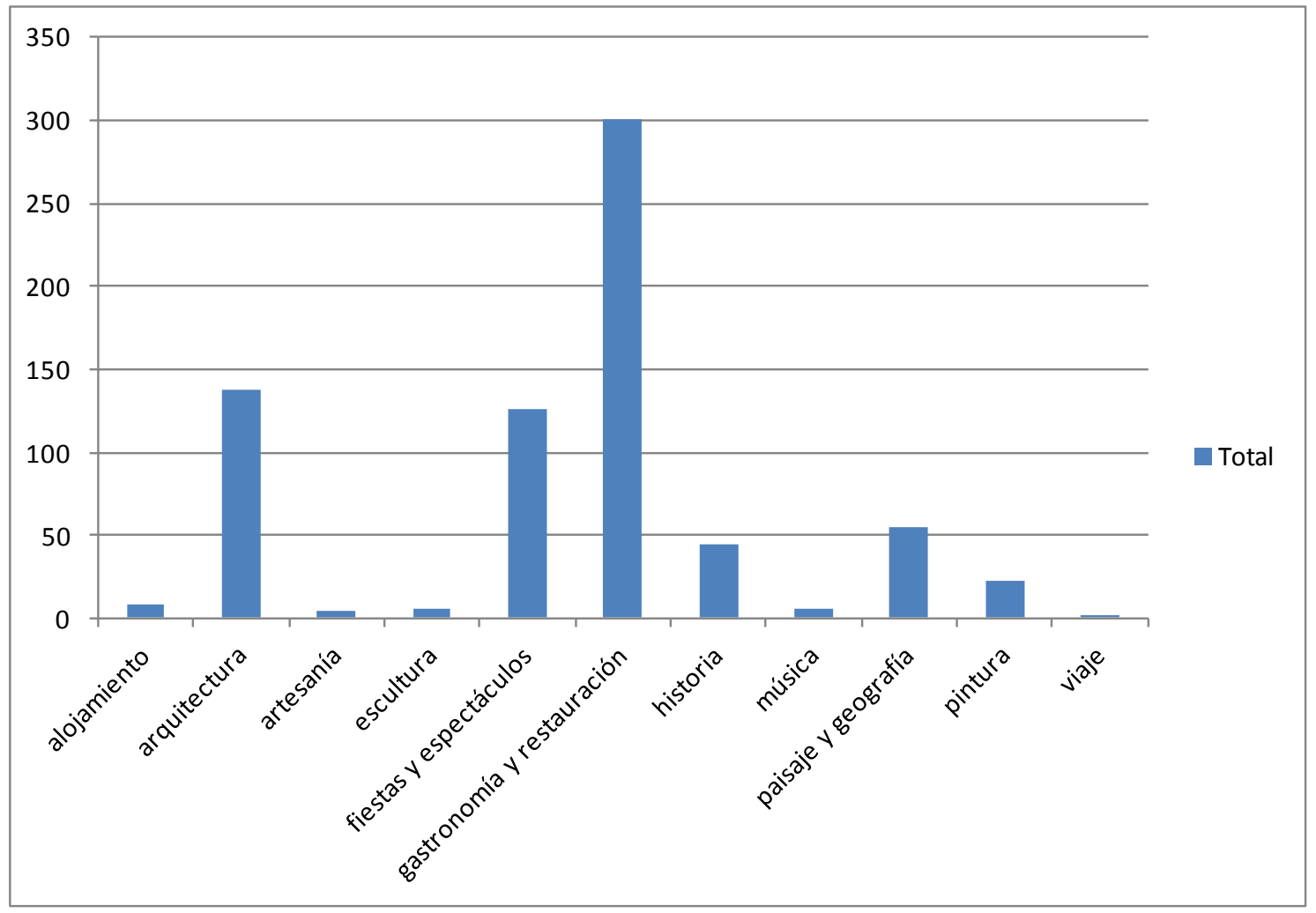

Los culturemas pertenecientes al campo semántico gastronomía y restauración suman en total 301, la cantidad más alta; arquitectura es el campo semántico que aporta el segundo mayor número de culturemas (138 elementos) y fiestas y espectáculos recoge un total de 126 culturemas. Podemos establecer un segundo grupo de campos semánticos que presentan una cantidad inferior (aunque similar en número) de culturemas. Se trata de paisaje y geografía, historia y pintura. Finalmente, encontramos campos semánticos como alojamiento, artesanía, escultura, música y viaje, en los que la presencia de culturemas es escasa.

En cuanto a la distribución y la frecuencia de las técnicas de traducción empleadas por los mediadores de las guías Lonely Planet, se observa que las técnicas combinadas son de nuevo las técnicas que predominan para traducir 
este tipo de elementos. La figura siguiente nos muestra el uso mayoritario de la combinación formada por el préstamo y la amplificación y el uso de otras combinaciones en triplete que suelen ser poco habituales:

Figura 28: Técnicas de traducción compuestas del campo semántico gastronomía y restauración

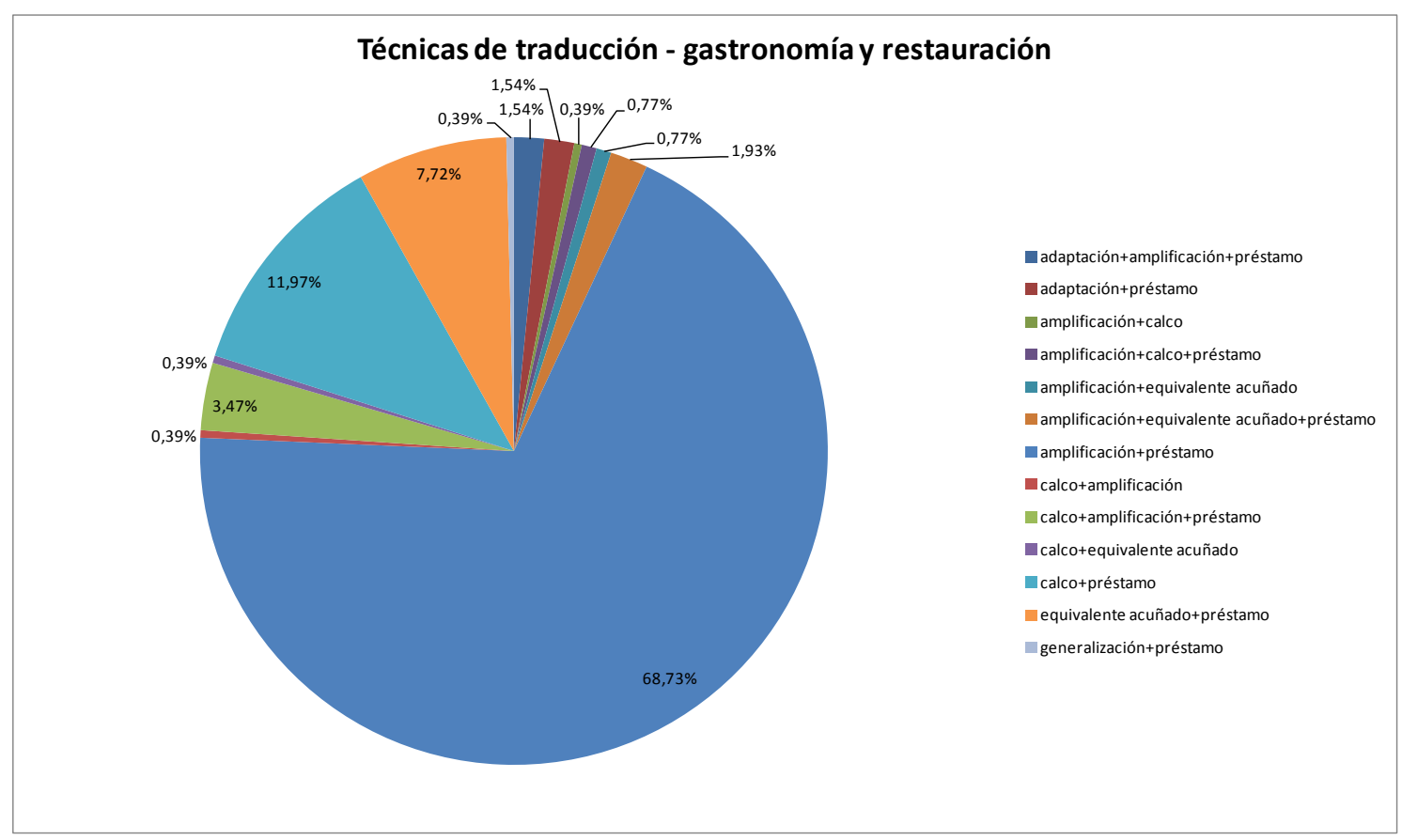

El resto de técnicas más utilizadas son técnicas compuestas, y responden a la combinación de calco más préstamo y equivalente acuñado más préstamo. A diferencia de otros campos semánticos, en gastronomía y restauración no existen equivalentes culturales de los que el mediador pueda valerse en su interpretación de la cultura de origen. Sí se aprecia el uso de algún equivalente funcional, que permite relacionar culturemas similares de una y otra cultura con el objetivo de transmitir la información fundamental del culturema. El uso del calco, del mismo modo, aparece de modo ocasional. 
De nuestro análisis de los culturemas del campo semántico gastronomía y restauración en las guías Lonely Planet, debemos destacar la complejidad que supone la traducción de los culturemas que representan un guiso o plato típico e incluyen un ingrediente genuino de la cocina española, sino también el sistema de valores, reglas y convenciones establecidas por los distintos grupos sociales que se derivan de los mismos.

Una de esas convenciones establecidas viene determinada, por ejemplo, por la tipología del establecimiento que ofrece comida o bebida y que se rige por unos patrones conductuales diferentes. Así, por ejemplo, el mediador de la guía LPBCN, pone el énfasis no tanto en la explicitación del significado de los distintos tipos de restaurantes, sino en el tipo de comida que allí se sirve y de qué modo:

Tabla 53: ficha de análisis del culturema mesón

ID

CODIGO GUÍA

GUÍA

PROVINCIA

ELEMENTO DE ANÁLISIS

TIPOLOGÍA

CAMPO SEMÁNTICO

CONTEXTO

TÉCNICA TRADUCCIÓN 1

TÉCNICA TRADUCCIÓN 2
537

LPBCN

Lonely Planet Barcelona

Barcelona

mesón

culturema

gastronomía y restauración

Many tavernes/tabernas, cerveserias/cervezerías (beer bars) and cellers/bodegas (wine cellars) offer some form of solid sustenance. This can range from entrepans/bocadillos (filled rolls) or flautas (a slimmer version), tapas and raciones to full meals served in menjadors/comedores (sit-down restaurants) out the back. For a full meal, you will most frequently end up in a restaurant/restaurante. Other establishments you may come across include a marisquería, which specialises in seafood, or a mesón (big table), which might (but not necessarily) indicate a more modest eatery

calco

préstamo 
En la ficha de análisis anterior, encontramos que se realiza la mediación sobre los distintos tipos de establecimientos como taberna, cervecería, bodega, restaurante, marisquería, que, en la mayoría de casos, no representan un problema en la transmisión del culturema, pues, en general, el mediador resuelve indicando el tipo de comida que se puede degustar. La dificultad, en estos casos, reside en la explicación del patrón conductual del grupo social en cada uno de estos establecimientos. Para ello el mediador opta por la explicitación indicando que los comedores son "sit-down restaurants", y los restaurantes son establecimientos en los que realiza una "full meal". La mediación en este caso resulta del todo acertada, teniendo en cuenta que la cultura de destino no comparte, en materia gastronómica, los patrones de conducta de la cultura de origen, como tampoco dedican el mismo tiempo ni la misma importancia al hecho de comer.

Destaca el uso de la técnica del calco para la mediación del culturema mesón, que se traduce como "big table". Este calco estructural no aporta información sobre este tipo de establecimiento típico, donde se sirven comidas y bebidas ${ }^{117}$, y no va más allá de la mediación realizada únicamente sobre la denominación del culturema.

Hemos constatado la dificultad que representan algunos culturemas que, en su denominación, no sólo albergan un contenido informativo que refiere a su composición e identificación, sino que además contienen una carga cultural que pertenece a un nivel cultural superior que es necesario conocer para poder

\footnotetext{
117 EI DRAE también define mesón como hospedaje público donde por dinero se daba albergue a
} viajeros, caballerías y carruajes. 
entender los usos y costumbres que vienen asociados a la cultura gastronómica española.

Este es el caso de vino de la casa. El mediador utiliza en el caso de este culturema el préstamo, como viene siendo habitual para su mediación. Sin embargo, es la amplificación, utilizada como recurso discursivo la que garantiza el éxito de la mediación, pues se trata de culturemas que necesitan obligatoriamente de una explicación de los usos y costumbres que imperan en España en lo que a elección de bebidas y vino se refiere:

Tabla 54: ficha de análisis del culturema vino de la casa

ID

CODIGO GUÍA

GUÍA

PROVINCIA

ELEMENTO DE ANÁLISIS

TIPOLOGÍA

CAMPO SEMÁNTICO

CONTEXTO

TÉCNICA TRADUCCIÓN 1

TÉCNICA TRADUCCIÓN 2 TÉCNICA TRADUCCIÓN 3
579

LPBCN

Lonely Planet Barcelona

Barcelona

vino de la casa

culturema

gastronomía y restauración

Apart from vi/vino de la casa (house wine), which is commonly ordered at lunchtime by the litre or half-litre, you will pay an average of $€ 10$ to $€ 15$ for a reasonable bottle, and considerably more for something classier. You can also generallyorder wine by the copa (glass) in bars and restaurants, although the choice will be morelimited. Not generally available in bars is the acquired taste of calimocho, a mix of Tetrabrik red wine and coke, beloved of penniless partying students across the country

calco

amplificación

préstamo

El mediador, en muchos casos, se encuentra con que debe adentrarse en la especialidad de alguno de los productos más típicos de las gastronomía de la cultura meta, en estos casos, resulta fundamental distinguir entre las distintas variedades dentro de la temática, como ocurre con la cerveza, que es, junto con el vino, la bebida preferida por los españoles. 
Con el objetivo de acercar las distintas variedades de cerveza al lector destinatario, el mediador utiliza el préstamo y en algunos casos, el calco, como se observa en la siguiente ficha de análisis del culturema rubia.

Tabla 55: ficha de análisis del culturema rubia

ID
CODIGO GUÍA
GUÍA
PROVINCIA
ELEMENTO DE ANÁLISIS
TIPOLOGÍA
CAMPO SEMÁNTICO
CONTEXTO

TÉCNICA TRADUCCIÓN 1 TÉCNICA TRADUCCIÓN 2

\begin{tabular}{l}
176 \\
LPA \\
Lonely Planet Andalucía \\
\hline Córdoba \\
rubia \\
\hline culturema \\
gastronomía y restauración \\
The beer comes in five tasty varieties: blonde rubia and tostada, \\
the dark caramelizada and morenita, and the especial, which \\
varies from season to season \\
calco \\
préstamo
\end{tabular}

Así pues, el mediador acerca a la cultura meta no únicamente la realidad y diversidad del producto, sino también el modo popular con el que se conoce. En este caso, el uso del préstamo no sólo implica que el TM adquiera un mayor color local, sino también una manera de acercar la LO y las acepciones populares de los culturemas al turista de la cultura meta.

Un elemento primordial que forma parte de las estructuras y sistemas de una de las capas más superficiales que describe Hofstede (1991) es, en el caso del campo semántico gastronomía y restauración, la distinción que se realiza con la 
Denominación de Origen ${ }^{118}$ de los productos. Las Denominaciones de Origen Protegidas (DOP) e Indicaciones Geográficas Protegidas (IGP) constituyen el sistema utilizado en nuestro país para el reconocimiento de una calidad diferenciada, consecuencia de características propias y diferenciales, debidas al medio geográfico en el que se producen las materias primas, se elaboran los productos, y a la influencia del factor humano que participa en las mismas.

El mediador debe tener un conocimiento de este tipo de estructuras y sistemas culturales para poder realizar la mediación con éxito. A continuación mostramos el culturema Denominación de Origen en contexto y analizamos su traducción:

Tabla 56: ficha de análisis del culturema denominación de origen

ID

CODIGO GUÍA

GuíA

PROVINCIA

ELEMENTO DE ANÁLISIS

TIPOLOGÍA

CAMPO SEMÁNTICO

CONTEXTO

TÉCNICA TRADUCCIÓN 1

TÉCNICA TRADUCCIÓN 2
188

LPA

Lonely Planet Andalucía

Córdoba

denominación de origen

culturema

gastronomía y restauración

The name 'Baena' is synonymous with fine olive oil. This small market town, surrounded by endless serried ranks of olive trees, produces olive oil of such superb quality, it has been accredited with its own Denominación de Origen (DO; a designation that indicates the product's unique geographical origins, production processes and quality) label.

amplificación

préstamo

118 La Denominación de Origen está regulada por el Ministerio de Medio Ambiente, Medio Rural y Marino. 
Las técnicas utilizadas para la mediación del culturema Denominación de Origen son el préstamo en combinación con la amplificación. De nuevo, la mediación se realiza indicando culturema en LO en modo abreviado como información práctica. Este tipo de culturemas representa una gran dificultad y puede pasar desapercibido para el mediador que no ha estado inmerso y ha participado de la cultura meta en cuestión. No es este el caso de los mediadores de las guías Lonely Planet, pues, como observamos, el mediador en este caso conoce las peculiaridades y características de esta distinción.

Del análisis de los elementos culturales del ámbito gastronómico destacamos la frecuencia de aparición de elementos culturales contextualizados geográficamente, es decir, aquellos que en su denominación poseen rasgos característicos de la zona geográfica a la que pertenecen. Destacamos algunos de estos culturemas como plato rondeño, ensalada catalana, y pulpo gallego.

La mediación realizada para el primer elemento cultural de este tipo, plato rondeño, se basa en el uso del calco de la estructura de la LO al inglés (rondeño dish), que, junto con la amplificación "dishes from Ronda", da el sentido de pertenencia al destino que se está describiendo, sin entrar en detalle acerca de las distintas variedades de los platos típicos de Ronda: 
ID

\section{CODIGO GUÍA}

GUÍA

PROVINCIA

ELEMENTO DE ANÁLISIS

TIPOLOGÍA

CAMPO SEMÁNTICO

CONTEXTO

TÉCNICA TRADUCCIÓN 1

TÉCNICA TRADUCCIÓN 2
466

LPA

Lonely Planet Andalucía

Málaga

plato rondeño

culturema

gastronomía y restauración

Restaurante Pedro Romero (\%952 8711 10; Calle Virgen de la

Paz 18; menú €16, mains €15-18) Opposite the bullring, this celebrated eatery dedicated to bullfighting turns out classic rondeño dishes (dishes from Ronda). This is a good place to try the rabo de toro (oxtail stew). Vegetarians will enjoy the fried goat's cheese starter served with apple sauce

calco

amplificación

Un caso similar es el de ensalada catalana. En la LPBCN observamos el uso de este culturema, para el que se utiliza la técnica en triplete de préstamo, amplificación y calco. En el caso del calco, de nuevo el mediador busca crear en la mente del turista el referente a través del equivalente salad. Sin embargo, es la amplificación la técnica que aporta el sentido cultural y en este caso, el elemento clave y fundamental de la ensalada catalana, que supone el añadido de embutido o companaje a rodajas.

Tabla 58: ficha de análisis del culturema ensalada catalana 
ID

CODIGO GUÍA

GUíA

PROVINCIA

ELEMENTO DE ANÁLISIS

TIPOLOGÍA

CAMPO SEMÁNTICO

CONTEXTO

TÉCNICA TRADUCCIÓN 1

TÉCNICA TRADUCCIÓN 2

TÉCNICA TRADUCCIÓN 3
515

LPBCN

Lonely Planet Barcelona

Barcelona

ensalada catalana

culturema

gastronomía y restauración

Amanida catalana (Catalan salad) Almost any mix of lettuce, olives, tomatoes, hard-boiled eggs, onions, chicory, celery, green peppers and garlic, with tuna (almost always canned), ham or sausage, and either mayonnaise or an oiland vinegar dressing calco amplificación

préstamo

No obstante, en algunos casos, la mediación se realiza únicamente mediante la adición de un término neutro, como podemos observar a continuación en la ficha de análisis del culturema pulpo a la gallega, donde a la gallega no refiere únicamente a un lugar geográfico concreto, como es el caso de plato rondeño, sino que alude también a unas características concretas de elaboración y presentación. En la ficha de análisis se observa la neutralización de esta particularidad a través del uso de la nominalización "Galician style":

Tabla 59: ficha de análisis del culturema pulpo a la gallega 


\begin{tabular}{|c|c|}
\hline ID & 642 \\
\hline CODIGO GUÍA & LPM \\
\hline GuÍA & Lonely Planet Madrid \\
\hline PROVINCIA & Madrid \\
\hline ELEMENTO DE ANÁLISIS & pulpo a la gallega \\
\hline TIPOLOGÍA & culturema \\
\hline CAMPO SEMÁNTICO & gastronomía y restauración \\
\hline CONTEXTO & $\begin{array}{l}\text { Las Bravas has long been the place for a caña (small glass of } \\
\text { beer) and the best patatas bravas (fried potatoes with a spicy } \\
\text { tomato sauce) in town; other good orders include pulpo a la } \\
\text { gallega, (octopus Galician style), calamares (calamari) and oreja } \\
\text { a la plancha (grilled pig's ear). }\end{array}$ \\
\hline TÉCNICA TRADUCCIÓN 1 & calco \\
\hline TÉCNICA TRADUCCIÓN 2 & préstamo \\
\hline
\end{tabular}

En estos tres casos observamos que una gran parte de los culturemas resultan fáciles de traducir por estar asociados, en parte, al lenguaje general y, aunque son propios de la cultura a la que pertenecen, el uso la técnica de amplificación asociada al préstamo y en algunos casos, al calco, permiten identificar fácilmente el referente. Sin embargo, la amplificación asociada a estas otras dos técnicas permite la transmisión completa del contenido cultural del elemento gastronómico.

Del mismo modo que en el campo semántico fiestas y espectáculos se ha constatado la presencia de culturemas que se han convertido en iconos de la cultura española (flamenco), en el campo semántico gastronomía y restauración existen algunos elementos que han traspado las fronteras nacionales para ser adoptados como propios por otras culturas. Es el caso de elementos como paella o tapas. En esta investigación nos proponemos analizar en detalle el uso de este último en las guías turísticas Lonely Planet y las técnicas de traducción utilizadas para la mediación de esta palabra global. 
En primer lugar se observa una elevada frecuencia de aparición de este culturema en las guías y un uso del préstamo puro como técnica de traducción para todas las ocurrencias del culturema:

Tabla 60: ficha de análisis del culturema tapas

ID

CODIGO GUÍA

GUíA

PROVINCIA

ELEMENTO DE ANÁLISIS

TIPOLOGÍA

CAMPO SEMÁNTICO

CONTEXTO

TÉCNICA TRADUCCIÓN 1
269

LPA

Lonely Planet Andalucía

Granada

tapas

palabra globalizada

gastronomía y restauración

Here's a place where gastronomy stays down to earth, but still experiments. Granada is one of the last bastions of that fantastic practice of free tapas with every drink. Take note: the more you drink, the better the tapas become. After you order each drink, you'll hear the barman shouting: 'primera!','segunda!' or 'tercera!' which means your first, second, and third tapas are on their way.

Como se observa en la ficha de análisis anterior, tapas es un elemento que se considera propio de la LM y se presupone por parte del mediador que el lector destinatario conoce el culturema. En cuanto a su definición, el Oxford English Dictionary recoge el vocablo tapas y lo define como "small Spanish savoury dishes, typically served with drinks at a bar". EI DRAE coincide plenamente con esta acepción indicando que se trata de una "pequeña porción de algún alimento que se sirve como acompañamiento de una bebida".

Debido a la internacionalización del culturema, son abundantes las ocurrencias de estas palabras en combinación con otros elementos, que resultan en 
colocaciones habituales en las que el culturema se utiliza como modificador de otro elemento. Este es el caso de tapas bars, una colocación que se ha identificado en numerosas ocasiones en las guías Lonely Planet:

Tabla 61: ficha de análisis del culturema tapas

ID
CODIGO GUÍA
GUÍA
PROVINCIA
ELEMENTO DE ANÁLISIS
TIPOLOGÍA
CAMPO SEMÁNTICO
CONTEXTO

TÉCNICA TRADUCCIÓN 1

\begin{tabular}{l}
269 \\
LPA \\
\hline Lonely Planet Andalucía \\
Granada \\
tapas \\
palabra globalizada \\
gastronomía y restauración \\
Here's a place where gastronomy stays down to earth, but still \\
experiments. Granada is one of the last bastions of that fantastic \\
practice of free tapas with every drink. Take note: the more you \\
drink, the better the tapas become. After you order each drink, \\
you'll hear the barman shouting: 'primera!','segunda!' or 'tercera!' \\
which means your first, second, and third tapas are on their way.
\end{tabular}

préstamo

Del mismo modo que ocurría con el culturema flamenco, el culturema tapas es uno de los referentes fundamentales de la cultura de origen, motivo por el cual, si bien no existe una traducción reconocida o previamente acuñada, son términos que se han filtrado directamente hasta la cultura meta y no representan una novedad para el lector. El conocimiento previo de dichos culturemas hace posible que sean usados de modo productivo en el texto turístico y, en este caso, en las guías Lonely Planet para crear nuevos referentes culturales totalmente transparentes para el lector (tapas bar, tapas tours, flamenco show, etc.) y que resultan de gran utilidad. 
La dificultad que entraña el término tapas está relacionado con una de las estructuras de la cultura que resultan más difíciles de entender, como son los gestos y los hábitos de los españoles al degustarlas.

En las guías Lonely Planet se observa un marcado esfuerzo por hacer llegar al lector no sólo la descripción de los elementos culturales más representativos, sino también la función de los hábitos o la gestualidad que acompaña un uso o costumbre determinado y que va asociado a dicho elemento cultural:

Tabla 62: ficha de análisis del culturema tapas

ID
CODIGO GUÍA
GUíA
PROVINCIA
ELEMENTO DE ANÁLISIS
TIPOLOGÍA
CAMPO SEMÁNTICO
CONTEXTO

269

LPA

Lonely Planet Andalucía

Granada

tapas

palabra globalizada

gastronomía y restauración

Here's a place where gastronomy stays down to earth, but still experiments. Granada is one of the last bastions of that fantastic practice of free tapas with every drink. Take note: the more you drink, the better the tapas become. After you order each drink, you'll hear the barman shouting: 'primera!','segunda!' or 'tercera!' which means your first, second, and third tapas are on their way.

préstamo

El mediador, como buen transmisor de la cultura, debe reflejar no sólo los elementos superficiales y más representativos de un culturema, sino un marco de referencia que haga comprensible dicho elemento dentro de la cultura de origen. En este caso, resulta muy práctico conocer que en determinados bares y regiones de España las tapas se sirven gratuitamente al pedir la bebida, o el modo en el cual se sirven y se piden para su elaboración. 
En muchos casos, es el mismo culturema tomado de la cultura de origen el que ayuda al mediador a transmitir otros culturemas relacionados que resultan de una mayor dificultad, como ocurre en el siguiente caso, en el que el mediador debe traducir el culturema ración:

Tabla 63: ficha de análisis del culturema ración

ID
CODIGO GUÍA
GUÍA
PROVINCIA
ELEMENTO DE ANÁLISIS
TIPOLOGÍA
CAMPO SEMÁNTICO
CONTEXTO

TÉCNICA TRADUCCIÓN 1 TÉCNICA TRADUCCIÓN 2
169

LPA

Lonely Planet Andalucía

Córdoba

ración

culturema

gastronomía y restauración

Run by the silversmiths' guild, this well-loved restaurant in a converted convent serves a selection of generous raciones (mealsized servings of tapas) in its light, glass-roofed patio amplificación préstamo

En este caso se define ración con el uso del préstamo y una amplificación que incluye una descripción que hace referencia a la cantidad o tamaño del plato (el cual se identifica como tapas). Se trata de una estrategia muy recurrente en las guías Lonely Planet: el uso de un culturema ya reconocido o previamente transmitido para la transmisión de un nuevo culturema relacionado. En el caso de ración o media ración, el mediador se halla ante la dificultad de tener que transmitir un esquema organizativo previo sin correspondencia alguna en la cultura meta, por lo que el uso de una paráfrasis explicativa resulta absolutamente necesaria.

Sin embargo, en ocasiones en las que el culturema resulta opaco y no existe ningún elemento cultural equivalente, el mediador se vale de la cultura compartida con el lector para intentar crear una imagen en la mente del lector 
que le proporcione una idea aproximada del elemento cultural en cuestión. Si observamos la mediación realizada para el culturema churros, podemos apreciar que, dada su complejidad, el mediador utiliza esta estrategia de emplear la cultura común para intentar transmitir el culturema:

Tabla 64: ficha de análisis del culturema churros

ID

CODIGO GUÍA

GUÍA

PROVINCIA

ELEMENTO DE ANÁLISIS

TIPOLOGÍA

CAMPO SEMÁNTICO

CONTEXTO

TÉCNICA TRADUCCIÓN 1

TÉCNICA TRADUCCIÓN 2
169

LPA

Lonely Planet Andalucía

Córdoba

ración

culturema

gastronomía y restauración

Run by the silversmiths' guild, this well-loved restaurant in a converted convent serves a selection of generous raciones (meal-

sized servings of tapas) in its light, glass-roofed patio

amplificación

préstamo

La amplificación junto con el préstamo son las técnicas usadas por el mediador para la transmisión del culturema churros. Sin embargo, debemos destacar también el uso de un equivalente funcional (doughnut), que es el elemento de su cultura de origen al que mediador de la provincia de Cádiz recurre para aproximarse al churro español. En LPM el mediador toma también el mismo referente propio de la cultura de origen para definir este culturema. Sin embargo, el conjunto de la amplificación utilizada por este último mediador para la transmisión de chocolate con churros resulta de mayor efectividad al incluir una descripción más detallada que aporta información sobre el modo de elaboración de este dulce típico: 
Tabla 65: ficha de análisis del culturema chocolate con churros

ID

CODIGO GUÍA

GUÍA

PROVINCIA

ELEMENTO DE ANÁLISIS

TIPOLOGÍA

CAMPO SEMÁNTICO

CONTEXTO

TÉCNICA TRADUCCIÓN 1

TÉCNICA TRADUCCIÓN 2

TÉCNICA TRADUCCIÓN 3
625

LPM

Lonely Planet Madrid

Madrid

chocolate con churros

culturema

gastronomía y restauración

Chocolate con churros (deep-fried doughnut strips dipped in hot

chocolate) - El Brillante ( p168 ) or Chocolatería de San Ginés

adaptación

amplificación

préstamo

Un caso similar encontramos para la transmisión del culturema fartons. El fartó (fartón en castellano) es un dulce de bollería alargado y con azúcar glaseado típico de Alboraya, un municipio de la provincia de Valencia. Aunque su nacimiento se lo debe a la horchata, al ser un bollo ligero y esponjoso combina perfectamente con otras bebidas calientes. Este dulce, que se caracteriza por ser tierno y esponjoso, fue elaborado para mojar en la horchata, una bebida refrescante obtenida a partir de la chufa ${ }^{119}$. En la guía Lonely Planet Valencia Encounter no podía faltar el culturema horchata, que no representa un problema de traducción, como observamos en la ficha de análisis del culturema fartons:

Tabla 66: ficha de análisis del culturema fartons

${ }^{119}$ El cultivo de la chufa en la Comunidad Valenciana se remonta a la dominación musulmana. La leche de chufas data del s.XIII. Hoy en día este cultivo está protegido con la denominación de origen Chufa de Valencia. 
ID

CODIGO GUÍA
GUÍA
PROVINCIA
ELEMENTO DE ANÁLISIS
TIPOLOGÍA
CAMPO SEMÁNTICO
CONTEXTO

TÉCNICA TRADUCCIÓN 1 TÉCNICA TRADUCCIÓN 2
32

LPVLC

Lonely Planet Valencia

Valencia

fartons

culturema

gastronomía y restauración

This sweet, opaque, very Valencian drink is made from pressed chufas (tiger nuts), into which you dip large finger-shaped buns called fartons; both name and taste are to savour. amplificación

préstamo

El culturema horchata se transmite a través del uso de una descripción que incluye el equivalente acuñado tiger nut (chufa). A través de esta descripción se consigue transmitir la información más importante acerca del culturema, su ingrediente principal. El elemento problemático en este caso es fartó. Del mismo modo que ocurre con churro, el mediador opta en este caso por valerse de algún elemento cultural propio de su cultura para poder transmitir el significado principal del culturema. En este caso, el equivalente funcional utilizado es bun, que el Oxford English Dictionary recoge como "a small cake, typically containing dried fruit". Creemos que en este caso bun no resulta útil como equivalente y que el uso de la técnica generalización a través de un elemento neutro evitaría posibles ambigüedades o confusión por parte del lector.

A pesar de que en el campo semántico gastronomía y restauración no existen equivalentes culturales que puedan servir de ayuda al traductor en su tarea, sí observamos el uso de una serie elementos de la LO que están acuñados en la LM y que facilitan sumamente la tarea del traductor. El mediador de la guía Lonely Planet Valencia hace uso de dichos equivalentes acuñados al transmitir el culturema turrón. 
Tabla 67: ficha de análisis del culturema turrón

ID
CODIGO GUÍA
GUÍA
PROVINCIA
ELEMENTO DE ANÁLISIS
TIPOLOGÍA
CAMPO SEMÁNTICO
CONTEXTO

TÉCNICA TRADUCCIÓN 1 TÉCNICA TRADUCCIÓN 2 TÉCNICA TRADUCCIÓN 3
25

LPVLC

Lonely Planet Valencia

Valencia

turrón

culturema

gastronomía y restauración

This particularly lipsmacking variant upon nougat makes a great locally made, handy-sized present. Traditionally eaten around Christmas time, it's a treat at any time of the year. There are two main kinds: Turrón de Jijona, soft and fudgelike, and Turrón de Alicante, altogether crisper and crunchier. Turrones Ramos sells turrón that comes from its own factory in Jijona.

amplificación

equivalente acuñado

préstamo

La técnica utilizada para la traducción de turrón es una combinación del préstamo y del equivalente establecido. Nougat es un elemento que no es propio de la cultura de origen, como tampoco de la cultura de llegada, pero sí es un elemento muy popular y conocido en la cultura de llegada ${ }^{120}$. El Oxford English Dictionary online lo define como "a sweet made from sugar or honey, nuts, and egg white". Además, el mismo Oxford Dictionary pone como ejemplo el turrón español (a Spanish almond nougat). El mediador de la LPVLC lo define como una variante de nougat para destacar la especificidad cultural y geográfica del turrón valenciano. Así pues, en este caso, la elección del equivalente cultural junto con una descripción de los condicionantes culturales que rodean esta

\footnotetext{
${ }^{120}$ El nougat es un dulce francés de aspecto y gusto parecidos al turrón.
} 
realidad cultural diferente consigue trasvasar la información más importante y el contenido cultural de este culturema.

A modo de resumen, se puede constatar que el campo semántico gastronomía y restauración es aquel el que se han identificado mayor número de culturemas, la mayoría de ellos realia. La dificultad que presentan estos culturemas es máxima, pues el mediador no dispone de equivalentes en su cultura de llegada, por lo que destaca el uso generalizado (con la excepción de la palabra global tapas) de la técnica de la amplificación.

La traducción de los culturemas pertenecientes a la gastronomía de una cultura es representa todo un reto porque una gran cantidad de estos elementos encierran una serie de normas, comportamientos establecidos en la cultura meta, por lo que resulta fundamental no sólo transmitir el culturema en sí mismo sino el universo de reglas conductuales que lo acompañan.

\subsubsection{Historia}

La historia es un campo semántico de gran relevancia por su conexión con la cultura de un pueblo. Los distintos pobladores de la Península Ibérica dejaron un legado histórico que se refleja en varios ámbitos de la cultura, como es la lengua, la gastronomía o las fiestas y tradiciones, que en muchos casos conmemoran gestas y batallas históricas.

En lo que respecta a las técnicas de traducción utilizadas en este campo semántico, se constata una gran variedad de técnicas traductológicas, si bien el préstamo y la amplificación son las más usadas, al igual que ocurre para la mayoría de campos semánticos que analizamos en este trabajo.

Resulta conveniente destacar el uso de la técnica combinada de préstamo y equivalente acuñado en este campo semántico, así como el uso de estas mismas 
dos técnicas usadas individualmente como se observa en la siguiente figura, que da cuenta de las técnicas de traducción (simples y combinadas) del campo semántico historia:

Figura 29: Técnicas de traducción del campo semántico historia

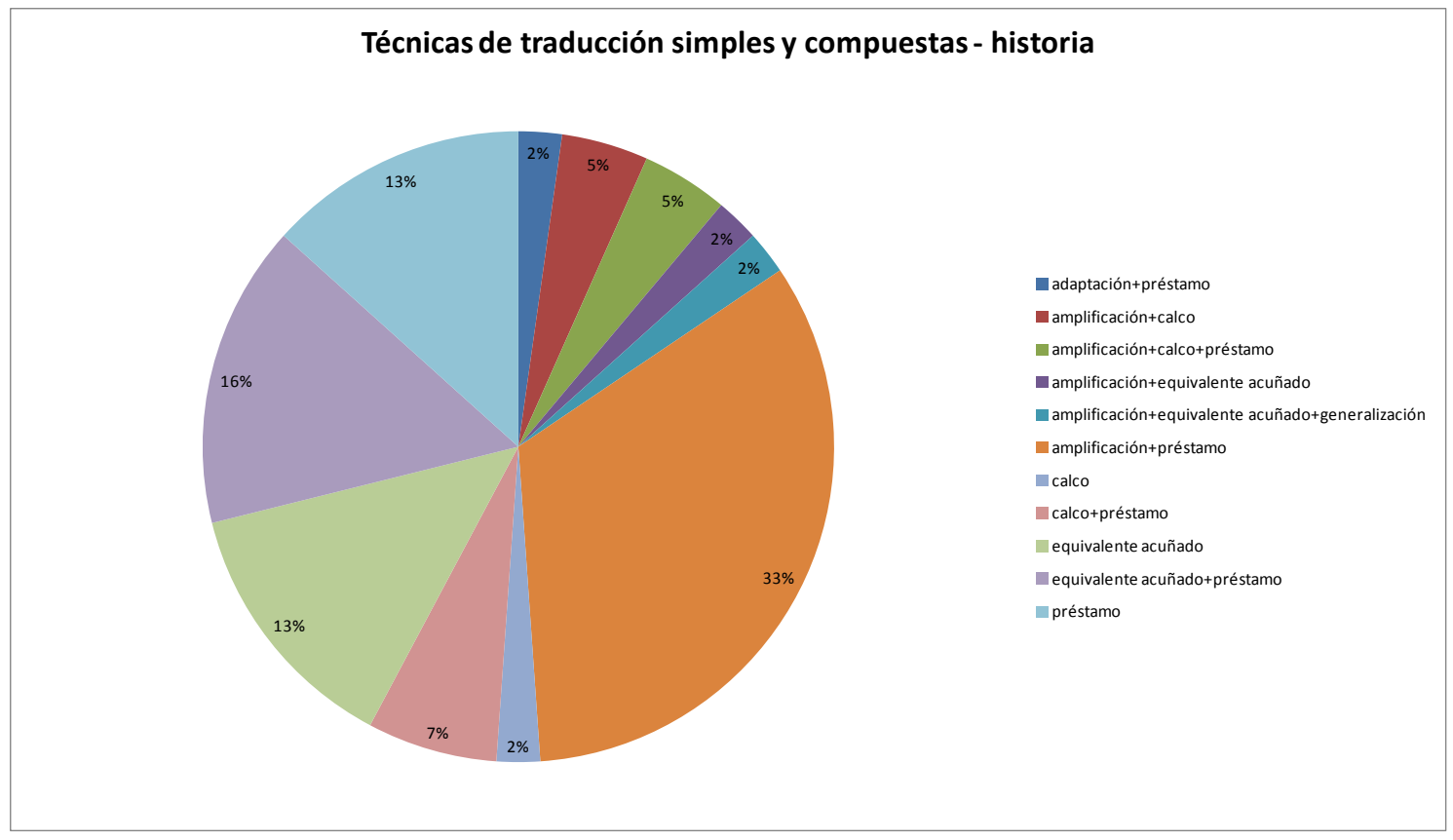

Del análisis detallado de culturemas, se observa que los distintos elementos históricos son de diversa índole y presentan retos diferentes en su traducción. Así, por ejemplo, destaca una gran cantidad de elementos culturales que son nombres propios de personajes históricos de gran relevancia pertenecientes a la historia española (Reyes Católicos) para los que existen equivalentes acuñados en la LM (los Reyes Católicos se conocen en lengua inglesa como Catholic Monarchs). Se trata, pues, de personajes que "han entrado a formar parte del universo cognitivo de los hablantes en lengua término" (Franco Aixelà, 2000: 
125), y por tanto, el mediador presupone un conocimiento previo lingüístico y cultural por parte del lector a la hora de efectuar la mediación.

No obstante, el reto del traductor se produce cuando se intenta transmitir un nombre propio sin equivalente en la LM. A continuación mostramos la ficha de análisis del culturema Alfonso X:

Tabla 68: ficha de análisis del culturema Alfonso $X$

ID

CODIGO GUÍA

GUíA

PROVINCIA

ELEMENTO DE ANÁLISIS

TIPOLOGÍA

CAMPO SEMÁNTICO

CONTEXTO

TÉCNICA TRADUCCIÓN 1

TÉCNICA TRADUCCIÓN 2
81

LPA

Lonely Planet Andalucía

Cádiz

alfonso $X$

culturema

historia

Two blocks southwest, then a block inland, stands the Castillo San Marcos (\%627 5693 35; Plaza Alfonso El Sabio 3; admission €2; h10am-2pm Tue). Heavily restored in the 20th century, the fine castle was built over a Muslim mosque by Alfonso $X$ of Castile after he took the town in 1260 amplificación préstamo

En el caso del nombre propio Alfonso $X$, se opta por el uso del préstamo y la amplificación, añadiendo la ubicación geográfica of Castile para situar al lector en el contexto de la Reconquista de Al-Andalus. Vemos, pues, que existen ciertos nombres propios que, por su pertenencia única a una lengua y una cultura, son difícilmente transmisibles.

Sin embargo, se dan casos en los que el el nombre propio en LO es transparente y puede transmitirse en su totalidad a la LM. La técnica empleada en esos casos es el calco, acompañado por el préstamo puro. A continuación mostramos la ficha de análisis del culturema Felipe el Hermoso para el que se utiliza la técnica 
del calco como técnica fundamental para la transmisión del culturema, si bien el uso de la amplificación aporta los detalles históricos fundamentales de filiación con los Reyes Católicos. Observamos la transparencia del culturema y el resultado de la mediación de Felipe el Hermoso en la siguiente ficha de análisis:

Tabla 69: ficha de análisis del culturema Felipe el Hermoso

ID
CODIGO GUÍA
GUÍA
PROVINCIA
ELEMENTO DE ANÁLISIS
TIPOLOGÍA
CAMPO SEMÁNTICO
CONTEXTO

TÉCNICA TRADUCCIÓN 1 TÉCNICA TRADUCCIÓN 2 TÉCNICA TRADUCCIÓN 3
247

LPA

Lonely Planet Andalucía

Granada

felipe el hermoso

culturema

historia

The monarchs lie with three relatives in simple lead coffins in the crypt, beneath their marble monuments in the chancel.The chancel is divided from the chapel's nave by a gilded screen made in 1520 by Maestro Bartolomé of Jaén - a masterpiece of wrought-iron artisanry. The coffins, from left to right, belong to Felipe El Hermoso (Philip the Handsome; the husband of the monarchs' daughter Juana la Loca, or (Joanna the Crazy), Fernando, Isabel, Juana Ia Loca and Miguel, the eldest grandchild of Isabel and Fernando.

amplificación

calco

préstamo

Es necesario destacar la introducción de una tercera lengua en las referencias a los nombres propios. En LPA se han identificado múltiples ejemplos del uso que el mediador realiza de nombres propios árabes naturalizados en castellano y, a la vez, con su denominación en lengua inglesa. El objetivo del mediador es introducir al lector en una nueva cultura, la cultura musulmana. Así, son numerosos los nombres propios de califas y personajes históricos de la España musulmana y el uso de denominaciones propias de títulos y designaciones jerárquicas dentro de un orden social concreto (califa, caliph; emir, emir) o territorios determinados (Al-Andalus, medieval Muslim Spain). 
En la mayoría de casos, observamos que el mediador opta por el uso del nombre propio acuñado en inglés para la transmisión del culturema. Sin embargo, también entra en juego la denominación en español, de modo que el lector cuenta con las dos denominaciones, tanto de la LO como de la LM. A continuación mostramos algunos ejemplos en contexto y analizamos las técnicas de traducción utilizadas.

Tabla 70: ficha de análisis del culturema Maimónides

ID
CODIGO GUÍA
GUíA
PROVINCIA
ELEMENTO DE ANÁLISIS
TIPOLOGÍA
CAMPO SEMÁNTICO
CONTEXTO

TÉCNICA TRADUCCIÓN 1 TÉCNICA TRADUCCIÓN 2
204

LPA

Lonely Planet Andalucía

Córdoba

maimónides

culturema

historia

It was home to two important 11thcentury philosopher-poets, Ibn Hazm (who wrote in Arabic) and Judah Ha-Levi (who wrote in Hebrew). Twelfth-century Córdoba produced the two most celebrated scholars of Al-Andalus - the Muslim philosopher Averroës (1126-98; p46) and the Jewish philosopher Moses ben Maimon (known as Maimónides; 1135-1204). Their philosophical efforts to harmonise religion with Aristotelian reason were met with ignorance and intolerance: the Almohads put Averroës in high office, and persecuted Maimónides until he fled to Egypt.

equivalente acuñado

préstamo

Para la transmisión del culturema Maimónides el mediador se vale de la técnica del préstamo y el equivalente acuñado en la LM. Observamos que esto solo se produce para uno de los nombres propios, y que el resto de personalidades relevantes como Averroes u otros filósofos e importantes 
poetas de la época quedan referenciados sólo con el nombre latinizado en algunos casos (Averroes en árabe es Ibn Rushd) o simplemente la transcripción al castellano del árabe, como en el caso de Judah Halevi. Destaca la insistencia del mediador en referenciar algunos nombres propios de personalidades no sólo en la LM a través del equivalente acuñado en lengua inglesa, sino también en la cultura española, la cultura heredera de la cultura árabe (Al-Mansur, Almanzor).

Otro tipo de elementos culturales que merecen especial mención en el campo semántico historia son aquellos que servían en el pasado para organizar política y administrativamente el territorio. Este es caso de los culturemas rafal y alquería. En el levante español y algunas zonas de Andalucía y Baleares son habituales este tipo de construcciones, que son una herencia de la arquitectura árabe y que se caracterizan por estar situadas en el campo, y servir para actividades agrícolas y ganaderas.

En la ficha de análisis del culturema rafal observamos que el mediador opta por la utilización de la técnica del préstamo y la adaptación a través del uso de hamlet, realidad perteneciente a la cultura meta:

Tabla 71: ficha de análisis del culturema rafal 
ID

CODIGO GUÍA

GUíA

PROVINCIA

ELEMENTO DE ANÁLISIS

TIPOLOGÍA

CAMPO SEMÁNTICO

CONTEXTO
688

LPMLL

Lonely Planet Mallorca

Mallorca

rafal

culturema

historia

With the conquest of Mallorca complete, Jaume I proceeded to divide it up among his lieutenants and allies. The Arab alqueries (farmsteads), rafals (hamlets) and villages were handed over to their new senyors (masters). Many changed name but a good number retained their Arab nomenclature. Places beginning with Bini (Sons of) are Arab hangovers. Many took on thenames of their new lord, preceded by the possessive particle son or sa (loosely translated as 'that which is of...'). Jaume I codified this division of the spoils in his Llibre del Repartiment.

TÉCNICA TRADUCCIÓN 1

adaptación

TÉCNICA TRADUCCIÓN 2

préstamo

En el Oxford Dictionary Online se recoge el término hamlet, que se define como "a small settlement, generally one smaller than a village, and strictly (in Britain) one without a church". El DRAE, por su parte, define rafal como "granja, casa o predio en el campo". Observamos, pues que no existe una correspondencia entre hamlet y rafal y que el mediador ha optado por naturalizar el culturema adaptándolo a una realidad próxima a la de la cultura meta.

En el caso de la mediación realizada para el culturema alquería, el mediador utiliza la técnica combinada de la amplificación y el préstamo. El DRAE define alquería como "casa de labor, con finca agrícola, típica del Levante peninsular". Con el uso de farmstead ${ }^{121}$ el mediador utiliza un elemento neutro en la lengua de llegada que da la idea principal del culturema y el mediador se vale del

\footnotetext{
${ }^{121}$ El Oxford English Dictionary Online define farmstead como a farm and its buildings.
} 
contexto en el que aparece la frase para transmitir los detalles históricoculturales propios de este tipo de construcciones árabes.

Un elemento de este campo semántico que se repite en LPA es taifa. Los reinos de taifas se produjeron durante la última fase de la dominación musulmana (s. XI-S.XIII) y supusieron la disgregación del poder del califato en pequeños territorios independientes. El mediador introduce este concepto para explicar una construcción destacada de Almería:

Tabla 72: ficha de análisis del culturema taifa

ID
CODIGO GUÍA
GUÍA
PROVINCIA
ELEMENTO DE ANÁLISIS
TIPOLOGÍA
CAMPO SEMÁNTICO
CONTEXTO

TÉCNICA TRADUCCIÓN 1 TÉCNICA TRADUCCIÓN 2
40

LPA

Lonely Planet Andalucía

Almería

taifa

culturema

historia

see the Muralla de la Hoya, a fortified wall built in the 11th century by Jairán, Almería's first taifa (small kingdom) ruler which descends the valley on the northern side of the Alcazaba and climbs the slopes of Cerro de San Cristóbal opposite, amplificación

préstamo

La técnica que utiliza el mediador es el préstamo y la amplificación. En este caso, la amplificación es una definición simplificada del concepto de taifa. Entendemos, pues, que se trata de una mediación que transmite la idea principal, aunque no refleja totalmente su contenido cultural en el contexto en el que aparece.

Por último destacamos la presencia de elementos que refieren batallas 
históricas o instituciones reguladoras de actividades empresariales. De nuestro estudio hemos identificado múltiples culturemas que, en la mayoría de los casos, pueden transmitirse fácilmente a través del uso del calco y de la amplificación, como se observa en la siguiente ficha de análisis:

Tabla 73: ficha de análisis del culturema Guerra de la Independencia Española

\begin{tabular}{|c|c|}
\hline ID & 58 \\
\hline CODIGO GUÍA & LPA \\
\hline GUÍA & Lonely Planet Andalucía \\
\hline PROVINCIA & Cádiz \\
\hline ELEMENTO DE ANÁLISIS & guerra de la independencia española \\
\hline TIPOLOGÍA & culturema \\
\hline CAMPO SEMÁNTICO & historia \\
\hline CONTEXTO & $\begin{array}{l}\text { During the Spanish War of Independence (part of the Napoleonic } \\
\text { Wars) Cádiz underwent a two-year French siege during which the } \\
\text { Cortes de Cádiz (the Spanish national parliament) convened here. } \\
\text { In } 1812 \text { this lopsidedly liberal gathering adopted Spain's first } \\
\text { constitution (known as La Pepa), proclaiming sovereignty of the } \\
\text { people. }\end{array}$ \\
\hline TÉCNICA TRADUCCIÓN 1 & amplificación \\
\hline TÉCNICA TRADUCCIÓN 2 & calco \\
\hline
\end{tabular}

La Guerra de la Independencia Española es un culturema transparente, fácil de traducir, pero encierra un contenido histórico que no pasa por alto al mediador de la Guía Lonely Planet Andalucía. Para traducir el culturema el mediador se vale del préstamo y el calco, que transmite los conceptos fundamentales y compartidos por ambas culturas como son independencia y guerra. La amplificación, no obstante, sitúa al lector en el contexto histórico al hacer referencia al hecho de que se trata de "part of Napoleonic Wars", haciendo referencia a un suceso histórico que forma parte de la historia del lector de la guía turística. De este modo, el lector puede, en caso de querer obtener mayor 
información acerca de este suceso histórico en España, acudir a otras referencias. El mismo contexto en el que aparece el culturema aporta la información que lector necesita para entender este período de la historia en España.

A modo de resumen del análisis realizado para el campo semántico historia, queda constatada la dificultad que entrañan, en primer lugar, los elementos culturales correspondientes a personajes históricos. Estos nombres propios tienen, dependiendo de su importancia en la historia, equivalentes acuñados de los que el mediador se vale para realizar la mediación. Sin embargo, muchos otros nombres propios no tienen equivalente establecido, por lo que el traductor utiliza la técnica del calco y de la amplificación (junto con la del préstamo) para trasvasar estos culturemas.

Del mismo modo, cabe señalar la presencia de culturemas que designan la distribución y organización territorial y administrativa en diferentes períodos históricos y la identificación de culturemas que refieren batallas y gestas históricas. En estos casos, el mediador suele optar por realizar una amplificación para situar al lector destinatario en el contexto histórico del que está informando.

\subsubsection{Música}

El campo semántico música da cuenta de todos aquellos culturemas que se refieren a este tipo de arte que está tan estrechamente relacionado con la cultura. En las guías Lonely Planet, especialmente en los apartados destinados a la información práctica sobre eventos culturales, destacan multitud de elementos propios de la cultura española. 
Existe una gran diversidad de elementos culturales que pertenecen a este campo semántico. Por un lado, se han identificado multitud de elementos que hacen referencia a estilos musicales relacionados con corrientes artísticoculturales (la Movida en LPM). Asimismo, son recurrentes los culturemas que designan instrumentos musicales tradicionales y aquellos que designan géneros musicales propios de una cultura determinada.

A continuación analizamos las técnicas de traducción de algunos de los culturemas identificados en el campo semántico música. En primer lugar, destacamos el culturema zarzuela.

En el contexto de este culturema observamos cómo el mediador describe Madrid como una ciudad puntera en cuanto a manifestaciones musicales y de danza que incluyen desde ópera hasta todo tipo de espectáculos musicales. En cuanto a la transmisión del culturema zarzuela, el mediador utiliza el préstamo más la amplificación haciendo referencia al origen madrileño de este género y describiéndolo como "un cruce entre ópera y danza". Así, el mediador se vale de elementos neutros para transmitir una idea aproximada del culturema:

Tabla 74: ficha de análisis del culturema zarzuela 
ID

CODIGO GUÍA
GUÍA
PROVINCIA
ELEMENTO DE ANÁLISIS
TIPOLOGÍA
CAMPO SEMÁNTICO
CONTEXTO

TÉCNICA TRADUCCIÓN 1 TÉCNICA TRADUCCIÓN 2
619

LPM

Lonely Planet Madrid

Madrid

zarzuela

culturema

música

You've killed the night by staying out till dawn and you've raced around to the major monuments and art galleries for which Madrid is famous. Time for a change of pace. Madrid's contribution to high artistic culture extends beyond the Museo del Prado and the city is an excellent place to take in a classical music, opera or dance performance, visit the engaging little private galleries scattered across the city or watch a blockbuster musical in one of the city's many theatres. Such performances are attended more often by locals than tourists, which may be an attraction in itself, but these genres take you deeper into the world of the Spanish-language arts that receive little coverage beyond the Spanish-speaking world. Indeed this is the best place in the world to see Spanish drama (both classical and modern) and zarzuela (a Madrid cross between opera and dance).

amplificación

préstamo

La zarzuela es una forma de música teatral o género musical escénico surgido en España con partes instrumentales, partes vocales (solos, dúos, coros...) y partes habladas. La zarzuela es la forma española de la Opereta, representación teatral que, a diferencia de la ópera, no es totalmente musical sino que alterna partes habladas y partes musicales.

EI DRAE define zarzuela como "obra dramática y musical en que alternativamente se declama y se canta" y considera zarzuela también "la letra de la obra de esta clase y la música de la misma obra". Observamos la dificultad que entraña el culturema y la necesidad de explicitación por parte del mediador, que consideramos no refleja del todo el contenido cultural del culturema. 
A pesar de lo diferentes que son las culturas de origen y cultura meta de nuestro estudio, se han identificado algunos elementos culturales que son similares en cuanto a su uso y su forma. Este es el caso de xeremeia. La xeremía es un instrumento musical típico de las Islas Baleares y está compuesta por un saco de piel u otro material denominado sac o sarró (saco o zurrón) en donde se acumula el aire y que tiene tres orificios principales: el primero destinado al bufador (soplador), que es por donde se sopla y se llena de aire el zurrón; otro para el grall (puntero), que es la parte que reproduce las notas musicales y por último el de los bordons (bordones), que suelen ser tres: el principal, la trompa o bordó (roncón). Tiene un sonido brillante y penetrante, característico, que ha venido acompañando las fiestas y actos de la vida en la isla desde tiempos remotos.

Se trata de un instrumento musical de viento similar a la gaita, instrumento perteneciente a la cultura meta, por lo que el mediador se vale de la técnica del equivalente cultural a través de una técnica combinada en triplete:

Tabla 75: ficha de análisis del culturema xeremeia 
ID

\section{CODIGO GUÍA}

GUíA

PROVINCIA

ELEMENTO DE ANÁLISIS

TIPOLOGÍA

CAMPO SEMÁNTICO

CONTEXTO

TÉCNICA TRADUCCIÓN 1

TÉCNICA TRADUCCIÓN 2

TÉCNICA TRADUCCIÓN 3
693

LPMLL

Lonely Planet Mallorca

Mallorca

xeremeia

culturema

música

Music Mallorca, like any other part of Spain, has a rich heritage in folk songs and ballads sung in mallorquí. At many traditional festes in Mallorcan towns you'll hear the sounds of the xeremiers, a duo of ambling musicians, one of whom plays the xeremia (similar to the bagpipes) and the other a flabiol (a high-pitched pipe).

equivalente cultural

amplificación

préstamo

Por su parte, el flabiol es un instrumento musical de madera y de viento, de la familia de las flautas de pico. Destaca por su corta medida y se maneja con una sola mano, la izquierda. El que toca el flabiol se llama flabioler o flabiolaire; la otra mano se utiliza para hacer sonar su percusión que acostumbra a ser un timbal, bombo o tamboril. En el caso de este culturema, observamos que el mediador lo traduce como high-pitch pipe, aludiendo a un instrumento de viento de la cultura meta, pipe $e^{122}$, y haciendo referencia al grado de altura de tonos y sonidos propios de este instrumento. Observamos que, a diferencia de xeremeia, la mediación en este caso incluye un referente cultural parcial, por lo que, cuando se realiza la mediación, se produce una pérdida de parte del contenido cultural del culturema en su traducción a la LM, pues nada se menciona del otro elemento de percusión que integra el instrumento.

122 El Oxford English Dictionary define pipe como " $a$ wind instrument consisting of a single tube with holes along its length that are covered by the fingers to produce different notes". 
Por último, señalamos la presencia de géneros musicales propios de otras culturas diferentes a la española, pero que tienen un lugar en ella y por tanto deben ser transmitidos en la cultura meta.

En nuestro estudio de las guías Lonely Planet nos hemos encontrado con que, en múltiples ocasiones, el mediador realiza una mediación transcultural, al tener que transmitir elementos culturales que no pertenecen a la cultura de origen desde la que se realiza la mediación, sino que se hallan presentes en ella. Uno de los culturemas extranjeros es por ejemplo fado. Este culturema se ha identificado en la guía LPBCN y a continuación presentamos su ficha de análisis:

Tabla 76: ficha de análisis del culturema fado

ID
CODIGO GUÍA
GUíA
PROVINCIA
ELEMENTO DE ANÁLISIS
TIPOLOGÍA
CAMPO SEMÁNTICO
CONTEXTO

TÉCNICA TRADUCCIÓN 1

\begin{tabular}{l}
600 \\
LPBCN \\
Lonely Planet Barcelona \\
\hline Barcelona \\
fado \\
culturema \\
música \\
Barcelona is blessed with a fine line-up of theatres for grand \\
performances of classical music, opera and more. The two \\
historic music houses are the Gran Teatre del Liceu and the Palau \\
de la Música Catalana. The former is the city's opera house and \\
the latter puts on an infinitely more eclectic programme, from \\
choral to Portuguese fado \\
préstamo
\end{tabular}

Tal como observamos, el mediador advierte al lector de que se halla ante un elemento que proviene de una lengua diferente y lo marca, como suele ser habitual en las guías Lonely Planet, con el uso de la cursiva. La técnica de traducción utilizada para transmitir fado es el préstamo puro, tomado de la 
lengua portuguesa, a la que el mediador ha situado geográficamente en Portugal gracias al adjetivo Portuguese. Probablemente nos hallemos en este caso ante una de las palabras globalizadas de la cultura portuguesa, pues, con el uso del préstamo, el mediador presupone que el lector conoce el culturema que está incluyendo en su descripción de la música que se ofrece en Barcelona.

En este punto cabe resaltar el hecho de que las palabras globalizadas que hemos identificado en este estudio se utilizan siempre por parte del traductor con la técnica del préstamo puro en técnica simple.

\subsubsection{Paisaje y geografía}

El campo semántico paisaje y geografía es un ámbito que recoge multitud de culturemas muy diversos entre sí. Esta sección abarca, en su mayoría, una gran diversidad de accidentes geográficos, pero también incluye elementos étnicos o incluso históricos que conforman el paisaje típico español. Existen características geográficas que son neutras $y$, en la mayoría de casos, conforman denominaciones extrapolables a cualquier cultura, pero en ocasiones su especificidad y el país de origen hacen de ellas elementos culturales en toda regla.

Si observamos la siguiente figura en la que se distribuye la frecuencia de uso de las técnicas de traducción del campo semántico paisaje y geografía, observamos que las técnicas más usadas son el préstamo y la amplificación en doblete y el préstamo puro usado como técnica individual. Otra de las técnicas usadas, aunque con menor frecuencia, es el doblete formado por el calco y el préstamo. Por último, se dan casos de uso de técnicas en triplete que incluyen asimismo técnicas como el equivalente acuñado. 
Figura 30: Técnicas de traducción simples y compuestas del campo semántico paisaje y geografía

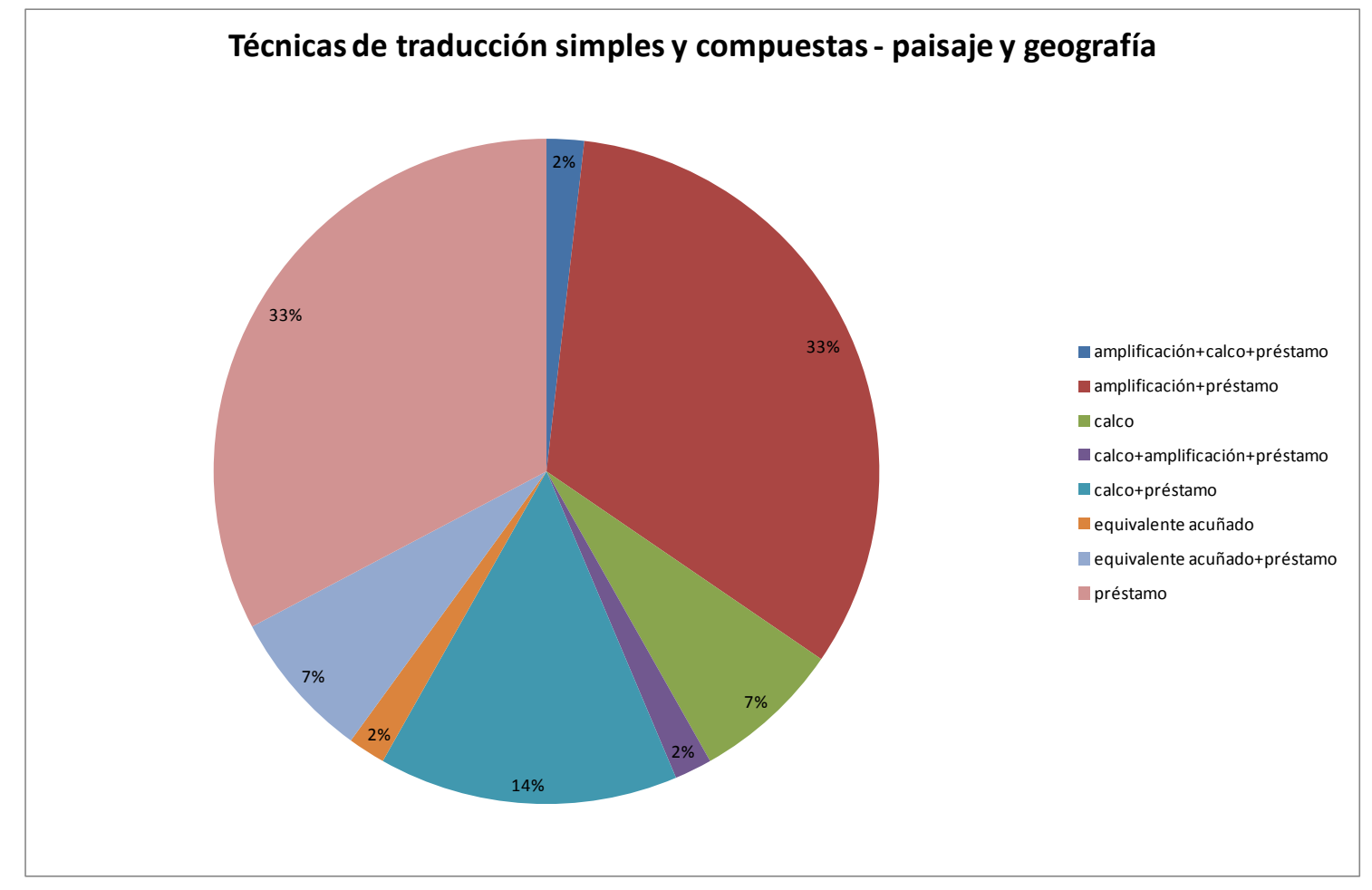

A continuación analizamos aquellos elementos culturales que destacan por su dificultad, y su frecuencia y que tienen un elevado contenido cultural y representan, por tanto, un reto para el mediador.

$\mathrm{Si}$ existe un elemento cultural por antonomasia relacionado con el paisaje levantino ese es paseo marítimo. En la guía LPVLC el mediador sugiere al turista un paseo al lado del mar del siguiente modo:

Tabla 77: ficha de análisis del culturema paseo marítimo 


ID
CODIGO GUÍA
GUÍA
PROVINCIA
ELEMENTO DE ANÁLISIS
TIPOLOGÍA
CAMPO SEMÁNTICO
CONTEXTO
TÉCNICA TRADUCCIÓN 2
19

LPVLC

Lonely Planet Valencia

Valencia

paseo marítimo

culturema

paisaje y geografía

Take the bus or high-speed tram for a sea-side morning, exploring the old port (p16), walking the paseo maritimo (the promenade), and perhaps relaxing on the beach and enjoying a swim.

equivalente acuñado

préstamo

El diccionario Oxford English Online define promenade como "a paved public walk, typically one along the seafront at a resort", con lo que el mediador no tiene dificultad en transferir el culturema al existir un equivalente cultural en la cultura meta. En el caso del levante español, los pueblos y ciudades costeros destacan por disponer de estos largos recorridos junto al mar, mientras que en la lengua meta promenade no se limita exclusivamente al paseo junto al mar, sino que es un término que abarca en su semántica cualquier tipo de paseo, ya sea en coche o bicicleta, por la vía pública. Por el contexto en el que el mediador usa promenade no es necesario desambiguar el significado en la LM, pues el turista es invitado a un sea-side morning.

Sin embargo, como hemos apuntado, abundan los elementos equivalentes en la LM para los accidentes geográficos usuales, pero es necesario recurrir a la amplificación como técnica de traducción para arrojar luz sobre el significado de algunos culturemas que, siendo similares a algún accidente geográfico habitual, presentan unas características propias que los convierte en únicos, como observamos en los siguientes ejemplos. 
El culturema huerta hace referencia a la conocida horta valenciana. Hemos recogido este culturema por tener unas particularidades especiales. La huerta valenciana es un realia muy difícil de traducir, pues no sólo es una extensión de terreno fecundo apto para el cultivo de determinadas frutas, hortalizas y arroz plagado de acequias, sino que además constituye uno de los paisajes más característicos valencianos por el tipo de construcciones que se erigen, como las alquerías o las barracas. A continuación observamos la mediación realizada sobre huerta.

Tabla 78: ficha de análisis del culturema huerta

ID

CODIGO GUÍA

4

GUÍA

PROVINCIA

ELEMENTO DE ANÁLISIS

TIPOLOGÍA

CAMPO SEMÁNTICO

CONTEXTO

TÉCNICA TRADUCCIÓN 1

TÉCNICA TRADUCCIÓN 2

\begin{tabular}{l}
\hline LPVLC \\
\hline Lonely Planet Valencia \\
\hline Valencia \\
\hline huerta \\
\hline culturema \\
paisaje y geografía \\
What they share is the freshest produce, plucked from la huerta, \\
the surrounding fertile agricultural plain. \\
amplificación \\
préstamo
\end{tabular}

La ficha correspondiente a este culturema indica que el doblete de préstamo y amplificación son las técnicas que se han usado en la traducción en las guías que conforman nuestro corpus. El mediador realiza la mediación con éxito, pues alude a la extensión de tierra cultivable, si bien no la contextualiza en el paisaje típico valenciano. La amplificación en este caso, que se realiza integrada en el discurso, aunque es larga, está más que justificada. 
A diferencia de lo que ocurre con el culturema analizado anteriormente, el culturema albufera sí hace referencia a un accidente geográfico. Una albufera (el origen de la palabra es la denominación árabe al-buhayra, el pequeño mar) es, según el DRAE, "una laguna litoral, en costa baja, de agua salina o ligeramente salobre, separada del mar por una lengua o cordón de arenas, como la de Valencia o la de Alcudia, en Mallorca". En este caso, tomamos el culturema albufera con las peculiaridades culturales que su significado contiene.

Las técnicas utilizadas para la transmisión de albufera, son al igual que para huerta, la amplificación y el préstamo. Sin embargo, en albufera, el mediador puede valerse de un término general como lake, que define las características principales del acccidente geográfico, como se observa a continuación en la siguiente ficha de análisis:

Tabla 79: ficha de análisis del culturema albufera

ID

CODIGO GUÍA

GUíA

PROVINCIA

ELEMENTO DE ANÁLISIS

TIPOLOGÍA

CAMPO SEMÁNTICO

CONTEXTO

TÉCNICA TRADUCCIÓN 1

TÉCNICA TRADUCCIÓN 2
9

LPVLC

Lonely Planet Valencia

Valencia

albufera

culturema

paisaje y geografía

Eels too, freshly hauled from the Albufera lake and still slithering.

amplificación

préstamo

Sin duda, la elección de los elementos que constituyen la amplificación del culturema, pueden ser de diversa índole, en algunos casos, se trata de una amplificación que incluye el calco en la LM y no provee de información cultural 
adicional; en otros se observa una intención por parte del mediador de aludir a la función, alguna característica principal, o componente del culturema, de modo que el mediador, a través de una paráfrasis corta debe condensar no sólo el contenido léxico fundamental del culturema, sino también su sustrato cultural. En el campo semántico paisaje y geografía se observan amplificaciones distintas en cuanto a su longitud, si bien en general se realiza la amplificación descriptiva con el uso limitado de palabras clave que definan al máximo, aunque en algunos casos, el contenido cultural no pueda ser transferido. Para ilustrar dos casos de amplificación larga y corta ofrecemos el análisis de los culturemas dehesa y carmen.

Por lo que respecta al culturema carmen, el DRAE recoge una de sus acepciones indicando que es "en Granada, quinta con huerto o jardín". Así pues, un carmen es una tipología de vivienda urbana con un espacio verde anexo, jardín y huerta a la vez, que constituye una extensión de aquella, típico de la ciudad de Granada. Se observa en este caso que la referencia a la cultura queda acotada geográficamente a un lugar determinado, y el mediador así lo describe en la guía LPA:

Tabla 80: ficha de análisis del culturema cármenes 
ID

CODIGO GUÍA
GUÍA
PROVINCIA
ELEMENTO DE ANÁLISIS
TIPOLOGÍA
CAMPO SEMÁNTICO
CONTEXTO

TÉCNICA TRADUCCIÓN 1 TÉCNICA TRADUCCIÓN 2
255

LPA

Lonely Planet Andalucía

Granada

cármenes

culturema

paisaje y geografía

Albayzín. Stretching and twisting its way up the hill that faces the Alhambra across the Darro Valley, the Albayzín (Map pp358-9) is one of Granada's most fabulous treasures. The steep winding streets with the gorgeous Carmen houses (large mansions with walled gardens, from the Arabic karm, for garden) reveal the best views of the Alhambra, and in fact it's almost as if the Albayzín and the Alhambra secretly fancy each other: the Albayzín doesn't look as enchanting from anywhere as it does from the Alhambra's tiled chambers,and the Alhambra looks like it rules the world when seen from one of the miradors of the Albayzín

amplificación

préstamo

La amplificación realizada para la transmisión de este culturema recoge los elementos más importantes que resultan definitorios del culturema, si bien el contenido fundamental se provee a través del elemento neutro houses. La amplificación de tipo descriptivo incluye los detalles más característicos y hace referencia directa al contenido cultural del elemento al incluir la etimología de la palabra en árabe y su significado. Con el uso de esta técnica a través de la descripción técnica la mediación se realiza con éxito, pues el lector puede, por un lado, identificar el tipo de casa y, por otro, conocer su procedencia o significado cultural.

La amplificación en el culturema dehesa es menor, tanto en su longitud como en su alcance semántico. El DRAE define dehesa como "tierra generalmente acotada y por lo común destinada a pastos". En general, una dehesa es un bosque claro de encinas o alcornoques, con estrato inferior de pastizales o 
matorrales, donde la actividad del ser humano ha sido intensa, y generalmente están destinados al mantenimiento del ganado, a la actividad cinegética y al aprovechamiento de otros productos forestales (leñas, corcho, setas, etc.).

El mediador de la guía LPA realiza una amplificación restringida del culturema, incluyendo únicamente las características principales a través de la explicitación "woodland pasture". Incluye la técnica de la generalización, pues no explicita qué tipo de árboles son los representativos de la dehesa. Y de nuevo, se sirve de un término general para identificar el culturema (pasture). Con esta explicitación, el aspecto cultural de este culturema no se refleja en su totalidad. Sin embargo, el contexto que le rodea acaba por dar la idea de territorio deshabitado y de pequeñas poblaciones rurales, como se observa en la ficha de análisis:

Tabla 81: ficha de análisis del culturema dehesa

ID
CODIGO GUÍA
GUÍA
PROVINCIA
ELEMENTO DE ANÁLISIS
TIPOLOGÍA
CAMPO SEMÁNTICO
CONTEXTO

TÉCNICA TRADUCCIÓN 1 TÉCNICA TRADUCCIÓN 2
182

LPA

Lonely Planet Andalucía

Córdoba

dehesa

culturema

paisaje y geografía

The N432 runs northwest into Extremadura, but after $50 \mathrm{~km}$, detour onto the lengthy N502, which will take you to the far north along some incredible landscapes in the area of Los Pedroches. This sparsely populated area is full of scattered granite-built settlements, occasional rocky outcrops and expanses of dehesa (woodland pasture).

amplificación

préstamo 
El campo semántico paisaje y geografía incluye también una serie de elementos típicos del lenguaje turístico recogidos en el capítulo 2 de este estudio y denominados marcas turísticas (cfr. 3.1.2). Estos elementos tienen una importancia fundamental pues representan la imagen de una población, ciudad o país y van asociados a la promoción turística institucional.

En este trabajo hemos querido observar la mediación que se realiza para este tipo de elementos, pues, si bien no son culturemas, pues han sido creados artificialmente por las instituciones gubernamentales para la promoción del turismo, sí persiguen crear en la mente del turista una imagen determinada.

La marca Costa Brava ${ }^{123}$ es una marca supracomarcal que en 2010 celebró sus 100 años de existencia. Comprende varias comarcas de la provincia de Girona. El término Costa Brava fue publicado por el periodista Ferran Agulló en las páginas de La Veu de Catalunya el 12 de septiembre de 1908. Con esta expresión el periodista quería describir el paisaje agreste y escarpado que caracteriza gran parte de la zona costera.

Ya por la década de 1930, los turistas llenaban las playas de la zona, pero aún se mezclaban con pescadores y agricultores que cultivaban cerca de la costa. A partir de la década de 1950 y 1960 el fenómeno turístico se generalizó y hubo un gran desarrollo urbanístico de algunas localidades de estas comarcas.

La Costa Brava se caracteriza por un sinfín de atractivos naturales, con parques naturales, jardines botánicos, lagos, pequeños archipiélagos y playas y calas. Para realizar transmitir precisamente este espectáculo de naturaleza, el mediador de la guía LPBCN realiza un calco sobre la LO que resulta de gran

\footnotetext{
${ }^{123}$ El sitio web oficial es www.costabrava.org
} 
efectividad en la LM con rugged coast, manteniendo la intencionalidad de la marca turística de aludir a lo escarpado de su orografía y paisaje:

Tabla 82: ficha de análisis de la marca turística Costa Brava

ID
CODIGO GUÍA
GUíA
PROVINCIA
ELEMENTO DE ANÁLISIS
TIPOLOGÍA
CAMPO SEMÁNTICO
CONTEXTO

TÉCNICA TRADUCCIÓN 1 TÉCNICA TRADUCCIÓN 2

680
LPBCN
Lonely Planet Barcelona
Barcelona
costa brava
marca turística
paisaje y geografía
RUGGED COAST Too often dismissed because of its tainted
package-holiday image, the bulk of the Costa Brava (Rugged
Coast, p253 ) is a joyous spectacle of nature. Blessed with high
blustery cliffs, myriad inlets and minuscule coves alternating
with long expanses of golden sand and thick stands of hardy
pine, it begs to be explored
calco
préstamo

680

Lonely Planet Barcelona

Barcelona

costa brava

marca turística

paisaje y geografía

package-holiday image, the bulk of the Costa Brava (Rugged Coast, p253) is a joyous spectacle of nature. Blessed with high blustery cliffs, myriad inlets and minuscule coves alternating with long expanses of golden sand and thick stands of hardy pine, it begs to be explored

préstamo

La consideración de la Costa del Sol como destino turístico internacional empieza a tomar cuerpo a partir de la segunda mitad del siglo pasado, en un momento en el que el turismo de élite, escaso y selectivo, busca nuevos lugares, período que también coincide con el de la incorporación a la actividad turística de unas capas sociales más amplias. Por lo que respecta a la denominación o marca Costa del Sol, hay varias paternidades y ninguna de ellas demasiado clara, pero lo que sí está documentado ${ }^{124}$ es que esta zona del litoral andaluz se publicitó con el nombre por el que hoy es conocida mundialmente en la Exposición Iberoamericana celebrada en Sevilla en 1929. Según algunos

\footnotetext{
${ }^{124}$ Véase el sitio web oficial www.visitacostadelsol.com
} 
testimonios, la denominación Costa del Sol fue acuñada por un cónsul austriaco que residía en Cádiz y viajaba con frecuencia a Almería. El desplazamiento lo realizaba por la costa y, necesariamente, tenía que pasar por las provincias de Málaga y Granada, y a toda esa franja litoral la denominó Costa del Sol tras comprobar la bondad climática de la zona. Años después, con el extraordinario despunte turístico del litoral malagueño, la Costa del Sol se circunscribió exclusivamente a la provincia de Málaga. Hoy se conoce a la Costa del Sol a la región litoral de la provincia de Málaga y el sector mediterráneo del Campo de Gibraltar, en la provincia de Cádiz.

A continuación observamos qué elementos atribuye este mediador a esta marca en la guía LPA en la ficha de análisis de Costa del Sol.

Tabla 83: ficha de análisis de la marca turística Costa del Sol

ID

CODIGO GUÍA
GUÍA
PROVINCIA
ELEMENTO DE ANÁLISIS
TIPOLOGÍA
CAMPO SEMÁNTICO
CONTEXTO

TÉCNICA TRADUCCIÓN 1
445

LPA

Lonely Planet Andalucía

Málaga

costa del sol

marca turística

paisaje y geografía

The Costa del Sol stretches along the Málaga seaboard like a wall of wedding cakes several kilometres thick. Its recipe for success is the certainty (more or less) of sunshine,convenient beaches, warm sea, cheap package deals and plenty of nightlife and entertainment

préstamo

En su conjunto, la provincia de Málaga cuenta con un clima que permite visitarla sin dificultad en cualquier época del año, pero especialmente la franja litoral, es decir, la Costa del Sol, que, resguardada de los vientos del 
interior por una sucesión de montañas de una considerable altitud, asegura más de 300 días de sol al año y una temperatura privilegiada. Esto queda reflejado en la descripción que el mediador realiza de la Costa del Sol, a la que atribuye sunshine y que define como un destino económico de playa y entretenimiento. Sin embargo, la marca Costa del Sol no transmite únicamente las bondades de un destino turístico de sol y playa, sino que, la zona a la que representa no sólo dispone de una gran oferta de plazas hoteleras rurales, numerosos campos de golf, parques zoológicos y de atracciones, palacios de congresos, puertos deportivos, etc. Sin embargo, es así como es percibida por los turistas extranjeros, que la consideran una de las mejores marcas turísticas y es uno de los destinos turísticos preferidos por turistas alemanes, británicos, escandinavos y franceses.

\subsubsection{Pintura}

En el campo semántico pintura se destaca la abundancia de culturemas que dan nombre a obras pictóricas o a otro tipo de manifestaciones de este tipo de arte. La pintura es una manifestación más de la cultura y la forma de vida de una sociedad, así como sus creencias religiosas. Es por este motivo que se han identificado múltiples obras pictóricas de gran valor artístico en museos que son de obligadas visita para el turista y que hacen referencia a pasajes bíblicos o personajes religiosos destacados (santos, vírgenes, la Sagrada Familia....) propios de la religión católica tan arraigada históricamente en la cultura y la vida española.

En cuanto a las técnicas de traducción utilizadas para la transmisión de los culturemas de este campo semántico, cabe señalar la gran variedad de técnicas usadas tanto en modo simple como combinado. 
En la gráfica siguiente se muestran las técnicas de traducción empleadas para la traducción de los culturemas del campo semántico pintura. Como se observa, no predomina el uso de una técnica determinada sobre las demás, sino que se da un equilibrio de técnicas de traducción utilizadas.

Figura 31: Técnicas de traducción del campo semántico pintura

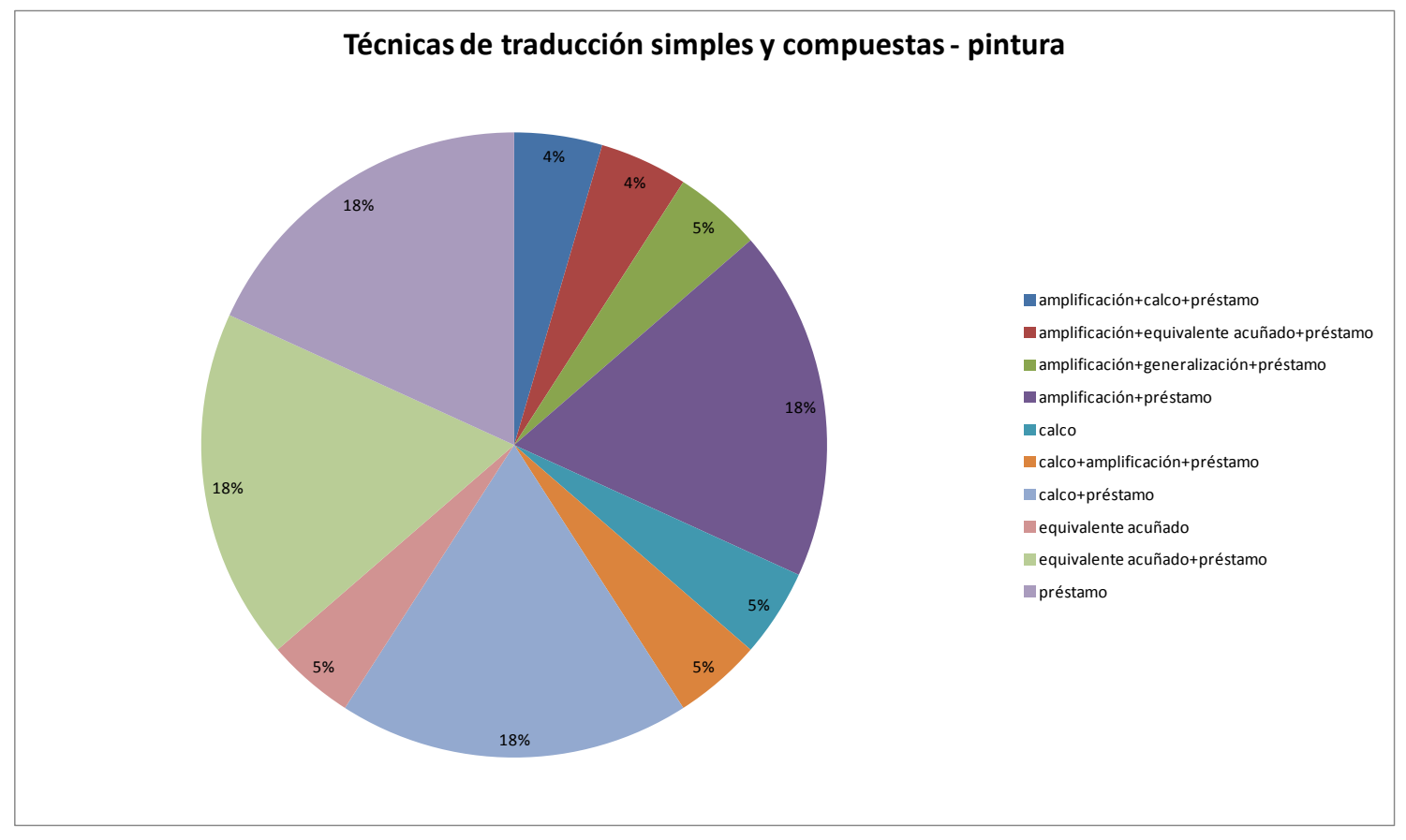

Así, por ejemplo, una de las técnicas que los mediadores emplean frecuentemente es la combinación de préstamo y el equivalente acuñado. Esta técnica es frecuente para transmitir las obras pictóricas que retratan escenas famosas de la vida y la muerte de Jesús, como es el caso de la última cena. En la LM existe un equivalente acuñado en inglés: The last supper, y con el que también se denominan diferentes obras realizadas por artistas de la cultura meta. El mediador se encuentra, en este caso, con un culturema conocido que no presenta dificultades en la traducción. El óleo Oración en el Huerto de los 
Olivos, traducido como Prayer in the Garden of Olives es otro ejemplo más de los equivalentes establecidos que representan escenas típicas de la vida y muerte de Jesús.

Algunos ejemplos de culturemas que se han transmitido a través del equivalente son obras que representan retratos como San Juan de Dios (St. John of God), Santiago Apóstol (Saint James the Apostle), San Juan Bautista (St. John the Baptist). Cabe señalar que los equivalentes establecidos con los que cuenta el traductor para poder transmitir los culturemas de una lengua a otra son incontables, pues son personajes que derivan de la Biblia y otros libros religiosos, que fueron los primeros libros en ser traducidos a diferentes lenguas. Existen, por tanto, equivalentes establecidos que posibilitan la mayoría de las traducciones que se refieren a personajes religiosas o escenas clave de la vida de Jesús.

Cabe señalar que el calco es una de las técnicas más productivas para la traducción de las obras pictóricas cuando no existe un equivalente acuñado en la LM. En la ficha de análisis de la última cena, observamos también la presencia de otro culturema, Las Ánimas del Purgatorio, que se traduce a través de la traducción literal de la estructura del culturema en la LO, Souls in Purgatory, y que tampoco representa una dificultad para el traductor cuando el culturema es transparente en su LO, como se observa en la siguiente ficha de análisis:

Tabla 84: ficha de análisis del culturema La Sagrada Cena 
ID

\section{CODIGO GUÍA}

GUíA

PROVINCIA

ELEMENTO DE ANÁLISIS

TIPOLOGÍA

CAMPO SEMÁNTICO

CONTEXTO
344

LPA

Lonely Planet Andalucía

Sevilla

la sagrada cena

culturema

pintura

Room III exhibits Sevillan Renaissance retables and early 17thcentury Sevillan paintings. The penetrating portrait of Don Cristóbal Suárez de Ribera by the young Velázquez grabs the attention, as does Alonso Cano's striking Las Ánimas del Purgatorio (Souls in Purgatory), in the corner between rooms III and IV.In room IV, devoted mainly to Mannerism (the transition from Renaissance to baroque), Alonso Vázquez's large Sagrada Cena (Last Supper) is the outstanding canvas.The lovely anonymous statuettes of the child Jesus and child St John the Baptistcontrast markedly with the grisly head of St John the Baptist (1591) by Gaspar Núñez Delgado in the centre of the room

equivalente acuñado

préstamo

TÉCNICA TRADUCCIÓN 1

TÉCNICA TRADUCCIÓN 2

Otra de las técnicas más usuales en este campo semántico es el préstamo, utilizado como técnica simple. En los casos en los que el mediador ha tomado la decisión de conservar la denominación en LO se observa una intencionalidad por parte del mediador que consiste en que el lector, haciendo uso de sus propios recursos lingüísticos y culturales, pueda establecer la conexión con el elemento cultural existente en LM.

Así, por ejemplo, cuando el mediador describe las Inmaculadas del pintor Murillo, utiliza el término en LO, pudiendo haber utilizado el equivalente establecido Immaculate, como se observa en la siguiente ficha de análisis:

Tabla 85: ficha de análisis del culturema Inmaculada 
ID

CODIGO GUÍA

GUÍA

PROVINCIA

ELEMENTO DE ANÁLISIS

TIPOLOGÍA

CAMPO SEMÁNTICO

CONTEXTO

TÉCNICA TRADUCCIÓN 1
62

LPA

Lonely Planet Andalucía

Cádiz

inmaculada

culturema

pintura

Along the street is the baroque church where the parliament actually met, the Oratorio de San Felipe Neri (\%956 2116 12; Plaza de San Felipe Neri; admission €2; h10am-1.30pm Mon-Sat).

This has an unusual and beautiful oval dome, and a masterly Murillo Inmaculada of1680 in itsmain retable

préstamo

Sin embargo, es posible que el mediador no sólo haya querido activar sus conocimientos lingüísticos, sino también hacer hincapié en la historia y las particularidades de este pintor, que dedicó la inmensa mayoría de su obra a retratar vírgenes denominadas por él Inmaculadas y por ello es considerado el pintor por antonomasia del tema de la Inmaculada Concepción.

En resumen, podemos establecer que, en general, los culturemas relativos al campo semántico pintura no representan un problema para el traductor. En nuestro caso, tras analizar los culturemas derivados de la pintura religiosa, hemos constatado una variedad de técnicas de traducción puestas en marcha a través de equivalentes acuñados en LM de personajes y escenas bíblicas, así como el calco en el caso de elementos que no disponen de equivalente funcional pero sí son transparentes y fácilmente reproducibles.

\subsubsection{Viaje}

El último campo semántico que se incluye en el análisis de los culturemas del sector turístico en las guías Lonely Planet es viaje. Este campo semántico suele 
caracterizarse por palabras o términos turísticos que hacen referencia al traslado o el desplazamiento de un lado a otro y no implican, necesariamente, una referencia cultural o una conexión especial con el pueblo o sociedad al que pertenecen, sino que forman parte de la lengua profesional del turismo.

Sin embargo, se han identificado algunos elementos culturales que no hace referencia al traslado o desplazamiento turístico en sí, sino al período en el que se realiza la actividad turística y que está íntimamente relacionado con las costumbres y normas imperantes de la sociedad a la que pertenece. Este tipo de culturemas identificados queda representado por el culturema puente.

El DRA define puente como "día o serie de días que entre dos festivos o sumándose a uno festivo se aprovechan para vacación". En España resulta habitual aprovechar los días laborales que quedan cercanos a un fin de semana o a otro día festivo para viajar y hacer turismo. Resultan frecuentes las ofertas y los paquetes turísticos para realizar escapadas a ciudades españolas o europeas.

En la ficha de análisis del culturema puente se observa que las técnicas utilizadas son el equivalente acuñado y el préstamo. "Long weekend" es la denominación que se suele utilizar en la LM para definir un fin de semana que dura más de dos días al caer un día festivo en lunes o viernes. No creemos que incluya con este significado, sin embargo, la costumbre española (también francesa ${ }^{125}$ ) de añadir algún día adicional a los festivos para alargar las vacaciones:

Tabla 86: ficha de análisis del culturema puente

\footnotetext{
${ }^{125}$ En francés sí existe equivalente cultural, pues se utiliza la expresión faire le pont para indicar que se añaden días de vacaciones adicionales a los festivos.
} 
ID

CODIGO GUÍA

GUíA

PROVINCIA

ELEMENTO DE ANÁLISIS

TIPOLOGÍA

CAMPO SEMÁNTICO

CONTEXTO

TÉCNICA TRADUCCIÓN 1

TÉCNICA TRADUCCIÓN 2

605

LPM

Lonely Planet Madrid

Madrid

puente

culturema

viaje

Jueves Santo (Good Thursday) kicks off the official holiday period known in Spain Las Semana Santa (Holy Week). Local cofradías (lay fraternities) organise colourful and often solemn religious processions where hooded men and barefoot women dragging chains around their ankles and bearing crosses are among the parading figures. The main procession concludes by crossing the Plaza Mayor to the Basílica de Nuestra Señora del Buen Consejo. For many madrileños it also marks the start of a much-needed puente (bridge, or long weekend) and they take the chance to escape the city

equivalente acuñado

préstamo

El término bridge en el Oxford English Dictionary no recoge la acepción de long weekend. Se trata de un elemento que incluye una traducción literal y que aporta un significado metafórico y de información metalingüística, que junto con el equivalente establecido consiguen transmitir la carga cultural principal del culturema.

Con el análisis del campo semántico viaje finalizamos nuestro estudio detallado de la transmisión cultural en las guías turísticas. A continuación exponemos las conclusiones fruto del análisis y los resultados obtenidos del estudio de las frecuencias de uso, así como de los campos semánticos anteriormente mencionados. 


\section{CONCLUSIONES}

\subsection{Reflexiones finales}

En este trabajo hemos abordado el estudio de la mediación intercultural en el texto turístico partiendo de la base de que lengua y cultura son inseparables, pues la lengua es parte fundamental de la cultura, y es, asimismo, el vehículo que la hace posible y permite su transmisión en cualquier acto comunicativo.

Con el paso del tiempo, los estudios de Traducción han abandonado la idea de que la traducción consiste en la transmisión fiel de los elementos lingüísticos, y se ha dado paso a la concepción de que la traducción es un acto complejo de comunicación intercultural, en el que forzosamente se ponen en juego elementos que resultan nuevos y desconocidos para los intervinientes en dicho acto comunicativo.

El mediador cultural surge como figura determinante en la comunicación intercultural, para facilitar el entendimiento y servir de puente entre las distintas culturas en juego. No se trata de un simple técnico lingüístico o un mero traductor especializado, sino de un comunicador-mediador que comparte tanto la cultura de origen como la de destino y es capaz de entender el acto de comunicación como un intercambio de presuposiciones implícitas, modos de pensar y de sentir, de ver el mundo que nos rodea.

Como hemos explicado a lo largo de la presente investigación, el sector turístico es un sector clave en la economía española (destaca su pujanza en la actual coyuntura económica) y en general, en la mayoría de países desarrollados. Se trata de un sector en permanente crecimiento, renovación e innovación. Por su 
parte, el fenómeno de la globalización obliga forzosamente a los individuos a conocer, a intercambiar, a viajar. La consecuencia es que el intercambio cultural se ha generalizado y que las sociedades desarrolladas consideran el turismo y las actividades de ocio como un elemento indispensable para su bienestar.

Por estos motivos, en el contexto de la comunicación intercultural, la traducción turística cobra especial relevancia, en modalidades de traducción convencionales y otras nuevas como la localización, surgidas de la presencia masiva de textos turísticos en Internet. Sin embargo, la traductología no ha dedicado la suficiente atención académica a este tipo de textos, con el consiguiente vacío académico. Tradicionalmente, la atención se ha centrado en denunciar los errores frecuentes que presentan muchas de las traducciones turísticas y a denostar a los traductores de las mismas. Una vez superada esa fase, han sido pocos los estudios de traducción que se hayan desvinculado de la perspectiva del error en traducción y que hayan descrito, argumentado y propuesto elementos teóricos que permitan un mayor conocimiento de los mecanismos que operan en la comunicación turística y de los condicionantes traductológicos que implican. Por nuestra parte, nuestra investigación ha pretendido ir más allá para ofrecer otro tipo de reflexiones que resultan de especial pertinencia en el discurso turístico, incluyendo el estudio de uno de los elementos que provoca mayor dificultad en la traducción turística como es la cultura.

A lo largo de este trabajo hemos abordado la cuestión de la mediación intercultural y la traducción del texto turístico a través del análisis de una serie de culturemas de la cultura española y de sus diferentes subculturas extraídos de cinco guías Lonely Planet. 
En el capítulo 2 nos hemos aproximado, desde la teoría, al concepto de cultura y funcionamiento desde las bases de la etnolingüística, una disciplina que intenta explicar la relación entre el lenguaje y la cultura. Seguidamente nos hemos sumergido en la descripción de las circunstancias que han promovido el giro cultural en traducción en la segunda mitad del s.XX, pues es a partir de este momento cuando la cultura pasa a ser la unidad de traducción de un texto y los antiguos y obsoletos conceptos de fidelidad e intraducibilidad quedan superados por otros conceptos como la adecuación cultural.

Para dar cuenta de las aportaciones previas en torno a la traducción de la cultura, hemos realizado un recorrido por un gran número de las aportaciones de la traductología moderna en cuanto a las distintas denominaciones que reciben los culturemas, las clasificaciones existentes según los ámbitos culturales y, por último, las diferentes propuestas de técnicas de transferencia cultural.

El capítulo 3, de base también teórica, ha puesto el acento en el texto turístico, género desde el cual extraemos los elementos para su posterior análisis. Asimismo, se ha realizado una caracterización del sector turístico en España, que ha resultado fundamental para poder entender la importancia de las labores de mediación turística en este sector. Este capítulo ha versado sobre el texto turístico y su tratamiento en traductología. También se ofrece una pincelada teórica sobre la localización de textos turísticos como una de las actividades con mayor recorrido en el ámbito de la investigación.

Después de los planteamientos teóricos, el capítulo 4 ha establecido la metodología de análisis a través de la cual se estudian en detalle los culturemas. Una vez identificados éstos, se ha procedido al análisis de las técnicas de traducción de dichos culturemas. Por un lado, se ha analizado la frecuencia de 
ocurrencia de los culturemas y de las técnicas de traducción y por otro, se ha procedido al análisis cualitativo de los culturemas pertenecientes a los distintos campos semánticos. Paralelamente se han ido desgranando los resultados que arroja el análisis traductológico.

Al finalizar nuestra investigación llegamos a la conclusión de que el texto turístico constituye una rama de la traducción especializada independiente que posee distintas modalidades discursivas, múltiples tipologías textuales y un caudal léxico tan variado y multitemático que le confieren una gran dificultad para la traducción y que necesitan de un mediador profesional y especializado en comunicación turística para que la comunicación intercultural se realice con éxito en este ámbito. Dicho mediador ha de ser necesariamente bicultural, de modo que ha de compartir no sólo dos lenguas, sino las culturas en las que éstas se inscriben, entendiéndose éstas como todo el conjunto de costumbres y tradiciones, los valores espirituales, todo el sistema conductual y de patrones de actuación y comportamiento, la interpretación del entorno y el universo que cada comunidad de hablantes posee, así como el conocimiento de su historia y su literatura. El traductor de textos turísticos debe hacer frente al reto que supone la existencia de objetos, costumbres, comidas, ideas, personajes célebres reales e imaginarios que son propios de una cultura y que no tienen correspondencia en otras culturas, incluso próximas a ellas.

Por lo que respecta a las dificultades encontradas en la elaboración de esta tesis, el vacío académico existente en torno a la traducción del texto turístico ha hecho que el proceso de documentación haya sido una tarea dificultosa, pues hemos encontrado publicaciones paralelas sobre el lenguaje del turismo, que, si bien no son abundantes, dan cuenta de la reflexión existente de este lenguaje de especialidad desde distintos puntos de vista (estudios del género, estudios 
con fines didácticos, etc). No obstante, es escasa la bibliografía disponible relativa al estudio traductológico del texto turístico en comparación con la bibliografía existente acerca de otras modalidades de traducción, al menos en lo que respecta a los medios académicos habituales.

La fase de identificación de culturemas ha sido relativamente sencilla. Sin embargo, hemos tenido dificultades, sobre todo en lo que concierne a la clasificación de las distintas técnicas de traducción aplicables a un culturema en contexto, pues, en la mayoría de casos, el mediador, utiliza técnicas en doblete o en triplete.

Durante el análisis hemos podido constatar las dificultades semánticopragmáticas que implica el trasvase de los culturemas. El reto de traducir la cultura convierte a la mediación en una actividad complejísima, por lo que elementos teóricos básicos de la metodología traductológica como las técnicas de traducción suponen un elemento que posibilita la sistematización de las actuaciones del mediador en su proceso traductor y facilita su descripción.

No obstante, a pesar de las dificultades encontradas, a lo largo de esta investigación se han conseguido alcanzar los objetivos que nos planteábamos al inicio del proyecto. En este sentido, esta tesis doctoral ha permitido analizar aspectos que, hasta la fecha, no habían sido abarcados desde una perspectiva traductológica.

Esta tesis doctoral pretende así contribuir al establecimiento de unas bases teórico-metodológicas de la traducción del texto turístico desde una perspectiva académica, que puedan servir de referencia para futuras investigaciones en el marco de la traducción especializada y, en concreto, en el ámbito turístico. A este respecto, lo novedoso de nuestra investigación radica en lo siguiente: 
- La perspectiva de análisis traductológico de la comunicación intercultural a través de un corpus monolingüe. Esto supone una novedad frente a los estudios previos, que utilizan corpus bilingües y en el que el mediador suele pertenecer a la cultura del TM. En nuestro caso, el autor del texto turístico es a la vez el mediador, y asiste al lector-turista como mediador intercultural, acercando la nueva cultura (española) al lector desde la cultura y la lengua compartida por ambos, desarrollando asimismo labores de mediación intracultural.

- El estudio integrado de los principales campos semánticos del lenguaje turístico. Las publicaciones acerca de la traducción del texto turístico suelen acometer el estudio de todo tipo de culturemas presentes en el texto turístico. Sin embargo, no hemos constatado la presencia de estudios previos que abarquen, a su vez, el análisis de campos semánticos separadamente y en su conjunto. Este estudio ha permitido analizar profundamente cada campo semántico, con sus peculiaridades, así como relacionar los fenómenos traductológicos propios de los culturemas de los distintos campos semánticos, y establecer generalizaciones por la gran cantidad de elementos culturales analizados y que forman parte del corpus.

- La elección de la tipología textual de la literatura de viajes y, en concreto, de las guías turísticas como objeto de estudio dentro del texto turístico. Se trata de una tipología que apenas ha recibido atención por parte de los traductólogos, que se han centrado en mayor medida en los folletos turísticos.

- La formulación de una nueva definición del texto turístico, que no sólo toma en consideración al turista como lector-destinatario y la modalidad descriptivo-exhortativa propia de los folletos publicitarios, sino que 
contempla también aquellos textos de índole profesional y las nuevas tipologías textuales surgidas en Internet.

- La propuesta de una clasificación de tipología de culturemas en función de la complejidad que presentan para su traducción. Ésta contempla tres tipos de culturemas: un primer grupo de culturemas que incluyen todos aquellos que son opacos y que suelen ser, por lo común realia de difícil transmisión (parador, churros, alpargata,..), así como elementos culturales propios de la cultura popular (puente, rubia, La Manquita,...). En segundo lugar, un segundo tipo de culturemas semi-transparentes, que suelen presentar un carga cultural parcial cuando el culturema contiene elementos léxicos provenientes del lenguaje general (sombrero cordobés, museo taurino, traje de flamenca, ensalada catalana,...) y, por último, una tercera categoría de elementos universales; y, por tanto, transparentes, que se consideran elementos globalizados y compartidos por las culturas en juego (tapas, paella, flamenco) y que son identificados rápidamente tanto por el mediador como por el lector destinatario.

Con respecto a las hipótesis que formaban el planteamiento de inicio de esta investigación, concluimos lo siguiente:

- El mediador del texto turístico se enfrenta a textos con una gran cantidad de culturemas o una ocurrencia menor de los mismos dependiendo de la temática o campo semántico sobre el que verse el texto. La gastronomía es el campo semántico con mayor presencia de estos elementos, seguido de aquellos culturemas que hacen referencia al campo semántico de las fiestas y tradiciones, así como la arquitectura.

- Aunque el mediador activa muchas técnicas a la vez, dependiendo de la estrategia previa y del tipo de texto al que se enfrente el mediador activará en mayor medida unas técnicas u otras. Los mediadores del 
texto turístico muestran, en general, un marcado interés por acercar la nueva cultura al lector. Podemos concluir que existe una suerte de norma entre los mediadores de las guías Lonely Planet, que priorizan el término en LO a través del uso del préstamo como técnica de traducción. Esto conlleva transmitir el color local proviente de la cultura que va a conocer el turista. La amplificación se confirma como técnica más productiva en combinación con el préstamo para transmitir del modo más preciso posible la máxima cantidad de carga informativa del culturema a partir de una explicitación del significado.

- La morfología del culturema, su grado de importancia en el texto y su pertenencia a un foco cultural y, especialmente, su complejidad a la hora de trasvasarlo, son los elementos clave que influyen en el uso de una técnica de traducción determinada. Existen culturemas opacos que necesitan de una amplificación que incluya varios contenidos característicos que conforman la razón de ser del culturema, mientras que, en otros casos, se trata de culturemas que pueden asociarse a un equivalente funcional en la otra cultura en cuestión, lo que posibilita una fácil aproximación hacia la nueva realidad cultural. Aquellos culturemas que son lingüística y culturalmente complejos de traducir suelen requerir un abanico de técnicas más elaborado o el uso de la técnica de la amplificación. Cuando nos hallamos ante culturemas sencillos para el mediador, éste no precisa de técnicas compuestas y se vale a menudo de calcos y del uso del préstamo puro. Esto confirma nuestra hipótesis inicial, por la que establecíamos que el mediador se vale de unas técnicas $\mathrm{u}$ otras dependiendo del grado de traducibilidad que presente el culturema. 
- Constatamos, a partir de los resultados obtenidos, que existen culturemas que se han internacionalizado y sus correspondientes manifestaciones culturales han traspasado fronteras y se han erigido en iconos de su cultura de origen, hasta el punto de que sus manifestaciones culturales han penetrado y han sido adoptadas por otras culturas y sus culturemas forman parte de su acervo lingüístico. Tres son los culturemas que han sufrido esta transformación convirtiéndose en culturemas globalizados o universales: paella, flamenco y tapas.

- La dificultad última de la transmisión de los culturemas no reside en la traducción del culturema en sí, sino en la transmisión del sistema de valores, reglas y convenciones, es decir, el marco de referencia establecido por el grupo social del que es propio el culturema y su correspondiente manifestación cultural. No basta, pues, con que el mediador tenga conocimientos de la cultura hacia la cual realiza la mediación, sino que es necesario vivir y experimentar la cultura para poder explicarla y transmitirla. Asimismo, el mediador necesita realizar una investigación rigurosa y contrastada de las expresiones artísticas para evitar que el lector destinatario caiga en malinterpretaciones tan propias de la comunicación intercultural. De nuestro estudio podemos afirmar que las guías Lonely Planet muestran un cuidadoso proceso de documentación y un especial interés en proveer de la máxima información en aquellos aspectos culturales que le resultan más atractivos para el lector de la cultura meta.

- Los mediadores no transmiten, en ocasiones, el 100\% de la carga cultural de un culturema debido a los condicionantes del propio texto turístico. Sin embargo, podemos concluir que sí logran, en la mayoría de casos, condensar la información primaria del culturema que permita al lector 
crear en su mente una representación muy básica del objeto, personaje o manifestación artística de que se trata. Muy a menudo el mediador se apoya en elementos paratextuales para transferir el contenido de un culturema. En otras ocasiones estos elementos provocan restricciones, y en consecuencia, el uso de una u otra técnica depende de la ausencia o presencia de este tipo de elementos no textuales. Existen otros elementos ajenos al proceso traductor que imponen restricciones a la traducción de los culturemas, como pueden ser la asimetría lingüística y las diferencias estructurales, estilísticas o retóricas entre las lenguas. Así pues, queda demostrado que existen diferentes grados de traducibilidad de los culturemas y que son múltiples los factores que la condicionan.

- La percepción de la cultura depende de factores muy diversos y todos ellos deben estudiarse para tener una visión global de cómo se percibe una cultura. Estos factores incluyen la distancia cultural e interlingüística, la edad del individuo y su conocimiento del mundo. En nuestro análisis hemos comprobado que el interés y la receptividad por la cultura de destino es un factor subjetivo muy destacado que el mediador de textos turísticos debe también considerar.

La importancia que la industria turística y del ocio ha adquirido en los últimos años, así como sus previsiones de crecimiento, provocan que el sector de la traducción de textos turísticos se perfile como una de las principales salidas profesionales en el ámbito de la traducción en la actualidad y en el futuro.

Al inicio de esta tesis nos propusimos el reto de investigar la traducción de los elementos culturales para poder ofrecer a los docentes, investigadores y, especialmente, los mediadores, herramientas con las que salvar los múltiples escollos que provoca la transmisión de la cultura. Con esta investigación esperamos haber contribuido, modestamente, a proporcionar algunos de los 
elementos necesarios para desarrollar una teoría válida y útil para la traducción de textos turísticos.

\subsection{Futuras vías de investigación}

Las posibilidades concretas de estudio que parten de este trabajo se centran fundamentalmente en cuatro:

1. Desde el punto de vista lingüístico, se abre una puerta al estudio de los elementos culturales globalizados, es decir, aquellos que han sufrido un proceso de internacionalización tal que son universales. Así, resultan automáticamente identificados con su cultura de origen y adaptados incluso por la cultura de destino. La investigación óptima debería abordar qué aspectos son los que provocan la internacionalización de dichos culturemas y en qué medida dichos culturemas han penetrado en las distintas culturas de destino.

2. Asimismo, resulta de gran interés académico realizar un estudio en profundidad sobre los falsos amigos culturales y la estereotipia lingüística en el texto turístico, que tiende a establecer una imagen de los destinos elaborada ad hoc, lo que contribuye a una visión idealizada y simplificada del destino turístico.

3. Desde el punto de vista de la traductología, el estudio derivado de esta investigación supone seguir ahondando en la traducción de la cultura través del estudio de las diferentes tipologías textuales del texto turístico. Sin embargo, la principal vía de investigación abierta actualmente se halla en la localización de los textos turísticos, debido a la abrumadora y creciente presencia de éstos en Internet. Asimismo, una 
vez identificados en el presente trabajo los campos semánticos que contienen los focos culturales más relevantes, se hace indispensable un estudio en profundidad e independiente de los mismos.

4. Finalmente, desde el punto de vista de la didáctica de la traducción, el estudio permite abrir nuevas perspectivas sobre los errores de traducción que los traductores noveles cometen frecuentemente cuando se enfrentan a la traducción inversa de textos turísticos. El catálogo de estrategias que hemos elaborado en esta tesis doctoral constituye una propuesta de estudio y reflexión, pues en éste se proponen soluciones novedosas para el trasvase de los culturemas desde la perspectiva del universo cultural del destinatario y que resultan de gran utilidad para el mediador. 


\section{BIBLIOGRAFÍA CITADA}

A.A.V.V. (2001). DRAE (Diccionario de la Real Academia Española). 22a ed. http://buscon.rae.es/drael/ [fecha de consulta: 20 de enero de 2011].

A.A. V.V. (2007). Andalucía. 5a edición. Londres: Lonely Planet Publications.

A.A. V.V. (2008). Barcelona. 6ạ edición. Londres: Lonely Planet Publications.

A.A. V.V. (2008). Madrid. 5a edición. Londres: Lonely Planet Publications.

A.A. V.V. (2008). Mallorca. 1a edición. Londres: Lonely Planet Publications.

A.A. V.V. (2009). Spain. 7ạ Edición. Londres: Lonely Planet Publications.

A.A. V.V. (2010). Valencia Encounter. 1ạ edición. Londres: Lonely Planet Publications.

A.A. V.V. (2012). Oxford Dictionaries Online. http://oxforddictionaries.com/ [fecha de consulta: 20 de enero de 2011].

ANECA (2005). Libro Blanco para el Título de Grado en Turismo. Disponible en URL:

http://www.aneca.es/var/media/359791/libroblanco_turismo_03.pdf [fecha de consulta: 15 de marzo de 2011].

Andalucía, Alcazaba de Almería. Disponible en URL: http://www.andalucia.org/turismo-cultural/visitas/almeria/alcazaba-dealmeria [fecha de consulta: 20 de noviembre de 2011]. 
Alcaraz Varó, E. (2000). El inglés profesional y académico. Madrid: Alianza Editorial.

Alcaraz Varó, E., Hughes, B., Campos Pardillos, M.A., Pina Medina, V.M., y Alesón Carbonell, M.A. (2006). Diccionario de términos de turismo y ocio: inglés- español, Spanish-English. 2aㅡ. Barcelona: Ariel.

Alesón Carbonell, M.A. (2001). "Translating E.S.P.: Introducing English for Tourism to future Translators", en Valero Garcés, C. y de la Cruz Cabanillas, I. (eds.), Traducción y nuevas tecnologías. Herramientas auxiliaries del traductor. Universidad de Alcalá, 105-113.

Álvarez, C. (1998). "Turismo y nuevas tecnologías". Revista Valenciana d'Estudis Autonòmics, 25, 135-150.

Bakhtin, M.M. (1978). Speech genre and other late essays. Austin: University of Texas Press.

Barthes, R. (1957). Mythologies. Paris: Seuil.

Bassnett-McGuire, S. (1988). Translation Studies. Londres: Routledge.

Bassnett-McGuire, S. y Lefevere, A. (eds.) (1990). "Introduction: Proust's grandmother and the Thousand One Nights", The Cultural Turn in Translation Studies. Translation, History and Culture. Londres y Nueva York: Pinter Publishers, 1-13.

Bassnett-McGuire, S. y Lefevere, A. (eds.) (1998). Constructing Cultures: Essays on Literary Translation. Clevedon: Multilingual Matters.

Becher, G. (2002). "El lenguaje propio del sector turístico: reflexiones en torno a un estudio terminológico y temático", Revista de Lenguas para Fines Específicos, 9-10, 13-30. 
Beeby, A. (1996). Teaching Translation from Spanish to English: worlds beyond words. Otawa: University of Otawa Press.

Bell, R.T. (1991). Translation and Translating. Londres: Longman.

Bernardi, U. y Filippi, V. (2002). “Dal Turismo ai turismi: trasformazioni sociali e sfide culturali", Aggiornamenti Sociali, 5, 398-409.

Bhatia, V.K. (1993). Analysing Genre. Language Use in Profesional Settings. Londres: Longman.

Bigné Alcañiz, J.E., Font Aulet, X. y Andreu Simó, L. (2000). Marketing de destinos turísticos. Análisis y estrategias de desarrollo. Madrid: ESIC.

Bodecker, B. y Frese, K. (1987). "Die Übersetzung von Realienbezeichnungen bei literarischen Texten: Eine Prototypologie", Textcontext, 2-3, 137-165.

Boorstin, D. (1961/1992). The Image. A Guide to Pseudo-Events in America. New York: Vintage Books.

Borja, A. (2000). El texto jurídico inglés y su traducción al español. Barcelona: Ariel.

Borrueco Rosa, M. (Coord.) (2006). "Sistemas conceptuales en la producción y recepción de textos turísticos. Estudio Aplicado", La especialización lingüística en el ámbito del turismo. Sevilla: Junta de Andalucía. Consejería de Turismo, Comercio y Deporte, 33-51.

Bowles, P. (1949 /2006). El cielo protector. Barcelona: Seix Barral. 
Brooks, D. (2000). "What Price Globalization? Managing Costs at Microsoft", en Sprung, R., Translating into success: cutting-edge strategies for going multilingual in a global age. Amsterdam: John Benjamins, 43-58.

Bugnot, M.A. (2005). Texto turístico y traducción especializada. Estudio crítico de un corpus español-francés sobre la Costa del Sol (1960-2004). Tesis Doctoral, Universidad de Málaga.

Buzard, J. (1993). The Beaten Track: European Tourism, Literature and the Ways to 'Culture' (1800-1918). Oxford: Clevendon Press.

Calvi, M.V. (2006). Lengua y comunicación en el español del turismo. Madrid: Arco Libros.

Calvi, M.V. (2010). "Los géneros discursivos en la lengua del turismo: una propuesta de clasificación". Ibérica, 19, 9-32.

Calvi, M.V. y Mapelli, G. (2010). "La presencia de términos culturales en las páginas web de turismo". Actas del XVI Congreso de la Asociación Internacional de Hispanismo, vol. 2., Iberoamericana.

Cambrils, J.C. (2010). "Estrategias y programa de la administración turística española". Conferencia presentada en Primeras Jornadas sobre Universidad, Empresa y Administración Turística, Escuela Politécnica Superior de Gandia, Gandía, 26 de noviembre de 2010.

Camilleri, C. (1985). Antropología cultural y educación. París: Unesco.

Campillo Arnaiz, L. (2005). Estudio de los elementos culturales en las obras de Shakespeare y sus traducciones al español por Macpherson, Astrana y Valverde. Tesis Doctoral, Universidad de Málaga. 
Candel Mora, Miguel Ángel (2010). "Explotación de corpus bilingües para la elaboración de recursos terminológicos para la traducción en el ámbito de la gestión del patrimonio", en Ortega Arjonilla, E. (ed.), Panorama actual de investigación en Traducción e Interpretación. Granada: Atrio, 117-138.

Carbonell i Cortés, O. (1997). Traducir al Otro. Traducción, Exotismo, Poscolonialismo. Escuela de Traductores de Toledo, 2. Cuenca: Ediciones de la Universidad de Castilla La Mancha.

Carbonell i Cortés, O. (1999). Traducción y cultura. De la ideología al texto. Salamanca: Colegio de España.

Casado Velarde, M. (1991). Lenguaje y cultura: la etnolingüística. Madrid: Síntesis.

Castillo García, G.S. (2006). La (auto)traducción como mediación entre culturas. Universidad de Alcalá.

Castellà, J.M. (1992). De la frase al text. Teories de l'ús lingüístic. Barcelona: Empúries.

Catford, J. C. (1965/1970). A linguistic theory of Translation: an Essay on Applied Linguistics. Londres: Oxford University Press.

Cerdá Redondo, E. (2001). "Tourism Industry and Translating Technology", en Valero Garcés, C. y de la Cruz Cabanillas, I. (eds.), Traducción y nuevas tecnologías. Herramientas auxiliaries del traductor. Universidad de Alcalá, 173-181.

Chamizo Sánchez, R. (2003). Introducción a la comunicación turística. Málaga: Universidad de Málaga. 
Chandler, H.M. (2005). The Game Localization Handbook. Massachussets: Charles River Media.

Cohen, E. (1972). "Towards sociology of international tourism", Social Research, 39, 164-182.

Comitré Narváez, I. (2004). "La traducción de culturemas en publicaciones del sector turístico. Un estudio empírico", en Gallegos Rosillo, J.A. y Benz Busch, H. (eds.), Traducción y cultura: el papel de la cultura en la comprensión del texto original. Málaga: Encasa, 115-138.

Cooper, C., Fletcher, J. Gilbert, D. y Wanhill, S. (1993). Tourism Principles and Practice. Gran Bretaña: Pitman Publishing.

Corte, N. (2002). "Localización e internacionalización de sitios web." Tradumàtica, 1.1 Disponible en URL: http://www.fti.uab.es/tradumatica/revista/articles/ncorte/art.htm [fecha de consulta: 25 de febrero de 2011]

Coseriu, E. (1981). "La socio- y la etnolingüística: sus fundamentos y sus tareas". Anuario de Letras, 19, 5-29.

Crampon, L.J. y Rothfield, M.L. (1976/2002). Tourism marketing: A destinationorientated programme for the marketing of international tourism. Londres: Tourism International Press.

Cronin, M. (2003). Translation and Globalization. Londres: Routledge.

Dann, G.M.S. (1996). The language of tourism: a sociolinguistic perspective. Wallingford: $C A B$ International.

De la Cruz Cabanillas, I y Valero Garcés, C. (2001). "La Traducción y las nuevas Tecnologías", en Valero Garcés, C. y de la Cruz Cabanillas, I. (eds.), 
Traducción y nuevas tecnologías. Herramientas auxiliaries del traductor. Universidad de Alcalá, 11-24.

De la Cruz Trainor, M. M. (2003). La Traducción de textos turísticos, propuesta de clasificación y análisis de muestras. Tesis Doctoral, Universidad de Málaga.

De la Cruz Trainor, M. M. (2004). "Traducción al inglés de términos culturales en textos turísticos", en Gallegos Rosillo, J.A. y Benz Busch, H. (eds.), Traducción y cultura: el papel de la cultura en la comprensión del texto original. Málaga: Encasa, 83-114.

Delisle, J. (1993). La traduction raisonnée. Manuel d'initiation à la traduction professionnelle de l'anglais vers le français. Ottawa: Presses de I'Université d'Ottawa.

Descubre la Costa del Sol. Disponible en URL: http://www.visitacostadelsol.com/descubre-la-costa-del-sol [fecha de consulta: 17 de diciembre de 2012].

Dingwaney, A. (1995). "Introduction: Translating Third World Cultures." Between Languages and Cultures. Translation and Cross-cultural Texts. Anuradha Dingwaney y Carol Maier (eds.). Pittsburgh, Pennsylvania: University of Pittsburgh Press, 3-15.

Dollerup, C. (1999). Tales and Translation: The Grimm Tales from Pan-Germanic narratives to shared international fairytales. Amsterdam \& Philadelphia: John Benjamins.

Dollerup, C. (2004). "The vanishing Original". Hermes, Journal of Linguistics, 32 185-199. También disponible en URL: http://download2.hermes.asb.dk/ archive/download/H32_09.pdf [fecha de consulta: 25 de febrero de 2011]. 
Dudley Evans, T y Saint-John, M.J. (1998). Developments in English for specific purposes: a multidisciplinary approach. New York: Cambridge.

Duff, A. (1981). The Third Language: Recurrent Problems of Translation into English. Oxford: Pergamon.

Dunne, K. (2006). Perspectives on Localization. Amsterdam, Philadelphia: John Benjamins.

Elena García, P. (1994). Aspectos teóricos y prácticos de la traducción. Salamanca: Ediciones de la Universidad de Salamanca.

Esselink, B. (2000a). A practical guide to localization. Amsterdam; Philadelphia, John Benjamins Pub. Co.

Esselink, B. (2000b). The localization Industry. Disponible en URL: http://www.translatortips.net/tranfreearchive/tf12-localizationthree.html [fecha de consulta: 25 de febrero de 2011].

Febas Borra, J.L. (1978). "Semiología del lenguaje turístico". Estudios Turísticos, 57-58, 17-192.

Fernández Guizetti, G. (1960). "Guillermo de Humboldt, padre de la etnolingüística. Esquemas para una historia de la etnolingüística", Cuadernos del Instituto Nacional de Investigaciones Folklóricas. Buenos Aires: Ministerio de Educación y Justicia, 229-245.

Fiódorov, A.V. (1953). Osnovy obschei teorii perevoda [Introducción a la teoría de la traducción]. Moscú: Biblioteca filologa.

Fischer, M. (-). "La Traducción inversa de textos turísticos como ejercicio para fomentar la competencia lingüística." Revista Espéculo, Universidad de Alcalá, disponible

en

URL: 
http://www.ucm.es/info/especulo/ele/alcala.html [fecha de consulta: 26 de marzo de 2011].

Florin, S. (1993). "Realia in translation", en Zlateva, P. (ed. y trad.), Translation as Social Action. Russian and Bulgarian Perspectives. Londres/Nueva York: Routledge, 122-128.

Franco Aixelá, J. (2000). La traducción condicionada de los nombres propios (Inglés-Español): Análisis descriptivo. Salamanca: Almar.

Fry, Deborah. (2003). The Localisation Primer. 2a edición. Disponible en URL: www.lisa.org/interact/LISAprimer.pdf [fecha de consulta: 25 de febrero de 2011].

Fuentes Luque, A. y Le Poder, M. E. (eds.) (2005). “El turismo en España: panorama introductorio". La traducción en el sector turístico. Granada: editorial Atrio.

Gamero Pérez, A. (2000). "La traducción de textos técnicos y la diversidad tipológica”, Sendebar, 10/11, 127-128.

García Izquierdo, I. (2005). “Traducción”, en López García, A. y Gallardo Paúls, B. (eds.), Conocimiento y Lenguaje, Valencia: Publicaciones de la Universidad de Valencia, 325-360.

Gotti, M. (2006). "The language of tourism as specialized discourse", en Palusci, O. y Francesconi, S. (eds.), Translating Tourism. Linguistic and Cultural representations. Trento: Università di Trento, 15-34.

Goytia, A. (1997). "Nuevas Tendencias de ocio y turismo", en III Foro Internacional de Turismo, Benidorm. 
Gross, R. (1998). "El texto turístico para alumnos no nativos: razón, sinrazón del empeño didáctico en traducción inversa castellano-alemán". Comunicación presentada en el European Society for Translation Studies. Universidad de Granada, 23-26 septiembre de 1998.

Hall, E. (1952). The Silent Language. New York: Doubleday.

Hall, E. (1982). The Hidden Dimension. New York: Doubleday

Halliday, M.A.K., y Hasan, R. (1985). Language, context, and text: aspects of language in a social-semiotic perspective. Oxford: Oxford University Press.

Hatim, B. y Mason, I. (1990). Discourse and the translator. Londres: Longman.

Hatim, B. y Mason, I. (1995). Teoría de la traducción. Una aproximación al discurso. Barcelona: Ariel.

Hervey, S. y Higgins, I. (1992). Thinking Translation. A course in Translation Method: French to English. Londres: Routledge.

Hewson, L. y Martin, J. (1991). Redefining translation. The variational approach. Londres: Routledge.

Holmes, J. (1988). Translated! Papers on Literary Translation and Translation Studies. Amsterdam: Rodopi

Hofstede, G. (1991). Cultures and organizations: Software of the Mind. London: McGraw-Hill.

Hurtado Albir, A. (2001/2008). Traducción y traductología. Madrid: Cátedra. 
Hymes, D. (1964). Language in culture and society (A reader in Linguistics and Anthropology). New York: Harper International Edition.

Instituto de Estudios Turísticos (2010). Informe Habitur 2010. Encuesta de hábitos turísticos. Hábitos de los turistas internacionales. Disponible en URL:http://www.iet.tourspain.es/informes/documentacion/frontur/Infor me\%20Habitur\%202010.pdf [fecha de consulta: 6 de diciembre de 2011].

Instituto de Turismo de España, Turespaña, (2010). Plan de objetivos para la promoción exterior del turismo. Disponible en URL: http://www.tourspain.es/NR/rdonlyres/13F1FB80-5E18-4AD1-9DB564D86F58EA5E/19896/PLANESTRATEGICAPORMERCADO20194.pdf [fecha de consulta: 6 de diciembre de 2011].

Jakobson, R. (1959/1966). "On Linguistic Aspects of Translation". On Translation, Reuben Browe (Ed.), Nueva York: Oxford University Press, 233-239.

Jiménez Crespo, M.A. (2008). El proceso de localización web: estudio contrastivo de un corpus comparable del género sitio web corporativo. Tesis Doctoral, Universidad de Granada.

Katan, D. (1999). Translating Cultures. An introduction for Translators, Interpreters and Mediators. Manchester: St. Jerome Publishing.

Kelly, D. (1997). "The translation of texts from the tourist sector: textual conventions, cultural distance and other constraints", Trans, 2, 33-42.

Kelly, D. (2000). "Text selection for developing translation competence: why texts from the tourist sector constitute suitable material. Schaeffner, Christina; Adab, Beverly (eds.), Developing Translation Competence. Amsterdam/Philadelphia: Benjamins, 157-167. 
Kristensen, T. (2002). "Localisation and Tourist Brochures". Perspectives: Studies in Translatology, 10, 3, 193-205.

Koller, W. (1992). Einführung in the Übersetzungswissenschaft. Heidelberg: Quelle und Meyer.

Kotler, P. (2000). Introducción al Márketing. Barcelona: Europea, Prentice Hall Iberia.

Leppihalme, R. (1997). Culture bumps. An empiric approach to the translation of allusions. Clevedon: Multilingual Matters.

Lommel, A. y Ray, R. (2007). LISA Globalization Industry Primer. Suiza: Romainmótier, LISA.

Lorenzo, E. (1996). Anglicismos hispánicos. Madrid: Gredos.

Lozano, L. (1975). "The Perils of the Translator", Michael S. Batts (Ed.), Translation and Interpretation: the Multi-Cultural Context. A Symposium. Vancouver: CAUTG, 61-67.

Majó, J. y Galí, N. (2000). Internet en la Información Turística. Disponible en URL: http://www.turismo.uma.es/turitec/turitec2002/actas/Microsoft\%20Wo rd\%20-\%2026.MAJOGIRONA.pdf [fecha de consulta: 25 de febrero de 2011]

Malinowski, B. (1923). "The Problem of Meaning in Primitive Languages", en Janet Maybin (ed.), Language and Literacy in Social Practice. Clevedon: Multilingual Matters, 1-10.

Málaga, Ciudad Genial. Alcazaba. Disponible en URL: http://www.malagaturismo.com/opencms/opencms/turismo/jsp/quever 
/detalle.jsp?ideqp=130\&id_idioma=1 [fecha de consulta: 20 de noviembre de 2011]

Margot, J.C. (1979). Traduire sans trahir: la théorie de la traduction et son application aux texts bibliques. Paris: L'age de l'homme.

Martí Marco, M.R. (2007). "Turismo y Publicidad: Análisis del discurso publicitario de Turespaña", en Borrueco Rosa, M. (coord.), El lenguaje publicitario en el turismo. Sevilla: Junta de Andalucía. Consejería de Turismo, Comercio y Deporte.

Martínez Almira, M. (2004). Material del curso Mediación Social Intercultural. Universidad de Alicante.

Martínez Motos, R. (2005). "Análisis comparativo de las convenciones textuales de textos turísticos en inglés y en español: los folletos editados por organismos oficiales", en A. Fuentes (Ed.), La Traducción en el Sector Turístico. Granada: Atrio.

Martínez Sierra, J. (2004). Estudio descriptivo y discursivo de la traducción del humor en textos audiovisuales. El caso de los Simpson. Tesis doctoral. Departament de Traducció i Comunicació, Universidad Jaume I.

Mayoral Asensio, R. (1994). "La explicitación de la información en la traducción intercultural", en Hurtado Albir, A. (ed.), Estudis sobre la Traducció. Castellón: Universitat Jaume I, 153 -170.

Mayoral Asensio, R. (1999/2000). "La traducción de referencias culturales", Sendebar, 10/11, 67-88.

Mayoral Asensio, R. (2001). Aspectos epistemológicos de la traducción. Castellón: Universidad Jaume I. 
McCannell, D. (1976). The Tourist: A New Theory of the Leisure Class. Nueva York: Schocken Books Inc.

Mengshuan, K. (2006). La traducción de los elementos lingüísticos culturales chino-español. Estudio de Sueño en las estancias rojas. Tesis Doctoral, Universitat Autònoma de Barcelona.

Mira Rueda, C. (2008). El Discurso Turístico en inglés y en español: su tratamiento lexicográfico. Tesis Doctoral: Universidad de Málaga.

Molina, L. (2001). Análisis descriptivo de la traducción de culturemas árabeespañol. Tesis Doctoral, Universitat Autònoma de Barcelona.

Molina, L. y Hurtado, E. (2002). "Translation techniques revisited: A dynamic and functionalist approach". Méta, 47, n 4, 498-512.

Moreno Peinado, A. (2006). La traducción de elementos culturales en el texto audiovisual. La obra de Pedro Almodóvar en alemán, francés e inglés. Tesis Doctoral, Universidad de Castilla La Mancha.

Morgan, N. Pritchard, A. y Pride, R. (2004). Destination Branding: Creating the Unique Destination Proposition. Oxford: Elsevier.

Moya, V. (2007). La Selva de la Traducción. Madrid: Cátedra.

Newmark, P. (1981). Approaches to translation. Oxford y Nueva York: Pergamon.

Newmark, P. (1988). A Textbook on translation. Hertfordshire: Prentice Hall.

Newmark, P. (1991). About Translation. Clevedon: Multilingual Matters. 
Newmark, P. (1998). More paragraphs on translation. Clevedon: Multilingual Matters.

Nida, E. (1964). Towards a Science of Translating, with special reference to principles and procedures involved in Bible translating. Leiden: E.J. Brill.

Nida, E., y Taber, Ch. (1986). La traducción. Teoría y Práctica. Madrid: Ediciones Cristiandad.

Nigro, M. G. (2006). Il linguaggio specialistico del turismo. Aspetti storici, teorici e traduttiviti. Roma: Aracne.

Niranjawa, T. (1992). Siting Translation: History, Poststructuralism and the Colonial Text. Berkeley y Los Angeles, California: University of California Press.

Nobs, M. L. (1996). "Introducción a la problemática específica de la traducción de textos procedentes del campo del turismo", en Iniestra Mena, E.M. (ed.), Perspectivas hispanas y rusas sobre la traducción. Actas del II Seminario Hispano-Ruso de Estudios de Traducción. Granada: Universidad de Granada, 239-253.

Nobs, M.L. (2006). La traducción de folletos turísticos: ¿Qué calidad demandan los turistas?. Granada: Comares.

Nord, C. (1991). Text Analysis in Translation. Amsterdam: Rodopi.

Nord, C. (1994). "It's tea-time in Wonderland. Culture-markers in fictional texts", en Pürschel, H. (ed.), Intercultural Communication. Duisburg: Leang.

Nord, C. (1997). Translating as a Purposeful Activity. Functionalist Approaches Explained. Manchester: St. Jerome Publishing. 
Olivares Guillón, A. y Urquía Muñoz, M.A. (2006) "Trayectoria y Consolidación de la lengua inglesa como idioma global en la industria del Turismo", en Borrueco, R. (coord.), La especialización lingüística en el ámbito del turismo. Sevilla: Junta de Andalucía. Consejería de Turismo, Comercio y Deporte.

OMT (2001). Tesauro de Turismo y Ocio. Disponible en URL: http://www.tourisme.equipement.gouv.fr/document/Thesaurus.htm [fecha de consulta: 15 de abril de 2011].

OMT (2002). Turismo: Panorama 2020. Previsiones Mundiales y Perfiles de los Segmentos de Mercado. Volumen 7. Disponible en URL: http://pub.unwto.org/WebRoot/Store/Shops/Infoshop/Products/1243/1 243-3.pdf [fecha de consulta: 15 de abril de 2011].

Ortega Arjonilla, E. (1996). Apuntes para una teoría hermenéutica de la traducción. Servicio de publicaciones de la Universidad de Málaga, Málaga.

Ortega Arjonilla, E. (2002). "Filosofía, Traducción y Cultura”, en Cartografías de la Traducción: del post-estructuralismo al multiculturalismo, en Álvarez, R. (ed.), Salamanca: Almar.

Parsons, D. (2000). "Nationalism or Continentalism? Representing Heritage Culture for a New Europe", en Hollis, A. (Ed.), Beyond Boundaries: textual Representations of European Identity. Yearbook of European Studies/Annaire d'Etudes Europeennesk, 15. Amsterdam: Rodopi.

Payo Peña, L. (2002). "La traducción de las referencias culturales en un texto turístico". Puentes: hacia nuevas investigaciones en la mediación intercultural, 1, 1, 33-45.

Paz, O. (1971/1990). Traducción, literatura y literalidad. Barcelona: Tusquets. 
Pegenaute, L. (2004). "La situación actual. Ámbito profesional. Ámbito educativo. Ámbito investigador", en Lafarga, F. y Pegenaute, L. (eds.), Historia de la Traducción en España. Salamanca: Ambos Mundos, 579619.

Pérez Fernández, L.M. (2010). La localización de videojuegos (inglés-español). Aspectos técnicos, metodológicos y profesionales. Tesis Doctoral, Universidad de Málaga.

Pérez Vicente, N. (2008). “El culturema en la tipología textual turística: ejemplos de traducción al italiano", en Pegenaute, L., Tricàs, M., de Cesaris, J., Bernal, E. (eds.), La traducción del futuro: mediación lingüística y cultural en el siglo XXI, vol. I, Barcelona: PPU, S.A.

Perton, N. (2010). La traducción de textos turísticos. Tesina de Fin de Carrera. Universiteit Utrecht Vertalen. Disponible en: http://igiturarchive.library.uu.nl/student-theses/2010-0922200350/Tesina_2010_Narda_Perton_3441695_15-06-2010.pdf [fecha de consulta: 30 de abril de 2011]

Ponce Márquez, N. (2008). “Ejercicio comparativo de un texto turístico original español con su traducción al alemán como fundamento metodológicopara alumnos de los primeros años de traducción". Revista Electrónica de Lingüística Aplicada, 7, 55-78.

Porzig, W. (1964). El mundo maravilloso del lenguaje. Madrid: Gredos.

Postigo Pinazo, E. (2007). "The Language of Tourism/Leisure: the Translation in English and Spanish of Documents Related to Leisure Activities". En Thelen, M. y Lewandowska-Tomaszczyk, B. (Eds.), Translation and Meaning. IV Coloquio Internacional, Maastricht: Universitaire Pers Maastricht, 319-329.

Pym, A. (2004). The Moving Text: Localization, Translation and Distribution. Amsterdam, Filadelfia: John Benjamins. 
Quilis, A. (2002). La lengua española en el mundo. Valladolid: Universidad de Valladolid, Secretariado de Publicaciones.

Quirion, M. (2003). “La formation en localisation à l'université: pour quoi faire?". Méta, 48 (4), 546-558.

Rabadán, R. (1991). Equivalencia y Traducción: Problemática de la equivalencia translémica inglés-español. Universidad de León.

Reiss, K. y Vermeer, H.J. (1996). Fundamentos para una teoría funcional de la traducción. Madrid: Akal.

Robins, R.H. (1971). "Malinowski, Firth and the context of situation", en Ardener, E. (ed.), Social Anthropology and Language. Londres: Tavistock Publications.

Robinson G. (1988). Crosscultural Understanding. Hemel Hempstead, Hertfordshire: Prentice Hall International.

Rodríguez Monroy, A. (1994). "De la traducción como mestizaje: hacia una descolonización del texto cultural". La Torre: Revista de la Universidad de Puerto Rico, 31, 281-307.

Samovar, L.A. y Porter, R.E. (1997). Intercultural Communication: a reader. Belmont, Wadsworth Publications.

Sancho, A. y Pérez, J.M. (1995). "Tourism demand in Spain: a panel data analysis. Tourism and Travel Econometrics", XLV International Conference of Applied Econometrics, Suiza.

Saorín Iborra, A.M. (2003). Las cartas de queja en el aula de inglés para turismo: implicaciones pedagógicas basadas en el uso de recursos de cortesía. Tesis Doctoral. Universitat Jaume I. 
Sapir, E. (1921). Language. Nueva York: Hartcourt, Brace \& World.

Seager, D. L. (1991). "Translating Bogotá to the Jungle: The Loss of Culture", en Luis, W., Rodríguez, J. y Schmidt, D. J. (eds.), Translating Latin America: Culture as text. National Resource Center for Translation and Interpretation: Binghamton, Nueva York, State University of New York, 197-204.

Secretaría General de Turismo (1990). Libro Blanco del Turismo Español, Madrid: Estudios Turísticos, 108, 3-91.

Secretaría General de Turismo y Comercio (2011). Spain's 50 Best Gourmet Products. Ministerio de Industria, Turismo y Comercio.

Sheldon, P. J. (1997). Tourism Information Technology. New York: CAB International.

Simon, S. (1996). Gender in Translation. Cultural Identity and the Politics of Transmission. Londres y Nueva York: Routledge.

Singh, N. y Pereira, A. (2005). The culturally customized Web site: customizing web sites for the global marketplace. Oxford: Elsevier.

Snell-Hornby, M. (1999). Estudios de traducción. Hacia una perspectiva integradora. Traducción de A. S. Ramírez. Salamanca: Almar.

Solà Climent, R. (2007). Análisis de las estrategias publicitarias de las campañas turísticas de la Comunitat Valenciana 1989-2006. Tesis Doctoral. Castellón: Universitat Jaume I.

Solà, R. y Bernad E. (-). Gestión del destino turístico Comunidad Valenciana a través del estudio de las marcas turísticas utilizadas en las campañas de publicidad televisivas.

Disponible

en

URL: 
http://www.esade.edu/cedit/pdfs/papers/pdf1.pdf [fecha de consulta: 23 de diciembre de 2011].

Swales, J.M. (1990). Genre Analysis in Academic and Research Settings. Cambridge: University Press.

Taft, R. (1981), "The Role and Personality in the Mediator", en S. Bochner (ed.), The Mediating Person: Bridges between cultures. Cambridge: Schenkman, 53-88.

Tercedor Sánchez, M. (2005). “Aspectos culturales en la localización de productos multimedia", Quaderns, Revista de Traducció, 12, 151-160.

Toury, G. (1995). Descriptive Translation Studies and Beyond. John Benjamins.

Torre de la Vela (Alhambra). Disponible en URL: http://www.alhambra.info/alhambra_guia_granada/guia_alhambra_mon umental.asp?zona=TorreVela [fecha de consulta: 20 de noviembre de 2011]

Trivedi, H. C. (1971). Cultural and Linguistic Problems in Translation. Surat, India: New Order Book.

Turner, L. y Ash, J. (1975). The Golden Hordes. International Tourism and the Pleasure Periphery. London: Constable.

Tylor, E. B. (1871). Primitive Culture: Researches into the Development of Mythology, Philosophy, Religion, Art, and Custom. London: John Murray.

Urry, J. (1990). The Tourist Gaze. Leisure and Travel in Contemporary Societies. Londres: SAGE. 
Valero Garcés, C. (1995). "Modes of translating culture: ethnography and translation". Méta, 40, 4.

Valls, J. F. (1992). La imagen de marca de los países. Madrid: McGraw Hill/ Interamericana de España.

Vázquez Ayora, G. (1977). Introducción a la traductología. Curso básico de traducción. Washington: Georgetown University Press.

Venuti, L. (1998). The Scandals of Translation. Towards an Ethic of Difference. London/New York: Routledge.

Vermeer, H. J. (1986). “Übersetzen als kultureller Transfer” en Snell-Hornby, M. (1990), Übersetzungswissenschaft: eine neue Orientierung. Tübingen: Francke, 30-53.

Vermeer, H.J. (1992). Skopos und Translationsauftrag-Aufsätze. Francfort d.M.

Vinay, J.P. y Darbelnet, J. (1958/1995). Stylistique comparée du français et de I'anglais. Méthode de traduction. Paris: Didier.

Vlakhov, S. y Florin, S. (1970). "Neperevodimoe v perevode: realii," [Lo intraducible en traducción, realia] en Mastersvo perevoda. Moscú: Sovetskii pisatel, 432-456.

Wilss, W. (1983). "Translation strategy, translation method and translation technique: a clarification of the three translational concepts". Révue de Phonétique Appliquée, 66/67/68, 143-152. 


\section{ANEXOS}

\subsection{Listado de culturemas analizados}

\begin{tabular}{|c|c|c|c|c|c|}
\hline ID & $\begin{array}{l}\text { TÍTULO } \\
\text { GUÍA }\end{array}$ & $\begin{array}{l}\text { ELEMENTO } \\
\text { DE ANÁLISIS }\end{array}$ & $\begin{array}{l}\text { CAMPO } \\
\text { SEMÁNTICO }\end{array}$ & $\begin{array}{l}\text { TÉCNICA } \\
\text { TRADUCCIÓN }\end{array}$ & $\begin{array}{l}\text { TIPO } \\
\text { TÉCNICA }\end{array}$ \\
\hline 1 & $\begin{array}{l}\text { Lonely } \\
\text { Planet } \\
\text { Valencia }\end{array}$ & $\begin{array}{l}\text { ciudad de las } \\
\text { artes y las } \\
\text { ciencias }\end{array}$ & arquitectura & calco & Simple \\
\hline 2 & $\begin{array}{l}\text { Lonely } \\
\text { Planet } \\
\text { Valencia }\end{array}$ & tapas & $\begin{array}{l}\text { gastronomía y } \\
\text { restauración }\end{array}$ & préstamo & Simple \\
\hline 3 & $\begin{array}{l}\text { Lonely } \\
\text { Planet } \\
\text { Valencia }\end{array}$ & fallas & $\begin{array}{l}\text { fiestas y } \\
\text { espectáculos }\end{array}$ & $\begin{array}{l}\text { amplificación + } \\
\text { préstamo }\end{array}$ & Compuesta \\
\hline 4 & $\begin{array}{l}\text { Lonely } \\
\text { Planet } \\
\text { Valencia }\end{array}$ & huerta & $\begin{array}{l}\text { paisaje y } \\
\text { geografía }\end{array}$ & $\begin{array}{l}\text { amplificación + } \\
\text { préstamo }\end{array}$ & Compuesta \\
\hline 5 & $\begin{array}{l}\text { Lonely } \\
\text { Planet } \\
\text { Valencia } \\
\end{array}$ & jamonero & arquitectura & calco + préstamo & Compuesta \\
\hline 6 & $\begin{array}{l}\text { Lonely } \\
\text { Planet } \\
\text { Valencia }\end{array}$ & trencadís & arquitectura & $\begin{array}{l}\text { amplificación + } \\
\text { préstamo }\end{array}$ & Compuesta \\
\hline 7 & $\begin{array}{l}\text { Lonely } \\
\text { Planet } \\
\text { Valencia }\end{array}$ & $\begin{array}{l}\text { tribunal de } \\
\text { las aguas }\end{array}$ & historia & $\begin{array}{l}\text { amplificación + calco + } \\
\text { préstamo }\end{array}$ & Compuesta \\
\hline 8 & $\begin{array}{l}\text { Lonely } \\
\text { Planet } \\
\text { Valencia }\end{array}$ & fallero & $\begin{array}{l}\text { fiestas y } \\
\text { espectáculos }\end{array}$ & $\begin{array}{l}\text { amplificación + } \\
\text { préstamo }\end{array}$ & Compuesta \\
\hline 9 & $\begin{array}{l}\text { Lonely } \\
\text { Planet } \\
\text { Valencia }\end{array}$ & albufera & $\begin{array}{l}\text { paisaje y } \\
\text { geografía }\end{array}$ & $\begin{array}{l}\text { amplificación + } \\
\text { préstamo }\end{array}$ & Compuesta \\
\hline 10 & $\begin{array}{l}\text { Lonely } \\
\text { Planet } \\
\text { Valencia }\end{array}$ & Ionja & arquitectura & préstamo & Simple \\
\hline 11 & $\begin{array}{l}\text { Lonely } \\
\text { Planet } \\
\text { Valencia }\end{array}$ & $\begin{array}{l}\text { sala de } \\
\text { contratación }\end{array}$ & arquitectura & $\begin{array}{l}\text { amplificación + } \\
\text { préstamo }\end{array}$ & Compuesta \\
\hline
\end{tabular}




\begin{tabular}{|c|c|c|c|c|c|}
\hline ID & \begin{tabular}{|l|} 
TíTULO \\
GUÍA
\end{tabular} & $\begin{array}{l}\text { ELEMENTO } \\
\text { DE ANÁLISIS }\end{array}$ & \begin{tabular}{|l|} 
CAMPO \\
SEMÁNTICO
\end{tabular} & $\begin{array}{l}\text { TÉCNICA } \\
\text { TRADUCCIÓN }\end{array}$ & $\begin{array}{l}\text { TIPO } \\
\text { TÉCNICA }\end{array}$ \\
\hline 12 & $\begin{array}{l}\text { Lonely } \\
\text { Planet } \\
\text { Valencia }\end{array}$ & $\begin{array}{l}\text { jardines del } \\
\text { turia }\end{array}$ & $\begin{array}{l}\text { paisaje y } \\
\text { geografía }\end{array}$ & $\begin{array}{l}\text { amplificación + } \\
\text { préstamo }\end{array}$ & Compuesta \\
\hline 13 & $\begin{array}{l}\text { Lonely } \\
\text { Planet } \\
\text { Valencia }\end{array}$ & paella & $\begin{array}{l}\text { gastronomía y } \\
\text { restauración }\end{array}$ & préstamo & Simple \\
\hline 14 & $\begin{array}{l}\text { Lonely } \\
\text { Planet } \\
\text { Valencia }\end{array}$ & mascletá & $\begin{array}{l}\text { fiestas y } \\
\text { espectáculos }\end{array}$ & $\begin{array}{l}\text { amplificación + } \\
\text { préstamo }\end{array}$ & Compuesta \\
\hline 15 & $\begin{array}{l}\text { Lonely } \\
\text { Planet } \\
\text { Valencia }\end{array}$ & tomatina & $\begin{array}{l}\text { fiestas y } \\
\text { espectáculos }\end{array}$ & $\begin{array}{l}\text { amplificación + } \\
\text { préstamo }\end{array}$ & Compuesta \\
\hline 16 & $\begin{array}{l}\text { Lonely } \\
\text { Planet } \\
\text { Valencia }\end{array}$ & castillo & $\begin{array}{l}\text { fiestas y } \\
\text { espectáculos }\end{array}$ & $\begin{array}{l}\text { amplificación + } \\
\text { préstamo }\end{array}$ & Compuesta \\
\hline 17 & $\begin{array}{l}\text { Lonely } \\
\text { Planet } \\
\text { Valencia }\end{array}$ & procesión & $\begin{array}{l}\text { fiestas y } \\
\text { espectáculos }\end{array}$ & calco & Simple \\
\hline 18 & $\begin{array}{l}\text { Lonely } \\
\text { Planet } \\
\text { Valencia }\end{array}$ & $\begin{array}{l}\text { moros y } \\
\text { cristianos }\end{array}$ & $\begin{array}{l}\text { fiestas y } \\
\text { espectáculos }\end{array}$ & $\begin{array}{l}\text { amplificación + calco + } \\
\text { préstamo }\end{array}$ & Compuesta \\
\hline 19 & $\begin{array}{l}\text { Lonely } \\
\text { Planet } \\
\text { Valencia } \\
\end{array}$ & $\begin{array}{l}\text { paseo } \\
\text { marítimo }\end{array}$ & $\begin{array}{l}\text { paisaje y } \\
\text { geografía }\end{array}$ & $\begin{array}{l}\text { equivalente acuñado + } \\
\text { préstamo }\end{array}$ & Compuesta \\
\hline 20 & $\begin{array}{l}\text { Lonely } \\
\text { Planet } \\
\text { Andalucía }\end{array}$ & $\begin{array}{l}\text { paseo } \\
\text { marítimo }\end{array}$ & $\begin{array}{l}\text { paisaje y } \\
\text { geografía }\end{array}$ & préstamo & Simple \\
\hline 21 & $\begin{array}{l}\text { Lonely } \\
\text { Planet } \\
\text { Valencia } \\
\end{array}$ & horchata & $\begin{array}{l}\text { gastronomía y } \\
\text { restauración }\end{array}$ & $\begin{array}{l}\text { amplificación + } \\
\text { préstamo }\end{array}$ & Compuesta \\
\hline 22 & $\begin{array}{l}\text { Lonely } \\
\text { Planet } \\
\text { Valencia }\end{array}$ & menú del día & $\begin{array}{l}\text { gastronomía y } \\
\text { restauración }\end{array}$ & $\begin{array}{l}\text { amplificación + } \\
\text { préstamo }\end{array}$ & Compuesta \\
\hline 23 & $\begin{array}{l}\text { Lonely } \\
\text { Planet } \\
\text { Valencia }\end{array}$ & $\begin{array}{l}\text { virgen de los } \\
\text { desamparad } \\
\text { os }\end{array}$ & $\begin{array}{l}\text { fiestas y } \\
\text { espectáculos }\end{array}$ & calco + préstamo & Compuesta \\
\hline 24 & $\begin{array}{l}\text { Lonely } \\
\text { Planet } \\
\text { Valencia }\end{array}$ & alpargatas & artesanía & $\begin{array}{l}\text { amplificación + } \\
\text { préstamo }\end{array}$ & Compuesta \\
\hline 25 & $\begin{array}{l}\text { Lonely } \\
\text { Planet } \\
\text { Valencia }\end{array}$ & turrón & $\begin{array}{l}\text { gastronomía y } \\
\text { restauración }\end{array}$ & $\begin{array}{l}\text { amplificación }+ \\
\text { equivalente acuñado + } \\
\text { préstamo }\end{array}$ & Compuesta \\
\hline
\end{tabular}




\begin{tabular}{|c|c|c|c|c|c|}
\hline ID & $\begin{array}{l}\text { TíTULO } \\
\text { GUÍA }\end{array}$ & $\begin{array}{l}\text { ELEMENTO } \\
\text { DE ANÁLISIS }\end{array}$ & $\begin{array}{l}\text { CAMPO } \\
\text { SEMÁNTICO }\end{array}$ & \begin{tabular}{|l} 
TÉCNICA \\
TRADUCCIÓN \\
\end{tabular} & \begin{tabular}{|l} 
TIPO \\
TÉCNICA \\
\end{tabular} \\
\hline 26 & $\begin{array}{l}\text { Lonely } \\
\text { Planet } \\
\text { Valencia }\end{array}$ & clóchinas & $\begin{array}{l}\text { gastronomía y } \\
\text { restauración }\end{array}$ & $\begin{array}{l}\text { amplificación + } \\
\text { préstamo }\end{array}$ & Compuesta \\
\hline 27 & $\begin{array}{l}\text { Lonely } \\
\text { Planet } \\
\text { Valencia }\end{array}$ & entero & $\begin{array}{l}\text { gastronomía y } \\
\text { restauración }\end{array}$ & $\begin{array}{l}\text { amplificación + } \\
\text { préstamo }\end{array}$ & Compuesta \\
\hline 28 & $\begin{array}{l}\text { Lonely } \\
\text { Planet } \\
\text { Valencia }\end{array}$ & montadito & $\begin{array}{l}\text { gastronomía y } \\
\text { restauración }\end{array}$ & $\begin{array}{l}\text { equivalente acuñado + } \\
\text { préstamo }\end{array}$ & Compuesta \\
\hline 29 & $\begin{array}{l}\text { Lonely } \\
\text { Planet } \\
\text { Valencia }\end{array}$ & flamenco & $\begin{array}{l}\text { fiestas y } \\
\text { espectáculos }\end{array}$ & préstamo & Simple \\
\hline 30 & $\begin{array}{l}\text { Lonely } \\
\text { Planet } \\
\text { Valencia }\end{array}$ & $\begin{array}{l}\text { morcilla de } \\
\text { Burgos }\end{array}$ & $\begin{array}{l}\text { gastronomía y } \\
\text { restauración }\end{array}$ & $\begin{array}{l}\text { amplificación + } \\
\text { préstamo }\end{array}$ & Compuesta \\
\hline 31 & $\begin{array}{l}\text { Lonely } \\
\text { Planet } \\
\text { Valencia }\end{array}$ & chufas & $\begin{array}{l}\text { gastronomía y } \\
\text { restauración }\end{array}$ & $\begin{array}{l}\text { amplificación + } \\
\text { equivalente acuñado + } \\
\text { préstamo }\end{array}$ & Compuesta \\
\hline 32 & $\begin{array}{l}\text { Lonely } \\
\text { Planet } \\
\text { Valencia } \\
\end{array}$ & fartons & $\begin{array}{l}\text { gastronomía y } \\
\text { restauración }\end{array}$ & $\begin{array}{l}\text { amplificación + } \\
\text { préstamo }\end{array}$ & Compuesta \\
\hline 33 & $\begin{array}{l}\text { Lonely } \\
\text { Planet } \\
\text { Andalucía } \\
\end{array}$ & alcazaba & arquitectura & préstamo & Simple \\
\hline 34 & $\begin{array}{l}\text { Lonely } \\
\text { Planet } \\
\text { Andalucía }\end{array}$ & alcazaba & arquitectura & $\begin{array}{l}\text { amplificación + } \\
\text { préstamo }\end{array}$ & Compuesta \\
\hline 35 & $\begin{array}{l}\text { Lonely } \\
\text { Planet } \\
\text { Andalucía }\end{array}$ & alcazaba & arquitectura & $\begin{array}{l}\text { amplificación + } \\
\text { préstamo }\end{array}$ & Compuesta \\
\hline 36 & $\begin{array}{l}\text { Lonely } \\
\text { Planet } \\
\text { Andalucía }\end{array}$ & alcazaba & arquitectura & $\begin{array}{l}\text { amplificación + } \\
\text { préstamo }\end{array}$ & Compuesta \\
\hline 37 & $\begin{array}{l}\text { Lonely } \\
\text { Planet } \\
\text { Andalucía }\end{array}$ & alcazaba & arquitectura & $\begin{array}{l}\text { amplificación + } \\
\text { préstamo }\end{array}$ & Compuesta \\
\hline 38 & $\begin{array}{l}\text { Lonely } \\
\text { Planet } \\
\text { Andalucía } \\
\end{array}$ & tapas & $\begin{array}{l}\text { gastronomía y } \\
\text { restauración }\end{array}$ & préstamo & Simple \\
\hline 39 & $\begin{array}{l}\text { Lonely } \\
\text { Planet } \\
\text { Andalucía }\end{array}$ & reconquista & historia & $\begin{array}{l}\text { amplificación + } \\
\text { préstamo }\end{array}$ & Compuesta \\
\hline
\end{tabular}




\begin{tabular}{|c|c|c|c|c|c|}
\hline ID & $\begin{array}{l}\text { TÍTULO } \\
\text { GUÍA }\end{array}$ & $\begin{array}{l}\text { ELEMENTO } \\
\text { DE ANÁLISIS }\end{array}$ & \begin{tabular}{|l|} 
CAMPO \\
SEMÁNTICO
\end{tabular} & $\begin{array}{l}\text { TÉCNICA } \\
\text { TRADUCCIÓN }\end{array}$ & \begin{tabular}{|l} 
TIPO \\
TÉCNICA
\end{tabular} \\
\hline 40 & $\begin{array}{l}\text { Lonely } \\
\text { Planet } \\
\text { Andalucía }\end{array}$ & taifa & historia & $\begin{array}{l}\text { amplificación + } \\
\text { préstamo }\end{array}$ & Compuesta \\
\hline 41 & $\begin{array}{l}\text { Lonely } \\
\text { Planet } \\
\text { Andalucía }\end{array}$ & ermita & arquitectura & $\begin{array}{l}\text { equivalente acuñado + } \\
\text { préstamo }\end{array}$ & Compuesta \\
\hline 42 & $\begin{array}{l}\text { Lonely } \\
\text { Planet } \\
\text { Andalucía }\end{array}$ & $\begin{array}{l}\text { reyes } \\
\text { católicos }\end{array}$ & historia & $\begin{array}{l}\text { equivalente acuñado + } \\
\text { préstamo }\end{array}$ & Compuesta \\
\hline 43 & $\begin{array}{l}\text { Lonely } \\
\text { Planet } \\
\text { Andalucía }\end{array}$ & $\begin{array}{l}\text { reyes } \\
\text { católicos }\end{array}$ & historia & equivalente acuñado & Simple \\
\hline 44 & $\begin{array}{l}\text { Lonely } \\
\text { Planet } \\
\text { Andalucía }\end{array}$ & $\begin{array}{l}\text { monumento } \\
\text { a los coloraos }\end{array}$ & arquitectura & $\begin{array}{l}\text { amplificación + calco + } \\
\text { préstamo }\end{array}$ & Compuesta \\
\hline 45 & $\begin{array}{l}\text { Lonely } \\
\text { Planet } \\
\text { Andalucía }\end{array}$ & tapas & $\begin{array}{l}\text { gastronomía y } \\
\text { restauración }\end{array}$ & préstamo & Simple \\
\hline 46 & $\begin{array}{l}\text { Lonely } \\
\text { Planet } \\
\text { Andalucía }\end{array}$ & jamón & $\begin{array}{l}\text { gastronomía y } \\
\text { restauración }\end{array}$ & $\begin{array}{l}\text { amplificación + calco + } \\
\text { préstamo }\end{array}$ & Compuesta \\
\hline 47 & $\begin{array}{l}\text { Lonely } \\
\text { Planet } \\
\text { Andalucía }\end{array}$ & Menú del día & $\begin{array}{l}\text { gastronomía y } \\
\text { restauración }\end{array}$ & amplificación + calco & Compuesta \\
\hline 48 & $\begin{array}{l}\text { Lonely } \\
\text { Planet } \\
\text { Andalucía }\end{array}$ & $\begin{array}{l}\text { parque } \\
\text { natural cabo } \\
\text { de gata-níjar }\end{array}$ & $\begin{array}{l}\text { paisaje y } \\
\text { geografía }\end{array}$ & préstamo & Simple \\
\hline 49 & $\begin{array}{l}\text { Lonely } \\
\text { Planet } \\
\text { Andalucía }\end{array}$ & agua amarga & $\begin{array}{l}\text { paisaje y } \\
\text { geografía }\end{array}$ & préstamo & Simple \\
\hline 50 & $\begin{array}{l}\text { Lonely } \\
\text { Planet } \\
\text { Andalucía }\end{array}$ & cabo de gata & $\begin{array}{l}\text { paisaje y } \\
\text { geografía }\end{array}$ & préstamo & Simple \\
\hline 51 & $\begin{array}{l}\text { Lonely } \\
\text { Planet } \\
\text { Andalucía }\end{array}$ & $\begin{array}{l}\text { cuevas de } \\
\text { sorbas }\end{array}$ & $\begin{array}{l}\text { paisaje y } \\
\text { geografía }\end{array}$ & $\begin{array}{l}\text { amplificación + } \\
\text { préstamo }\end{array}$ & Compuesta \\
\hline 52 & $\begin{array}{l}\text { Lonely } \\
\text { Planet } \\
\text { Andalucía }\end{array}$ & costa del sol & $\begin{array}{l}\text { paisaje y } \\
\text { geografía }\end{array}$ & préstamo & Simple \\
\hline 53 & $\begin{array}{l}\text { Lonely } \\
\text { Planet } \\
\text { Andalucía }\end{array}$ & $\begin{array}{l}\text { parque } \\
\text { natural sierra } \\
\text { de maría-los } \\
\text { vélez. }\end{array}$ & $\begin{array}{l}\text { paisaje y } \\
\text { geografía }\end{array}$ & préstamo & Simple \\
\hline
\end{tabular}




\begin{tabular}{|c|c|c|c|c|c|}
\hline ID & \begin{tabular}{|l|} 
TíTULO \\
GUÍA
\end{tabular} & \begin{tabular}{|l} 
ELEMENTO \\
DE ANÁLISIS
\end{tabular} & \begin{tabular}{|l|} 
CAMPO \\
SEMÁNTICO
\end{tabular} & \begin{tabular}{|l} 
TÉCNICA \\
TRADUCCIÓN
\end{tabular} & \begin{tabular}{|l} 
TIPO \\
TÉCNICA
\end{tabular} \\
\hline 54 & $\begin{array}{l}\text { Lonely } \\
\text { Planet } \\
\text { Andalucía }\end{array}$ & $\begin{array}{l}\text { castillo de los } \\
\text { fajardo }\end{array}$ & arquitectura & préstamo & Simple \\
\hline 55 & $\begin{array}{l}\text { Lonely } \\
\text { Planet } \\
\text { Andalucía }\end{array}$ & indalo & pintura & $\begin{array}{l}\text { amplificación + } \\
\text { préstamo }\end{array}$ & Compuesta \\
\hline 56 & $\begin{array}{l}\text { Lonely } \\
\text { Planet } \\
\text { Andalucía }\end{array}$ & $\begin{array}{l}\text { parque } \\
\text { natural } \\
\text { sierras de } \\
\text { cazorla, } \\
\text { segura y las } \\
\text { villas }\end{array}$ & $\begin{array}{l}\text { paisaje y } \\
\text { geografía }\end{array}$ & préstamo & Simple \\
\hline 57 & $\begin{array}{l}\text { Lonely } \\
\text { Planet } \\
\text { Andalucía } \\
\end{array}$ & $\begin{array}{l}\text { cortes de } \\
\text { cádiz }\end{array}$ & historia & $\begin{array}{l}\text { amplificación + } \\
\text { préstamo }\end{array}$ & Compuesta \\
\hline 58 & $\begin{array}{l}\text { Lonely } \\
\text { Planet } \\
\text { Andalucía } \\
\end{array}$ & \begin{tabular}{|l|} 
guerra de la \\
independenci \\
a española \\
\end{tabular} & historia & amplificación + calco & Compuesta \\
\hline 59 & $\begin{array}{l}\text { Lonely } \\
\text { Planet } \\
\text { Andalucía } \\
\end{array}$ & $\begin{array}{l}\text { teatro } \\
\text { romano }\end{array}$ & arquitectura & calco + préstamo & Compuesta \\
\hline 60 & $\begin{array}{l}\text { Lonely } \\
\text { Planet } \\
\text { Andalucía } \\
\end{array}$ & $\begin{array}{l}\text { casa de la } \\
\text { contratación }\end{array}$ & arquitectura & $\begin{array}{l}\text { amplificación + } \\
\text { préstamo }\end{array}$ & Compuesta \\
\hline 61 & $\begin{array}{l}\text { Lonely } \\
\text { Planet } \\
\text { Andalucía } \\
\end{array}$ & $\begin{array}{l}\text { extasis de s. } \\
\text { francisco }\end{array}$ & pintura & calco + préstamo & Compuesta \\
\hline 62 & $\begin{array}{l}\text { Lonely } \\
\text { Planet } \\
\text { Andalucía } \\
\end{array}$ & inmaculada & pintura & préstamo & Simple \\
\hline 63 & $\begin{array}{l}\text { Lonely } \\
\text { Planet } \\
\text { Andalucía } \\
\end{array}$ & $\begin{array}{l}\text { playa de la } \\
\text { victoria }\end{array}$ & $\begin{array}{l}\text { paisaje y } \\
\text { geografía }\end{array}$ & préstamo & Simple \\
\hline 64 & $\begin{array}{l}\text { Lonely } \\
\text { Planet } \\
\text { Andalucía }\end{array}$ & $\begin{array}{l}\text { carnaval de } \\
\text { cádiz }\end{array}$ & $\begin{array}{l}\text { fiestas y } \\
\text { espectáculos }\end{array}$ & $\begin{array}{l}\text { amplificación + } \\
\text { préstamo }\end{array}$ & Compuesta \\
\hline 65 & $\begin{array}{l}\text { Lonely } \\
\text { Planet } \\
\text { Andalucía }\end{array}$ & murgas & $\begin{array}{l}\text { fiestas y } \\
\text { espectáculos }\end{array}$ & $\begin{array}{l}\text { amplificación + } \\
\text { préstamo }\end{array}$ & Compuesta \\
\hline 66 & $\begin{array}{l}\text { Lonely } \\
\text { Planet } \\
\text { Andalucía }\end{array}$ & montadito & $\begin{array}{l}\text { gastronomía y } \\
\text { restauración }\end{array}$ & $\begin{array}{l}\text { amplificación + } \\
\text { préstamo }\end{array}$ & Compuesta \\
\hline
\end{tabular}




\begin{tabular}{|c|c|c|c|c|c|}
\hline ID & \begin{tabular}{|l|} 
TíTULO \\
GUÍA
\end{tabular} & $\begin{array}{l}\text { ELEMENTO } \\
\text { DE ANÁLISIS }\end{array}$ & \begin{tabular}{|l|} 
CAMPO \\
SEMÁNTICO
\end{tabular} & $\begin{array}{l}\text { TÉCNICA } \\
\text { TRADUCCIÓN }\end{array}$ & \begin{tabular}{|l} 
TIPO \\
TÉCNICA
\end{tabular} \\
\hline 67 & $\begin{array}{l}\text { Lonely } \\
\text { Planet } \\
\text { Andalucía }\end{array}$ & guiso & $\begin{array}{l}\text { gastronomía y } \\
\text { restauración }\end{array}$ & $\begin{array}{l}\text { equivalente acuñado + } \\
\text { préstamo }\end{array}$ & Compuesta \\
\hline 68 & $\begin{array}{l}\text { Lonely } \\
\text { Planet } \\
\text { Andalucía }\end{array}$ & surtido & $\begin{array}{l}\text { gastronomía y } \\
\text { restauración }\end{array}$ & $\begin{array}{l}\text { amplificación + } \\
\text { préstamo }\end{array}$ & Compuesta \\
\hline 69 & $\begin{array}{l}\text { Lonely } \\
\text { Planet } \\
\text { Andalucía }\end{array}$ & chicharrones & $\begin{array}{l}\text { gastronomía y } \\
\text { restauración }\end{array}$ & $\begin{array}{l}\text { amplificación + } \\
\text { préstamo }\end{array}$ & Compuesta \\
\hline 70 & $\begin{array}{l}\text { Lonely } \\
\text { Planet } \\
\text { Andalucía }\end{array}$ & flamenco & $\begin{array}{l}\text { fiestas y } \\
\text { espectáculos }\end{array}$ & préstamo & Simple \\
\hline 71 & $\begin{array}{l}\text { Lonely } \\
\text { Planet } \\
\text { Andalucía }\end{array}$ & terraza & $\begin{array}{l}\text { paisaje y } \\
\text { geografía }\end{array}$ & $\begin{array}{l}\text { equivalente acuñado + } \\
\text { préstamo }\end{array}$ & Compuesta \\
\hline 72 & $\begin{array}{l}\text { Lonely } \\
\text { Planet } \\
\text { Andalucía }\end{array}$ & $\begin{array}{l}\text { solomillo } \\
\text { ibérico }\end{array}$ & $\begin{array}{l}\text { gastronomía y } \\
\text { restauración }\end{array}$ & $\begin{array}{l}\text { amplificación + } \\
\text { préstamo }\end{array}$ & Compuesta \\
\hline 73 & $\begin{array}{l}\text { Lonely } \\
\text { Planet } \\
\text { Andalucía }\end{array}$ & vino tinto & $\begin{array}{l}\text { gastronomía y } \\
\text { restauración }\end{array}$ & $\begin{array}{l}\text { equivalente acuñado + } \\
\text { préstamo }\end{array}$ & Compuesta \\
\hline 74 & $\begin{array}{l}\text { Lonely } \\
\text { Planet } \\
\text { Andalucía }\end{array}$ & flamenco & $\begin{array}{l}\text { fiestas y } \\
\text { espectáculos }\end{array}$ & préstamo & Simple \\
\hline 75 & $\begin{array}{l}\text { Lonely } \\
\text { Planet } \\
\text { Andalucía }\end{array}$ & el vapor & viaje & $\begin{array}{l}\text { amplificación + } \\
\text { préstamo }\end{array}$ & Compuesta \\
\hline 76 & $\begin{array}{l}\text { Lonely } \\
\text { Planet } \\
\text { Andalucía }\end{array}$ & jerez & $\begin{array}{l}\text { gastronomía y } \\
\text { restauración }\end{array}$ & $\begin{array}{l}\text { amplificación + } \\
\text { equivalente acuñado }\end{array}$ & Compuesta \\
\hline 77 & $\begin{array}{l}\text { Lonely } \\
\text { Planet } \\
\text { Andalucía }\end{array}$ & $\begin{array}{l}\text { parque } \\
\text { nacional de } \\
\text { doñana }\end{array}$ & $\begin{array}{l}\text { paisaje y } \\
\text { geografía }\end{array}$ & préstamo & Simple \\
\hline 78 & $\begin{array}{l}\text { Lonely } \\
\text { Planet } \\
\text { Andalucía }\end{array}$ & $\begin{array}{l}\text { ciudad de los } \\
\text { cien palacios }\end{array}$ & historia & calco + préstamo & Compuesta \\
\hline 79 & $\begin{array}{l}\text { Lonely } \\
\text { Planet } \\
\text { Andalucía }\end{array}$ & $\begin{array}{l}\text { plaza de } \\
\text { toros }\end{array}$ & $\begin{array}{l}\text { fiestas y } \\
\text { espectáculos }\end{array}$ & $\begin{array}{l}\text { equivalente acuñado + } \\
\text { préstamo }\end{array}$ & Compuesta \\
\hline 80 & $\begin{array}{l}\text { Lonely } \\
\text { Planet } \\
\text { Andalucía }\end{array}$ & $\begin{array}{l}\text { castillo san } \\
\text { marcos }\end{array}$ & arquitectura & $\begin{array}{l}\text { equivalente acuñado + } \\
\text { préstamo }\end{array}$ & Compuesta \\
\hline
\end{tabular}




\begin{tabular}{|c|c|c|c|c|c|}
\hline ID & \begin{tabular}{|l|} 
TíTULO \\
GUÍA
\end{tabular} & $\begin{array}{l}\text { ELEMENTO } \\
\text { DE ANÁLISIS }\end{array}$ & \begin{tabular}{|l|} 
CAMPO \\
SEMÁNTICO
\end{tabular} & $\begin{array}{l}\text { TÉCNICA } \\
\text { TRADUCCIÓN }\end{array}$ & $\begin{array}{l}\text { TIPO } \\
\text { TÉCNICA }\end{array}$ \\
\hline 81 & $\begin{array}{l}\text { Lonely } \\
\text { Planet } \\
\text { Andalucía }\end{array}$ & alfonso X & historia & $\begin{array}{l}\text { amplificación + } \\
\text { préstamo }\end{array}$ & Compuesta \\
\hline 82 & $\begin{array}{l}\text { Lonely } \\
\text { Planet } \\
\text { Andalucía }\end{array}$ & $\begin{array}{l}\text { fuente de las } \\
\text { galeras } \\
\text { reales }\end{array}$ & arquitectura & calco + préstamo & Compuesta \\
\hline 83 & $\begin{array}{l}\text { Lonely } \\
\text { Planet } \\
\text { Andalucía }\end{array}$ & $\begin{array}{l}\text { plaza de } \\
\text { toros }\end{array}$ & $\begin{array}{l}\text { fiestas y } \\
\text { espectáculos }\end{array}$ & $\begin{array}{l}\text { equivalente acuñado + } \\
\text { préstamo }\end{array}$ & Compuesta \\
\hline 84 & $\begin{array}{l}\text { Lonely } \\
\text { Planet } \\
\text { Andalucía }\end{array}$ & $\begin{array}{l}\text { corrida de } \\
\text { toros }\end{array}$ & $\begin{array}{l}\text { fiestas y } \\
\text { espectáculos }\end{array}$ & equivalente acuñado & Simple \\
\hline 85 & $\begin{array}{l}\text { Lonely } \\
\text { Planet } \\
\text { Andalucía }\end{array}$ & bodega & $\begin{array}{l}\text { gastronomía y } \\
\text { restauración }\end{array}$ & $\begin{array}{l}\text { equivalente acuñado + } \\
\text { préstamo }\end{array}$ & Compuesta \\
\hline 86 & $\begin{array}{l}\text { Lonely } \\
\text { Planet } \\
\text { Andalucía }\end{array}$ & $\begin{array}{l}\text { festividad de } \\
\text { la virgen del } \\
\text { carmen }\end{array}$ & $\begin{array}{l}\text { fiestas y } \\
\text { espectáculos }\end{array}$ & $\begin{array}{l}\text { amplificación + } \\
\text { préstamo }\end{array}$ & Compuesta \\
\hline 87 & $\begin{array}{l}\text { Lonely } \\
\text { Planet } \\
\text { Andalucía } \\
\end{array}$ & urta roteña & $\begin{array}{l}\text { gastronomía y } \\
\text { restauración }\end{array}$ & $\begin{array}{l}\text { amplificación + } \\
\text { préstamo }\end{array}$ & Compuesta \\
\hline 88 & $\begin{array}{l}\text { Lonely } \\
\text { Planet } \\
\text { Andalucía }\end{array}$ & media ración & $\begin{array}{l}\text { gastronomía y } \\
\text { restauración }\end{array}$ & préstamo & Simple \\
\hline 89 & $\begin{array}{l}\text { Lonely } \\
\text { Planet } \\
\text { Andalucía } \\
\end{array}$ & serranito & $\begin{array}{l}\text { gastronomía y } \\
\text { restauración }\end{array}$ & $\begin{array}{l}\text { amplificación + } \\
\text { préstamo }\end{array}$ & Compuesta \\
\hline 90 & $\begin{array}{l}\text { Lonely } \\
\text { Planet } \\
\text { Andalucía }\end{array}$ & tapas & $\begin{array}{l}\text { gastronomía y } \\
\text { restauración }\end{array}$ & préstamo & Simple \\
\hline 91 & $\begin{array}{l}\text { Lonely } \\
\text { Planet } \\
\text { Andalucía }\end{array}$ & hojaldre & $\begin{array}{l}\text { gastronomía y } \\
\text { restauración }\end{array}$ & $\begin{array}{l}\text { equivalente acuñado + } \\
\text { préstamo }\end{array}$ & Compuesta \\
\hline 92 & $\begin{array}{l}\text { Lonely } \\
\text { Planet } \\
\text { Andalucía }\end{array}$ & lasaña & $\begin{array}{l}\text { gastronomía y } \\
\text { restauración }\end{array}$ & préstamo & Simple \\
\hline 93 & $\begin{array}{l}\text { Lonely } \\
\text { Planet } \\
\text { Andalucía }\end{array}$ & parrillada & $\begin{array}{l}\text { gastronomía y } \\
\text { restauración }\end{array}$ & $\begin{array}{l}\text { amplificación + } \\
\text { préstamo }\end{array}$ & Compuesta \\
\hline 94 & $\begin{array}{l}\text { Lonely } \\
\text { Planet } \\
\text { Andalucía }\end{array}$ & $\begin{array}{l}\text { toro de } \\
\text { osborne }\end{array}$ & $\begin{array}{l}\text { paisaje y } \\
\text { geografía }\end{array}$ & $\begin{array}{l}\text { amplificación + } \\
\text { préstamo }\end{array}$ & Compuesta \\
\hline
\end{tabular}




\begin{tabular}{|c|c|c|c|c|c|}
\hline ID & $\begin{array}{l}\text { TíTULO } \\
\text { GUÍA }\end{array}$ & \begin{tabular}{|l|} 
ELEMENTO \\
DE ANÁLISIS
\end{tabular} & $\begin{array}{l}\text { CAMPO } \\
\text { SEMÁNTICO }\end{array}$ & \begin{tabular}{|l|} 
TÉCNICA \\
TRADUCCIÓN \\
\end{tabular} & \begin{tabular}{|l} 
TIPO \\
TÉCNICA \\
\end{tabular} \\
\hline 95 & $\begin{array}{l}\text { Lonely } \\
\text { Planet } \\
\text { Andalucía }\end{array}$ & flamenco & $\begin{array}{l}\text { fiestas y } \\
\text { espectáculos }\end{array}$ & préstamo & Simple \\
\hline 96 & $\begin{array}{l}\text { Lonely } \\
\text { Planet } \\
\text { Andalucía }\end{array}$ & torero & $\begin{array}{l}\text { fiestas y } \\
\text { espectáculos }\end{array}$ & equivalente acuñado & Simple \\
\hline 97 & $\begin{array}{l}\text { Lonely } \\
\text { Planet } \\
\text { Andalucía }\end{array}$ & flamenco & \begin{tabular}{|l} 
fiestas y \\
espectáculos
\end{tabular} & préstamo & Simple \\
\hline 98 & $\begin{array}{l}\text { Lonely } \\
\text { Planet }\end{array}$ & manzanilla & $\begin{array}{l}\text { gastronomía y } \\
\text { restauración }\end{array}$ & $\begin{array}{l}\text { amplificación + } \\
\text { préstamo }\end{array}$ & Compuesta \\
\hline 99 & \begin{tabular}{|l|} 
Lonely \\
Planet
\end{tabular} & bodega & $\begin{array}{l}\text { gastronomía y } \\
\text { restauración }\end{array}$ & préstamo & Simple \\
\hline 100 & $\begin{array}{l}\text { Lonely } \\
\text { Planet }\end{array}$ & manzanilla & $\begin{array}{l}\text { gastronomía y } \\
\text { restauración }\end{array}$ & $\begin{array}{l}\text { amplificación + } \\
\text { préstamo }\end{array}$ & Compuesta \\
\hline 101 & \begin{tabular}{|l|} 
Lonely \\
Planet
\end{tabular} & manzanilla & $\begin{array}{l}\text { gastronomía y } \\
\text { restauración }\end{array}$ & $\begin{array}{l}\text { amplificación + } \\
\text { préstamo }\end{array}$ & Compuesta \\
\hline 102 & \begin{tabular}{|l|l|} 
Lonely \\
Planet \\
\end{tabular} & romería & \begin{tabular}{|l|} 
fiestas y \\
espectáculos \\
\end{tabular} & $\begin{array}{l}\text { amplificación + } \\
\text { préstamo }\end{array}$ & Compuesta \\
\hline 103 & \begin{tabular}{|l|} 
Lonely \\
Planet \\
Andalucía \\
\end{tabular} & flamenco & $\begin{array}{l}\text { fiestas y } \\
\text { espectáculos }\end{array}$ & préstamo & Simple \\
\hline 104 & \begin{tabular}{|l|} 
Lonely \\
Planet \\
Andalucía \\
\end{tabular} & $\begin{array}{l}\text { cóctel de } \\
\text { bogavante }\end{array}$ & $\begin{array}{l}\text { gastronomía y } \\
\text { restauración }\end{array}$ & $\begin{array}{l}\text { amplificación + } \\
\text { préstamo }\end{array}$ & Compuesta \\
\hline 105 & $\begin{array}{l}\text { Lonely } \\
\text { Planet } \\
\text { Andalucía } \\
\end{array}$ & manzanilla & $\begin{array}{l}\text { gastronomía y } \\
\text { restauración }\end{array}$ & préstamo & Simple \\
\hline 106 & $\begin{array}{l}\text { Lonely } \\
\text { Planet } \\
\text { Andalucía }\end{array}$ & ración & $\begin{array}{l}\text { gastronomía y } \\
\text { restauración }\end{array}$ & préstamo & Simple \\
\hline 107 & \begin{tabular}{|l|} 
Lonely \\
Planet \\
Andalucía \\
\end{tabular} & gitano & historia & $\begin{array}{l}\text { equivalente acuñado + } \\
\text { préstamo }\end{array}$ & Compuesta \\
\hline 108 & \begin{tabular}{|l|} 
Lonely \\
Planet \\
Andalucía \\
\end{tabular} & alcázar & arquitectura & préstamo & Simple \\
\hline 109 & \begin{tabular}{|l|} 
Lonely \\
Planet \\
Andalucía
\end{tabular} & cabildo & arquitectura & calco + préstamo & Compuesta \\
\hline 110 & $\begin{array}{l}\text { Lonely } \\
\text { Planet } \\
\text { Andalucía }\end{array}$ & gitano & historia & préstamo & Simple \\
\hline
\end{tabular}




\begin{tabular}{|c|c|c|c|c|c|}
\hline ID & \begin{tabular}{|l|} 
TíTULO \\
GUÍA
\end{tabular} & $\begin{array}{l}\text { ELEMENTO } \\
\text { DE ANÁLISIS }\end{array}$ & \begin{tabular}{|l|} 
CAMPO \\
SEMÁNTICO
\end{tabular} & $\begin{array}{l}\text { TÉCNICA } \\
\text { TRADUCCIÓN }\end{array}$ & $\begin{array}{l}\text { TIPO } \\
\text { TÉCNICA }\end{array}$ \\
\hline 111 & $\begin{array}{l}\text { Lonely } \\
\text { Planet } \\
\text { Andalucía }\end{array}$ & $\begin{array}{l}\text { real escuela } \\
\text { andaluza de } \\
\text { arte ecuestre }\end{array}$ & $\begin{array}{l}\text { fiestas y } \\
\text { espectáculos }\end{array}$ & calco + préstamo & Compuesta \\
\hline 112 & $\begin{array}{l}\text { Lonely } \\
\text { Planet } \\
\text { Andalucía }\end{array}$ & lince ibérico & $\begin{array}{l}\text { paisaje y } \\
\text { geografía }\end{array}$ & equivalente acuñado & Simple \\
\hline 113 & $\begin{array}{l}\text { Lonely } \\
\text { Planet } \\
\text { Andalucía }\end{array}$ & $\begin{array}{l}\text { feria del } \\
\text { caballo }\end{array}$ & $\begin{array}{l}\text { fiestas y } \\
\text { espectáculos }\end{array}$ & calco + préstamo & Compuesta \\
\hline 114 & $\begin{array}{l}\text { Lonely } \\
\text { Planet } \\
\text { Andalucía } \\
\end{array}$ & crupera & $\begin{array}{l}\text { fiestas y } \\
\text { espectáculos }\end{array}$ & $\begin{array}{l}\text { amplificación + } \\
\text { préstamo }\end{array}$ & Compuesta \\
\hline 115 & $\begin{array}{l}\text { Lonely } \\
\text { Planet } \\
\text { Andalucía } \\
\end{array}$ & $\begin{array}{l}\text { fiestas de } \\
\text { otoño }\end{array}$ & $\begin{array}{l}\text { fiestas y } \\
\text { espectáculos }\end{array}$ & calco + préstamo & Compuesta \\
\hline 116 & $\begin{array}{l}\text { Lonely } \\
\text { Planet } \\
\text { Andalucía } \\
\end{array}$ & bodega & $\begin{array}{l}\text { gastronomía y } \\
\text { restauración }\end{array}$ & $\begin{array}{l}\text { equivalente acuñado + } \\
\text { préstamo }\end{array}$ & Compuesta \\
\hline 117 & $\begin{array}{l}\text { Lonely } \\
\text { Planet } \\
\text { Andalucía } \\
\end{array}$ & coñac & $\begin{array}{l}\text { gastronomía y } \\
\text { restauración }\end{array}$ & $\begin{array}{l}\text { equivalente acuñado + } \\
\text { préstamo }\end{array}$ & Compuesta \\
\hline 118 & $\begin{array}{l}\text { Lonely } \\
\text { Planet } \\
\text { Andalucía } \\
\end{array}$ & $\begin{array}{l}\text { riñones al } \\
\text { jerez }\end{array}$ & $\begin{array}{l}\text { gastronomía y } \\
\text { restauración }\end{array}$ & calco + préstamo & Compuesta \\
\hline 119 & $\begin{array}{l}\text { Lonely } \\
\text { Planet } \\
\text { Andalucía } \\
\end{array}$ & rabo de toro & $\begin{array}{l}\text { gastronomía y } \\
\text { restauración }\end{array}$ & calco + préstamo & Compuesta \\
\hline 120 & $\begin{array}{l}\text { Lonely } \\
\text { Planet } \\
\text { Andalucía } \\
\end{array}$ & churros & $\begin{array}{l}\text { gastronomía y } \\
\text { restauración }\end{array}$ & $\begin{array}{l}\text { amplificación + } \\
\text { préstamo }\end{array}$ & Compuesta \\
\hline 121 & $\begin{array}{l}\text { Lonely } \\
\text { Planet } \\
\text { Andalucía }\end{array}$ & baños árabes & arquitectura & $\begin{array}{l}\text { amplificación + } \\
\text { préstamo }\end{array}$ & Compuesta \\
\hline 122 & $\begin{array}{l}\text { Lonely } \\
\text { Planet } \\
\text { Andalucía } \\
\end{array}$ & al-andalus & historia & $\begin{array}{l}\text { amplificación + } \\
\text { préstamo }\end{array}$ & Compuesta \\
\hline 123 & $\begin{array}{l}\text { Lonely } \\
\text { Planet } \\
\text { Andalucía } \\
\end{array}$ & fino & $\begin{array}{l}\text { gastronomía y } \\
\text { restauración }\end{array}$ & préstamo & Simple \\
\hline 124 & $\begin{array}{l}\text { Lonely } \\
\text { Planet } \\
\text { Andalucía }\end{array}$ & $\begin{array}{l}\text { tabla de } \\
\text { patés y } \\
\text { quesos }\end{array}$ & $\begin{array}{l}\text { gastronomía y } \\
\text { restauración }\end{array}$ & $\begin{array}{l}\text { amplificación + } \\
\text { préstamo }\end{array}$ & Compuesta \\
\hline
\end{tabular}




\begin{tabular}{|c|c|c|c|c|c|}
\hline ID & \begin{tabular}{|l|} 
TíTULO \\
GUÍA
\end{tabular} & \begin{tabular}{|l} 
ELEMENTO \\
DE ANÁLISIS
\end{tabular} & \begin{tabular}{|l} 
CAMPO \\
SEMÁNTICO
\end{tabular} & \begin{tabular}{|l|} 
TÉCNICA \\
TRADUCCIÓN \\
\end{tabular} & \begin{tabular}{|l} 
TIPO \\
TÉCNICA \\
\end{tabular} \\
\hline 125 & \begin{tabular}{|l|} 
Lonely \\
Planet \\
Andalucía
\end{tabular} & \begin{tabular}{|l|} 
patatas \\
bravas
\end{tabular} & $\begin{array}{l}\text { gastronomía y } \\
\text { restauración }\end{array}$ & $\begin{array}{l}\text { amplificación + } \\
\text { préstamo }\end{array}$ & Compuesta \\
\hline 126 & $\begin{array}{l}\text { Lonely } \\
\text { Planet } \\
\text { Andalucía }\end{array}$ & montadito & $\begin{array}{l}\text { gastronomía y } \\
\text { restauración }\end{array}$ & $\begin{array}{l}\text { amplificación + } \\
\text { préstamo }\end{array}$ & Compuesta \\
\hline 127 & \begin{tabular}{|l} 
Lonely \\
Planet \\
Andalucía
\end{tabular} & $\begin{array}{l}\text { peña } \\
\text { flamenca }\end{array}$ & \begin{tabular}{|l} 
fiestas y \\
espectáculos
\end{tabular} & $\begin{array}{l}\text { amplificación + } \\
\text { adaptación }\end{array}$ & Compuesta \\
\hline 128 & \begin{tabular}{|l|} 
Lonely \\
Planet \\
Andalucía
\end{tabular} & $\begin{array}{l}\text { caballo } \\
\text { cartujano }\end{array}$ & $\begin{array}{l}\text { fiestas y } \\
\text { espectáculos }\end{array}$ & $\begin{array}{l}\text { amplificación + } \\
\text { préstamo }\end{array}$ & Compuesta \\
\hline 129 & $\begin{array}{l}\text { Lonely } \\
\text { Planet } \\
\text { Andalucía }\end{array}$ & $\begin{array}{l}\text { sierra de } \\
\text { grazalema }\end{array}$ & $\begin{array}{l}\text { paisaje y } \\
\text { geografía }\end{array}$ & $\begin{array}{l}\text { amplificación + } \\
\text { préstamo }\end{array}$ & Compuesta \\
\hline 130 & $\begin{array}{l}\text { Lonely } \\
\text { Planet } \\
\text { Andalucía }\end{array}$ & salmorejo & $\begin{array}{l}\text { gastronomía y } \\
\text { restauración }\end{array}$ & $\begin{array}{l}\text { amplificación + } \\
\text { préstamo }\end{array}$ & Compuesta \\
\hline 131 & \begin{tabular}{|l|} 
Lonely \\
Planet \\
Andalucía \\
\end{tabular} & judería & $\begin{array}{l}\text { paisaje y } \\
\text { geografía }\end{array}$ & $\begin{array}{l}\text { amplificación + } \\
\text { préstamo }\end{array}$ & Compuesta \\
\hline 132 & \begin{tabular}{|l|} 
Lonely \\
Planet \\
Andalucía
\end{tabular} & mezquita & arquitectura & préstamo & Simple \\
\hline 133 & \begin{tabular}{|l|} 
Lonely \\
Planet \\
Andalucía
\end{tabular} & $\begin{array}{l}\text { medina } \\
\text { azahara }\end{array}$ & arquitectura & préstamo & Simple \\
\hline 134 & \begin{tabular}{|l} 
Lonely \\
Planet \\
Andalucía
\end{tabular} & patio & arquitectura & préstamo & Simple \\
\hline 135 & \begin{tabular}{|l|} 
Lonely \\
Planet \\
Andalucía
\end{tabular} & castilla & historia & equivalente acuñado & Simple \\
\hline 136 & \begin{tabular}{|l|} 
Lonely \\
Planet \\
Andalucía \\
\end{tabular} & cataluña & historia & equivalente acuñado & Simple \\
\hline 137 & \begin{tabular}{|l|} 
Lonely \\
Planet \\
Andalucía \\
\end{tabular} & sevilla & historia & equivalente acuñado & Simple \\
\hline 138 & \begin{tabular}{|l|} 
Lonely \\
Planet \\
Andalucía \\
\end{tabular} & taifa & historia & $\begin{array}{l}\text { amplificación + } \\
\text { préstamo }\end{array}$ & Compuesta \\
\hline
\end{tabular}




\begin{tabular}{|c|c|c|c|c|c|}
\hline ID & \begin{tabular}{|l|} 
TÍTULO \\
GUÍA
\end{tabular} & $\begin{array}{l}\text { ELEMENTO } \\
\text { DE ANÁLISIS }\end{array}$ & \begin{tabular}{|l|} 
CAMPO \\
SEMÁNTICO
\end{tabular} & $\begin{array}{l}\text { TÉCNICA } \\
\text { TRADUCCIÓN }\end{array}$ & $\begin{array}{l}\text { TIPO } \\
\text { TÉCNICA }\end{array}$ \\
\hline 139 & $\begin{array}{l}\text { Lonely } \\
\text { Planet } \\
\text { Andalucía }\end{array}$ & mozárabe & historia & $\begin{array}{l}\text { amplificación + } \\
\text { equivalente acuñado + } \\
\text { generalización }\end{array}$ & Compuesta \\
\hline 140 & $\begin{array}{l}\text { Lonely } \\
\text { Planet } \\
\text { Andalucía }\end{array}$ & mezquita & arquitectura & préstamo & Simple \\
\hline 141 & $\begin{array}{l}\text { Lonely } \\
\text { Planet } \\
\text { Andalucía }\end{array}$ & bodega & $\begin{array}{l}\text { gastronomía y } \\
\text { restauración }\end{array}$ & $\begin{array}{l}\text { amplificación + } \\
\text { préstamo }\end{array}$ & Compuesta \\
\hline 142 & $\begin{array}{l}\text { Lonely } \\
\text { Planet } \\
\text { Andalucía }\end{array}$ & patio & arquitectura & préstamo & Simple \\
\hline 143 & $\begin{array}{l}\text { Lonely } \\
\text { Planet } \\
\text { Andalucía }\end{array}$ & califa & historia & $\begin{array}{l}\text { amplificación }+ \\
\text { equivalente acuñado }\end{array}$ & Compuesta \\
\hline 144 & \begin{tabular}{|l|} 
Lonely \\
Planet \\
Andalucía \\
\end{tabular} & giralda & arquitectura & préstamo & Simple \\
\hline 145 & $\begin{array}{l}\text { Lonely } \\
\text { Planet } \\
\text { Andalucía } \\
\end{array}$ & reconquista & historia & $\begin{array}{l}\text { amplificación + } \\
\text { préstamo }\end{array}$ & Compuesta \\
\hline 146 & \begin{tabular}{|l} 
Lonely \\
Planet \\
Andalucía \\
\end{tabular} & capilla & arquitectura & $\begin{array}{l}\text { amplificación + } \\
\text { préstamo }\end{array}$ & Compuesta \\
\hline 147 & \begin{tabular}{|l} 
Lonely \\
Planet \\
Andalucía
\end{tabular} & $\begin{array}{l}\text { palacio } \\
\text { episcopal }\end{array}$ & arquitectura & calco + préstamo & Compuesta \\
\hline 148 & \begin{tabular}{|l} 
Lonely \\
Planet \\
Andalucía
\end{tabular} & $\begin{array}{l}\text { virgen de las } \\
\text { huertas }\end{array}$ & escultura & $\begin{array}{l}\text { amplificación + } \\
\text { préstamo }\end{array}$ & Compuesta \\
\hline 149 & $\begin{array}{l}\text { Lonely } \\
\text { Planet } \\
\text { Andalucía }\end{array}$ & $\begin{array}{l}\text { alcázar de los } \\
\text { reyes } \\
\text { cristianos }\end{array}$ & arquitectura & $\begin{array}{l}\text { amplificación + calco + } \\
\text { préstamo }\end{array}$ & Compuesta \\
\hline 150 & $\begin{array}{l}\text { Lonely } \\
\text { Planet } \\
\text { Andalucía }\end{array}$ & $\begin{array}{l}\text { puente } \\
\text { romano }\end{array}$ & arquitectura & calco + préstamo & Compuesta \\
\hline 151 & $\begin{array}{l}\text { Lonely } \\
\text { Planet } \\
\text { Andalucía }\end{array}$ & $\begin{array}{l}\text { museo } \\
\text { taurino }\end{array}$ & $\begin{array}{l}\text { fiestas y } \\
\text { espectáculos }\end{array}$ & calco + préstamo & Compuesta \\
\hline 152 & \begin{tabular}{|l} 
Lonely \\
Planet \\
Andalucía
\end{tabular} & $\begin{array}{l}\text { plaza del } \\
\text { potro }\end{array}$ & $\begin{array}{l}\text { paisaje y } \\
\text { geografía }\end{array}$ & calco + préstamo & Compuesta \\
\hline
\end{tabular}




\begin{tabular}{|c|c|c|c|c|c|}
\hline ID & \begin{tabular}{|l|} 
TíTULO \\
GUÍA
\end{tabular} & $\begin{array}{l}\text { ELEMENTO } \\
\text { DE ANÁLISIS }\end{array}$ & \begin{tabular}{|l|} 
CAMPO \\
SEMÁNTICO
\end{tabular} & $\begin{array}{l}\text { TÉCNICA } \\
\text { TRADUCCIÓN }\end{array}$ & \begin{tabular}{|l} 
TIPO \\
TÉCNICA
\end{tabular} \\
\hline 153 & $\begin{array}{l}\text { Lonely } \\
\text { Planet } \\
\text { Andalucía }\end{array}$ & posada & alojamiento & $\begin{array}{l}\text { equivalente acuñado + } \\
\text { préstamo }\end{array}$ & Compuesta \\
\hline 154 & $\begin{array}{l}\text { Lonely } \\
\text { Planet } \\
\text { Andalucía }\end{array}$ & $\begin{array}{l}\text { concurso de } \\
\text { patios }\end{array}$ & $\begin{array}{l}\text { paisaje y } \\
\text { geografía }\end{array}$ & $\begin{array}{l}\text { amplificación + calco + } \\
\text { préstamo }\end{array}$ & Compuesta \\
\hline 155 & $\begin{array}{l}\text { Lonely } \\
\text { Planet } \\
\text { Andalucía } \\
\end{array}$ & tetería & $\begin{array}{l}\text { gastronomía y } \\
\text { restauración }\end{array}$ & $\begin{array}{l}\text { equivalente acuñado + } \\
\text { préstamo }\end{array}$ & Compuesta \\
\hline 156 & $\begin{array}{l}\text { Lonely } \\
\text { Planet } \\
\text { Andalucía }\end{array}$ & $\begin{array}{l}\text { semana } \\
\text { santa }\end{array}$ & $\begin{array}{l}\text { fiestas y } \\
\text { espectáculos }\end{array}$ & $\begin{array}{l}\text { equivalente acuñado + } \\
\text { préstamo }\end{array}$ & Compuesta \\
\hline 157 & $\begin{array}{l}\text { Lonely } \\
\text { Planet } \\
\text { Andalucía } \\
\end{array}$ & paso & $\begin{array}{l}\text { fiestas y } \\
\text { espectáculos }\end{array}$ & $\begin{array}{l}\text { amplificación + } \\
\text { préstamo }\end{array}$ & Compuesta \\
\hline 158 & $\begin{array}{l}\text { Lonely } \\
\text { Planet } \\
\text { Andalucía } \\
\end{array}$ & madrugá & $\begin{array}{l}\text { fiestas y } \\
\text { espectáculos }\end{array}$ & calco + préstamo & Compuesta \\
\hline 159 & $\begin{array}{l}\text { Lonely } \\
\text { Planet } \\
\text { Andalucía } \\
\end{array}$ & hostal & alojamiento & $\begin{array}{l}\text { amplificación + } \\
\text { préstamo }\end{array}$ & Compuesta \\
\hline 160 & $\begin{array}{l}\text { Lonely } \\
\text { Planet } \\
\text { Andalucía } \\
\end{array}$ & pensión & alojamiento & $\begin{array}{l}\text { equivalente acuñado + } \\
\text { préstamo }\end{array}$ & Compuesta \\
\hline 161 & $\begin{array}{l}\text { Lonely } \\
\text { Planet } \\
\text { Andalucía } \\
\end{array}$ & hostal & alojamiento & préstamo & Simple \\
\hline 162 & $\begin{array}{l}\text { Lonely } \\
\text { Planet } \\
\text { Andalucía }\end{array}$ & parador & alojamiento & $\begin{array}{l}\text { amplificación + } \\
\text { préstamo }\end{array}$ & Compuesta \\
\hline 163 & $\begin{array}{l}\text { Lonely } \\
\text { Planet } \\
\text { Andalucía }\end{array}$ & salmorejo & $\begin{array}{l}\text { gastronomía y } \\
\text { restauración }\end{array}$ & $\begin{array}{l}\text { amplificación + } \\
\text { préstamo }\end{array}$ & Compuesta \\
\hline 164 & $\begin{array}{l}\text { Lonely } \\
\text { Planet } \\
\text { Andalucía }\end{array}$ & jamón & $\begin{array}{l}\text { gastronomía y } \\
\text { restauración }\end{array}$ & calco + préstamo & Compuesta \\
\hline 165 & $\begin{array}{l}\text { Lonely } \\
\text { Planet } \\
\text { Andalucía } \\
\end{array}$ & rabo de toro & $\begin{array}{l}\text { gastronomía y } \\
\text { restauración }\end{array}$ & $\begin{array}{l}\text { amplificación + } \\
\text { préstamo }\end{array}$ & Compuesta \\
\hline 166 & $\begin{array}{l}\text { Lonely } \\
\text { Planet } \\
\text { Andalucía }\end{array}$ & taberna & $\begin{array}{l}\text { gastronomía y } \\
\text { restauración }\end{array}$ & $\begin{array}{l}\text { amplificación }+ \\
\text { equivalente acuñado + } \\
\text { préstamo }\end{array}$ & Compuesta \\
\hline
\end{tabular}




\begin{tabular}{|c|c|c|c|c|c|}
\hline ID & \begin{tabular}{|l|} 
TíTULO \\
GUÍA \\
\end{tabular} & $\begin{array}{l}\text { ELEMENTO } \\
\text { DE ANÁLISIS }\end{array}$ & \begin{tabular}{|l|} 
CAMPO \\
SEMÁNTICO \\
\end{tabular} & \begin{tabular}{|l|} 
TÉCNICA \\
TRADUCCIÓN
\end{tabular} & $\begin{array}{l}\text { TIPO } \\
\text { TÉCNICA }\end{array}$ \\
\hline 167 & $\begin{array}{l}\text { Lonely } \\
\text { Planet } \\
\text { Andalucía }\end{array}$ & jamón & $\begin{array}{l}\text { gastronomía y } \\
\text { restauración }\end{array}$ & préstamo & Simple \\
\hline 168 & $\begin{array}{l}\text { Lonely } \\
\text { Planet } \\
\text { Andalucía }\end{array}$ & media ración & $\begin{array}{l}\text { gastronomía y } \\
\text { restauración }\end{array}$ & $\begin{array}{l}\text { amplificación + } \\
\text { préstamo }\end{array}$ & Compuesta \\
\hline 169 & $\begin{array}{l}\text { Lonely } \\
\text { Planet } \\
\text { Andalucía }\end{array}$ & ración & $\begin{array}{l}\text { gastronomía y } \\
\text { restauración }\end{array}$ & $\begin{array}{l}\text { amplificación + } \\
\text { préstamo }\end{array}$ & Compuesta \\
\hline 170 & $\begin{array}{l}\text { Lonely } \\
\text { planet } \\
\text { andalucía }\end{array}$ & flamenquín & $\begin{array}{l}\text { gastronomía y } \\
\text { restauración }\end{array}$ & $\begin{array}{l}\text { amplificación + } \\
\text { préstamo }\end{array}$ & Compuesta \\
\hline 171 & $\begin{array}{l}\text { Lonely } \\
\text { planet } \\
\text { andalucía }\end{array}$ & kofte & $\begin{array}{l}\text { gastronomía y } \\
\text { restauración }\end{array}$ & préstamo & Simple \\
\hline 172 & $\begin{array}{l}\text { Lonely } \\
\text { planet } \\
\text { andalucía }\end{array}$ & menú & $\begin{array}{l}\text { gastronomía y } \\
\text { restauración }\end{array}$ & $\begin{array}{l}\text { amplificación + } \\
\text { préstamo }\end{array}$ & Compuesta \\
\hline 173 & $\begin{array}{l}\text { Lonely } \\
\text { Planet } \\
\text { Andalucía }\end{array}$ & salmorejo & $\begin{array}{l}\text { gastronomía y } \\
\text { restauración }\end{array}$ & préstamo & Simple \\
\hline 174 & $\begin{array}{l}\text { Lonely } \\
\text { Planet } \\
\text { Andalucía } \\
\end{array}$ & tacos & $\begin{array}{l}\text { gastronomía y } \\
\text { restauración }\end{array}$ & préstamo & Simple \\
\hline 175 & $\begin{array}{l}\text { Lonely } \\
\text { Planet } \\
\text { Andalucía }\end{array}$ & media ración & $\begin{array}{l}\text { gastronomía y } \\
\text { restauración }\end{array}$ & préstamo & Simple \\
\hline 176 & $\begin{array}{l}\text { Lonely } \\
\text { Planet } \\
\text { Andalucía }\end{array}$ & rubia & $\begin{array}{l}\text { gastronomía y } \\
\text { restauración }\end{array}$ & calco + préstamo & Compuesta \\
\hline 177 & $\begin{array}{l}\text { Lonely } \\
\text { Planet } \\
\text { Andalucía }\end{array}$ & churrasco & $\begin{array}{l}\text { gastronomía y } \\
\text { restauración }\end{array}$ & $\begin{array}{l}\text { amplificación + } \\
\text { préstamo }\end{array}$ & Compuesta \\
\hline 178 & $\begin{array}{l}\text { Lonely } \\
\text { Planet } \\
\text { Andalucía }\end{array}$ & flamenco & $\begin{array}{l}\text { gastronomía y } \\
\text { restauración }\end{array}$ & préstamo & Simple \\
\hline 179 & $\begin{array}{l}\text { Lonely } \\
\text { Planet } \\
\text { Andalucía }\end{array}$ & flamenco & $\begin{array}{l}\text { gastronomía y } \\
\text { restauración }\end{array}$ & $\begin{array}{l}\text { amplificación + } \\
\text { préstamo }\end{array}$ & Compuesta \\
\hline 180 & $\begin{array}{l}\text { Lonely } \\
\text { Planet } \\
\text { Andalucía }\end{array}$ & $\begin{array}{l}\text { cuero } \\
\text { repujado }\end{array}$ & artesanía & $\begin{array}{l}\text { amplificación + } \\
\text { préstamo }\end{array}$ & Compuesta \\
\hline
\end{tabular}




\begin{tabular}{|c|c|c|c|c|c|}
\hline ID & \begin{tabular}{|l|} 
TíTULO \\
GUÍA
\end{tabular} & $\begin{array}{l}\text { ELEMENTO } \\
\text { DE ANÁLISIS }\end{array}$ & \begin{tabular}{|l|} 
CAMPO \\
SEMÁNTICO
\end{tabular} & $\begin{array}{l}\text { TÉCNICA } \\
\text { TRADUCCIÓN }\end{array}$ & $\begin{array}{l}\text { TIPO } \\
\text { TÉCNICA }\end{array}$ \\
\hline 181 & $\begin{array}{l}\text { Lonely } \\
\text { Planet } \\
\text { Andalucía }\end{array}$ & $\begin{array}{l}\text { plato } \\
\text { combinado }\end{array}$ & $\begin{array}{l}\text { gastronomía y } \\
\text { restauración }\end{array}$ & $\begin{array}{l}\text { amplificación + } \\
\text { préstamo }\end{array}$ & Compuesta \\
\hline 182 & $\begin{array}{l}\text { Lonely } \\
\text { Planet } \\
\text { Andalucía }\end{array}$ & dehesa & $\begin{array}{l}\text { paisaje y } \\
\text { geografía }\end{array}$ & $\begin{array}{l}\text { amplificación + } \\
\text { préstamo }\end{array}$ & Compuesta \\
\hline 183 & $\begin{array}{l}\text { Lonely } \\
\text { Planet } \\
\text { Andalucía } \\
\end{array}$ & jabugo & $\begin{array}{l}\text { gastronomía y } \\
\text { restauración }\end{array}$ & $\begin{array}{l}\text { amplificación + } \\
\text { préstamo }\end{array}$ & Compuesta \\
\hline 184 & $\begin{array}{l}\text { Lonely } \\
\text { Planet } \\
\text { Andalucía } \\
\end{array}$ & $\begin{array}{l}\text { jamón } \\
\text { ibérico }\end{array}$ & $\begin{array}{l}\text { gastronomía y } \\
\text { restauración }\end{array}$ & $\begin{array}{l}\text { amplificación + } \\
\text { préstamo }\end{array}$ & Compuesta \\
\hline 185 & $\begin{array}{l}\text { Lonely } \\
\text { Planet } \\
\text { Andalucía } \\
\end{array}$ & ermita & arquitectura & $\begin{array}{l}\text { equivalente acuñado + } \\
\text { préstamo }\end{array}$ & Compuesta \\
\hline 186 & $\begin{array}{l}\text { Lonely } \\
\text { Planet } \\
\text { Andalucía } \\
\end{array}$ & menú & $\begin{array}{l}\text { gastronomía y } \\
\text { restauración }\end{array}$ & $\begin{array}{l}\text { amplificación + } \\
\text { préstamo }\end{array}$ & Compuesta \\
\hline 187 & $\begin{array}{l}\text { Lonely } \\
\text { Planet } \\
\text { Andalucía } \\
\end{array}$ & menú & $\begin{array}{l}\text { gastronomía y } \\
\text { restauración }\end{array}$ & préstamo & Simple \\
\hline 188 & $\begin{array}{l}\text { Lonely } \\
\text { Planet } \\
\text { Andalucía } \\
\end{array}$ & $\begin{array}{l}\text { denominació } \\
\mathrm{n} \text { de origen }\end{array}$ & $\begin{array}{l}\text { gastronomía y } \\
\text { restauración }\end{array}$ & $\begin{array}{l}\text { amplificación + } \\
\text { préstamo }\end{array}$ & Compuesta \\
\hline 189 & $\begin{array}{l}\text { Lonely } \\
\text { Planet } \\
\text { Andalucía } \\
\end{array}$ & campiña & $\begin{array}{l}\text { paisaje y } \\
\text { geografía }\end{array}$ & $\begin{array}{l}\text { equivalente acuñado + } \\
\text { préstamo }\end{array}$ & Compuesta \\
\hline 190 & $\begin{array}{l}\text { Lonely } \\
\text { Planet } \\
\text { Andalucía } \\
\end{array}$ & $\begin{array}{l}\text { capilla del } \\
\text { Sagrario }\end{array}$ & arquitectura & $\begin{array}{l}\text { amplificación + } \\
\text { equivalente acuñado + } \\
\text { préstamo }\end{array}$ & Compuesta \\
\hline 191 & $\begin{array}{l}\text { Lonely } \\
\text { Planet } \\
\text { Andalucía }\end{array}$ & $\begin{array}{l}\text { castillo de } \\
\text { priego }\end{array}$ & arquitectura & $\begin{array}{l}\text { amplificación + } \\
\text { préstamo }\end{array}$ & Compuesta \\
\hline 192 & $\begin{array}{l}\text { Lonely } \\
\text { Planet } \\
\text { Andalucía }\end{array}$ & $\begin{array}{l}\text { fuente del } \\
\text { rey }\end{array}$ & arquitectura & calco + préstamo & Compuesta \\
\hline 193 & $\begin{array}{l}\text { Lonely } \\
\text { Planet } \\
\text { Andalucía } \\
\end{array}$ & $\begin{array}{l}\text { fuente de la } \\
\text { virgen de la } \\
\text { salud }\end{array}$ & arquitectura & préstamo & Simple \\
\hline 194 & $\begin{array}{l}\text { Lonely } \\
\text { Planet } \\
\text { Andalucía }\end{array}$ & revuelto & $\begin{array}{l}\text { gastronomía y } \\
\text { restauración }\end{array}$ & $\begin{array}{l}\text { equivalente acuñado + } \\
\text { préstamo }\end{array}$ & Compuesta \\
\hline
\end{tabular}




\begin{tabular}{|c|c|c|c|c|c|}
\hline ID & \begin{tabular}{|l|} 
TíTULO \\
GUÍA
\end{tabular} & \begin{tabular}{|l|} 
ELEMENTO \\
DE ANÁLISIS \\
\end{tabular} & \begin{tabular}{|l|} 
CAMPO \\
SEMÁNTICO \\
\end{tabular} & $\begin{array}{l}\text { TÉCNICA } \\
\text { TRADUCCIÓN }\end{array}$ & \begin{tabular}{|l|} 
TIPO \\
TÉCNICA
\end{tabular} \\
\hline 195 & $\begin{array}{l}\text { Lonely } \\
\text { Planet } \\
\text { Andalucía }\end{array}$ & $\begin{array}{l}\text { plaza de san } \\
\text { josé }\end{array}$ & arquitectura & préstamo & Simple \\
\hline 196 & $\begin{array}{l}\text { Lonely } \\
\text { Planet } \\
\text { Andalucía }\end{array}$ & $\begin{array}{l}\text { torre civil de } \\
\text { reloj }\end{array}$ & arquitectura & calco + préstamo & Compuesta \\
\hline 197 & $\begin{array}{l}\text { Lonely } \\
\text { Planet } \\
\text { Andalucía }\end{array}$ & $\begin{array}{l}\text { iglesia de } \\
\text { santa maría } \\
\text { de soterraño }\end{array}$ & arquitectura & $\begin{array}{l}\text { amplificación + } \\
\text { préstamo }\end{array}$ & Compuesta \\
\hline 198 & $\begin{array}{l}\text { Lonely } \\
\text { Planet } \\
\text { Andalucía } \\
\end{array}$ & campiña & $\begin{array}{l}\text { paisaje y } \\
\text { geografía }\end{array}$ & $\begin{array}{l}\text { equivalente acuñado + } \\
\text { préstamo }\end{array}$ & Compuesta \\
\hline 199 & $\begin{array}{l}\text { Lonely } \\
\text { Planet } \\
\text { Andalucía }\end{array}$ & montilla & $\begin{array}{l}\text { gastronomía y } \\
\text { restauración }\end{array}$ & $\begin{array}{l}\text { amplificación + } \\
\text { préstamo }\end{array}$ & Compuesta \\
\hline 200 & \begin{tabular}{|l} 
Lonely \\
Planet \\
Andalucía \\
\end{tabular} & tinajas & $\begin{array}{l}\text { gastronomía y } \\
\text { restauración }\end{array}$ & préstamo & Simple \\
\hline 201 & $\begin{array}{l}\text { Lonely } \\
\text { Planet } \\
\text { Andalucía } \\
\end{array}$ & abderramán & historia & préstamo & Simple \\
\hline 202 & $\begin{array}{l}\text { Lonely } \\
\text { Planet } \\
\text { Andalucía } \\
\end{array}$ & almanzor & historia & $\begin{array}{l}\text { equivalente acuñado + } \\
\text { préstamo }\end{array}$ & Compuesta \\
\hline 203 & $\begin{array}{l}\text { Lonely } \\
\text { Planet } \\
\text { Andalucía } \\
\end{array}$ & averroes & historia & préstamo & Simple \\
\hline 204 & $\begin{array}{l}\text { Lonely } \\
\text { Planet } \\
\text { Andalucía } \\
\end{array}$ & maimónides & historia & $\begin{array}{l}\text { equivalente acuñado + } \\
\text { préstamo }\end{array}$ & Compuesta \\
\hline 205 & $\begin{array}{l}\text { Lonely } \\
\text { Planet } \\
\text { Andalucía }\end{array}$ & flamenco & $\begin{array}{l}\text { fiestas y } \\
\text { espectáculos }\end{array}$ & préstamo & Simple \\
\hline 206 & $\begin{array}{l}\text { Lonely } \\
\text { Planet } \\
\text { Andalucía }\end{array}$ & $\begin{array}{l}\text { mohammed } \\
\text { ibn ysuf ibn } \\
\text { nasr }\end{array}$ & historia & préstamo & Simple \\
\hline 207 & $\begin{array}{l}\text { Lonely } \\
\text { Planet } \\
\text { Andalucía } \\
\end{array}$ & boabdil & historia & préstamo & Simple \\
\hline 208 & $\begin{array}{l}\text { Lonely } \\
\text { Planet } \\
\text { Andalucía }\end{array}$ & abu al hasan & historia & préstamo & Simple \\
\hline
\end{tabular}




\begin{tabular}{|c|c|c|c|c|c|}
\hline ID & \begin{tabular}{|l|} 
TíTULO \\
GUÍA
\end{tabular} & \begin{tabular}{|l|} 
ELEMENTO \\
DE ANÁLISIS \\
\end{tabular} & \begin{tabular}{|l|} 
CAMPO \\
SEMÁNTICO \\
\end{tabular} & \begin{tabular}{|l|} 
TÉCNICA \\
TRADUCCIÓN
\end{tabular} & \begin{tabular}{|l|} 
TIPO \\
TÉCNICA \\
\end{tabular} \\
\hline 209 & \begin{tabular}{|l} 
Lonely \\
Planet \\
Andalucía
\end{tabular} & las alpujarras & \begin{tabular}{|l} 
paisaje y \\
geografía
\end{tabular} & $\begin{array}{l}\text { amplificación + } \\
\text { préstamo }\end{array}$ & Compuesta \\
\hline 210 & $\begin{array}{l}\text { Lonely } \\
\text { Planet } \\
\text { Andalucía }\end{array}$ & $\begin{array}{l}\text { reyes } \\
\text { católicos }\end{array}$ & historia & $\begin{array}{l}\text { equivalente acuñado + } \\
\text { préstamo }\end{array}$ & Compuesta \\
\hline 211 & \begin{tabular}{|l|} 
Lonely \\
Planet \\
Andalucía
\end{tabular} & sierra nevada & \begin{tabular}{|l} 
paisaje y \\
geografía
\end{tabular} & $\begin{array}{l}\text { amplificación + } \\
\text { préstamo }\end{array}$ & Compuesta \\
\hline 212 & \begin{tabular}{|l|} 
Lonely \\
Planet \\
Andalucía \\
\end{tabular} & $\begin{array}{l}\text { palacio } \\
\text { nazaríes }\end{array}$ & arquitectura & $\begin{array}{l}\text { equivalente acuñado + } \\
\text { préstamo }\end{array}$ & Compuesta \\
\hline 213 & \begin{tabular}{|l|} 
Lonely \\
Planet \\
Andalucía
\end{tabular} & generalife & arquitectura & $\begin{array}{l}\text { amplificación + } \\
\text { préstamo }\end{array}$ & Compuesta \\
\hline 214 & \begin{tabular}{|l|} 
Lonely \\
Planet \\
Andalucía \\
\end{tabular} & alcazaba & arquitectura & calco + préstamo & Compuesta \\
\hline 215 & \begin{tabular}{|l|} 
Lonely \\
Planet \\
Andalucía \\
\end{tabular} & alhambra & arquitectura & $\begin{array}{l}\text { amplificación + } \\
\text { préstamo }\end{array}$ & Compuesta \\
\hline 216 & \begin{tabular}{|l|} 
Lonely \\
Planet \\
Andalucía \\
\end{tabular} & reconquista & historia & $\begin{array}{l}\text { amplificación + } \\
\text { préstamo }\end{array}$ & Compuesta \\
\hline 217 & \begin{tabular}{|l|} 
Lonely \\
Planet \\
Andalucía
\end{tabular} & \begin{tabular}{|l} 
reyes \\
católicos
\end{tabular} & historia & equivalente acuñado & Simple \\
\hline 218 & \begin{tabular}{|l|} 
Lonely \\
Planet \\
Andalucía \\
\end{tabular} & $\begin{array}{l}\text { cuesta de } \\
\text { gomérez }\end{array}$ & \begin{tabular}{|l|} 
paisaje y \\
geografía
\end{tabular} & préstamo & Simple \\
\hline 219 & \begin{tabular}{|l|} 
Lonely \\
Planet \\
Andalucía
\end{tabular} & $\begin{array}{l}\text { puerta de las } \\
\text { granadas }\end{array}$ & $\begin{array}{l}\text { paisaje y } \\
\text { geografía }\end{array}$ & calco + préstamo & Compuesta \\
\hline 220 & $\begin{array}{l}\text { Lonely } \\
\text { Planet } \\
\text { Andalucía }\end{array}$ & $\begin{array}{l}\text { cuesta de los } \\
\text { chinos }\end{array}$ & $\begin{array}{l}\text { paisaje y } \\
\text { geografía }\end{array}$ & préstamo & Simple \\
\hline 221 & \begin{tabular}{|l|} 
Lonely \\
Planet \\
Andalucía \\
\end{tabular} & $\begin{array}{l}\text { cuesta } \\
\text { empedrada }\end{array}$ & $\begin{array}{l}\text { paisaje y } \\
\text { geografía }\end{array}$ & préstamo & Simple \\
\hline 222 & \begin{tabular}{|l|} 
Lonely \\
Planet \\
Andalucía
\end{tabular} & $\begin{array}{l}\text { pilar de } \\
\text { carlos V }\end{array}$ & arquitectura & $\begin{array}{l}\text { amplificación + } \\
\text { préstamo }\end{array}$ & Compuesta \\
\hline
\end{tabular}




\begin{tabular}{|c|c|c|c|c|c|}
\hline ID & $\begin{array}{l}\text { TÍTULO } \\
\text { GUÍA }\end{array}$ & $\begin{array}{l}\text { ELEMENTO } \\
\text { DE ANÁLISIS }\end{array}$ & \begin{tabular}{|l|} 
CAMPO \\
SEMÁNTICO
\end{tabular} & $\begin{array}{l}\text { TÉCNICA } \\
\text { TRADUCCIÓN }\end{array}$ & \begin{tabular}{|l} 
TIPO \\
TÉCNICA
\end{tabular} \\
\hline 223 & $\begin{array}{l}\text { Lonely } \\
\text { Planet } \\
\text { Andalucía }\end{array}$ & $\begin{array}{l}\text { puerta de la } \\
\text { justicia }\end{array}$ & arquitectura & calco + préstamo & Compuesta \\
\hline 224 & $\begin{array}{l}\text { Lonely } \\
\text { Planet } \\
\text { Andalucía }\end{array}$ & $\begin{array}{l}\text { torre de la } \\
\text { vela }\end{array}$ & arquitectura & calco + préstamo & Compuesta \\
\hline 225 & $\begin{array}{l}\text { Lonely } \\
\text { Planet } \\
\text { Andalucía }\end{array}$ & muqarna & arquitectura & $\begin{array}{l}\text { amplificación + calco + } \\
\text { préstamo }\end{array}$ & Compuesta \\
\hline 226 & \begin{tabular}{|l|} 
Lonely \\
Planet \\
Andalucía \\
\end{tabular} & \begin{tabular}{|l|} 
patio del \\
cuarto \\
dorado \\
\end{tabular} & arquitectura & $\begin{array}{l}\text { amplificación + } \\
\text { préstamo }\end{array}$ & Compuesta \\
\hline 227 & $\begin{array}{l}\text { Lonely } \\
\text { Planet } \\
\text { Andalucía }\end{array}$ & $\begin{array}{l}\text { palacio de } \\
\text { comares }\end{array}$ & arquitectura & $\begin{array}{l}\text { amplificación + } \\
\text { préstamo }\end{array}$ & Compuesta \\
\hline 228 & \begin{tabular}{|l|} 
Lonely \\
Planet \\
Andalucía \\
\end{tabular} & $\begin{array}{l}\text { patio de los } \\
\text { arrayanes }\end{array}$ & arquitectura & $\begin{array}{l}\text { amplificación + calco + } \\
\text { préstamo }\end{array}$ & Compuesta \\
\hline 229 & \begin{tabular}{|l|} 
Lonely \\
Planet \\
Andalucía \\
\end{tabular} & $\begin{array}{l}\text { sala de la } \\
\text { barca }\end{array}$ & arquitectura & $\begin{array}{l}\text { amplificación + calco + } \\
\text { préstamo }\end{array}$ & Compuesta \\
\hline 230 & \begin{tabular}{|l|} 
Lonely \\
Planet \\
Andalucía \\
\end{tabular} & $\begin{array}{l}\text { salón de } \\
\text { comares }\end{array}$ & arquitectura & calco + préstamo & Compuesta \\
\hline 231 & \begin{tabular}{|l|} 
Lonely \\
Planet \\
Andalucía
\end{tabular} & $\begin{array}{l}\text { patio de los } \\
\text { leones }\end{array}$ & arquitectura & $\begin{array}{l}\text { amplificación + calco + } \\
\text { préstamo }\end{array}$ & Compuesta \\
\hline 232 & \begin{tabular}{|l|} 
Lonely \\
Planet \\
Andalucía
\end{tabular} & $\begin{array}{l}\text { sala de los } \\
\text { abencerrajes }\end{array}$ & arquitectura & $\begin{array}{l}\text { amplificación + } \\
\text { préstamo }\end{array}$ & Compuesta \\
\hline 233 & $\begin{array}{l}\text { Lonely } \\
\text { Planet } \\
\text { Andalucía }\end{array}$ & $\begin{array}{l}\text { sala de los } \\
\text { reyes }\end{array}$ & arquitectura & $\begin{array}{l}\text { amplificación + calco + } \\
\text { préstamo }\end{array}$ & Compuesta \\
\hline 234 & \begin{tabular}{|l|} 
Lonely \\
Planet \\
Andalucía \\
\end{tabular} & $\begin{array}{l}\text { sala de las } \\
\text { dos } \\
\text { hermanas }\end{array}$ & arquitectura & calco + préstamo & Compuesta \\
\hline 235 & $\begin{array}{l}\text { Lonely } \\
\text { Planet } \\
\text { Andalucía }\end{array}$ & $\begin{array}{l}\text { sala de los } \\
\text { ajimeces }\end{array}$ & arquitectura & préstamo & Simple \\
\hline 236 & $\begin{array}{l}\text { Lonely } \\
\text { Planet } \\
\text { Andalucía }\end{array}$ & $\begin{array}{l}\text { palacio de } \\
\text { carlos V }\end{array}$ & arquitectura & préstamo & Simple \\
\hline
\end{tabular}




\begin{tabular}{|c|c|c|c|c|c|}
\hline ID & \begin{tabular}{|l|} 
TÍTULO \\
GUÍA
\end{tabular} & \begin{tabular}{|l|} 
ELEMENTO \\
DE ANÁLISIS
\end{tabular} & \begin{tabular}{|l|} 
CAMPO \\
SEMÁNTICO \\
\end{tabular} & $\begin{array}{l}\text { TÉCNICA } \\
\text { TRADUCCIÓN }\end{array}$ & \begin{tabular}{|l|} 
TIPO \\
TÉCNICA \\
\end{tabular} \\
\hline 237 & $\begin{array}{l}\text { Lonely } \\
\text { Planet } \\
\text { Andalucía }\end{array}$ & $\begin{array}{l}\text { patio de la } \\
\text { reja }\end{array}$ & arquitectura & calco + préstamo & Compuesta \\
\hline 238 & $\begin{array}{l}\text { Lonely } \\
\text { Planet } \\
\text { Andalucía }\end{array}$ & $\begin{array}{l}\text { patio de la } \\
\text { lindaraja }\end{array}$ & arquitectura & préstamo & Simple \\
\hline 239 & \begin{tabular}{|l} 
Lonely \\
Planet \\
Andalucía
\end{tabular} & $\begin{array}{l}\text { palacio del } \\
\text { pórtico }\end{array}$ & arquitectura & $\begin{array}{l}\text { amplificación + calco + } \\
\text { préstamo }\end{array}$ & Compuesta \\
\hline 240 & \begin{tabular}{|l} 
Lonely \\
Planet \\
Andalucía \\
\end{tabular} & morisco & historia & $\begin{array}{l}\text { amplificación + } \\
\text { préstamo }\end{array}$ & Compuesta \\
\hline 241 & \begin{tabular}{|l} 
Lonely \\
Planet \\
Andalucía
\end{tabular} & $\begin{array}{l}\text { jardines } \\
\text { nuevos }\end{array}$ & $\begin{array}{l}\text { paisaje y } \\
\text { geografía }\end{array}$ & calco + préstamo & Compuesta \\
\hline 242 & \begin{tabular}{|l|} 
Lonely \\
Planet \\
Andalucía \\
\end{tabular} & $\begin{array}{l}\text { patio de la } \\
\text { acequia }\end{array}$ & arquitectura & calco + préstamo & Compuesta \\
\hline 243 & \begin{tabular}{|l} 
Lonely \\
Planet \\
Andalucía \\
\end{tabular} & $\begin{array}{l}\text { jardín de la } \\
\text { sultana }\end{array}$ & arquitectura & $\begin{array}{l}\text { amplificación + calco + } \\
\text { préstamo }\end{array}$ & Compuesta \\
\hline 244 & \begin{tabular}{|l} 
Lonely \\
Planet \\
Andalucía \\
\end{tabular} & jardines altos & arquitectura & calco + préstamo & Compuesta \\
\hline 245 & \begin{tabular}{|l} 
Lonely \\
Planet \\
Andalucía
\end{tabular} & $\begin{array}{l}\text { escalera del } \\
\text { agua }\end{array}$ & arquitectura & calco + préstamo & Compuesta \\
\hline 246 & \begin{tabular}{|l} 
Lonely \\
Planet \\
Andalucía \\
\end{tabular} & capilla real & arquitectura & calco + préstamo & Compuesta \\
\hline 247 & $\begin{array}{l}\text { Lonely } \\
\text { Planet } \\
\text { Andalucía }\end{array}$ & $\begin{array}{l}\text { felipe el } \\
\text { hermoso }\end{array}$ & historia & $\begin{array}{l}\text { amplificación + calco + } \\
\text { préstamo }\end{array}$ & Compuesta \\
\hline 248 & \begin{tabular}{|l} 
Lonely \\
Planet \\
Andalucía \\
\end{tabular} & juana la loca & historia & amplificación + calco & Compuesta \\
\hline 249 & \begin{tabular}{|l} 
Lonely \\
Planet \\
Andalucía \\
\end{tabular} & $\begin{array}{l}\text { oración en el } \\
\text { huerto de los } \\
\text { olivos }\end{array}$ & pintura & equivalente acuñado & Simple \\
\hline 250 & \begin{tabular}{|l} 
Lonely \\
Planet \\
Andalucía
\end{tabular} & $\begin{array}{l}\text { puerta del } \\
\text { perdón }\end{array}$ & arquitectura & préstamo & Simple \\
\hline
\end{tabular}




\begin{tabular}{|c|c|c|c|c|c|}
\hline ID & $\begin{array}{l}\text { TíTULO } \\
\text { GUÍA }\end{array}$ & $\begin{array}{l}\text { ELEMENTO } \\
\text { DE ANÁLISIS }\end{array}$ & $\begin{array}{l}\text { CAMPO } \\
\text { SEMÁNTICO }\end{array}$ & $\begin{array}{l}\text { TÉCNICA } \\
\text { TRADUCCIÓN }\end{array}$ & $\begin{array}{l}\text { TIPO } \\
\text { TÉCNICA }\end{array}$ \\
\hline 251 & $\begin{array}{l}\text { Lonely } \\
\text { Planet } \\
\text { Andalucía }\end{array}$ & $\begin{array}{l}\text { centro josé } \\
\text { guerrero }\end{array}$ & pintura & $\begin{array}{l}\text { amplificación + } \\
\text { generalización + } \\
\text { préstamo }\end{array}$ & Compuesta \\
\hline 252 & $\begin{array}{l}\text { Lonely } \\
\text { Planet } \\
\text { Andalucía }\end{array}$ & la madraza & arquitectura & $\begin{array}{l}\text { amplificación + } \\
\text { préstamo }\end{array}$ & Compuesta \\
\hline 253 & $\begin{array}{l}\text { Lonely } \\
\text { Planet } \\
\text { Andalucía }\end{array}$ & alcaicería & arquitectura & $\begin{array}{l}\text { amplificación + } \\
\text { préstamo }\end{array}$ & Compuesta \\
\hline 254 & $\begin{array}{l}\text { Lonely } \\
\text { Planet } \\
\text { Andalucía } \\
\end{array}$ & $\begin{array}{l}\text { corral del } \\
\text { carbón }\end{array}$ & arquitectura & $\begin{array}{l}\text { amplificación + calco + } \\
\text { préstamo }\end{array}$ & Compuesta \\
\hline 255 & $\begin{array}{l}\text { Lonely } \\
\text { Planet } \\
\text { Andalucía } \\
\end{array}$ & cármenes & $\begin{array}{l}\text { paisaje y } \\
\text { geografía }\end{array}$ & $\begin{array}{l}\text { amplificación + } \\
\text { préstamo }\end{array}$ & Compuesta \\
\hline 256 & $\begin{array}{l}\text { Lonely } \\
\text { Planet } \\
\text { Andalucía } \\
\end{array}$ & albaicín & arquitectura & $\begin{array}{l}\text { amplificación + } \\
\text { préstamo }\end{array}$ & Compuesta \\
\hline 257 & $\begin{array}{l}\text { Lonely } \\
\text { Planet } \\
\text { Andalucía } \\
\end{array}$ & $\begin{array}{l}\text { Peña de la } \\
\text { Platería }\end{array}$ & $\begin{array}{l}\text { fiestas y } \\
\text { espectáculos }\end{array}$ & $\begin{array}{l}\text { amplificación + } \\
\text { préstamo }\end{array}$ & Compuesta \\
\hline 258 & $\begin{array}{l}\text { Lonely } \\
\text { Planet } \\
\text { Andalucía } \\
\end{array}$ & $\begin{array}{l}\text { colegiata del } \\
\text { salvador }\end{array}$ & arquitectura & $\begin{array}{l}\text { amplificación + } \\
\text { préstamo }\end{array}$ & Compuesta \\
\hline 259 & $\begin{array}{l}\text { Lonely } \\
\text { Planet } \\
\text { Andalucía } \\
\end{array}$ & $\begin{array}{l}\text { convento de } \\
\text { santa isabel } \\
\text { la real }\end{array}$ & arquitectura & $\begin{array}{l}\text { amplificación + calco + } \\
\text { préstamo }\end{array}$ & Compuesta \\
\hline 260 & $\begin{array}{l}\text { Lonely } \\
\text { Planet } \\
\text { Andalucía } \\
\end{array}$ & $\begin{array}{l}\text { arco de las } \\
\text { pesas }\end{array}$ & arquitectura & $\begin{array}{l}\text { amplificación + } \\
\text { préstamo }\end{array}$ & Compuesta \\
\hline 261 & $\begin{array}{l}\text { Lonely } \\
\text { Planet } \\
\text { Andalucía }\end{array}$ & $\begin{array}{l}\text { alminar de } \\
\text { san josé }\end{array}$ & arquitectura & $\begin{array}{l}\text { amplificación + calco + } \\
\text { préstamo }\end{array}$ & Compuesta \\
\hline 262 & $\begin{array}{l}\text { Lonely } \\
\text { Planet } \\
\text { Andalucía }\end{array}$ & tetería & $\begin{array}{l}\text { gastronomía y } \\
\text { restauración }\end{array}$ & $\begin{array}{l}\text { equivalente acuñado + } \\
\text { préstamo }\end{array}$ & Compuesta \\
\hline 263 & $\begin{array}{l}\text { Lonely } \\
\text { Planet } \\
\text { Andalucía } \\
\end{array}$ & $\begin{array}{l}\text { mármol de } \\
\text { lanjarón }\end{array}$ & arquitectura & $\begin{array}{l}\text { amplificación + } \\
\text { préstamo }\end{array}$ & Compuesta \\
\hline 264 & $\begin{array}{l}\text { Lonely } \\
\text { Planet } \\
\text { Andalucía }\end{array}$ & baños árabes & arquitectura & calco + préstamo & Compuesta \\
\hline
\end{tabular}




\begin{tabular}{|c|c|c|c|c|c|}
\hline ID & \begin{tabular}{|l|} 
TíTULO \\
GUÍA
\end{tabular} & $\begin{array}{l}\text { ELEMENTO } \\
\text { DE ANÁLISIS }\end{array}$ & \begin{tabular}{|l|} 
CAMPO \\
SEMÁNTICO
\end{tabular} & $\begin{array}{l}\text { TÉCNICA } \\
\text { TRADUCCIÓN }\end{array}$ & $\begin{array}{l}\text { TIPO } \\
\text { TÉCNICA }\end{array}$ \\
\hline 265 & $\begin{array}{l}\text { Lonely } \\
\text { Planet } \\
\text { Andalucía }\end{array}$ & procesión & $\begin{array}{l}\text { fiestas y } \\
\text { espectáculos }\end{array}$ & calco + préstamo & Compuesta \\
\hline 266 & $\begin{array}{l}\text { Lonely } \\
\text { Planet } \\
\text { Andalucía }\end{array}$ & sevillanas & $\begin{array}{l}\text { fiestas y } \\
\text { espectáculos }\end{array}$ & $\begin{array}{l}\text { amplificación + } \\
\text { préstamo }\end{array}$ & Compuesta \\
\hline 267 & $\begin{array}{l}\text { Lonely } \\
\text { Planet } \\
\text { Andalucía }\end{array}$ & cármenes & $\begin{array}{l}\text { paisaje y } \\
\text { geografía }\end{array}$ & $\begin{array}{l}\text { amplificación + } \\
\text { préstamo }\end{array}$ & Compuesta \\
\hline 268 & $\begin{array}{l}\text { Lonely } \\
\text { Planet } \\
\text { Andalucía }\end{array}$ & tapas & $\begin{array}{l}\text { gastronomía y } \\
\text { restauración }\end{array}$ & préstamo & Simple \\
\hline 269 & $\begin{array}{l}\text { Lonely } \\
\text { Planet } \\
\text { Andalucía }\end{array}$ & tapas & $\begin{array}{l}\text { gastronomía y } \\
\text { restauración }\end{array}$ & préstamo & Simple \\
\hline 270 & $\begin{array}{l}\text { Lonely } \\
\text { Planet } \\
\text { Andalucía }\end{array}$ & alioli & $\begin{array}{l}\text { gastronomía y } \\
\text { restauración }\end{array}$ & $\begin{array}{l}\text { amplificación + } \\
\text { préstamo }\end{array}$ & Compuesta \\
\hline 271 & $\begin{array}{l}\text { Lonely } \\
\text { Planet } \\
\text { Andalucía } \\
\end{array}$ & montadito & $\begin{array}{l}\text { gastronomía y } \\
\text { restauración }\end{array}$ & $\begin{array}{l}\text { amplificación + } \\
\text { préstamo }\end{array}$ & Compuesta \\
\hline 272 & $\begin{array}{l}\text { Lonely } \\
\text { Planet } \\
\text { Andalucía } \\
\end{array}$ & caña & $\begin{array}{l}\text { gastronomía y } \\
\text { restauración }\end{array}$ & $\begin{array}{l}\text { amplificación + } \\
\text { préstamo }\end{array}$ & Compuesta \\
\hline 273 & $\begin{array}{l}\text { Lonely } \\
\text { Planet } \\
\text { Andalucía }\end{array}$ & $\begin{array}{l}\text { jamón } \\
\text { ibérico }\end{array}$ & $\begin{array}{l}\text { gastronomía y } \\
\text { restauración }\end{array}$ & $\begin{array}{l}\text { amplificación + } \\
\text { préstamo }\end{array}$ & Compuesta \\
\hline 274 & $\begin{array}{l}\text { Lonely } \\
\text { Planet } \\
\text { Andalucía }\end{array}$ & $\begin{array}{l}\text { jamón } \\
\text { serrano }\end{array}$ & $\begin{array}{l}\text { gastronomía y } \\
\text { restauración }\end{array}$ & $\begin{array}{l}\text { amplificación + } \\
\text { préstamo }\end{array}$ & Compuesta \\
\hline 275 & $\begin{array}{l}\text { Lonely } \\
\text { Planet } \\
\text { Andalucía }\end{array}$ & $\begin{array}{l}\text { pimientos de } \\
\text { piquillo }\end{array}$ & $\begin{array}{l}\text { gastronomía y } \\
\text { restauración }\end{array}$ & $\begin{array}{l}\text { amplificación + } \\
\text { préstamo }\end{array}$ & Compuesta \\
\hline 276 & $\begin{array}{l}\text { Lonely } \\
\text { Planet } \\
\text { Andalucía }\end{array}$ & bocadillo & $\begin{array}{l}\text { gastronomía y } \\
\text { restauración }\end{array}$ & $\begin{array}{l}\text { amplificación + } \\
\text { préstamo }\end{array}$ & Compuesta \\
\hline 277 & $\begin{array}{l}\text { Lonely } \\
\text { Planet } \\
\text { Andalucía } \\
\end{array}$ & flamenco & $\begin{array}{l}\text { fiestas y } \\
\text { espectáculos }\end{array}$ & préstamo & Simple \\
\hline 278 & $\begin{array}{l}\text { Lonely } \\
\text { Planet } \\
\text { Andalucía }\end{array}$ & $\begin{array}{l}\text { semana } \\
\text { santa }\end{array}$ & $\begin{array}{l}\text { fiestas y } \\
\text { espectáculos }\end{array}$ & $\begin{array}{l}\text { equivalente acuñado + } \\
\text { préstamo }\end{array}$ & Compuesta \\
\hline
\end{tabular}




\begin{tabular}{|c|c|c|c|c|c|}
\hline ID & \begin{tabular}{|l|} 
TíTULO \\
GUÍA
\end{tabular} & \begin{tabular}{|l|} 
ELEMENTO \\
DE ANÁLISIS \\
\end{tabular} & \begin{tabular}{|l|} 
CAMPO \\
SEMÁNTICO
\end{tabular} & \begin{tabular}{|l|} 
TÉCNICA \\
TRADUCCIÓN
\end{tabular} & \begin{tabular}{|l|} 
TIPO \\
TÉCNICA \\
\end{tabular} \\
\hline 279 & \begin{tabular}{|l} 
Lonely \\
Planet \\
Andalucía
\end{tabular} & feria de abril & $\begin{array}{l}\text { fiestas y } \\
\text { espectáculos }\end{array}$ & préstamo & Simple \\
\hline 280 & $\begin{array}{l}\text { Lonely } \\
\text { Planet } \\
\text { Andalucía }\end{array}$ & procesión & $\begin{array}{l}\text { fiestas y } \\
\text { espectáculos }\end{array}$ & calco + préstamo & Compuesta \\
\hline 281 & \begin{tabular}{|l|} 
Lonely \\
Planet \\
Andalucía
\end{tabular} & tapas & $\begin{array}{l}\text { gastronomía y } \\
\text { restauración }\end{array}$ & préstamo & Simple \\
\hline 282 & \begin{tabular}{|l|} 
Lonely \\
Planet \\
Andalucía \\
\end{tabular} & torero & $\begin{array}{l}\text { fiestas y } \\
\text { espectáculos }\end{array}$ & $\begin{array}{l}\text { equivalente acuñado + } \\
\text { préstamo }\end{array}$ & Compuesta \\
\hline 283 & \begin{tabular}{|l|} 
Lonely \\
Planet \\
Andalucía
\end{tabular} & feria de abril & $\begin{array}{l}\text { fiestas y } \\
\text { espectáculos }\end{array}$ & calco + préstamo & Compuesta \\
\hline 284 & \begin{tabular}{|l|} 
Lonely \\
Planet \\
Andalucía \\
\end{tabular} & feria de abril & $\begin{array}{l}\text { fiestas y } \\
\text { espectáculos }\end{array}$ & calco + préstamo & Compuesta \\
\hline 285 & \begin{tabular}{|l|} 
Lonely \\
Planet \\
Andalucía \\
\end{tabular} & $\begin{array}{l}\text { fernando III } \\
\text { el santo }\end{array}$ & historia & calco + préstamo & Compuesta \\
\hline 286 & \begin{tabular}{|l|} 
Lonely \\
Planet \\
Andalucía \\
\end{tabular} & giralda & arquitectura & $\begin{array}{l}\text { amplificación + } \\
\text { préstamo }\end{array}$ & Compuesta \\
\hline 287 & \begin{tabular}{|l|} 
Lonely \\
Planet \\
Andalucía
\end{tabular} & $\begin{array}{l}\text { casa de la } \\
\text { contratación }\end{array}$ & arquitectura & $\begin{array}{l}\text { amplificación + } \\
\text { préstamo }\end{array}$ & Compuesta \\
\hline 288 & \begin{tabular}{|l|} 
Lonely \\
Planet \\
Andalucía \\
\end{tabular} & $\begin{array}{l}\text { puente de } \\
\text { triana }\end{array}$ & arquitectura & $\begin{array}{l}\text { amplificación + } \\
\text { préstamo }\end{array}$ & Compuesta \\
\hline 289 & \begin{tabular}{|l|} 
Lonely \\
Planet \\
Andalucía
\end{tabular} & giralda & arquitectura & $\begin{array}{l}\text { amplificación + } \\
\text { préstamo }\end{array}$ & Compuesta \\
\hline 290 & $\begin{array}{l}\text { Lonely } \\
\text { Planet } \\
\text { Andalucía }\end{array}$ & alcázar & arquitectura & $\begin{array}{l}\text { amplificación + } \\
\text { préstamo }\end{array}$ & Compuesta \\
\hline 291 & \begin{tabular}{|l|} 
Lonely \\
Planet \\
Andalucía \\
\end{tabular} & giralda & arquitectura & $\begin{array}{l}\text { amplificación + } \\
\text { préstamo }\end{array}$ & Compuesta \\
\hline 292 & \begin{tabular}{|l|} 
Lonely \\
Planet \\
Andalucía
\end{tabular} & $\begin{array}{l}\text { puerta del } \\
\text { perdón }\end{array}$ & arquitectura & $\begin{array}{l}\text { amplificación + } \\
\text { préstamo }\end{array}$ & Compuesta \\
\hline
\end{tabular}




\begin{tabular}{|c|c|c|c|c|c|}
\hline ID & \begin{tabular}{|l|} 
TÍTULO \\
GUÍA
\end{tabular} & \begin{tabular}{|l|} 
ELEMENTO \\
DE ANÁLISIS
\end{tabular} & \begin{tabular}{|l|} 
CAMPO \\
SEMÁNTICO \\
\end{tabular} & $\begin{array}{l}\text { TÉCNICA } \\
\text { TRADUCCIÓN }\end{array}$ & \begin{tabular}{|l|} 
TIPO \\
TÉCNICA \\
\end{tabular} \\
\hline 293 & \begin{tabular}{|l} 
Lonely \\
Planet \\
Andalucía
\end{tabular} & giralda & arquitectura & $\begin{array}{l}\text { amplificación + } \\
\text { préstamo }\end{array}$ & Compuesta \\
\hline 294 & $\begin{array}{l}\text { Lonely } \\
\text { Planet } \\
\text { Andalucía }\end{array}$ & $\begin{array}{l}\text { sala del } \\
\text { pabellón }\end{array}$ & arquitectura & $\begin{array}{l}\text { amplificación + } \\
\text { préstamo }\end{array}$ & Compuesta \\
\hline 295 & $\begin{array}{l}\text { Lonely } \\
\text { Planet } \\
\text { Andalucía }\end{array}$ & $\begin{array}{l}\text { capilla de san } \\
\text { antonio }\end{array}$ & arquitectura & $\begin{array}{l}\text { amplificación + } \\
\text { préstamo }\end{array}$ & Compuesta \\
\hline 296 & \begin{tabular}{|l|} 
Lonely \\
Planet \\
Andalucía \\
\end{tabular} & $\begin{array}{l}\text { puerta de los } \\
\text { príncipes }\end{array}$ & arquitectura & préstamo & Simple \\
\hline 297 & \begin{tabular}{|l|} 
Lonely \\
Planet \\
Andalucía \\
\end{tabular} & $\begin{array}{l}\text { virgen de la } \\
\text { sede }\end{array}$ & escultura & $\begin{array}{l}\text { amplificación + calco + } \\
\text { préstamo }\end{array}$ & Compuesta \\
\hline 298 & \begin{tabular}{|l} 
Lonely \\
Planet \\
Andalucía
\end{tabular} & capilla mayor & arquitectura & calco + préstamo & Compuesta \\
\hline 299 & \begin{tabular}{|l|} 
Lonely \\
Planet \\
Andalucía \\
\end{tabular} & capilla real & arquitectura & calco + préstamo & Compuesta \\
\hline 300 & \begin{tabular}{|l|} 
Lonely \\
Planet \\
Andalucía \\
\end{tabular} & $\begin{array}{l}\text { sacristía de } \\
\text { los cálices }\end{array}$ & arquitectura & calco + préstamo & Compuesta \\
\hline 301 & \begin{tabular}{|l|} 
Lonely \\
Planet \\
Andalucía
\end{tabular} & $\begin{array}{l}\text { santas justa y } \\
\text { rufina }\end{array}$ & pintura & $\begin{array}{l}\text { amplificación + } \\
\text { préstamo }\end{array}$ & Compuesta \\
\hline 302 & \begin{tabular}{|l|} 
Lonely \\
Planet \\
Andalucía \\
\end{tabular} & $\begin{array}{l}\text { descendimie } \\
\text { nto }\end{array}$ & pintura & $\begin{array}{l}\text { amplificación + } \\
\text { préstamo }\end{array}$ & Compuesta \\
\hline 303 & \begin{tabular}{|l|} 
Lonely \\
Planet \\
Andalucía
\end{tabular} & santa teresa & pintura & préstamo & Simple \\
\hline 304 & $\begin{array}{l}\text { Lonely } \\
\text { Planet } \\
\text { Andalucía }\end{array}$ & san fernando & escultura & $\begin{array}{l}\text { amplificación + } \\
\text { préstamo }\end{array}$ & Compuesta \\
\hline 305 & $\begin{array}{l}\text { Lonely } \\
\text { Planet } \\
\text { Andalucía }\end{array}$ & inmaculada & escultura & $\begin{array}{l}\text { amplificación + } \\
\text { préstamo }\end{array}$ & Compuesta \\
\hline 306 & \begin{tabular}{|l|} 
Lonely \\
Planet \\
Andalucía
\end{tabular} & sala capitular & arquitectura & $\begin{array}{l}\text { amplificación + } \\
\text { préstamo }\end{array}$ & Compuesta \\
\hline
\end{tabular}




\begin{tabular}{|c|c|c|c|c|c|}
\hline ID & \begin{tabular}{|l|} 
TíTULO \\
GUÍA
\end{tabular} & $\begin{array}{l}\text { ELEMENTO } \\
\text { DE ANÁLISIS }\end{array}$ & \begin{tabular}{|l|} 
CAMPO \\
SEMÁNTICO
\end{tabular} & $\begin{array}{l}\text { TÉCNICA } \\
\text { TRADUCCIÓN }\end{array}$ & $\begin{array}{l}\text { TIPO } \\
\text { TÉCNICA }\end{array}$ \\
\hline 307 & $\begin{array}{l}\text { Lonely } \\
\text { Planet } \\
\text { Andalucía }\end{array}$ & inmaculada & pintura & préstamo & Simple \\
\hline 308 & $\begin{array}{l}\text { Lonely } \\
\text { Planet } \\
\text { Andalucía }\end{array}$ & $\begin{array}{l}\text { patio de los } \\
\text { naranjos }\end{array}$ & arquitectura & $\begin{array}{l}\text { amplificación + } \\
\text { préstamo }\end{array}$ & Compuesta \\
\hline 309 & $\begin{array}{l}\text { Lonely } \\
\text { Planet } \\
\text { Andalucía }\end{array}$ & alcázar & arquitectura & $\begin{array}{l}\text { amplificación + } \\
\text { préstamo }\end{array}$ & Compuesta \\
\hline 310 & $\begin{array}{l}\text { Lonely } \\
\text { Planet } \\
\text { Andalucía } \\
\end{array}$ & $\begin{array}{l}\text { patio del } \\
\text { crucero }\end{array}$ & arquitectura & $\begin{array}{l}\text { amplificación + } \\
\text { préstamo }\end{array}$ & Compuesta \\
\hline 311 & $\begin{array}{l}\text { Lonely } \\
\text { Planet } \\
\text { Andalucía }\end{array}$ & $\begin{array}{l}\text { patio del } \\
\text { león }\end{array}$ & arquitectura & $\begin{array}{l}\text { amplificación + calco + } \\
\text { préstamo }\end{array}$ & Compuesta \\
\hline 312 & $\begin{array}{l}\text { Lonely } \\
\text { Planet } \\
\text { Andalucía }\end{array}$ & $\begin{array}{l}\text { puerta del } \\
\text { león }\end{array}$ & arquitectura & calco + préstamo & Compuesta \\
\hline 313 & $\begin{array}{l}\text { Lonely } \\
\text { Planet } \\
\text { Andalucía } \\
\end{array}$ & $\begin{array}{l}\text { sala de la } \\
\text { justicia }\end{array}$ & arquitectura & $\begin{array}{l}\text { amplificación + calco + } \\
\text { préstamo }\end{array}$ & Compuesta \\
\hline 314 & $\begin{array}{l}\text { Lonely } \\
\text { Planet } \\
\text { Andalucía } \\
\end{array}$ & artesonado & arquitectura & amplificación + calco & Compuesta \\
\hline 315 & $\begin{array}{l}\text { Lonely } \\
\text { Planet } \\
\text { Andalucía }\end{array}$ & $\begin{array}{l}\text { patio del } \\
\text { yeso }\end{array}$ & arquitectura & $\begin{array}{l}\text { amplificación + } \\
\text { préstamo }\end{array}$ & Compuesta \\
\hline 316 & $\begin{array}{l}\text { Lonely } \\
\text { Planet } \\
\text { Andalucía }\end{array}$ & $\begin{array}{l}\text { salón del } \\
\text { almirante }\end{array}$ & arquitectura & $\begin{array}{l}\text { amplificación + calco + } \\
\text { préstamo }\end{array}$ & Compuesta \\
\hline 317 & $\begin{array}{l}\text { Lonely } \\
\text { Planet } \\
\text { Andalucía }\end{array}$ & $\begin{array}{l}\text { sala de } \\
\text { audiencias }\end{array}$ & arquitectura & $\begin{array}{l}\text { amplificación + calco + } \\
\text { préstamo }\end{array}$ & Compuesta \\
\hline 318 & $\begin{array}{l}\text { Lonely } \\
\text { Planet } \\
\text { Andalucía }\end{array}$ & $\begin{array}{l}\text { virgen de los } \\
\text { mareantes }\end{array}$ & pintura & $\begin{array}{l}\text { calco + amplificación + } \\
\text { préstamo }\end{array}$ & Compuesta \\
\hline 319 & $\begin{array}{l}\text { Lonely } \\
\text { Planet } \\
\text { Andalucía }\end{array}$ & $\begin{array}{l}\text { patio de la } \\
\text { montería }\end{array}$ & arquitectura & $\begin{array}{l}\text { amplificación + } \\
\text { préstamo }\end{array}$ & Compuesta \\
\hline 320 & $\begin{array}{l}\text { Lonely } \\
\text { Planet } \\
\text { Andalucía }\end{array}$ & $\begin{array}{l}\text { patio de las } \\
\text { doncellas }\end{array}$ & arquitectura & $\begin{array}{l}\text { amplificación + calco + } \\
\text { préstamo }\end{array}$ & Compuesta \\
\hline
\end{tabular}




\begin{tabular}{|c|c|c|c|c|c|}
\hline ID & $\begin{array}{l}\text { TíTULO } \\
\text { GUÍA }\end{array}$ & $\begin{array}{l}\text { ELEMENTO } \\
\text { DE ANÁLISIS }\end{array}$ & $\begin{array}{l}\text { CAMPO } \\
\text { SEMÁNTICO }\end{array}$ & $\begin{array}{l}\text { TÉCNICA } \\
\text { TRADUCCIÓN }\end{array}$ & $\begin{array}{l}\text { TIPO } \\
\text { TÉCNICA }\end{array}$ \\
\hline 321 & $\begin{array}{l}\text { Lonely } \\
\text { Planet } \\
\text { Andalucía }\end{array}$ & $\begin{array}{l}\text { patio de las } \\
\text { muñecas }\end{array}$ & arquitectura & $\begin{array}{l}\text { amplificación + calco + } \\
\text { préstamo }\end{array}$ & Compuesta \\
\hline 322 & $\begin{array}{l}\text { Lonely } \\
\text { Planet } \\
\text { Andalucía }\end{array}$ & $\begin{array}{l}\text { salón de } \\
\text { embajadores }\end{array}$ & arquitectura & $\begin{array}{l}\text { amplificación + calco + } \\
\text { préstamo }\end{array}$ & Compuesta \\
\hline 323 & $\begin{array}{l}\text { Lonely } \\
\text { Planet } \\
\text { Andalucía }\end{array}$ & $\begin{array}{l}\text { sala de la } \\
\text { media } \\
\text { naranja }\end{array}$ & arquitectura & $\begin{array}{l}\text { amplificación + calco + } \\
\text { préstamo }\end{array}$ & Compuesta \\
\hline 324 & $\begin{array}{l}\text { Lonely } \\
\text { Planet } \\
\text { Andalucía } \\
\end{array}$ & $\begin{array}{l}\text { arco de } \\
\text { pavones }\end{array}$ & arquitectura & $\begin{array}{l}\text { amplificación + } \\
\text { préstamo }\end{array}$ & Compuesta \\
\hline 325 & $\begin{array}{l}\text { Lonely } \\
\text { Planet } \\
\text { Andalucía }\end{array}$ & $\begin{array}{l}\text { salón del } \\
\text { techo de } \\
\text { felipe II }\end{array}$ & arquitectura & $\begin{array}{l}\text { amplificación + } \\
\text { préstamo }\end{array}$ & Compuesta \\
\hline 326 & $\begin{array}{l}\text { Lonely } \\
\text { Planet } \\
\text { Andalucía }\end{array}$ & $\begin{array}{l}\text { sala de las } \\
\text { bóvedas }\end{array}$ & arquitectura & $\begin{array}{l}\text { amplificación + calco + } \\
\text { préstamo }\end{array}$ & Compuesta \\
\hline 327 & $\begin{array}{l}\text { Lonely } \\
\text { Planet } \\
\text { Andalucía } \\
\end{array}$ & $\begin{array}{l}\text { patio del } \\
\text { crucero }\end{array}$ & arquitectura & $\begin{array}{l}\text { amplificación + } \\
\text { préstamo }\end{array}$ & Compuesta \\
\hline 328 & $\begin{array}{l}\text { Lonely } \\
\text { Planet } \\
\text { Andalucía } \\
\end{array}$ & $\begin{array}{l}\text { jardín de las } \\
\text { danzas }\end{array}$ & $\begin{array}{l}\text { paisaje y } \\
\text { geografía }\end{array}$ & calco + préstamo & Compuesta \\
\hline 329 & $\begin{array}{l}\text { Lonely } \\
\text { Planet } \\
\text { Andalucía }\end{array}$ & $\begin{array}{l}\text { baños de } \\
\text { doña maria } \\
\text { de padilla }\end{array}$ & arquitectura & $\begin{array}{l}\text { amplificación + calco + } \\
\text { préstamo }\end{array}$ & Compuesta \\
\hline 330 & $\begin{array}{l}\text { Lonely } \\
\text { Planet } \\
\text { Andalucía }\end{array}$ & $\begin{array}{l}\text { patio de las } \\
\text { banderas }\end{array}$ & arquitectura & calco + préstamo & Compuesta \\
\hline 331 & $\begin{array}{l}\text { Lonely } \\
\text { Planet } \\
\text { Andalucía }\end{array}$ & torre del oro & arquitectura & $\begin{array}{l}\text { amplificación + calco + } \\
\text { préstamo }\end{array}$ & Compuesta \\
\hline 332 & $\begin{array}{l}\text { Lonely } \\
\text { Planet } \\
\text { Andalucía }\end{array}$ & caña & $\begin{array}{l}\text { gastronomía y } \\
\text { restauración }\end{array}$ & $\begin{array}{l}\text { amplificación + } \\
\text { préstamo }\end{array}$ & Compuesta \\
\hline 333 & $\begin{array}{l}\text { Lonely } \\
\text { Planet } \\
\text { Andalucía } \\
\end{array}$ & $\begin{array}{l}\text { archivo de } \\
\text { indias }\end{array}$ & arquitectura & $\begin{array}{l}\text { amplificación + calco + } \\
\text { préstamo }\end{array}$ & Compuesta \\
\hline 334 & $\begin{array}{l}\text { Lonely } \\
\text { Planet } \\
\text { Andalucía }\end{array}$ & judería & arquitectura & $\begin{array}{l}\text { equivalente acuñado + } \\
\text { préstamo }\end{array}$ & Compuesta \\
\hline
\end{tabular}




\begin{tabular}{|c|c|c|c|c|c|}
\hline ID & $\begin{array}{l}\text { TíTULO } \\
\text { GUÍA }\end{array}$ & $\begin{array}{l}\text { ELEMENTO } \\
\text { DE ANÁLISIS }\end{array}$ & $\begin{array}{l}\text { CAMPO } \\
\text { SEMÁNTICO }\end{array}$ & $\begin{array}{l}\text { TÉCNICA } \\
\text { TRADUCCIÓN }\end{array}$ & $\begin{array}{l}\text { TIPO } \\
\text { TÉCNICA }\end{array}$ \\
\hline 335 & $\begin{array}{l}\text { Lonely } \\
\text { Planet } \\
\text { Andalucía }\end{array}$ & $\begin{array}{l}\text { casa de la } \\
\text { memoria de } \\
\text { al-andalus }\end{array}$ & arquitectura & $\begin{array}{l}\text { amplificación + } \\
\text { préstamo }\end{array}$ & Compuesta \\
\hline 336 & $\begin{array}{l}\text { Lonely } \\
\text { Planet } \\
\text { Andalucía }\end{array}$ & anunciación & pintura & $\begin{array}{l}\text { equivalente acuñado + } \\
\text { préstamo }\end{array}$ & Compuesta \\
\hline 337 & $\begin{array}{l}\text { Lonely } \\
\text { Planet } \\
\text { Andalucía }\end{array}$ & $\begin{array}{l}\text { san juan de } \\
\text { dios }\end{array}$ & pintura & $\begin{array}{l}\text { equivalente acuñado + } \\
\text { préstamo }\end{array}$ & Compuesta \\
\hline 338 & $\begin{array}{l}\text { Lonely } \\
\text { Planet } \\
\text { Andalucía } \\
\end{array}$ & $\begin{array}{l}\text { santa isabel } \\
\text { de hungría }\end{array}$ & pintura & calco + préstamo & Compuesta \\
\hline 339 & $\begin{array}{l}\text { Lonely } \\
\text { Planet } \\
\text { Andalucía }\end{array}$ & $\begin{array}{l}\text { plaza de } \\
\text { toros }\end{array}$ & $\begin{array}{l}\text { fiestas y } \\
\text { espectáculos }\end{array}$ & $\begin{array}{l}\text { amplificación + } \\
\text { equivalente acuñado + } \\
\text { préstamo }\end{array}$ & Compuesta \\
\hline 340 & $\begin{array}{l}\text { Lonely } \\
\text { Planet } \\
\text { Andalucía } \\
\end{array}$ & $\begin{array}{l}\text { hermandad } \\
\text { de la quinta } \\
\text { angustia }\end{array}$ & $\begin{array}{l}\text { fiestas y } \\
\text { espectáculos }\end{array}$ & $\begin{array}{l}\text { equivalente acuñado + } \\
\text { préstamo }\end{array}$ & Compuesta \\
\hline 341 & $\begin{array}{l}\text { Lonely } \\
\text { Planet } \\
\text { Andalucía } \\
\end{array}$ & $\begin{array}{l}\text { cristo del } \\
\text { calvario }\end{array}$ & pintura & calco + préstamo & Compuesta \\
\hline 342 & $\begin{array}{l}\text { Lonely } \\
\text { Planet } \\
\text { Andalucía } \\
\end{array}$ & $\begin{array}{l}\text { descendimie } \\
\text { nto }\end{array}$ & escultura & $\begin{array}{l}\text { amplificación + } \\
\text { préstamo }\end{array}$ & Compuesta \\
\hline 343 & $\begin{array}{l}\text { Lonely } \\
\text { Planet } \\
\text { Andalucía } \\
\end{array}$ & $\begin{array}{l}\text { las ánimas } \\
\text { del } \\
\text { purgatorio }\end{array}$ & pintura & calco + préstamo & Compuesta \\
\hline 344 & $\begin{array}{l}\text { Lonely } \\
\text { Planet } \\
\text { Andalucía } \\
\end{array}$ & $\begin{array}{l}\text { la sagrada } \\
\text { cena }\end{array}$ & pintura & $\begin{array}{l}\text { equivalente acuñado + } \\
\text { préstamo }\end{array}$ & Compuesta \\
\hline 345 & $\begin{array}{l}\text { Lonely } \\
\text { Planet } \\
\text { Andalucía }\end{array}$ & $\begin{array}{l}\text { inmaculada } \\
\text { concepcion } \\
\text { grande }\end{array}$ & pintura & préstamo & Simple \\
\hline 346 & $\begin{array}{l}\text { Lonely } \\
\text { Planet } \\
\text { Andalucía }\end{array}$ & $\begin{array}{l}\text { santiago } \\
\text { apóstol }\end{array}$ & pintura & $\begin{array}{l}\text { equivalente acuñado + } \\
\text { préstamo }\end{array}$ & Compuesta \\
\hline 347 & $\begin{array}{l}\text { Lonely } \\
\text { Planet } \\
\text { Andalucía } \\
\end{array}$ & $\begin{array}{l}\text { cristo } \\
\text { crucificado }\end{array}$ & pintura & $\begin{array}{l}\text { amplificación }+ \\
\text { equivalente acuñado + } \\
\text { préstamo }\end{array}$ & Compuesta \\
\hline 348 & $\begin{array}{l}\text { Lonely } \\
\text { Planet } \\
\text { Andalucía }\end{array}$ & $\begin{array}{l}\text { visita de s. } \\
\text { bruno a } \\
\text { urbano II }\end{array}$ & pintura & $\begin{array}{l}\text { amplificación + } \\
\text { préstamo }\end{array}$ & Compuesta \\
\hline
\end{tabular}




\begin{tabular}{|c|c|c|c|c|c|}
\hline ID & $\begin{array}{l}\text { TíTULO } \\
\text { GUÍA }\end{array}$ & $\begin{array}{l}\text { ELEMENTO } \\
\text { DE ANÁLISIS }\end{array}$ & $\begin{array}{l}\text { CAMPO } \\
\text { SEMÁNTICO }\end{array}$ & $\begin{array}{l}\text { TÉCNICA } \\
\text { TRADUCCIÓN }\end{array}$ & $\begin{array}{l}\text { TIPO } \\
\text { TÉCNICA }\end{array}$ \\
\hline 349 & $\begin{array}{l}\text { Lonely } \\
\text { Planet } \\
\text { Andalucía }\end{array}$ & $\begin{array}{l}\text { retrato de } \\
\text { don josé } \\
\text { duaso }\end{array}$ & pintura & $\begin{array}{l}\text { amplificación + calco + } \\
\text { préstamo }\end{array}$ & Compuesta \\
\hline 350 & $\begin{array}{l}\text { Lonely } \\
\text { Planet } \\
\text { Andalucía }\end{array}$ & $\begin{array}{l}\text { casa de } \\
\text { pilatos }\end{array}$ & arquitectura & $\begin{array}{l}\text { amplificación + } \\
\text { préstamo }\end{array}$ & Compuesta \\
\hline 351 & $\begin{array}{l}\text { Lonely } \\
\text { Planet } \\
\text { Andalucía }\end{array}$ & via crucis & $\begin{array}{l}\text { fiestas y } \\
\text { espectáculos }\end{array}$ & $\begin{array}{l}\text { equivalente acuñado + } \\
\text { préstamo }\end{array}$ & Compuesta \\
\hline 352 & $\begin{array}{l}\text { Lonely } \\
\text { Planet } \\
\text { Andalucía }\end{array}$ & $\begin{array}{l}\text { patio } \\
\text { principal }\end{array}$ & arquitectura & préstamo & Simple \\
\hline 353 & $\begin{array}{l}\text { Lonely } \\
\text { Planet } \\
\text { Andalucía }\end{array}$ & $\begin{array}{l}\text { descanso de } \\
\text { los jueces }\end{array}$ & arquitectura & calco + préstamo & Compuesta \\
\hline 354 & $\begin{array}{l}\text { Lonely } \\
\text { Planet } \\
\text { Andalucía }\end{array}$ & $\begin{array}{l}\text { salón } \\
\text { pretorio }\end{array}$ & arquitectura & calco + préstamo & Compuesta \\
\hline 355 & $\begin{array}{l}\text { Lonely } \\
\text { Planet } \\
\text { Andalucía } \\
\end{array}$ & jardín grande & $\begin{array}{l}\text { paisaje y } \\
\text { geografía }\end{array}$ & calco + préstamo & Compuesta \\
\hline 356 & $\begin{array}{l}\text { Lonely } \\
\text { Planet } \\
\text { Andalucía } \\
\end{array}$ & $\begin{array}{l}\text { cristo del } \\
\text { cachorro }\end{array}$ & escultura & $\begin{array}{l}\text { amplificación + calco + } \\
\text { préstamo }\end{array}$ & Compuesta \\
\hline 357 & \begin{tabular}{|l} 
Lonely \\
Planet \\
Andalucía
\end{tabular} & $\begin{array}{l}\text { hermandad } \\
\text { del rocío de } \\
\text { triana }\end{array}$ & $\begin{array}{l}\text { fiestas y } \\
\text { espectáculos }\end{array}$ & préstamo & Simple \\
\hline 358 & \begin{tabular}{|l} 
Lonely \\
Planet \\
Andalucía
\end{tabular} & procesión & $\begin{array}{l}\text { fiestas y } \\
\text { espectáculos }\end{array}$ & amplificación + calco & Compuesta \\
\hline 359 & $\begin{array}{l}\text { Lonely } \\
\text { Planet } \\
\text { Andalucía }\end{array}$ & $\begin{array}{l}\text { virgen de la } \\
\text { esperanza }\end{array}$ & $\begin{array}{l}\text { fiestas y } \\
\text { espectáculos }\end{array}$ & $\begin{array}{l}\text { amplificación + calco + } \\
\text { préstamo }\end{array}$ & Compuesta \\
\hline 360 & $\begin{array}{l}\text { Lonely } \\
\text { Planet } \\
\text { Andalucía }\end{array}$ & $\begin{array}{l}\text { semana } \\
\text { santa }\end{array}$ & $\begin{array}{l}\text { fiestas y } \\
\text { espectáculos }\end{array}$ & préstamo & Simple \\
\hline 361 & $\begin{array}{l}\text { Lonely } \\
\text { Planet } \\
\text { Andalucía } \\
\end{array}$ & el negro & $\begin{array}{l}\text { fiestas y } \\
\text { espectáculos }\end{array}$ & $\begin{array}{l}\text { amplificación + } \\
\text { préstamo }\end{array}$ & Compuesta \\
\hline 362 & \begin{tabular}{|l} 
Lonely \\
Planet \\
Andalucía
\end{tabular} & $\begin{array}{l}\text { virgen de la } \\
\text { macarena }\end{array}$ & $\begin{array}{l}\text { fiestas y } \\
\text { espectáculos }\end{array}$ & $\begin{array}{l}\text { amplificación + calco + } \\
\text { préstamo }\end{array}$ & Compuesta \\
\hline
\end{tabular}




\begin{tabular}{|c|c|c|c|c|c|}
\hline ID & \begin{tabular}{|l|} 
TÍTULO \\
GUÍA
\end{tabular} & $\begin{array}{l}\text { ELEMENTO } \\
\text { DE ANÁLISIS }\end{array}$ & \begin{tabular}{|l|} 
CAMPO \\
SEMÁNTICO
\end{tabular} & $\begin{array}{l}\text { TÉCNICA } \\
\text { TRADUCCIÓN }\end{array}$ & $\begin{array}{l}\text { TIPO } \\
\text { TÉCNICA }\end{array}$ \\
\hline 363 & \begin{tabular}{|l} 
Lonely \\
Planet \\
Andalucía
\end{tabular} & torero & $\begin{array}{l}\text { fiestas y } \\
\text { espectáculos }\end{array}$ & equivalente acuñado & Simple \\
\hline 364 & $\begin{array}{l}\text { Lonely } \\
\text { Planet } \\
\text { Andalucía }\end{array}$ & madrugá & $\begin{array}{l}\text { fiestas y } \\
\text { espectáculos }\end{array}$ & $\begin{array}{l}\text { generalización + } \\
\text { préstamo }\end{array}$ & Compuesta \\
\hline 365 & $\begin{array}{l}\text { Lonely } \\
\text { Planet } \\
\text { Andalucía }\end{array}$ & saeta & $\begin{array}{l}\text { fiestas y } \\
\text { espectáculos }\end{array}$ & $\begin{array}{l}\text { amplificación + } \\
\text { préstamo }\end{array}$ & Compuesta \\
\hline 366 & \begin{tabular}{|l|} 
Lonely \\
Planet \\
Andalucía \\
\end{tabular} & $\begin{array}{l}\text { cristo de la } \\
\text { sentencia }\end{array}$ & $\begin{array}{l}\text { fiestas y } \\
\text { espectáculos }\end{array}$ & calco + préstamo & Compuesta \\
\hline 367 & \begin{tabular}{|l} 
Lonely \\
Planet \\
Andalucía
\end{tabular} & paso & $\begin{array}{l}\text { fiestas y } \\
\text { espectáculos }\end{array}$ & $\begin{array}{l}\text { amplificación + } \\
\text { préstamo }\end{array}$ & Compuesta \\
\hline 368 & \begin{tabular}{|l|} 
Lonely \\
Planet \\
Andalucía \\
\end{tabular} & procesión & $\begin{array}{l}\text { fiestas y } \\
\text { espectáculos }\end{array}$ & calco & Simple \\
\hline 369 & \begin{tabular}{|l|} 
Lonely \\
Planet \\
Andalucía \\
\end{tabular} & feria de abril & $\begin{array}{l}\text { fiestas y } \\
\text { espectáculos }\end{array}$ & $\begin{array}{l}\text { amplificación + calco + } \\
\text { préstamo }\end{array}$ & Compuesta \\
\hline 370 & \begin{tabular}{|l|} 
Lonely \\
Planet \\
Andalucía \\
\end{tabular} & cofradía & $\begin{array}{l}\text { fiestas y } \\
\text { espectáculos }\end{array}$ & $\begin{array}{l}\text { equivalente acuñado + } \\
\text { préstamo }\end{array}$ & Compuesta \\
\hline 371 & \begin{tabular}{|l|} 
Lonely \\
Planet \\
Andalucía
\end{tabular} & hermandad & \begin{tabular}{|l|} 
fiestas y \\
espectáculos
\end{tabular} & $\begin{array}{l}\text { equivalente acuñado + } \\
\text { préstamo }\end{array}$ & Compuesta \\
\hline 372 & \begin{tabular}{|l|} 
Lonely \\
Planet \\
Andalucía
\end{tabular} & paso & $\begin{array}{l}\text { fiestas y } \\
\text { espectáculos }\end{array}$ & $\begin{array}{l}\text { amplificación + } \\
\text { préstamo }\end{array}$ & Compuesta \\
\hline 373 & \begin{tabular}{|l} 
Lonely \\
Planet \\
Andalucía
\end{tabular} & costalero & $\begin{array}{l}\text { fiestas y } \\
\text { espectáculos }\end{array}$ & $\begin{array}{l}\text { amplificación + } \\
\text { préstamo }\end{array}$ & Compuesta \\
\hline 374 & \begin{tabular}{|l} 
Lonely \\
Planet \\
Andalucía
\end{tabular} & capataz & $\begin{array}{l}\text { fiestas y } \\
\text { espectáculos }\end{array}$ & $\begin{array}{l}\text { amplificación + } \\
\text { préstamo }\end{array}$ & Compuesta \\
\hline 375 & \begin{tabular}{|l|} 
Lonely \\
Planet \\
Andalucía \\
\end{tabular} & nazarenos & $\begin{array}{l}\text { fiestas y } \\
\text { espectáculos }\end{array}$ & $\begin{array}{l}\text { amplificación + } \\
\text { préstamo }\end{array}$ & Compuesta \\
\hline 376 & \begin{tabular}{|l} 
Lonely \\
Planet \\
Andalucía
\end{tabular} & corral & arquitectura & $\begin{array}{l}\text { amplificación + } \\
\text { préstamo }\end{array}$ & Compuesta \\
\hline
\end{tabular}




\begin{tabular}{|c|c|c|c|c|c|}
\hline ID & \begin{tabular}{|l|} 
TÍTULO \\
GUÍA
\end{tabular} & $\begin{array}{l}\text { ELEMENTO } \\
\text { DE ANÁLISIS }\end{array}$ & \begin{tabular}{|l|} 
CAMPO \\
SEMÁNTICO \\
\end{tabular} & \begin{tabular}{|l|} 
TÉCNICA \\
TRADUCCIÓN
\end{tabular} & $\begin{array}{l}\text { TIPO } \\
\text { TÉCNICA }\end{array}$ \\
\hline 377 & \begin{tabular}{|l} 
Lonely \\
Planet \\
Andalucía
\end{tabular} & gazpacho & $\begin{array}{l}\text { gastronomía y } \\
\text { restauración }\end{array}$ & préstamo & Simple \\
\hline 378 & $\begin{array}{l}\text { Lonely } \\
\text { Planet } \\
\text { Andalucía }\end{array}$ & manzanilla & $\begin{array}{l}\text { gastronomía y } \\
\text { restauración }\end{array}$ & préstamo & Simple \\
\hline 379 & \begin{tabular}{|l} 
Lonely \\
Planet \\
Andalucía
\end{tabular} & salmorejo & $\begin{array}{l}\text { gastronomía y } \\
\text { restauración }\end{array}$ & $\begin{array}{l}\text { amplificación + } \\
\text { préstamo }\end{array}$ & Compuesta \\
\hline 380 & \begin{tabular}{|l|} 
Lonely \\
Planet \\
Andalucía \\
\end{tabular} & $\begin{array}{l}\text { pechuga } \\
\text { bechamel }\end{array}$ & $\begin{array}{l}\text { gastronomía y } \\
\text { restauración }\end{array}$ & $\begin{array}{l}\text { amplificación + } \\
\text { préstamo }\end{array}$ & Compuesta \\
\hline 381 & \begin{tabular}{|l|} 
Lonely \\
Planet \\
Andalucía \\
\end{tabular} & $\begin{array}{l}\text { tortilla de } \\
\text { patata }\end{array}$ & $\begin{array}{l}\text { gastronomía y } \\
\text { restauración }\end{array}$ & $\begin{array}{l}\text { amplificación + } \\
\text { préstamo }\end{array}$ & Compuesta \\
\hline 382 & \begin{tabular}{|l|} 
Lonely \\
Planet \\
Andalucía \\
\end{tabular} & jamón & $\begin{array}{l}\text { gastronomía y } \\
\text { restauración }\end{array}$ & préstamo & Simple \\
\hline 383 & \begin{tabular}{|l|} 
Lonely \\
Planet \\
Andalucía \\
\end{tabular} & ración & $\begin{array}{l}\text { gastronomía y } \\
\text { restauración }\end{array}$ & $\begin{array}{l}\text { amplificación + } \\
\text { préstamo }\end{array}$ & Compuesta \\
\hline 384 & \begin{tabular}{|l|} 
Lonely \\
Planet \\
Andalucía \\
\end{tabular} & caldereta & $\begin{array}{l}\text { gastronomía y } \\
\text { restauración }\end{array}$ & $\begin{array}{l}\text { amplificación + } \\
\text { préstamo }\end{array}$ & Compuesta \\
\hline 385 & \begin{tabular}{|l|} 
Lonely \\
Planet \\
Andalucía
\end{tabular} & chorizo & $\begin{array}{l}\text { gastronomía y } \\
\text { restauración }\end{array}$ & préstamo & Simple \\
\hline 386 & \begin{tabular}{|l|} 
Lonely \\
Planet \\
Andalucía
\end{tabular} & $\begin{array}{l}\text { jamón de } \\
\text { jabugo }\end{array}$ & $\begin{array}{l}\text { gastronomía y } \\
\text { restauración }\end{array}$ & $\begin{array}{l}\text { amplificación + calco + } \\
\text { préstamo }\end{array}$ & Compuesta \\
\hline 387 & \begin{tabular}{|l} 
Lonely \\
Planet \\
Andalucía
\end{tabular} & serranito & $\begin{array}{l}\text { gastronomía y } \\
\text { restauración }\end{array}$ & $\begin{array}{l}\text { amplificación + } \\
\text { préstamo }\end{array}$ & Compuesta \\
\hline 388 & \begin{tabular}{|l} 
Lonely \\
Planet \\
Andalucía
\end{tabular} & bocadillo & $\begin{array}{l}\text { gastronomía y } \\
\text { restauración }\end{array}$ & $\begin{array}{l}\text { adaptación + } \\
\text { préstamo }\end{array}$ & Compuesta \\
\hline 389 & \begin{tabular}{|l|} 
Lonely \\
Planet \\
Andalucía \\
\end{tabular} & yema & $\begin{array}{l}\text { gastronomía y } \\
\text { restauración }\end{array}$ & $\begin{array}{l}\text { amplificación + } \\
\text { préstamo }\end{array}$ & Compuesta \\
\hline 390 & \begin{tabular}{|l} 
Lonely \\
Planet \\
Andalucía
\end{tabular} & nata & $\begin{array}{l}\text { gastronomía y } \\
\text { restauración }\end{array}$ & $\begin{array}{l}\text { amplificación + } \\
\text { préstamo }\end{array}$ & Compuesta \\
\hline
\end{tabular}




\begin{tabular}{|c|c|c|c|c|c|}
\hline ID & \begin{tabular}{|l|} 
TíTULO \\
GUÍA
\end{tabular} & $\begin{array}{l}\text { ELEMENTO } \\
\text { DE ANÁLISIS }\end{array}$ & \begin{tabular}{|l|} 
CAMPO \\
SEMÁNTICO
\end{tabular} & $\begin{array}{l}\text { TÉCNICA } \\
\text { TRADUCCIÓN }\end{array}$ & $\begin{array}{l}\text { TIPO } \\
\text { TÉCNICA }\end{array}$ \\
\hline 391 & $\begin{array}{l}\text { Lonely } \\
\text { Planet } \\
\text { Andalucía }\end{array}$ & bocadillo & $\begin{array}{l}\text { gastronomía y } \\
\text { restauración }\end{array}$ & préstamo & Simple \\
\hline 392 & $\begin{array}{l}\text { Lonely } \\
\text { Planet } \\
\text { Andalucía }\end{array}$ & $\begin{array}{l}\text { jamón } \\
\text { serrano }\end{array}$ & $\begin{array}{l}\text { gastronomía y } \\
\text { restauración }\end{array}$ & $\begin{array}{l}\text { amplificación + } \\
\text { préstamo }\end{array}$ & Compuesta \\
\hline 393 & $\begin{array}{l}\text { Lonely } \\
\text { Planet } \\
\text { Andalucía }\end{array}$ & $\begin{array}{l}\text { churros con } \\
\text { chocolate }\end{array}$ & $\begin{array}{l}\text { gastronomía y } \\
\text { restauración }\end{array}$ & $\begin{array}{l}\text { amplificación + } \\
\text { préstamo }\end{array}$ & Compuesta \\
\hline 394 & $\begin{array}{l}\text { Lonely } \\
\text { Planet } \\
\text { Andalucía }\end{array}$ & jamón & $\begin{array}{l}\text { gastronomía y } \\
\text { restauración }\end{array}$ & préstamo & Simple \\
\hline 395 & $\begin{array}{l}\text { Lonely } \\
\text { Planet } \\
\text { Andalucía }\end{array}$ & bocadillo & $\begin{array}{l}\text { gastronomía y } \\
\text { restauración }\end{array}$ & préstamo & Simple \\
\hline 396 & $\begin{array}{l}\text { Lonely } \\
\text { Planet } \\
\text { Andalucía }\end{array}$ & pringá & $\begin{array}{l}\text { gastronomía y } \\
\text { restauración }\end{array}$ & $\begin{array}{l}\text { amplificación + } \\
\text { préstamo }\end{array}$ & Compuesta \\
\hline 397 & $\begin{array}{l}\text { Lonely } \\
\text { Planet } \\
\text { Andalucía } \\
\end{array}$ & $\begin{array}{l}\text { solomillo } \\
\text { ibérico }\end{array}$ & $\begin{array}{l}\text { gastronomía y } \\
\text { restauración }\end{array}$ & $\begin{array}{l}\text { amplificación + } \\
\text { préstamo }\end{array}$ & Compuesta \\
\hline 398 & $\begin{array}{l}\text { Lonely } \\
\text { Planet } \\
\text { Andalucía } \\
\end{array}$ & fino & $\begin{array}{l}\text { gastronomía y } \\
\text { restauración }\end{array}$ & préstamo & Simple \\
\hline 399 & $\begin{array}{l}\text { Lonely } \\
\text { Planet } \\
\text { Andalucía }\end{array}$ & revuelto & $\begin{array}{l}\text { gastronomía y } \\
\text { restauración }\end{array}$ & $\begin{array}{l}\text { equivalente acuñado + } \\
\text { préstamo }\end{array}$ & Compuesta \\
\hline 400 & $\begin{array}{l}\text { Lonely } \\
\text { Planet } \\
\text { Andalucía }\end{array}$ & ropa vieja & $\begin{array}{l}\text { gastronomía y } \\
\text { restauración }\end{array}$ & $\begin{array}{l}\text { calco + amplificación + } \\
\text { préstamo }\end{array}$ & Compuesta \\
\hline 401 & $\begin{array}{l}\text { Lonely } \\
\text { Planet } \\
\text { Andalucía }\end{array}$ & albóndigas & $\begin{array}{l}\text { gastronomía y } \\
\text { restauración }\end{array}$ & $\begin{array}{l}\text { amplificación + } \\
\text { préstamo }\end{array}$ & Compuesta \\
\hline 402 & $\begin{array}{l}\text { Lonely } \\
\text { Planet } \\
\text { Andalucía }\end{array}$ & $\begin{array}{l}\text { gambas al } \\
\text { ajillo }\end{array}$ & $\begin{array}{l}\text { gastronomía y } \\
\text { restauración }\end{array}$ & calco + préstamo & Compuesta \\
\hline 403 & $\begin{array}{l}\text { Lonely } \\
\text { Planet } \\
\text { Andalucía } \\
\end{array}$ & $\begin{array}{l}\text { pescadito } \\
\text { frito }\end{array}$ & $\begin{array}{l}\text { gastronomía y } \\
\text { restauración }\end{array}$ & calco + préstamo & Compuesta \\
\hline 404 & $\begin{array}{l}\text { Lonely } \\
\text { Planet } \\
\text { Andalucía }\end{array}$ & pisto & $\begin{array}{l}\text { gastronomía y } \\
\text { restauración }\end{array}$ & $\begin{array}{l}\text { adaptación + } \\
\text { préstamo }\end{array}$ & Compuesta \\
\hline
\end{tabular}




\begin{tabular}{|c|c|c|c|c|c|}
\hline ID & \begin{tabular}{|l|} 
TíTULO \\
GUÍA
\end{tabular} & $\begin{array}{l}\text { ELEMENTO } \\
\text { DE ANÁLISIS }\end{array}$ & \begin{tabular}{|l|} 
CAMPO \\
SEMÁNTICO
\end{tabular} & $\begin{array}{l}\text { TÉCNICA } \\
\text { TRADUCCIÓN }\end{array}$ & $\begin{array}{l}\text { TIPO } \\
\text { TÉCNICA }\end{array}$ \\
\hline 405 & $\begin{array}{l}\text { Lonely } \\
\text { Planet } \\
\text { Andalucía }\end{array}$ & novillada & $\begin{array}{l}\text { fiestas y } \\
\text { espectáculos }\end{array}$ & $\begin{array}{l}\text { amplificación + } \\
\text { préstamo }\end{array}$ & Compuesta \\
\hline 406 & $\begin{array}{l}\text { Lonely } \\
\text { Planet } \\
\text { Andalucía }\end{array}$ & $\begin{array}{l}\text { traje de } \\
\text { flamenca }\end{array}$ & artesanía & calco + préstamo & Compuesta \\
\hline 407 & $\begin{array}{l}\text { Lonely } \\
\text { Planet } \\
\text { Andalucía }\end{array}$ & $\begin{array}{l}\text { guzmán el } \\
\text { bueno }\end{array}$ & historia & $\begin{array}{l}\text { amplificación + } \\
\text { préstamo }\end{array}$ & Compuesta \\
\hline 408 & $\begin{array}{l}\text { Lonely } \\
\text { Planet } \\
\text { Andalucía }\end{array}$ & $\begin{array}{l}\text { patio de los } \\
\text { evangelistas }\end{array}$ & $\begin{array}{l}\text { paisaje y } \\
\text { geografía }\end{array}$ & préstamo & Simple \\
\hline 409 & $\begin{array}{l}\text { Lonely } \\
\text { Planet } \\
\text { Andalucía }\end{array}$ & $\begin{array}{l}\text { queso } \\
\text { manchego }\end{array}$ & $\begin{array}{l}\text { gastronomía y } \\
\text { restauración }\end{array}$ & calco + préstamo & Compuesta \\
\hline 410 & $\begin{array}{l}\text { Lonely } \\
\text { Planet } \\
\text { Andalucía }\end{array}$ & $\begin{array}{l}\text { fuente el } \\
\text { chorrillo }\end{array}$ & arquitectura & calco + préstamo & Compuesta \\
\hline 411 & $\begin{array}{l}\text { Lonely } \\
\text { Planet } \\
\text { Andalucía } \\
\end{array}$ & $\begin{array}{l}\text { puente de los } \\
\text { tres ojos }\end{array}$ & arquitectura & $\begin{array}{l}\text { amplificación + } \\
\text { préstamo }\end{array}$ & Compuesta \\
\hline 412 & $\begin{array}{l}\text { Lonely } \\
\text { Planet } \\
\text { Andalucía } \\
\end{array}$ & $\begin{array}{l}\text { puente del } \\
\text { castillejo }\end{array}$ & arquitectura & $\begin{array}{l}\text { amplificación + } \\
\text { préstamo }\end{array}$ & Compuesta \\
\hline 413 & $\begin{array}{l}\text { Lonely } \\
\text { Planet } \\
\text { Andalucía }\end{array}$ & sevillanas & \begin{tabular}{|l|} 
fiestas y \\
espectáculos
\end{tabular} & $\begin{array}{l}\text { amplificación + } \\
\text { préstamo }\end{array}$ & Compuesta \\
\hline 414 & $\begin{array}{l}\text { Lonely } \\
\text { Planet } \\
\text { Andalucía }\end{array}$ & $\begin{array}{l}\text { hospedería } \\
\text { de la cartuja }\end{array}$ & alojamiento & $\begin{array}{l}\text { amplificación + } \\
\text { préstamo }\end{array}$ & Compuesta \\
\hline 415 & $\begin{array}{l}\text { Lonely } \\
\text { Planet } \\
\text { Andalucía }\end{array}$ & anisado & $\begin{array}{l}\text { gastronomía y } \\
\text { restauración }\end{array}$ & $\begin{array}{l}\text { amplificación + } \\
\text { préstamo }\end{array}$ & Compuesta \\
\hline 416 & $\begin{array}{l}\text { Lonely } \\
\text { Planet } \\
\text { Andalucía }\end{array}$ & guinda & $\begin{array}{l}\text { gastronomía y } \\
\text { restauración }\end{array}$ & $\begin{array}{l}\text { equivalente acuñado + } \\
\text { préstamo }\end{array}$ & Compuesta \\
\hline 417 & $\begin{array}{l}\text { Lonely } \\
\text { Planet } \\
\text { Andalucía } \\
\end{array}$ & la manquita & arquitectura & $\begin{array}{l}\text { amplificación + calco + } \\
\text { préstamo }\end{array}$ & Compuesta \\
\hline 418 & $\begin{array}{l}\text { Lonely } \\
\text { Planet } \\
\text { Andalucía }\end{array}$ & $\begin{array}{l}\text { palacio } \\
\text { episcopal }\end{array}$ & arquitectura & calco + préstamo & Compuesta \\
\hline
\end{tabular}




\begin{tabular}{|c|c|c|c|c|c|}
\hline ID & \begin{tabular}{|l|} 
TíTULO \\
GUÍA
\end{tabular} & $\begin{array}{l}\text { ELEMENTO } \\
\text { DE ANÁLISIS }\end{array}$ & \begin{tabular}{|l|} 
CAMPO \\
SEMÁNTICO
\end{tabular} & $\begin{array}{l}\text { TÉCNICA } \\
\text { TRADUCCIÓN }\end{array}$ & $\begin{array}{l}\text { TIPO } \\
\text { TÉCNICA }\end{array}$ \\
\hline 419 & $\begin{array}{l}\text { Lonely } \\
\text { Planet } \\
\text { Andalucía }\end{array}$ & $\begin{array}{l}\text { palacio de los } \\
\text { condes de } \\
\text { buenavista }\end{array}$ & arquitectura & $\begin{array}{l}\text { amplificación + } \\
\text { préstamo }\end{array}$ & Compuesta \\
\hline 420 & $\begin{array}{l}\text { Lonely } \\
\text { Planet } \\
\text { Andalucía }\end{array}$ & costa del sol & $\begin{array}{l}\text { paisaje y } \\
\text { geografía }\end{array}$ & préstamo & Simple \\
\hline 421 & $\begin{array}{l}\text { Lonely } \\
\text { Planet } \\
\text { Andalucía }\end{array}$ & alcazaba & arquitectura & $\begin{array}{l}\text { amplificación + } \\
\text { préstamo }\end{array}$ & Compuesta \\
\hline 422 & $\begin{array}{l}\text { Lonely } \\
\text { Planet } \\
\text { Andalucía } \\
\end{array}$ & $\begin{array}{l}\text { museo } \\
\text { militar }\end{array}$ & arquitectura & calco & Simple \\
\hline 423 & $\begin{array}{l}\text { Lonely } \\
\text { Planet } \\
\text { Andalucía }\end{array}$ & $\begin{array}{l}\text { olga } \\
\text { kokhlova con } \\
\text { mantilla }\end{array}$ & pintura & calco & Simple \\
\hline 424 & $\begin{array}{l}\text { Lonely } \\
\text { Planet } \\
\text { Andalucía } \\
\end{array}$ & $\begin{array}{l}\text { alameda } \\
\text { principal }\end{array}$ & $\begin{array}{l}\text { paisaje y } \\
\text { geografía }\end{array}$ & $\begin{array}{l}\text { amplificación + } \\
\text { préstamo }\end{array}$ & Compuesta \\
\hline 425 & $\begin{array}{l}\text { Lonely } \\
\text { Planet } \\
\text { Andalucía } \\
\end{array}$ & baños árabes & arquitectura & amplificación + calco & Compuesta \\
\hline 426 & $\begin{array}{l}\text { Lonely } \\
\text { Planet } \\
\text { Andalucía } \\
\end{array}$ & $\begin{array}{l}\text { paseo del } \\
\text { parque }\end{array}$ & $\begin{array}{l}\text { paisaje y } \\
\text { geografía }\end{array}$ & $\begin{array}{l}\text { amplificación + } \\
\text { préstamo }\end{array}$ & Compuesta \\
\hline 427 & $\begin{array}{l}\text { Lonely } \\
\text { Planet } \\
\text { Andalucía } \\
\end{array}$ & $\begin{array}{l}\text { paseo de } \\
\text { españa }\end{array}$ & $\begin{array}{l}\text { paisaje y } \\
\text { geografía }\end{array}$ & $\begin{array}{l}\text { amplificación + } \\
\text { préstamo }\end{array}$ & Compuesta \\
\hline 428 & $\begin{array}{l}\text { Lonely } \\
\text { Planet } \\
\text { Andalucía } \\
\end{array}$ & $\begin{array}{l}\text { palacio de la } \\
\text { aduana }\end{array}$ & arquitectura & $\begin{array}{l}\text { generalización + } \\
\text { préstamo }\end{array}$ & Compuesta \\
\hline 429 & $\begin{array}{l}\text { Lonely } \\
\text { Planet } \\
\text { Andalucía }\end{array}$ & costa del sol & $\begin{array}{l}\text { paisaje y } \\
\text { geografía }\end{array}$ & préstamo & Simple \\
\hline 430 & $\begin{array}{l}\text { Lonely } \\
\text { Planet } \\
\text { Andalucía }\end{array}$ & $\begin{array}{l}\text { semana } \\
\text { santa }\end{array}$ & $\begin{array}{l}\text { fiestas y } \\
\text { espectáculos }\end{array}$ & $\begin{array}{l}\text { equivalente acuñado + } \\
\text { préstamo }\end{array}$ & Compuesta \\
\hline 431 & $\begin{array}{l}\text { Lonely } \\
\text { Planet } \\
\text { Andalucía }\end{array}$ & cofradía & $\begin{array}{l}\text { fiestas y } \\
\text { espectáculos }\end{array}$ & $\begin{array}{l}\text { equivalente acuñado + } \\
\text { préstamo }\end{array}$ & Compuesta \\
\hline 432 & $\begin{array}{l}\text { Lonely } \\
\text { Planet } \\
\text { Andalucía }\end{array}$ & $\begin{array}{l}\text { feria de } \\
\text { málaga }\end{array}$ & $\begin{array}{l}\text { fiestas y } \\
\text { espectáculos }\end{array}$ & calco + préstamo & Compuesta \\
\hline
\end{tabular}




\begin{tabular}{|c|c|c|c|c|c|}
\hline ID & $\begin{array}{l}\text { TíTULO } \\
\text { GUÍA }\end{array}$ & \begin{tabular}{|l} 
ELEMENTO \\
DE ANÁLISIS
\end{tabular} & \begin{tabular}{|l|} 
CAMPO \\
SEMÁNTICO
\end{tabular} & \begin{tabular}{|l} 
TÉCNICA \\
TRADUCCIÓN
\end{tabular} & \begin{tabular}{|l} 
TIPO \\
TÉCNICA
\end{tabular} \\
\hline 433 & $\begin{array}{l}\text { Lonely } \\
\text { Planet } \\
\text { Andalucía }\end{array}$ & $\begin{array}{l}\text { fiesta mayor } \\
\text { de verdiales }\end{array}$ & \begin{tabular}{|l|} 
fiestas y \\
espectáculos
\end{tabular} & $\begin{array}{l}\text { amplificación + } \\
\text { préstamo }\end{array}$ & Compuesta \\
\hline 434 & $\begin{array}{l}\text { Lonely } \\
\text { Planet } \\
\text { Andalucía }\end{array}$ & cortijo & arquitectura & $\begin{array}{l}\text { amplificación + } \\
\text { préstamo }\end{array}$ & Compuesta \\
\hline 435 & \begin{tabular}{|l} 
Lonely \\
Planet \\
Andalucía
\end{tabular} & $\begin{array}{l}\text { fritura } \\
\text { malagueña }\end{array}$ & $\begin{array}{l}\text { gastronomía y } \\
\text { restauración }\end{array}$ & $\begin{array}{l}\text { amplificación + } \\
\text { préstamo }\end{array}$ & Compuesta \\
\hline 436 & $\begin{array}{l}\text { Lonely } \\
\text { Planet } \\
\text { Andalucía } \\
\end{array}$ & gazpacho & $\begin{array}{l}\text { gastronomía y } \\
\text { restauración }\end{array}$ & $\begin{array}{l}\text { amplificación + } \\
\text { préstamo }\end{array}$ & Compuesta \\
\hline 437 & $\begin{array}{l}\text { Lonely } \\
\text { Planet } \\
\text { Andalucía } \\
\end{array}$ & sopa de ajo & $\begin{array}{l}\text { gastronomía y } \\
\text { restauración }\end{array}$ & calco + préstamo & Compuesta \\
\hline 438 & \begin{tabular}{|l} 
Lonely \\
Planet \\
Andalucía \\
\end{tabular} & $\begin{array}{l}\text { sopa de } \\
\text { almendra } \\
\text { con uvas } \\
\end{array}$ & $\begin{array}{l}\text { gastronomía y } \\
\text { restauración }\end{array}$ & calco + préstamo & Compuesta \\
\hline 439 & $\begin{array}{l}\text { Lonely } \\
\text { Planet } \\
\text { Andalucía } \\
\end{array}$ & bocadillo & $\begin{array}{l}\text { gastronomía y } \\
\text { restauración }\end{array}$ & $\begin{array}{l}\text { amplificación + } \\
\text { préstamo }\end{array}$ & Compuesta \\
\hline 440 & $\begin{array}{l}\text { Lonely } \\
\text { Planet } \\
\text { Andalucía } \\
\end{array}$ & rosada frita & $\begin{array}{l}\text { gastronomía y } \\
\text { restauración }\end{array}$ & calco + préstamo & Compuesta \\
\hline 441 & $\begin{array}{l}\text { Lonely } \\
\text { Planet } \\
\text { Andalucía } \\
\end{array}$ & tagine & $\begin{array}{l}\text { gastronomía y } \\
\text { restauración }\end{array}$ & $\begin{array}{l}\text { amplificación + } \\
\text { préstamo }\end{array}$ & Compuesta \\
\hline 442 & $\begin{array}{l}\text { Lonely } \\
\text { Planet } \\
\text { Andalucía } \\
\end{array}$ & couscous & $\begin{array}{l}\text { gastronomía y } \\
\text { restauración }\end{array}$ & préstamo & Simple \\
\hline 443 & $\begin{array}{l}\text { Lonely } \\
\text { Planet } \\
\text { Andalucía }\end{array}$ & \begin{tabular}{|l|} 
fritura de \\
pescaítos a la \\
malagueña
\end{tabular} & $\begin{array}{l}\text { gastronomía y } \\
\text { restauración }\end{array}$ & calco & Simple \\
\hline 444 & $\begin{array}{l}\text { Lonely } \\
\text { Planet } \\
\text { Andalucía }\end{array}$ & mojito & $\begin{array}{l}\text { gastronomía y } \\
\text { restauración }\end{array}$ & préstamo & Simple \\
\hline 445 & $\begin{array}{l}\text { Lonely } \\
\text { Planet } \\
\text { Andalucía }\end{array}$ & costa del sol & $\begin{array}{l}\text { paisaje y } \\
\text { geografía }\end{array}$ & préstamo & Simple \\
\hline 446 & $\begin{array}{l}\text { Lonely } \\
\text { Planet } \\
\text { Andalucía }\end{array}$ & $\begin{array}{l}\text { paseo } \\
\text { marítimo }\end{array}$ & $\begin{array}{l}\text { paisaje y } \\
\text { geografía }\end{array}$ & calco + préstamo & Compuesta \\
\hline
\end{tabular}




\begin{tabular}{|c|c|c|c|c|c|}
\hline ID & $\begin{array}{l}\text { TíTULO } \\
\text { GUÍA }\end{array}$ & $\begin{array}{l}\text { ELEMENTO } \\
\text { DE ANÁLISIS }\end{array}$ & $\begin{array}{l}\text { CAMPO } \\
\text { SEMÁNTICO }\end{array}$ & $\begin{array}{l}\text { TÉCNICA } \\
\text { TRADUCCIÓN }\end{array}$ & $\begin{array}{l}\text { TIPO } \\
\text { TÉCNICA }\end{array}$ \\
\hline 447 & $\begin{array}{l}\text { Lonely } \\
\text { Planet } \\
\text { Andalucía }\end{array}$ & $\begin{array}{l}\text { torre de los } \\
\text { molinos }\end{array}$ & arquitectura & $\begin{array}{l}\text { amplificación + calco + } \\
\text { préstamo }\end{array}$ & Compuesta \\
\hline 448 & $\begin{array}{l}\text { Lonely } \\
\text { Planet } \\
\text { Andalucía }\end{array}$ & $\begin{array}{l}\text { las cruces de } \\
\text { mayo }\end{array}$ & $\begin{array}{l}\text { fiestas y } \\
\text { espectáculos }\end{array}$ & calco & Simple \\
\hline 449 & $\begin{array}{l}\text { Lonely } \\
\text { Planet } \\
\text { Andalucía }\end{array}$ & $\begin{array}{l}\text { romería de } \\
\text { san miguel }\end{array}$ & $\begin{array}{l}\text { fiestas y } \\
\text { espectáculos }\end{array}$ & $\begin{array}{l}\text { amplificación + } \\
\text { préstamo }\end{array}$ & Compuesta \\
\hline 450 & $\begin{array}{l}\text { Lonely } \\
\text { Planet } \\
\text { Andalucía } \\
\end{array}$ & ración & $\begin{array}{l}\text { gastronomía y } \\
\text { restauración }\end{array}$ & $\begin{array}{l}\text { amplificación + } \\
\text { préstamo }\end{array}$ & Compuesta \\
\hline 451 & $\begin{array}{l}\text { Lonely } \\
\text { Planet } \\
\text { Andalucía }\end{array}$ & $\begin{array}{l}\text { brocheta de } \\
\text { pescado }\end{array}$ & $\begin{array}{l}\text { gastronomía y } \\
\text { restauración }\end{array}$ & $\begin{array}{l}\text { adaptación + } \\
\text { préstamo }\end{array}$ & Compuesta \\
\hline 452 & $\begin{array}{l}\text { Lonely } \\
\text { Planet } \\
\text { Andalucía }\end{array}$ & rosquillas & $\begin{array}{l}\text { gastronomía y } \\
\text { restauración }\end{array}$ & $\begin{array}{l}\text { adaptación + } \\
\text { préstamo }\end{array}$ & Compuesta \\
\hline 453 & $\begin{array}{l}\text { Lonely } \\
\text { Planet } \\
\text { Andalucía } \\
\end{array}$ & pintxos & $\begin{array}{l}\text { gastronomía y } \\
\text { restauración }\end{array}$ & $\begin{array}{l}\text { amplificación + } \\
\text { préstamo }\end{array}$ & Compuesta \\
\hline 454 & $\begin{array}{l}\text { Lonely } \\
\text { Planet } \\
\text { Andalucía } \\
\end{array}$ & pintxos & $\begin{array}{l}\text { gastronomía y } \\
\text { restauración }\end{array}$ & $\begin{array}{l}\text { amplificación + } \\
\text { préstamo }\end{array}$ & Compuesta \\
\hline 455 & $\begin{array}{l}\text { Lonely } \\
\text { Planet } \\
\text { Andalucía }\end{array}$ & costa del sol & $\begin{array}{l}\text { paisaje y } \\
\text { geografía }\end{array}$ & préstamo & Simple \\
\hline 456 & $\begin{array}{l}\text { Lonely } \\
\text { Planet } \\
\text { Andalucía }\end{array}$ & $\begin{array}{l}\text { feria de san } \\
\text { bernabé }\end{array}$ & $\begin{array}{l}\text { fiestas y } \\
\text { espectáculos }\end{array}$ & $\begin{array}{l}\text { amplificación + } \\
\text { préstamo }\end{array}$ & Compuesta \\
\hline 457 & $\begin{array}{l}\text { Lonely } \\
\text { Planet } \\
\text { Andalucía }\end{array}$ & bandolero & historia & $\begin{array}{l}\text { equivalente acuñado + } \\
\text { préstamo }\end{array}$ & Compuesta \\
\hline 458 & $\begin{array}{l}\text { Lonely } \\
\text { Planet } \\
\text { Andalucía }\end{array}$ & cuadrilla & $\begin{array}{l}\text { fiestas y } \\
\text { espectáculos }\end{array}$ & $\begin{array}{l}\text { amplificación + } \\
\text { préstamo }\end{array}$ & Compuesta \\
\hline 459 & $\begin{array}{l}\text { Lonely } \\
\text { Planet } \\
\text { Andalucía } \\
\end{array}$ & banderillero & $\begin{array}{l}\text { fiestas y } \\
\text { espectáculos }\end{array}$ & $\begin{array}{l}\text { amplificación + } \\
\text { préstamo }\end{array}$ & Compuesta \\
\hline 460 & $\begin{array}{l}\text { Lonely } \\
\text { Planet } \\
\text { Andalucía }\end{array}$ & picador & $\begin{array}{l}\text { fiestas y } \\
\text { espectáculos }\end{array}$ & $\begin{array}{l}\text { amplificación + } \\
\text { préstamo }\end{array}$ & Compuesta \\
\hline
\end{tabular}




\begin{tabular}{|c|c|c|c|c|c|}
\hline ID & \begin{tabular}{|l|} 
TíTULO \\
GUÍA
\end{tabular} & $\begin{array}{l}\text { ELEMENTO } \\
\text { DE ANÁLISIS }\end{array}$ & \begin{tabular}{|l|} 
CAMPO \\
SEMÁNTICO
\end{tabular} & $\begin{array}{l}\text { TÉCNICA } \\
\text { TRADUCCIÓN }\end{array}$ & $\begin{array}{l}\text { TIPO } \\
\text { TÉCNICA }\end{array}$ \\
\hline 461 & $\begin{array}{l}\text { Lonely } \\
\text { Planet } \\
\text { Andalucía }\end{array}$ & muleta & $\begin{array}{l}\text { fiestas y } \\
\text { espectáculos }\end{array}$ & $\begin{array}{l}\text { amplificación + } \\
\text { préstamo }\end{array}$ & Compuesta \\
\hline 462 & $\begin{array}{l}\text { Lonely } \\
\text { Planet } \\
\text { Andalucía }\end{array}$ & $\begin{array}{l}\text { corrida } \\
\text { goyesca }\end{array}$ & $\begin{array}{l}\text { fiestas y } \\
\text { espectáculos }\end{array}$ & $\begin{array}{l}\text { amplificación + } \\
\text { préstamo }\end{array}$ & Compuesta \\
\hline 463 & $\begin{array}{l}\text { Lonely } \\
\text { Planet } \\
\text { Andalucía }\end{array}$ & cocido & $\begin{array}{l}\text { gastronomía y } \\
\text { restauración }\end{array}$ & $\begin{array}{l}\text { equivalente acuñado + } \\
\text { préstamo }\end{array}$ & Compuesta \\
\hline 464 & $\begin{array}{l}\text { Lonely } \\
\text { Planet } \\
\text { Andalucía }\end{array}$ & estofado & $\begin{array}{l}\text { gastronomía y } \\
\text { restauración }\end{array}$ & $\begin{array}{l}\text { equivalente acuñado + } \\
\text { préstamo }\end{array}$ & Compuesta \\
\hline 465 & $\begin{array}{l}\text { Lonely } \\
\text { Planet } \\
\text { Andalucía } \\
\end{array}$ & cazuela & $\begin{array}{l}\text { gastronomía y } \\
\text { restauración }\end{array}$ & $\begin{array}{l}\text { equivalente acuñado + } \\
\text { préstamo }\end{array}$ & Compuesta \\
\hline 466 & $\begin{array}{l}\text { Lonely } \\
\text { Planet } \\
\text { Andalucía }\end{array}$ & $\begin{array}{l}\text { plato } \\
\text { rondeño }\end{array}$ & $\begin{array}{l}\text { gastronomía y } \\
\text { restauración }\end{array}$ & calco + amplificación & Compuesta \\
\hline 467 & $\begin{array}{l}\text { Lonely } \\
\text { Planet } \\
\text { Andalucía } \\
\end{array}$ & rabo de toro & $\begin{array}{l}\text { gastronomía y } \\
\text { restauración }\end{array}$ & $\begin{array}{l}\text { amplificación + } \\
\text { préstamo }\end{array}$ & Compuesta \\
\hline 468 & $\begin{array}{l}\text { Lonely } \\
\text { Planet } \\
\text { Andalucía } \\
\end{array}$ & $\begin{array}{l}\text { serranía de } \\
\text { ronda }\end{array}$ & $\begin{array}{l}\text { paisaje y } \\
\text { geografía }\end{array}$ & $\begin{array}{l}\text { amplificación + } \\
\text { préstamo }\end{array}$ & Compuesta \\
\hline 469 & $\begin{array}{l}\text { Lonely } \\
\text { Planet } \\
\text { Andalucía }\end{array}$ & $\begin{array}{l}\text { valle del } \\
\text { guadiaro }\end{array}$ & $\begin{array}{l}\text { paisaje y } \\
\text { geografía }\end{array}$ & calco & Simple \\
\hline 470 & $\begin{array}{l}\text { Lonely } \\
\text { Planet } \\
\text { Andalucía } \\
\end{array}$ & $\begin{array}{l}\text { valle del } \\
\text { genal }\end{array}$ & $\begin{array}{l}\text { paisaje y } \\
\text { geografía }\end{array}$ & calco & Simple \\
\hline 471 & $\begin{array}{l}\text { Lonely } \\
\text { Planet } \\
\text { Andalucía }\end{array}$ & $\begin{array}{l}\text { parque } \\
\text { natural de } \\
\text { sierra de } \\
\text { grazalema }\end{array}$ & $\begin{array}{l}\text { paisaje y } \\
\text { geografía }\end{array}$ & calco & Simple \\
\hline 472 & $\begin{array}{l}\text { Lonely } \\
\text { Planet } \\
\text { Andalucía }\end{array}$ & $\begin{array}{l}\text { parque } \\
\text { natural de } \\
\text { los } \\
\text { alcornocales }\end{array}$ & $\begin{array}{l}\text { paisaje y } \\
\text { geografía }\end{array}$ & calco & Simple \\
\hline 473 & $\begin{array}{l}\text { Lonely } \\
\text { Planet } \\
\text { Andalucía }\end{array}$ & $\begin{array}{l}\text { parque } \\
\text { natural sierra } \\
\text { de las nieves } \\
\end{array}$ & $\begin{array}{l}\text { paisaje y } \\
\text { geografía }\end{array}$ & préstamo & Simple \\
\hline 474 & $\begin{array}{l}\text { Lonely } \\
\text { Planet } \\
\text { Andalucía }\end{array}$ & pinsapo & $\begin{array}{l}\text { paisaje y } \\
\text { geografía }\end{array}$ & $\begin{array}{l}\text { amplificación + } \\
\text { préstamo }\end{array}$ & Compuesta \\
\hline
\end{tabular}




\begin{tabular}{|c|c|c|c|c|c|}
\hline ID & $\begin{array}{l}\text { TíTULO } \\
\text { GUÍA }\end{array}$ & $\begin{array}{l}\text { ELEMENTO } \\
\text { DE ANÁLISIS }\end{array}$ & $\begin{array}{l}\text { CAMPO } \\
\text { SEMÁNTICO }\end{array}$ & $\begin{array}{l}\text { TÉCNICA } \\
\text { TRADUCCIÓN }\end{array}$ & $\begin{array}{l}\text { TIPO } \\
\text { TÉCNICA }\end{array}$ \\
\hline 475 & $\begin{array}{l}\text { Lonely } \\
\text { Planet } \\
\text { Andalucía }\end{array}$ & $\begin{array}{l}\text { garganta del } \\
\text { chorro }\end{array}$ & $\begin{array}{l}\text { paisaje y } \\
\text { geografía }\end{array}$ & $\begin{array}{l}\text { calco + amplificación + } \\
\text { préstamo }\end{array}$ & Compuesta \\
\hline 476 & $\begin{array}{l}\text { Lonely } \\
\text { Planet } \\
\text { Andalucía }\end{array}$ & alcazaba & arquitectura & $\begin{array}{l}\text { amplificación + } \\
\text { préstamo }\end{array}$ & Compuesta \\
\hline 477 & $\begin{array}{l}\text { Lonely } \\
\text { Planet } \\
\text { Andalucía }\end{array}$ & $\begin{array}{l}\text { torre del } \\
\text { homenaje }\end{array}$ & arquitectura & préstamo & Simple \\
\hline 478 & $\begin{array}{l}\text { Lonely } \\
\text { Planet } \\
\text { Andalucía }\end{array}$ & $\begin{array}{l}\text { peña de los } \\
\text { enamorados }\end{array}$ & $\begin{array}{l}\text { paisaje y } \\
\text { geografía }\end{array}$ & calco + préstamo & Compuesta \\
\hline 479 & $\begin{array}{l}\text { Lonely } \\
\text { Planet } \\
\text { Andalucía }\end{array}$ & artesonado & arquitectura & $\begin{array}{l}\text { amplificación + } \\
\text { préstamo }\end{array}$ & Compuesta \\
\hline 480 & $\begin{array}{l}\text { Lonely } \\
\text { Planet } \\
\text { Andalucía }\end{array}$ & $\begin{array}{l}\text { convento de } \\
\text { las carmelitas } \\
\text { descalzas } \\
\end{array}$ & arquitectura & calco & Simple \\
\hline 481 & $\begin{array}{l}\text { Lonely } \\
\text { Planet } \\
\text { Andalucía }\end{array}$ & $\begin{array}{l}\text { real feria de } \\
\text { agosto }\end{array}$ & $\begin{array}{l}\text { fiestas y } \\
\text { espectáculos }\end{array}$ & $\begin{array}{l}\text { amplificación + } \\
\text { préstamo }\end{array}$ & Compuesta \\
\hline 482 & $\begin{array}{l}\text { Lonely } \\
\text { Planet } \\
\text { Andalucía }\end{array}$ & hospedería & alojamiento & $\begin{array}{l}\text { amplificación + } \\
\text { préstamo }\end{array}$ & Compuesta \\
\hline 483 & $\begin{array}{l}\text { Lonely } \\
\text { Planet } \\
\text { Andalucía }\end{array}$ & cortijo & alojamiento & préstamo & Simple \\
\hline 484 & $\begin{array}{l}\text { Lonely } \\
\text { Planet } \\
\text { Andalucía }\end{array}$ & $\begin{array}{l}\text { porra } \\
\text { antequerana }\end{array}$ & $\begin{array}{l}\text { gastronomía y } \\
\text { restauración }\end{array}$ & $\begin{array}{l}\text { amplificación + } \\
\text { préstamo }\end{array}$ & Compuesta \\
\hline 485 & $\begin{array}{l}\text { Lonely } \\
\text { Planet } \\
\text { Andalucía }\end{array}$ & bienmesabe & $\begin{array}{l}\text { gastronomía y } \\
\text { restauración }\end{array}$ & $\begin{array}{l}\text { calco + amplificación + } \\
\text { préstamo }\end{array}$ & Compuesta \\
\hline 486 & $\begin{array}{l}\text { Lonely } \\
\text { Planet } \\
\text { Andalucía }\end{array}$ & angelorum & $\begin{array}{l}\text { gastronomía y } \\
\text { restauración }\end{array}$ & $\begin{array}{l}\text { amplificación + } \\
\text { préstamo }\end{array}$ & Compuesta \\
\hline 487 & $\begin{array}{l}\text { Lonely } \\
\text { Planet } \\
\text { Andalucía }\end{array}$ & mollete & $\begin{array}{l}\text { gastronomía y } \\
\text { restauración }\end{array}$ & $\begin{array}{l}\text { amplificación + } \\
\text { préstamo }\end{array}$ & Compuesta \\
\hline 488 & $\begin{array}{l}\text { Lonely } \\
\text { Planet } \\
\text { Andalucía }\end{array}$ & $\begin{array}{l}\text { huevos a la } \\
\text { bestia }\end{array}$ & $\begin{array}{l}\text { gastronomía y } \\
\text { restauración }\end{array}$ & $\begin{array}{l}\text { amplificación + } \\
\text { préstamo }\end{array}$ & Compuesta \\
\hline
\end{tabular}




\begin{tabular}{|c|c|c|c|c|c|}
\hline ID & \begin{tabular}{|l|} 
TÍTULO \\
GUÍA
\end{tabular} & $\begin{array}{l}\text { ELEMENTO } \\
\text { DE ANÁLISIS }\end{array}$ & \begin{tabular}{|l|} 
CAMPO \\
SEMÁNTICO \\
\end{tabular} & $\begin{array}{l}\text { TÉCNICA } \\
\text { TRADUCCIÓN }\end{array}$ & $\begin{array}{l}\text { TIPO } \\
\text { TÉCNICA }\end{array}$ \\
\hline 489 & $\begin{array}{l}\text { Lonely } \\
\text { Planet } \\
\text { Andalucía }\end{array}$ & $\begin{array}{l}\text { noche del } \\
\text { vino }\end{array}$ & \begin{tabular}{|l|} 
fiestas y \\
espectáculos
\end{tabular} & calco + préstamo & Compuesta \\
\hline 490 & $\begin{array}{l}\text { Lonely } \\
\text { Planet } \\
\text { Andalucía }\end{array}$ & $\begin{array}{l}\text { noche de s. } \\
\text { Juan }\end{array}$ & $\begin{array}{l}\text { fiestas y } \\
\text { espectáculos }\end{array}$ & $\begin{array}{l}\text { amplificación + } \\
\text { préstamo }\end{array}$ & Compuesta \\
\hline 491 & $\begin{array}{l}\text { Lonely } \\
\text { Planet } \\
\text { Barcelona }\end{array}$ & $\begin{array}{l}\text { mar i } \\
\text { muntanya }\end{array}$ & $\begin{array}{l}\text { gastronomía y } \\
\text { restauración }\end{array}$ & $\begin{array}{l}\text { amplificación + } \\
\text { equivalente acuñado + } \\
\text { préstamo }\end{array}$ & Compuesta \\
\hline 492 & \begin{tabular}{|l} 
Lonely \\
Planet \\
Barcelona
\end{tabular} & garum & $\begin{array}{l}\text { gastronomía y } \\
\text { restauración }\end{array}$ & $\begin{array}{l}\text { amplificación + } \\
\text { préstamo }\end{array}$ & Compuesta \\
\hline 493 & \begin{tabular}{|l|} 
Lonely \\
Planet \\
Barcelona \\
\end{tabular} & canya & $\begin{array}{l}\text { gastronomía y } \\
\text { restauración }\end{array}$ & préstamo & Simple \\
\hline 494 & $\begin{array}{l}\text { Lonely } \\
\text { Planet } \\
\text { Barcelona }\end{array}$ & ensaïmada & $\begin{array}{l}\text { gastronomía y } \\
\text { restauración }\end{array}$ & Préstamo & Simple \\
\hline 495 & \begin{tabular}{|l} 
Lonely \\
Planet \\
Barcelona \\
\end{tabular} & bikini & $\begin{array}{l}\text { gastronomía y } \\
\text { restauración }\end{array}$ & $\begin{array}{l}\text { amplificación + } \\
\text { préstamo }\end{array}$ & Compuesta \\
\hline 496 & \begin{tabular}{|l|} 
Lonely \\
Planet \\
Barcelona \\
\end{tabular} & torrada & $\begin{array}{l}\text { gastronomía y } \\
\text { restauración }\end{array}$ & $\begin{array}{l}\text { amplificación + } \\
\text { préstamo }\end{array}$ & Compuesta \\
\hline 497 & $\begin{array}{l}\text { Lonely } \\
\text { Planet } \\
\text { Barcelona } \\
\end{array}$ & pica-pica & $\begin{array}{l}\text { gastronomía y } \\
\text { restauración }\end{array}$ & $\begin{array}{l}\text { amplificación + } \\
\text { préstamo }\end{array}$ & Compuesta \\
\hline 498 & \begin{tabular}{|l} 
Lonely \\
Planet \\
Barcelona \\
\end{tabular} & $\begin{array}{l}\text { tinto de } \\
\text { verano }\end{array}$ & $\begin{array}{l}\text { gastronomía y } \\
\text { restauración }\end{array}$ & calco + préstamo & Compuesta \\
\hline 499 & $\begin{array}{l}\text { Lonely } \\
\text { Planet } \\
\text { Barcelona }\end{array}$ & $\begin{array}{l}\text { ensaladilla } \\
\text { rusa }\end{array}$ & $\begin{array}{l}\text { gastronomía y } \\
\text { restauración }\end{array}$ & $\begin{array}{l}\text { amplificación + } \\
\text { préstamo }\end{array}$ & Compuesta \\
\hline 500 & $\begin{array}{l}\text { Lonely } \\
\text { Planet } \\
\text { Barcelona }\end{array}$ & $\begin{array}{l}\text { pan con } \\
\text { tomate }\end{array}$ & $\begin{array}{l}\text { gastronomía y } \\
\text { restauración }\end{array}$ & $\begin{array}{l}\text { amplificación + } \\
\text { préstamo }\end{array}$ & Compuesta \\
\hline 501 & $\begin{array}{l}\text { Lonely } \\
\text { Planet } \\
\text { Barcelona }\end{array}$ & txacolí & $\begin{array}{l}\text { gastronomía y } \\
\text { restauración }\end{array}$ & $\begin{array}{l}\text { amplificación + } \\
\text { préstamo }\end{array}$ & Compuesta \\
\hline 502 & \begin{tabular}{|l|} 
Lonely \\
Planet \\
Barcelona
\end{tabular} & montadito & $\begin{array}{l}\text { gastronomía y } \\
\text { restauración }\end{array}$ & $\begin{array}{l}\text { amplificación + } \\
\text { préstamo }\end{array}$ & Compuesta \\
\hline
\end{tabular}




\begin{tabular}{|c|c|c|c|c|c|}
\hline ID & $\begin{array}{l}\text { TíTULO } \\
\text { GUÍA }\end{array}$ & $\begin{array}{l}\text { ELEMENTO } \\
\text { DE ANÁLISIS }\end{array}$ & $\begin{array}{l}\text { CAMPO } \\
\text { SEMÁNTICO }\end{array}$ & $\begin{array}{l}\text { TÉCNICA } \\
\text { TRADUCCIÓN }\end{array}$ & $\begin{array}{l}\text { TIPO } \\
\text { TÉCNICA }\end{array}$ \\
\hline 503 & $\begin{array}{l}\text { Lonely } \\
\text { Planet } \\
\text { Barcelona }\end{array}$ & $\begin{array}{l}\text { boquerones } \\
\text { en vinagre }\end{array}$ & $\begin{array}{l}\text { gastronomía y } \\
\text { restauración }\end{array}$ & calco + préstamo & Compuesta \\
\hline 504 & $\begin{array}{l}\text { Lonely } \\
\text { Planet } \\
\text { Barcelona }\end{array}$ & $\begin{array}{l}\text { pimientos de } \\
\text { padrón }\end{array}$ & $\begin{array}{l}\text { gastronomía y } \\
\text { restauración }\end{array}$ & $\begin{array}{l}\text { amplificación + } \\
\text { préstamo }\end{array}$ & Compuesta \\
\hline 505 & $\begin{array}{l}\text { Lonely } \\
\text { Planet } \\
\text { Barcelona }\end{array}$ & $\begin{array}{l}\text { patatas } \\
\text { bravas }\end{array}$ & $\begin{array}{l}\text { gastronomía y } \\
\text { restauración }\end{array}$ & $\begin{array}{l}\text { amplificación + } \\
\text { préstamo }\end{array}$ & Compuesta \\
\hline 506 & $\begin{array}{l}\text { Lonely } \\
\text { Planet } \\
\text { Barcelona }\end{array}$ & $\begin{array}{l}\text { gambas al } \\
\text { ajillo }\end{array}$ & $\begin{array}{l}\text { gastronomía y } \\
\text { restauración }\end{array}$ & calco + préstamo & Compuesta \\
\hline 507 & $\begin{array}{l}\text { Lonely } \\
\text { Planet } \\
\text { Barcelona } \\
\end{array}$ & chipirones & $\begin{array}{l}\text { gastronomía y } \\
\text { restauración }\end{array}$ & $\begin{array}{l}\text { equivalente acuñado + } \\
\text { préstamo }\end{array}$ & Compuesta \\
\hline 508 & $\begin{array}{l}\text { Lonely } \\
\text { Planet } \\
\text { Barcelona }\end{array}$ & $\begin{array}{l}\text { calamares a } \\
\text { la romana }\end{array}$ & $\begin{array}{l}\text { gastronomía y } \\
\text { restauración }\end{array}$ & $\begin{array}{l}\text { amplificación + } \\
\text { préstamo }\end{array}$ & Compuesta \\
\hline 509 & $\begin{array}{l}\text { Lonely } \\
\text { Planet } \\
\text { Barcelona } \\
\end{array}$ & sofrito & $\begin{array}{l}\text { gastronomía y } \\
\text { restauración }\end{array}$ & $\begin{array}{l}\text { amplificación + } \\
\text { préstamo }\end{array}$ & Compuesta \\
\hline 510 & $\begin{array}{l}\text { Lonely } \\
\text { Planet } \\
\text { Barcelona } \\
\end{array}$ & samfaina & $\begin{array}{l}\text { gastronomía y } \\
\text { restauración }\end{array}$ & $\begin{array}{l}\text { amplificación + } \\
\text { préstamo }\end{array}$ & Compuesta \\
\hline 511 & $\begin{array}{l}\text { Lonely } \\
\text { Planet } \\
\text { Barcelona } \\
\end{array}$ & picada & $\begin{array}{l}\text { gastronomía y } \\
\text { restauración }\end{array}$ & $\begin{array}{l}\text { amplificación + } \\
\text { préstamo }\end{array}$ & Compuesta \\
\hline 512 & $\begin{array}{l}\text { Lonely } \\
\text { Planet } \\
\text { Barcelona } \\
\end{array}$ & alioli & $\begin{array}{l}\text { gastronomía y } \\
\text { restauración }\end{array}$ & $\begin{array}{l}\text { amplificación + } \\
\text { préstamo }\end{array}$ & Compuesta \\
\hline 513 & $\begin{array}{l}\text { Lonely } \\
\text { Planet } \\
\text { Barcelona }\end{array}$ & romesco & $\begin{array}{l}\text { gastronomía y } \\
\text { restauración }\end{array}$ & $\begin{array}{l}\text { amplificación + } \\
\text { préstamo }\end{array}$ & Compuesta \\
\hline 514 & $\begin{array}{l}\text { Lonely } \\
\text { Planet } \\
\text { Barcelona }\end{array}$ & $\begin{array}{l}\text { coca de s. } \\
\text { Juan }\end{array}$ & $\begin{array}{l}\text { gastronomía y } \\
\text { restauración }\end{array}$ & $\begin{array}{l}\text { adaptación + } \\
\text { amplificación + } \\
\text { préstamo }\end{array}$ & Compuesta \\
\hline 515 & $\begin{array}{l}\text { Lonely } \\
\text { Planet } \\
\text { Barcelona } \\
\end{array}$ & $\begin{array}{l}\text { ensalada } \\
\text { catalana }\end{array}$ & $\begin{array}{l}\text { gastronomía y } \\
\text { restauración }\end{array}$ & $\begin{array}{l}\text { calco + amplificación + } \\
\text { préstamo }\end{array}$ & Compuesta \\
\hline 516 & $\begin{array}{l}\text { Lonely } \\
\text { Planet } \\
\text { Barcelona }\end{array}$ & calçots & $\begin{array}{l}\text { gastronomía y } \\
\text { restauración }\end{array}$ & $\begin{array}{l}\text { amplificación + } \\
\text { préstamo }\end{array}$ & Compuesta \\
\hline
\end{tabular}




\begin{tabular}{|c|c|c|c|c|c|}
\hline ID & $\begin{array}{l}\text { TíTULO } \\
\text { GUÍA }\end{array}$ & $\begin{array}{l}\text { ELEMENTO } \\
\text { DE ANÁLISIS }\end{array}$ & $\begin{array}{l}\text { CAMPO } \\
\text { SEMÁNTICO }\end{array}$ & $\begin{array}{l}\text { TÉCNICA } \\
\text { TRADUCCIÓN }\end{array}$ & $\begin{array}{l}\text { TIPO } \\
\text { TÉCNICA }\end{array}$ \\
\hline 517 & $\begin{array}{l}\text { Lonely } \\
\text { Planet } \\
\text { Barcelona }\end{array}$ & escalivada & $\begin{array}{l}\text { gastronomía y } \\
\text { restauración }\end{array}$ & $\begin{array}{l}\text { amplificación + } \\
\text { préstamo }\end{array}$ & Compuesta \\
\hline 518 & $\begin{array}{l}\text { Lonely } \\
\text { Planet } \\
\text { Barcelona }\end{array}$ & esqueixada & $\begin{array}{l}\text { gastronomía y } \\
\text { restauración }\end{array}$ & $\begin{array}{l}\text { amplificación + } \\
\text { préstamo }\end{array}$ & Compuesta \\
\hline 519 & $\begin{array}{l}\text { Lonely } \\
\text { Planet } \\
\text { Barcelona }\end{array}$ & $\begin{array}{l}\text { arroz a } \\
\text { cazuela }\end{array}$ & $\begin{array}{l}\text { gastronomía y } \\
\text { restauración }\end{array}$ & $\begin{array}{l}\text { amplificación + } \\
\text { préstamo }\end{array}$ & Compuesta \\
\hline 520 & $\begin{array}{l}\text { Lonely } \\
\text { Planet } \\
\text { Barcelona } \\
\end{array}$ & fideuà & $\begin{array}{l}\text { gastronomía y } \\
\text { restauración }\end{array}$ & $\begin{array}{l}\text { amplificación + } \\
\text { préstamo }\end{array}$ & Compuesta \\
\hline 521 & $\begin{array}{l}\text { Lonely } \\
\text { Planet } \\
\text { Barcelona }\end{array}$ & escudella & $\begin{array}{l}\text { gastronomía y } \\
\text { restauración }\end{array}$ & $\begin{array}{l}\text { amplificación + } \\
\text { préstamo }\end{array}$ & Compuesta \\
\hline 522 & $\begin{array}{l}\text { Lonely } \\
\text { Planet } \\
\text { Barcelona } \\
\end{array}$ & caracoles & $\begin{array}{l}\text { gastronomía y } \\
\text { restauración }\end{array}$ & $\begin{array}{l}\text { amplificación + } \\
\text { préstamo }\end{array}$ & Compuesta \\
\hline 523 & $\begin{array}{l}\text { Lonely } \\
\text { Planet } \\
\text { Barcelona } \\
\end{array}$ & $\begin{array}{l}\text { botifarra } \\
\text { amb } \\
\text { mongetes }\end{array}$ & $\begin{array}{l}\text { gastronomía y } \\
\text { restauración }\end{array}$ & $\begin{array}{l}\text { amplificación + } \\
\text { préstamo }\end{array}$ & Compuesta \\
\hline 524 & $\begin{array}{l}\text { Lonely } \\
\text { Planet } \\
\text { Barcelona } \\
\end{array}$ & $\begin{array}{l}\text { bacallà a la } \\
\text { llauna }\end{array}$ & $\begin{array}{l}\text { gastronomía y } \\
\text { restauración }\end{array}$ & $\begin{array}{l}\text { amplificación + } \\
\text { préstamo }\end{array}$ & Compuesta \\
\hline 525 & $\begin{array}{l}\text { Lonely } \\
\text { Planet } \\
\text { Barcelona } \\
\end{array}$ & fricandó & $\begin{array}{l}\text { gastronomía y } \\
\text { restauración }\end{array}$ & $\begin{array}{l}\text { amplificación + } \\
\text { préstamo }\end{array}$ & Compuesta \\
\hline 526 & $\begin{array}{l}\text { Lonely } \\
\text { Planet } \\
\text { Barcelona }\end{array}$ & zarzuela & $\begin{array}{l}\text { gastronomía y } \\
\text { restauración }\end{array}$ & $\begin{array}{l}\text { amplificación + } \\
\text { préstamo }\end{array}$ & Compuesta \\
\hline 527 & $\begin{array}{l}\text { Lonely } \\
\text { Planet } \\
\text { Barcelona }\end{array}$ & $\begin{array}{l}\text { suquet de } \\
\text { peix }\end{array}$ & $\begin{array}{l}\text { gastronomía y } \\
\text { restauración }\end{array}$ & $\begin{array}{l}\text { amplificación + } \\
\text { préstamo }\end{array}$ & Compuesta \\
\hline 528 & $\begin{array}{l}\text { Lonely } \\
\text { Planet } \\
\text { Barcelona }\end{array}$ & $\begin{array}{l}\text { tortilla de } \\
\text { botifarra }\end{array}$ & $\begin{array}{l}\text { gastronomía y } \\
\text { restauración }\end{array}$ & $\begin{array}{l}\text { calco + amplificación + } \\
\text { préstamo }\end{array}$ & Compuesta \\
\hline 529 & $\begin{array}{l}\text { Lonely } \\
\text { Planet } \\
\text { Barcelona } \\
\end{array}$ & $\begin{array}{l}\text { crema } \\
\text { catalana }\end{array}$ & $\begin{array}{l}\text { gastronomía y } \\
\text { restauración }\end{array}$ & $\begin{array}{l}\text { amplificación + } \\
\text { préstamo }\end{array}$ & Compuesta \\
\hline 530 & $\begin{array}{l}\text { Lonely } \\
\text { Planet } \\
\text { Barcelona }\end{array}$ & $\begin{array}{l}\text { requesón con } \\
\text { miel }\end{array}$ & $\begin{array}{l}\text { gastronomía y } \\
\text { restauración }\end{array}$ & $\begin{array}{l}\text { amplificación + } \\
\text { préstamo }\end{array}$ & Compuesta \\
\hline
\end{tabular}




\begin{tabular}{|c|c|c|c|c|c|}
\hline ID & $\begin{array}{l}\text { TíTULO } \\
\text { GUÍA }\end{array}$ & \begin{tabular}{|l} 
ELEMENTO \\
DE ANÁLISIS
\end{tabular} & \begin{tabular}{|l|} 
CAMPO \\
SEMÁNTICO
\end{tabular} & $\begin{array}{l}\text { TÉCNICA } \\
\text { TRADUCCIÓN }\end{array}$ & $\begin{array}{l}\text { TIPO } \\
\text { TÉCNICA }\end{array}$ \\
\hline 531 & $\begin{array}{l}\text { Lonely } \\
\text { Planet } \\
\text { Barcelona }\end{array}$ & $\begin{array}{l}\text { postre } \\
\text { músico }\end{array}$ & $\begin{array}{l}\text { gastronomía y } \\
\text { restauración }\end{array}$ & $\begin{array}{l}\text { amplificación + } \\
\text { préstamo }\end{array}$ & Compuesta \\
\hline 532 & $\begin{array}{l}\text { Lonely } \\
\text { Planet } \\
\text { Barcelona }\end{array}$ & bolets & $\begin{array}{l}\text { gastronomía y } \\
\text { restauración }\end{array}$ & $\begin{array}{l}\text { generalización + } \\
\text { préstamo }\end{array}$ & Compuesta \\
\hline 533 & $\begin{array}{l}\text { Lonely } \\
\text { Planet } \\
\text { Barcelona }\end{array}$ & rovellones & $\begin{array}{l}\text { gastronomía y } \\
\text { restauración }\end{array}$ & préstamo & Simple \\
\hline 534 & $\begin{array}{l}\text { Lonely } \\
\text { Planet } \\
\text { Barcelona }\end{array}$ & $\begin{array}{l}\text { trompetas de } \\
\text { la muerte }\end{array}$ & $\begin{array}{l}\text { gastronomía y } \\
\text { restauración }\end{array}$ & calco + préstamo & Compuesta \\
\hline 535 & $\begin{array}{l}\text { Lonely } \\
\text { Planet } \\
\text { Barcelona }\end{array}$ & $\begin{array}{l}\text { queso de } \\
\text { tupí }\end{array}$ & $\begin{array}{l}\text { gastronomía y } \\
\text { restauración }\end{array}$ & $\begin{array}{l}\text { amplificación + } \\
\text { préstamo }\end{array}$ & Compuesta \\
\hline 536 & $\begin{array}{l}\text { Lonely } \\
\text { Planet } \\
\text { Barcelona }\end{array}$ & marisquería & $\begin{array}{l}\text { gastronomía y } \\
\text { restauración }\end{array}$ & $\begin{array}{l}\text { amplificación + } \\
\text { préstamo }\end{array}$ & Compuesta \\
\hline 537 & $\begin{array}{l}\text { Lonely } \\
\text { Planet } \\
\text { Barcelona } \\
\end{array}$ & mesón & $\begin{array}{l}\text { gastronomía y } \\
\text { restauración }\end{array}$ & calco + préstamo & Compuesta \\
\hline 538 & $\begin{array}{l}\text { Lonely } \\
\text { Planet } \\
\text { Barcelona } \\
\end{array}$ & flauta & $\begin{array}{l}\text { gastronomía y } \\
\text { restauración }\end{array}$ & $\begin{array}{l}\text { amplificación + } \\
\text { préstamo }\end{array}$ & Compuesta \\
\hline 539 & $\begin{array}{l}\text { Lonely } \\
\text { Planet } \\
\text { Barcelona }\end{array}$ & menú del día & $\begin{array}{l}\text { gastronomía y } \\
\text { restauración }\end{array}$ & $\begin{array}{l}\text { amplificación + } \\
\text { préstamo }\end{array}$ & Compuesta \\
\hline 540 & $\begin{array}{l}\text { Lonely } \\
\text { Planet } \\
\text { Barcelona } \\
\end{array}$ & $\begin{array}{l}\text { menú de } \\
\text { degustación }\end{array}$ & $\begin{array}{l}\text { gastronomía y } \\
\text { restauración }\end{array}$ & $\begin{array}{l}\text { amplificación + } \\
\text { préstamo }\end{array}$ & Compuesta \\
\hline 541 & $\begin{array}{l}\text { Lonely } \\
\text { Planet } \\
\text { Barcelona }\end{array}$ & suizo & $\begin{array}{l}\text { gastronomía y } \\
\text { restauración }\end{array}$ & $\begin{array}{l}\text { amplificación + } \\
\text { préstamo }\end{array}$ & Compuesta \\
\hline 542 & $\begin{array}{l}\text { Lonely } \\
\text { Planet } \\
\text { Barcelona }\end{array}$ & $\begin{array}{l}\text { bacallà amb } \\
\text { cigronets del } \\
\text { pla de } \\
\text { llerona }\end{array}$ & $\begin{array}{l}\text { gastronomía y } \\
\text { restauración }\end{array}$ & calco + préstamo & Compuesta \\
\hline 543 & $\begin{array}{l}\text { Lonely } \\
\text { Planet } \\
\text { Barcelona }\end{array}$ & $\begin{array}{l}\text { ciervo } \\
\text { estofado con } \\
\text { pasta } \\
\text { laminada y } \\
\text { puré }\end{array}$ & $\begin{array}{l}\text { gastronomía y } \\
\text { restauración }\end{array}$ & $\begin{array}{l}\text { amplificación + } \\
\text { préstamo }\end{array}$ & Compuesta \\
\hline
\end{tabular}




\begin{tabular}{|c|c|c|c|c|c|}
\hline ID & $\begin{array}{l}\text { TíTULO } \\
\text { GUÍA }\end{array}$ & $\begin{array}{l}\text { ELEMENTO } \\
\text { DE ANÁLISIS }\end{array}$ & $\begin{array}{l}\text { CAMPO } \\
\text { SEMÁNTICO }\end{array}$ & $\begin{array}{l}\text { TÉCNICA } \\
\text { TRADUCCIÓN }\end{array}$ & $\begin{array}{l}\text { TIPO } \\
\text { TÉCNICA }\end{array}$ \\
\hline 544 & $\begin{array}{l}\text { Lonely } \\
\text { Planet } \\
\text { Barcelona }\end{array}$ & $\begin{array}{l}\text { calamares } \\
\text { rellenos }\end{array}$ & $\begin{array}{l}\text { gastronomía y } \\
\text { restauración }\end{array}$ & calco + préstamo & Compuesta \\
\hline 545 & $\begin{array}{l}\text { Lonely } \\
\text { Planet } \\
\text { Barcelona }\end{array}$ & $\begin{array}{l}\text { cassola mar i } \\
\text { muntanya }\end{array}$ & $\begin{array}{l}\text { gastronomía y } \\
\text { restauración }\end{array}$ & $\begin{array}{l}\text { calco + equivalente } \\
\text { acuñado }\end{array}$ & Compuesta \\
\hline 546 & $\begin{array}{l}\text { Lonely } \\
\text { Planet } \\
\text { Barcelona }\end{array}$ & ragú de jabalí & $\begin{array}{l}\text { gastronomía y } \\
\text { restauración }\end{array}$ & $\begin{array}{l}\text { amplificación + } \\
\text { préstamo }\end{array}$ & Compuesta \\
\hline 547 & $\begin{array}{l}\text { Lonely } \\
\text { Planet } \\
\text { Barcelona } \\
\end{array}$ & caldo gallego & $\begin{array}{l}\text { gastronomía y } \\
\text { restauración }\end{array}$ & $\begin{array}{l}\text { amplificación + } \\
\text { préstamo }\end{array}$ & Compuesta \\
\hline 548 & $\begin{array}{l}\text { Lonely } \\
\text { Planet } \\
\text { Barcelona }\end{array}$ & $\begin{array}{l}\text { lechazo } \\
\text { asado }\end{array}$ & $\begin{array}{l}\text { gastronomía y } \\
\text { restauración }\end{array}$ & $\begin{array}{l}\text { amplificación + } \\
\text { préstamo }\end{array}$ & Compuesta \\
\hline 549 & $\begin{array}{l}\text { Lonely } \\
\text { Planet } \\
\text { Barcelona } \\
\end{array}$ & $\begin{array}{l}\text { fideuà amb } \\
\text { cloïsses i } \\
\text { gambes }\end{array}$ & $\begin{array}{l}\text { gastronomía y } \\
\text { restauración }\end{array}$ & $\begin{array}{l}\text { amplificación + } \\
\text { préstamo }\end{array}$ & Compuesta \\
\hline 550 & $\begin{array}{l}\text { Lonely } \\
\text { Planet } \\
\text { Barcelona } \\
\end{array}$ & mariscada & $\begin{array}{l}\text { gastronomía y } \\
\text { restauración }\end{array}$ & $\begin{array}{l}\text { amplificación + } \\
\text { préstamo }\end{array}$ & Compuesta \\
\hline 551 & $\begin{array}{l}\text { Lonely } \\
\text { Planet } \\
\text { Barcelona } \\
\end{array}$ & vino turbio & $\begin{array}{l}\text { gastronomía y } \\
\text { restauración }\end{array}$ & $\begin{array}{l}\text { amplificación + } \\
\text { préstamo }\end{array}$ & Compuesta \\
\hline 552 & $\begin{array}{l}\text { Lonely } \\
\text { Planet } \\
\text { Barcelona } \\
\end{array}$ & peus de porc & $\begin{array}{l}\text { gastronomía y } \\
\text { restauración }\end{array}$ & $\begin{array}{l}\text { equivalente acuñado + } \\
\text { préstamo }\end{array}$ & Compuesta \\
\hline 553 & $\begin{array}{l}\text { Lonely } \\
\text { Planet } \\
\text { Barcelona } \\
\end{array}$ & $\begin{array}{l}\text { cochinillo } \\
\text { ibérico } \\
\text { deshuesado }\end{array}$ & $\begin{array}{l}\text { gastronomía y } \\
\text { restauración }\end{array}$ & calco + préstamo & Compuesta \\
\hline 554 & $\begin{array}{l}\text { Lonely } \\
\text { Planet } \\
\text { Barcelona }\end{array}$ & nécora & $\begin{array}{l}\text { gastronomía y } \\
\text { restauración }\end{array}$ & $\begin{array}{l}\text { amplificación + } \\
\text { préstamo }\end{array}$ & Compuesta \\
\hline 555 & $\begin{array}{l}\text { Lonely } \\
\text { Planet } \\
\text { Barcelona }\end{array}$ & cañaílla & $\begin{array}{l}\text { gastronomía y } \\
\text { restauración }\end{array}$ & $\begin{array}{l}\text { amplificación + } \\
\text { préstamo }\end{array}$ & Compuesta \\
\hline 556 & $\begin{array}{l}\text { Lonely } \\
\text { Planet } \\
\text { Barcelona } \\
\end{array}$ & \begin{tabular}{|l|} 
arroz con \\
ñora y cigalas
\end{tabular} & $\begin{array}{l}\text { gastronomía y } \\
\text { restauración }\end{array}$ & $\begin{array}{l}\text { amplificación + } \\
\text { préstamo }\end{array}$ & Compuesta \\
\hline 557 & $\begin{array}{l}\text { Lonely } \\
\text { Planet } \\
\text { Barcelona }\end{array}$ & $\begin{array}{l}\text { carrillera de } \\
\text { ternera }\end{array}$ & $\begin{array}{l}\text { gastronomía y } \\
\text { restauración }\end{array}$ & $\begin{array}{l}\text { amplificación + } \\
\text { préstamo }\end{array}$ & Compuesta \\
\hline
\end{tabular}




\begin{tabular}{|c|c|c|c|c|c|}
\hline ID & $\begin{array}{l}\text { TíTULO } \\
\text { GUÍA }\end{array}$ & $\begin{array}{l}\text { ELEMENTO } \\
\text { DE ANÁLISIS }\end{array}$ & \begin{tabular}{|l|} 
CAMPO \\
SEMÁNTICO
\end{tabular} & $\begin{array}{l}\text { TÉCNICA } \\
\text { TRADUCCIÓN }\end{array}$ & $\begin{array}{l}\text { TIPO } \\
\text { TÉCNICA }\end{array}$ \\
\hline 558 & $\begin{array}{l}\text { Lonely } \\
\text { Planet } \\
\text { Barcelona }\end{array}$ & $\begin{array}{l}\text { chuletón a la } \\
\text { parrilla }\end{array}$ & $\begin{array}{l}\text { gastronomía y } \\
\text { restauración }\end{array}$ & $\begin{array}{l}\text { amplificación + } \\
\text { préstamo }\end{array}$ & Compuesta \\
\hline 559 & $\begin{array}{l}\text { Lonely } \\
\text { Planet } \\
\text { Barcelona }\end{array}$ & $\begin{array}{l}\text { cochinillo } \\
\text { confitado } \\
\text { con peras }\end{array}$ & $\begin{array}{l}\text { gastronomía y } \\
\text { restauración }\end{array}$ & calco + préstamo & Compuesta \\
\hline 560 & $\begin{array}{l}\text { Lonely } \\
\text { Planet } \\
\text { Barcelona }\end{array}$ & $\begin{array}{l}\text { paella de } \\
\text { marisco }\end{array}$ & $\begin{array}{l}\text { gastronomía y } \\
\text { restauración }\end{array}$ & calco & Simple \\
\hline 561 & $\begin{array}{l}\text { Lonely } \\
\text { Planet } \\
\text { Barcelona } \\
\end{array}$ & $\begin{array}{l}\text { pincho } \\
\text { moruno de } \\
\text { pollo }\end{array}$ & $\begin{array}{l}\text { gastronomía y } \\
\text { restauración }\end{array}$ & $\begin{array}{l}\text { amplificación + } \\
\text { préstamo }\end{array}$ & Compuesta \\
\hline 562 & $\begin{array}{l}\text { Lonely } \\
\text { Planet } \\
\text { Barcelona }\end{array}$ & montadito & $\begin{array}{l}\text { gastronomía y } \\
\text { restauración }\end{array}$ & $\begin{array}{l}\text { amplificación + } \\
\text { préstamo }\end{array}$ & Compuesta \\
\hline 563 & $\begin{array}{l}\text { Lonely } \\
\text { Planet } \\
\text { Barcelona } \\
\end{array}$ & empanadilla & $\begin{array}{l}\text { gastronomía y } \\
\text { restauración }\end{array}$ & calco + préstamo & Compuesta \\
\hline 564 & $\begin{array}{l}\text { Lonely } \\
\text { Planet } \\
\text { Barcelona } \\
\end{array}$ & $\begin{array}{l}\text { buñuelos de } \\
\text { chocolate }\end{array}$ & $\begin{array}{l}\text { gastronomía y } \\
\text { restauración }\end{array}$ & $\begin{array}{l}\text { amplificación + } \\
\text { préstamo }\end{array}$ & Compuesta \\
\hline 565 & $\begin{array}{l}\text { Lonely } \\
\text { Planet } \\
\text { Barcelona } \\
\end{array}$ & percebes & $\begin{array}{l}\text { gastronomía y } \\
\text { restauración }\end{array}$ & $\begin{array}{l}\text { amplificación + } \\
\text { préstamo }\end{array}$ & Compuesta \\
\hline 566 & $\begin{array}{l}\text { Lonely } \\
\text { Planet } \\
\text { Barcelona } \\
\end{array}$ & croquetas & $\begin{array}{l}\text { gastronomía y } \\
\text { restauración }\end{array}$ & calco + préstamo & Compuesta \\
\hline 567 & $\begin{array}{l}\text { Lonely } \\
\text { Planet } \\
\text { Barcelona } \\
\end{array}$ & merguez & $\begin{array}{l}\text { gastronomía y } \\
\text { restauración }\end{array}$ & $\begin{array}{l}\text { amplificación + } \\
\text { préstamo }\end{array}$ & Compuesta \\
\hline 568 & $\begin{array}{l}\text { Lonely } \\
\text { Planet } \\
\text { Barcelona }\end{array}$ & kefta & $\begin{array}{l}\text { gastronomía y } \\
\text { restauración }\end{array}$ & $\begin{array}{l}\text { amplificación + } \\
\text { préstamo }\end{array}$ & Compuesta \\
\hline 569 & $\begin{array}{l}\text { Lonely } \\
\text { Planet } \\
\text { Barcelona }\end{array}$ & tajine & $\begin{array}{l}\text { gastronomía y } \\
\text { restauración }\end{array}$ & $\begin{array}{l}\text { amplificación + } \\
\text { préstamo }\end{array}$ & Compuesta \\
\hline 570 & $\begin{array}{l}\text { Lonely } \\
\text { Planet } \\
\text { Barcelona } \\
\end{array}$ & $\begin{array}{l}\text { filete de toro } \\
\text { a la crema de } \\
\text { foie }\end{array}$ & $\begin{array}{l}\text { gastronomía y } \\
\text { restauración }\end{array}$ & $\begin{array}{l}\text { amplificación + } \\
\text { préstamo }\end{array}$ & Compuesta \\
\hline 571 & $\begin{array}{l}\text { Lonely } \\
\text { Planet } \\
\text { Barcelona }\end{array}$ & $\begin{array}{l}\text { caragols a la } \\
\text { llauna }\end{array}$ & $\begin{array}{l}\text { gastronomía y } \\
\text { restauración }\end{array}$ & $\begin{array}{l}\text { amplificación + } \\
\text { préstamo }\end{array}$ & Compuesta \\
\hline
\end{tabular}




\begin{tabular}{|c|c|c|c|c|c|}
\hline ID & $\begin{array}{l}\text { TíTULO } \\
\text { GUÍA }\end{array}$ & $\begin{array}{l}\text { ELEMENTO } \\
\text { DE ANÁLISIS }\end{array}$ & $\begin{array}{l}\text { CAMPO } \\
\text { SEMÁNTICO }\end{array}$ & $\begin{array}{l}\text { TÉCNICA } \\
\text { TRADUCCIÓN }\end{array}$ & $\begin{array}{l}\text { TIPO } \\
\text { TÉCNICA }\end{array}$ \\
\hline 572 & $\begin{array}{l}\text { Lonely } \\
\text { Planet } \\
\text { Barcelona }\end{array}$ & $\begin{array}{l}\text { tocinillo de } \\
\text { cielo }\end{array}$ & $\begin{array}{l}\text { gastronomía y } \\
\text { restauración }\end{array}$ & $\begin{array}{l}\text { amplificación + } \\
\text { préstamo }\end{array}$ & Compuesta \\
\hline 573 & $\begin{array}{l}\text { Lonely } \\
\text { Planet } \\
\text { Barcelona }\end{array}$ & $\begin{array}{l}\text { parrillada de } \\
\text { verduras }\end{array}$ & $\begin{array}{l}\text { gastronomía y } \\
\text { restauración }\end{array}$ & $\begin{array}{l}\text { amplificación + } \\
\text { préstamo }\end{array}$ & Compuesta \\
\hline 574 & $\begin{array}{l}\text { Lonely } \\
\text { Planet } \\
\text { Barcelona }\end{array}$ & sardana & $\begin{array}{l}\text { fiestas y } \\
\text { espectáculos }\end{array}$ & $\begin{array}{l}\text { amplificación + } \\
\text { préstamo }\end{array}$ & Compuesta \\
\hline 575 & $\begin{array}{l}\text { Lonely } \\
\text { Planet } \\
\text { Barcelona } \\
\end{array}$ & tablao & $\begin{array}{l}\text { fiestas y } \\
\text { espectáculos }\end{array}$ & $\begin{array}{l}\text { amplificación + } \\
\text { préstamo }\end{array}$ & Compuesta \\
\hline 576 & $\begin{array}{l}\text { Lonely } \\
\text { Planet } \\
\text { Barcelona } \\
\end{array}$ & fado & $\begin{array}{l}\text { fiestas y } \\
\text { espectáculos }\end{array}$ & préstamo & Simple \\
\hline 577 & $\begin{array}{l}\text { Lonely } \\
\text { Planet } \\
\text { Barcelona }\end{array}$ & $\begin{array}{l}\text { peña } \\
\text { flamenca }\end{array}$ & $\begin{array}{l}\text { fiestas y } \\
\text { espectáculos }\end{array}$ & adaptación & Simple \\
\hline 578 & $\begin{array}{l}\text { Lonely } \\
\text { Planet } \\
\text { Barcelona } \\
\end{array}$ & bailaora & $\begin{array}{l}\text { fiestas y } \\
\text { espectáculos }\end{array}$ & $\begin{array}{l}\text { amplificación + } \\
\text { préstamo }\end{array}$ & Compuesta \\
\hline 579 & $\begin{array}{l}\text { Lonely } \\
\text { Planet } \\
\text { Barcelona } \\
\end{array}$ & $\begin{array}{l}\text { vino de la } \\
\text { casa }\end{array}$ & $\begin{array}{l}\text { gastronomía y } \\
\text { restauración }\end{array}$ & $\begin{array}{l}\text { calco + amplificación + } \\
\text { préstamo }\end{array}$ & Compuesta \\
\hline 580 & $\begin{array}{l}\text { Lonely } \\
\text { Planet } \\
\text { Barcelona } \\
\end{array}$ & calimocho & $\begin{array}{l}\text { gastronomía y } \\
\text { restauración }\end{array}$ & $\begin{array}{l}\text { amplificación + } \\
\text { préstamo }\end{array}$ & Compuesta \\
\hline 581 & $\begin{array}{l}\text { Lonely } \\
\text { Planet } \\
\text { Barcelona } \\
\end{array}$ & sangría & $\begin{array}{l}\text { gastronomía y } \\
\text { restauración }\end{array}$ & $\begin{array}{l}\text { amplificación + } \\
\text { préstamo }\end{array}$ & Compuesta \\
\hline 582 & $\begin{array}{l}\text { Lonely } \\
\text { Planet } \\
\text { Barcelona }\end{array}$ & $\begin{array}{l}\text { sangría de } \\
\text { cava }\end{array}$ & $\begin{array}{l}\text { gastronomía y } \\
\text { restauración }\end{array}$ & $\begin{array}{l}\text { amplificación + } \\
\text { préstamo }\end{array}$ & Compuesta \\
\hline 583 & $\begin{array}{l}\text { Lonely } \\
\text { Planet } \\
\text { Barcelona }\end{array}$ & $\begin{array}{l}\text { tinto de } \\
\text { verano }\end{array}$ & $\begin{array}{l}\text { gastronomía y } \\
\text { restauración }\end{array}$ & $\begin{array}{l}\text { calco + amplificación + } \\
\text { préstamo }\end{array}$ & Compuesta \\
\hline 584 & $\begin{array}{l}\text { Lonely } \\
\text { Planet } \\
\text { Barcelona } \\
\end{array}$ & gaseosa & $\begin{array}{l}\text { gastronomía y } \\
\text { restauración }\end{array}$ & $\begin{array}{l}\text { amplificación + } \\
\text { préstamo }\end{array}$ & Compuesta \\
\hline 585 & $\begin{array}{l}\text { Lonely } \\
\text { Planet } \\
\text { Barcelona }\end{array}$ & clara & $\begin{array}{l}\text { gastronomía y } \\
\text { restauración }\end{array}$ & $\begin{array}{l}\text { amplificación }+ \\
\text { equivalente acuñado + } \\
\text { préstamo }\end{array}$ & Compuesta \\
\hline
\end{tabular}




\begin{tabular}{|c|c|c|c|c|c|}
\hline ID & \begin{tabular}{|l|} 
TÍTULO \\
GUÍA
\end{tabular} & $\begin{array}{l}\text { ELEMENTO } \\
\text { DE ANÁLISIS }\end{array}$ & \begin{tabular}{|l|} 
CAMPO \\
SEMÁNTICO
\end{tabular} & $\begin{array}{l}\text { TÉCNICA } \\
\text { TRADUCCIÓN }\end{array}$ & $\begin{array}{l}\text { TIPO } \\
\text { TÉCNICA }\end{array}$ \\
\hline 586 & $\begin{array}{l}\text { Lonely } \\
\text { Planet } \\
\text { Barcelona }\end{array}$ & chupito & $\begin{array}{l}\text { gastronomía y } \\
\text { restauración }\end{array}$ & $\begin{array}{l}\text { amplificación + } \\
\text { préstamo }\end{array}$ & Compuesta \\
\hline 587 & $\begin{array}{l}\text { Lonely } \\
\text { Planet } \\
\text { Barcelona }\end{array}$ & orujo & $\begin{array}{l}\text { gastronomía y } \\
\text { restauración }\end{array}$ & $\begin{array}{l}\text { adaptación + } \\
\text { amplificación + } \\
\text { préstamo }\end{array}$ & Compuesta \\
\hline 588 & \begin{tabular}{|l|} 
Lonely \\
Planet \\
Barcelona
\end{tabular} & ratafia & $\begin{array}{l}\text { gastronomía y } \\
\text { restauración }\end{array}$ & $\begin{array}{l}\text { adaptación + } \\
\text { amplificación + } \\
\text { préstamo }\end{array}$ & Compuesta \\
\hline 589 & \begin{tabular}{|l} 
Lonely \\
Planet \\
Barcelona
\end{tabular} & día de reyes & $\begin{array}{l}\text { fiestas y } \\
\text { espectáculos }\end{array}$ & calco + préstamo & Compuesta \\
\hline 590 & \begin{tabular}{|l|} 
Lonely \\
Planet \\
Barcelona \\
\end{tabular} & $\begin{array}{l}\text { festes dels } \\
\text { tres tombs }\end{array}$ & $\begin{array}{l}\text { fiestas y } \\
\text { espectáculos }\end{array}$ & $\begin{array}{l}\text { calco + amplificación + } \\
\text { préstamo }\end{array}$ & Compuesta \\
\hline 591 & $\begin{array}{l}\text { Lonely } \\
\text { Planet } \\
\text { Barcelona }\end{array}$ & carnaval & $\begin{array}{l}\text { fiestas y } \\
\text { espectáculos }\end{array}$ & $\begin{array}{l}\text { amplificación + } \\
\text { préstamo }\end{array}$ & Compuesta \\
\hline 592 & \begin{tabular}{|l} 
Lonely \\
Planet \\
Barcelona \\
\end{tabular} & $\begin{array}{l}\text { festes de } \\
\text { santa eulàlia }\end{array}$ & $\begin{array}{l}\text { fiestas y } \\
\text { espectáculos }\end{array}$ & amplificación & Simple \\
\hline 593 & \begin{tabular}{|l} 
Lonely \\
Planet \\
Barcelona \\
\end{tabular} & castellers & $\begin{array}{l}\text { fiestas y } \\
\text { espectáculos }\end{array}$ & $\begin{array}{l}\text { amplificación + } \\
\text { préstamo }\end{array}$ & Compuesta \\
\hline 594 & $\begin{array}{l}\text { Lonely } \\
\text { Planet } \\
\text { Barcelona } \\
\end{array}$ & sant jordi & \begin{tabular}{|l|} 
fiestas y \\
espectáculos
\end{tabular} & $\begin{array}{l}\text { amplificación }+ \\
\text { equivalente acuñado + } \\
\text { préstamo }\end{array}$ & Compuesta \\
\hline 595 & \begin{tabular}{|l} 
Lonely \\
Planet \\
Barcelona \\
\end{tabular} & $\begin{array}{l}\text { verbena de } \mathrm{s} . \\
\text { Joan }\end{array}$ & $\begin{array}{l}\text { fiestas y } \\
\text { espectáculos }\end{array}$ & $\begin{array}{l}\text { calco + amplificación + } \\
\text { préstamo }\end{array}$ & Compuesta \\
\hline 596 & $\begin{array}{l}\text { Lonely } \\
\text { Planet } \\
\text { Barcelona }\end{array}$ & correfoc & $\begin{array}{l}\text { fiestas y } \\
\text { espectáculos }\end{array}$ & $\begin{array}{l}\text { amplificación + } \\
\text { préstamo }\end{array}$ & Compuesta \\
\hline 597 & $\begin{array}{l}\text { Lonely } \\
\text { Planet } \\
\text { Barcelona }\end{array}$ & $\begin{array}{l}\text { l'ou com } \\
\text { balla }\end{array}$ & $\begin{array}{l}\text { fiestas y } \\
\text { espectáculos }\end{array}$ & $\begin{array}{l}\text { calco + amplificación + } \\
\text { préstamo }\end{array}$ & Compuesta \\
\hline 598 & \begin{tabular}{|l} 
Lonely \\
Planet \\
Barcelona \\
\end{tabular} & klezmer & $\begin{array}{l}\text { fiestas y } \\
\text { espectáculos }\end{array}$ & $\begin{array}{l}\text { amplificación + } \\
\text { préstamo }\end{array}$ & Compuesta \\
\hline 599 & \begin{tabular}{|l|} 
Lonely \\
Planet \\
Barcelona
\end{tabular} & $\begin{array}{l}\text { palau de la } \\
\text { musica }\end{array}$ & música & préstamo & Simple \\
\hline
\end{tabular}




\begin{tabular}{|c|c|c|c|c|c|}
\hline ID & \begin{tabular}{|l|} 
TÍTULO \\
GUÍA
\end{tabular} & $\begin{array}{l}\text { ELEMENTO } \\
\text { DE ANÁLISIS }\end{array}$ & \begin{tabular}{|l|} 
CAMPO \\
SEMÁNTICO \\
\end{tabular} & \begin{tabular}{|l|} 
TÉCNICA \\
TRADUCCIÓN
\end{tabular} & $\begin{array}{l}\text { TIPO } \\
\text { TÉCNICA }\end{array}$ \\
\hline 600 & $\begin{array}{l}\text { Lonely } \\
\text { Planet } \\
\text { Barcelona }\end{array}$ & fado & música & préstamo & Simple \\
\hline 601 & $\begin{array}{l}\text { Lonely } \\
\text { Planet } \\
\text { Barcelona }\end{array}$ & castells & $\begin{array}{l}\text { fiestas y } \\
\text { espectáculos }\end{array}$ & calco + préstamo & Compuesta \\
\hline 602 & $\begin{array}{l}\text { Lonely } \\
\text { Planet } \\
\text { Barcelona }\end{array}$ & anxaneta & $\begin{array}{l}\text { fiestas y } \\
\text { espectáculos }\end{array}$ & $\begin{array}{l}\text { amplificación + } \\
\text { préstamo }\end{array}$ & Compuesta \\
\hline 603 & \begin{tabular}{|l} 
Lonely \\
Planet \\
Barcelona \\
\end{tabular} & folre & $\begin{array}{l}\text { fiestas y } \\
\text { espectáculos }\end{array}$ & $\begin{array}{l}\text { amplificación + } \\
\text { préstamo }\end{array}$ & Compuesta \\
\hline 604 & $\begin{array}{l}\text { Lonely } \\
\text { Planet } \\
\text { Madrid }\end{array}$ & $\begin{array}{l}\text { las } 12 \\
\text { campanadas }\end{array}$ & $\begin{array}{l}\text { fiestas y } \\
\text { espectáculos }\end{array}$ & calco + préstamo & Compuesta \\
\hline 605 & $\begin{array}{l}\text { Lonely } \\
\text { Planet } \\
\text { Madrid }\end{array}$ & puente & viaje & $\begin{array}{l}\text { equivalente acuñado + } \\
\text { préstamo }\end{array}$ & Compuesta \\
\hline 606 & $\begin{array}{l}\text { Lonely } \\
\text { Planet } \\
\text { Madrid } \\
\end{array}$ & $\begin{array}{l}\text { cabalgata de } \\
\text { los reyes } \\
\text { magos }\end{array}$ & $\begin{array}{l}\text { fiestas y } \\
\text { espectáculos }\end{array}$ & $\begin{array}{l}\text { amplificación + } \\
\text { préstamo }\end{array}$ & Compuesta \\
\hline 607 & $\begin{array}{l}\text { Lonely } \\
\text { Planet } \\
\text { Madrid }\end{array}$ & tablao & $\begin{array}{l}\text { fiestas y } \\
\text { espectáculos }\end{array}$ & $\begin{array}{l}\text { amplificación + } \\
\text { préstamo }\end{array}$ & Compuesta \\
\hline 608 & $\begin{array}{l}\text { Lonely } \\
\text { Planet } \\
\text { Madrid }\end{array}$ & san isidro & \begin{tabular}{|l|} 
fiestas y \\
espectáculos
\end{tabular} & $\begin{array}{l}\text { calco + amplificación + } \\
\text { préstamo }\end{array}$ & Compuesta \\
\hline 609 & $\begin{array}{l}\text { Lonely } \\
\text { Planet } \\
\text { Madrid } \\
\end{array}$ & barquillos & $\begin{array}{l}\text { gastronomía y } \\
\text { restauración }\end{array}$ & $\begin{array}{l}\text { amplificación + } \\
\text { préstamo }\end{array}$ & Compuesta \\
\hline 610 & $\begin{array}{l}\text { Lonely } \\
\text { Planet } \\
\text { Madrid }\end{array}$ & $\begin{array}{l}\text { la noche en } \\
\text { blanco }\end{array}$ & $\begin{array}{l}\text { fiestas y } \\
\text { espectáculos }\end{array}$ & calco + préstamo & Compuesta \\
\hline 611 & $\begin{array}{l}\text { Lonely } \\
\text { Planet } \\
\text { Madrid }\end{array}$ & $\begin{array}{l}\text { veranos de la } \\
\text { villas }\end{array}$ & $\begin{array}{l}\text { fiestas y } \\
\text { espectáculos }\end{array}$ & $\begin{array}{l}\text { calco + amplificación + } \\
\text { préstamo }\end{array}$ & Compuesta \\
\hline 612 & $\begin{array}{l}\text { Lonely } \\
\text { Planet } \\
\text { Madrid }\end{array}$ & $\begin{array}{l}\text { fiesta de } \\
\text { otoño }\end{array}$ & $\begin{array}{l}\text { fiestas y } \\
\text { espectáculos }\end{array}$ & $\begin{array}{l}\text { calco + amplificación + } \\
\text { préstamo }\end{array}$ & Compuesta \\
\hline 613 & $\begin{array}{l}\text { Lonely } \\
\text { Planet } \\
\text { Madrid }\end{array}$ & castizo & $\begin{array}{l}\text { fiestas y } \\
\text { espectáculos }\end{array}$ & $\begin{array}{l}\text { amplificación + } \\
\text { préstamo }\end{array}$ & Compuesta \\
\hline
\end{tabular}




\begin{tabular}{|c|c|c|c|c|c|}
\hline ID & \begin{tabular}{|l} 
TíTULO \\
GUÍA
\end{tabular} & $\begin{array}{l}\text { ELEMENTO } \\
\text { DE ANÁLISIS }\end{array}$ & $\begin{array}{l}\text { CAMPO } \\
\text { SEMÁNTICO }\end{array}$ & $\begin{array}{l}\text { TÉCNICA } \\
\text { TRADUCCIÓN }\end{array}$ & \begin{tabular}{|l} 
TIPO \\
TÉCNICA
\end{tabular} \\
\hline 614 & $\begin{array}{l}\text { Lonely } \\
\text { Planet } \\
\text { Madrid }\end{array}$ & besapié & $\begin{array}{l}\text { fiestas y } \\
\text { espectáculos }\end{array}$ & $\begin{array}{l}\text { calco + amplificación + } \\
\text { préstamo }\end{array}$ & Compuesta \\
\hline 615 & $\begin{array}{l}\text { Lonely } \\
\text { Planet } \\
\text { Madrid }\end{array}$ & chulapo & $\begin{array}{l}\text { fiestas y } \\
\text { espectáculos }\end{array}$ & $\begin{array}{l}\text { amplificación + } \\
\text { préstamo }\end{array}$ & Compuesta \\
\hline 616 & $\begin{array}{l}\text { Lonely } \\
\text { Planet } \\
\text { Madrid }\end{array}$ & manola & $\begin{array}{l}\text { fiestas y } \\
\text { espectáculos }\end{array}$ & $\begin{array}{l}\text { amplificación + } \\
\text { préstamo }\end{array}$ & Compuesta \\
\hline 617 & $\begin{array}{l}\text { Lonely } \\
\text { Planet } \\
\text { Madrid }\end{array}$ & $\begin{array}{l}\text { mantón de } \\
\text { manila }\end{array}$ & $\begin{array}{l}\text { fiestas y } \\
\text { espectáculos }\end{array}$ & $\begin{array}{l}\text { amplificación + } \\
\text { préstamo }\end{array}$ & Compuesta \\
\hline 618 & $\begin{array}{l}\text { Lonely } \\
\text { Planet } \\
\text { Madrid }\end{array}$ & chotis & $\begin{array}{l}\text { fiestas y } \\
\text { espectáculos }\end{array}$ & $\begin{array}{l}\text { adaptación + } \\
\text { amplificación + } \\
\text { préstamo }\end{array}$ & Compuesta \\
\hline 619 & $\begin{array}{l}\text { Lonely } \\
\text { Planet } \\
\text { Madrid }\end{array}$ & zarzuela & música & $\begin{array}{l}\text { amplificación + } \\
\text { préstamo }\end{array}$ & Compuesta \\
\hline 620 & $\begin{array}{l}\text { Lonely } \\
\text { Planet } \\
\text { Madrid } \\
\end{array}$ & movida & $\begin{array}{l}\text { fiestas y } \\
\text { espectáculos }\end{array}$ & préstamo & Simple \\
\hline 621 & $\begin{array}{l}\text { Lonely } \\
\text { Planet } \\
\text { Madrid }\end{array}$ & zarzuela & música & $\begin{array}{l}\text { amplificación + } \\
\text { préstamo }\end{array}$ & Compuesta \\
\hline 622 & $\begin{array}{l}\text { Lonely } \\
\text { Planet } \\
\text { Madrid }\end{array}$ & $\begin{array}{l}\text { callos a la } \\
\text { madrileña }\end{array}$ & $\begin{array}{l}\text { gastronomía y } \\
\text { restauración }\end{array}$ & $\begin{array}{l}\text { amplificación + } \\
\text { préstamo }\end{array}$ & Compuesta \\
\hline 623 & $\begin{array}{l}\text { Lonely } \\
\text { Planet } \\
\text { Madrid } \\
\end{array}$ & $\begin{array}{l}\text { cocido a la } \\
\text { madrileña }\end{array}$ & $\begin{array}{l}\text { gastronomía y } \\
\text { restauración }\end{array}$ & calco + préstamo & Compuesta \\
\hline 624 & $\begin{array}{l}\text { Lonely } \\
\text { Planet } \\
\text { Madrid }\end{array}$ & sopa de ajo & $\begin{array}{l}\text { gastronomía y } \\
\text { restauración }\end{array}$ & $\begin{array}{l}\text { amplificación + } \\
\text { préstamo }\end{array}$ & Compuesta \\
\hline 625 & $\begin{array}{l}\text { Lonely } \\
\text { Planet } \\
\text { Madrid }\end{array}$ & $\begin{array}{l}\text { chocolate } \\
\text { con churros }\end{array}$ & $\begin{array}{l}\text { gastronomía y } \\
\text { restauración }\end{array}$ & $\begin{array}{l}\text { adaptación + } \\
\text { amplificación + } \\
\text { préstamo }\end{array}$ & Compuesta \\
\hline 626 & $\begin{array}{l}\text { Lonely } \\
\text { Planet } \\
\text { Madrid }\end{array}$ & $\begin{array}{l}\text { bocadillo de } \\
\text { calamares }\end{array}$ & $\begin{array}{l}\text { gastronomía y } \\
\text { restauración }\end{array}$ & $\begin{array}{l}\text { amplificación + } \\
\text { préstamo }\end{array}$ & Compuesta \\
\hline 627 & $\begin{array}{l}\text { Lonely } \\
\text { Planet } \\
\text { Madrid }\end{array}$ & $\begin{array}{l}\text { cocido a la } \\
\text { madrileña }\end{array}$ & $\begin{array}{l}\text { gastronomía y } \\
\text { restauración }\end{array}$ & $\begin{array}{l}\text { amplificación + } \\
\text { préstamo }\end{array}$ & Compuesta \\
\hline
\end{tabular}




\begin{tabular}{|c|c|c|c|c|c|}
\hline ID & \begin{tabular}{|l} 
TíTULO \\
GUÍA
\end{tabular} & $\begin{array}{l}\text { ELEMENTO } \\
\text { DE ANÁLISIS }\end{array}$ & \begin{tabular}{|l|} 
CAMPO \\
SEMÁNTICO
\end{tabular} & $\begin{array}{l}\text { TÉCNICA } \\
\text { TRADUCCIÓN }\end{array}$ & $\begin{array}{l}\text { TIPO } \\
\text { TÉCNICA }\end{array}$ \\
\hline 628 & $\begin{array}{l}\text { Lonely } \\
\text { Planet } \\
\text { Madrid }\end{array}$ & $\begin{array}{l}\text { cordero } \\
\text { asado }\end{array}$ & $\begin{array}{l}\text { gastronomía y } \\
\text { restauración }\end{array}$ & calco + préstamo & Compuesta \\
\hline 629 & $\begin{array}{l}\text { Lonely } \\
\text { Planet } \\
\text { Madrid }\end{array}$ & $\begin{array}{l}\text { patatas con } \\
\text { huevos fritos }\end{array}$ & $\begin{array}{l}\text { gastronomía y } \\
\text { restauración }\end{array}$ & $\begin{array}{l}\text { amplificación + } \\
\text { préstamo }\end{array}$ & Compuesta \\
\hline 630 & $\begin{array}{l}\text { Lonely } \\
\text { Planet } \\
\text { Madrid }\end{array}$ & $\begin{array}{l}\text { tortilla de } \\
\text { patata }\end{array}$ & $\begin{array}{l}\text { gastronomía y } \\
\text { restauración }\end{array}$ & $\begin{array}{l}\text { amplificación + } \\
\text { préstamo }\end{array}$ & Compuesta \\
\hline 631 & $\begin{array}{l}\text { Lonely } \\
\text { Planet } \\
\text { Madrid }\end{array}$ & torreznos & $\begin{array}{l}\text { gastronomía y } \\
\text { restauración }\end{array}$ & $\begin{array}{l}\text { amplificación + } \\
\text { préstamo }\end{array}$ & Compuesta \\
\hline 632 & $\begin{array}{l}\text { Lonely } \\
\text { Planet } \\
\text { Madrid }\end{array}$ & albóndigas & $\begin{array}{l}\text { gastronomía y } \\
\text { restauración }\end{array}$ & $\begin{array}{l}\text { amplificación + } \\
\text { préstamo }\end{array}$ & Compuesta \\
\hline 633 & $\begin{array}{l}\text { Lonely } \\
\text { Planet } \\
\text { Madrid }\end{array}$ & jamón & $\begin{array}{l}\text { gastronomía y } \\
\text { restauración }\end{array}$ & préstamo & Simple \\
\hline 634 & $\begin{array}{l}\text { Lonely } \\
\text { Planet } \\
\text { Madrid }\end{array}$ & pintxos & $\begin{array}{l}\text { gastronomía y } \\
\text { restauración }\end{array}$ & $\begin{array}{l}\text { amplificación + } \\
\text { préstamo }\end{array}$ & Compuesta \\
\hline 635 & $\begin{array}{l}\text { Lonely } \\
\text { Planet } \\
\text { Madrid }\end{array}$ & tostas & $\begin{array}{l}\text { gastronomía y } \\
\text { restauración }\end{array}$ & $\begin{array}{l}\text { amplificación }+ \\
\text { equivalente acuñado }\end{array}$ & Compuesta \\
\hline 636 & $\begin{array}{l}\text { Lonely } \\
\text { Planet } \\
\text { Madrid }\end{array}$ & taberna & $\begin{array}{l}\text { gastronomía y } \\
\text { restauración }\end{array}$ & préstamo & Simple \\
\hline 637 & $\begin{array}{l}\text { Lonely } \\
\text { Planet } \\
\text { Madrid } \\
\end{array}$ & huevos rotos & $\begin{array}{l}\text { gastronomía y } \\
\text { restauración }\end{array}$ & calco + préstamo & Compuesta \\
\hline 638 & $\begin{array}{l}\text { Lonely } \\
\text { Planet } \\
\text { Madrid }\end{array}$ & chato & $\begin{array}{l}\text { gastronomía y } \\
\text { restauración }\end{array}$ & $\begin{array}{l}\text { amplificación + } \\
\text { préstamo }\end{array}$ & Compuesta \\
\hline 639 & $\begin{array}{l}\text { Lonely } \\
\text { Planet } \\
\text { Madrid }\end{array}$ & $\begin{array}{l}\text { gambas al } \\
\text { ajillo }\end{array}$ & $\begin{array}{l}\text { gastronomía y } \\
\text { restauración }\end{array}$ & $\begin{array}{l}\text { amplificación + } \\
\text { préstamo }\end{array}$ & Compuesta \\
\hline 640 & $\begin{array}{l}\text { Lonely } \\
\text { Planet } \\
\text { Madrid }\end{array}$ & cojimar & $\begin{array}{l}\text { gastronomía y } \\
\text { restauración }\end{array}$ & $\begin{array}{l}\text { amplificación + } \\
\text { préstamo }\end{array}$ & Compuesta \\
\hline 641 & $\begin{array}{l}\text { Lonely } \\
\text { Planet } \\
\text { Madrid }\end{array}$ & $\begin{array}{l}\text { oreja a la } \\
\text { plancha }\end{array}$ & $\begin{array}{l}\text { gastronomía y } \\
\text { restauración }\end{array}$ & calco + préstamo & Compuesta \\
\hline
\end{tabular}




\begin{tabular}{|c|c|c|c|c|c|}
\hline ID & \begin{tabular}{|l} 
TíTULO \\
GUÍA
\end{tabular} & $\begin{array}{l}\text { ELEMENTO } \\
\text { DE ANÁLISIS }\end{array}$ & \begin{tabular}{|l|} 
CAMPO \\
SEMÁNTICO
\end{tabular} & $\begin{array}{l}\text { TÉCNICA } \\
\text { TRADUCCIÓN }\end{array}$ & $\begin{array}{l}\text { TIPO } \\
\text { TÉCNICA }\end{array}$ \\
\hline 642 & $\begin{array}{l}\text { Lonely } \\
\text { Planet } \\
\text { Madrid }\end{array}$ & $\begin{array}{l}\text { pulpo a la } \\
\text { gallega }\end{array}$ & $\begin{array}{l}\text { gastronomía y } \\
\text { restauración }\end{array}$ & calco + préstamo & Compuesta \\
\hline 643 & $\begin{array}{l}\text { Lonely } \\
\text { Planet } \\
\text { Madrid }\end{array}$ & caña & $\begin{array}{l}\text { gastronomía y } \\
\text { restauración }\end{array}$ & $\begin{array}{l}\text { amplificación + } \\
\text { préstamo }\end{array}$ & Compuesta \\
\hline 644 & $\begin{array}{l}\text { Lonely } \\
\text { Planet } \\
\text { Madrid }\end{array}$ & salmorejo & $\begin{array}{l}\text { gastronomía y } \\
\text { restauración }\end{array}$ & $\begin{array}{l}\text { amplificación + } \\
\text { préstamo }\end{array}$ & Compuesta \\
\hline 645 & $\begin{array}{l}\text { Lonely } \\
\text { Planet } \\
\text { Madrid }\end{array}$ & chistorra & $\begin{array}{l}\text { gastronomía y } \\
\text { restauración }\end{array}$ & $\begin{array}{l}\text { amplificación + } \\
\text { préstamo }\end{array}$ & Compuesta \\
\hline 646 & $\begin{array}{l}\text { Lonely } \\
\text { Planet } \\
\text { Madrid }\end{array}$ & ruso & $\begin{array}{l}\text { gastronomía y } \\
\text { restauración }\end{array}$ & $\begin{array}{l}\text { amplificación + } \\
\text { préstamo }\end{array}$ & Compuesta \\
\hline 647 & $\begin{array}{l}\text { Lonely } \\
\text { Planet } \\
\text { Madrid }\end{array}$ & $\begin{array}{l}\text { tarta } \\
\text { milhojas }\end{array}$ & $\begin{array}{l}\text { gastronomía y } \\
\text { restauración }\end{array}$ & $\begin{array}{l}\text { amplificación + } \\
\text { préstamo }\end{array}$ & Compuesta \\
\hline 648 & $\begin{array}{l}\text { Lonely } \\
\text { Planet } \\
\text { Madrid }\end{array}$ & pisto & $\begin{array}{l}\text { gastronomía y } \\
\text { restauración }\end{array}$ & préstamo & Simple \\
\hline 649 & $\begin{array}{l}\text { Lonely } \\
\text { Planet } \\
\text { Madrid } \\
\end{array}$ & $\begin{array}{l}\text { berenjena } \\
\text { con miel de } \\
\text { caña }\end{array}$ & $\begin{array}{l}\text { gastronomía y } \\
\text { restauración }\end{array}$ & $\begin{array}{l}\text { amplificación + } \\
\text { préstamo }\end{array}$ & Compuesta \\
\hline 650 & $\begin{array}{l}\text { Lonely } \\
\text { Planet } \\
\text { Madrid }\end{array}$ & $\begin{array}{l}\text { fabada } \\
\text { asturiana }\end{array}$ & $\begin{array}{l}\text { gastronomía y } \\
\text { restauración }\end{array}$ & $\begin{array}{l}\text { amplificación + } \\
\text { préstamo }\end{array}$ & Compuesta \\
\hline 651 & $\begin{array}{l}\text { Lonely } \\
\text { Planet } \\
\text { Madrid } \\
\end{array}$ & sidra & $\begin{array}{l}\text { gastronomía y } \\
\text { restauración }\end{array}$ & $\begin{array}{l}\text { equivalente acuñado + } \\
\text { préstamo }\end{array}$ & Compuesta \\
\hline 652 & $\begin{array}{l}\text { Lonely } \\
\text { Planet } \\
\text { Madrid }\end{array}$ & callos & $\begin{array}{l}\text { gastronomía y } \\
\text { restauración }\end{array}$ & préstamo & Simple \\
\hline 653 & $\begin{array}{l}\text { Lonely } \\
\text { Planet } \\
\text { Madrid }\end{array}$ & $\begin{array}{l}\text { calamares en } \\
\text { su tinta }\end{array}$ & $\begin{array}{l}\text { gastronomía y } \\
\text { restauración }\end{array}$ & calco + préstamo & Compuesta \\
\hline 654 & $\begin{array}{l}\text { Lonely } \\
\text { Planet } \\
\text { Madrid }\end{array}$ & pollo asado & $\begin{array}{l}\text { gastronomía y } \\
\text { restauración }\end{array}$ & calco + préstamo & Compuesta \\
\hline 655 & $\begin{array}{l}\text { Lonely } \\
\text { Planet } \\
\text { Madrid }\end{array}$ & $\begin{array}{l}\text { queso de } \\
\text { cabrales }\end{array}$ & $\begin{array}{l}\text { gastronomía y } \\
\text { restauración }\end{array}$ & $\begin{array}{l}\text { amplificación + } \\
\text { préstamo }\end{array}$ & Compuesta \\
\hline
\end{tabular}




\begin{tabular}{|c|c|c|c|c|c|}
\hline ID & \begin{tabular}{|l|} 
TíTULO \\
GUÍA \\
\end{tabular} & $\begin{array}{l}\text { ELEMENTO } \\
\text { DE ANÁLISIS }\end{array}$ & \begin{tabular}{|l|} 
CAMPO \\
SEMÁNTICO \\
\end{tabular} & $\begin{array}{l}\text { TÉCNICA } \\
\text { TRADUCCIÓN }\end{array}$ & $\begin{array}{l}\text { TIPO } \\
\text { TÉCNICA }\end{array}$ \\
\hline 656 & $\begin{array}{l}\text { Lonely } \\
\text { Planet } \\
\text { Madrid }\end{array}$ & $\begin{array}{l}\text { chorizo a la } \\
\text { sidra }\end{array}$ & $\begin{array}{l}\text { gastronomía y } \\
\text { restauración }\end{array}$ & calco + préstamo & Compuesta \\
\hline 657 & $\begin{array}{l}\text { Lonely } \\
\text { Planet } \\
\text { Madrid }\end{array}$ & vino de mesa & $\begin{array}{l}\text { gastronomía y } \\
\text { restauración }\end{array}$ & calco + préstamo & Compuesta \\
\hline 658 & $\begin{array}{l}\text { Lonely } \\
\text { Planet } \\
\text { Madrid }\end{array}$ & sangría & $\begin{array}{l}\text { gastronomía y } \\
\text { restauración }\end{array}$ & $\begin{array}{l}\text { amplificación + } \\
\text { préstamo }\end{array}$ & Compuesta \\
\hline 659 & $\begin{array}{l}\text { Lonely } \\
\text { Planet } \\
\text { Madrid }\end{array}$ & gaseosa & $\begin{array}{l}\text { gastronomía y } \\
\text { restauración }\end{array}$ & $\begin{array}{l}\text { equivalente acuñado + } \\
\text { préstamo }\end{array}$ & Compuesta \\
\hline 660 & $\begin{array}{l}\text { Lonely } \\
\text { Planet } \\
\text { Madrid }\end{array}$ & pacharán & $\begin{array}{l}\text { gastronomía y } \\
\text { restauración }\end{array}$ & $\begin{array}{l}\text { amplificación + } \\
\text { préstamo }\end{array}$ & Compuesta \\
\hline 661 & $\begin{array}{l}\text { Lonely } \\
\text { Planet } \\
\text { Madrid }\end{array}$ & $\begin{array}{l}\text { licor de } \\
\text { madroño }\end{array}$ & $\begin{array}{l}\text { gastronomía y } \\
\text { restauración }\end{array}$ & $\begin{array}{l}\text { amplificación + } \\
\text { préstamo }\end{array}$ & Compuesta \\
\hline 662 & $\begin{array}{l}\text { Lonely } \\
\text { Planet } \\
\text { Madrid } \\
\end{array}$ & $\begin{array}{l}\text { anisado de } \\
\text { Chinchón }\end{array}$ & $\begin{array}{l}\text { gastronomía y } \\
\text { restauración }\end{array}$ & $\begin{array}{l}\text { amplificación + } \\
\text { préstamo }\end{array}$ & Compuesta \\
\hline 663 & $\begin{array}{l}\text { Lonely } \\
\text { Planet } \\
\text { Madrid }\end{array}$ & $\begin{array}{l}\text { café con } \\
\text { leche }\end{array}$ & $\begin{array}{l}\text { gastronomía y } \\
\text { restauración }\end{array}$ & $\begin{array}{l}\text { amplificación + } \\
\text { préstamo }\end{array}$ & Compuesta \\
\hline 664 & $\begin{array}{l}\text { Lonely } \\
\text { Planet } \\
\text { Madrid }\end{array}$ & café solo & $\begin{array}{l}\text { gastronomía y } \\
\text { restauración }\end{array}$ & $\begin{array}{l}\text { amplificación + } \\
\text { préstamo }\end{array}$ & Compuesta \\
\hline 665 & $\begin{array}{l}\text { Lonely } \\
\text { Planet } \\
\text { Madrid }\end{array}$ & $\begin{array}{l}\text { café con } \\
\text { hielo }\end{array}$ & $\begin{array}{l}\text { gastronomía y } \\
\text { restauración }\end{array}$ & $\begin{array}{l}\text { amplificación + } \\
\text { préstamo }\end{array}$ & Compuesta \\
\hline 666 & $\begin{array}{l}\text { Lonely } \\
\text { Planet } \\
\text { Madrid }\end{array}$ & café cortado & $\begin{array}{l}\text { gastronomía y } \\
\text { restauración }\end{array}$ & $\begin{array}{l}\text { equivalente acuñado + } \\
\text { préstamo }\end{array}$ & Compuesta \\
\hline 667 & $\begin{array}{l}\text { Lonely } \\
\text { Planet } \\
\text { Andalucía }\end{array}$ & cante jondo & $\begin{array}{l}\text { fiestas y } \\
\text { espectáculos }\end{array}$ & calco + préstamo & Compuesta \\
\hline 668 & $\begin{array}{l}\text { Lonely } \\
\text { Planet } \\
\text { Andalucía }\end{array}$ & cantaor & $\begin{array}{l}\text { fiestas y } \\
\text { espectáculos }\end{array}$ & $\begin{array}{l}\text { amplificación + } \\
\text { préstamo }\end{array}$ & Compuesta \\
\hline 669 & $\begin{array}{l}\text { Lonely } \\
\text { Planet } \\
\text { Andalucía }\end{array}$ & bailaor & $\begin{array}{l}\text { fiestas y } \\
\text { espectáculos }\end{array}$ & $\begin{array}{l}\text { amplificación + } \\
\text { préstamo }\end{array}$ & Compuesta \\
\hline
\end{tabular}




\begin{tabular}{|c|c|c|c|c|c|}
\hline ID & \begin{tabular}{|l|} 
TíTULO \\
GUÍA \\
\end{tabular} & $\begin{array}{l}\text { ELEMENTO } \\
\text { DE ANÁLISIS }\end{array}$ & $\begin{array}{l}\text { CAMPO } \\
\text { SEMÁNTICO }\end{array}$ & \begin{tabular}{|l|} 
TÉCNICA \\
TRADUCCIÓN \\
\end{tabular} & \begin{tabular}{|l} 
TIPO \\
TÉCNICA \\
\end{tabular} \\
\hline 670 & \begin{tabular}{|l|} 
Lonely \\
Planet \\
Andalucía
\end{tabular} & tocaor & $\begin{array}{l}\text { fiestas y } \\
\text { espectáculos }\end{array}$ & $\begin{array}{l}\text { amplificación + } \\
\text { préstamo }\end{array}$ & Compuesta \\
\hline 671 & $\begin{array}{l}\text { Lonely } \\
\text { Planet } \\
\text { Andalucía }\end{array}$ & castañuelas & $\begin{array}{l}\text { fiestas y } \\
\text { espectáculos }\end{array}$ & equivalente acuñado & Simple \\
\hline 672 & \begin{tabular}{|l} 
Lonely \\
Planet \\
Andalucía
\end{tabular} & taconeo & $\begin{array}{l}\text { fiestas y } \\
\text { espectáculos }\end{array}$ & amplificación & Simple \\
\hline 673 & \begin{tabular}{|l|} 
Lonely \\
Planet \\
Andalucía
\end{tabular} & coplas & $\begin{array}{l}\text { fiestas y } \\
\text { espectáculos }\end{array}$ & $\begin{array}{l}\text { generalización + } \\
\text { préstamo }\end{array}$ & Compuesta \\
\hline 674 & $\begin{array}{l}\text { Lonely } \\
\text { Planet } \\
\text { Andalucía }\end{array}$ & soleá & $\begin{array}{l}\text { fiestas y } \\
\text { espectáculos }\end{array}$ & préstamo & Simple \\
\hline 675 & $\begin{array}{l}\text { Lonely } \\
\text { Planet } \\
\text { Andalucía }\end{array}$ & siguiriya & $\begin{array}{l}\text { fiestas y } \\
\text { espectáculos }\end{array}$ & préstamo & Simple \\
\hline 676 & \begin{tabular}{|l|} 
Lonely \\
Planet \\
Andalucía \\
\end{tabular} & bata de cola & $\begin{array}{l}\text { fiestas y } \\
\text { espectáculos }\end{array}$ & $\begin{array}{l}\text { generalización + } \\
\text { préstamo }\end{array}$ & Compuesta \\
\hline 677 & \begin{tabular}{|l|} 
Lonely \\
Planet \\
Andalucía
\end{tabular} & $\begin{array}{l}\text { sombrero } \\
\text { cordobés }\end{array}$ & \begin{tabular}{|l|} 
fiestas y \\
espectáculos
\end{tabular} & calco & Simple \\
\hline 678 & \begin{tabular}{|l|} 
Lonely \\
Planet \\
Barcelona
\end{tabular} & Costa Brava & \begin{tabular}{|l|} 
paisaje y \\
geografía
\end{tabular} & $\begin{array}{l}\text { amplificación + } \\
\text { préstamo }\end{array}$ & Compuesta \\
\hline 679 & \begin{tabular}{|l|} 
Lonely \\
Planet \\
Barcelona
\end{tabular} & día de reyes & $\begin{array}{l}\text { fiestas y } \\
\text { espectáculos }\end{array}$ & calco + préstamo & Compuesta \\
\hline 680 & \begin{tabular}{|l|} 
Lonely \\
Planet \\
Barcelona \\
\end{tabular} & costa brava & $\begin{array}{l}\text { paisaje y } \\
\text { geografía }\end{array}$ & calco + préstamo & Compuesta \\
\hline 681 & \begin{tabular}{|l|} 
Lonely \\
Planet \\
Mallorca \\
\end{tabular} & talayots & historia & $\begin{array}{l}\text { amplificación + } \\
\text { préstamo }\end{array}$ & Compuesta \\
\hline 682 & \begin{tabular}{|l|} 
Lonely \\
Planet \\
Mallorca \\
\end{tabular} & almorávides & historia & $\begin{array}{l}\text { equivalente acuñado + } \\
\text { préstamo }\end{array}$ & Compuesta \\
\hline 683 & \begin{tabular}{|l} 
Lonely \\
Planet \\
Mallorca
\end{tabular} & almohades & historia & equivalente acuñado & Simple \\
\hline
\end{tabular}




\begin{tabular}{|c|c|c|c|c|c|}
\hline ID & \begin{tabular}{|l|} 
TÍTULO \\
GUÍA \\
\end{tabular} & $\begin{array}{l}\text { ELEMENTO } \\
\text { DE ANÁLISIS }\end{array}$ & \begin{tabular}{|l} 
CAMPO \\
SEMÁNTICO
\end{tabular} & \begin{tabular}{|l|} 
TÉCNICA \\
TRADUCCIÓN \\
\end{tabular} & \begin{tabular}{|l} 
TIPO \\
TÉCNICA \\
\end{tabular} \\
\hline 684 & $\begin{array}{l}\text { Lonely } \\
\text { Planet } \\
\text { Mallorca }\end{array}$ & reconquista & historia & $\begin{array}{l}\text { amplificación + } \\
\text { préstamo }\end{array}$ & Compuesta \\
\hline 685 & $\begin{array}{l}\text { Lonely } \\
\text { Planet } \\
\text { Mallorca }\end{array}$ & $\begin{array}{l}\text { batalla de las } \\
\text { navas de } \\
\text { tolosa }\end{array}$ & historia & calco + préstamo & Compuesta \\
\hline 686 & $\begin{array}{l}\text { Lonely } \\
\text { Planet } \\
\text { Mallorca }\end{array}$ & $\begin{array}{l}\text { llibre del } \\
\text { repartiment }\end{array}$ & historia & $\begin{array}{l}\text { amplificación + } \\
\text { préstamo }\end{array}$ & Compuesta \\
\hline 687 & $\begin{array}{l}\text { Lonely } \\
\text { Planet } \\
\text { Mallorca }\end{array}$ & alquería & historia & $\begin{array}{l}\text { amplificación + } \\
\text { préstamo }\end{array}$ & Compuesta \\
\hline 688 & $\begin{array}{l}\text { Lonely } \\
\text { Planet } \\
\text { Mallorca } \\
\end{array}$ & rafal & historia & $\begin{array}{l}\text { adaptación + } \\
\text { préstamo }\end{array}$ & Compuesta \\
\hline 689 & $\begin{array}{l}\text { Lonely } \\
\text { Planet } \\
\text { Mallorca } \\
\end{array}$ & $\begin{array}{l}\text { corona de } \\
\text { aragón }\end{array}$ & historia & calco & Simple \\
\hline 690 & $\begin{array}{l}\text { Lonely } \\
\text { Planet } \\
\text { Mallorca } \\
\end{array}$ & el call & historia & $\begin{array}{l}\text { amplificación + } \\
\text { préstamo }\end{array}$ & Compuesta \\
\hline 691 & $\begin{array}{l}\text { Lonely } \\
\text { Planet } \\
\text { Mallorca }\end{array}$ & aperitivo & $\begin{array}{l}\text { gastronomía y } \\
\text { restauración }\end{array}$ & préstamo & Simple \\
\hline 692 & $\begin{array}{l}\text { Lonely } \\
\text { Planet } \\
\text { Mallorca }\end{array}$ & siurells & artesanía & $\begin{array}{l}\text { amplificación + } \\
\text { préstamo }\end{array}$ & Compuesta \\
\hline 693 & $\begin{array}{l}\text { Lonely } \\
\text { Planet } \\
\text { Mallorca } \\
\end{array}$ & xeremeia & música & $\begin{array}{l}\text { adaptación + } \\
\text { amplificación + } \\
\text { préstamo }\end{array}$ & Compuesta \\
\hline 694 & $\begin{array}{l}\text { Lonely } \\
\text { Planet } \\
\text { Mallorca }\end{array}$ & flabiol & música & $\begin{array}{l}\text { amplificación + } \\
\text { préstamo }\end{array}$ & Compuesta \\
\hline 695 & \begin{tabular}{|l} 
Lonely \\
Planet \\
Mallorca \\
\end{tabular} & trencadís & arquitectura & $\begin{array}{l}\text { amplificación + } \\
\text { préstamo }\end{array}$ & Compuesta \\
\hline 696 & $\begin{array}{l}\text { Lonely } \\
\text { Planet } \\
\text { Mallorca }\end{array}$ & pa amb oli & $\begin{array}{l}\text { gastronomía y } \\
\text { restauración }\end{array}$ & calco + préstamo & Compuesta \\
\hline 697 & $\begin{array}{l}\text { Lonely } \\
\text { Planet } \\
\text { Mallorca }\end{array}$ & $\begin{array}{l}\text { queso de } \\
\text { mahón }\end{array}$ & $\begin{array}{l}\text { gastronomía y } \\
\text { restauración }\end{array}$ & $\begin{array}{l}\text { amplificación + } \\
\text { préstamo }\end{array}$ & Compuesta \\
\hline
\end{tabular}




\begin{tabular}{|c|c|c|c|c|c|}
\hline ID & \begin{tabular}{|l|} 
TíTULO \\
GUÍA \\
\end{tabular} & $\begin{array}{l}\text { ELEMENTO } \\
\text { DE ANÁLISIS }\end{array}$ & \begin{tabular}{|l|} 
CAMPO \\
SEMÁNTICO \\
\end{tabular} & $\begin{array}{l}\text { TÉCNICA } \\
\text { TRADUCCIÓN }\end{array}$ & $\begin{array}{l}\text { TIPO } \\
\text { TÉCNICA }\end{array}$ \\
\hline 698 & $\begin{array}{l}\text { Lonely } \\
\text { Planet } \\
\text { Mallorca }\end{array}$ & piris & $\begin{array}{l}\text { gastronomía y } \\
\text { restauración }\end{array}$ & $\begin{array}{l}\text { amplificación + } \\
\text { préstamo }\end{array}$ & Compuesta \\
\hline 699 & $\begin{array}{l}\text { Lonely } \\
\text { Planet } \\
\text { Mallorca }\end{array}$ & arròs brut & $\begin{array}{l}\text { gastronomía y } \\
\text { restauración }\end{array}$ & $\begin{array}{l}\text { calco + amplificación + } \\
\text { préstamo }\end{array}$ & Compuesta \\
\hline 700 & $\begin{array}{l}\text { Lonely } \\
\text { Planet } \\
\text { Mallorca }\end{array}$ & frit mallorquí & $\begin{array}{l}\text { gastronomía y } \\
\text { restauración }\end{array}$ & $\begin{array}{l}\text { amplificación + } \\
\text { préstamo }\end{array}$ & Compuesta \\
\hline 701 & $\begin{array}{l}\text { Lonely } \\
\text { Planet } \\
\text { Mallorca }\end{array}$ & sobrasada & $\begin{array}{l}\text { gastronomía y } \\
\text { restauración }\end{array}$ & $\begin{array}{l}\text { amplificación + } \\
\text { préstamo }\end{array}$ & Compuesta \\
\hline 702 & $\begin{array}{l}\text { Lonely } \\
\text { Planet } \\
\text { Mallorca }\end{array}$ & botifarra & $\begin{array}{l}\text { gastronomía y } \\
\text { restauración }\end{array}$ & $\begin{array}{l}\text { amplificación + } \\
\text { préstamo }\end{array}$ & Compuesta \\
\hline 703 & $\begin{array}{l}\text { Lonely } \\
\text { Planet } \\
\text { Mallorca }\end{array}$ & botifarró & $\begin{array}{l}\text { gastronomía y } \\
\text { restauración }\end{array}$ & $\begin{array}{l}\text { amplificación + } \\
\text { préstamo }\end{array}$ & Compuesta \\
\hline 704 & $\begin{array}{l}\text { Lonely } \\
\text { Planet } \\
\text { Mallorca }\end{array}$ & $\begin{array}{l}\text { cap roig a la } \\
\text { sal }\end{array}$ & $\begin{array}{l}\text { gastronomía y } \\
\text { restauración }\end{array}$ & $\begin{array}{l}\text { amplificación + } \\
\text { préstamo }\end{array}$ & Compuesta \\
\hline 705 & $\begin{array}{l}\text { Lonely } \\
\text { Planet } \\
\text { Mallorca }\end{array}$ & $\begin{array}{l}\text { gató } \\
\text { mallorquí }\end{array}$ & $\begin{array}{l}\text { gastronomía y } \\
\text { restauración }\end{array}$ & $\begin{array}{l}\text { amplificación + } \\
\text { préstamo }\end{array}$ & Compuesta \\
\hline 706 & $\begin{array}{l}\text { Lonely } \\
\text { Planet } \\
\text { Mallorca }\end{array}$ & ensaimada & $\begin{array}{l}\text { gastronomía y } \\
\text { restauración }\end{array}$ & $\begin{array}{l}\text { amplificación + } \\
\text { préstamo }\end{array}$ & Compuesta \\
\hline 707 & $\begin{array}{l}\text { Lonely } \\
\text { Planet } \\
\text { Mallorca }\end{array}$ & quart & $\begin{array}{l}\text { gastronomía y } \\
\text { restauración }\end{array}$ & $\begin{array}{l}\text { amplificación + } \\
\text { préstamo }\end{array}$ & Compuesta \\
\hline 708 & $\begin{array}{l}\text { Lonely } \\
\text { Planet } \\
\text { Mallorca }\end{array}$ & palo & $\begin{array}{l}\text { gastronomía y } \\
\text { restauración }\end{array}$ & $\begin{array}{l}\text { calco + amplificación + } \\
\text { préstamo }\end{array}$ & Compuesta \\
\hline 709 & $\begin{array}{l}\text { Lonely } \\
\text { Planet } \\
\text { Mallorca }\end{array}$ & matanza & $\begin{array}{l}\text { gastronomía y } \\
\text { restauración }\end{array}$ & $\begin{array}{l}\text { calco + amplificación + } \\
\text { préstamo }\end{array}$ & Compuesta \\
\hline 710 & $\begin{array}{l}\text { Lonely } \\
\text { Planet } \\
\text { Mallorca }\end{array}$ & Ilonganissa & $\begin{array}{l}\text { gastronomía y } \\
\text { restauración }\end{array}$ & $\begin{array}{l}\text { amplificación + } \\
\text { préstamo }\end{array}$ & Compuesta \\
\hline 711 & $\begin{array}{l}\text { Lonely } \\
\text { Planet } \\
\text { Mallorca }\end{array}$ & trampó & $\begin{array}{l}\text { gastronomía y } \\
\text { restauración }\end{array}$ & $\begin{array}{l}\text { amplificación + } \\
\text { préstamo }\end{array}$ & Compuesta \\
\hline
\end{tabular}




\begin{tabular}{|l|l|l|l|l|l|}
\hline ID & $\begin{array}{l}\text { TíTULO } \\
\text { GUÍA }\end{array}$ & $\begin{array}{l}\text { ELEMENTO } \\
\text { DE ANÁLISIS }\end{array}$ & $\begin{array}{l}\text { CAMPO } \\
\text { SEMÁNTICO }\end{array}$ & $\begin{array}{l}\text { TÉCNICA } \\
\text { TRADUCCIÓN }\end{array}$ & $\begin{array}{l}\text { TIPO } \\
\text { TÉCNICA }\end{array}$ \\
\hline 712 & $\begin{array}{l}\text { Lonely } \\
\text { Planet } \\
\text { Barcelona }\end{array}$ & $\begin{array}{l}\text { monas de } \\
\text { pascua }\end{array}$ & $\begin{array}{l}\text { gastronomía y } \\
\text { restauración }\end{array}$ & $\begin{array}{l}\text { amplificación + } \\
\text { préstamo }\end{array}$ & Compuesta \\
\hline 713 & $\begin{array}{l}\text { Lonely } \\
\text { Planet } \\
\text { Madrid }\end{array}$ & torrijas & $\begin{array}{l}\text { gastronomía y } \\
\text { restauración }\end{array}$ & $\begin{array}{l}\text { amplificación + } \\
\text { préstamo }\end{array}$ & Compuesta \\
\hline
\end{tabular}


